\title{
Deteç̧ão de anomalias, interpolação e previsão em tempo real de séries temporais para operação de reservatórios e distribuição de água
}

\author{
Leonardo Fonseca Larrubia
}

\author{
DISSERTAÇÃO APRESENTADA \\ $\mathrm{AO}$ \\ Instituto DE MATEMÁTICA E ESTATÍSTICA \\ DA DIVERSIDADE DE SÃO PAULO \\ PARA \\ OBTENÇÄO DO TÍTULO \\ DE \\ Mestre EM CIÊNCIAS
}

Programa: Estatística

Orientadora: Profa. Dra. Chang Chiann

Durante o desenvolvimento deste trabalho o autor recebeu auxílio financeiro da FAPESP

Processo $n^{0}$ 2018/26592-5, Fundação de Amparo à Pesquisa do Estado de São Paulo (FAPESP)

São Paulo, abril de 2021 


\section{Detecção de anomalias, interpolação e previsão em tempo real de séries temporais para operação de reservatórios e distribuição de água}

Esta versão da dissertação/tese contém as correções e alterações sugeridas pela Comissão Julgadora durante a defesa da versão original do trabalho, realizada em 08/04/2021. Uma cópia da versão original está disponível no

Instituto de Matemática e Estatística da Universidade de São Paulo.

Comissão Julgadora:

- Prof $^{\mathrm{a}}$. Dr ${ }^{\mathrm{a}}$. Chang Chiann (orientadora) - IME-USP

- Prof. Dr. Marcelo Magalhães Taddeo - UFBA

- Prof. Ph.D. Valderio Anselmo Reisen - UFES 


\section{Resumo}

LARRUBIA, L.F. Detecção de anomalias, interpolação e previsão em tempo real de séries temporais para operação de reservatórios e distribuição de água. 2021. 209 f. Dissertação (Mestrado) - Instituto de Matemática e Estatística, Universidade de São Paulo, São Paulo, 2021.

Desenvolvemos uma solução via análise de séries temporais visando resolver um problema recorrente em Centros de Controle Operacionais de distribuição de água: anomalias em dados recebidos das estações de telemetria em tempo real para tomadas de decisão. A solução desenvolvida consiste em fazer detecção de outliers, reconstrução de valores omissos e previsão. Para tanto, foram utilizadas séries temporais geradas por equipamentos de medição de nível, vazões de entrada e de saídas do reservatório e de pressões a montante e a jusante de válvulas que controlam o fluxo de água. Os dados, referentes ao sistema de distribuição de água da cidade de Peruíbe, foram fornecidos pela Sabesp da Baixada Santista e sua amostragem temporal é a cada hora, indo das 1:00 do dia $1^{\underline{O}}$ de janeiro de 2017 até às 23:00 do dia 31 de dezembro de 2018. Para a detecção de outliers e preenchimento de valores omissos, foram propostos procedimentos que usam três técnicas principais: ajuste de curvas via regressão, decomposição clássica junto a regressão e decomposição STL. Já para previsão, foram utilizadas técnicas de rolling analysis em combinação com modelos SARIMA, modelos de regressão com erros auto correlacionados e modelos BATS e TBATS. Os resultados demonstraram que os métodos propostos, tanto para detecção de outliers e preenchimento de valores omissos, como para a previsão, possuem desempenhos muito bons para a maioria das séries.

Palavras-chave: séries temporais, valores omissos, valores atípicos, previsão, indústria da água, tempo real, big data. 



\section{Abstract}

LARRUBIA, L.F. Anomaly detection, interpolation and real-time forecasting of time series for reservoir operation and water distribution. 2021. 209 f. Dissertação (Mestrado) Instituto de Matemática e Estatística, Universidade de São Paulo, São Paulo, 2021.

We developed a time series analysis solution for a recurring problem in Operational Control Centers of water distribution systems: anomalies in real time data received from telemetry stations. The developed solution consists of detecting outliers, reconstructing missing values and forecasting. For this purpose, we analyzed time series generated by measuring equipment: level, input and output flows of reservoir and upstream and downstream pressures of valves that control the flow of water. The data, referring to the water distribution system of the city of Peruíbe, were provided by Sabesp located in Baixada Santista and it is sampled every hour from 1:00 a.m. on January 1, 2017 to 11:00 p.m. on December 31, 2018. We propose procedures that use three main techniques for the detection of outliers and imputation of missing values: adjustment of curves by regression, classical decomposition combined with regression and STL decomposition. For forecasting, we used rolling analysis techniques in combination with SARIMA models, regression models with autocorrelated errors and BATS and TBATS models. The results showed that the proposed methods, both for detecting outliers and imputing of missing values, as well as for forecasting, perform very well for most time series.

Keywords: time series, missing data, outliers, forecasting, water industry, real time, big data. 



\section{Sumário}

Lista de Abreviaturas $\quad$ vii

$\begin{array}{lc}\text { Lista de Símbolos } & \text { ix }\end{array}$

Lista de Figuras $\quad$ xi

Lista de Tabelas $\quad$ Xv

$\begin{array}{ll}\text { Introdução } & 1\end{array}$

1 Revisão teórica $\quad \mathbf{5}$

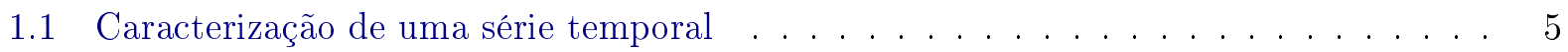

1.2 Modelos de decomposição . . . . . . . . . . . . . . . . . . 7

1.2.1 Decomposição via ajuste de curvas de regressão . . . . . . . . . . . . 8

1.2 .2 Decomposição clássica . . . . . . . . . . . . . . . . . . . . . 9

1.2 .3 STL . . . . . . . . . . . . . . . . . . . . . 10

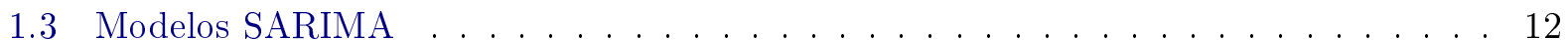

1.3.1 Modelos autorregresivos . . . . . . . . . . . . . . . . 13

1.3.2 Modelos de médias móveis . . . . . . . . . . . . . . . . . . . . . . . 13

1.3.3 Modelos autorregresivos e de médias móveis . . . . . . . . . . . . . . . . . . 14

1.3.4 Estimação dos modelos ARMA . . . . . . . . . . . . . . . . . . . 14

1.3.5 Modelos autorregresivos integrados e de médias móveis . . . . . . . . . . . 15

1.3.6 Modelos multiplicativos sazonais autorregresivos integrados e de médias móveis 16

1.3.7 Identificação: um procedimento de seleção de modelos SARIMA . . . . . . . . . 17

1.4 Regressão com erros autocorrelacionados . . . . . . . . . . . . . . . . 18

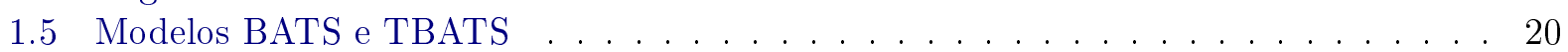

1.5.1 Seleção de modelos BATS e TBATS . . . . . . . . . . . . . . . . 22

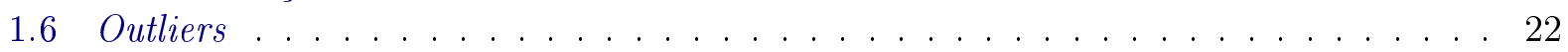

1.6.1 Uma definição de outliers . . . . . . . . . . . . . . . . . . 23

1.6.2 Um método robusto e iterativo de tratamento de outliers . . . . . . . . . . 24

1.7 Rolling analysis de séries temporais . . . . . . . . . . . . . . 24

1.7.1 Medidas de acurácia . . . . . . . . . . . . . . . 25

1.7 .2 Modificações úteis . . . . . . . . . . . . . . . . 26

2 Métodos e materiais $\quad 29$

2.1 Descrição dos dados . . . . . . . . . . . . . . . . . . 30

2.2 Limpeza primária das séries . . . . . . . . . . . . . . . . . . 32

2.3 Processo iterativo de tratamento de outliers e valores omissos . . . . . . . . . . 33

2.3.1 Procedimentos de ajuste de curvas via regressão . . . . . . . . . . . . . 34

2.3.2 Procedimentos de ajuste de curvas via regressão + decomposição clássica . . 36

2.3 .3 Procedimentos de decomposição STL . . . . . . . . . . . . . . . . 36

2.3.4 Arranjos experimentais e avaliação dos procedimentos . . . . . . . . . . 37

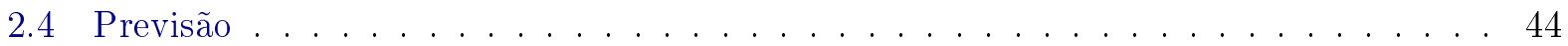


2.4.1 Modelos SARIMA . . . . . . . . . . . . . . . . . . 45

2.4.2 Modelos de regressão com erros autocorrelacionados . . . . . . . . . . . . 45

2.4 .3 Modelos BATS e TBATS . . . . . . . . . . . . . . . . . 46

2.4 .4 Métodos de previsão Benchmark . . . . . . . . . . . . . . . . . . 46

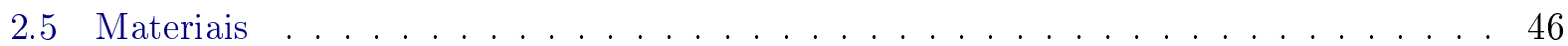

3 Resultados e discussão $\quad 49$

3.1 Vazão de entrada do reservatório Peruíbe . . . . . . . . . . . . . . . . . 49

3.1.1 Preenchimento de valores omissos . . . . . . . . . . . . . . . . . 50

3.1.2 Detecção e tratamento de outliers . . . . . . . . . . . . . . . . 53

3.1 .3 Previsão . . . . . . . . . . . . . . . . . . . . . 54

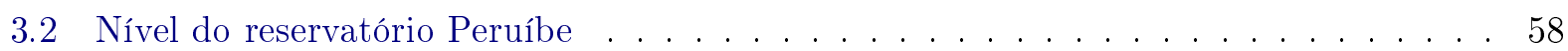

3.2.1 Preenchimento de valores omissos . . . . . . . . . . . . . . . . . . 59

3.2 .2 Detecção e tratamento de outliers . . . . . . . . . . . . . . . . 61

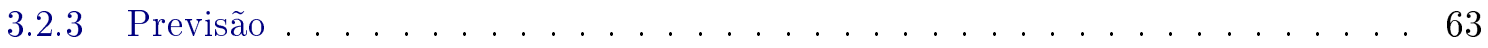

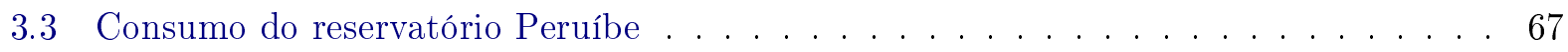

3.3.1 Preenchimento de valores omissos . . . . . . . . . . . . . . . 68

3.3.2 Deteç̧ão e tratamento de outliers . . . . . . . . . . . . . . 70

3.3 .3 Previsão . . . . . . . . . . . . . . . . . . . . . . . . 72

3.4 Vazão de saída do reservatório para o Norte de Peruíbe . . . . . . . . . . . . 76

3.4.1 Preenchimento de valores omissos . . . . . . . . . . . . . . . . . 77

3.4.2 Detecção e tratamento de outliers . . . . . . . . . . . . . . . . . . 79

3.4 .3 Previsão . . . . . . . . . . . . . . . . . . . . . 81

3.5 Vazão de saída do reservatório para o Sul de Peruíbe . . . . . . . . . . . . . 85

3.5.1 Preenchimento de valores omissos . . . . . . . . . . . . . . 86

3.5.2 Detecção e tratamento de outliers . . . . . . . . . . . . . . . . 88

3.5.3 Previsão . . . . . . . . . . . . . . . . . . . . . . . 90

3.6 Pressão a montante no Norte de Peruíbe . . . . . . . . . . . . . . . . . . . . . . 94

3.6.1 Preenchimento de valores omissos . . . . . . . . . . . . . . . . 95

3.6.2 Deteç̧ão e tratamento de outliers . . . . . . . . . . . . . . . . . 98

3.6.3 Previsão . . . . . . . . . . . . . . . . . . . . . . 100

3.7 Pressão a montante no Sul de Peruíbe ． . . . . . . . . . . . . . . . . . 104

3.7 .1 Preenchimento de valores omissos . . . . . . . . . . . . . . . . 104

3.7.2 Detecção e tratamento de outliers . . . . . . . . . . . . . . . . . 107

3.7 .3 Previsão . . . . . . . . . . . . . . . . . . . . . . . . . . . 109

3.8 Pressão a jusante no Norte de Peruíbe . . . . . . . . . . . . . . . . . . . 113

3.8.1 Preenchimento de valores omissos . . . . . . . . . . . . . . . 113

3.8.2 Detecção e tratamento de outliers . . . . . . . . . . . . . . . 116

3.8 .3 Previsão . . . . . . . . . . . . . . . . . . . . . . . . . 119

3.9 Pressão a jusante no Sul de Peruíbe . . . . . . . . . . . . . . . . . . . . . . 122

3.9.1 Preenchimento de valores omissos . . . . . . . . . . . . . . . 122

3.9.2 Detecção e tratamento de outliers . . . . . . . . . . . . . . 125

3.9 .3 Previsão . . . . . . . . . . . . . . . . . . . . . . . . . 128

3.10 Discussão geral . . . . . . . . . . . . . . . . . . . . . 132

4 Conclusões $\quad 137$

A Informações descritivas das séries originais $\quad 139$

B Informações descritivas após a limpeza primária $\quad 159$

C Informações descritivas após tratamento de outliers e preenchimento de omissos187 


\section{Lista de Abreviaturas}

\begin{tabular}{|c|c|}
\hline $\mathrm{AIC}$ & Critério de informação de Akaike (Akaike Information Criterion) \\
\hline $\mathrm{AICc}$ & $\begin{array}{l}\text { Critério de informação de Akaike Corrigido (Corrected Akaike Information } \\
\text { Criterion) }\end{array}$ \\
\hline $\mathrm{AO}$ & Outlier Aditivo (Additive Outlier) \\
\hline $\mathrm{AR}$ & Autorregressivo (Autoregressive) \\
\hline ARIMA & $\begin{array}{l}\text { Autorregressivo Integrado de Médias Móveis (Autoregressive Integrated Mo- } \\
\text { ving Average) }\end{array}$ \\
\hline ARMA & Autorregressivo de Médias Móveis (Autoregressive-Moving-Average) \\
\hline BATS & $\begin{array}{l}\text { Transformação Box-Cox, Erros ARMA, Componentes Sazonais e Tendência } \\
\text { (Box-Cox transformation, ARMA erros, Trend and Seasonal components) }\end{array}$ \\
\hline BIC & Critério de informação Bayesiano (Bayesian Information Criterion) \\
\hline $\mathrm{CCO}$ & Centro de Controle Operacional \\
\hline $\mathrm{CD}$ & Crescimento e Decrescimento \\
\hline IIoT & Internet das Coisas industrial (Industrial Internet of Things) \\
\hline IO & Outlier de Inovação (Innovational Outlier) \\
\hline IoS & Internet dos Serviços (Internet of Sevices) \\
\hline IoT & Internet das Coisas (Internet of Things) \\
\hline IPT & Instituto de Pesquisas Tecnológicas \\
\hline $\mathrm{LC}$ & Outlier de Mudança de Nível (Level Change) \\
\hline MA & Médias móveis (Moving Average) \\
\hline MAE & Erro Absoluto Médio (Mean Absolut Error) \\
\hline MAPE & Média Percentual Absoluta do Erro (Mean Absolute Percentage Error) \\
\hline $\mathrm{ME}$ & Erro Médio (Mean Error) \\
\hline MSE & Erro Quadrático Médio (Mean-Square Error) \\
\hline PROP & Proporção \\
\hline RMBS & Região Metropolitana da Baixada Santista \\
\hline RMSE & Raiz do Erro Quadrático Médio (Root-Mean-Square Error) \\
\hline RMSP & Região Metropolitana de São Paulo \\
\hline SARIMA & $\begin{array}{l}\text { Sazonal Autorregressivo Integrado de Médias Móveis (Seasonal Autoregressive } \\
\text { Integrated Moving Average) }\end{array}$ \\
\hline SARMA & Sazonal Autorregressivo de Médias Móveis (Autoregressive-Moving-Average) \\
\hline SCADA & $\begin{array}{l}\text { Sistemas de Supervisão e Aquisição de Dados (Supervisory Control and Data } \\
\text { Acquisition) }\end{array}$ \\
\hline STL & $\begin{array}{l}\text { Decomposição Sazonal e de Tendência por Loess (Seasonal-Trend Decomposi- } \\
\text { tion Procedure Based on Loess) }\end{array}$ \\
\hline TBATS & $\begin{array}{l}\text { Transformação Box-Cox, Erros ARMA, Componentes Sazonais Trigonométri- } \\
\text { cos e Tendência (Trigonometric, Box-Cox transformation, ARMA erros, Trend } \\
\text { and Seasonal components) }\end{array}$ \\
\hline & Outlier de Mudança Transitória de Nível (Transient Level Change) \\
\hline
\end{tabular}





\title{
Lista de Símbolos
}

\author{
Conceitos básicos \\ Z Processo estocástico discreto ou série temporal \\ $Z_{t} \quad$ Valor aleatório no tempo $t$ \\ $\hat{Z}_{t} \quad$ Valor estimado de $Z_{t}$ \\ $\bar{Z}_{t} \quad$ Média amostral de $Z_{t}$ \\ $\tau \quad$ Conjunto discreto de indexação \\ $\mu \quad$ Média \\ $\sigma^{2} \quad$ Variância \\ $\xi_{t} \quad$ Ruído branco \\ $E[$.$] \quad Função esperança$ \\ $\operatorname{Cov}[.,$.$] \quad Função covariância$ \\ $\operatorname{Var}[$.$] \quad Função variância$ \\ $\gamma(.,$.$) \quad Função autocovariância$ \\ $\rho(.,$.$) \quad Função autocorrelação$ \\ $B^{m} \quad$ Operador translação $m$ passos para o passado \\ $\Delta_{s}^{m} \quad$ Operador diferença de ordem $m$ e defasagem $s$ \\ $T_{t} \quad$ Componente de tendência no tempo $t$ \\ $S_{t} \quad$ Componente de sazonalidade no tempo $t$ \\ $R_{t} \quad$ Componente ruído no tempo $t$ \\ $Z_{t}^{(\lambda)} \quad$ Transformação Box-Cox de parâmetro $\lambda$
}

\section{Modelos de Regressão}

$\beta_{i} \quad i$-ésimo parâmetros de tendência

$D_{j, t} \quad i$-ésimo parâmetros de sazonalidade

$\beta \quad$ Vetor de parâmetros do modelo Regressão

$\boldsymbol{R} \quad$ Vetor de parâmetros de resíduos

$\boldsymbol{X} \quad$ Matriz de planejamento

$\hat{\boldsymbol{\beta}} \quad$ Vetor de estimativas dos parâmetros $\boldsymbol{\beta}$

\section{Decomposição STL}

$W($.$) \quad Função tri-cúbica$

$B($.$) \quad Função bi-quadrática$

$v_{i}(x) \quad$ Função de pesos usando a função tri-cúbica

$\rho_{t} \quad$ Função de pesos usando a função bi-quadrática

$n_{(p)} \quad$ Parâmetro do tamanho do período sazonal da série

$n_{(l)} \quad$ Parâmetro de suavização do filtro passa baixo

$n_{(s)} \quad$ Parâmetro de suavização da componente sazonal

$n_{(t)} \quad$ Parâmetro de suavização da componente de tendência

$n_{(i)} \quad$ Número de iterações do loop interno

$n_{(e)} \quad$ Número de iterações do loop externo 


\section{Modelos ARIMA}

$\phi_{i} \quad i$-ésimo parâmetro autorregressivo

$\theta_{i} \quad i$-ésimo parâmetro de médias móveis

$\Phi_{i} \quad i$-ésimo parâmetro autorregressivos sazonais

$\Theta_{i} \quad i$-ésimo parâmetro de médias móveis sazonais

$\phi(B) \quad$ Operador autorregressivo

$\boldsymbol{\theta}(B) \quad$ Operador de médias móveis

$\Phi(B) \quad$ Operador autorregressivo sazonal

$\boldsymbol{\Theta}(B) \quad$ Operador de médias móveis sazonal

$\nu$ Vetor de parâmetros dos ARIMA

$\boldsymbol{\nu} \quad$ Vetor de parâmetros dos ARIMA

$L(. \mid ., .,$.$) \quad Função de verossimilhança$

$l(. \mid ., .,$.$) \quad Função de log-verossimilhança$

$S(. \mid ., .,$.$) \quad Soma de quadrados condicional$

\section{Modelos BATS e TBATS}

$\omega \quad$ Parâmetro da transformação Box-Cox

$T \quad$ Quantidade de padrões sazonais

$\ell_{t} \quad$ Nível local no tempo $t$

$\varphi \quad$ Parâmetro de amortecimento de tendência

$b_{t} \quad$ Tendência de curto prazo

$b \quad$ Tendência de longo prazo

$s_{t}^{(i)} \quad i$-ésima componente sazonal no tempo $t$

$m_{i} \quad i$-ésimo período sazonal

$d_{t} \quad$ Processo ARMA $(p, q)$

$k_{i} \quad$ Número de harmônicos da $i$-ésima componente sazonal

$s_{j, t}^{(i)} \quad$ Nível estocástico da $i$-ésima componente sazonal

$s_{j, t}^{*(i)} \quad$ Crescimento estocástico no nível da $i$-ésima componente sazonal

$\alpha \quad$ Parâmetro de suavização

$\beta \quad$ Parâmetro de suavização

$\gamma \quad$ Parâmetro de suavização

$\gamma_{1}^{(i)} \quad$ Parâmetro de suavização

$\gamma_{2}^{(i)} \quad$ Parâmetro de suavização

\section{Outliers e valores omissos}

$\omega_{a} \quad$ Intensidadede impacto do efeito atípico $a$

$g_{a}(., .,$.$) \quad Forma do impacto do efeito atípico a$

$q_{a}^{(i)} \quad$ Quantil $a$ da $i$-ésima iteração

$q_{b}^{(i)} \quad$ Quantil $b$ da $i$-ésima iteração

$I_{(a, b)}^{(i)} \quad$ Intervalo quantílico da $i$-ésima iteração

$M \quad$ Número máximo de iterações

\section{Rolling Analysis}

$N \quad$ Tamanho da série

$n \quad$ Tamanho de uma subsérie

$\hat{\boldsymbol{v}} \quad$ Vetor de estatísticas

$\boldsymbol{V}_{\boldsymbol{k} \times \boldsymbol{N}-\boldsymbol{n}+\mathbf{1}}$ Matriz de estatísticas usando rolling analysis

$M \quad$ Número amostrado de rolling windows 


\section{Lista de Figuras}

1.1 Esquema do algoritmo de busca de modelos ARIMA proposto por Hyndman e Khandakar . . . . . . . . . . . . . . . . . . . . 19

1.2 Funcionamento do método de rolling analysis . . . . . . . . . . . . . . . 25

1.3 Funcionamento do método de rolling analysis modificado . . . . . . . . . . . 26

2.1 Procedimento adotado para a análise das séries . . . . . . . . . . . . . . 29

2.2 Esquema do sistema de abastecimento de água referente ao reservatório de Peruíbe . 31

2.3 Exemplos de valores outliers nas séries . . . . . . . . . . . . . . . . 31

2.4 Exemplos de mudança no comportamento da série . . . . . . . . . . . . . . 32

2.5 Exemplos do comportamento da séries de nível e vazão de entrada do reservatório . . 32

2.6 Tipos de efeitos atípicos: forma de impacto . . . . . . . . . . . . . . . 43

2.7 Tipos de efeitos atípicos: exemplo em série . . . . . . . . . . . . . . . . . . . 44

3.1 Série vazão de entrada no reservatório Peruíbe: Exemplo . . . . . . . . . . . . . . 50

3.2 Série vazão de entrada no reservatório Peruíbe: Exemplos de preenchimento de valores

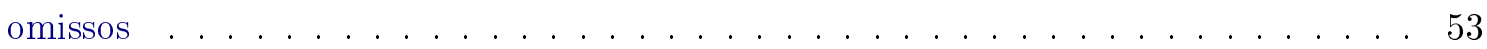

3.3 Série vazão de entrada no reservatório Peruíbe: Exemplos de detecção e tratamento dos outliers inseridos na série . . . . . . . . . . . . . 56

3.4 Série vazão de entrada no reservatório Peruíbe: Exemplos de previsão . . . . . . . . 58

3.5 Série nível do reservatório Peruíbe: Exemplo . . . . . . . . . . . . . . . . . 59

3.6 Série nível do reservatório Peruíbe: Exemplos de preenchimento de valores omissos . 62

3.7 Série nível do reservatório Peruíbe: Exemplos de detecção e tratamento dos outliers

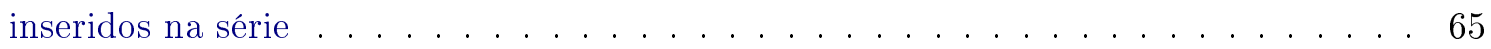

3.8 Série nível do reservatório Peruíbe: Exemplos de previsão . . . . . . . . . . . . . 67

3.9 Série consumo demandado do reservatório Peruíbe: Exemplo . . . . . . . . . . . . . 68

3.10 Série consumo demandado do reservatório Peruíbe: Exemplos de preenchimento de valores omissos . . . . . . . . . . . . . . . . . . . 71

3.11 Série consumo demandado do reservatório Peruíbe: Exemplos de detecção e tratamento dos outliers inseridos na série . . . . . . . . . . . . . . . . 74

3.12 Série consumo demandado do reservatório Peruíbe: Exemplos de previsão $\quad \ldots$. . . 76

3.13 Série vazão de saída para o Norte de Peruíbe: Exemplo . . . . . . . . . . . . . . 77

3.14 Série vazão de saída para o Norte de Peruíbe: Exemplos de preenchimento de valores

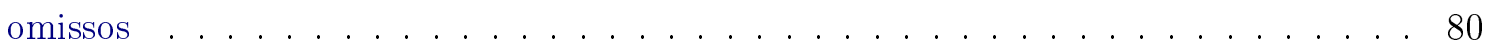

3.15 Série vazão de saída para o Norte de Peruíbe: Exemplos de detecção e tratamento dos outliers inseridos na série . . . . . . . . . . . . . 83

3.16 Série vazão de saída para o Norte de Peruíbe: Exemplos de previsão . . . . . . . . . 85

3.17 Série vazão de saída para o Sul de Peruíbe: Exemplo . . . . . . . . . . . . . . 86

3.18 Série vazão de saída para o Sul de Peruíbe: Exemplos de preenchimento de valores

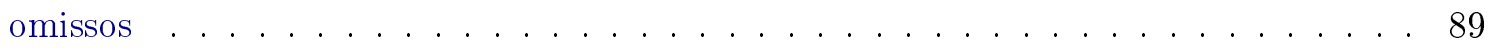

3.19 Série vazão de saída para o Sul de Peruíbe: Exemplos de detecção e tratamento dos outliers inseridos na série . . . . . . . . . . . . . . . . 92

3.20 Série vazão de saída para o Sul de Peruíbe: Exemplos de previsão . . . . . . . . . . . 94 
3.21 Série pressão a montante ao Norte de Peruíbe: Exemplo

3.22 Série pressão a montante ao Norte de Peruíbe: Exemplos de preenchimento de valores

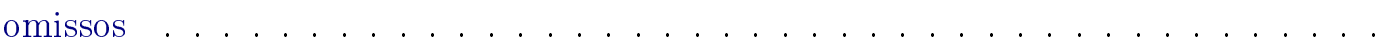

3.23 Série pressão a montante ao Norte de Peruíbe: Exemplos de detecção e tratamento dos outliers inseridos na série . . . . . . . . . . . . . . . . . . 101

3.24 Série pressão a montante ao Norte de Peruíbe: Exemplos de previsão . . . . . . . . . 103

3.25 Série pressão a montante ao Sul de Peruíbe: Exemplo . . . . . . . . . . . . . . . . . 104

3.26 Série pressão a montante ao Sul de Peruíbe: Exemplos de preenchimento de valores omissos . . . . . . . . . . . . . . . . . . . 107

3.27 Série pressão a montante ao Sul de Peruíbe: Exemplos de detecção e tratamento dos outliers inseridos na série . . . . . . . . . . . . . . . . 110

3.28 Série pressão a montante ao Sul de Peruíbe: Exemplos de previsão . . . . . . . . . 112

3.29 Série pressão a jusante ao Norte de Peruíbe: Exemplo . . . . . . . . . . . . . . . . 113

3.30 Série pressão a jusante ao Norte de Peruíbe: Exemplos de preenchimento de valores

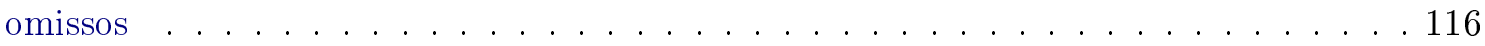

3.31 Série pressão a jusante ao Norte de Peruíbe: Exemplos de detecção e tratamento dos outliers inseridos na série . . . . . . . . . . . . . . . . . . . . . 119

3.32 Série pressão a jusante ao Norte de Peruíbe: Exemplos de previsão . . . . . . . . . 121

3.33 Série pressão a jusante ao Sul de Peruíbe: Exemplo . . . . . . . . . . . . . . . . 122

3.34 Série pressão a jusante ao Sul de Peruíbe: Exemplos de preenchimento de valores

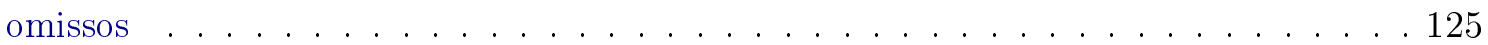

3.35 Série pressão a jusante ao Sul de Peruíbe: Exemplos de detecção e tratamento dos outliers inseridos na série . . . . . . . . . . . . . . . . . 128

3.36 Série pressão a jusante ao Sul de Peruíbe: Exemplos de previsão . . . . . . . . . . . 130

A.1 Descritiva da série original de nível . . . . . . . . . . . . . . . . . . . 141

A.2 Descritiva da série original de consumo . . . . . . . . . . . . . . . . 143

A.3 Descritiva da série original de vazão de entrada . . . . . . . . . . . . . . . 145

A.4 Descritiva da série original de vazão de saída Norte . . . . . . . . . . . . . . . . . 147

A.5 Descritiva da série original de vazão de saída Sul . . . . . . . . . . . . . . . . . 149

A.6 Descritiva da série original de pressão a montante ao Norte . . . . . . . . . . . . . 151

A.7 Descritiva da série original de pressão a montante ao Sul . . . . . . . . . . . . . . 153

A.8 Descritiva da série original de pressão a jusante ao Norte . . . . . . . . . . . . 155

A.9 Descritiva da série original de pressão a jusante ao Sul . . . . . . . . . . . . 157

B.1 Descritiva da série após limpeza primária de nível . . . . . . . . . . . . . . . . 161

B.2 Descritiva dos valores omissos na série de nível . . . . . . . . . . . . . . 162

B.3 Descritiva da série após limpeza primária de consumo . . . . . . . . . . . . . . . 164

B.4 Descritiva dos valores omissos na série de consumo . . . . . . . . . . . . . 165

B.5 Descritiva da série após limpeza primária de vazão de entrada . . . . . . . . . . . . 167

B.6 Descritiva dos valores omissos na série de vazão de entrada . . . . . . . . . . . . 168

B.7 Descritiva da série após limpeza primária de vazão de saída Norte . . . . . . . . . . 170

B.8 Descritiva dos valores omissos na série de vazão de saída Norte . . . . . . . . . . 171

B.9 Descritiva da série após limpeza primária de vazão de saída Sul . . . . . . . . . . 173

B.10 Descritiva dos valores omissos na série de vazão de saída Sul . . . . . . . . . . . . 174

B.11 Descritiva da série após limpeza primária de pressão a montante ao Norte . . . . 176

B.12 Descritiva dos valores omissos na série de pressão a montante ao Norte . . . . . . . 177

B.13 Descritiva da série após limpeza primária de pressão a montante ao Sul . . . . . . . . 179

B.14 Descritiva dos valores omissos na série de pressão a montante ao Sul . . . . . . . 180

B.15 Descritiva da série após limpeza primária de pressão a jusante ao Norte . . . . . 182

B.16 Descritiva dos valores omissos na série de pressão a jusante ao Norte . . . . . . . . 183

B.17 Descritiva da série após limpeza primária de pressão a jusante ao Sul . . . . . . . . 185

B.18 Descritiva dos valores omissos na série de pressão a jusante ao Sul . . . . . . . . . 186 
C.1 Descritiva da série tratada de nível . . . . . . . . . . . . . . . . . . 189

C.2 Descritiva da série tratada de consumo . . . . . . . . . . . . . . . . . 191

C.3 Descritiva da série tratada de vazão de entrada . . . . . . . . . . . . . . . . . 193

C.4 Descritiva da série tratada de vazão de saída Norte . . . . . . . . . . . . . . . . . 195

C.5 Descritiva da série tratada de vazão de saída Sul . . . . . . . . . . . . . . . . . 197

C.6 Descritiva da série tratada de pressão a montante ao Norte . . . . . . . . . . . . . . . 199

C.7 Descritiva da série tratada de pressão a montante ao Sul . . . . . . . . . . . . . . 201

C.8 Descritiva da série tratada de pressão a jusante ao Norte . . . . . . . . . . . . . . 203

C.9 Descritiva da série tratada de pressão a jusante ao Sul . . . . . . . . . . . . . 205 



\section{Lista de Tabelas}

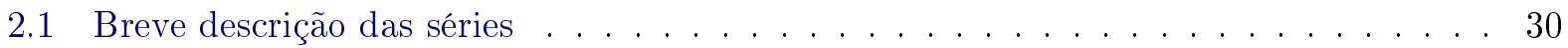

2.2 Breve descrição da quantidade de valores omissos . . . . . . . . . . . . . . . 33

2.3 Imputação de valores omissos: Experimentos de regressão . . . . . . . . . . . . . 38

2.4 Imputação de valores omissos: Experimentos de decomposição clássica . . . . . . . . 39

2.5 Imputação de valores omissos: Experimentos de decomposição STL . . . . . . . . . . 40

3.1 Série vazão de entrada no reservatório Peruíbe: RMSE dos 12 melhores métodos de preenchimento de dados omissos usando regressão . . . . . . . . . . . . . 51

3.2 Série vazão de entrada no reservatório Peruíbe: RMSE dos 12 melhores métodos de preenchimento de dados omissos usando decomposição clássica . . . . . . . . . . . 51

3.3 Série vazão de entrada no reservatório Peruíbe: RMSE dos 12 melhores métodos de preenchimento de dados omissos usando decomposição STL . . . . . . . . . . . . 51

3.4 Série vazão de entrada no reservatório Peruíbe: RMSE dos métodos benchmark de preenchimento de dados omissos. . . . . . . . . . . . . . . . . 52

3.5 Série vazão de entrada no reservatório Peruíbe: Proporção de detecção de outliers usando o melhor método de preenchimento de valores omissos. . . . . . . . . . . . . . 54

3.6 Série vazão de entrada no reservatório Peruíbe: RMSE da detecção de outliers usando o melhor método de preenchimento de valores omissos. . . . . . . . . . . . 55

3.7 Série vazão de entrada no reservatório Peruíbe: detecção de anomalias por estágio . . 55

3.8 Série vazão de entrada no reservatório Peruíbe: RMSE dos modelos de previsão . . . 57

3.9 Série nível do reservatório Peruíbe: RMSE dos 12 melhores métodos de preenchimento de dados omissos usando regressão . . . . . . . . . . . . . . . . . 59

3.10 Série nível do reservatório Peruíbe: RMSE dos 12 melhores métodos de preenchimento de dados omissos usando decomposição clássica . . . . . . . . . . . . . . . . 60

3.11 Série nível do reservatório Peruíbe: RMSE dos 12 melhores métodos de preenchimento de dados omissos usando decomposição STL . . . . . . . . . . . . . . . . 60

3.12 Série nível do reservatório Peruíbe: RMSE dos métodos benchmark de preenchimento de dados omissos. . . . . . . . . . . . . . . . . . . 6 60

3.13 Série nível do reservatório Peruíbe: Proporção de detecção de outliers usando o melhor método de preenchimento de valores omissos. . . . . . . . . . . . 63

3.14 Série nível do reservatório Peruíbe: RMSE da detecção de outliers usando o melhor método de preenchimento de valores omissos. . . . . . . . . . . . . . . . 64

3.15 Série nível do reservatório Peruíbe: detecção de anomalias por estágio . . . . . . . . . 64

3.16 Série nível do reservatório Peruíbe: RMSE dos modelos de previsão . . . . . . . . . . 66

3.17 Série consumo demandado do reservatório Peruíbe: RMSE dos 12 melhores métodos de preenchimento de dados omissos usando regressão . . . . . . . . . . . . . 68

3.18 Série consumo demandado do reservatório Peruíbe: RMSE dos 12 melhores métodos de preenchimento de dados omissos usando decomposição clássica . . . . . . . . . . 69

3.19 Série consumo demandado do reservatório Peruíbe: RMSE dos 12 melhores métodos de preenchimento de dados omissos usando decomposição STL . . . . . . . . . . . 69

3.20 Série consumo demandado do reservatório Peruíbe: RMSE dos métodos benchmark de preenchimento de dados omissos. . . . . . . . . . . . . . . . . 69 
3.21 Série consumo demandado do reservatório Peruíbe: Proporção de detecção de outliers usando o melhor método de preenchimento de valores omissos. . . . . . . . . . . . . 72

3.22 Série consumo demandado do reservatório Peruíbe: RMSE da detecção de outliers usando o melhor método de preenchimento de valores omissos. . . . . . . . . . . . . 73

3.23 Série consumo demandado do reservatório Peruíbe: detecção de anomalias por estágio 73

3.24 Série consumo demandado do reservatório Peruíbe: RMSE dos modelos de previsão . 75

3.25 Série vazão de saída para o Norte de Peruíbe: RMSE dos 12 melhores métodos de preenchimento de dados omissos usando regressão . . . . . . . . . . . . . . 77

3.26 Série vazão de saída para o Norte de Peruíbe: RMSE dos 12 melhores métodos de preenchimento de dados omissos usando decomposição clássica . . . . . . . . . . . . 78

3.27 Série vazão de saída para o Norte de Peruíbe: RMSE dos 12 melhores métodos de preenchimento de dados omissos usando decomposição STL . . . . . . . . . . . 78

3.28 Série vazão de saída para o Norte de Peruíbe: RMSE dos métodos benchmark de preenchimento de dados omissos. . . . . . . . . . . . . . . . 78

3.29 Série vazão de saída para o Norte de Peruíbe: Proporção de detecção de outliers usando o melhor método de preenchimento de valores omissos. . . . . . . . . . . 81

3.30 Série vazão de saída para o Norte de Peruíbe: RMSE da detecção de outliers usando o melhor método de preenchimento de valores omissos. . . . . . . . . . . . . 82

3.31 Série vazão de saída para o Norte de Peruíbe: detecção de anomalias por estágio . . . 82

3.32 Série vazão de saída para o Norte de Peruíbe: RMSE dos modelos de previsão . . . . 84

3.33 Série vazão de saída para o Sul de Peruíbe: RMSE dos 12 melhores métodos de preenchimento de dados omissos usando regressão . . . . . . . . . . . . . 86

3.34 Série vazão de saída para o Sul de Peruíbe: RMSE dos 12 melhores métodos de preenchimento de dados omissos usando decomposição clássica . . . . . . . . . . . . 87

3.35 Série vazão de saída para o Sul de Peruíbe: RMSE dos 12 melhores métodos de preenchimento de dados omissos usando decomposição STL . . . . . . . . . . . . . 87

3.36 Série vazão de saída para o Sul de Peruíbe: RMSE dos métodos benchmark de preenchimento de dados omissos. . . . . . . . . . . . . . . . . 87

3.37 Série vazão de saída para o Sul de Peruíbe: Proporção de detecção de outliers usando o melhor método de preenchimento de valores omissos. . . . . . . . . . . . . . 90

3.38 Série vazão de saída para o Sul de Peruíbe: RMSE da detecção de outliers usando o melhor método de preenchimento de valores omissos. . . . . . . . . . . . . . . . . 91

3.39 Série vazão de saída para o Sul de Peruíbe: detecção de anomalias por estágio . . . 91

3.40 Série vazão de saída para o Sul de Peruíbe: RMSE dos modelos de previsão . . . . . 93

3.41 Série pressão a montante ao Norte de Peruíbe: RMSE dos 12 melhores métodos de preenchimento de dados omissos usando regressão . . . . . . . . . . . . . . . 96

3.42 Série pressão a montante ao Norte de Peruíbe: RMSE dos 12 melhores métodos de preenchimento de dados omissos usando decomposição clássica . . . . . . . . . . . . 96

3.43 Série pressão a montante ao Norte de Peruíbe: RMSE dos 12 melhores métodos de preenchimento de dados omissos usando decomposição STL . . . . . . . . . . . . . 96

3.44 Série pressão a montante ao Norte de Peruíbe: RMSE dos métodos benchmark de preenchimento de dados omissos. . . . . . . . . . . . . . . . 97

3.45 Série pressão a montante ao Norte de Peruíbe: Proporção de detecção de outliers usando o melhor método de preenchimento de valores omissos. . . . . . . . . . . . . . 99

3.46 Série pressão a montante ao Norte de Peruíbe: RMSE da detecção de outliers usando o melhor método de preenchimento de valores omissos. . . . . . . . . . . . . . 100

3.47 Série pressão a montante ao Norte de Peruíbe: detecção de anomalias por estágio . 100

3.48 Série pressão a montante ao Norte de Peruíbe: RMSE dos modelos de previsão . . 102

3.49 Série pressão a montante ao Sul de Peruíbe: RMSE dos 12 melhores métodos de preenchimento de dados omissos usando regressão . . . . . . . . . . . . 105

3.50 Série pressão a montante ao Sul de Peruíbe: RMSE dos 12 melhores métodos de preenchimento de dados omissos usando decomposição clássica . . . . . . . . . . . . 105 
3.51 Série pressão a montante ao Sul de Peruíbe: RMSE dos 12 melhores métodos de preenchimento de dados omissos usando decomposição STL . . . . . . . . . . . . . . 105

3.52 Série pressão a montante ao Sul de Peruíbe: RMSE dos métodos benchmark de preenchimento de dados omissos. . . . . . . . . . . . . . . . . . . . 106

3.53 Série pressão a montante ao Sul de Peruíbe: Proporção de detecção de outliers usando o melhor método de preenchimento de valores omissos. . . . . . . . . . . . . . . 108

3.54 Série pressão a montante ao Sul de Peruíbe: RMSE da deteç̧ão de outliers usando o melhor método de preenchimento de valores omissos. . . . . . . . . . . . . 109

3.55 Série pressão a montante ao Sul de Peruíbe: detecção de anomalias por estágio . . . . 109

3.56 Série pressão a montante ao Sul de Peruíbe: RMSE dos modelos de previsão . . . . . 111

3.57 Série pressão a jusante ao Norte de Peruíbe: RMSE dos 12 melhores métodos de preenchimento de dados omissos usando regressão . . . . . . . . . . . . . . . . 114

3.58 Série pressão a jusante ao Norte de Peruíbe: RMSE dos 12 melhores métodos de preenchimento de dados omissos usando decomposição clássica . . . . . . . . . . . . . 114

3.59 Série pressão a jusante ao Norte de Peruíbe: RMSE dos 12 melhores métodos de preenchimento de dados omissos usando decomposição STL . . . . . . . . . . . . . 114

3.60 Série pressão a jusante ao Norte de Peruíbe: RMSE dos métodos benchmark de preenchimento de dados omissos. . . . . . . . . . . . . . . . . . 115

3.61 Série pressão a jusante ao Norte de Peruíbe: Proporção de detecção de outliers usando o melhor método de preenchimento de valores omissos. . . . . . . . . . . . . . . . . 117

3.62 Série pressão a jusante ao Norte de Peruíbe: RMSE da deteç̧ão de outliers usando o melhor método de preenchimento de valores omissos. . . . . . . . . . . . . . 118

3.63 Série pressão a jusante ao Norte de Peruíbe: detecção de anomalias por estágio . . . 118

3.64 Série pressão a jusante ao Norte de Peruíbe: RMSE dos modelos de previsão . . . . . 120

3.65 Série pressão a jusante ao Sul de Peruíbe: RMSE dos 12 melhores métodos de preenchimento de dados omissos usando regressão . . . . . . . . . . . . . . . . 123

3.66 Série pressão a jusante ao Sul de Peruíbe: RMSE dos 12 melhores métodos de preenchimento de dados omissos usando decomposição clássica . . . . . . . . . . . . 123

3.67 Série pressão a jusante ao Sul de Peruíbe: RMSE dos 12 melhores métodos de preenchimento de dados omissos usando decomposição STL . . . . . . . . . . . . . . 123

3.68 Série pressão a jusante ao Sul de Peruíbe: RMSE dos métodos benchmark de preenchimento de dados omissos. . . . . . . . . . . . . . . . . . . . 124

3.69 Série pressão a jusante ao Sul de Peruíbe: Proporção de detecção de outliers usando o melhor método de preenchimento de valores omissos. . . . . . . . . . . . . 126

3.70 Série pressão a jusante ao Sul de Peruíbe: RMSE da detecção de outliers usando o melhor método de preenchimento de valores omissos. . . . . . . . . . . . . . . 127

3.71 Série pressão a jusante ao Sul de Peruíbe: detecção de anomalias por estágio . . . . . 127

3.72 Série pressão a jusante ao Sul de Peruíbe: RMSE dos modelos de previsão . . . . . . 129

3.73 Procedimentos de detecção de outliers e preenchimento de valores omissos selecionados 132

3.74 Procedimentos de previsão selecionados . . . . . . . . . . . . . . . . 134

A.1 Medidas descritivas da série original de nível do reservatório de Peruíbe . . . . . . 140

A.2 Medidas descritivas da série original de consumo demandado do reservatório de Peruíbe142

A.3 Medidas descritivas da série original de vazão de entrada do reservatório de Peruíbe . 144

A.4 Medidas descritivas da série original de vazão de saída do reservatório para o Norte de Peruíbe . . . . . . . . . . . . . . . . . . . . . . . 146

A.5 Medidas descritivas da série original de vazão de saída do reservatório para o Sul de Peruíbe . . . . . . . . . . . . . . . . . . . . . 148

A.6 Medidas descritivas da série original de pressão a montante ao Norte de Peruíbe . . . 150

A.7 Medidas descritivas da série original de pressão a montante ao Sul de Peruíbe . . . . 152

A.8 Medidas descritivas da série original de pressão a jusante ao Norte de Peruíbe . . . . 154

A.9 Medidas descritivas da série original de pressão a jusante ao Sul de Peruíbe . . . . . 156 
B.1 Medidas descritivas da série após limpeza primária de nível do reservatório de Peruíbe160

B.2 Medidas descritivas da série após limpeza primária de consumo demandado do reservatório de Perúbe . . . . . . . . . . . . . . . . . . . . . 163

B.3 Medidas descritivas da série após limpeza primária de vazão de entrada do reservatório de Peruíbe . . . . . . . . . . . . . . . . . . . 166

B.4 Medidas descritivas da série após limpeza primária de vazão de saída do reservatório para o Norte de Peruíbe . . . . . . . . . . . . . . . . . . . . . . 169

B.5 Medidas descritivas da série após limpeza primária de vazão de saída do reservatório para o Sul de Peruíbe . . . . . . . . . . . . . . . . . . . . 172

B.6 Medidas descritivas da série após limpeza primária de pressão a montante ao Norte de Peruíbe . . . . . . . . . . . . . . . . . . . . . . . . . 175

B.7 Medidas descritivas da série após limpeza primária de pressão a montante ao Sul de

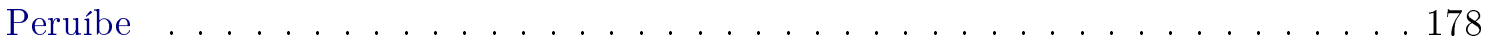

B.8 Medidas descritivas da série após limpeza primária de pressão a jusante ao Norte de

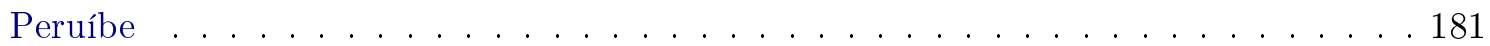

B.9 Medidas descritivas da série após limpeza primária de pressão a jusante ao Sul de

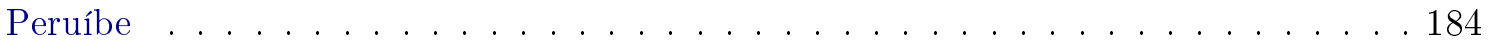

C.1 Medidas descritivas da série tratada de nível do reservatório de Peruíbe . . . . . . . 188

C.2 Medidas descritivas da série tratada de consumo demandado do reservatório de Peruíbe190

C.3 Medidas descritivas da série tratada de vazão de entrada do reservatório de Peruíbe . 192

C.4 Medidas descritivas da série tratada de vazão de saída do reservatório para o Norte de Peruíbe . . . . . . . . . . . . . . . . . . . . . . 194

C.5 Medidas descritivas da série tratada de vazão de saída do reservatório para o Sul de Peruíbe . . . . . . . . . . . . . . . . . . 196

C.6 Medidas descritivas da série tratada de pressão a montante ao Norte de Peruíbe . . . 198

C.7 Medidas descritivas da série tratada de pressão a montante ao Sul de Peruíbe . . . . 200

C.8 Medidas descritivas da série tratada de pressão a jusante ao Norte de Peruíbe . . . 202

C.9 Medidas descritivas da série tratada de pressão a jusante ao Sul de Peruíbe . . . . 204 


\section{Introdução}

Nos últimos anos o setor industrial tem passado por aquilo que se convencionou chamar de a quarta revolução industrial, ou, mais concisamente, Indústria 4.0. O termo Indústria 4.0 foi mencionado pela primeira vez em 2011, na Alemanha, a partir de uma proposta para o desenvolvimento de um novo conceito de política econômica alemã baseado em estratégias de alta tecnologia (ROBLEK; MEŠKO; KRAPEŽ, 2016 [RMK16]). Se as três primeiras revoluções industriais consistiram no surgimento da produção em massa, das linhas de montagem, no uso da eletricidade e na automação robótica, a quarta revolução industrial é pautada em conceitos e tecnologias que incluem, por exemplo, a fusão do mundo físico, digital e biológico, o uso de internet das coisas (IoT), de internet dos serviços (IoS), de inteligência artificial e o uso exaustivo de Big Data.

A Indústria 4.0 é uma jornada de desenvolvimento tecnológico pela qual cada setor industrial de cada país deverá percorrer. São grandes as expectativas dos fornecedores de máquinas, equipamentos, medidores e sensores; nomes como General Electric, Siemens, Amazon, IBM e Google já lançaram suas plataformas IoT na expectativa de serem provedores de informações oriundas dos dados brutos de sensores e equipamentos para os prestadores de serviços, como, por exemplo, as operadoras de distribuição de água, visto a presença de uma enorme infraestrutura de sensores, dispositivos de comunicação, redes de telemetria, redes próprias, concentradores de comunicação e supervisórios distribuídos que consolidam os dados gerados em ambientes centralizados com soluções SCADA (Supervisory Control and Data Acquisition). A presença dessa enorme infraestrutura deve acelerar a transformação digital na Indústria da água, promovendo uma maior automação do controle operacional dos sistemas adutores direcionada por dados.

Em meio a essa jornada, está a Sabesp, 5a maior empresa de saneamento do mundo. Foram várias as iniciativas dos colaboradores da companhia para automatizar a operação de etapas da adução e distribuição de água fazendo uso de seu big data. Tais iniciativas buscavam criar modelos previsionais de demanda de água, já que, em geral, a regularidade do perfil temporal do consumo da população em nível regional é alta. O Instituto de Pesquisas Tecnológicas (IPT) desenvolveu um modelo previsional de demanda de água por hora (modelos auto regressivo com variáveis exógenas) para a Sabesp em 2002 com resultados bastante satisfatórios (YOSHIDA, 2002 [Yos02]). Os modelos foram desenvolvidos para sete reservatórios de água do sistema adutor da região metropolitana de São Paulo (RMSP) que abastecem boa parte da área Leste da RMSP, nos quais foi possível notar um padrão reprodutivo no perfil de demanda. Já Santos e Pereira (2014) [DP14] propuseram uma abordagem com o uso de redes neurais para a previsão da demanda consumo por hora nos reservatórios da Sabesp localizados na RMSP. Diversos trabalhos, usando dados de outras empresas de saneamento, também propuseram usar redes neurais para predizer o consumo de água, tais como Bougadis et al. (2005) [BAD05], Rodriguez et al. (2017) [RPFL17], Antunes et al. (2018) [AACSLO18] e Pacchin et al. (2019) [PGAF19]. 
Outros dois trabalhos a serem destacados são os de Quevedo et al. (2010) [QPC $\left.{ }^{+} 10\right]$ e o de Barrela (2015) [Bar15]. Quevedo et al. (2010) usaram dados do consumo água da cidade de Barcelona, na Espanha, para fazer uma modelagem com funções trigonométricas, cujos objetivos eram fazer previsões e criar regras de decisão que verificavam se uma futura observação era ou não um possível outlier. Já Barrela (2015) usou o modelo sugerido por Quevedo et al (2010) e os modelos BATS e TBATS para fazer reconstrução de valores omissos das séries de consumo de água na cidade de Lisboa, em Portugal, utilizando-se da combinação de técnicas de forecasting e backcasting a partir de uma ponderação dos valores preditos gerados por esses dois métodos.

Logo, propomos neste trabalho uma solução de análise de séries temporais para a indústria da água que busca detectar anomalias, reconstruir valores omissos e, então, fazer previsão. Utilizamos os dados gerados pelo sistema de adução e distribuição de água referentes ao reservatório de Peruíbe localizado na cidade de mesmo nome. As séries, mantidas em historiadores de sistemas supervisórios para serem monitoráveis em tempo real, foram fornecidos pela Sabesp da Baixada Santista e sua amostragem temporal é a cada hora, indo das 1:00 do dia $1^{0}$ de janeiro de 2017 até às 23:00 do dia 31 de dezembro de 2018. Diferente dos trabalhos citados anteriormente, as séries aqui analisadas não se referem ao consumo de água explicito atribuído ao reservatório, mas são obtidas diretamente do medidor de vazão na entrada do reservatório, do medidor de nível no reservatório e dos medidores de vazões e de pressões instalados na rede de distribuição da cidade, o que pode muitas vezes resultar num comportamento não tão bem definidos como aqueles observados nos trabalhos mencionados.

Além da sua utilização para previsões de demanda de água na área de concessão da empresa de saneamento, as séries são utilizadas para acionar equipes de manutenção das estações elevatórias e dos reservatórios de distribuição, cuja operação é centralizada no Centro de Controle Operacional (CCO). O CCO fica distante das estações elevatórias e dos reservatórios onde estão localizados os pontos de medição e telemetria. Visto que por lei a qualquer tempo não pode haver interrupção no fornecimento de água no município, a integridade dos registros das séries temporais recebidas no $\mathrm{CCO}$ emitidas pelos equipamentos e sensores é fundamental, no entanto, a ocorrência de vazios e anomalias nos registros das séries temporais é frequente. Embora haja regras de classificação da qualidade do dado enviado (em Good ou Bad), estas indicam a frequência de apenas 1\% a 1,5\% de erros nas séries temporais, não correspondendo as indicações de uma análise exploratória dessas séries. Essas regras foram desenvolvidas há muito tempo, necessitando, assim, de atualizações e de correções. Pelos motivos expostos, a primeira meta deste trabalho é desenvolver um procedimento para indicar a qualidade dos dados enviados ao CCO. Uma vez que as anomalias da série foram identificadas, tais valores podem ser considerados como omissos. Assim, a segunda meta é propor métodos de preenchimento dos vazios das séries temporais. A terceira meta é desenvolver modelos previsionais com boa acurácia que antecipem os valores das séries temporais, em tempo real, das próximas horas, para alimentar ou apoiar a programação diária da operação dos reservatórios e distribuição da água num município. A hipótese das metas é que a regularidade do comportamento humano no consumo de água impacta na reprodutibilidade do ciclo sazonal das séries temporais analisadas, o que contribui positivamente para o desenvolvimento de métodos de qualificação e tratamento dos dados.

O objetivo principal deste projeto é contribuir para a Transformação Digital da Indústria e das Cidades, conforme previsto no "Plano de Desenvolvimento Institucional na Área de Transformação Digital: Manufatura Avançada e Cidades Inteligentes e Sustentáveis" do IPT em projeto apoiado 
pela FAPESP (Processo FAPESP: 2017/50343-2). Este plano de desenvolvimento busca desenvolver competências, tanto no IPT quanto nas universidades, para contribuírem na Transformação Digital que se anuncia em todos os segmentos de mercado. Este trabalho de mestrado busca contribuir para a Transformação Digital da Indústria da água.

Esta dissertação possui a seguinte estrutura: o Capítulo 1 é destinado a fazer uma revisão teórica dos métodos e modelos usados nas análises; o Capítulo 2 descreve a metodologia e o procedimento adotado para aplicar os modelos descritos no Capítulo 2 aos nossos objetivos; o Capítulo 3 mostra os resultados da aplicação dos procedimentos fazendo, concomitantemente, uma discussão desse resultados. Por fim, o Capítulo 4 apresenta as conclusões. 


\section{Capítulo 1}

\section{Revisão teórica}

Neste capítulo apresentamos uma breve revisão teórica de alguns conceitos essenciais em Séries Temporais e faremos uma breve descrição dos modelos utilizados neste trabalho.

A seção 1.1 é dedicada a revisar os princípios básicos e a fazer algumas definições e introdução de notações. A partir da seção 1.2 entramos na apresentação de procedimentos e modelos que serão a base dos métodos propostos no capítulo 2, a saber, os modelos de decomposição (Seção 1.2), os modelos SARIMA (Seção 1.3), os modelos de regressão com erros autocorrelacionados (Seção 1.4), os modelos BATS e TBATS (Seção 1.5), os procedimentos de deteç̧ão de outliers (Seção 1.6) e, por fim, a técnica de rolling analysis de séries temporais (Seção 1.7).

\subsection{Caracterização de uma série temporal}

Começaremos definindo alguns conceitos mais básicos: o de processo estocástico e o de série temporal.

Definição 1.1. Um processo estocástico discreto $\mathbf{Z}$ é uma sequência de variáveis aleatórias $\left\{Z_{t}\right\}_{t \in \tau}$ indexadas por um conjunto $\tau=\{0,1,2, \ldots\}$.

Definição 1.2. Uma série temporal é um conjunto de observações indexadas no tempo gerado por um processo estocástico.

Embora as definições de processo estocástico e série temporal sejam distintas, não faremos nenhuma distinção de notação quando $\mathbf{Z}$ se referir a um processo estocástico ou a uma série temporal. Também usaremos a notação $\mathbf{Z}$ ou $\left\{Z_{t}\right\}_{t \in \tau}$ qual for a mais conveniente em dado contexto para representar uma série temporal ou processo estocástico.

A seguir são apresentadas algumas definições que procuram especificar algumas características de um processo estocástico.

Definição 1.3. A função média do processo $\mathbf{Z}$ é definida como

$$
\mu_{t}=E\left[Z_{t}\right]=\int_{-\infty}^{\infty} z f(z ; t) d z .
$$


Definição 1.4. A função de autocovariância é definida como

$$
\gamma\left(t_{1}, t_{2}\right)=\operatorname{Cov}\left[Z_{t_{1}}, Z_{t_{2}}\right]=E\left[\left(Z_{t_{1}}-\mu_{t_{1}}\right)\left(Z_{t_{2}}-\mu_{t_{2}}\right)\right],
$$

para todos $\tau_{1}, t_{2} \in \tau$. Em particular, se $t_{1}=t_{2}=t$, obtemos a função variância

$$
\gamma\left(t_{1}, t_{2}\right)=\operatorname{Var}\left[Z_{t}\right]=E\left[Z_{t}^{2}\right]-\mu_{t}^{2} .
$$

Definição 1.5. A função de autocorrelação é definida como

$$
\rho\left(t_{1}, t_{2}\right)=\frac{\gamma\left(t_{1}, t_{2}\right)}{\sqrt{\gamma\left(t_{1}, t_{1}\right) \gamma\left(t_{2}, t_{2}\right)}},
$$

para todo $t_{1}, t_{2} \in \tau$.

Uma classe de processos estocásticos de bastante importância no contexto da análise de séries temporais é a classe dos processos fracamente estacionários, definidos a seguir.

Definição 1.6. O processo $Z_{t}$ é estacionário de segunda ordem (ou fracamente estacionário) se

- $E\left[Z_{t}\right]=\mu, \quad \forall \in \tau$

- $E\left[Z_{t}^{2}\right]<\infty, \quad \forall \in \tau$;

- $\gamma\left(t_{1}, t_{2}\right)$ depende apenas de $\left|t_{1}-t_{2}\right|, \quad \forall t_{1}, t_{2} \in \tau$.

Nota-se que se um processo $\mathbf{Z}$ é estacionário, então sua função de autocorrelação, por exemplo, $\gamma(0, h)$ depende apenas de $h$, assim como $\gamma(t, t+h)$ também depende apenas de $h$, implicando que $\gamma(0, h)=\gamma(t, t+h)$. Logo, convém reescrever as definições 1.4 e 1.5 para o caso em que o processo for estacionário.

Definição 1.7. A função de autocovariância de um processo estacionário $\left\{Z_{t}\right\}_{t \in \tau}$ é definida como

$$
\gamma(h)=\operatorname{Cov}\left[Z_{t}, Z_{t+h}\right]=E\left[\left(Z_{t}-\mu\right)\left(Z_{t+h}-\mu\right)\right] .
$$

Definição 1.8. A função de autocovariância de um processo estacionário $\left\{Z_{t}\right\}_{t \in \tau}$ é definida como

$$
\rho(h)=\frac{\gamma(t, t+h)}{\sqrt{\gamma(t, t) \gamma(t+h, t+h)}}=\frac{\gamma(h)}{\gamma(0)} .
$$

Introduziremos a seguir alguns operados que nos ajudará a manipular alguns dos modelos a serem apresentados. 
Definição 1.9. O operador translação $m$ passos para o passado $B$ é definido como

$$
B^{m} Z_{t}=Z_{t-m}
$$

Definição 1.10. O operador diferença $\Delta_{s}^{m}$ de ordem $m$ e defasagem $s$ é definido como

$$
\Delta_{s}^{m} Z_{t}=\left(1-B^{s}\right)^{m} Z_{t}=\left(1-B^{s}\right)^{m-1}\left(1-B^{s}\right) Z_{t}=\Delta_{s}^{m-1}\left(\Delta_{s} Z_{t}\right),
$$

sendo que

$$
\Delta_{s} Z_{t}=\left(1-B^{s}\right) Z_{t}=Z_{t}-Z_{t-s}
$$

As próximas seções são dedicadas a apresentar métodos e modelos que nos serão úteis nas análises das séries temporais consideradas neste trabalho.

\subsection{Modelos de decomposição}

Um tipo de procedimento comumente utilizado em análises de séries temporais é a decomposição da série em componentes que buscam descrever alguns de seus comportamentos intrínsecos. Geralmente, essas componentes são descritas como tendência $(T)$, sazonalidade $(S)$ e ruído $(R)$.

A decomposição de uma série $\left\{Z_{t}\right\}_{t \in \tau}$ pode ser aditiva, supondo que a série é formada pela soma das componentes

$$
Z_{t}=T_{t}+S_{t}+R_{t}
$$

ou também pode ser multiplicativa, supondo que a série é formada pela multiplicação das componentes

$$
Z_{t}=T_{t} \times S_{t} \times R_{t}
$$

Nota-se que se tomarmos o $\log$ de $Z_{t}$ na equação (1.10) a decomposição torna-se aditiva

$$
\log Z_{t}=\log T_{t}+\log S_{t}+\log R_{t}
$$

Uma transformação mais geral, que muitas vezes é utilizada para estabilizar a variância ou para tornar em aditivas séries que apresentam um comportamento multiplicativo ou um comportamento que seja uma mistura entre o multiplicativo e o aditivo, é a transformação de Box-Cox [BC64], definida a seguir.

Definição 1.11. A transformação de Box-Cox é definida como

$$
Z_{t}^{(\lambda)}=\left\{\begin{array}{rr}
\frac{\left(Z_{t}\right)^{\lambda}-1}{\lambda}, & \lambda \neq 0 \\
\log Z_{t}, & \lambda=0 .
\end{array}\right.
$$


Existem diversas formas para a escolha do melhor parâmetro $\lambda$ de acordo com a série $\left\{Z_{t}\right\}_{t \in \tau}$. Adotaremos aqui a abordagem de Guerrero (1993) [Gue93], na qual é escolhido o $\lambda$ que minimiza o coeficiente de variação das subséries de $\left\{Z_{t}\right\}_{t \in \tau}$.

Logo, podemos assumir que as técnicas de análises de séries aditivas também são aplicáveis a séries que se tornam em aditivas através de alguma transformação. Porém, vale mencionar que as estimativas geradas a partir da série transformada são em geral enviesadas, sendo necessário, em algumas situações, fazer correções de vieses que nem sempre são fáceis de se obter. Mais detalhes, ver Hyndman e Athanasopoulos (2019) [HA19].

Nas próximas subseções são apresentados métodos de decomposição que pressupõem que a série $\left\{Z_{t}\right\}_{t \in \tau}$ seja formada por componentes aditivas.

\subsubsection{Decomposição via ajuste de curvas de regressão}

Um procedimento frequentemente utilizado é modelar os componentes $T_{t}$ e $S_{t}$ da equação (1.9) usando modelos de regressão. Podemos modelar a tendência por um polinômio de ordem $m$

$$
T_{t}=\beta_{0}+\beta_{1} t+\ldots+\beta_{m} t^{m}=\sum_{i=0}^{m} \beta_{i} t^{i},
$$

em que $m$ é bem menor do que a quantidade de observações na série. Já o componente sazonal pode ser modelado por

$$
S_{t}=\alpha_{1} D_{1, t}+\ldots+\alpha_{s-1} D_{s-1, t}=\sum_{j=1}^{s-1} \alpha_{j} D_{j, t},
$$

em que $s$ representa o período da série e $D_{1, t}, \ldots, D_{s-1, t}$ podem ser variáveis dummies tais que

$$
D_{j, t}=\left\{\begin{aligned}
-1, & \text { se } t \equiv 0(\bmod s) \\
1, & \text { se } t \equiv j(\bmod s) \\
0, & \text { c.c. }
\end{aligned}\right.
$$

Assim a equação (1.9) é escrita como

$$
Z_{t}=\sum_{i=0}^{m} \beta_{i} t^{i}+\sum_{j=1}^{s-1} \alpha_{j} D_{j, t}+R_{t}
$$

ou, em notação matricial

$$
Z=X \beta+R
$$

em que

$$
\boldsymbol{Z}=\left[\begin{array}{c}
Z_{1} \\
\vdots \\
Z_{N}
\end{array}\right]_{N \times 1}, \quad \boldsymbol{\beta}=\left[\begin{array}{c}
\beta_{0} \\
\vdots \\
\beta_{m} \\
\alpha_{1} \\
\vdots \\
\alpha_{s-1}
\end{array}\right]_{(m+s) \times 1} \quad, \quad \boldsymbol{R}=\left[\begin{array}{c}
R_{1} \\
\vdots \\
R_{N}
\end{array}\right]_{N \times 1}
$$




$$
\boldsymbol{X}=\left[\begin{array}{cccccccc}
1^{0} & 1^{1} & \ldots & 1^{m} & D_{1,1} & D_{2,1} & \ldots & D_{s-1,1} \\
2^{0} & 2^{1} & \ldots & 2^{m} & D_{1,2} & D_{2,2} & \ldots & D_{s-1,2} \\
\vdots & \vdots & \ddots & \vdots & \vdots & \vdots & \ddots & \vdots \\
N^{0} & N^{1} & \ldots & N^{m} & D_{1, N} & D_{2, N} & \ldots & D_{s-1, N}
\end{array}\right]_{N \times(m+s)}
$$

A estimativa $\hat{\beta}$ dos parâmetros do vetor $\beta$ do modelo (1.13) pode ser realizada via mínimos quadrados, ou seja,

$$
\hat{\boldsymbol{\beta}}=\left(\boldsymbol{X}^{\prime} \boldsymbol{X}\right)^{-1} \boldsymbol{X}^{\prime} \boldsymbol{Z}
$$

Para uma discussão mais detalhada do uso de modelos de regressão ver Draper e Smith (1998) [DS98] ou Kutner et al. (2005) [KNNL05].

\subsubsection{Decomposição clássica}

A decomposição clássica surgiu por volta da década de 1920 e foi vastamente usada até a década de 1950. É um método simples que consiste na aplicação sucessivas de filtros de médias móveis com intuito de primeiro calcular a tendência e depois a sazonalidade. Antes de descrevermos o método em si, apresentamos uma definição de filtro de médias móveis.

Definição 1.12. Um filtro de média móveis com janela de tamanho $m$, denotado por $m$ - $M A$, é dado por

$$
\bar{Z}_{t}=\frac{1}{m} \sum_{i=-k}^{k} Z_{t+i}
$$

se $m$ for ímpar e com $m=2 k+1, k \in \mathbb{N}$, ou será dado por

$$
\bar{Z}_{t}=\frac{1}{m}\left[\frac{1}{2} Z_{t-k}+\left(\sum_{i=-(k-1)}^{k-1} Z_{t+i}\right)+\frac{1}{2} Z_{t+k}\right],
$$

se $\mathrm{m}$ for par e com $m=2 k, k \in \mathbb{N}$.

Uma vez definido o filtro de médias móveis, podemos descrever algoritmo da decomposição. De acordo com Hyndman e Athanasopoulos (2019) [HA19], um algoritmo para a decomposição clássica consiste nos seguintes passos:

1. Seja $s$ o número de observações de um período da série, a uma estimativa $\hat{T}_{t}$ da tendência é obtido aplicando um filtro de médias móveis de janela de tamanho $s$.

2. Calcula-se a série livre de tendência $Z_{t}-\hat{T}_{t}$.

3. Calcula-se as médias de cada nível sazonal usando todos os valores para este nível disponível na série livre de tendência $Z_{t}-\hat{T}_{t}$. Essas médias serão uma estimativa da sazonalidade $\hat{S}_{t}$.

4. Calcula-se o componente ruído: $\hat{R}_{t}=Z_{t}-\hat{T}_{t}-\hat{S}_{t}$.

Os autores ainda discutem que 
- A decomposição clássica assume que a sazonalidade é a mesma durante toda a série, assim, para séries muito longas, essa não seria uma premissa razoável;

- Não é possível fazer uma estimativa da tendência para os primeiros $\frac{s-1}{2}$ e os últimos $\frac{s-1}{2}$ valores da série no caso de $s$ impar. No caso de $s$ par não teremos as estimativas de tendência dos primeiros e últimos $\frac{s}{2}$ valores.

- Valores atípicos podem ter um grande impacto nas estimativas $\hat{T}_{t}$ e $\hat{S}_{t}$.

- A decomposição não consegue lidar com valores omissos.

\subsubsection{STL}

Proposto por Cleveland et al. (1990) [CCMT90], o STL (Seasonal-Trend Decomposition Procedure Based on Loess) é um procedimento de decomposição de uma série temporal aditiva nas três componentes dadas na equação (1.9). O STL é um procedimento robusto, iterativo e baseado na aplicação sucessivas de suavizações loess em combinação com filtros de médias móveis.

\section{loess}

Começamos descrevendo a suavização loess. Sejam $x_{i}$ e $y_{i}$, com $i=1, \ldots, N$, medidas de uma variável explicativa e resposta. Seja $\hat{g}(x)$ uma curva de suavização de $y$, dado $x$. Essa curva é definida para todo $x$ e não apenas para $x_{i}$ o que permite lidar com valores omissos.

Para o computo de $\hat{g}(x)$ um valor positivo $q$ é escolhido. Se $q \ll n$, os $q$ valores próximos de $x$ são escolhidos e é atribuído a eles pesos $v_{i}(x)$ de tal forma a considerar a distância em relação a $x$. Os pesos são dados por

$$
v_{i}(x)=W\left(\frac{\left|x_{i}-x\right|}{\max \left(\left|x_{i}-x\right|\right)}\right)
$$

em que $W$ é a função tri cúbica

$$
W(u)=\left\{\begin{aligned}
\left(1-u^{3}\right)^{3}, & \text { se } 0 \leq u \leq 1 \\
0, & \text { se } u \geq 1 .
\end{aligned}\right.
$$

O próximo passo é ajustar um polinômio de ordem $d$ com peso $v_{i}(x)$ no ponto $\left(x_{i}, y_{i}\right)$. Agora se $q>n$, faz-se uma pequena modificação na expressão (1.17):

$$
v_{i}(x)=W\left(\frac{\left|x_{i}-x\right|}{\frac{q}{n} \max \left(\left|x_{i}-x\right|\right)}\right) .
$$

\section{Processo iterativo}

O STL consiste de dois processos interativos: a aplicação de um loop interno dentro de um loop externo. Em cada passagem pelo loop interno, ambas a tendência e a sazonalidade são atualizadas. O loop interno possui $n_{(i)}$ iterações. Cada loop externo consiste de um loop interno seguido pelo cálculo dos pesos robustos. Esses pesos são usados no próximo passo do loop interno a fim de reduzir o breve comportamento discrepante na tendência e sazonalidade. O passo inicial do loop externo é realizado com todos os pesos iguais a 1 e então todas as $n_{(e)}$ iterações do loop externo são realizadas. Denotaremos por $n_{(p)}$ o tamanho do período da série e chamaremos de subsérie de ciclo uma 
sequência de observações referentes a uma mesma componente sazonal. Assim, por exemplo, uma série mensal com começo em janeiro de 2008 e término em dezembro de 2017 terá $n_{(p)}=12$ e a subsérie de ciclo referente ao mês de fevereiro é composta sequencialmente pelos valores de fevereiro de cada ano, totalizando 10 valores.

\section{loop interno}

Cada passo do loop interno consiste de uma suavização sazonal que atualiza o componente sazonal, seguido por uma suavização da tendência que atualiza o componente de tendência. Dessa forma, para cada $t=1, \ldots, N$ teremos uma componente $S_{t}^{(k)}$ e $T_{t}^{(k)}$ ao final do $k$-ésima iteração do loop interno. A atualização da $(k+1)$ iteração é realizada da seguinte forma:

1. Calcula-se a série livre de tendência $Z_{t}-T_{i}^{(k)}$. Se $Z_{t}$ for um valor omisso, então o valor de $Z_{t}-T_{i}^{(k)}$ também será omisso.

2. Cada subsérie de ciclo da série livre de tendência é suavizada por um loess com $q=n_{(s)}$ e $d=1$. Os valores suavizados são calculados para todas as posições da subsérie de ciclo, incluindo àqueles omissos, e também para as posições seguinte e anterior da subsérie de ciclo. Dessa forma, o conjunto dos $C_{t}^{(k+1)}$ valores suavizados contém $N+2 n_{(p)}$ valores, com $t=-n_{(p)}+1, \ldots, N+n_{(p)}$.

3. Um filtro de médias móveis de tamanho $n_{(p)}$ é aplicado aos valores $C_{t}^{(k+1)}$. Seguidamente é aplicado outro filtro de médias móveis de tamanho 3 e por fim uma suavização loess com $d=1$ e $q=n_{(l)}$. Teremos como resultado uma série $L_{t}^{(k+1)}$ definida para $t=1, \ldots, N$.

4. A componente sazonal da $(k+1)$-ésima iteração é $S_{t}^{(k+1)}=C_{t}^{(k+1)}-L_{t}^{(k+1)}$, para $t=1, \ldots, N$.

5. Calcula-se a série sazonalmente ajustada $Z_{t}-S_{i}^{(k+1)}$. Se $Z_{t}$ for um valor omisso, então o valor de $Z_{t}-S_{i}^{(k+1)}$ também será omisso.

6. A série sazonalmente ajustada $Z_{t}-S_{i}^{(k+1)}$ é suavizada por loess com $q=n_{(T)}$ e $d=1$. Os valores suavizados são calculados para todas as posições de 1 até $N$, incluindo aquelas com valores omissos. O resultado desse passo é o componente tendência da $(k+1)$-ésima iteração, $T_{t}^{(k+1)}$.

Para iniciar o procedimento acima, é necessário fornecer os valores de $T_{i}^{(0)}$. Geralmente usa-se $T_{i}^{(0)}=\mathbf{0}$, fazendo com que, a princípio, toda a tendência seja incluída em $C_{t}^{(1)}$, o que não é um problema, já que depois ela é praticamente removida no passo 4.

\section{loop externo}

Após a passagem de um loop interno, o ruído é

$$
R_{t}=Z_{t}-T_{t}-S_{t}
$$

Definiremos pesos robustos, $\rho_{t}$, para cada ponto onde $Z_{t}$ é observado. Estes pesos dependerão do quão grande for o valor de $\left|R_{t}\right|$. Ou seja

$$
\rho_{t}=B\left(\frac{\left|R_{t}\right|}{6 \text { mediana }\left(\left|R_{t}\right|\right)}\right)
$$


em que $B$ é a função bi quadrática:

$$
B(u)=\left\{\begin{aligned}
\left(1-u^{2}\right)^{2}, & \text { se } 0 \leq u \leq 1 \\
0, & \text { se } u \geq 1 .
\end{aligned}\right.
$$

Após isto, o loop interno é repetido, porém nas suavizações dos passos 2 e 6 os pesos das vizinhanças serão multiplicados por $\rho_{t}$. O objetivo disso é trazer uma confiabilidade maior aos pesos dados a cada observação. O total de repetições do loop externo é $n_{(e)}$ e em cada uma delas, ao iniciar o loop interno, tomaremos $T_{i}^{(0)}=\mathbf{0}$.

\section{Escolha dos parâmetros}

O modelo tem no total seis parâmetros, e que devem ser escolhidos levando em conta as seguintes características:

- Tamanho do período sazonal da série $n_{(p)}$ : é escolhido de acordo com a frequência apresentada pela série;

- Parâmetro de suavização do filtro passa baixo $n_{(l)}$ : é o menor inteiro impar maior ou igual a $n_{(p)}$;

- Parâmetro de suavização da componente sazonal $n_{(s)}$ : é um inteiro impar maior ou igual a 7 e é escolhido de acordo com o conhecimento sobre a série;

- Parâmetro de suavização da componente de tendência $n_{(t)}$ : é o menor inteiro impar maior ou igual a $\frac{1,5 n_{(p)}}{1-1,5 n_{(s)}}$;

- Número de iterações do loop interno $n_{(i)}$ : se a robustez não for necessária $n_{(i)}=2$, caso contrário $n_{(i)}=1$;

- Número de iterações do loop externo $n_{(e)}$ : se a robustez não for necessária $n_{(e)}=0$, caso contrário $n_{(e)}=5$ já produz bons resultados, sendo que $n_{(e)}=10$ produz uma convergência quase certa.

Para uma discussão mais detalhada sobre a escolha dos parâmetros e sobre a implementação do método ver Cleveland et al. (1990).

\subsection{Modelos SARIMA}

Nosso principal objetivo nesta seção é descrever os modelos autorregressivo e de médias móveis sazonal multiplicativo, ou SARIMA. Para isso, começamos apresentando os modelos que pressupõe que a série temporal $\left\{Z_{t}\right\}_{t \in \tau}$ seja estacionária de segunda ordem de acordo com a definição 1.6. Esses são os modelos autorregressivos puro (AR), os de médias móveis puro (MA) e os autorregressivos e de médias móveis (ARMA). Depois introduziremos os modelos autorregressivos integrados e de médias móveis (ARIMA) que lidam com séries orginalmente não estacionária, mas que se tornam estacionária após tomada algumas diferenças de acordo com a equação (1.8). Por fim discutiremos os modelos autorregressivo e de médias móveis sazonal multiplicativo. Discussões mais detalhadas sobre a classe de modelos ARIMA podem ser encontradas em Morettin e Toloi (2006) [MT06] ou em Box et al. (2013) [BJR13]. 


\subsubsection{Modelos autorregresivos}

Em muitas aplicações, é usual supor que o valor atual $Z_{t}$ depende de alguns valores passados $Z_{t-1}, Z_{t-2}, \ldots, Z_{t-p}$, em que $p$ é o total de passo do passado que influenciam no valor de $Z_{t}$. Uma forma de modelar essa relação é através dos modelos autorregressivos.

Definição 1.13. Um modelo autorregressivo de ordem $p, \operatorname{AR}(p)$, é escrito da forma

$$
Z_{t}-\mu=\phi_{1}\left(Z_{t-1}-\mu\right)+\ldots+\phi_{p}\left(Z_{t-p}-\mu\right)+\xi_{t}
$$

em que $Z_{t}$ é um processo estacionário de segunda ordem, $E\left[Z_{t}\right]=\mu, \xi_{t} \sim R B\left(0, \sigma^{2}\right)$ e $\phi_{1}, \ldots, \phi_{p}$ são os parâmetros autorregressivos.

Em alguns casos é conveniente supor, sem perca de generalidade, que a média do processo $Z_{t}$ vale 0 . Assim a formula de (1.19) se reduz a

$$
Z_{t}=\phi_{1} Z_{t-1}+\ldots+\phi_{p} Z_{t-p}+\xi_{t}
$$

Também é conveniente usar a notação de operadores introduzida pela expressão (1.7) para representar o processo (1.20),

$$
\left(1-\phi_{1} B-\ldots-\phi_{p} B^{p}\right) Z_{t}=\xi_{t}
$$

o que nos permite introduzir o operador autorregressivo:

$$
\phi(B)=\left(1-\phi_{1} B-\ldots-\phi_{p} B^{p}\right)
$$

e, assim, a equação (1.21) pode ser resumida em

$$
\phi(B) Z_{t}=\xi_{t} .
$$

\subsubsection{Modelos de médias móveis}

Como uma alternativa aos modelos autorregressivos, temos os modelos de médias móveis.

Definição 1.14. Um modelo de médias móveis de ordem $q, \mathrm{MA}(q)$, é escrito da forma

$$
Z_{t}-\mu=\xi_{t}+\theta_{1} \xi_{t-1}+\ldots+\theta_{q} \xi_{t-q}
$$

em que $Z_{t}$ é um processo estacionário de segunda ordem, $E\left[Z_{t}\right]=\mu, \xi_{t} \sim R B\left(0, \sigma^{2}\right)$ e $\theta_{1}, \ldots, \theta_{q}$ são os parâmetros de médias móveis.

Se $E\left[Z_{t}\right]=0$, então o processo

$$
Z_{t}=\xi_{t}+\theta_{1} \xi_{t-1}+\ldots+\theta_{q} \xi_{t-q}
$$

Usando a notação de operadores para representar o processo (1.25), teremos

$$
Z_{t}=\left(1+\theta_{1} B+\ldots+\theta_{q} B^{q}\right) \xi_{t},
$$


o que nos permite introduzir o operador de médias móveis:

$$
\boldsymbol{\theta}(B)=\left(1+\theta_{1} B+\ldots+\theta_{q} B^{q}\right)
$$

e, assim, a equação (1.26) pode ser resumida em

$$
Z_{t}=\boldsymbol{\theta}(B) \xi_{t}
$$

\subsubsection{Modelos autorregresivos e de médias móveis}

Na modelagem de muitas séries temporais estacionárias, podemos diminuir a quantidade de parâmetros se usarmos modelos que possuam termos autorregressivos e de médias móveis. Surgem, então, os modelos ARMA $(p, q)$ definidos a seguir.

Definição 1.15. Um modelo autorregressivo e de médias móveis de ordens p e q, $\operatorname{ARMA}(p, q)$, é escrito da forma

$$
Z_{t}-\mu=\phi_{1}\left(Z_{t-1}-\mu\right)+\ldots+\phi_{p}\left(Z_{t-p}-\mu\right)+\xi_{t}+\theta_{1} \xi_{t-1}+\ldots+\theta_{q} \xi_{t-q},
$$

em que $Z_{t}$ é um processo estacionário de segunda ordem, $E\left[Z_{t}\right]=\mu, \xi_{t} \sim R B\left(0, \sigma^{2}\right), \phi_{1}, \ldots, \phi_{p}$ são os parâmetros autorregressivos e $\theta_{1}, \ldots, \theta_{q}$ são os parâmetros de médias móveis.

Também podemos escrever o modelo (1.29) em termos dos operadores autorregressivos e de médias móveis

$$
\phi(B)\left(Z_{t}-\mu\right)=\boldsymbol{\theta}(B) \xi_{t} .
$$

Se o processo tem média 0, então a equação (1.30) fica simplesmente

$$
\boldsymbol{\phi}(B) Z_{t}=\boldsymbol{\theta}(B) \xi_{t}
$$

\subsubsection{Estimação dos modelos ARMA}

Vamos considerar o problema de estimar os parâmetros de modelo ARMA $(p, q)$. Seja $Z_{1}, \ldots, Z_{N}$ uma série observada gerada por um processo $\operatorname{ARMA}(p, q)$ e

$$
\boldsymbol{\nu}=\left(\phi_{1}, \ldots, \phi_{p}, \theta_{1}, \ldots, \theta_{q}, \mu, \sigma^{2}\right)^{\prime}
$$

um vetor com todos os parâmetros do modelo. Para determinar o estimador de máxima verossimilhança (EMV) iremos supor que $\xi_{t} \sim N\left(0, \sigma^{2}\right)$, assim, o EMV será próximo do estimado de mínimos quadrados (EMQ).

Isolando o termo $\xi_{t}$ da expressão (1.29), teremos a seguinte equação

$$
\xi_{t}=\left(Z_{t}-\mu\right)-\phi_{1}\left(Z_{t-1}-\mu\right)-\ldots-\phi_{p}\left(Z_{t-p}-\mu\right)-\theta_{1} \xi_{t-1}-\ldots-\theta_{q} \xi_{t-q} .
$$

Para que a equação (1.33) seja válida para todo $t$ é necessário se ter valores iniciais de $\mathbf{Z}$ e $\boldsymbol{\xi}$, denotados aqui por $\boldsymbol{Z}^{*}=\left(Z_{0}, \ldots, Z_{1-p}\right)$ e $\boldsymbol{\xi}^{*}=\xi_{0}, \ldots, \xi_{1-q}$. 
A função de verossimilhança condicionada à escolha de $Z^{*}$ e $\xi^{*}$ é dada por:

$$
\begin{aligned}
L\left(\boldsymbol{\nu} \mid \boldsymbol{Z}, \boldsymbol{Z}^{*}, \boldsymbol{\xi}^{*}\right) & =\left(2 \pi \sigma^{2}\right)^{-\frac{n}{2}} \exp \left\{-\frac{1}{2 \sigma^{2}} \sum_{t=1}^{N}\left[\left(Z_{t}-\mu\right)-\phi_{1}\left(Z_{t-1}-\mu\right)-\ldots\right.\right. \\
& \left.\left.-\phi_{p}\left(Z_{t-p}-\mu\right)-\theta_{1} \xi_{t-1}-\ldots-\theta_{q} \xi_{t-q}\right]^{2}\right\} .
\end{aligned}
$$

Chamaremos o somatório da equação (1.34) de soma de quadrados condicional e o denotaremos por

$$
\begin{aligned}
S\left(\boldsymbol{\nu} \mid \boldsymbol{Z}, \boldsymbol{Z}^{*}, \boldsymbol{\xi}^{*}\right) & =\sum_{t=1}^{N}\left[\left(Z_{t}-\mu\right)-\phi_{1}\left(Z_{t-1}-\mu\right)-\ldots\right. \\
& \left.-\phi_{p}\left(Z_{t-p}-\mu\right)-\theta_{1} \xi_{t-1}-\ldots-\theta_{q} \xi_{t-q}\right]^{2}
\end{aligned}
$$

Ao tomar o log da função (1.34), obtemos que

$$
l\left(\boldsymbol{\nu} \mid \boldsymbol{Z}, \boldsymbol{Z}^{*}, \boldsymbol{\xi}^{*}\right) \propto-N \log \sigma^{2}-\frac{S\left(\boldsymbol{\nu} \mid \boldsymbol{Z}, \boldsymbol{Z}^{*}, \boldsymbol{\xi}^{*}\right)}{2 \sigma^{2}} .
$$

A estimava de máxima verossimilhança condicionada é obtida encontrando os parâmetros que maximizam a expressão (1.36) ou que minimizam a soma de quadrados da equação (1.35).

\subsubsection{Modelos autorregresivos integrados e de médias móveis}

Muitas das séries analisadas na prática não são estacionárias, mas ao tomarmos algumas diferenças (geralmente uma ou duas) a série se torna estacionária. Ou seja, a série $\left\{Z_{t}\right\}_{t \in \tau}$ não é estacionária, mas a série $\left\{\Delta^{d} Z_{t}\right\}_{t \in \tau}$ é estacionária, sendo $\Delta^{d}$ o operador de diferenças definido pela expressão (1.8). Esses tipos de séries são chamados de não estacionária homogêneas ou portadoras de raízes unitárias. A seguir é definido uma classe de modelos que lidam com esses tipos de séries, os modelos ARIMA.

Definição 1.16. Um modelo autorregressivo, integrado e de médias móveis de ordens $p, d$ e $q$, $\operatorname{ARIMA}(p, d, q)$, é escrito da forma

$$
\Delta^{d} Z_{t}=\phi_{1} \Delta^{d} Z_{t-1}+\ldots+\phi_{p} \Delta^{d} Z_{t-p}+\xi_{t}+\theta_{1} \xi_{t-1}+\ldots+\theta_{q} \xi_{t-q}
$$

em que $Z_{t}$ é um processo estacionário, $E\left[Z_{t}\right]=\mu, \xi_{t} \sim R B\left(0, \sigma^{2}\right), \phi_{1}, \ldots, \phi_{p}$ são os parâmetros autorregressivos e $\theta_{1}, \ldots, \theta_{q}$ são os parâmetros de médias móveis.

Escrevendo o processo em termos de operadores, temos

$$
\phi(B) \Delta^{d} Z_{t}=\boldsymbol{\theta}(B) \xi_{t}
$$

A escolha de $d$ é realizada de acordo com o comportamento da série. Pode-se usar testes de raiz unitária, como KPSS (KWIATKOWSKI et al., 1992 [KPSS92]), PP (PERRON, 1988 [Per88]) ou ADF (DICKEY; FULLER, 1981 [DF81]), para ajudar na escolha de $d$ : aplica-se o teste de raízes unitária na série $\left\{Z_{t}\right\}_{t \in \tau}$, se a hipótese de estacionariedade for rejeitada, então toma-se a série de uma diferença $\left\{\Delta Z_{t}\right\}_{t \in \tau}$ e aplica-se o teste novamente. O procedimento é realizado até encontrar uma diferença $d$ que torne a série estacionária. Geralmente o valor de $d$ não excede 2 . 
A estimação dos demais parâmetros do modelo $\operatorname{ARIMA}(p, d, q)$ é análogo ao dos modelos $\operatorname{ARMA}(p, q)$, já que uma vez que o valor $d$ é conhecido, o processo $\left\{\Delta Z_{t}\right\}_{t \in \tau}$ é um ARMA $(p, q)$. O que muda, neste caso, é que, em geral, a série diferenciada possui média 0 , logo o parâmetro $\mu$ da equação (1.32) não precisará ser estimado. Nota-se também que ao tomar as diferenças a quantidade de elementos na amostra "diminui", ou seja, se a série $\left\{Z_{t}\right\}_{t \in \tau}$ possui $N$ elementos, a série diferenciada $\left\{\Delta Z_{t}\right\}_{t \in \tau}$ possuirá $N-1$ elementos.

\subsubsection{Modelos multiplicativos sazonais autorregresivos integrados e de médias móveis}

Após apresentar toda a construção dos modelos ARIMA, chegamos, enfim, aos modelos SARIMA, cuja a principal característica é usar toda a estrutura dos modelos ARIMA para modelar sazonalidade estocástica que uma série possa vir apresentar. Sua definição é dada a seguir.

Definição 1.17. Um modelo autorregressivo e de médias móveis sazonal multiplicativo, SARIMA $(p, d, q) \times(P, D, Q)_{[s]}$, é escrito da forma

$$
\boldsymbol{\phi}(B) \boldsymbol{\Phi}\left(B^{s}\right) \Delta_{s}^{D} \Delta^{d} Z_{t}=\boldsymbol{\theta}(B) \boldsymbol{\Theta}\left(B^{s}\right) \xi_{t},
$$

em que $\Delta_{s}^{D} \Delta^{d} Z_{t}$ é um processo estacionário; $E\left[Z_{t}\right]=0 ; \xi_{t} \sim R B\left(0, \sigma^{2}\right)$ e

- $\phi(B)=\left(1-\phi_{1} B-\ldots-\phi_{p} B^{p}\right)$ é o operador autorregressivo não sazonal;

- $\boldsymbol{\theta}(B)=\left(1+\theta_{1} B+\ldots+\theta_{q} B^{q}\right)$ é o operador de médias móveis não sazonal;

- $\Phi\left(B^{s}\right)=\left(1-\Phi_{1} B^{s}-\ldots-\Phi_{P} B^{s P}\right)$ é o operador autorregressivo sazonal;

- $\boldsymbol{\Theta}\left(B^{s}\right)=\left(1+\Theta_{1} B^{s}+\ldots+\Theta_{Q} B^{s Q}\right)$ é o operador de médias móveis sazonal.

Todo modelo $\operatorname{SARIMA}(p, 0, q) \times(P, 0, Q)_{[s]}$ pode ser escrito sob a forma de um modelo ARMA, o que faz com a estimação de seus parâmetros sejam equivalentes ao apresentado para os modelos ARMA.

A previsão de $h$ passos à frente é

$$
\begin{aligned}
& \Delta^{d} \Delta_{s}^{D} \hat{Z}_{t+h \mid t}=\hat{\phi}_{1}\left[\Delta^{d} \Delta_{s}^{D} Z_{t+h-1 \mid t}\right]+\ldots \\
& \quad+\hat{\phi}_{p+s P}\left[\Delta^{d} \Delta_{s}^{D} Z_{t+h-p-s P \mid t}\right]+\hat{\theta}_{1}\left[\xi_{t+h-1 \mid t}\right]+\ldots \\
& \quad+\hat{\theta}_{q+s Q}\left[\xi_{t+h-q-s Q \mid t}\right]+\left[\xi_{t+h \mid t}\right]
\end{aligned}
$$

ou, se adotarmos a notação de operados para $\Delta^{d} \Delta_{s}^{D}=(1-B)^{d}\left(1-B^{s}\right)^{D}$

$$
\begin{aligned}
& \hat{Z}_{t+h \mid t}=\hat{\phi}_{1}^{*}\left[Z_{t+h-1 \mid t}\right]+\ldots+\hat{\phi}_{p+d+s P+s D}^{*}\left[Z_{t+h-p-d-s P-s D \mid t}\right]+\hat{\theta}_{1}\left[\xi_{t+h-1}\right]-\ldots \\
& \quad+\hat{\theta}_{q+s Q}\left[\xi_{t+h-q-s Q \mid t}\right]+\left[\xi_{t+h \mid t}\right]
\end{aligned}
$$

de modo que

$$
Z_{t+k}=\left\{\begin{array}{cc}
\hat{Z}_{t+k \mid t}, & \text { se } k>0 \\
\hat{Z}_{t+k}, & \text { se } k \leq 0
\end{array}\right.
$$




$$
\xi_{t+k}=\left\{\begin{aligned}
0, & \text { se } k>0 \\
\xi_{t+k}, & \text { se } k \leq 0 .
\end{aligned}\right.
$$

Vale ressaltar que para calcular $\hat{Z}_{t+h \mid t}$, precisamos de $\hat{Z}_{t+h-1 \mid t}, \ldots, \hat{Z}_{t+1 \mid t}$, que são obtidos recursivamente.

\subsubsection{Identificação: um procedimento de seleção de modelos SARIMA}

Um dos principais desafios na aplicação dos modelos SARIMA $(p, d, q) \times(P, D, Q)_{[s]}$ é a identificação das ordens do modelo, sobretudo dos parâmetros $p, q, P$ e $Q$. Um procedimento bastante famoso é o que foi proposto por Box e Jenkins, no qual o processo de identificação se baseia na análise das funções de autocorrelações e autocorrelações parciais amostrais da amostra. Porém, este procedimento é de difícil automatização e inviável quando se planeja trabalhar com muitas séries temporais ao mesmo tempo.

Se $d$ e $D$ são conhecidos, uma alternativa é estimar um conjunto de modelos e escolher aquele que apresentar o menor AIC ou algum outro critério de informação. O maior problema desse procedimento é definir qual seria o conjunto de modelos a serem estimados, sendo a solução mais simples definir as ordens máxima para p, q, P e Q e ajustar todos os possíveis modelos. Nota-se que esse procedimento sofre de um custo computacional muito alto, pois se, por exemplo, as ordens máximas fossem $p=q=3$ e $P=Q=2$ teríamos um total de $4 \times 4 \times 3 \times 3=144$ modelos para serem estimados, se consideramos que pode haver um parâmetro de intercepto, teríamos o dobro desse valor. Logo necessitaríamos de uma maneira de reduzir essa quantidade de modelos.

Pensando nessa problemática, Hyndman e Khandakar (2008) [RY08] propuseram um algoritmo de seleção de modelos SARIMA baseado em critérios de informação, o qual empregam um procedimento chamado por eles de "stepwise". O algoritmo consiste em duas etapas: a primeira encontra os valores de $D$ e $d$, enquanto que a segunda emprega o algoritmo stepwise para encontrar os valores $p, q, P$ e $Q$. Mais explicitamente, seja $\left\{Z_{t}\right\}_{t \in \tau}$ uma série temporal, o algoritmo é:

Etapa 1: Encontrar os valores de $d$ e $D$.

1. O número de diferenças $D$ pode ser obtido de acordo com a medida de força da sazonalidade proposta por Wang et al. (2006) [WSH06] ou usando testes de raiz unitárias como o HEGY (HYLLEBERG; 1995 [Hy195]) OCSB (OSBORN ET AL.; 1988 [OCSB88]) e o Canova-Hansen (CANOVA E HANSEN; 1995 [CH95]) considerando a série $\left\{Z_{t}\right\}_{t \in \tau}$.

2. A série $\left\{\Delta_{s}^{D} Z_{t}\right\}_{t \in \tau}$ é calculada;

3. A escolha de $d$ é feita usando testes de raiz unitárias, como o KPSS (KWIATKOWSKI et al., 1992 [KPSS92]), PP (PERRON, 1988 [Per88]) ou ADF (DICKEY; FULLER, 1981 [DF81]) considerando a série $\left\{\Delta_{s}^{D} Z_{t}\right\}_{t \in \tau}$;

4. A série $\left\{\Delta^{d} \Delta_{s}^{D} Z_{t}\right\}_{t \in \tau}$ é calculada.

Etapa 2: Encontrar os valores de $p, q, P$ e $Q$ com o emprego do algoritmo stepwise.

1. Fixa-os valores máximos para $p, q, P$ e $Q$ e pode-se fixar também o valor total $p+q+P+Q$.

2. Fixa-se uma medida de informação, que pode ser AIC, AICc ou BIC.

3. Quatro modelos iniciais são propostos: 
- SARIMA $(0, d, 0) \times(0, d, 0)$;

- SARIMA $(1, d, 0) \times(1, d, 0)$;

- $\operatorname{SARIMA}(0, d, 1) \times(0, d, 1)$;

- $\operatorname{SARIMA}(2, d, 2) \times(1, D, 1)$.

4. Os modelos são ajustados e calcula-se a medida de informação de cada um.

5. O modelo que tiver a melhor medida de informação (como por exemplo, menor AIC) é selecionado e considerado como modelo atual.

6. Consideraremos treze possíveis variações de acordo com o modelo atual:

- apenas uma das ordens p, q, P e Q são permitidas variar em \pm 1 ;

- ambas as ordens p e q são permitidas variar em \pm 1 ;

- ambas as ordens $\mathrm{P}$ e Q são permitidas variar em \pm 1 ;

- uma constante é incluída no modelo se o modelo atual não possui constante ou excluída se o modelo atual possui a constante.

7. Se um modelo com melhor medida de informação for encontrado então tal modelo se torna o novo modelo atual e procedimento 6 é repetido. Se houver mais de um modelo com uma melhor medida de informação que do que o modelo atual, então seleciona-se aquele que entre aqueles tiver o melhor valor. Se não houver modelos com melhor medida de informação em relação ao atual, então o modelo atual é o selecionado e procedimento termina.

São consideradas algumas restrições visando evitar problemas com convergências próximas raiz unitárias, tais como a rejeição de qualquer modelo que esteja próximo da não invertibilidade ou da não estacionaridade e se tiver algum erro advindo da rotina de otimização linear usada para a estimação, então o modelo também é rejeitado.

A figura 1.1, extraída de Hyndman e Athanasopoulos (2019) [HA19], ilustra como que ocorre o procedimento de busca pelo melhor modelos no caso de um ARIMA não sazonal.

\subsection{Regressão com erros autocorrelacionados}

Há situações em que se tem a disponibilidade de $m$ séries $\left\{x_{i, t}\right\}_{t \in \tau}$, com $i=1,2 \ldots, m$, de variáveis que estão intimamente relacionaciadas com a série $\left\{Z_{t}\right\}_{t \in \tau}$, o que sugere o uso de modelos de regressão com erros autocorrelacionados para modelar as dependências existentes entre as séries e a dependência temporal simultaneamente. Assim, o modelo de regressão com erros autocorrelacionados é dado por

$$
Z_{t}=\sum_{i=1}^{m} \beta_{i} x_{i, t}+W_{t},
$$

de modo que $W_{t}$ é um processo estacionário $\operatorname{ARMA}(p, q)$,

$$
W_{t}=\phi_{1} W_{t-1}+\ldots+\phi_{p} W_{t-p}+\xi_{t}+\theta_{1} \xi_{t-1}+\ldots+\theta_{q} \xi_{t-q},
$$

$\operatorname{com} E\left[W_{t}\right]=0, \xi_{t} \sim R B\left(0, \sigma^{2}\right), \phi_{1}, \ldots, \phi_{p}$ são os parâmetros autorregressivos e $\theta_{1}, \ldots, \theta_{q}$ são os parâmetros de médias móveis. 


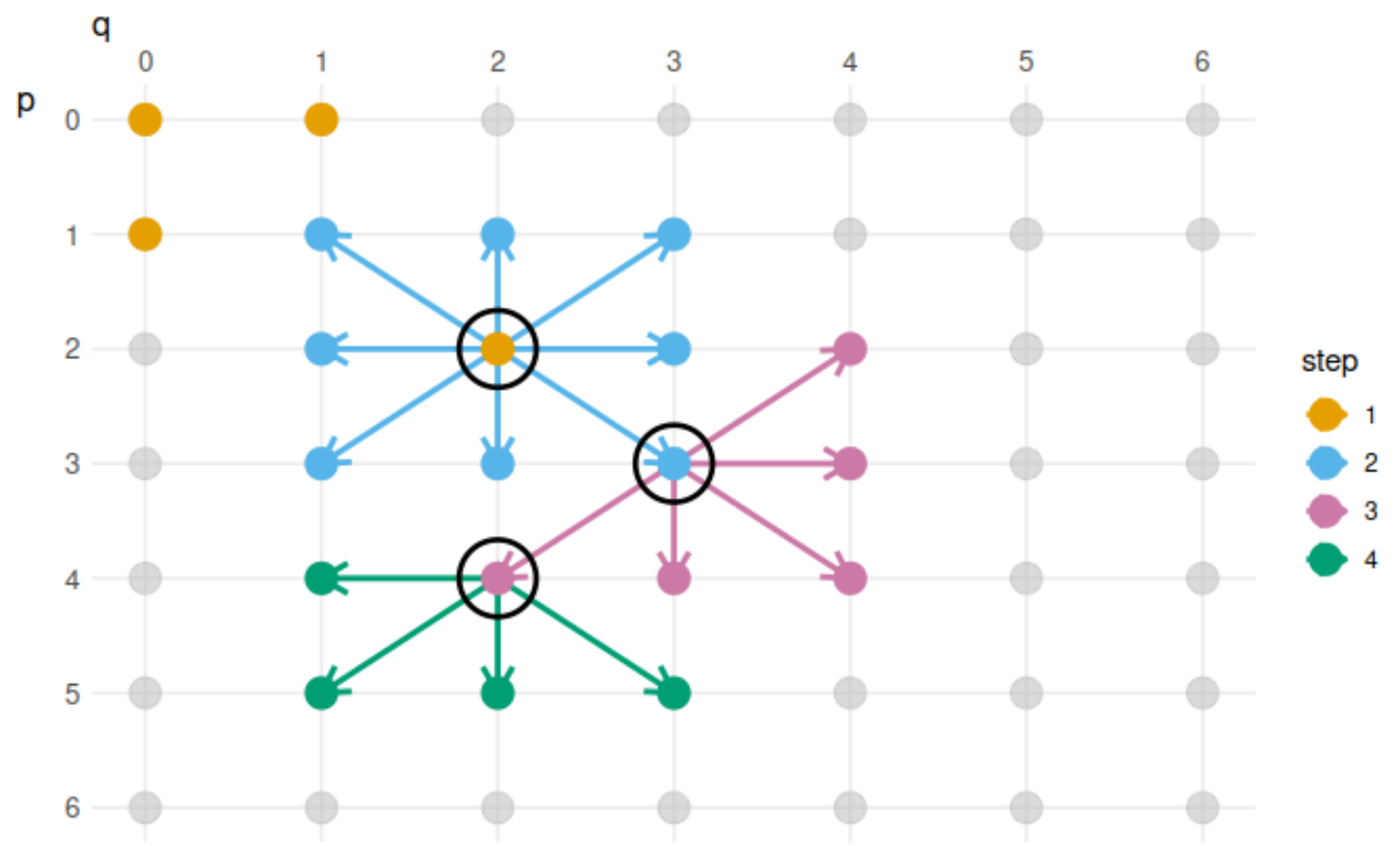

Figura 1.1: Esquema de como ocorre a etapa do stepwise na busca pelo melhor modelo ARIMA $(p, d, q)$ usando o algoritmo proposto por Hyndman e Khandakar [RY08]

Adotando a notação de operadores, podemos reescrever (1.43) como

$$
\boldsymbol{\phi}(B) W_{t}=\boldsymbol{\theta}(B) \xi_{t}
$$

e, consequentemente, podemos reescrever (1.42) como

$$
Z_{t}=\sum_{i=1}^{m} \beta_{i} x_{i, t}+\frac{\boldsymbol{\theta}(B)}{\boldsymbol{\phi}(B)} \xi_{t}
$$

de onde vem que

$$
\xi_{t}=\frac{\boldsymbol{\phi}(B)}{\boldsymbol{\theta}(B)} Z_{t}-\sum_{i=1}^{m} \beta_{i} \frac{\boldsymbol{\phi}(B)}{\boldsymbol{\theta}(B)} x_{i, t}
$$

Seja $Z_{1}, \ldots, Z_{N}$ uma série observada e $\boldsymbol{v}=\left(\phi_{1}, \ldots, \phi_{p}, \theta_{1}, \ldots, \theta_{p}, \beta_{1}, \ldots, \beta_{k}\right)^{\prime}$ o vetor de parâmetros do modelo, o estimador de mínimos quadrados é obtido minimizando a soma do quadrado dos erros

$$
\hat{\boldsymbol{v}}_{M Q}=\underset{\boldsymbol{v}}{\arg \max }\left\{\sum_{i=1}^{N} \xi_{i}^{2}\right\}=\arg \max \left\{\sum_{i=1}^{N}\left[\frac{\boldsymbol{\phi}(B)}{\boldsymbol{\theta}(B)} Z_{t}-\sum_{i=1}^{m} \beta_{i} \frac{\boldsymbol{\phi}(B)}{\boldsymbol{\theta}(B)} x_{i, t}\right]^{2}\right\} .
$$

A solução de (1.46) é obtida usando métodos numéricos (SHUMWAY; STOFFER, 2017) [SS17]. As previsões usando os modelos de regressão com erros autocorrelacionados são realizadas substituindo os parâmetros da equação (1.42) por suas estimativas e calculando o valor de $\hat{Z}_{t}$. Ou seja, 


$$
\hat{Z}_{t}=\sum_{i=1}^{m} \hat{\beta}_{i} x_{i, t}+\hat{W}_{t}
$$

com

$$
\hat{W}_{t}=\hat{\phi}_{1} W_{t-1}+\ldots+\hat{\phi}_{p} W_{t-p}+\xi_{t}+\hat{\theta}_{1} \xi_{t-1}+\ldots+\hat{\theta}_{q} \xi_{t-q} .
$$

\subsection{Modelos BATS e TBATS}

Propostos por De Livera et al. (2011) [dLHS11], os modelos BATS (Box-Cox transformation, ARMA erros, Trend and Seasonal components) e TBATS (Trigonometric, Box-Cox transformation, ARMA erros, Trend and Seasonal components) são extensões dos modelos de suavização exponencial que buscam lidar com séries temporais que apresentem "comportamento complexo", tais como sazonalidade cuja frequência é um número não inteiro, séries com frequências muito longas ou com a presença de mais de uma sazonalidade. A seguir, é apresentada uma definição formal do modelo BATS.

Definição 1.18. Seja $\left\{Z_{t}^{(\omega)}\right\}_{t \in \tau}$ a série resultante da transformação de Box-Cox de $Z_{t}$ dada em (1.11), o modelo BATS $\left(\omega, \varphi, p, q, m_{1}, \ldots, m_{T}\right)$ com $T$ padrões sazonais, é definido como

$$
Z_{t}^{(\omega)}=\ell_{t-1}+\varphi b_{t-1}+\sum_{i=1}^{T} s_{t-m_{i}}^{(i)}+d_{t},
$$

em que:

- $\ell_{t}$ é o nível local no tempo $t$ e vale

$$
\ell_{t}=\ell_{t-1}+\varphi b_{t-1}+\alpha d_{t}
$$

- $\varphi$ é parâmetro de amortecimento de tendência;

- $b_{t}$ é a tendência de curto prazo e é dada por

$$
b_{t}=(1-\varphi) b+\varphi b_{t-1}+\beta d_{t},
$$

sendo $b$ a tendência de longo prazo;

- $s_{t}^{(i)}$ representa a $i$-ésima componente sazonal no tempo $t$ e é dada por

$$
s_{t}^{(i)}=s_{t-m_{i}}^{(i)}+\gamma_{i} d_{t}
$$

- $m_{1}, \ldots m_{T}$ denotam os períodos sazonais;

- $d_{t}$ é um processo ARMA $(p, q)$, ou seja

$$
d_{t}=\sum_{i=1}^{p} \phi_{i} d_{t-i}+\sum_{i=1}^{q} \theta_{i} \xi_{t-i}+\xi_{t},
$$

com $\xi_{t} \sim N\left(0, \sigma^{2}\right)$ e os $\phi_{i}$ são os parâmetros autorregressores e $\theta_{i}$ são os parâmetros de médias móveis; 
- $\alpha, \beta$ e $\gamma_{i}, \operatorname{com} i=1, \ldots, T$, são parâmetros de suavização.

Daremos agora uma definição para o modelo TBATS.

Definição 1.19. Seja $\left\{Z_{t}^{(\omega)}\right\}_{t \in \tau}$ a série resultante da transformação de Box-Cox de $Z_{t}$ dada em (1.11), o modelo TBATS $\left(\omega, \varphi, p, q,\left\{m_{1}, k_{1}\right\}, \ldots,\left\{m_{T}, k_{T}\right\}\right)$ com $T$ padrões sazonais é definido como

$$
Z_{t}^{(\omega)}=\ell_{t-1}+\varphi b_{t-1}+\sum_{i=1}^{T} s_{t-m_{i}}^{(i)}+d_{t}
$$

em que:

- $\ell_{t}$ é o nível local no tempo $t$ e vale

$$
\ell_{t}=\ell_{t-1}+\varphi b_{t-1}+\alpha d_{t}
$$

- $\varphi$ é parâmetro de amortecimento de tendência;

- $b_{t}$ é a tendência de curto prazo e é dada por

$$
b_{t}=(1-\varphi) b+\varphi b_{t-1}+\beta d_{t}
$$

sendo $b$ a tendência de longo prazo;

- $s_{t}^{(i)}$ representa a $i$-ésima componente sazonal no tempo $t$ e é dada por

$$
s_{t}^{(i)}=\sum_{j=1}^{k_{i}} s_{j, t}^{(i)}
$$

no qual $k_{i}$ representa o número de harmônicos necessários para a $i$-ésima componente sazonal e $s_{j, t}^{(i)}$ é o nível estocástico da $i$-ésima componente sazonal modelado por

$$
s_{j, t}^{(i)}=s_{j, t-1}^{(i)} \cos \lambda_{j}^{(i)}+s_{j, t-1}^{*(i)} \sin \lambda_{j}^{(i)}+\gamma_{1}^{(i)} d_{t}
$$

$\operatorname{com} \lambda_{j}^{(i)}=\frac{2 \pi j}{m_{i}}$ e $s_{j, t}^{*(i)}$ sendo o crescimento estocástico no nível da $i$-ésima componente sazonal, de modo que

$$
s_{j, t}^{*(i)}=-s_{j, t-1} \sin \lambda_{j}^{(i)}+s_{j, t-1}^{*(i)} \cos \lambda_{j}^{(i)}+\gamma_{2}^{(i)} d_{t}
$$

- $m_{1}, \ldots m_{T}$ denotam os períodos sazonais;

- $d_{t}$ é um processo $\operatorname{ARMA}(p, q)$, ou seja

$$
d_{t}=\sum_{i=1}^{p} \phi_{i} d_{t-i}+\sum_{i=1}^{q} \theta_{i} \xi_{t-i}+\xi_{t},
$$

com $\xi_{t} \sim N\left(0, \sigma^{2}\right)$ e os $\phi_{i}$ são os parâmetros autorregressores e $\theta_{i}$ são os parâmetros de médias móveis; 
- $\alpha, \beta, \gamma_{1}^{(i)}$ e $\gamma_{2}^{(i)}$, com $i=1, \ldots, T$, são parâmetros de suavização.

A diferença entre os modelos BATS e TBATS é a forma com que a sazonalidade é modelada: no modelo TBATS ela é modelada por componentes trigonométricas, o que permite reduzir a quantidade de parâmetros a serem estimados.

A estimação dos parâmetros dos modelos BATS e TBATS é realizada escrevendo os modelos na forma de equações de estado-espaço, de onde são derivados os estimadores de máxima verossimilhança condicionada ou os estimadores que minimizam a soma dos erros ao quadrado. As previsões também são derivadas das equações de estado-espaço através do filtro de Kalman. Mais detalhes sobre os procedimentos de estimação e previsão podem ser encontrados em De Livera et al. (2011) [dLHS11].

\subsubsection{Seleção de modelos BATS e TBATS}

Os modelos BATS e TBATS possuem uma quantidade de parâmetros que nem sempre são necessários e que, se em excesso, pode prejudicar a qualidade das previsões. Logo, De Livera et al. (2011) [dLHS11] propõem um procedimento de seleção de modelo usando basicamente o AIC. O procedimento consiste em ajustar o modelo com e sem determinado parâmetro e selecionar aquele com o menor valor de AIC. Por exemplo, no caso dos modelos TBATS, o procedimento para determinar a quantidade de harmônicos $k_{i}$, usado para modelar as componentes sazonais, consiste em adicionar um a um as componentes ao modelo e calcular o AIC, quando o menor AIC for encontrado o procedimento para. O procedimento se faz necessário, pois, em muitas aplicações, considerar todos os parâmetros é impraticável, além de que usar um modelo com uma quantidade desnecessária de parâmetros pode prejudicar a acurácia da previsão.

O procedimento usado para selecionar a ordem do modelo ARMA para o ruído é equivalente àquele descrito na seção 1.3.7, porém aqui é realizado em três estágios: primeiro estima-se o modelo supondo ruído branco, depois seleciona um modelo ARMA aos ruídos de acordo com o método descrito na seção 1.3.7 e então, com o modelo ARMA foi identificado, todo o modelo BATS ou TBATS é reajustado considerando o processo ARMA selecionado.

Os detalhes sobre a seleção automática dos modelos BATS e TABTS pode ser encontrado em De Livera et al. (2011) [dLHS11].

\subsection{Outliers}

É comum observarmos valores discrepantes em séries temporais de forma que parecem estar em desacordo com comportamento geral da série. Essas observações são os chamados outliers, acerca dos quais faremos uma discussão sobre suas detecções e sobre os efeitos das suas presenças nas séries temporais. A detecção dos outliers, em geral, pode ter o objetivo de se fazer um estudo mais aprofundado sobre as motivações de ocorrência de tais valores ou, então, evitar que tais valores discrepantes influenciem demasiadamentes nos cálculos de estatistiscas, como, por exemplo, estimativas dos parâmetros de um determinado modelo. O nosso objetivo neste trabalho é detectar e tratar os outliers na perspectiva de amenizar suas influências sobre os valores previstos gerados por um determinado modelo ou método. 
A literatura de Estatística é dotada de vastos textos sobre como detectar e tratar a presença de outliers em um conjunto de dados. Talvez o método mais simples e conhecido de detectar os outliers seja através do uso do boxplot, método este que foi popularizado pelos trabalhos Tukey. Também são usadas frequentemente medidas de distâncias da observações em relação a alguma medida de posição central dos dados, como as distâncias em relação a mediana ou em relação a média. Dessa forma, as observações cuja a distância ultrapassa um limiar pré definido são consideradas outliers. Porém, a maioria dessas metodologias consideram que o conjunto de dados seja composto por observações independentes entre si, algo que não ocorre no caso das séries temporais.

O estudo sobre a presença de outliers em séries temporais teve início com os trabalhos de Fox (1972)[Fox72], no qual foi analisado dois tipos de outliers: os additive outlier (AO) e os innovational outlier (IO). Os outliers AO correspondem a situações em que ocorre algum tipo erro que afeta somente a uma única observação, enquanto que outliers IO correspondem a situações bem mais extremas, nas quais um possível evento atípico afeta não unicamente uma obsevação, mas todo um conjunto de observações em sequência. Tsay (1988)[TR88] considerou mais dois tipos de outliers: level change (LC) e o transient level change (TC). Divesos outros trabalhos abordaram a temática, dos quais podemos destacar Chen e Liu (1993)[CL93], onde é apresentado um procedimento iterativo de detecção e tratamento dos outliers. Porém, em todos esses trabalhos é assumido que a série livre dos outliers é um processo ARMA, o que nem sempre pode ser verificado na realidade, além de descreverem algoritmos de deteç̧ão e tratamento de outliers que demandam um alto custo computacional quando a série temporal é muito longa.

Logo, damos aqui uma abordagem mais simples e robusta para a detecção e tratamento de outliers. A subseção 1.6.1 define uma estrutura para os outlier, enquanto que a subseção 1.6.2 descreve o método de detecção e tratamento.

\subsubsection{Uma definição de outliers}

Antes de definir outliers, vamos dar uma definição sobre o que é um efeito atípico.

Definição 1.20. Efeito atípico é todo efeito que induz anormalias na série temporal.

Assim, um efeito atípico pode influenciar uma única observação ou pode afetar uma sucessão de observações. Podemos, portanto, definir outlier:

Definição 1.21. Seja $\left\{Z_{t}\right\}_{t \in \tau}$ uma série temporal gerada por um processo aleatório $f(),$.$A conjunto$ de todos os efeitos atípicos que influem sobre a série e a um elemento de $A$, um outlier é toda observação influenciada por um efeito atípico e pode ser escrito da seguinte forma

$$
Z_{t}=f(t)+\omega_{a} g_{a}\left(t, t_{1}, k\right),
$$

em que $a$ é um efeito atípico, $\omega_{a}$ é a intensidade do efeito atípico $a, g_{a}($.$) é a forma com que efeito$ atípico $a$ ocorre, $t_{1}$ é o índice da observação em que começa o efeito atipico $a$ e $k>0$ é a duração do efeito.

A definição acima nos ajudará a propor experimentos nos quais se queira avaliar a eficiência de métodos de deteç̧ão e tratamento de outliers. 


\subsubsection{Um método robusto e iterativo de tratamento de outliers}

Uma vez definido o que é um outlier, o próximo desafio é elaborar um método para detectar e tratar todos eles. Adotaremos aqui um procedimento relativamente simples, inspirado na construção do diagrama boxplot.

Seja $\left\{Z_{t}\right\}_{t \in \tau}$ uma série temporal gerada por um processo aleatório $f($.$) e seja M$ o máximo de iterações desejada, a $i$-ésima iteração do procedimento iterativo de detecção dos outliers é:

1. Defina uma função ou método $\hat{f}_{i}($.$) para calcular as estimativas \hat{Z}_{t}^{(i)}$;

2. Estime os resíduos $\hat{R}_{t}^{(i)}=Z_{t}-\hat{Z}_{t}^{(i)}$;

3. Calcule os quantis $q_{a}^{(i)}$ e $q_{b}^{(i)}$ dos $\hat{R}_{t}^{(i)}$, em que $q_{a}^{(i)}<q_{b}^{(i)}$;

4. Tome $I_{(a, b)}^{(i)}=q_{b}^{(i)}-q_{a}^{(i)}$;

5. Sendo $c$ uma constante já conhecida, classifique $Z_{t}$ como outlier se

$$
\hat{R}_{t}^{(i)} \notin\left[q_{a}^{(i)}-c \times I_{(a, b)}^{(i)} ; \quad q_{b}^{(i)}+c \times I_{(a, b)}^{(i)}\right] ;
$$

6. Se $Z_{t}$ for outlier, substitua seu valor por $\hat{Z}_{t}^{(i)}$ ou por alguma outra estimativa apropriada;

7. Se forem detectados outliers ou se $i \leq M$, faça $i=i+1$ e volte ao passo 1 , caso contrário, o processo está terminado.

\subsection{Rolling analysis de séries temporais}

Rolling analysis de séries temporais é uma técnica utilizada para se verificar o comportamento da estabilidade dos parâmetros de um modelo ao longo do tempo, assim como para se avaliar a acurácia de determinado modelo com o uso de backtest (ZIVOT; WANG, 2006) [ZW06]. A seguir, é dada uma definição do procedimento.

Definição 1.22. Seja $\left\{Z_{t}\right\}$ uma série temporal de tamanho $N$ e $f($.$) uma função da amostra que$ gere $k$ estatísticas $\hat{\boldsymbol{v}}=\left(\hat{v}_{1}, \ldots, \hat{v}_{k}\right)$, dizemos que um conjunto de vetores de estatísticas, ou matriz de estatísticas $\boldsymbol{V}_{\boldsymbol{k} \times \boldsymbol{N}-\boldsymbol{n + 1}}=\left(\hat{\boldsymbol{v}}_{\mathbf{1}}^{\prime}, \ldots, \hat{\boldsymbol{v}}_{\boldsymbol{N}-\boldsymbol{n}+\mathbf{1}}^{\prime},\right)$, foi estimado usando rolling analysis com rolling window de tamanho $n$ se para cada $i=1, \ldots, N-n+1$ é realizado o seguinte procedimento.

1. O vetor de observações $\boldsymbol{Z}_{i}^{(n)}=\left(Z_{i}, \ldots, Z_{i+n-1}\right)$ de tamanho $n$ é selecionado;

2. O vetor $\hat{\boldsymbol{v}}_{\boldsymbol{i}}^{\prime}$ é calculado aplicando-se $f($.$) ao vetor \boldsymbol{Z}_{i}^{(n)}$.

Nota-se que a quantidade total de janelas rolling window é $N-n+1$. A Figura 1.2 ilustra o funcionamento do método de rolling analysis.

A função $f($.$) pode ser desde simples funções de análises descritivas, como médias e variâncias$ amostrais, até funções mais complexas, como aquelas que estimam parâmetros de modelos. Dessa forma, pode-se analisar o comportamento dessas estatísticas ao longo do tempo, como, por exemplo, se uma série é estacionária (apresentando médias e variância constantes em todas as rolling window) 


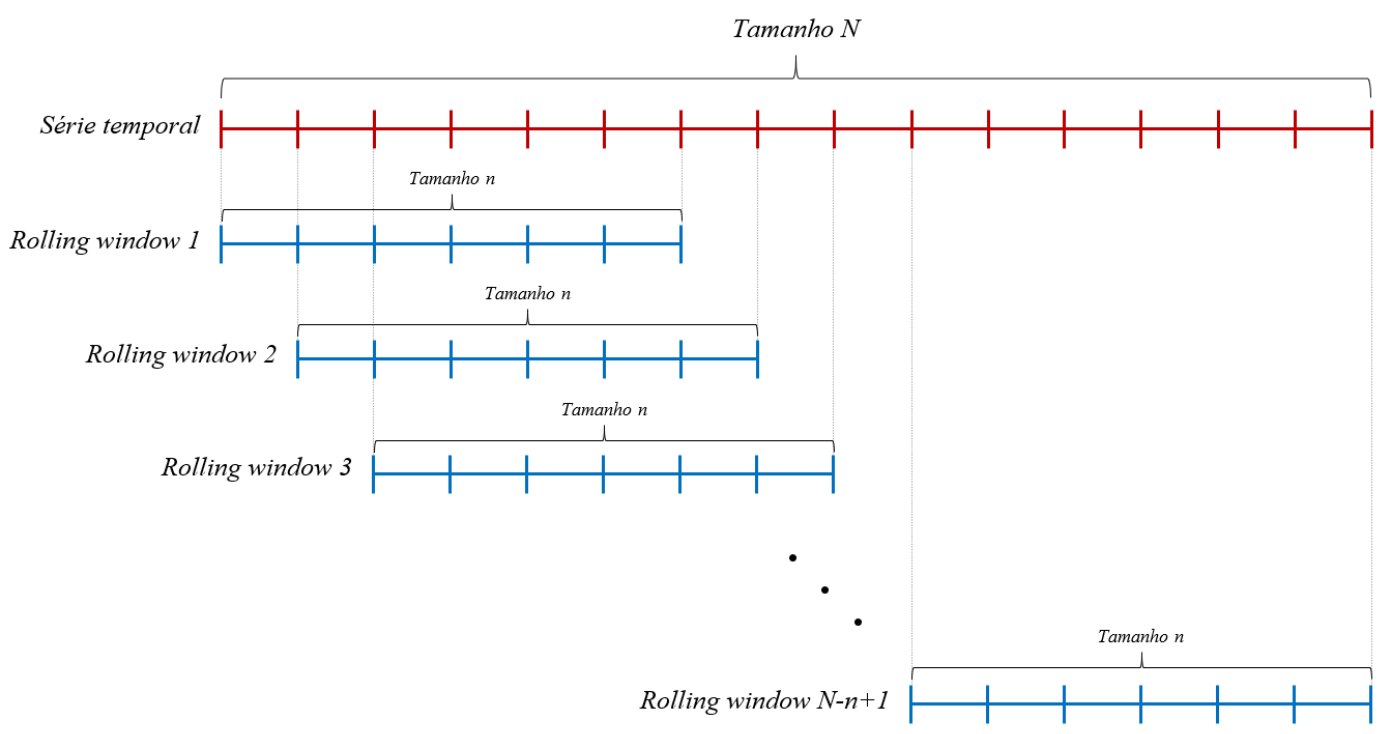

Figura 1.2: Ilustração de como são formadas as rolling windows do método de rolling analysis. A série (em vermelho) possui tamanho $N$, da qual são formadas $N-n+1$ rolling windows (em azul) de tamanho $n$.

ou se os parâmetros estimados de um modelo são estáveis (de modo a justificar que um modelo é adequado para a modelagem da série).

O método de rolling analysis também pode ser usado para verificar a acurácia preditiva de modelos e métodos preditivos. Neste caso, se queremos fazer previsões de horizonte até $h$ então temos que fazer uma modificação na definição 1.22 de modo que $i=1, \ldots, N-n-h+1$, ou seja, a quantidade de janelas será $N-n-h+1$ e a função $f($.$) é um modelo preditivo que gera o vetor$ $\hat{\boldsymbol{v}}=\left(\hat{v}_{1}, \ldots, \hat{v}_{h}\right)$ de previsões ou apenas um valor, se o objetivo for apenas calcular a previsão do passo $h$, o que daria $\hat{\boldsymbol{v}}=\left(\hat{v}_{h}\right)$. Assim, a matriz $\mathbf{V}$ teria dimensões $\boldsymbol{k} \times \boldsymbol{N}-\boldsymbol{n}-\mathbf{h}+\mathbf{1}$, com cada linha representando uma amostra de previsão de $j$ passos à frente, com $j=1, \ldots, h$ e, a partir disso, seria possível medir a qualidade da previsibilidade do modelo de acordo com alguma medida de acurácia.

\subsubsection{Medidas de acurácia}

Daremos aqui algumas medidas de acurácias geralmente usadas na avalição da previsão de modelos preditivos com o uso de rolling analysis. Sejam $\hat{\varepsilon}_{t+h \mid t}=Z_{t+h}-\hat{Z}_{t+h \mid t}$ erros de previsão de $h$ passos a frente calculados de acordo com as estimativas $\hat{Z}_{t+h \mid t}$ geradas por algum modelo $f($.) e usando o método de rolling window. Algumas medidas de acurácias são

$$
\begin{gathered}
M E(h)=\frac{1}{N-n-h+1} \sum_{t=n}^{N-h} \hat{\varepsilon}_{t+h \mid t}, \\
M S E(h)=\frac{1}{N-n-h+1} \sum_{t=n}^{N-h} \hat{\varepsilon}_{t+h \mid t}^{2}, \\
R M S E(h)=\sqrt{M S E(h)}, \\
M A E(h)=\frac{1}{N-n-h+1} \sum_{t=n}^{N-h}\left|\hat{\varepsilon}_{t+h \mid t}\right|,
\end{gathered}
$$




$$
M A P E(h)=\frac{1}{N-n-h+1} \sum_{t=n}^{N-h}\left|\frac{\hat{\varepsilon}_{t+h \mid t}}{Z_{t+h}}\right| .
$$

A medida $M E(h)$ busca analisar os possíveis vieses de previsão, enquanto que a demais medidas analisam tanto viés e precisão da previsão.

\subsubsection{Modificações úteis}

Em certas aplicações, quando a série temporal possui um tamanho muito grande (o que poderia implicar numa enorme quantidade de rolling windows) e/ou a função $f($.$) é muito complexa, vale a$ pena fazer algumas modificações no método de rolling analysis visando diminuir o tempo total de execução. Se o objetivo for avaliar apenas a acurácia de modelos preditivos, uma modificação plausível seria fazer uma amostragem aletória simples das rolling windows, ao invés de usar todas como no método original. A Figura 1.3 ilustra o procedimento de rolling analysis usando a modificação proposta, na qual apenas algumas rolling windows são selecinadas e em cada uma delas é ajustado algum modelo e realizado a respectiva previsão de horizonte $h$.

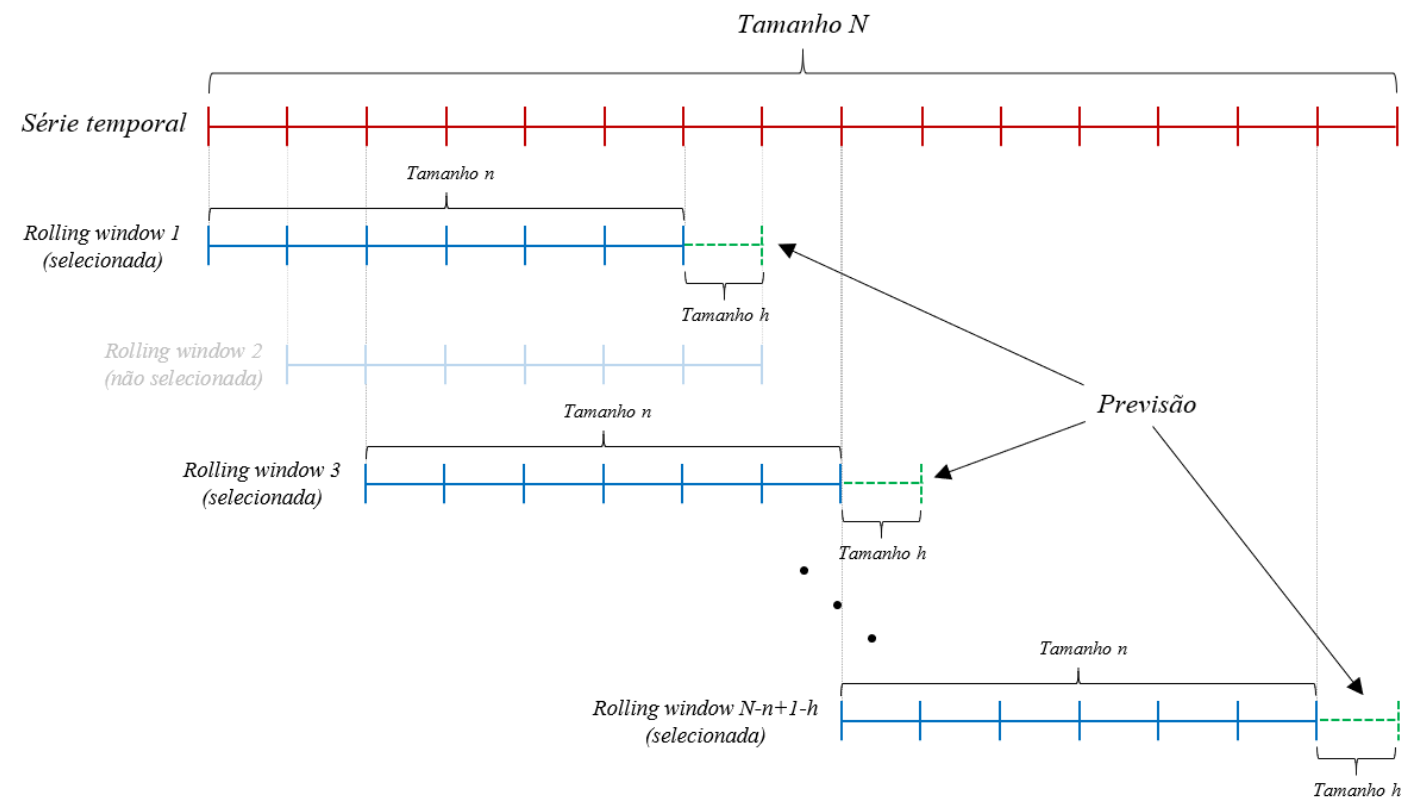

Figura 1.3: Ilustração de como são formadas e selecionadas as rolling windows do método de rolling analysis para se fazer previsões. A série (em vermelho) possui tamanho $N$, da qual são amostras rolling windows de um total de $N-n+1$ rolling windows de tamanho $n$. Em cada rolling windows amostrada (em azul) é ajustado um modelo que gera previsões (em verde) de horizonte de tamanho $h$.

Devido a modificação no método de rolling analysis, as medidas de acurácias apresentadas na subseção anterior seriam modificadas para:

$$
\begin{gathered}
M E(h)=\frac{1}{M} \sum_{t \in \tau} \hat{\varepsilon}_{t+h \mid t}, \\
M S E(h)=\frac{1}{M} \sum_{t \in \tau} \hat{\varepsilon}_{t+h \mid t}^{2}, \\
\operatorname{RMSE}(h)=\sqrt{M S E(h)},
\end{gathered}
$$




$$
\begin{aligned}
M A E & (h)=\frac{1}{M} \sum_{t \in \tau}\left|\hat{\varepsilon}_{t+h \mid t}\right|, \\
M A P E(h) & =\frac{1}{M} \sum_{t \in \tau}\left|\frac{\hat{\varepsilon}_{t+h \mid t}}{Z_{t+h}}\right| .
\end{aligned}
$$

em que $M$ é a quantidade de rolling windows amostradas e $\tau$ é o conjunto que indexa todas as rolling windows amostradas.

Vale mencionar que, se o objetivo for, por exemplo, analisar a estabilidade das estimavas dos parâmetros de um determinado modelo ao longo tempo, uma solução seria fazer uma amostragem sistemática das rolling windows ao invés de uma amostragem aleatória simples. 


\section{Capítulo 2}

\section{Métodos e materiais}

Este capítulo é destinado a propor metodologias que visam lidar com alguns dos principais problemas encontrados na área de aquisição e análise de dados da indústria da água sob o contexto da indústria 4.0, a saber: deteç̧ão e tratamento de valores outliers, reconstrução de dados omissos e previsão. Com esse objetivo, analisamos um conjunto de dados fornecido pela Sabesp da Baixada Santista referentes às medições de sensores instalados ao longo do sistema de adução, tratamento e distribuição de água referentes a cidade de Peruíbe. A seção 2.1 faz uma explanação detalhada sobre o conjunto de dados, buscando montar um panorama geral do comportamento e estabelecer características das séries analisadas.

A seção 2.2 descreve os procedimentos de uma limpeza primária que basicamente consiste na deteç̧ão e exclusão de valores impossíveis de ocorrer ou gerados automaticamente pelo sistema SCADA. Dessa forma, temos o que seria uma primeira deteç̧ão de valores imprecisos.

Após a limpeza primaria das séries, vem necessidade de se detectar e tratar os possíveis valores outliers remanescentes nas séries e imputar os valores omissos. A seção 2.3 expõe os procedimentos que cumprem com esse objetivo e propõe experimentos com o intuito de comparar a performance de cada um desses procedimentos.

A seção 2.4 apresenta metodologias que lidam com o nosso último problema: a necessidade de se fazer previsão. São usados modelos que se adequam aos comportamentos das séries e são estabelecidos alguns experimentos para avaliar a performance dos modelos de previsão.

Por fim, a seção 2.5 descreve os materiais utilizados.

A Figura 2.1 esquematiza todo o processo de análise das séries.

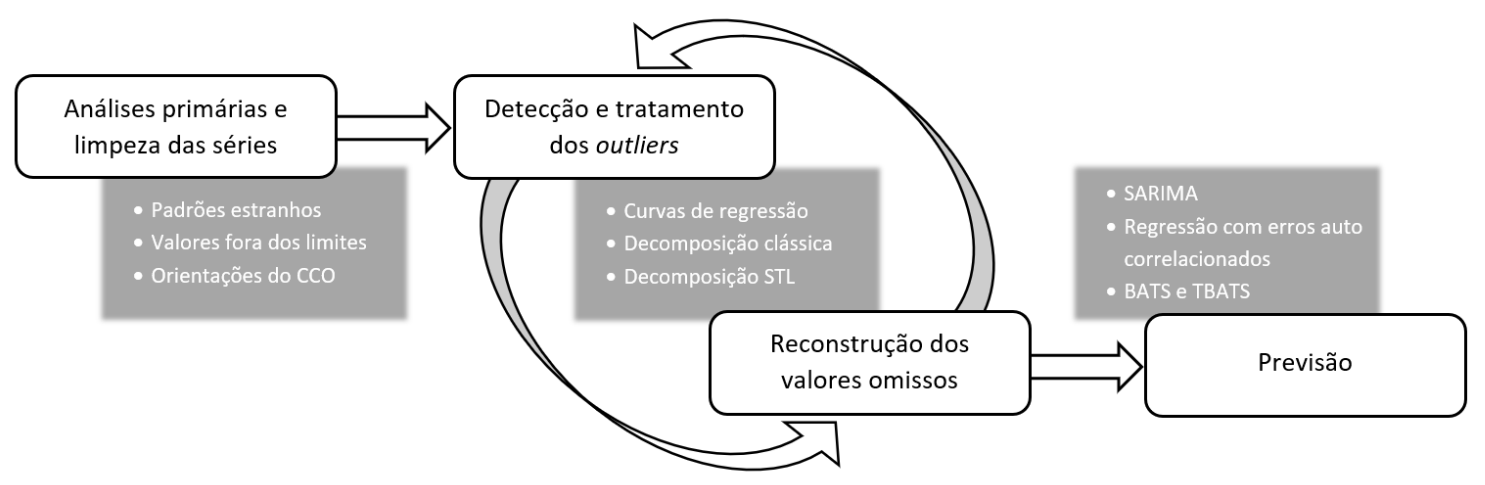

Figura 2.1: Esquema geral do procedimento adotado para a análise das séries. 


\subsection{Descrição dos dados}

Embora o sistema de adução, tratamento e distribuição de água da Sabesp da Baixada Santista abranja um total de nove municípios, analisamos somente uma parte do sistema referente ao reservatório principal de Peruíbe e responsável por grande parte do abastecimento da cidade. O nosso objeto de estudo é composto por séries temporais de algumas variáveis medidas ao longo do sistema distribuição de água e criadas pela amostragem a cada uma hora durante o período das 1:00 do dia $1^{0}$ de janeiro de 2017 até às 23:00 do dia 31 de dezembro de 2018. A série de consumo é um pouco diferente das demais por ser uma função das séries de vazão de saída Sul e Norte. Ou seja, o consumo é dado por

$$
C_{t}=\left(V N_{t}+V S_{t}\right) \times \frac{360}{1000},
$$

em que $C_{t}, V N_{t}$ e $V S_{t}$ são, respectivamente, o consumo em $m^{3}$, a vazão de saída Norte e vazão de saída Sul em $l / s$ no tempo $t$. A Tabela 2.1 mostra uma breve descrição das séries consideradas.

Tabela 2.1: Breve descrição das séries temporais analisadas. O tamanho total de cada série é $N=17519$

\begin{tabular}{|c|c|c|c|c|}
\hline Tag do Equipamento & Série temporal & Medida & Valor máximo & Valor mínimo \\
\hline $\begin{array}{l}\text { CCOBS. } 1300 / 020 / \\
\text { FI_01.F_CV }\end{array}$ & $\begin{array}{l}\text { Vazão de entrada no } \\
\text { reservatório Peruíbe }\end{array}$ & $\begin{array}{l}\text { Litros por segundo } \\
(1 / \mathrm{s})\end{array}$ & 300,0 & 0 \\
\hline $\begin{array}{l}\text { CCOBS. } 1300 / 020 / \\
\mathrm{LT}_{-} 01 . \mathrm{F} \_\mathrm{CV}\end{array}$ & $\begin{array}{c}\text { Nível do reservatório } \\
\text { Peruíbe }\end{array}$ & Metros (m) & 7,8 & 0 \\
\hline- & Consumo & Metros cúbicos $\left(\mathrm{m}^{\mathbf{3}}\right)$ & $1.800,0$ & 0 \\
\hline $\begin{array}{l}\text { CCOBS. } 1300 / 010 / \\
\text { VRP_01_FI_01.F_CV }\end{array}$ & $\begin{array}{c}\text { Vazão de saída para o Norte } \\
\text { de Peruíbe }\end{array}$ & $\begin{array}{l}\text { Litros por segundo } \\
(1 / \mathrm{s})\end{array}$ & 250,0 & 0 \\
\hline $\begin{array}{l}\text { CCOBS. } 1300 / 010 / \\
\text { VRP_02_FI_01.F_CV }\end{array}$ & $\begin{array}{c}\text { Vazão de saída para o Sul } \\
\text { de Peruíbe }\end{array}$ & $\begin{array}{l}\text { Litros por segundo } \\
(1 / \mathrm{s})\end{array}$ & 250,0 & 0 \\
\hline $\begin{array}{l}\text { CCOBS. } 1300 / 010 / \\
\text { VRP_01_PI_01.F_CV }\end{array}$ & $\begin{array}{l}\text { Pressão a montante ao } \\
\text { Norte de Peruíbe }\end{array}$ & $\begin{array}{l}\text { Metros de coluna de } \\
\text { água (mca) }\end{array}$ & 70,0 & 0 \\
\hline $\begin{array}{l}\text { CCOBS. } 1300 / 010 / \\
\text { VRP_02_PI_01.F_CV }\end{array}$ & $\begin{array}{c}\text { Pressão a montante ao Sul } \\
\text { de Peruíbe }\end{array}$ & $\begin{array}{l}\text { Metros de coluna de } \\
\text { água (mca) }\end{array}$ & 70,0 & 0 \\
\hline $\begin{array}{l}\text { CCOBS. } 1300 / 010 / \\
\text { VRP }+01_{-}{ }^{P I}{ }_{-} 02 . F_{-} C V\end{array}$ & $\begin{array}{c}\text { Pressão a jusante ao Norte } \\
\text { de Peruíbe }\end{array}$ & $\begin{array}{l}\text { Metros de coluna de } \\
\text { água (mca) }\end{array}$ & 70,0 & 0 \\
\hline $\begin{array}{l}\text { CCOBS. } 1300 / 010 / \\
\text { VRP_02_PI_02.F_CV }\end{array}$ & $\begin{array}{c}\text { Pressão a jusante ao Sul de } \\
\text { Peruíbe }\end{array}$ & $\begin{array}{l}\text { Metros de coluna de } \\
\text { água (mca) }\end{array}$ & 70,0 & 0 \\
\hline
\end{tabular}

A Figura 2.2 mostra um esquema do funcionamento do sistema e de como as séries foram obtidas. As informações obtidas em cada ponto de medição são transmitidas em tempo real e gravadas na base de dados.

Durante todo o processo de geração, transmissão e gravação podem ocorrer diversas falhas que causam alguma anomalia nos dados, tais como: falha nos medidores, medidas reais que extrapolam o fundo de escala dos medidores, queda da rede de transmissão de dados e entre outros. É possível notar essas falhas no comportamento das séries. A Figura 2.3 traz alguns exemplos dessas anomalias.

De modo geral, as séries apresentam comportamento sazonal de acordo com os horários do dia. Embora esperada, uma possível sazonalidade referente aos dias da semana é quase imperceptível para todas as séries. Vale notar que as séries apresentam mudanças de tendências ou de comportamento sazonal ao longo do tempo, como por exemplo, na virada do ano, demonstrado na Figura 2.4 .

Das séries consideradas, as únicas que possuem frequentemente momentos de comportamentos 


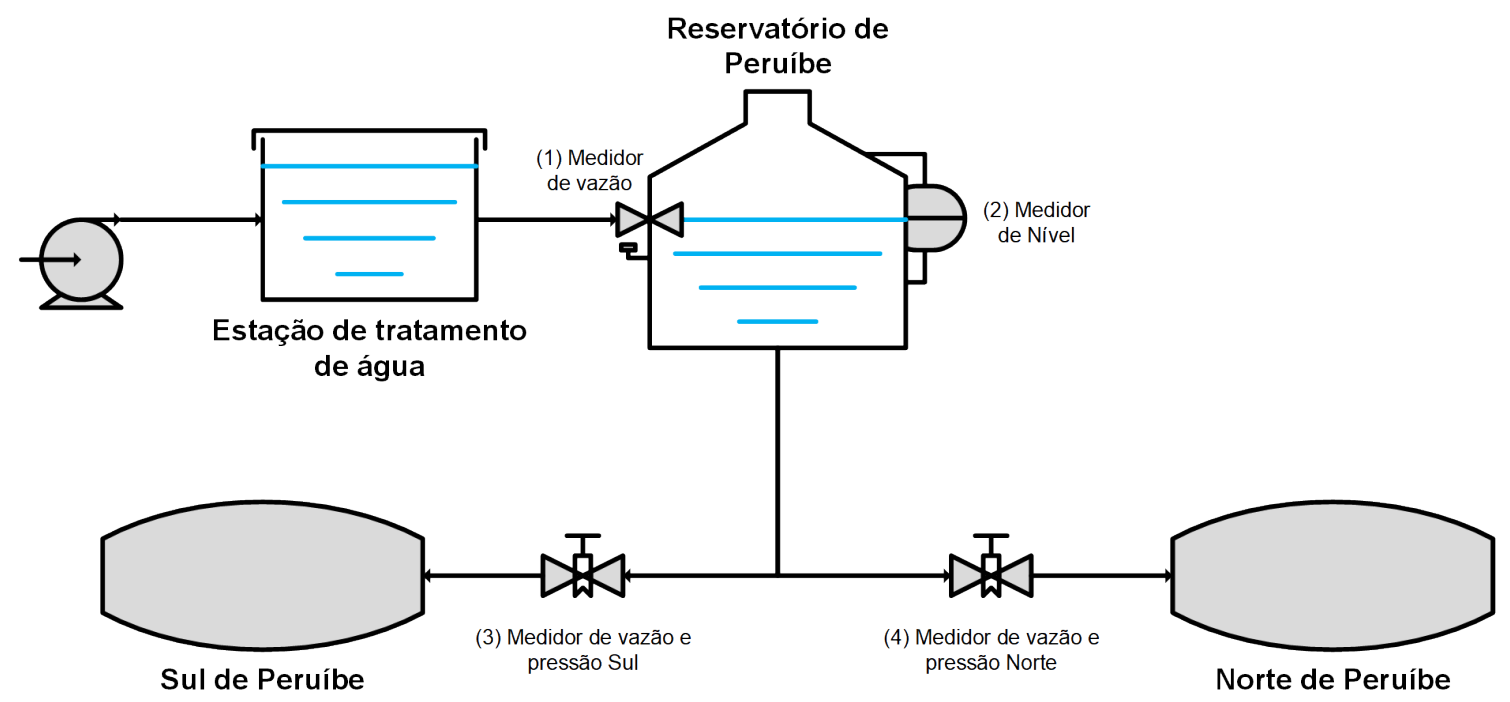

Figura 2.2: Esquema do sistema de abastecimento de água referente ao reservatório de Peruibe. A série de vazão de entrada do reservatório é medida em (1). A série de nivel do reservatório é medida em (2). As séries de vazão de saída Sul, pressão a montante Sul e pressão a jusante Sul são obtidas em (3). As séries de vazão de saída Norte, pressão a montante Norte e pressão a jusante Norte são obtidas em (4).
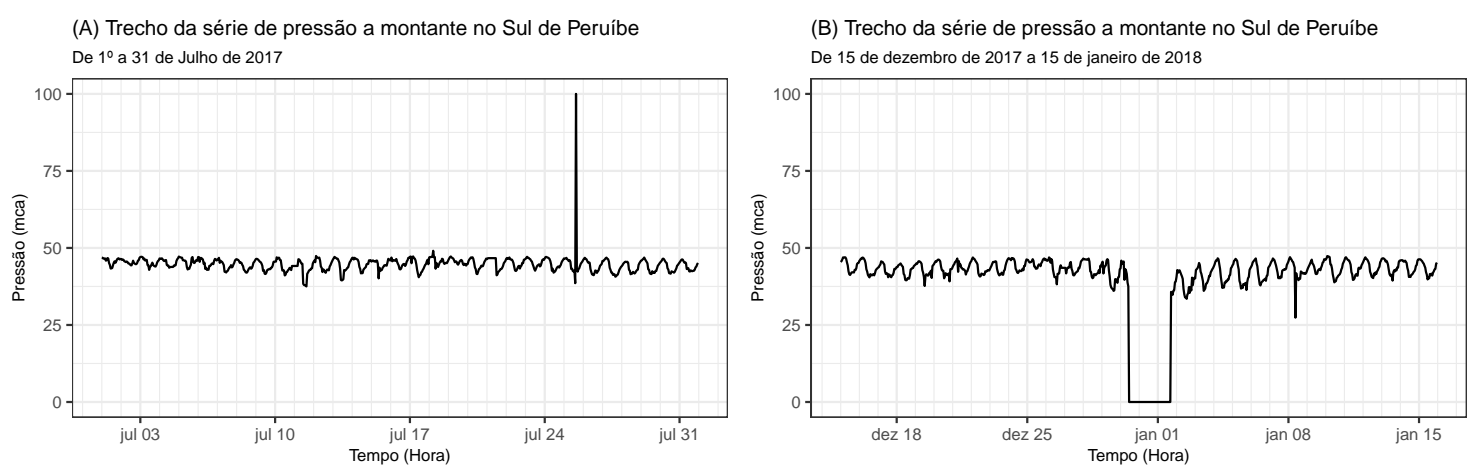

Figura 2.3: Trecho da série de pressão a montante ao Sul de Peruíbe. O gráfico a esquerda refere-se ao periodo de $1^{o}$ a 31 de julho de 2017 , onde é possivel notar a presença de um outlier por volta do dia 25 de julho causado, possivelmente, por algum ruído no sistema. O gráfico a direita se referente ao período de 15 de dezembro de 2017 a 15 de janeiro de 2018, onde é possivel notar uma falha no sistema de medição que deixou as observações nos dias próximos a $1^{0}$ de janeiro valendo 0.

irregulares, ou seja, sem uma presença clara de sazonalidade, são as séries de nível e vazão de entrada do reservatório de Peruíbe, sendo isto um grande problema de se modelar. A Figura 2.5 exemplifica tais comportamentos. A irregularidade presente nas séries é possivelmente devida a sua natureza: são séries cujos valores dependem diretamente do controle do operador do sistema, que recorrentemente é algo não tão bem definido sazonalmente, enquanto que as demais séries são mais afetadas pela demanda por água da população de Peruíbe.

Visto as características das séries, temos para todas elas o objetivo de se fazer a detecção de anomalias e o preenchimento de valores omisssos. Já o objetivo de fazer previsão é mais direcionado às séries que possuem forte influência do comportamento de consumo da população de Peruíbe, ou seja, as séries de vazões de saída do reservatório, consumo e as de pressões na rede de distribuição. Embora fazer previsão não seja um dos principais objetivos das séries de nível e de vazão de entrada do reservatório, aplicamos os mesmo métodos previsionais a estas no intuito de avaliar se o comportamento do CCO em controlar o volume de água que entra no reservatório possui, de certa 


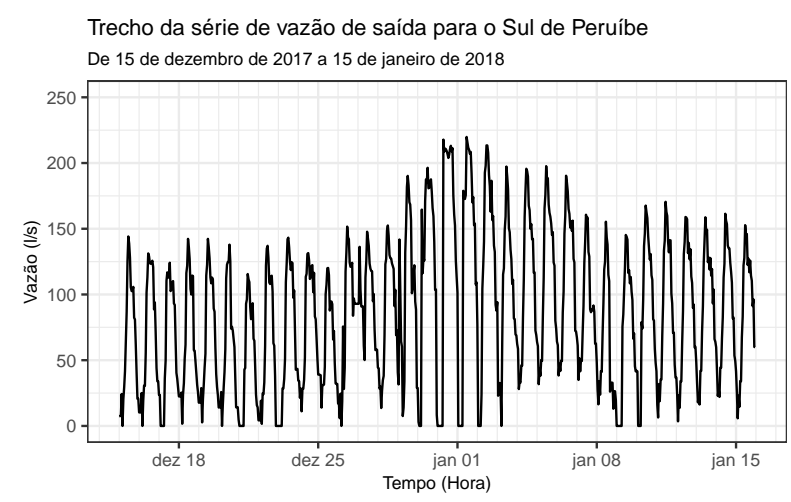

Figura 2.4: Trecho da série de vazão de saída para o Sul de Peruíbe referente ao período de 15 de dezembro de 2017 a 15 de janeiro de 2018. Nota-se que uma mudança no comportamento da série nos dias próximos ao dia $1^{o}$ de janeiro.
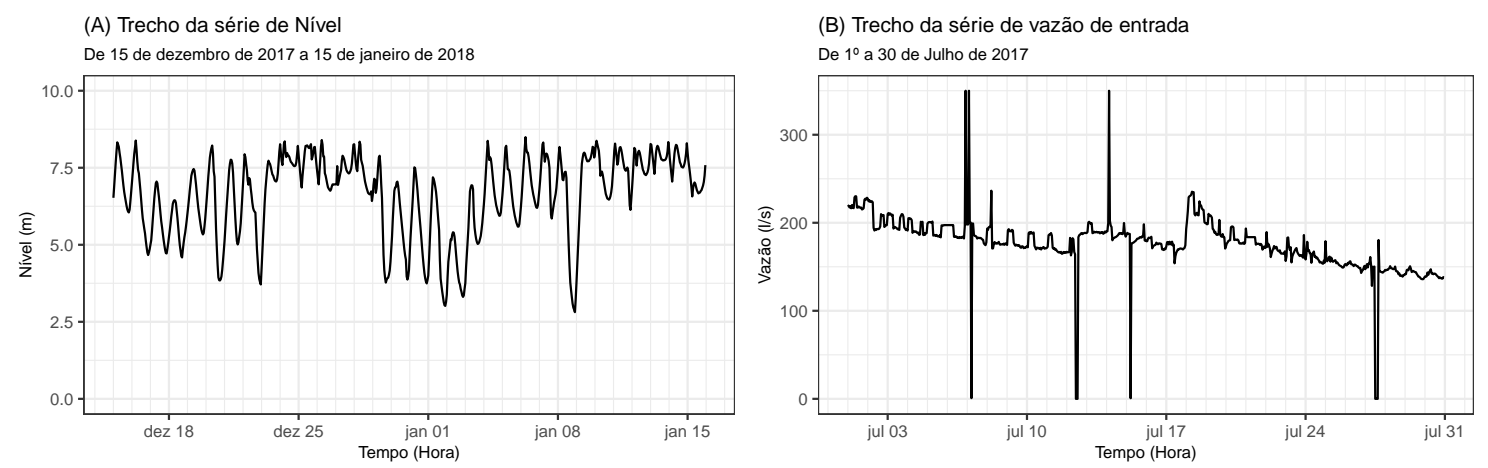

Figura 2.5: Trecho das série de nível à esquerda (A) e da série de vazão de entrada à direita (B). Ambas as séries apresentam comportamento irrelagular, principalmente a série de vazão de entrada.

forma, alguma previsibilidade de acordo com os modelos aqui adotados.

Gráficos e tabelas para uma análise descritiva mais detalhada das séries são apresentados no Apêndice A.

\subsection{Limpeza primária das séries}

Após o entendimento do comportamento das séries e de uma análise descritiva preliminar, o próximo passo é eliminar das séries aqueles valores que certamente são impossíveis de ocorrer. De modo geral, tais valores são aqueles que ocorrem devido a alguma falha no sistema e que são detectados da seguinte forma:

- Valores fora dos limites máximo e mínimo da série de acordo com os parâmetros físico do sistema. Geralmente esses valores são registrados de modo pontual ou há uma mudança súbita do comportamento da série para o nível desses valores, onde fica por algum tempo antes de voltar ao nível normal.

- Valores automaticamente interpolados pelo sistema de envio de dados. Esses valores são identificados pela repetição em sequência de um mesmo valor ou pelo aparecimento de alguma reta que liga dois pontos da série interpolando vários valores.

- Valores considerados imprecisos de acordo com os técnicos do centro de controle da Sabesp. 
Foi elaborado um procedimento que relaciona os valores de vazão de entrada no reservatório no tempo t com o valor do nível do reservatório no instante $t+1$. É aplicável somente a séries de nível e vazão de entrada do reservatório Peruíbe.

A Tabela 2.2 mostra as quantidades de sequências de observações omissas presente em cada uma das séries. Muitos dos valores omissos ocorrem em sequências pequenas (de 1 a 12 observações seguidas), porém também há a presença de sequências muito grandes de valores omisso (mais de dois dias seguidos).

Tabela 2.2: Descrição da quantidade de valores omissos em sequência em cada série analisada. O tamanho total de cada série é $N=17519$

\begin{tabular}{|c|c|c|c|c|c|c|c|c|c|c|c|}
\hline \multirow[b]{2}{*}{ Série } & \multicolumn{11}{|c|}{ Quantidade de valores omissos em sequência } \\
\hline & 1 & 2 & 3 & 4 & 5 & 6 & 7 a 12 & 13 a 24 & 25 a 48 & 48 a 168 & Mais que 168 \\
\hline Nível (m) & 367 & 21 & 7 & 4 & 3 & 2 & 8 & 6 & 7 & 3 & 0 \\
\hline Vazão de entrada $(1 / \mathrm{s})$ & 510 & 24 & 11 & 6 & 5 & 5 & 8 & 6 & 7 & 4 & 0 \\
\hline Vazão de saída: Norte (1/s) & 340 & 124 & 47 & 17 & 13 & 9 & 14 & 9 & 13 & 4 & 1 \\
\hline Vazão de saída: Sul $(1 / \mathrm{s})$ & 431 & 83 & 24 & 28 & 25 & 33 & 197 & 13 & 11 & 6 & 1 \\
\hline Pressão a montante: Norte (mca) & 327 & 26 & 8 & 9 & 8 & 6 & 11 & 8 & 11 & 5 & 1 \\
\hline Pressão a montante: Sul (mca) & 624 & 44 & 16 & 8 & 9 & 5 & 11 & 8 & 11 & 6 & 1 \\
\hline Pressão a jusante: Norte (mca) & 307 & 24 & 7 & 8 & 8 & 6 & 11 & 8 & 11 & 5 & 1 \\
\hline Pressão a jusante: Sul (mca) & 287 & 22 & 7 & 7 & 8 & 6 & 11 & 8 & 11 & 5 & 1 \\
\hline Consumo $\left(\mathrm{m}^{3} / \mathrm{h}\right)$ & 571 & 126 & 41 & 30 & 30 & 33 & 204 & 13 & 12 & 6 & 1 \\
\hline
\end{tabular}

Nota-se que a série de vazão de saída para o Sul de Peruíbe é a que apresenta maior quantidade de valores omissos. A série de vazão de saída para o Norte de Peruíbe também apresenta uma quantidade razoável de valores omissos. Por causa da série de consumo ser uma função direta da vazão de saída norte e vazão de saída sul, ela também acaba contendo muitos valores omisso.

Gráficos e tabelas mais detalhados sobre os valores omissos são apresentados no Apêndice B.

\subsection{Processo iterativo de tratamento de outliers e valores omissos}

Após uma primeira limpeza há a necessidade de detectar e tratar os possíveis outliers remanescentes nas séries temporais e, ainda, reconstruir todos os valores omissos resultantes dos processos de limpeza. Com esse objetivo, adotamos um procedimento similar ao descrito na subseção 1.6.2, porém com uma modificação a partir do passo 6: ao invés de substituir o valor $Z_{t}$ pela sua estimativa $\hat{Z}_{t}^{(i)}$, gerada por $\hat{f}($.$) , vamos excluí-lo da série, ou seja, Z_{t}$ é considerado um valor omisso. Depois, aplicamos algum método de preenchimento de valores omissos a nova série. Mais formalmente, seja $M$ a quantidade máxima de iterações, a $i$-ésima iteração do algoritmo é:

1. Defina uma função ou método $\hat{f}_{O U T}^{(i)}($.$) para calcular as estimativas \hat{Z}_{t}^{(i)}$ a partir da série $Z_{t}^{(i)}$. Se $i=1$, então $Z_{t}^{(1)}=Z_{t}$;

2. Estime os resíduos $\hat{R}_{t}^{(i)}=Z_{t}-\hat{Z}_{t}^{(i)}$;

3. Calcule os quantis $q_{a}^{(i)}$ e $q_{b}^{(i)}$ dos $\hat{R}_{t}^{(i)}$, de modo que $q_{a}^{(i)}<q_{b}^{(i)}$;

4. Tome o intervalo $I_{(a, b)}^{(i)}=q_{b}^{(i)}-q_{a}^{(i)}$;

5. Seja $c$ uma constante já fixada, classifique cada $Z_{t}, t \in \tau$, como outlier se

$$
\hat{R}_{t}^{(i)} \notin\left[q_{a}^{(i)}-c \times I_{(a, b)}^{(i)} ; \quad q_{b}^{(i)}+c \times I_{(a, b)}^{(i)}\right] ;
$$


6. Se $Z_{t}$ for outlier, classifique-o como valor omisso. A nova série "livre de outliers" e, possivelmente com valores omissos, será denotada por $\left\{Z_{t}^{\text {OUT }}\right\}_{t \in \tau}$;

7. Se $\left\{Z_{t}^{\text {OUT }}\right\}_{t \in \tau}$ não possuir valores omissos, o processo está terminado, caso contrário, continue para o proximo passo.

8. Impute os valores omissos da série de acordo com uma função ou método $\hat{f}_{O M I}^{(i)}($.$) . A série$ imputada será denotada por $\left\{Z_{t}^{O M I}\right\}_{t \in \tau}$;

9. Se $i<M$, faça $i=i+1$, tome $Z_{t}^{(i)}=\left\{Z_{t}^{O M I}\right\}_{t \in \tau}$ e volte ao passo 1 , caso contrário, o processo está terminado.

De modo geral, iremos sempre adotar o mesmo procedimento $\hat{f}_{O U T}^{(i)}()=.\hat{f}_{O U T}($.$) para todos os$ $i=1, \ldots, M$. A execeção será apenas em algumas situações em que $\hat{f}_{O U T}($.$) não é robusto a valores$ omissos, implicando na escolha de um outro $\hat{f}_{O U T}^{(1)}($.$) que seja robusto a valores omissos somente$ para a primeira iteração, já que provavelmente a série original contém valores omissos.

Também adotaremos o mesmo procedimento $\hat{f}_{O M I}^{(i)}()=.\hat{f}_{O M I}($.$) para todos os i=1, \ldots, M$.

Tanto os métodos escolhidos para $\hat{f}_{O U T}($.$) , quanto para \hat{f}_{O M I}($.$) se baseiam em decompor a série$ nas componentes de tendência, sazonalidade e ruído descritos na seção 1.2. Essencialmente, usamos três métodos diferentes com algumas variações, a saber, ajuste de curva de regressão, regressão combinado com decomposição clássica e decomposição STL. As próximas subseções detalham cada método adotado.

\subsubsection{Procedimentos de ajuste de curvas via regressão}

O primeiro método de estimação de valores das séries é baseado no ajuste de curvas apresentado na seção 1.2.1. Os ajustes são realizados considerando uma tendência polinomial e a sazonalidade é modelada de acordo com os horários dos dias e, possivelmente, com os dias da semana.

Devido ao fato das séries serem longas, verifica-se que seus comportamentos podem não seguir o mesmo padrão ao longo do tempo, assim, ajustamos as curvas de regressão em subséries da série original. Caso o objetivo seja detectar outliers, as subséries são uma partição da série temporal de modo que cada subsérie tenha tamanho $k$, exceto a última subsérie, que poderá ter um tamanho entre $k / 2$ e $3 k / 2$, porque não impomos que $k$ seja um múltiplo da quantidade total de observações. Se o objetivo for imputação de dados, para cada sequência ininterrupta de valores omissos considerouse a menor subsérie que contém os $k$ valores não omissos mais próximos de tal sequência. Note que neste caso podemos ter subséries com trechos sobrepostos às outras.

Uma vez que as subséries estejam bem estabelecidas, o primeiro tipo de modelo de regressão considera uma possível tendência polinomial e uma sazonalidade observada durante os horários do dia, ou seja

$$
Z_{t}=\sum_{i=0}^{m} \beta_{i} t^{i}+\sum_{j=1}^{23} \alpha_{j} D_{j, t}+R_{t}
$$

em que

- $m$ é o grau do polinômio usado para modelar a tendência;

- $t^{i}$ é o $i$-ésimo termo do polinômio de grau $m$; 
- $\beta_{i}$ é o parâmetro associado ao $i$-ésimo grau do polinômio;

- $\alpha_{j}$ é o parâmetro associado ao j-ésimo horário do dia;

- $D_{j, t}$ é o $j$-ésimo horário associado ao tempo $t$;

- $R_{t}$ é o ruído do modelo.

Logo, o valor estimado para a observação $Z_{t}$ é

$$
\hat{Z}_{t}^{R e g}=\sum_{i=0}^{m} \hat{\beta}_{i} t^{i}+\sum_{j=1}^{23} \hat{\alpha}_{j} D_{j, t}+\hat{R}_{t},
$$

no qual os $\hat{\beta}_{i}$ e $\hat{\alpha}_{j}$ são as estimativas de mínimos quadrados dadas em (1.14), enquanto que $\hat{R}_{t}$ recebe dois tipos de tratamentos. No primeiro tratamento, é simplesmente assumido que $\hat{R}_{t}=0$. Esse tratamento é adotado tanto para a detecção de outliers, quanto para a imputação de valores omissos. A segunda forma é adotada apenas para imputação de valores omissos. Nela, $\hat{R}_{t}$ é o resultado de uma interpolação linear, usando como referências o último resíduos estimado antes do início da sequência de valores omissos (denotado por $\hat{R}^{(0)}$ ) e o primeiro resíduo estimado depois do término da sequência de valores omissos (denotado por $\hat{R}^{(1)}$ ), o que nos dá a seguinte estimativa

$$
\hat{R}_{t}=\hat{R}^{(0)}\left(1-\frac{t-t^{(0)}}{t^{(1)}-t^{(0)}}\right)+\hat{R}^{(1)}\left(1-\frac{t^{(1)}-t}{t^{(1)}-t^{(0)}}\right),
$$

em que $t^{(0)}$ e $t^{(1)}$ são, respectivamente, índices de $\hat{R}^{(0)}$ e $\hat{R}^{(1)}$.

A ideia da interpolação é preservar, mesmo que de uma forma grosseira, uma possível dependência serial que ainda pode estar presente nos resíduos.

O segundo tipo de modelo abordado consiste no acréscimo de uma componente ao lado direto do modelo (2.2) que lida com uma possível sazonalidade semanal. Mais explicitamente, o modelo é

$$
Z_{t}=\sum_{i=0}^{m} \beta_{i} t^{i}+\sum_{j=1}^{23} \alpha_{j} D_{j, t}+\sum_{j=1}^{6} \gamma_{j} S_{j, t}+R_{t},
$$

em que $m, t^{i}, \beta_{i}, \alpha_{i}, D_{j, t}$ e $R_{t}$ são equivalente aos descritos em modelo (2.2) e

- $\gamma_{j}$ é o parâmetro associado ao $j$-ésimo dia da semana;

- $S_{j, t}$ é o $j$-ésimo dia da semana associado ao tempo $t$.

O valor estimado para $Z_{t}$ será

$$
\hat{Z}_{t}^{R e g}=\sum_{i=0}^{m} \hat{\beta}_{i} t^{i}+\sum_{j=1}^{23} \hat{\alpha}_{j} D_{j, t}+\sum_{j=1}^{6} \hat{\gamma}_{j} S_{j, t}+\hat{R}_{t},
$$

em que os $\hat{\beta}_{i}$, os $\hat{\alpha}_{j}$ e os $\hat{\gamma}_{j}$ são as estimativas de mínimos quadrados e $\hat{R}_{t}$, novamente, ou valerá 0 ou terá o valor dado pela equação (2.4) de acordo com o objetivo e com o tipo de experimento desejado. 


\subsubsection{Procedimentos de ajuste de curvas via regressão + decomposição clássica}

O método de decomposição clássica consiste basicamente em aplicar o algoritmo descrito na seção 1.2.2 à série temporal. Porém, não aplicaremos a decomposição em toda a série temporal de uma única vez, pois, como no caso do ajuste de curvas de regressão, a série pode não ter o mesmo comportamento ao longo do tempo. Logo, consideramos aqui as mesmas subséries que foram estabelecidas para o ajuste de curvas de regressão.

É fato que decomposição clássica não consegue lidar com a presença de valores omissos, o que nos faz introduzir ajustes caso a série na qual for aplicada decomposição tenha valores omissos.

Caso o objetivo seja deteç̧ão de outliers, substituíremos a decomposição clássica por algum procedimento de ajuste de regressão para fazer a detecção dos outliers na primeira iteração do algoritmo da seção 2.3. Nas demais iterações, faz-se o uso da decomposição clássica, pois a partir da segunda iteração a série a ser verificada não terá mais valores omissos, em teoria.

Se o propósito for imputação de valores omissos, então o processo terá duas etapas: a primeira é o ajuste de curvas e preenchimento dos valores omissos de acordo com o descrito na seção 2.3.1 e a segunda etapa é a aplicação da decomposição clássica de fato. Ou seja, se $Z_{t}$ é um valor omisso na série original e considerando a série $\left\{Z_{t}^{R e g}\right\}_{t \in \tau}$ tal que

$$
Z_{t}^{\text {Reg }}=\left\{\begin{array}{cl}
\hat{Z}_{t}^{\text {Reg }}, & \text { se } Z_{t} \text { é omisso } \\
Z_{t}, & \text { caso contrário }
\end{array}\right.
$$

em que $\hat{Z}_{t}^{\text {Reg }}$ é a estimativa de valores omissos de acordo com algum dos procedimentos da seção 2.3.1, então a estimativa por decomposição clássica $\hat{Z}_{t}^{D c c}$ é dada por

$$
\hat{Z}_{t}^{D c c}=\hat{S}_{t}+\hat{T}_{t}+\hat{R}_{t}
$$

no qual $\hat{S}_{t}$ e $\hat{T}_{t}$ são obtidos aplicando o passo-a-passo descrito na seção 1.2 .2 na subsérie $\left\{Z_{t}^{R e g}\right\}_{t \in \tau}$ que considera apenas os $k$ valores mais próximos da sequência de observações originalmente omissas. Quanto aos $\hat{R}_{t}$, consideramos os mesmo dois casos: $\hat{R}_{t}=0$ e $\hat{R}_{t}$ como resultado da interpolação dada pela equação (2.4).

A motivação para se aplicar a decomposição clássica como uma etapa no preenchimento de valores omissos é que, embora não consiga lidar diretamente com a falta de tais valores, seu uso seria uma forma de suavizar as estimativas obtidas pelo método de ajuste de curvas de regressão.

\subsubsection{Procedimentos de decomposição STL}

O STL é um método eficaz na decomposição da série em componentes de tendência e sazonalidade. Por de ser robusto a possíveis mudanças no comportamento da série temporal, seu uso não exige o divisão da série em subséries. Outra vantagem é ser robusto, também, a falta de observações, apresentando estimativas para tais valores.

Sem mais delongas, o valor estimado para $Z_{t}$ usando o procedimento STL é dado por

$$
\hat{Z}_{t}^{S t l}=\hat{S}_{t}+\hat{T}_{t}+\hat{R}_{t}
$$

em que $\hat{S}_{t}$ e $\hat{T}_{t}$ são obtidos seguindo o passo-a-passo da decomposição por STL descrito na seção 1.2.3 e para os $\hat{R}_{t}$ consideraremos os mesmo dois casos: $\hat{R}_{t}=0$ e $\hat{R}_{t}$ como resultado da interpolação 
dada pela equação (2.4), sendo este só usado no preenchimento de valores omissos.

Em geral, fixado um valor para $n_{(s)}$, consideraremos três situações propostas pelos autores desenvolvedores do método com diferentes valores de parâmetros para a aplicação do STL:

- STL não robusta: $n_{(i)}=2, n_{(e)}=0$;

- STL robusta: $n_{(i)}=1, n_{(e)}=5$;

- STL robusta com convergência: $n_{(i)}=1, n_{(e)}=10$.

\subsubsection{Arranjos experimentais e avaliação dos procedimentos}

Descrevemos aqui alguns experimentos a fim de avaliar os diversos procedimentos propostos nas subseções anteriores. Primeiro, avaliamos o desempenho dos procedimentos quanto a acurácia em preencher os valores omissos. A partir disso, estabelecemos qual seria o melhor procedimento em imputar os valores omissos e elaboramos outros experimentos para analisar como que tal procedimento consegue lidar com outliers. As séries temporais foram oficialmente tratadas usando a técnica que apresentou melhor resultado em preencher os valores omissos. As próximas subseções descrevem os experimentos propostos.

\section{Valores omissos}

Damos aqui uma descrição de cada experimento elaborado. Para o procedimento de ajuste de curvas de regressão estabelecemos as seguinte situações experimentais:

- O uso ou não de interpolação dos resíduos;

- O uso ou não da sazonalidade semanal;

- O grau do polinônio que modela a tendência: $m=1,2$ e 5 , o que poderia ser traduzido em tendência linear, quadrática e com bastante curvaturas;

- A quantidade de valores não omissos usados no estabelecimento das subséries: $k=168,336$ e 720, que seriam uma aproximação para 7,14 e 30 dias;

- O valores de $c$ utilizados para estabelecer os limites de corte para a detecção de outliers no passo 5 do algoritmo proposto: $c=2,3$ e 5 , valores escolhidos de acordo com análises prévias da séries de modo a não classificar um número excessivo de observações como outliers ou não deixar passar pela deteç̧ão muitos valores que explicitamente são outliers.

Em todos os experimentos de regressão, o algoritmo proposto foi executado com $q_{a}^{(i)}$ e $q_{b}^{(i)}$ sendo, respectivamente, o primeiro e o terceiro quartil dos resíduos da $i$-ésima iteração e a quantidade máxima de iterações $M$ do algoritmo é 3. A lista dos experimentos é apresentada na Tabela 2.3.

Para o procedimento de decomposição clássica estabelecemos as seguinte situações experimentais:

- O uso ou não de interpolação dos resíduos;

- A quantidade de valores não omissos usados no estabelecimento das subséries: $k=168,336 \mathrm{e}$ 720, que seriam uma aproximação para 7,14 e 30 dias; 
Tabela 2.3: Descrição dos experimentos de imputação de valores omissos que usam como base procedimentos de ajuste de curvas de regressão.

\begin{tabular}{|c|c|c|c|c|c|c|c|c|c|c|c|}
\hline ID & $\begin{array}{l}\text { Interpolação } \\
\quad \text { de } R_{t}\end{array}$ & $\begin{array}{c}\text { Dia da } \\
\text { semana }\end{array}$ & $\begin{array}{l}\text { Grau do } \\
\text { polinômio }\end{array}$ & Janela & $c$ & ID & $\begin{array}{l}\text { Interpolação } \\
\text { de } R_{t}\end{array}$ & $\begin{array}{c}\text { Dia da } \\
\text { semana }\end{array}$ & $\begin{array}{l}\text { Grau do } \\
\text { polinômio }\end{array}$ & Janela & $c$ \\
\hline reg1 & Não & Não & 1 & 168 & 2 & reg55 & $\mathrm{Sim}$ & Não & 1 & 168 & 3 \\
\hline reg2 & Não & Não & 1 & 336 & 2 & reg56 & Sim & Não & 1 & 336 & 3 \\
\hline reg3 & Não & Não & 1 & 720 & 2 & reg5 5 & $\mathrm{Sim}$ & Não & 1 & 720 & 3 \\
\hline reg 4 & Não & Não & 2 & 168 & 2 & reg58 & Sim & Não & 2 & 168 & 3 \\
\hline reg 5 & Não & Não & 2 & 336 & 2 & $\operatorname{reg} 59$ & Sim & Não & 2 & 336 & 3 \\
\hline reg6 & Não & Não & 2 & 720 & 2 & reg60 & $\mathrm{Sim}$ & Não & 2 & 720 & 3 \\
\hline reg7 & Não & Não & 5 & 168 & 2 & reg61 & Sim & Não & 5 & 168 & 3 \\
\hline reg8 & Não & Não & 5 & 336 & 2 & reg6 2 & Sim & Não & 5 & 336 & 3 \\
\hline reg9 & Não & Não & 5 & 720 & 2 & reg63 & $\mathrm{Sim}$ & Não & 5 & 720 & 3 \\
\hline reg 10 & Não & Sim & 1 & 168 & 2 & reg64 & Sim & $\mathrm{Sim}$ & 1 & 168 & 3 \\
\hline reg11 & Não & $\mathrm{Sim}$ & 1 & 336 & 2 & reg6 65 & Sim & $\mathrm{Sim}$ & 1 & 336 & 3 \\
\hline reg12 & Não & Sim & 1 & 720 & 2 & reg66 & Sim & Sim & 1 & 720 & 3 \\
\hline reg13 & Não & $\operatorname{Sim}$ & 2 & 168 & 2 & reg67 & $\operatorname{Sim}$ & Sim & 2 & 168 & 3 \\
\hline reg14 & Não & Sim & 2 & 336 & 2 & $\operatorname{reg} 68$ & Sim & Sim & 2 & 336 & 3 \\
\hline reg15 & Não & $\mathrm{Sim}$ & 2 & 720 & 2 & reg69 & Sim & $\mathrm{Sim}$ & 2 & 720 & 3 \\
\hline $\operatorname{reg} 16$ & Não & $\mathrm{Sim}$ & 5 & 168 & 2 & reg70 & Sim & $\mathrm{Sim}$ & 5 & 168 & 3 \\
\hline reg17 & Não & Sim & 5 & 336 & 2 & reg71 & Sim & $\mathrm{Sim}$ & 5 & 336 & 3 \\
\hline reg18 & Não & Sim & 5 & 720 & 2 & reg72 & Sim & $\mathrm{Sim}$ & 5 & 720 & 3 \\
\hline reg19 & Sim & Não & 1 & 168 & 2 & reg73 & Não & Não & 1 & 168 & 5 \\
\hline $\operatorname{reg} 20$ & Sim & Não & 1 & 336 & 2 & reg74 & Não & Não & 1 & 336 & 5 \\
\hline $\operatorname{reg} 21$ & Sim & Não & 1 & 720 & 2 & $\operatorname{reg} 75$ & Não & Não & 1 & 720 & 5 \\
\hline $\operatorname{reg} 22$ & Sim & Não & 2 & 168 & 2 & reg76 & Não & Não & 2 & 168 & 5 \\
\hline $\operatorname{reg} 23$ & Sim & Não & 2 & 336 & 2 & reg77 & Não & Não & 2 & 336 & 5 \\
\hline reg24 & Sim & Não & 2 & 720 & 2 & reg78 & Não & Não & 2 & 720 & 5 \\
\hline $\operatorname{reg} 25$ & $\mathrm{Sim}$ & Não & 5 & 168 & 2 & reg79 & Não & Não & 5 & 168 & 5 \\
\hline $\operatorname{reg} 26$ & $\mathrm{Sim}$ & Não & 5 & 336 & 2 & reg80 & Não & Não & 5 & 336 & 5 \\
\hline $\operatorname{reg} 27$ & Sim & Não & 5 & 720 & 2 & reg 81 & Não & Não & 5 & 720 & 5 \\
\hline $\operatorname{reg} 28$ & Sim & Sim & 1 & 168 & 2 & reg 82 & Não & Sim & 1 & 168 & 5 \\
\hline reg 29 & Sim & Sim & 1 & 336 & 2 & reg83 & Não & Sim & 1 & 336 & 5 \\
\hline reg30 & Sim & Sim & 1 & 720 & 2 & reg84 & Não & $\mathrm{Sim}$ & 1 & 720 & 5 \\
\hline reg31 & $\mathrm{Sim}$ & $\mathrm{Sim}$ & 2 & 168 & 2 & reg85 & Não & Sim & 2 & 168 & 5 \\
\hline $\operatorname{reg} 32$ & Sim & $\mathrm{Sim}$ & 2 & 336 & 2 & reg86 & Não & Sim & 2 & 336 & 5 \\
\hline reg 33 & Sim & Sim & 2 & 720 & 2 & reg87 & Não & Sim & 2 & 720 & 5 \\
\hline reg34 & Sim & Sim & 5 & 168 & 2 & reg88 & Não & Sim & 5 & 168 & 5 \\
\hline reg35 & $\operatorname{Sim}$ & Sim & 5 & 336 & 2 & reg89 & Não & Sim & 5 & 336 & 5 \\
\hline reg36 & Sim & Sim & 5 & 720 & 2 & reg90 & Não & $\mathrm{Sim}$ & 5 & 720 & 5 \\
\hline $\operatorname{reg} 37$ & Não & Não & 1 & 168 & 3 & reg91 & Sim & Não & 1 & 168 & 5 \\
\hline reg38 & Não & Não & 1 & 336 & 3 & reg92 & Sim & Não & 1 & 336 & 5 \\
\hline reg39 & Não & Não & 1 & 720 & 3 & reg93 & Sim & Não & 1 & 720 & 5 \\
\hline reg 40 & Não & Não & 2 & 168 & 3 & reg94 & Sim & Não & 2 & 168 & 5 \\
\hline reg41 & Não & Não & 2 & 336 & 3 & reg95 & Sim & Não & 2 & 336 & 5 \\
\hline $\operatorname{reg} 42$ & Não & Não & 2 & 720 & 3 & reg96 & Sim & Não & 2 & 720 & 5 \\
\hline reg 43 & Não & Não & 5 & 168 & 3 & reg97 & Sim & Não & 5 & 168 & 5 \\
\hline reg 44 & Não & Não & 5 & 336 & 3 & reg98 & Sim & Não & 5 & 336 & 5 \\
\hline reg 45 & Não & Não & 5 & 720 & 3 & reg99 & Sim & Não & 5 & 720 & 5 \\
\hline $\operatorname{reg} 46$ & Não & $\operatorname{Sim}$ & 1 & 168 & 3 & $\operatorname{reg} 100$ & $\mathrm{Sim}$ & $\mathrm{Sim}$ & 1 & 168 & 5 \\
\hline $\operatorname{reg} 47$ & Não & $\mathrm{Sim}$ & 1 & 336 & 3 & reg101 & Sim & $\mathrm{Sim}$ & 1 & 336 & 5 \\
\hline $\operatorname{reg} 48$ & Não & Sim & 1 & 720 & 3 & reg102 & Sim & $\mathrm{Sim}$ & 1 & 720 & 5 \\
\hline reg 49 & Não & Sim & 2 & 168 & 3 & reg103 & Sim & Sim & 2 & 168 & 5 \\
\hline reg 50 & Não & Sim & 2 & 336 & 3 & reg104 & Sim & Sim & 2 & 336 & 5 \\
\hline $\operatorname{reg} 51$ & Não & Sim & 2 & 720 & 3 & reg105 & Sim & $\mathrm{Sim}$ & 2 & 720 & 5 \\
\hline $\operatorname{reg} 52$ & Não & Sim & 5 & 168 & 3 & reg106 & Sim & Sim & 5 & 168 & 5 \\
\hline reg 53 & Não & Sim & 5 & 336 & 3 & reg107 & Sim & Sim & 5 & 336 & 5 \\
\hline reg 54 & Não & Sim & 5 & 720 & 3 & reg108 & Sim & Sim & 5 & 720 & 5 \\
\hline
\end{tabular}

- O valores de $c$ utilizados para estabelecer os limites de corte para a detecção de outliers no passo 5 do algoritmo proposto: $c=2,3$ e 5 , valores escolhidos de acordo com análises prévias da séries de modo a não classificar um número excessivo de observações como outliers ou não deixar passar pela detecção muitos valores que explicitamente são outliers.

Em todos os experimentos de decomposição clássica usamos o melhor modelos de regressão na detecção de outliers da primeira iteração e na primeira fase de preenchimenho de valores omisos. 
Também consideramos que o algoritmo proposto será executado com $q_{a}$ e $q_{b}$ sendo, respectivamente, o primeiro e terceiro quartil dos resíduos e que a quantidade máxima de iterações $M$ do algoritmo é 4 , pois na primeira iteração a deteç̧ão de outliers é usado o procedimento de regressão já mencionado. A lista dos experimentos é apresentado na Tabela 2.4.

Tabela 2.4: Descrição dos experimentos de imputação de valores omissos que usam como base procedimentos de ajuste de curvas de regressão combinado com decomposição clássica.

\begin{tabular}{|c|c|c|c|c|c|c|c|}
\hline ID & $\begin{array}{l}\text { Interpolação } \\
\quad \text { de } R_{t}\end{array}$ & Janela & $c$ & ID & $\begin{array}{l}\text { Interpolação } \\
\quad \text { de } R_{t}\end{array}$ & Janela & $c$ \\
\hline $\operatorname{dec} 1$ & Não & 168 & 2 & $\operatorname{dec} 10$ & Sim & 168 & 3 \\
\hline $\operatorname{dec} 2$ & Não & 336 & 2 & $\operatorname{dec} 11$ & $\mathrm{Sim}$ & 336 & 3 \\
\hline $\operatorname{dec} 3$ & Não & 720 & 2 & $\operatorname{dec} 12$ & Sim & 720 & 3 \\
\hline $\operatorname{dec} 4$ & Sim & 168 & 2 & $\operatorname{dec} 13$ & Não & 168 & 5 \\
\hline $\operatorname{dec} 5$ & Sim & 336 & 2 & $\operatorname{dec} 14$ & Não & 336 & 5 \\
\hline dec6 & Sim & 720 & 2 & $\operatorname{dec} 15$ & Não & 720 & 5 \\
\hline $\operatorname{dec} 7$ & Não & 168 & 3 & $\operatorname{dec} 16$ & Sim & 168 & 5 \\
\hline $\operatorname{dec} 8$ & Não & 336 & 3 & $\operatorname{dec} 17$ & $\mathrm{Sim}$ & 336 & 5 \\
\hline $\operatorname{dec} 9$ & Não & 720 & 3 & $\operatorname{dec} 18$ & $\mathrm{Sim}$ & 720 & 5 \\
\hline
\end{tabular}

Por fim, para o procedimento de decomposição STL estabelecemos as seguinte situações experimentais:

- O uso ou não de interpolação dos resíduos;

- O valor do parâmetro $n_{(s)}: n_{(s)}=25,37$ e 49, valores escolhidos de acordo com análises prévias das séries;

- A robutez da decomposição: não robusta $\left(n_{(i)}=2, n_{(e)}=0\right)$, robusta $\left(n_{(i)}=1, n_{(e)}=5\right)$, e robusta com convergência $\left(n_{(i)}=1, n_{(e)}=10\right)$, valores sugeridos pelos autores do método;

- O valores de $c$ utilizados para estabelecer os limites de corte para a detecção de outliers no passo 5 do algoritmo proposto: $c=2,3$ e 5 , valores escolhidos de acordo com análises prévias da séries de modo a não classicar um número excessivo de observações como outliers ou não deixar passar pela detecção muitos valores que explicitamente são outliers.

Em todos os experimentos de decomposição STL, o algoritmo proposto foi executado com $q_{a}$ e $q_{b}$ sendo, respectivamente, o primeiro e terceiro quartil dos resíduos e a quantidade máxima de iterações $M$ do algoritmo é 3. A lista dos experiementos é apresentado na Tabela 2.5.

Visando analisar se os procedimentos propostos anteriormente são realmente eficientes, propomos alguns experimentos de preenchimento dos valores omissos para servirem como benchmark. Logo, para cada lacuna de valores omissos presentes nas séries têm-se as seguintes formas de imputação:

Média Calcula-se a média das $k$ observações mais próximas da lacuna de valores omissos e usa-se essa média como valor de imputação;

Mediana Calcula-se a mediana das $k$ observações mais próximas da lacuna de valores omissos e usa-se essa mediana como valor de imputação;

Interpolação Aplica-se uma interpolação linear considerando as duas observações não omissas, sucessora e antecessora em relação a lacuna de valores omissos, para imputar tais observações. 
Tabela 2.5: Descrição dos experimentos de imputação de valores omissos que usam como base procedimentos de decomposição $S T L$.

\begin{tabular}{|c|c|c|c|c|c|c|c|c|c|c|c|}
\hline ID & $\begin{array}{l}\text { Interpolação } \\
\quad \text { de } R_{t}\end{array}$ & $n_{(i)}$ & $n_{(e)}$ & $n_{(s)}$ & $c$ & ID & $\begin{array}{l}\text { Interpolação } \\
\text { de } R_{t}\end{array}$ & $n_{(i)}$ & $n_{(e)}$ & $n_{(s)}$ & $c$ \\
\hline stl1 & Não & 2 & 0 & 25 & 2 & st128 & Sim & 2 & 0 & 25 & 3 \\
\hline st12 & Não & 2 & 0 & 37 & 2 & st129 & Sim & 2 & 0 & 37 & 3 \\
\hline st13 & Não & 2 & 0 & 49 & 2 & st130 & Sim & 2 & 0 & 49 & 3 \\
\hline st14 & Não & 1 & 5 & 25 & 2 & st131 & Sim & 1 & 5 & 25 & 3 \\
\hline st15 & Não & 1 & 5 & 37 & 2 & st132 & Sim & 1 & 5 & 37 & 3 \\
\hline st16 & Não & 1 & 5 & 49 & 2 & st133 & Sim & 1 & 5 & 49 & 3 \\
\hline st17 & Não & 1 & 10 & 25 & 2 & st134 & $\operatorname{Sim}$ & 1 & 10 & 25 & 3 \\
\hline st18 & Não & 1 & 10 & 37 & 2 & st135 & Sim & 1 & 10 & 37 & 3 \\
\hline st19 & Não & 1 & 10 & 49 & 2 & st136 & Sim & 1 & 10 & 49 & 3 \\
\hline st110 & Sim & 2 & 0 & 25 & 2 & st137 & Não & 2 & 0 & 25 & 5 \\
\hline st111 & Sim & 2 & 0 & 37 & 2 & st138 & Não & 2 & 0 & 37 & 5 \\
\hline st11 2 & Sim & 2 & 0 & 49 & 2 & st139 & Não & 2 & 0 & 49 & 5 \\
\hline st113 & Sim & 1 & 5 & 25 & 2 & st140 & Não & 1 & 5 & 25 & 5 \\
\hline st114 & Sim & 1 & 5 & 37 & 2 & st141 & Não & 1 & 5 & 37 & 5 \\
\hline st11 5 & Sim & 1 & 5 & 49 & 2 & st142 & Não & 1 & 5 & 49 & 5 \\
\hline st116 & Sim & 1 & 10 & 25 & 2 & st143 & Não & 1 & 10 & 25 & 5 \\
\hline st117 & Sim & 1 & 10 & 37 & 2 & st144 & Não & 1 & 10 & 37 & 5 \\
\hline st118 & Sim & 1 & 10 & 49 & 2 & st145 & Não & 1 & 10 & 49 & 5 \\
\hline st119 & Não & 2 & 0 & 25 & 3 & st146 & Sim & 2 & 0 & 25 & 5 \\
\hline st120 & Não & 2 & 0 & 37 & 3 & st147 & Sim & 2 & 0 & 37 & 5 \\
\hline st121 & Não & 2 & 0 & 49 & 3 & st148 & Sim & 2 & 0 & 49 & 5 \\
\hline st122 & Não & 1 & 5 & 25 & 3 & st149 & Sim & 1 & 5 & 25 & 5 \\
\hline st123 & Não & 1 & 5 & 37 & 3 & st150 & Sim & 1 & 5 & 37 & 5 \\
\hline st124 & Não & 1 & 5 & 49 & 3 & st151 & Sim & 1 & 5 & 49 & 5 \\
\hline st125 & Não & 1 & 10 & 25 & 3 & st152 & Sim & 1 & 10 & 25 & 5 \\
\hline st126 & Não & 1 & 10 & 37 & 3 & st153 & Sim & 1 & 10 & 37 & 5 \\
\hline st127 & Não & 1 & 10 & 49 & 3 & st154 & Sim & 1 & 10 & 49 & 5 \\
\hline
\end{tabular}

Para avaliar a performance dos métodos, retiramos aleatoriamente algumas sequências de valores não omissos nas séries. Consideramos sequências de tamanhos 1, 3, 6, 12, 24, 18 e 48, de modo que o total de observações omissas inseridas artificialmente fossem 576 em cada caso. Assim, por exemplo, foram inseridas 576 sequências de tamanho 1, 192 sequências de tamanho 3, 96 sequências de tamanho 6 e assim por diante. Depois calculamos as estimativas desses valores omissos de acordo com os experimentos propostos e, por fim, verificamos o quão fidedigno são as estimativas em relação ao valor real. Para isso, utilizamos as medidas de acurácia definidas a seguir.

Sejam $I$ o conjunto de índices dos valores que propositalmente foram retirados da série para comparação e $n$ a cardinalidade de $I$, as medidas de acurácia são

$$
\begin{array}{ll}
M E & =\frac{1}{n} \sum_{i \in I}\left(Z_{i}-\hat{Z}_{i}\right), \\
M S E & =\frac{1}{n} \sum_{i \in I}\left(Z_{i}-\hat{Z}_{i}\right)^{2}, \\
R M S E & =\sqrt{M S E}, \\
M A E & =\frac{1}{n} \sum_{i \in I}\left|Z_{i}-\hat{Z}_{i}\right|, \\
M A P E & =\frac{1}{n} \sum_{i \in I}\left[\frac{\left|\hat{Z}_{i}-Z_{i}\right|}{Z_{i}} \times 100\right] .
\end{array}
$$

Para cada experimento realizado calculamos as medidas de acurácia com as quais comparamos a performance de cada experimento. Por uma questão de praticidade, a maioria das nossas análises tiveram um enfoque no uso do RMSE. Assim, o experimento que apresentou o menor valor de RMSE foi usado oficialmente para preencher os valores omissos. 


\section{Outliers}

Propomos um experimento a fim de avaliar o comportamento dos métodos em relação a detecção e tratamento dos outliers. O experimento consiste basicamente em introduzir alguns outliers nas séries temporais e verificar como que os procedimentos propostos anteriormente conseguem lidar com esses valores.

Para isso, foram criados outliers de acordo com a equação (1.60), na qual consideramos os seguinte tipos de comportamentos:

Único: caracterizado por ser um único valor atípico, descrito por

$$
g_{a}\left(t, t_{1}, k\right)=1,5 \mathbb{1}_{\left\{t_{1}\right\}}(t) .
$$

Platô: caracterizado por ter o mesmo efeito em uma sêquecia de observação, descrito por

$$
g_{a}\left(t, t_{1}, k\right)=\mathbb{1}_{\left\{t_{1}, \ldots, t_{k}\right\}}(t) .
$$

Pulso: caracterizado por um brupto valor atípico cujo efeito vai decaindo exponencialmente nas próximas observações, assim

$$
g_{a}\left(t, t_{1}, k\right)=\left\{e^{\frac{-t+t_{1}+k}{k}}-1\right\} \mathbb{1}_{\left\{t_{1}, \ldots, t_{k}\right\}}(t) .
$$

Crescimento e decrescimento linear: caracterizado por um crescimento linear até um pico e depois por um decrescimento na mesma taxa, o que é expresso por,

$$
g_{a}\left(t, t_{1}, k\right)= \begin{cases}3 \frac{t-t_{1}+1}{k}, & \text { se } t-t_{1}+1 \leq \frac{k}{2} \\ 3 \frac{k-t+t_{1}}{k}, & \text { se } t-t_{1}+1>\frac{k}{2}\end{cases}
$$

se k é par ou por

$$
g_{a}\left(t, t_{1}, k\right)= \begin{cases}3 \frac{t-t_{1}+1}{k}, & \text { se } t-t_{1}+1 \leq \frac{k+1}{2} \\ 3 \frac{k-t+t_{1}}{k}, & \text { se } t-t_{1}+1>\frac{k+1}{2}\end{cases}
$$

se k é ímpar.

Crescimento e decrescimento exponencial: caracterizado por um crescimento exponencial até um pico e depois por um decrescimento de mesma forma, o que é expresso por,

$$
g_{a}\left(t, t_{1}, k\right)= \begin{cases}\exp \left\{2 \frac{t-t_{1}+1}{k}\right\}, & \text { se } t-t_{1}+1 \leq \frac{k}{2} \\ \exp \left\{2 \frac{k-t+t_{1}}{k}\right\}, & \text { se } t-t_{1}+1>\frac{k}{2}\end{cases}
$$


se $\mathrm{k}$ é par ou por

$$
g_{a}\left(t, t_{1}, k\right)=\left\{\begin{array}{ll}
\exp \left\{2 \frac{t-t_{1}+1}{k}\right. \\
\exp \left\{2 \frac{k-t+t_{1}}{k}\right.
\end{array}\right\}, \begin{aligned}
& \text { se } t-t_{1}+1 \leq \frac{k+1}{2} \\
& \text { se } t-t_{1}+1>\frac{k+1}{2}
\end{aligned}
$$

se k é ímpar.

Crescimento e decrescimento logarítmico: caracterizado por um crescimento logarítmico até um pico e depois por um decrescimento de mesma forma, o que é expresso por,

$$
g_{a}\left(t, t_{1}, k\right)=\left\{\begin{array}{l}
2 \log \left\{2 \frac{\left(t-t_{1}+1\right)}{k}+1\right. \\
2 \log \left\{2 \frac{\left(k-t+t_{1}\right)}{k}+1\right.
\end{array}\right\}, \begin{aligned}
& \text { se } t-t_{1}+1 \leq \frac{k}{2} \\
& \text { se } t-t_{1}+1>\frac{k}{2}
\end{aligned}
$$

se $\mathrm{k}$ é par ou por

$$
g_{a}\left(t, t_{1}, k\right)=\left\{\begin{array}{l}
2 \log \left\{2 \frac{\left(t-t_{1}+1\right)}{k}+1\right. \\
2 \log \left\{2 \frac{\left(k-t+t_{1}\right)}{k}+1\right.
\end{array}\right\}, \begin{aligned}
& \text { se } t-t_{1}+1 \leq \frac{k+1}{2} ; \\
& \text { se } t-t_{1}+1>\frac{k+1}{2}
\end{aligned}
$$

se k é ímpar.

A Figura 2.6 ilustra a forma de impacto de cada um dos tipos de efeitos atípicos descritos anteriormente.

O valor de $\omega_{a}$ foi definido como sendo 2 vezes o desvio padrão amostral de $48+k$ observações: 24 observações anteriores às observações afetadas pelo efeito atípico, mais os valores originais das $k$ observações afetadas pelo efeito atípico e mais as 24 observações posteriores ao mesmo grupo de observações. A Figura 2.7 mostra um exemplo do impacto dos efeitos atípicos em uma série simulada, com $k=1$ no efeito do tipo único e $k=21$ para os demais tipos de efeitos atípicos.

Para cada tipo de comportamento, consideramos $k=3,6,12$ e 24, com exeção do efeito único, no qual $k$ é sempre 1. Portanto, dada uma série temporal e um tipo de comportamento, inserimos ao todo 60 efeitos atípicos. Ou seja, 15 efeitos com $k=3,15$ com $k=6$ e assim por diante. Nota-se que o total de observações afetadas é $15 \times(3+6+12+24)=675$. A execeção é do efeito único, pois como $k$ sempre vale 1 acaba implicando que somente 60 observações foram afetadas.

Após introduzirmos os outliers em uma dada série, executamos alguns experimentos de detecção de outliers que se baseiam no procedimento que apresentou melhor resultado dentre os experimentos de preenchimento de valores omissos, de acordo com o menor RMSE total. Isto é, se nos experimentos de imputação de valores omissos o melhor procedimento foi o de decomposição STL não robusto $\left(n_{(i)=2}\right.$ e $\left.n_{(e)}=0\right)$, com interpolação dos resíduos $R_{t}, n_{(s)}=24$ e valor de corte $c=5$, então usamos este procedimento nos experimentos de detecção de outliers, mas variando o valor de $c=2,3,4,5$ e a quantidade de iterações máxima $M=1,3,5$ (nos experimentos de valores omissos a quantidade máxima estava fixada em 3 ou em 4).

Vale salientar que cada tipo de comportamento foi avaliado separadamente nas séries, não sendo inseridos simultamenteamente dois tipos de comportamentos diferentes.

A avaliação do procedimento se dará de duas formas: pela taxa de detecção e pela acurácia em 
(A) Único

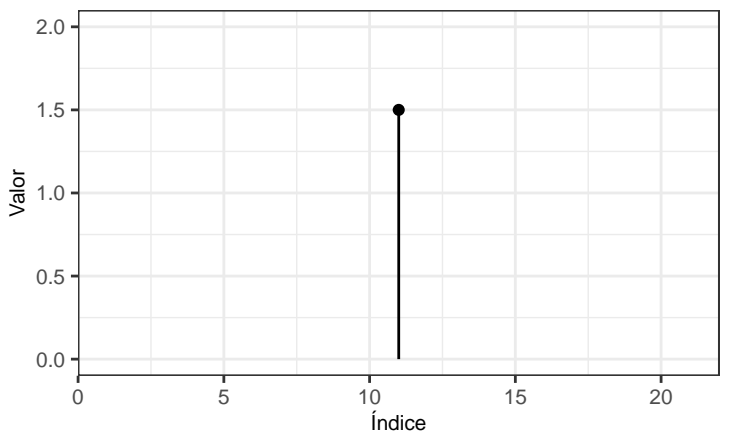

(C) Pulso

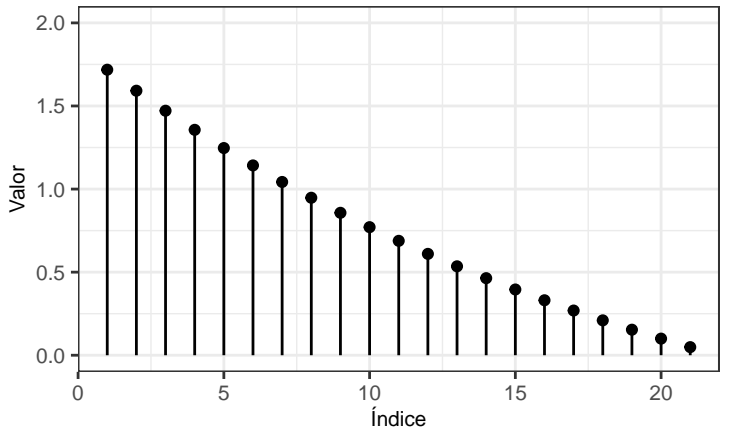

(E) CD Exponencial

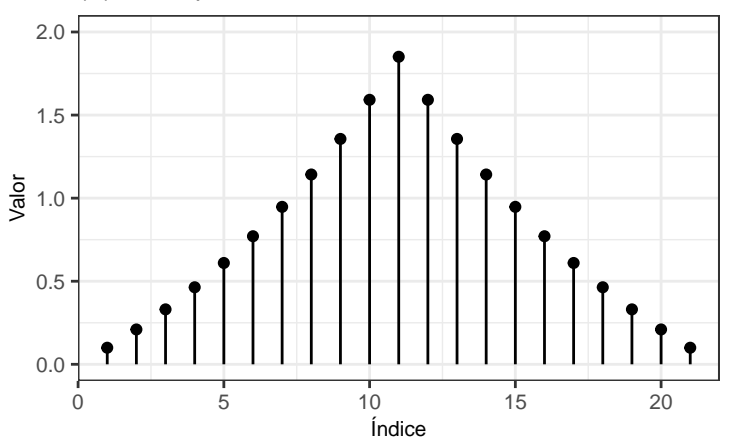

(B) Platô

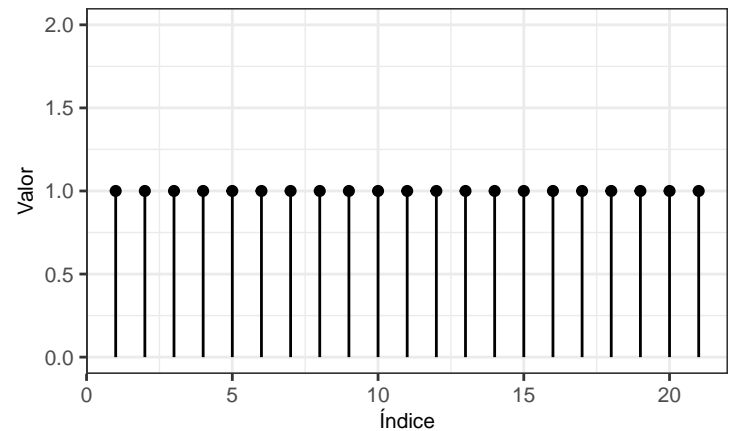

(D) CD Linear

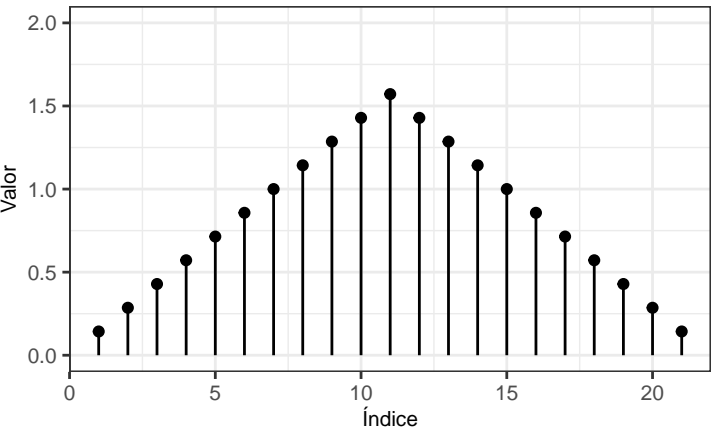

(F) CD Logarítmico

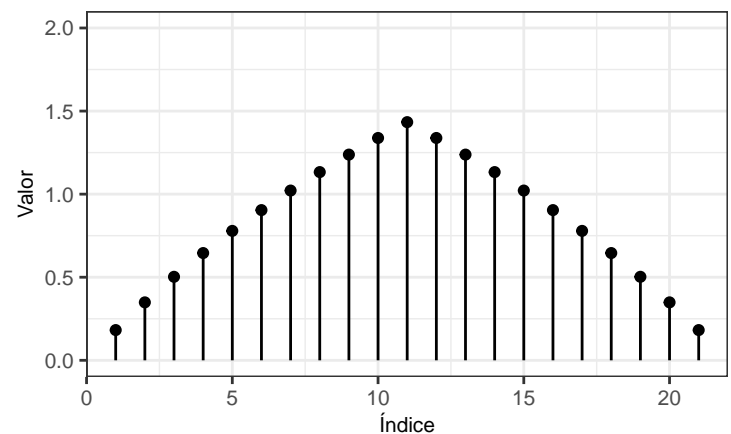

Figura 2.6: Forma do impacto dos tipos de efeitos atipicos considerados neste trabalho.

corrigir as anormalias. No caso da taxa de detecção, verificamos qual foi a proporção de observações outliers inseridas artificialmente que foram detectadas pela aplicação do procedimento. Mais precisamente, seja $\left\{t_{1}, \ldots, t_{n}\right\}$ índices das observações afetadas pelas inserção dos efeitos atípicos e seja $\left\{t_{1}^{*}, \ldots, t_{m}^{*}\right\}$ os índices das observações detectadas como outliers pelos procedimentos propostos, a medida de taxa de detecção é

$$
P R O P=\sum_{i=1}^{n} \mathbb{1}_{\left\{t_{1}^{*}, \ldots, t_{m}^{*}\right\}}\left(t_{i}\right),
$$

no caso, $n=60$ para os efeitos de comportamento do tipo único e $n=675$ para os demais.

Devido a muitas observações terem uma influência muito pequena do efeito atípico, consideramos uma medida de proporção secundária, na qual consideramos apenas a observação que teve a maior influência do efeito atípico. A maneira de cáculo é análoga a equação (2.17).

Já a acurácia é calculda de acordo com as mesmas medidas apresentada anteriormente. Logo, seja $\left\{t_{1}, \ldots, t_{n}\right\}$ índices das observações afetadas pelas inserção dos efeitos atípicos as medidas de acurácias são: 
(A) Único

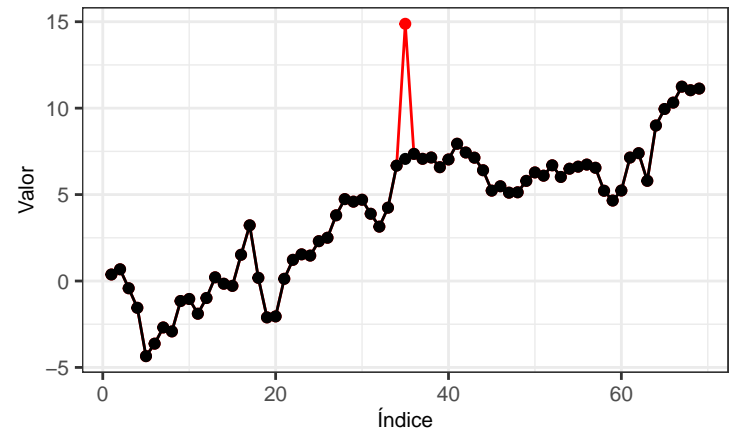

(C) Pulso

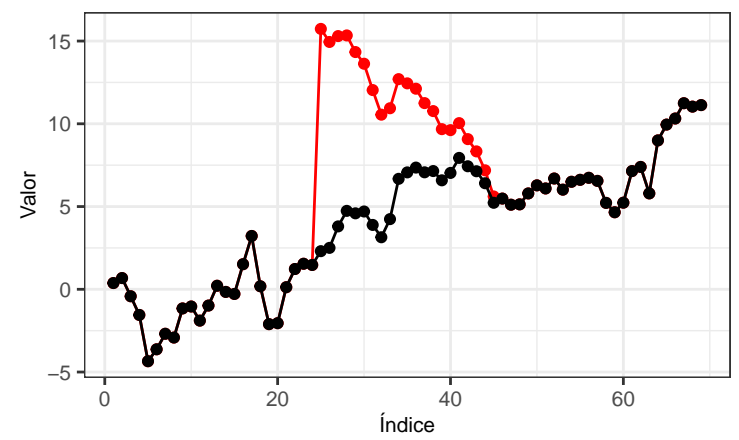

(E) CD Exponencial

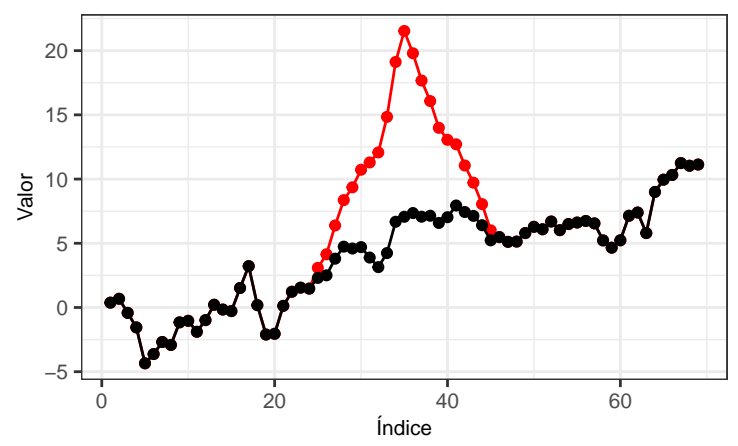

(B) Platô

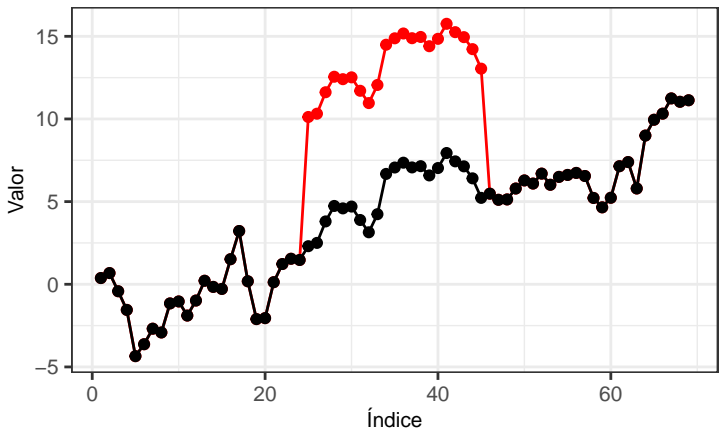

(D) CD Linear

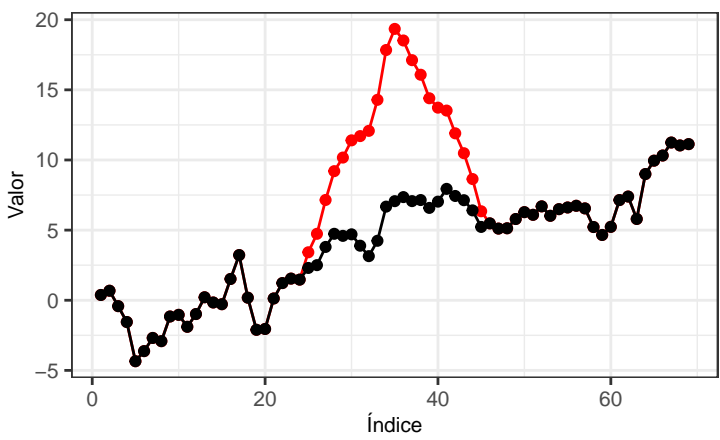

(F) CD Logarítmico

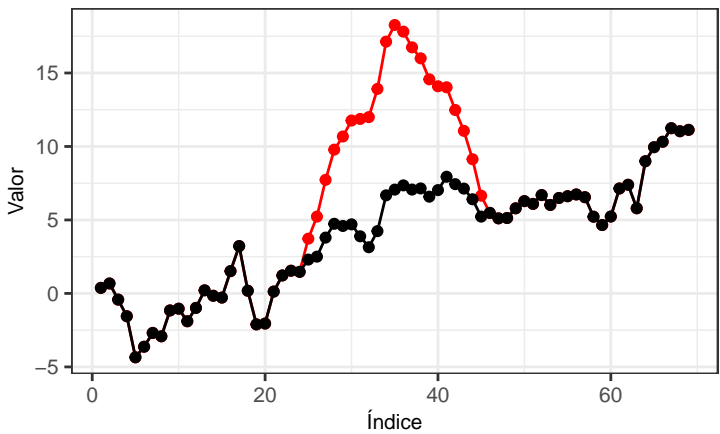

Figura 2.7: Exemplo dos impactos que os efeitos atípicos tem numa série temporal. A série considerada é um passeio aleátorio normal. O impacto do efeito atípico está em vermelho e sua intensidade é proporcional a 2 vezes o desvio padrão dos valores originais e vizinhança

$$
\begin{array}{ll}
M E & =\frac{1}{n} \sum_{i=1}^{n}\left(Z_{t_{i}}-\hat{Z}_{t_{i}}\right), \\
M S E & =\frac{1}{n} \sum_{i=1}^{n}\left(Z_{t_{i}}-\hat{Z}_{t_{i}}\right)^{2}, \\
R M S E & =\sqrt{M S E} \\
M A E & =\frac{1}{n} \sum_{i=1}^{n}\left|Z_{t_{i}}-\hat{Z}_{t_{i}}\right|, \\
M A P E & =\frac{1}{n} \sum_{i=1}^{n}\left[\frac{\left|\hat{Z}_{t_{i}}-Z_{t_{i}}\right|}{Z_{t_{i}}} \times 100\right] .
\end{array}
$$

Em geral, trabalhamos mais exaustivamente com o PROP e RMSE.

\subsection{Previsão}

Uma vez com as séries reconstruídas e livres dos outliers, nosso último objetivo é fazer previsão. São propostos três tipos de modelos principais: modelos SARIMA, modelos de regressão com erros 
autocorrelacionados e modelos BATS e TBATS.

A descrição de cada um desses modelos foi dada no capítulo 1 e daremos apenas a explicação dos experimentos para se avaliar aplicação de cada tipo de modelo.

Em todos os experimentos utilizamos a técnica de rolling analisys modificada abordada na seção 1.7.2. Para isso, estabelecemos uma amostra sistemática de $n=30$ janelas e avaliamos a acurácia de cada procedimento de acordo com as medidas apresentadas na mesma seção, dado uma preferência a análise do RMSE.

\subsubsection{Modelos SARIMA}

É possível notar um comportamento sazonal com período de 24 horas em quase todas as séries temporais, o que naturalmente nos leva a considerar um dos modelos mais usados para a modelagem de séries sazonais, os modelos SARIMA. Assim, o primeiro método de modelagem visando fazer previsão consiste no uso de alguns conjuntos de modelos SARIMA. Para identificar a ordem do modelo, utilizamos o procedimento de identificação prosposto na seção 1.3.7. Analisamos dois tipos de estratégias de ajuste dos modelos em relação às rolling windows:

Tipo 1: Em cada rolling window usa-se o algoritmo descrito na seção 1.3.7 para identificar o modelo e, com o modelo já identificado, faz-se o ajuste e a previsão de $h$ passos a frente;

Tipo 2: Aplica-se o algoritmo descrito na seção 1.3.7 para identificar o modelo somente na primeira rolling window e utiliza-se esse mesmo modelo identificado em todas as demais rolling windows, mas reestimando os parâmetros de acordo com observações contidas em cada uma delas. Uma vez que os parâmetros foram reestimados, faz-se a previsão de horizonte $h$.

A ideia de fazer esses dois procedimento é verificar se o custo de selecionar um modelo em cada rolling window realmente vale a pena, já que este é um procedimento bastante custoso sob o ponto de vista computacional, principalmente quando a série usada possui muitas observações.

\subsubsection{Modelos de regressão com erros autocorrelacionados}

Propomos aqui o uso de modelos semelhantes aos apresentados pelas equações (2.2) e (2.5), mas sob a perspectiva da teoria apresentado na seção 1.4, na qual os erros $R_{t}$ seriam modelados por algum processo da família ARIMA. Assim, os modelos de regressão com erros autocorrelacionados considerados são:

$$
\begin{aligned}
& Z_{t}=\beta_{0}+\sum_{j=1}^{23} \alpha_{j} D_{j, t}+R_{t}, \\
& Z_{t}=\beta_{0}+\beta_{1} t+\sum_{j=1}^{23} \alpha_{j} D_{j, t}+R_{t}, \\
& Z_{t}=\beta_{0}+\sum_{j=1}^{23} \alpha_{j} D_{j, t}+\sum_{i=1}^{6} \gamma_{i} S_{i, t}+R_{t}, \\
& Z_{t}=\beta_{0}+\beta_{1} t+\sum_{j=1}^{23} \alpha_{j} D_{j, t}+\sum_{i=1}^{6} \gamma_{i} S_{i, t}+R_{t},
\end{aligned}
$$

em que $\beta_{0}, \beta_{1}, \alpha_{j}, \gamma_{i}$ são parâmetros do modelos, $D_{j, t}$ e $S_{i, t}$ são, respectivamente, o $j$-ésimo horário e o $i$-ésimo dia da semana associados ao tempo $t$ e $R_{t}$ é um processo $\operatorname{SARIMA}(p, d, q) \times(P, D, Q)$ 
Para cada tipo de modelo, analisamos estratégias análogas às apresentadas para os modelos SARIMA:

Tipo 1: Em cada rolling window usa-se o algoritmo descrito na seção 1.3.7 para identificar a parte SARIMA do modelo e, com o modelo identificado, faz-se o ajuste e a previsão de $h$ passos a frente;

Tipo 2: Aplica-se o algoritmo descrito na seção 1.3.7 para identificar a parte SARIMA do modelo somente na primeira rolling window e utiliza-se esse mesmo modelo em todas as demais rolling windows, mas reestimando os parâmetros usando as observações de cada uma delas. Uma vez que os parâmetros forem reestimados, faz-se a previsão de horizonte $h$.

\subsubsection{Modelos BATS e TBATS}

A última categoria de modelos que utilizamos são os modelos BATS e TBATS abordados na seção 1.5. Aqui usamos a estratégia de seleção de modelo proposta por seus criadores em cada uma das rolling window. Consideramos os modelos de duas formas: com uma sazonalidade de período de 24 horas ou com duas sazonalidades de períodos de 24 e 168 horas (equivalente 7 dias), assim, teremos os seguintes tipos de modelos:

- BATS com sazonalidade de 24 horas;

- BATS com sazonalidades de 24 e 168 horas;

- TBATS com sazonalidade de 24 horas;

- TBATS com sazonalidades de 24 e 168 horas.

\subsubsection{Métodos de previsão Benchmark}

Para fazermos uma comparação da eficiência de previsão dos modelos propostos, ultilizamos alguns métodos de previsão que funcionam como benchmarks. Esse métodos são:

Média: Calcula-se a média das observações da rolling window e usa-se esse valor como previsão nos $h$ passos a frente;

Mediana: Calcula-se a mediana das observações da rolling window e usa-se esse valor como previsão nos $h$ passos a frente;

Última Observação: Usa-se o valor da última observação como previsão nos $h$ passos a frente.

\subsection{Materiais}

Todos os experimentos são realizados usando o software R [R C20] com a auxílio do RStudio [RSt20] instalados no sistema operacional Windows 10 Home Single Language. Os pacotes utilizados foram:

forecast $\left[\mathrm{HAB}^{+}\right.$20]: possui funções que aplicam o algoritmo de busca pelo melhor modelo SARIMA usando o procedimento proposto por Hyndman e Khandakar (2008) [RY08], além de funções de identificação e ajuste dos modelos BATS e TBATS; 
stlplus [Haf16]: executa o algoritmo de decomposição STL que consegue lidar com séries que possuem valores omissos;

tidyverse $\left[\mathrm{WAB}^{+} 19\right]$ : reúne vários pacotes importantes para ciência de dados, dentre os quais, usamos ggplot2, dplyr, tidyr, readr, tibble e stringr;

ggplot2 [Wic16]: cria diversos gráficos de forma pratica usando uma gramática de gráficos;

ggpubr [Kas20]: possui funções e gráficos complementares ao pacote ggplot2;

dplyr [WFHM20]: fornece uma gramática para a manipulação de dados;

tidyr [Wic20]: reúne funções para a manipulação e limpeza de dados;

readr [WH20]: reúne funções para a leitura e escrita de arquivos de dados retangular, como csv, tsv, fwt;

tibble [MW20b]: fornece uma forma mais cômoda de estrutura de dados para se fazer análises;

stringr [Wic19]: reúne funções para a manipulação de data e horários;

lubridate [GW11]: fornece uma gramática para a manipulação de dados;

foreach [MW20a]: junto ao pacote doParallel, reúne funções para execuções de tarefas em paralelo;

doParallel [CW20]: junto ao pacote foreach, reúne funções para execuções de tarefas em paralelo;

kableExtra [Zhu20]: auxilia na formatação de tabelas para o fomato Latex.

Quanto ao hardware, foi usado um notebook com as seguintes especificações:

CPU E CHIPSET: Intel@ Core ${ }^{T M}$ i7-9750H, $9^{\text {a }}$ Geração, Hexa Core, Frequência: 2.6 à 4.5 GHz, $12 \mathrm{MB}$ de SmartCache, Chipset: Intel HM370;

MEMÓRIA RAM: 32 GB (2x16GB) RAM, DDR4, até 2400MHz;

ARMAZENAMENTO: 128GB SATA 3 SSD M.2 2280. 


\section{Capítulo 3}

\section{Resultados e discussão}

Este capítulo é dedicado a apresentar os resultados e a fazer uma avaliação da aplicação das metodologias propostas no capítulo anterior. Cada seção se refere aos resultados obtidos por uma série temporal específica, a saber, nível do reservatório de Peruíbe (Seção 3.2), consumo demandado do reservatório (Seção 3.3), vazão de entrada no reservatório (Seção 3.1), vazão de saída do reservatório para o Norte de Peruíbe (Seção 3.4), vazão de saída do reservatório para o Sul de Peruíbe (Seção 3.5), pressão a montante no Norte de Peruíbe (Seção 3.6), pressão a montante no Sul de Peruíbe (Seção 3.7), pressão a jusante no Norte de Peruíbe (Seção 3.8) e pressão a jusante no Sul de Peruíbe (Seção 3.9). Cada uma dessas seções possui uma estrutura bem padronizada: no início é apresentado e discutido um resumo dos principais resultados e nas subseções seguintes esses resultados são apresentados e discutidos de forma bem mais detalhadas, ou seja, as seções são dividas em subseções que discutem os procedimentos de preenchimento de valores omissos, a detecção e tratamento de outliers do melhor procedimento de preenchimento de valores omissos e os métodos de previsão. Como mencionado no capítulo anterior, embora fazer previsão não seja um dos principais objetivos das séries de nível e de vazão de entrada do reservatório, os resultados da aplicação dos métodos previsionais também são apresentados para essas séries.

Para ser mais sucinto, as análises apresentadas neste capítulo utilizam apenas o RMSE como medida de acurácia. Gráficos e tabelas mais detalhados das séries após passarem pelo tratamento dos outliers e preenchimento dos valores omissos são apresentados no Apêndice C.

Por fim, a seção 3.10 faz uma discussão geral dos resultados obtidos.

\subsection{Vazão de entrada do reservatório Peruíbe}

Nesta seção é apresentado e discutido os resultados das aplicações dos procedimentos de imputação de valores omissos e detecção de outliers e dos métodos de previsão relacionados a série de vazão de entrada no reservatório Peruíbe. A Figura 3.1 exibe um trecho da série que exemplifica seu comportamento. O gráfico (A) se refere a série original, enquanto que o gráfico (B) é mesmo trecho após limpeza e aplicação do métodos de detecção de outlier e preenchimento de valores omissos.

O método escolhido para a detecção de outliers e preenchimentos dos valores omissos, por possuir o menor RMSE total entre todos os experimentos realizados, com o valor de 10,11, foi o ajuste de curvas de regressão com polinômio de grau 5 modelando a tendência, com interpolação de $R_{t}$, sem sazonalidade semanal, janela de tamanho 336 e valor de corte $c=5$. O total de valores classificados como anomalias após aplicação do método selecionado foi de 1566 (8,94 \%), vis-à- 
(A) Trecho da série original

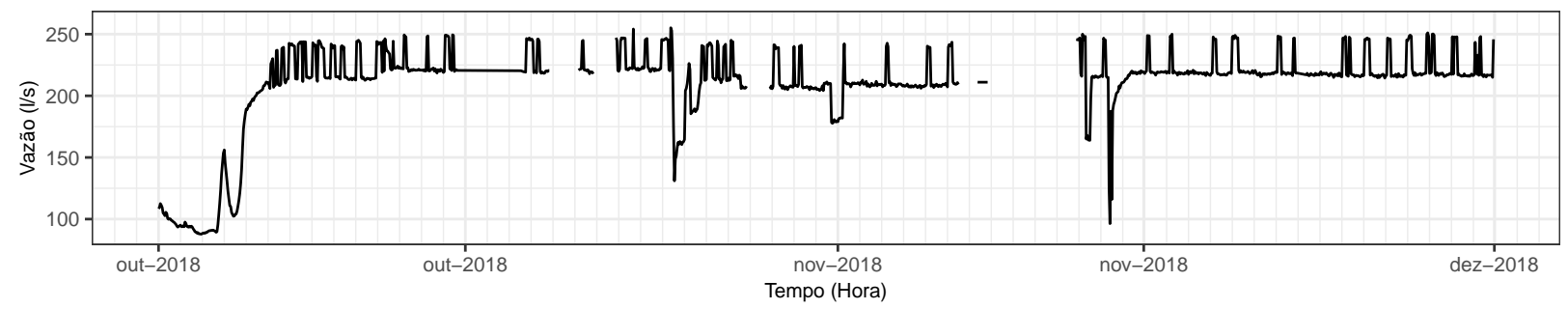

(B) Trecho da série após limpeza e preenchimento de valores omissos

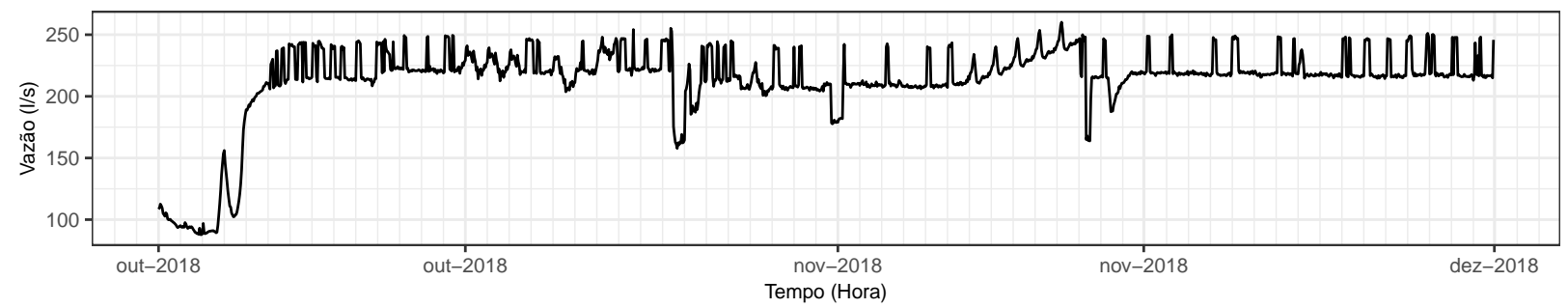

Figura 3.1: Trecho da série de vazão de entrada no reservatório Peruíbe que exemplificam seu comportamento. O gráfico (A) é referente a série original e o gráfico (B) mostra a série após as limpezas, tratamento dos outliers detectados e preenchimento dos valores omissos de acordo com o método escolhido.

vis à quantidade de $1416(8,08 \%)$ após a limpeza primária e à quantidade original de $205(1,17$ \%). Em relação a previsão, o método que apresentou melhor desempenho nos experimentos foi o que usou modelos TBATS sem sazonalidade semanal e com rolling windows de tamanho 336, apresentando o valor de RMSE total de 23,074. Os resultados mostram que os métodos de detecção de outliers e preenchimento de valores omissos não performaram tão bem para a série de vazão de entrada no reservatório Peruíbe devido ao seu comportamento irregular ao longo do tempo, com desempenhos muito próximos ou inferiores ao melhor dos método benchmarks. O mesmo pode ser dito sobre os resultados dos métodos de previsão o que é uma evidência de que o CCO não possui um comportamento previsível de acordo com os métodos previsionais aqui sugeridos.

As próximas subseções apresentam e discutem os resultados de forma mais detalhada.

\subsubsection{Preenchimento de valores omissos}

As tabelas 3.1 à 3.3 mostram os resultados dos 12 melhores experimentos de cada tipo de procedimento de preenchimento de valores omissos, usando como medida de avaliação o RMSE. Em todas as tabelas os experimentos são apresentados em ordem decrescente de RMSE. Já a tabela 3.4 apresenta os resultados dos procedimentos de preenchimento de valores omissos usados como benchmark. Nesta, os experimentos são ordenados pelo ID.

De acordo com as informações apresentadas nas tabelas 3.1 à 3.4 podemos verificar que, em geral:

- Os melhores procedimentos de regressão, de acordo com o RMSE total, foram aqueles que consideraram a sazonalidade semanal, que usaram interpolação nos resíduos $R_{t}$ e que usaram valore de corte $c=5$, sendo que o melhor procedimento de regressão para imputação de valores omissos foi o que usou polinômio de grau 5 modelando a tendência, com interpolação de $R_{t}$, sem sazonalidade semanal, janela de tamanho 336 e valor de corte $c=5$, apresentando um RMSE total igual a 10,11. Os parâmetros desse modelo de regressão foram os usados na aplicação do método de decomposição clássica. 
Tabela 3.1: RMSE dos 12 melhores métodos de preenchimento de dados omissos baseados no ajuste de modelos de regressão, selecionados de acordo com menor RMSE. Os resultados se referem a aplicação dos métodos a série de vazão de entrada no reservatório Peruíbe.

\begin{tabular}{|c|c|c|c|c|c|c|c|c|c|c|c|c|c|}
\hline \multicolumn{6}{|c|}{ Experimentos de regressão } & \multicolumn{8}{|c|}{ Quantidade de valores omissos em sequência } \\
\hline ID & $\begin{array}{l}\text { Interpolação } \\
\quad \text { de } R_{t}\end{array}$ & $\begin{array}{c}\text { Dia da } \\
\text { semana }\end{array}$ & $\begin{array}{l}\text { Grau do } \\
\text { polinômio }\end{array}$ & Janela & $c$ & 1 & 3 & 6 & 12 & 18 & 24 & 48 & Total \\
\hline reg98 & Sim & Sim & 5 & 336 & 5 & 6,64 & 5,61 & 9,06 & 12,4 & 11,7 & 11,3 & 14,0 & 10,1 \\
\hline reg 97 & $\mathrm{Sim}$ & Sim & 5 & 168 & 5 & 6,06 & 6,59 & 9,14 & 12,6 & 12,3 & 11,4 & 13,3 & 10,2 \\
\hline reg108 & $\operatorname{Sim}$ & $\operatorname{Sim}$ & 5 & 720 & 5 & 6,56 & 5,45 & 7,66 & 12,9 & 11,7 & 11,7 & 15,7 & 10,2 \\
\hline reg96 & Sim & Sim & 2 & 720 & 5 & 8,83 & 5,59 & 7,69 & 12,8 & 11,6 & 11,2 & 14,5 & 10,3 \\
\hline reg94 & Sim & Sim & 2 & 168 & 5 & 6,72 & 6,30 & 9,28 & 12,8 & 12,0 & 12,0 & 13,2 & 10,3 \\
\hline reg93 & $\operatorname{Sim}$ & Sim & 1 & 720 & 5 & 9,14 & 5,65 & 7,33 & 12,8 & 11,7 & 11,3 & 14,9 & 10,4 \\
\hline reg99 & Sim & Sim & 5 & 720 & 5 & 9,21 & 5,62 & 7,68 & 13,1 & 11,8 & 11,3 & 14,6 & 10,5 \\
\hline reg95 & $\mathrm{Sim}$ & Sim & 2 & 336 & 5 & 9,18 & 5,90 & 8,09 & 12,7 & 12,0 & 11,5 & 14,0 & 10,5 \\
\hline reg102 & $\operatorname{Sim}$ & Sim & 1 & 720 & 5 & 8,79 & 5,62 & 7,32 & 12,9 & 11,6 & 11,6 & 15,9 & 10,5 \\
\hline reg104 & Sim & Sim & 2 & 336 & 5 & 9,18 & 5,42 & 7,55 & 12,9 & 11,9 & 11,8 & 15,2 & 10,6 \\
\hline reg105 & Sim & Sim & 2 & 720 & 5 & 8,81 & 5,51 & 7,71 & 12,9 & 11,7 & 11,6 & 16,2 & 10,6 \\
\hline reg92 & Sim & Sim & 1 & 336 & 5 & 9,37 & 6,18 & 8,14 & 12,9 & 11,8 & 11,6 & 14,5 & 10,6 \\
\hline
\end{tabular}

Tabela 3.2: RMSE dos 12 melhores métodos de preenchimento de dados omissos baseados no ajuste de modelo de regressão acompanhado de decomposições clássica, selecionados de acordo com menor RMSE. O modelo de regressão usado em conjundo com a decomposição clássica, por apresentar menor RMSE, foi o que possui polinômio de grau 5, com interpolação dos resíduos, sem sazonalidade semanal e janela de tamanho 336. Os resultados se referem a aplicação dos métodos a série de vazão de entrada no reservatório Peruíbe.

\begin{tabular}{|c|c|c|c|c|c|c|c|c|c|c|c|}
\hline \multicolumn{4}{|c|}{ Experimentos de decomposição clássica } & \multicolumn{8}{|c|}{ Quantidade de valores omissos em sequência } \\
\hline ID & $\begin{array}{l}\text { Interpolação } \\
\text { de } R_{t}\end{array}$ & Janela & $c$ & 1 & 3 & 6 & 12 & 18 & 24 & 48 & Total \\
\hline $\operatorname{dec} 16$ & Sim & 168 & 5 & 6,61 & 5,66 & 8,86 & 12,8 & 12,3 & 11,5 & 14,5 & 10,3 \\
\hline $\operatorname{dec} 17$ & Sim & 336 & 5 & 6,44 & 5,53 & 8,85 & 12,5 & 12,2 & 11,8 & 15,2 & 10,3 \\
\hline $\operatorname{dec} 18$ & Sim & 720 & 5 & 6,35 & 5,50 & 8,93 & 12,8 & 12,3 & 11,9 & 16,1 & 10,5 \\
\hline $\operatorname{dec} 10$ & Sim & 168 & 3 & 7,11 & 6,27 & 9,20 & 13,2 & 11,9 & 12,5 & 15,1 & 10,8 \\
\hline $\operatorname{dec} 11$ & Sim & 336 & 3 & 7,11 & 6,17 & 9,17 & 13,0 & 11,8 & 12,7 & 15,5 & 10,8 \\
\hline $\operatorname{dec} 12$ & Sim & 720 & 3 & 7,03 & 6,16 & 9,19 & 13,3 & 11,8 & 12,6 & 16,2 & 10,9 \\
\hline $\operatorname{dec} 13$ & Não & 168 & 5 & 8,87 & 7,79 & 9,81 & 13,0 & 12,2 & 11,5 & 14,1 & 11,0 \\
\hline $\operatorname{dec} 14$ & Não & 336 & 5 & 9,02 & 7,94 & 9,94 & 12,8 & 12,0 & 11,6 & 14,1 & 11,1 \\
\hline $\operatorname{dec} 15$ & Não & 720 & 5 & 9,14 & 7,90 & 10,04 & 13,1 & 12,0 & 11,6 & 14,3 & 11,1 \\
\hline $\operatorname{dec} 7$ & Não & 168 & 3 & 9,15 & 8,21 & 10,12 & 13,3 & 11,9 & 12,5 & 14,6 & 11,4 \\
\hline $\operatorname{dec} 8$ & Não & 336 & 3 & 9,31 & 8,40 & 10,30 & 13,2 & 11,7 & 12,5 & 14,7 & 11,4 \\
\hline $\operatorname{dec} 9$ & Não & 720 & 3 & 9,43 & 8,38 & 10,42 & 13,4 & 11,7 & 12,5 & 14,8 & 11,5 \\
\hline
\end{tabular}

Tabela 3.3: RMSE dos 12 melhores métodos de preenchimento de dados omissos baseados em decomposição STL, selecionados de acordo com menor RMSE. Os resultados se referem a aplicação dos métodos a série de vazão de entrada no reservatório Peruíbe.

\begin{tabular}{|c|c|c|c|c|c|c|c|c|c|c|c|c|c|}
\hline \multicolumn{6}{|c|}{ Experimentos de decomposição STL } & \multicolumn{8}{|c|}{ Quantidade de valores omissos em sequência } \\
\hline ID & $\begin{array}{l}\text { Interpolação } \\
\text { de } R_{t}\end{array}$ & $n_{(i)}$ & $n_{(e)}$ & $n_{(s)}$ & $c$ & 1 & 3 & 6 & 12 & 18 & 24 & 48 & Total \\
\hline st146 & $\operatorname{Sim}$ & 2 & 0 & 25 & 5 & 6,96 & 5,57 & 6,99 & 12,5 & 11,8 & 11,6 & 16,4 & 10,3 \\
\hline st147 & Sim & 2 & 0 & 37 & 5 & 6,89 & 5,50 & 7,13 & 12,5 & 11,8 & 11,7 & 17,0 & 10,4 \\
\hline st148 & $\operatorname{Sim}$ & 2 & 0 & 49 & 5 & 6,86 & 5,45 & 7,14 & 12,6 & 12,0 & 11,7 & 17,3 & 10,4 \\
\hline st128 & Sim & 2 & 0 & 25 & 3 & 6,73 & 5,91 & 9,40 & 12,7 & 12,3 & 11,4 & 17,0 & 10,8 \\
\hline st129 & Sim & 2 & 0 & 37 & 3 & 6,81 & 6,26 & 9,46 & 12,8 & 12,5 & 11,4 & 17,6 & 11,0 \\
\hline st130 & Sim & 2 & 0 & 49 & 3 & 6,68 & 6,24 & 9,46 & 12,8 & 12,6 & 11,4 & 17,8 & 11,0 \\
\hline st110 & $\operatorname{Sim}$ & 2 & 0 & 25 & 2 & 8,04 & 7,17 & 9,87 & 12,7 & 13,0 & 11,4 & 16,8 & 11,3 \\
\hline st111 & Sim & 2 & 0 & 37 & 2 & 7,82 & 7,05 & 9,83 & 13,3 & 13,0 & 11,1 & 17,2 & 11,3 \\
\hline st112 & Sim & 2 & 0 & 49 & 2 & 8,03 & 7,03 & 9,82 & 13,3 & 13,0 & 11,1 & 17,4 & 11,4 \\
\hline st138 & Não & 2 & 0 & 37 & 5 & 8,97 & 8,78 & 9,88 & 13,4 & 12,8 & 12,0 & 16,6 & 11,8 \\
\hline st137 & Não & 2 & 0 & 25 & 5 & 9,23 & 9,12 & 9,48 & 13,4 & 13,1 & 12,1 & 16,3 & 11,8 \\
\hline st139 & Não & 2 & 0 & 49 & 5 & 8,96 & 8,80 & 9,99 & 13,5 & 12,9 & 12,0 & 16,6 & 11,8 \\
\hline
\end{tabular}

- Os procedimentos de decomposição clássica que tiveram melhor desempenho, de acordo com o RMSE total, foram aqueles que aplicaram interpolações nos resíduos $R_{t}$ e que, aparentemente, possuem maiores valores de corte $c$. O melhor procedimento foi aquele que usou decomposição 
Tabela 3.4: RMSE dos métodos benchmark de preenchimento de dados omissos. Os resultados se referem a aplicação dos métodos a série de vazão de entrada no reservatório Peruíbe.

\begin{tabular}{|c|c|c|c|c|c|c|c|c|c|c|}
\hline \multicolumn{3}{|c|}{ Experimentos emphbenchmark } & \multicolumn{8}{|c|}{ Quantidade de valores omissos em sequência } \\
\hline ID & $\begin{array}{c}\text { Forma de } \\
\text { benchmark }\end{array}$ & Janela & 1 & 3 & 6 & 12 & 18 & 24 & 48 & Total \\
\hline ben1 & Média & 168 & 16,82 & 16,25 & 17,04 & 17,0 & 19,6 & 21,5 & 22,3 & 18,6 \\
\hline ben 2 & Média & 336 & 19,52 & 21,31 & 19,49 & 17,0 & 22,6 & 24,0 & 27,3 & 21,6 \\
\hline ben 3 & Média & 720 & 22,24 & 24,61 & 21,97 & 19,2 & 23,9 & 25,0 & 29,6 & 23,8 \\
\hline ben 4 & Mediana & 168 & 16,39 & 17,16 & 15,20 & 15,3 & 16,7 & 20,4 & 24,7 & 18,0 \\
\hline ben5 & Mediana & 336 & 18,85 & 21,38 & 19,12 & 16,5 & 21,9 & 24,9 & 29,9 & 21,8 \\
\hline ben 6 & Mediana & 720 & 20,47 & 23,52 & 21,21 & 17,7 & 25,7 & 26,9 & 30,7 & 23,7 \\
\hline ben 7 & Interpolação & - & 5,61 & 5,39 & 6,88 & 13,0 & 12,7 & 12,4 & 15,2 & 10,2 \\
\hline
\end{tabular}

com interpolação de $R_{t}$, janela de tamanho 168 e valor de corte $c=5$, apresentando um RMSE total igual a 10,333 .

- Os tipos de decomposição STL que tiveram melhores resultados, de acordo com o RMSE total, foram os que possuem interpolação nos resíduos $R_{t}$, usaram decomposição STL não robusta $\left(n_{(i)}=2\right.$ e $\left.n_{(e)}=0\right)$ e que, aparentemente, possui maior valor de corte $c$. O melhor procedimento foi o de decomposição não robusta $\left(n_{(i)}=2\right.$ e $\left.n_{(e)}=0\right)$, com interpolação de $R_{t}, n_{(s)}=25$ e valor de corte $c=5$, apresentando um RMSE total igual a 10,259.

- Dentre os métodos de benchmark, o que teve melhor desempenho foi o que interpola linearmente os valores da série, apresentando um RMSE total igual a 10,166. Vale mencionar que o melhor método benchmark teve performance superior a quase todos os procedimentos propostos. Outro ponto a se observar que o método de interpolação também teve bom desempenho em preencher sequências curtas de valores omissos.

- Dentre todos os experimentos, o que apresentou melhor resultado foi o procedimento de ajuste de curvas de regressão com polinômio de grau 5 modelando a tendência, com interpolação de $R_{t}$, sem sazonalidade semanal, janela de tamanho 336 e valor de corte $c=5$, apresentando um valor de RMSE total de 10,11. Este é o procedimento para o qual é apresentado uma análise de outliers na próxima subseção e que é usado oficialmente para preencher os valores omissos da série.

A Figura 3.2 exemplifica alguns experimentos de preenchimento de valores omissos. Cada gráfico representa um trecho da série temporal de vazão de entrada no reservatório Peruíbe no qual propositalmente foi removido uma sequência de valores. Todos os gráficos se referem a uma lacuna de tamanho 48 horas acompanhado de 12 valores anteriores e posteriores à lacuna principal. Os procedimentos de preenchimento adotados para ilustrar os gráficos são o melhor experimento, de acordo com o RMSE total, de cada tipo de procedimento apresentados nas tabelas 3.1 à 3.4.

Verifica-se que os procedimentos propostos não conseguiram fazer uma boa estimativa dos valores omissos, pois a série não possui um comportamento sazonal definido. O gráfico (C) ainda mostra uma possível sazonalidade captadas pelos procedimentos de preenchimento, porém, nos demais, a imputação foi muito aquém do desejado. Isso explica o porquê da maioria dos métodos propostos serem pior do que o método benchmark de interpolação. Tal resultado já era esperado, visto que a vazão de entrada no reservatório praticamente depende muito mais da decisão do controlador do CCO do que do perfil de consumo da população. 
(A)

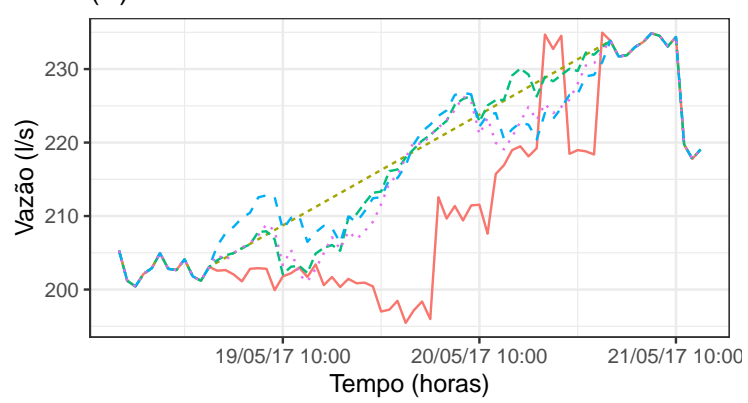

(C)

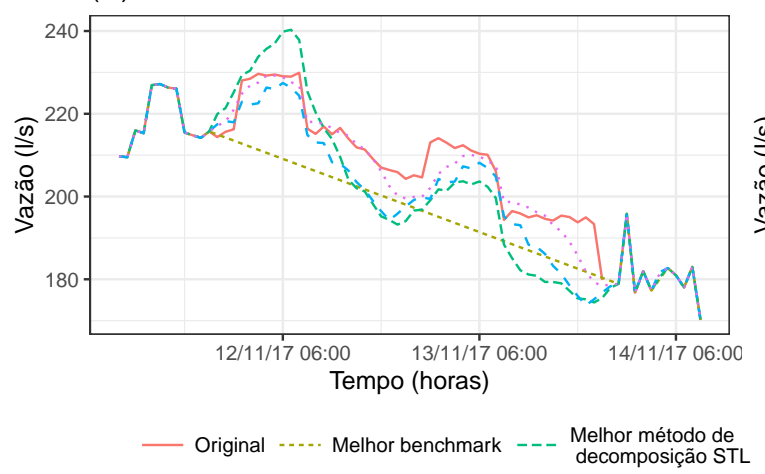

(B)

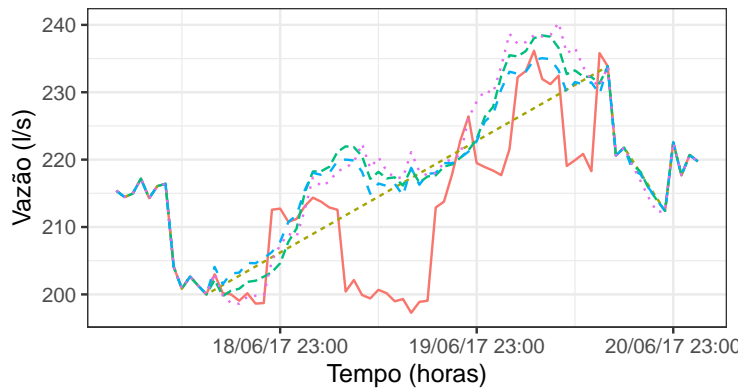

(D)

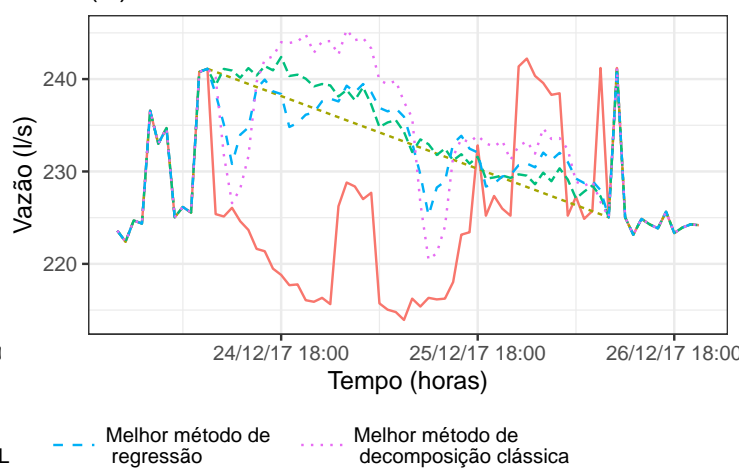

Figura 3.2: Alguns trechos da série de vazão de entrada no reservatório Peruỉe que exemplificam a aplicação dos procedimentos de preenchimento de valores omissos. É apresentado o melhor experimento de imputação de valores omissos de cada tipo de procedimento de acordo com o RMSE, descritos nas tabelas 3.1 à 3.4. A lacuna principal de valores omissos usada em cada gráfico foi inserida artificialmente na série temporal a fim de avaliar a performance dos procedimentos de preenchimento de valores omissos. O tamanho da lacuna principal é de 48 horas, sendo precedida e sucedida de 12 horas de valores originais.

\subsubsection{Detecção e tratamento de outliers}

As tabelas 3.5 e 3.6 mostram os resultados dos experimentos elaborados para avaliar o desempenho em detectar e tratar os outliers do melhor procedimento selecionado para a imputação dos valores omissos. A Tabela 3.5 apresenta as taxas de detecção dos outliers, sendo dividida em duas partes: na parte superior o cálculo das taxas considera todas as observações afetadas pelo efeito atípico, enquanto que na parte inferior é considerado apenas a observação mais afetada pelo efeito atípico. Vale lembrar que no caso do efeito atípico do tipo platô todas as observações foram consideradas como sendo as mais afetadas devido ao efeito se distribuir igualmente entre elas. Já a tabela 3.6 é destinada a verificar a acurácia do procedimento ao corrigir os valores dos outliers. Sua estrutura é análoga à da tabela 3.5, sendo que a linha total é o RMSE do efeito atípico nas observações.

A partir das tabelas, podemos verificar que:

- As taxas de deteç̧ão dos outliers foram, em geral, baixas. Os motivos mais prováveis para essa baixa taxa de detecção é termos usado uma contante $\omega$ relativamente baixo para a produção dos outliers e pela a série apresentar comportamento bem irregular, sem uma sazonalidade bem definida, o que pode dificultar a deteç̧ão de tais valores atípicos. Vale ressaltar que a baixa taxa de detecção reflete na baixa acurácia em corrigir os valores.

- É possivel ver que a quantidade iteração não interfere muito na taxa de detecção dos outliers e, consequentemente, também não ajuda muito a melhorar a acurácia ao corrigir os valores atípicos. 
Tabela 3.5: Taxa de deteç̧ão de outliers de acordo com o procedimento que apresentou melhor desempenho em preencher valores omissos. O procedimento foi o de ajuste de curvas de regressão com polinômio de grau 5 modelando a tendência, com interpolação de $R_{t}$, sem sazonalidade semanal, janela de tamanho 336 e valor de corte $c=5$. Variou-se o valor de corte $c$ e a quantidade de iterações máxima com o objetivo de verificar se a mudança desses parâmetros causam algum impacto na deteç̧ão dos outliers. A aplicação se refere a série de vazão de entrada no reservatório Peruıbe.

\begin{tabular}{|c|c|c|c|c|c|c|c|c|}
\hline \multicolumn{3}{|c|}{ Experimentos } & \multicolumn{6}{|c|}{ Tipo de efeitos atípicos } \\
\hline ID & c & $\begin{array}{l}\mathrm{N}^{0} \text { máximo } \\
\text { de iterações }\end{array}$ & Único & Platô & Pulso & $\begin{array}{l}\text { C.D. } \\
\text { linear }\end{array}$ & $\begin{array}{c}\text { C.D. } \\
\text { exponencial }\end{array}$ & $\begin{array}{c}\text { C.D. } \\
\text { logaritmico }\end{array}$ \\
\hline \multicolumn{9}{|c|}{ Todas as observações afetadas } \\
\hline out1 & 2 & 1 & 0,400 & 0,166 & 0,201 & 0,169 & 0,187 & 0,163 \\
\hline out 2 & 3 & 1 & 0,200 & 0,130 & 0,119 & 0,114 & 0,121 & 0,111 \\
\hline out3 & 4 & 1 & 0,150 & 0,104 & 0,071 & 0,087 & 0,092 & 0,087 \\
\hline out4 & 5 & 1 & 0,117 & 0,077 & 0,053 & 0,062 & 0,068 & 0,067 \\
\hline out5 & 2 & 3 & 0,483 & 0,200 & 0,246 & 0,230 & 0,231 & 0,219 \\
\hline out 6 & 3 & 3 & 0,300 & 0,135 & 0,147 & 0,132 & 0,144 & 0,130 \\
\hline out7 & 4 & 3 & 0,150 & 0,110 & 0,087 & 0,107 & 0,105 & 0,101 \\
\hline out8 & 5 & 3 & 0,133 & 0,086 & 0,068 & 0,077 & 0,079 & 0,080 \\
\hline out9 & 2 & 5 & 0,483 & 0,200 & 0,252 & 0,231 & 0,234 & 0,222 \\
\hline out10 & 3 & 5 & 0,300 & 0,135 & 0,148 & 0,132 & 0,144 & 0,130 \\
\hline out11 & 4 & 5 & 0,150 & 0,110 & 0,087 & 0,107 & 0,108 & 0,101 \\
\hline out12 & 5 & 5 & 0,133 & 0,086 & 0,068 & 0,077 & 0,079 & 0,080 \\
\hline Total & - & - & 1,000 & 1,000 & 1,000 & 1,000 & 1,000 & 1,000 \\
\hline \multicolumn{9}{|c|}{ Somente observações mais afetadas } \\
\hline out1 & 2 & 1 & 0,400 & 0,166 & 0,483 & 0,352 & 0,476 & 0,305 \\
\hline out 2 & 3 & 1 & 0,200 & 0,130 & 0,300 & 0,229 & 0,305 & 0,210 \\
\hline out3 & 4 & 1 & 0,150 & 0,104 & 0,200 & 0,171 & 0,219 & 0,152 \\
\hline out4 & 5 & 1 & 0,117 & 0,077 & 0,150 & 0,133 & 0,200 & 0,133 \\
\hline out 5 & 2 & 3 & 0,483 & 0,200 & 0,550 & 0,467 & 0,533 & 0,400 \\
\hline out 6 & 3 & 3 & 0,300 & 0,135 & 0,367 & 0,267 & 0,352 & 0,238 \\
\hline out7 & 4 & 3 & 0,150 & 0,110 & 0,200 & 0,200 & 0,238 & 0,162 \\
\hline out 8 & 5 & 3 & 0,133 & 0,086 & 0,167 & 0,143 & 0,200 & 0,133 \\
\hline out9 & 2 & 5 & 0,483 & 0,200 & 0,550 & 0,467 & 0,533 & 0,400 \\
\hline out10 & 3 & 5 & 0,300 & 0,135 & 0,367 & 0,267 & 0,352 & 0,238 \\
\hline out11 & 4 & 5 & 0,150 & 0,110 & 0,200 & 0,200 & 0,238 & 0,162 \\
\hline out12 & 5 & 5 & 0,133 & 0,086 & 0,167 & 0,143 & 0,200 & 0,133 \\
\hline Total & - & - & 1,000 & 1,000 & 1,000 & 1,000 & 1,000 & 1,000 \\
\hline
\end{tabular}

- Como o esperado, percebe-se claramente que o valor de corte $c$ influencia na taxa de detecção, sendo que quanto menor for valor de corte $c$, melhor é a taxa de deteç̧ão. Também verifica-se um melhor valor de RMSE para os valores mais baixos de $c$. Lembramos que, embora um valor de corte baixo aumente a taxa de detecção de outliers, ele também aumenta a taxa de detecção de valores que possivelmente não seriam outliers.

A Figura 3.3 exemplifica as constatações realizadas. É possível observar que os procedimentos não conseguiram dar um bom tratamento aos outliers, sendo que, na maioria dos casos, os procedimentos classificaram boa quantidade dos outliers como sendo parte normal da série, enquanto que alguns valores que originalmente não eram outliers foram erroneamente classifiados como sendo.

A Tabela 3.7 apresenta a quantidade de anomalias detectadas em cada fase do tratamento dado a série de vazão de entrada no reservatório Peruíbe. Nota-se que a maior parte das observações anômalas foram detectadas durante a fase de limpeza primária, o que dá a quantidade de 1211 observações ou 6,9 \% do total. Durante todo o processo, foram detectadas 1566 (8,9 \%) observações anormais.

\subsubsection{Previsão}

A Tabela 3.8 traz os resultados de acurácia dos experimentos de previsão de acordo com RMSE. Ela é dividida em duas partes: a parte superior é dedicada a mostrar os resultados que usaram rolling windows de tamanho 336 horas (14 dias) e a parte inferior mostra os resultados referentes ao uso de rolling windows de tamanho 720 horas (30 dias). Os experimentos estão agrupados por tipo de 
Tabela 3.6: RMSE do tratamento dos outliers de acordo com o procedimento que apresentou melhor desempenho em preencher valores omissos. O procedimento foi o de ajuste de curvas de regressão com polinômio de grau 5 modelando a tendência, com interpolação de $R_{t}$, sem sazonalidade semanal, janela de tamanho 336 e valor de corte $c=5$. Variou-se o valor de corte c e a quantidade de iterações máxima com o objetivo de verificar se a mudança desses parâmetros causam algum impacto na detecção dos outliers. A linha total é o RMSE das observações ouliers em relação ao seu valor original. A aplicação se refere a série de vazão de entrada no reservatório Peruibe.

\begin{tabular}{|c|c|c|c|c|c|c|c|c|}
\hline \multicolumn{3}{|c|}{ Experimentos } & \multicolumn{6}{|c|}{ Tipo de efeitos atípicos } \\
\hline ID & c & $\begin{array}{l}\text { № máximo } \\
\text { de iterações }\end{array}$ & Único & Platô & Pulso & $\begin{array}{l}\text { C.D. } \\
\text { linear }\end{array}$ & $\begin{array}{c}\text { C.D. } \\
\text { exponencial }\end{array}$ & $\begin{array}{c}\text { C.D. } \\
\text { logaritmico }\end{array}$ \\
\hline \multicolumn{9}{|c|}{ Todas as observações afetadas } \\
\hline out1 & 2 & 1 & 18,0 & 21,2 & 17,0 & 20,1 & 19,3 & 20,1 \\
\hline out 2 & 3 & 1 & 22,5 & 22,0 & 18,9 & 21,6 & 21,4 & 22,1 \\
\hline out 3 & 4 & 1 & 25,1 & 23,3 & 20,9 & 23,6 & 23,4 & 23,6 \\
\hline out 4 & 5 & 1 & 26,4 & 24,3 & 22,2 & 25,5 & 24,9 & 25,2 \\
\hline out 5 & 2 & 3 & 16,4 & 20,8 & 16,4 & 17,9 & 17,5 & 18,6 \\
\hline out 6 & 3 & 3 & 20,1 & 21,9 & 18,0 & 20,6 & 20,0 & 20,8 \\
\hline out 7 & 4 & 3 & 25,1 & 23,2 & 20,3 & 22,4 & 22,4 & 22,7 \\
\hline out 8 & 5 & 3 & 25,7 & 24,0 & 21,6 & 24,8 & 24,3 & 24,7 \\
\hline out 9 & 2 & 5 & 16,4 & 20,8 & 16,4 & 17,9 & 17,5 & 18,5 \\
\hline out 10 & 3 & 5 & 20,1 & 21,9 & 17,9 & 20,6 & 20,0 & 20,8 \\
\hline out11 & 4 & 5 & 25,1 & 23,2 & 20,3 & 22,4 & 22,3 & 22,7 \\
\hline out12 & 5 & 5 & 25,7 & 24,0 & 21,6 & 24,8 & 24,3 & 24,7 \\
\hline Total & - & - & 37,9 & 32,4 & 30,2 & 31,3 & 32,9 & 30,8 \\
\hline \multicolumn{9}{|c|}{ Somente observações mais afetadas } \\
\hline out1 & 2 & 1 & 18,0 & 21,2 & 19,8 & 25,8 & 26,2 & 24,7 \\
\hline out 2 & 3 & 1 & 22,5 & 22,0 & 24,5 & 29,2 & 30,8 & 28,2 \\
\hline out 3 & 4 & 1 & 25,1 & 23,3 & 28,9 & 32,3 & 34,8 & 30,5 \\
\hline out 4 & 5 & 1 & 26,4 & 24,3 & 31,2 & 35,3 & 36,5 & 32,9 \\
\hline out 5 & 2 & 3 & 16,4 & 20,8 & 18,4 & 22,6 & 23,6 & 22,4 \\
\hline out6 & 3 & 3 & 20,1 & 21,9 & 22,8 & 27,7 & 28,7 & 26,5 \\
\hline out7 & 4 & 3 & 25,1 & 23,2 & 28,9 & 31,0 & 33,7 & 29,8 \\
\hline out 8 & 5 & 3 & 25,7 & 24,0 & 30,6 & 34,4 & 36,1 & 32,2 \\
\hline out9 & 2 & 5 & 16,4 & 20,8 & 18,4 & 22,6 & 23,5 & 22,4 \\
\hline out10 & 3 & 5 & 20,1 & 21,9 & 22,8 & 27,6 & 28,7 & 26,5 \\
\hline out11 & 4 & 5 & 25,1 & 23,2 & 28,9 & 31,0 & 33,7 & 29,8 \\
\hline out12 & 5 & 5 & 25,7 & 24,0 & 30,6 & 34,4 & 36,1 & 32,2 \\
\hline Total & - & - & 37,9 & 32,4 & 50,3 & 46,8 & 55,2 & 42,9 \\
\hline
\end{tabular}

Tabela 3.7: Quantidade de valores detectados como anomalias em cada estágio de tratamento da série de vazão de entrada no reservatório Peruibe. A primeira linha da tabela se refere a quantidade de valores classificados pelo sistema da Sabesp como bad e que, portanto, eram omissos na série original. A segunda linha se refere aos valores detectados como anomalias pela limpeza primária. A terceira linha se refere a quantidade de valores detectados como outliers pela aplicação do algoritmo proposto.

\begin{tabular}{|c|c|c|c|c|}
\hline Fase de detecção de anomalias & Frequência absoluta & Frequência relativa & Acumulado absoluto & Acumulado relativo \\
\hline Originalmente & 205 & $1,2 \%$ & 205 & $1,2 \%$ \\
\hline Limpeza primária & 1.211 & $6,9 \%$ & 1.416 & $8,1 \%$ \\
\hline Algoritmo de detecção de outliers & 150 & $0,9 \%$ & 1.566 & $8,9 \%$ \\
\hline Tamanho da série & 17.519 & $100 \%$ & 19.085 & $100 \%$ \\
\hline
\end{tabular}

modelos. A partir dessa tabela, verifica-se que:

- O melhor procedimento de previsão com modelos SARIMA, de acordo com o RMSE total, foi o que usou estratégia do tipo 2 e rolling windows de tamanho 336, apresentando RMSE total de 24,049. Um ponto a se observar é que a estratégia de tipo 2 teve um desempenho consideravelmente melhor do que a de tipo 1 no uso rolling window de tamanho 336, o que é um resultado um tanto inusitado, já que o esperado era que o desempenho de um modelo identificado usando as observações da própria rolling window fosse superior àquele que usasse as observações de uma outra rolling window para identicar o modelo.

- O melhor procedimento de regressão com erros autocorrelacionados, de acordo com o RMSE total, foi o que usou polinômio de grau 0 modelando a tendência, sem sazonalidade semanal, com o uso da estratégia do tipo 2 para os erros SARIMA e rolling windows de tamanho 336, 
(A) Único

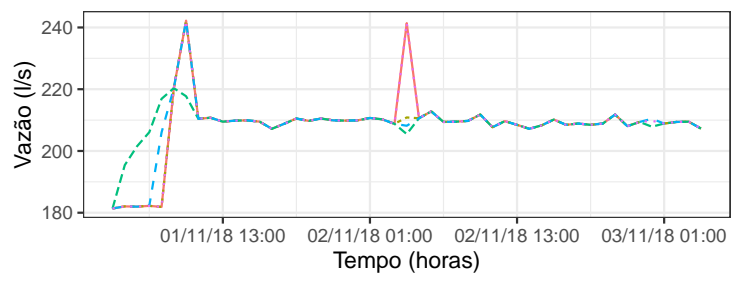

(C) Pulso

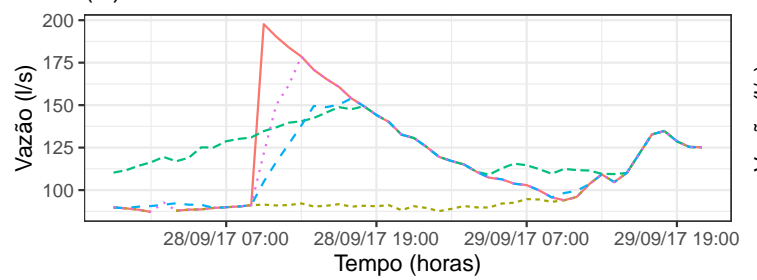

(E) C.D. Exponencial

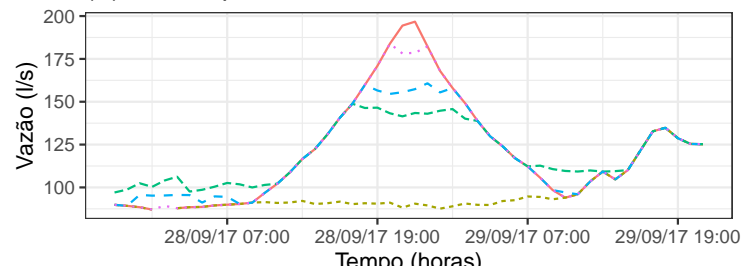

(B) Platô

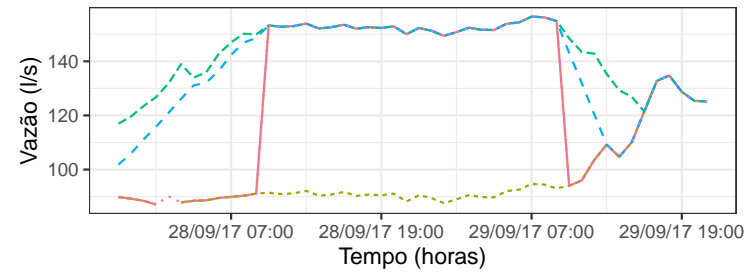

(D) C.D. Linear

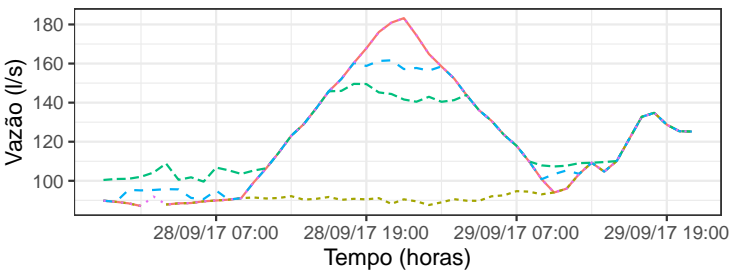

(F) C.D. Logaritmico

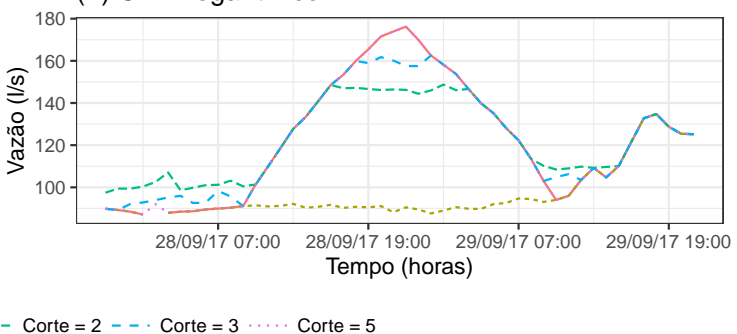

Figura 3.3: Exemplos de deteç̧ão e tratamento dos outliers inseridos na série de vazão de entrada no reservatório Peruíbe. Os trechos mostrados possuem tamanho 48 e são centrados nas observações afetadas pelo efeito atípico. Os gráficos de $(A)$ a $(F)$ exemplificam cada tipo de efeito atípico na série. A quantidade de iteração máxima dos experimentos selecionados é 3.

apresentando RMSE total de 24,297.

- Dentre os procedimentos BATS e TBATS, o que teve melhor desempenho de acordo com o RMSE total foi o que usou modelos TBATS sem sazonalidade semanal e com rolling windows de tamanho 336, apresentando RMSE total de 23,074.

- Verifica-se que o uso de rolling windows de tamanho 720 teve, em geral, um desempenho pior do que o uso das de tamanho 366, o que indicaria uma frequente mudança no comportamento da série.

- Os métodos de previsão propostos não tiveram desempenhos tão superiores aos métodos benchmark, sendo que alguns deles apresentaram desempenho inferior. Isso evidência que os métodos propostos provavelmente não sejam tão eficientes para fazer previsão da série de vazão de entrada no reservatório Peruíbe.

- Dentre todos os procedimentos de previsão propostos, o melhor foi o que usou modelos TBATS sem sazonalidade semanal e com rolling windows de tamanho 336, apresentando o valor de RMSE total de 23,074.

Os resultados não tão bons obtidos podem ser explicados pelo comportamento irregular que a série apresenta ao longo do tempo, sendo, na maioria das vezes, com nenhuma sazonalidade, o que prejudica demasiadamente a escolha de um modelo preditivo. Tal constatação pode ser observada na Figura 3.4, na qual são mostrados alguns exemplos de previsão para cada tipo de modelo 
Tabela 3.8: RMSE dos experimentos de previsão aplicados a série de vazão de entrada no reservatório Peruibe. As estratégias de tipo 1 se referem a aplicação do algoritmo de seleção de modelo em cada uma das rollings windows, enquanto que as de tipo 2 se referem a aplicação do algoritmo somente na primeira rolling window e do ajuste modelo selecionado nas demais rolling windows, reestimando os parâmetros. $O R M S E$ "Todos"é calculado usando todos os valores preditos de horizonte $h=1, \ldots ., 168$, incluido aqueles que não aparecem na tabela.

\begin{tabular}{|c|c|c|c|c|c|c|c|c|c|c|c|c|c|c|}
\hline \multicolumn{4}{|c|}{ Experimentos } & \multicolumn{11}{|c|}{ Horizonte de previsão } \\
\hline Modelos & $\begin{array}{c}\text { Grau do } \\
\text { polinô- } \\
\text { mio }\end{array}$ & $\begin{array}{l}\text { Sazonalidade } \\
\text { semanal }\end{array}$ & $\begin{array}{l}\text { Estratégia } \\
\text { de ajuste }\end{array}$ & $\mathrm{N}$ & 1 & 2 & 3 & 6 & 12 & 18 & 24 & 48 & 168 & Todos \\
\hline \multicolumn{15}{|c|}{ Rolling windows de tamanho 336} \\
\hline \multirow{2}{*}{ SARIMA } & - & - & Tipo 1 & 30 & 6,63 & 6,75 & 7,53 & 11,5 & 14,6 & 18,4 & 24,1 & 25,4 & 41,7 & 31,8 \\
\hline & - & - & Tipo 2 & 29 & 6,53 & 7,20 & 7,62 & 13,2 & 16,8 & 19,0 & 22,8 & 21,4 & 24,8 & 24,0 \\
\hline \multirow{8}{*}{$\begin{array}{c}\text { Regressão } \\
\text { com erros } \\
\text { SARIMA }\end{array}$} & 0 & $\operatorname{Sim}$ & Tipo 1 & 30 & 8,68 & 10,38 & 12,09 & 15,0 & 16,4 & 19,7 & 22,5 & 24,2 & 26,1 & 27,1 \\
\hline & 0 & Sim & Tipo 2 & 30 & 8,77 & 9,30 & 10,98 & 13,8 & 17,3 & 21,2 & 22,6 & 22,5 & 24,7 & 24,8 \\
\hline & 1 & $\operatorname{Sim}$ & Tipo 1 & 30 & 7,54 & 8,30 & 9,09 & 16,8 & 20,0 & 23,0 & 25,9 & 27,0 & 34,8 & 29,1 \\
\hline & 1 & $\operatorname{Sim}$ & Tipo 2 & 30 & 7,63 & 8,02 & 9,21 & 16,3 & 20,9 & 25,1 & 26,9 & 30,0 & 37,3 & 32,1 \\
\hline & 0 & Não & Tipo 1 & 30 & 9,85 & 10,65 & 11,67 & 13,4 & 17,8 & 20,6 & 22,6 & 25,1 & 27,6 & 27,5 \\
\hline & 0 & Não & Tipo 2 & 30 & 8,77 & 9,29 & 10,97 & 13,4 & 16,8 & 20,9 & 22,4 & 21,7 & 24,7 & 24,3 \\
\hline & 1 & Não & Tipo 1 & 30 & 8,23 & 8,49 & 9,22 & 13,3 & 15,8 & 20,1 & 24,4 & 26,4 & 33,9 & 27,8 \\
\hline & 1 & Não & Tipo 2 & 30 & 7,78 & 7,98 & 9,21 & 14,9 & 19,7 & 23,9 & 25,6 & 28,0 & 36,1 & 30,5 \\
\hline \multirow{2}{*}{ BATS } & - & Não & Tipo 1 & 30 & 7,66 & 7,08 & 7,92 & 10,2 & 13,7 & 16,5 & 20,7 & 21,0 & 31,7 & 25,3 \\
\hline & - & $\operatorname{Sim}$ & Tipo 1 & 30 & 9,68 & 7,89 & 9,01 & 11,7 & 14,9 & 18,2 & 20,9 & 21,1 & 23,7 & 23,7 \\
\hline \multirow{2}{*}{ TBATS } & - & Não & Tipo 1 & 30 & 6,86 & 7,58 & 8,34 & 10,2 & 13,2 & 16,1 & 20,7 & 19,9 & 25,0 & 23,1 \\
\hline & - & Sim & Tipo 1 & 30 & 7,05 & 7,96 & 8,32 & 10,8 & 13,7 & 17,4 & 23,4 & 26,5 & 25,3 & 25,5 \\
\hline \multirow[b]{3}{*}{ Benchmark } & - & - & Média & 30 & 26,25 & 26,18 & 26,18 & 27,5 & 27,6 & 31,3 & 29,2 & 28,9 & 29,7 & 31,3 \\
\hline & - & - & Mediana & 30 & 29,44 & 29,49 & 29,50 & 30,8 & 30,4 & 34,6 & 32,1 & 31,7 & 31,8 & 34,3 \\
\hline & - & - & Ûlt. Obs. & 30 & 7,63 & 8,73 & 10,05 & 14,0 & 16,0 & 20,0 & 22,4 & 21,7 & 24,7 & 24,3 \\
\hline \multicolumn{15}{|c|}{ Rolling windows de tamanho 720} \\
\hline \multirow{2}{*}{ SARIMA } & - & - & Tipo 1 & 30 & 6,98 & 8,01 & 8,31 & 13,9 & 16,2 & 20,7 & 22,9 & 16,3 & 35,3 & 29,1 \\
\hline & - & - & Tipo 2 & 30 & 6,62 & 7,22 & 7,95 & 14,2 & 16,7 & 21,6 & 22,8 & 16,2 & 34,3 & 29,4 \\
\hline \multirow{8}{*}{$\begin{array}{c}\text { Regressão } \\
\text { com erros } \\
\text { SARIMA }\end{array}$} & 0 & Sim & Tipo 1 & 30 & 9,65 & 11,30 & 11,74 & 16,6 & 17,8 & 20,0 & 20,4 & 18,5 & 34,5 & 29,6 \\
\hline & 0 & $\operatorname{Sim}$ & Tipo 2 & 30 & 6,57 & 7,75 & 8,13 & 13,2 & 14,9 & 19,9 & 21,8 & 15,0 & 33,8 & 27,9 \\
\hline & 1 & Sim & Tipo 1 & 30 & 7,07 & 7,93 & 8,65 & 12,1 & 15,2 & 21,7 & 25,1 & 18,9 & 36,9 & 29,3 \\
\hline & 1 & Sim & Tipo 2 & 30 & 7,37 & 7,96 & 8,62 & 13,4 & 16,5 & 22,7 & 25,9 & 19,5 & 38,2 & 30,4 \\
\hline & 0 & Não & Tipo 1 & 30 & 9,31 & 10,47 & 11,08 & 14,9 & 16,8 & 20,6 & 21,2 & 18,5 & 33,6 & 29,8 \\
\hline & 0 & Não & Tipo 2 & 30 & 6,58 & 7,61 & 8,07 & 12,4 & 14,3 & 19,9 & 21,9 & 15,2 & 33,8 & 28,4 \\
\hline & 1 & Não & Tipo 1 & 30 & 7,30 & 8,38 & 9,27 & 11,4 & 14,9 & 21,8 & 25,2 & 19,7 & 37,8 & 30,2 \\
\hline & 1 & Não & Tipo 2 & 30 & 7,37 & 7,97 & 8,73 & 12,6 & 16,0 & 22,7 & 25,9 & 20,0 & 37,9 & 30,7 \\
\hline \multirow{2}{*}{ BATS } & - & Não & Tipo 1 & 30 & 7,48 & 7,70 & 8,41 & 14,0 & 16,5 & 20,8 & 22,5 & 15,8 & 34,6 & 29,4 \\
\hline & - & Sim & Tipo 1 & 30 & 7,07 & 7,61 & 8,06 & 14,9 & 17,0 & 21,3 & 22,6 & 16,2 & 33,3 & 28,9 \\
\hline \multirow{2}{*}{ TBATS } & - & Não & Tipo 1 & 30 & 6,88 & 7,37 & 7,73 & 13,9 & 15,8 & 20,6 & 22,4 & 15,6 & 33,9 & 28,9 \\
\hline & - & $\mathrm{Sim}$ & Tipo 1 & 30 & 6,83 & 7,36 & 7,75 & 14,1 & 15,7 & 21,0 & 22,4 & 16,2 & 33,6 & 29,3 \\
\hline \multirow{3}{*}{ Benchmark } & - & - & Média & 30 & 21,30 & 21,48 & 22,38 & 24,3 & 25,2 & 25,8 & 23,9 & 21,8 & 33,7 & 31,7 \\
\hline & - & - & Mediana & 30 & 17,50 & 17,56 & 18,68 & 21,1 & 22,8 & 26,6 & 25,1 & 20,3 & 33,9 & 31,7 \\
\hline & - & - & Últ. Obs. & 30 & 7,09 & 7,77 & 8,58 & 17,1 & 20,0 & 23,2 & 24,9 & 17,4 & 35,4 & 30,8 \\
\hline
\end{tabular}

que reforçam as observações realizadas. Nota-se, por exemplo, nos gráficos (A) e (B) que muitas previsões acabaram por não incorporar a componente sazonal devido a uma falta de sazonalidade característica na série. Mesmo nos trechos da série em que parace haver uma sazonalidade, esta não é muito regular, como evidenciados nos graficos (C) e (D).

Para a elaboração dos gráficos da Figura 3.4, decidiu-se não selecionar as previsões que usaram a estratégia do tipo 2, por tal método nem sempre conseguir estimar os parâmetros dos modelos, o que acaba resultando no uso de uma quantidade menor de rolling windows. Assim, as previsões SARIMA se referem ao uso de estratégia do tipo 1 e rolling windows de tamanho 720; as de regressão com erros autocorrelacionados se referem ao uso de polinômio de grau 0 modelando a tendência, com sazonalidade semanal, com o uso da estratégia do tipo 1 para os erros SARIMA e rolling windows de tamanho 336; as previsões BATS se referem ao uso de modelos com sazonalidade semanal e rolling windows de tamanho 336; as previsões TBATS se referem ao uso de modelos sem sazonalidade semanal e rolling windows de tamanho 336 e as previsões benchmark se referem ao uso da repetição da última observação e rolling windows de tamanho 336 . 

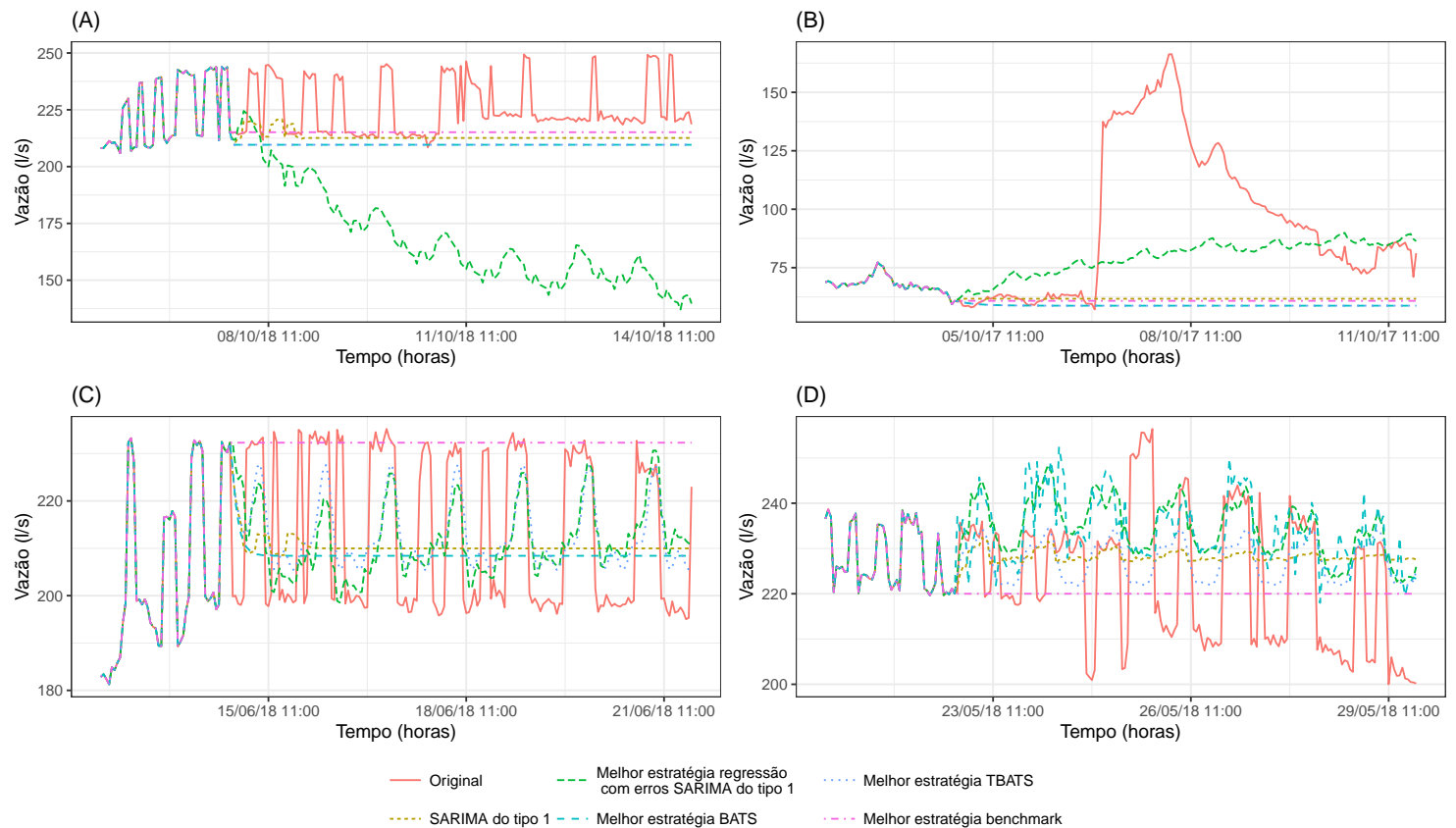

Figura 3.4: Alguns trechos da série de vazão de entrada no reservatório Peruı̉be que exemplificam a aplicação dos modelos de previsão. São apresentados o melhor procedimento de ajuste de cada família de modelos, de acordo com o melhor RMSE de previsão, para os dois tamanhos de rolling window descritos na tabela 3.8. Para a seleção dos procedimentos, exluiu-se os que utilizaram a estratégia de tipo 2. Os gráficos exibem 48 horas da série seguidas de 168 horas de previsão. Os gráficos da esquerda se referem aos ajustes que usaram rolling windows de tamanho 336, já os da direita, de tamanho 720

\subsection{Nível do reservatório Peruíbe}

Nesta seção é apresentado e discutido os resultados das aplicações dos procedimentos de imputação de valores omissos e deteç̧ão de outliers e dos métodos de previsão relacionados a série de nível do reservatório Peruíbe. A Figura 3.5 exibe um trecho da série que exemplifica seu comportamento. O gráfico (A) se refere a série original, enquanto que o gráfico (B) é mesmo trecho após limpeza e aplicação do métodos de deteç̧ão de outlier e preenchimento de valores omissos.

O método escolhido para a detecção de outliers e preenchimentos dos valores omissos, por possuir o menor RMSE total entre todos os experimentos realizados, com o valor de 0,45 , foi o ajuste de curvas de regressão com polinômio de grau 5 modelando a tendência, com interpolação de $R_{t}$, sem sazonalidade semanal, janela de tamanho 336 e valor de corte $c=5$. O total de valores classificados como anomalias após aplicação do método selecionado foi de 1139 (6,5\%), vis-à-vis à quantidade de 1136 (6,48 \%) após a limpeza primária e à quantidade original de 205 (1,17\%). Em relação a previsão, o método que apresentou melhor desempenho nos experimentos foi o que usou modelos BATS sem sazonalidade semanal e com rolling windows de tamanho 336, apresentando o valor de RMSE total de 0,922. Os resultados mostram que os métodos de detecção de outliers e preenchimento de valores omissos não performaram tão bem para a série de nível do reservatório Peruíbe devido ao seu comportamento não tão bem regular ao longo do tempo, porém o desempenho ainda foi melhor do que o dos métodos benchmarks. O mesmo pode ser dito sobre os resultados dos métodos de previsão, o que é uma evidência de que na maior parte do tempo o CCO não possui um comportamento previsível de acordo com os métodos previsionais aqui sugeridos.

As próximas subseções apresentam e discutem os resultados de forma mais detalhada. 
(A) Trecho da série original

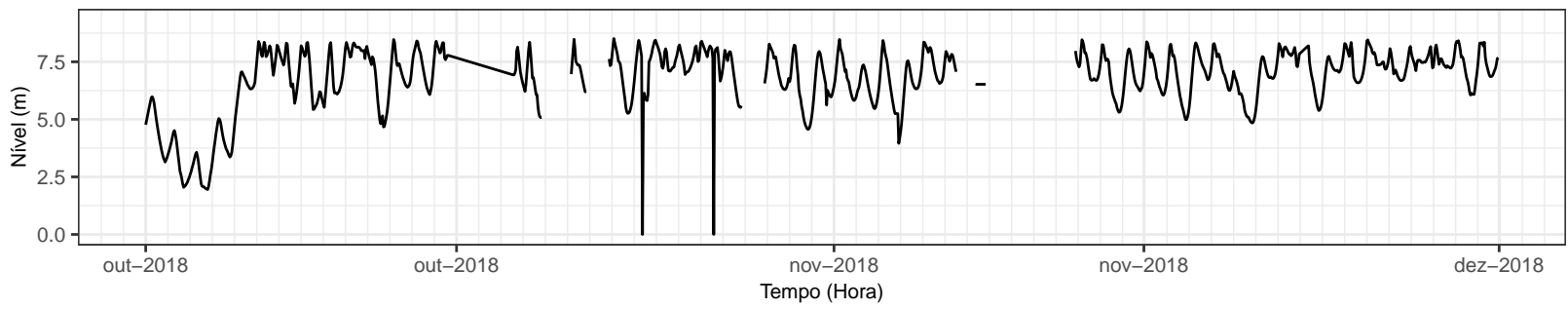

(B) Trecho da série após limpeza e preenchimento de valores omissos

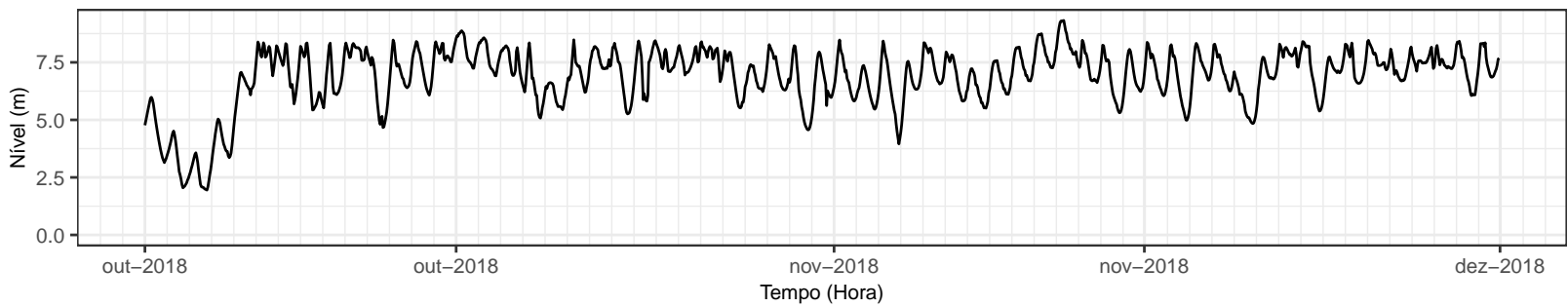

Figura 3.5: Trecho da série de nível do reservatório Peruíbe que exemplificam seu comportamento. O gráfico (A) é referente a série original e o gráfico (B) mostra a série após as limpezas, tratamento dos outliers detectados e preenchimento dos valores omissos de acordo com o método escolhido.

\subsubsection{Preenchimento de valores omissos}

As tabelas 3.9 à 3.11 mostram os resultados dos 12 melhores experimentos de cada tipo de procedimento de preenchimento de valores omissos, usando como medida de avaliação o RMSE. Em todas as tabelas os experimentos são apresentados em ordem decrescente de RMSE. Já a tabela 3.12 apresenta os resultados dos procedimentos de preenchimento de valores omissos usados como benchmark. Nesta, os experimentos são ordenados pelo ID.

Tabela 3.9: RMSE dos 12 melhores métodos de preenchimento de dados omissos baseados no ajuste de modelos de regressão, selecionados de acordo com menor RMSE. Os resultados se referem a aplicação dos métodos a série de nivel do reservatório Peruíbe.

\begin{tabular}{|c|c|c|c|c|c|c|c|c|c|c|c|c|c|}
\hline \multicolumn{6}{|c|}{ Experimentos de regressão } & \multicolumn{8}{|c|}{ Quantidade de valores omissos em sequência } \\
\hline ID & $\begin{array}{l}\text { Interpolação } \\
\text { de } R_{t}\end{array}$ & $\begin{array}{c}\text { Dia da } \\
\text { semana }\end{array}$ & $\begin{array}{l}\text { Grau do } \\
\text { polinômio }\end{array}$ & Janela & $c$ & 1 & 3 & 6 & 12 & 18 & 24 & 48 & Total \\
\hline reg98 & Sim & Sim & 5 & 336 & 5 & 0,137 & 0,202 & 0,335 & 0,510 & 0,638 & 0,646 & 0,679 & 0,450 \\
\hline reg95 & Sim & $\operatorname{Sim}$ & 2 & 336 & 5 & 0,140 & 0,206 & 0,338 & 0,510 & 0,638 & 0,646 & 0,683 & 0,451 \\
\hline reg62 & Sim & Sim & 5 & 336 & 3 & 0,169 & 0,225 & 0,329 & 0,505 & 0,646 & 0,654 & 0,686 & 0,459 \\
\hline reg94 & Sim & Sim & 2 & 168 & 5 & 0,191 & 0,252 & 0,345 & 0,512 & 0,647 & 0,616 & 0,659 & 0,460 \\
\hline reg97 & Sim & Sim & 5 & 168 & 5 & 0,175 & 0,240 & 0,350 & 0,510 & 0,653 & 0,635 & 0,659 & 0,460 \\
\hline reg63 & Sim & Sim & 5 & 720 & 3 & 0,122 & 0,198 & 0,316 & 0,511 & 0,662 & 0,722 & 0,700 & 0,462 \\
\hline reg99 & Sim & Sim & 5 & 720 & 5 & 0,111 & 0,196 & 0,319 & 0,510 & 0,661 & 0,715 & 0,722 & 0,462 \\
\hline reg59 & Sim & Sim & 2 & 336 & 3 & 0,171 & 0,234 & 0,331 & 0,507 & 0,645 & 0,656 & 0,692 & 0,462 \\
\hline reg91 & Sim & Sim & 1 & 168 & 5 & 0,208 & 0,262 & 0,350 & 0,508 & 0,637 & 0,631 & 0,654 & 0,464 \\
\hline reg56 & Sim & Sim & 1 & 336 & 3 & 0,174 & 0,233 & 0,331 & 0,507 & 0,634 & 0,667 & 0,708 & 0,465 \\
\hline reg60 & Sim & Sim & 2 & 720 & 3 & 0,130 & 0,204 & 0,314 & 0,511 & 0,653 & 0,722 & 0,723 & 0,465 \\
\hline reg26 & Sim & Sim & 5 & 336 & 2 & 0,209 & 0,234 & 0,330 & 0,513 & 0,645 & 0,651 & 0,677 & 0,466 \\
\hline
\end{tabular}

De acordo com as informações apresentadas nas tabelas 3.9 à 3.12 podemos verificar que, em geral:

- Os melhores procedimentos de regressão, de acordo com o RMSE total, foram aqueles que consideraram a sazonalidade semanal e que usaram interpolação nos resíduos $R_{t}$ e, aparentemente, janela de ajuste de tamanho 336, sendo que o melhor procedimento de regressão para imputação de valores omissos foi o que usou polinômio de grau 5 modelando a tendência, com 
Tabela 3.10: RMSE dos 12 melhores métodos de preenchimento de dados omissos baseados no ajuste de modelo de regressão acompanhado de decomposições clássica, selecionados de acordo com menor RMSE. $O$ modelo de regressão usado em conjundo com a decomposição clássica, por apresentar menor RMSE, foi o que possui polinômio de grau 5, com interpolação dos resíduos, sem sazonalidade semanal e janela de tamanho 336. Os resultados se referem a aplicação dos métodos a série de nivel do reservatório Peruibe.

\begin{tabular}{|c|c|c|c|c|c|c|c|c|c|c|c|}
\hline \multicolumn{4}{|c|}{ Experimentos de decomposição clássica } & \multicolumn{8}{|c|}{ Quantidade de valores omissos em sequência } \\
\hline ID & $\begin{array}{l}\text { Interpolação } \\
\text { de } R_{t}\end{array}$ & Janela & $c$ & 1 & 3 & 6 & 12 & 18 & 24 & 48 & Total \\
\hline $\operatorname{dec} 16$ & $\operatorname{Sim}$ & 168 & 5 & 0,104 & 0,204 & 0,321 & 0,490 & 0,684 & 0,663 & 0,770 & 0,462 \\
\hline $\operatorname{dec} 10$ & $\mathrm{Sim}$ & 168 & 3 & 0,141 & 0,224 & 0,314 & 0,486 & 0,689 & 0,671 & 0,772 & 0,471 \\
\hline $\operatorname{dec} 17$ & Sim & 336 & 5 & 0,101 & 0,192 & 0,318 & 0,505 & 0,695 & 0,696 & 0,800 & 0,472 \\
\hline $\operatorname{dec} 4$ & Sim & 168 & 2 & 0,191 & 0,232 & 0,317 & 0,487 & 0,688 & 0,669 & 0,736 & 0,474 \\
\hline $\operatorname{dec} 11$ & $\mathrm{Sim}$ & 336 & 3 & 0,138 & 0,210 & 0,314 & 0,502 & 0,699 & 0,702 & 0,799 & 0,481 \\
\hline $\operatorname{dec} 5$ & Sim & 336 & 2 & 0,184 & 0,214 & 0,315 & 0,505 & 0,699 & 0,702 & 0,750 & 0,481 \\
\hline $\operatorname{dec} 18$ & Sim & 720 & 5 & 0,096 & 0,189 & 0,317 & 0,510 & 0,701 & 0,772 & 0,853 & 0,491 \\
\hline dec6 & Sim & 720 & 2 & 0,175 & 0,212 & 0,316 & 0,514 & 0,703 & 0,782 & 0,788 & 0,498 \\
\hline $\operatorname{dec} 12$ & $\operatorname{Sim}$ & 720 & 3 & 0,133 & 0,209 & 0,315 & 0,510 & 0,703 & 0,779 & 0,852 & 0,500 \\
\hline $\operatorname{dec} 13$ & Não & 168 & 5 & 0,453 & 0,446 & 0,490 & 0,562 & 0,669 & 0,663 & 0,684 & 0,567 \\
\hline $\operatorname{dec} 7$ & Não & 168 & 3 & 0,463 & 0,458 & 0,480 & 0,558 & 0,675 & 0,670 & 0,689 & 0,570 \\
\hline $\operatorname{dec} 1$ & Não & 168 & 2 & 0,474 & 0,458 & 0,481 & 0,564 & 0,675 & 0,667 & 0,677 & 0,571 \\
\hline
\end{tabular}

Tabela 3.11: RMSE dos 12 melhores métodos de preenchimento de dados omissos baseados em decomposição STL, selecionados de acordo com menor RMSE. Os resultados se referem a aplicação dos métodos a série de nivel do reservatório Peruíbe.

\begin{tabular}{|c|c|c|c|c|c|c|c|c|c|c|c|c|c|}
\hline \multicolumn{6}{|c|}{ Experimentos de decomposição STL } & \multicolumn{8}{|c|}{ Quantidade de valores omissos em sequência } \\
\hline ID & $\begin{array}{l}\text { Interpolação } \\
\quad \text { de } R_{t}\end{array}$ & $n_{(i)}$ & $n_{(e)}$ & $n_{(s)}$ & $c$ & 1 & 3 & 6 & 12 & 18 & 24 & 48 & Total \\
\hline st146 & Sim & 2 & 0 & 25 & 5 & 0,121 & 0,198 & 0,326 & 0,507 & 0,641 & 0,612 & 0,856 & 0,466 \\
\hline st150 & $\operatorname{Sim}$ & 1 & 5 & 37 & 5 & 0,158 & 0,221 & 0,321 & 0,501 & 0,641 & 0,664 & 0,758 & 0,466 \\
\hline st149 & Sim & 1 & 5 & 25 & 5 & 0,182 & 0,236 & 0,334 & 0,492 & 0,648 & 0,654 & 0,718 & 0,466 \\
\hline st147 & Sim & 2 & 0 & 37 & 5 & 0,110 & 0,193 & 0,323 & 0,507 & 0,631 & 0,615 & 0,903 & 0,469 \\
\hline st151 & Sim & 1 & 5 & 49 & 5 & 0,147 & 0,213 & 0,317 & 0,514 & 0,645 & 0,688 & 0,759 & 0,469 \\
\hline st128 & $\operatorname{Sim}$ & 2 & 0 & 25 & 3 & 0,137 & 0,218 & 0,323 & 0,504 & 0,641 & 0,612 & 0,858 & 0,470 \\
\hline st129 & Sim & 2 & 0 & 37 & 3 & 0,116 & 0,210 & 0,322 & 0,506 & 0,631 & 0,614 & 0,899 & 0,471 \\
\hline st148 & Sim & 2 & 0 & 49 & 5 & 0,105 & 0,190 & 0,321 & 0,513 & 0,631 & 0,635 & 0,930 & 0,475 \\
\hline st110 & $\operatorname{Sim}$ & 2 & 0 & 25 & 2 & 0,167 & 0,235 & 0,333 & 0,502 & 0,645 & 0,621 & 0,823 & 0,475 \\
\hline st130 & $\operatorname{Sim}$ & 2 & 0 & 49 & 3 & 0,110 & 0,205 & 0,321 & 0,512 & 0,631 & 0,636 & 0,923 & 0,477 \\
\hline st111 & Sim & 2 & 0 & 37 & 2 & 0,150 & 0,221 & 0,330 & 0,509 & 0,632 & 0,625 & 0,885 & 0,479 \\
\hline st112 & Sim & 2 & 0 & 49 & 2 & 0,134 & 0,217 & 0,325 & 0,513 & 0,635 & 0,646 & 0,906 & 0,482 \\
\hline
\end{tabular}

Tabela 3.12: RMSE dos métodos benchmark de preenchimento de dados omissos. Os resultados se referem a aplicação dos métodos a série de nível do reservatório Peruíbe.

\begin{tabular}{|c|c|c|c|c|c|c|c|c|c|c|}
\hline \multicolumn{3}{|c|}{ Experimentos emphbenchmark } & \multicolumn{8}{|c|}{ Quantidade de valores omissos em sequência } \\
\hline ID & $\begin{array}{c}\text { Forma de } \\
\text { benchmark }\end{array}$ & Janela & 1 & 3 & 6 & 12 & 18 & 24 & 48 & Total \\
\hline ben 1 & Média & 168 & 0,878 & 0,961 & 0,813 & 0,922 & 0,762 & 0,920 & 0,794 & 0,864 \\
\hline ben 2 & Média & 336 & 0,913 & 1,009 & 0,860 & 0,996 & 0,754 & 0,927 & 0,771 & 0,890 \\
\hline ben 3 & Média & 720 & 0,986 & 1,066 & 0,923 & 1,023 & 0,814 & 0,966 & 0,788 & 0,938 \\
\hline ben 4 & Mediana & 168 & 0,875 & 0,952 & 0,809 & 0,913 & 0,735 & 0,876 & 0,775 & 0,848 \\
\hline ben 5 & Mediana & 336 & 0,911 & 1,034 & 0,855 & 0,988 & 0,739 & 0,918 & 0,746 & 0,884 \\
\hline ben 6 & Mediana & 720 & 0,983 & 1,093 & 0,931 & 1,065 & 0,812 & 0,972 & 0,809 & 0,952 \\
\hline ben 7 & Interpolação & - & 0,096 & 0,188 & 0,335 & 0,618 & 0,866 & 0,920 & 0,858 & 0,554 \\
\hline
\end{tabular}

interpolação de $R_{t}$, sem sazonalidade semanal, janela de tamanho 336 e valor de corte $c=5$, apresentando um RMSE total igual a 0,45. Os parâmetros desse modelo de regressão foram os usados na aplicação do método de decomposição clássica.

- Os procedimentos de decomposição clássica que tiveram melhor desempenho, de acordo com o RMSE total, foram aqueles que não aplicaram interpolações nos resíduos $R_{t}$ e que, aparentemente, possuem janela de tamanho 168. O melhor procedimento foi aquele que usou 
decomposição com interpolação de $R_{t}$, janela de tamanho 168 e valor de corte $c=5$, apresentando um RMSE total igual a 0,462.

- Os tipos de decomposição STL que tiveram melhores resultados, de acordo com o RMSE total, foram os que possuem interpolação nos resíduos $R_{t}$, usaram decomposição STL não robusta $\left(n_{(i)}=2\right.$ e $\left.n_{(e)}=0\right)$ e que, aparentemente, possui maior valor de corte $c$. O melhor procedimento foi o de decomposição não robusta $\left(n_{(i)}=2\right.$ e $\left.n_{(e)}=0\right)$, com interpolação de $R_{t}, n_{(s)}=25$ e valor de corte $c=5$, apresentando um RMSE total igual a 0,466 .

- Dentre os métodos de benchmark, o que teve melhor desempenho foi o que interpola linearmente os valores da série. Vale mencionar que o melhor método benchmark teve performance superior a alguns dos procedimentos propostos, mas que não estão listados nas tabelas. Outro ponto a se observar que o método de interpolação também teve bom desempenho em preencher sequências curtas de valores omissos.

- Dentre todos os experimentos, o que apresentou melhor resultado foi o procedimento de ajuste de curvas de regressão com polinômio de grau 5 modelando a tendência, com interpolação de $R_{t}$, sem sazonalidade semanal, janela de tamanho 336 e valor de corte $c=5$, apresentando um valor de RMSE total de 0,45. Este é o procedimento para o qual é apresentado uma análise de outliers na próxima subseção e que é usado oficialmente para preencher os valores omissos da série.

A Figura 3.6 exemplifica alguns experimentos de preenchimento de valores omissos. Cada gráfico representa um trecho da série temporal de nível do reservatório Peruíbe no qual propositalmente foi removido uma sequência de valores. Todos os gráficos se referem a uma lacuna de tamanho 48 horas acompanhado de 12 valores anteriores e posteriores à lacuna principal. Os procedimentos de preenchimento adotados para ilustrar os gráficos são o melhor experimento, de acordo com o RMSE total, de cada tipo de procedimento apresentados nas tabelas 3.9 à 3.12 .

Pode-se verificar que nos trechos em que a série de nível do resevatório possui sazonalidade mais bem definida os métodos de imputação propostos tiveram performance superior à mera interpolação linear dos valores da série (gráficos $(\mathrm{A})$ e $(\mathrm{C})$ ), ao passo que nos trechos em que seu comportamento é bem irregular a interpolação teve uma performace próxima (gráfico (B)) ou até mesmo visivelmente superior (gráfico (D)) do que os procedimentos propostos.

\subsubsection{Detecção e tratamento de outliers}

As tabelas 3.13 e 3.14 mostram os resultados dos experimentos elaborados para avaliar o desempenho em detectar e tratar os outliers do melhor procedimento selecionado para a imputação dos valores omissos. A Tabela 3.13 apresenta as taxas de detecção dos outliers, sendo dividida em duas partes: na parte superior o cálculo das taxas considera todas as observações afetadas pelo efeito atípico, enquanto que na parte inferior é considerado apenas a observação mais afetada pelo efeito atípico. Vale lembrar que no caso do efeito atípico do tipo platô todas as observações foram consideradas como sendo as mais afetadas devido ao efeito se distribuir igualmente entre elas. Já a tabela 3.14 é destinada a verificar a acurácia do procedimento ao corrigir os valores dos outliers. Sua estrutura é análoga à da tabela 3.13, sendo que a linha total é o RMSE do efeito atípico nas observações.

A partir das tabelas, podemos verificar que: 
(A)

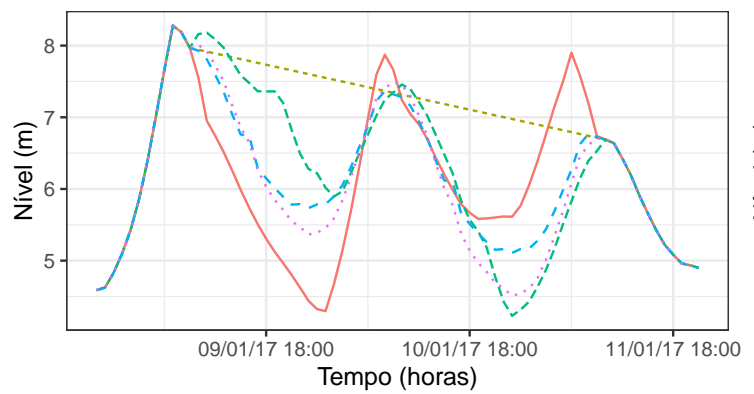

(C)

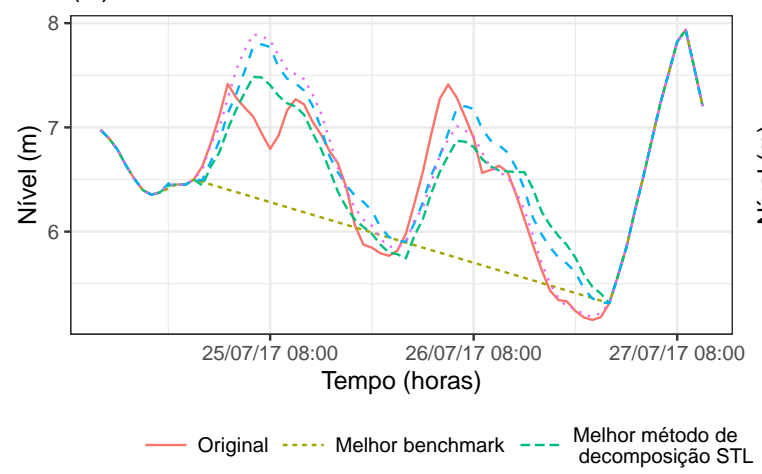

(B)

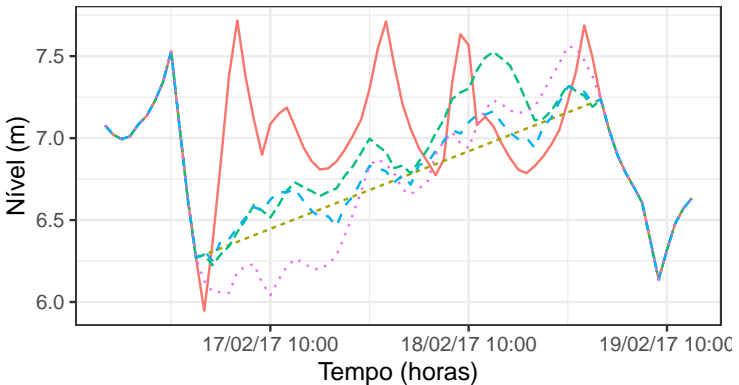

(D)

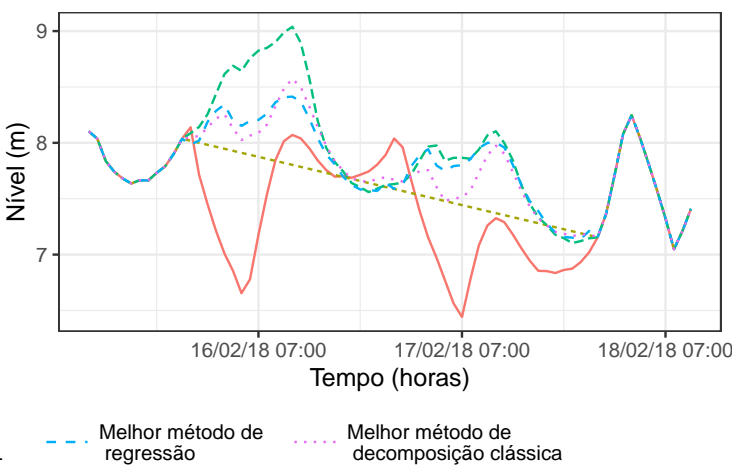

Figura 3.6: Alguns trechos da série de nível do reservatório Peruíbe que exemplificam a aplicação dos procedimentos de preenchimento de valores omissos. É apresentado o melhor experimento de imputação de valores omissos de cada tipo de procedimento de acordo com o RMSE, descritos nas tabelas 3.9 à 3.12. A lacuna principal de valores omissos usada em cada gráfico foi inserida artificialmente na série temporal a fim de avaliar a performance dos procedimentos de preenchimento de valores omissos. O tamanho da lacuna principal é de 48 horas, sendo precedida e sucedida de 12 horas de valores originais.

- As taxas de detecção dos outliers foram, em geral, baixas, sobretudo quando $c=5$ e a quantidade de iterações máximas é 3, que são os valores usados no método escolhido para impututar os valores omissos da série. Os motivos mais prováveis para essa baixa taxa de detecção é termos usado uma contante $\omega$ relativamente baixo para a produção dos outliers e pela a série apresentar momentos com comportamento bem irregular, ou sem uma sazonalidade bem definida, o que pode dificultar a detecção de tais valores atípicos. Vale ressaltar que a baixa taxa de detecção reflete na baixa acurácia em corrigir os valores.

- É possivel ver que a quantidade iteração não interfere muito na taxa de detecção dos outliers e, consequentemente, também não ajuda muito a melhorar a acurácia ao corrigir os valores atípicos.

- Como o esperado, percebe-se claramente que o valor de corte $c$ influencia na taxa de detecção, sendo que quanto menor for valor de corte $c$, melhor é a taxa de detecção. Também verifica-se um melhor valor de RMSE para os valores mais baixos de $c$. Lembramos que, embora um valor de corte baixo aumente a taxa de detecção de outliers, ele também aumenta a taxa de detecção de valores que possivelmente não seriam outliers.

A Figura 3.7 exemplifica as constatações realizadas. É possível observar que os procedimentos não conseguiram dar uma bom tratamentos aos outliers, sendo que, na maioria dos casos, os procedimentos não conseguiram detectar os outliers (gráficos $(\mathrm{A}),(\mathrm{D}),(\mathrm{E})$ e $(\mathrm{F})$ ) e naqueles em que houve a detecção do efeito atípico, não houve a detecção da maioria das observações afetadas por 
Tabela 3.13: Taxa de deteç̧̃̃o de outliers de acordo com o procedimento que apresentou melhor desempenho em preencher valores omissos. O procedimento foi o de ajuste de curvas de regressão com polinômio de grau 5 modelando a tendência, com interpolação de $R_{t}$, sem sazonalidade semanal, janela de tamanho 336 e valor de corte $c=5$. Variou-se o valor de corte $c$ e a quantidade de iterações máxima com o objetivo de verificar se a mudança desses parâmetros causam algum impacto na deteç̧ão dos outliers. A aplicação se refere a série de nivel do reservatório Peruibe.

\begin{tabular}{|c|c|c|c|c|c|c|c|c|}
\hline \multicolumn{3}{|c|}{ Experimentos } & \multicolumn{6}{|c|}{ Tipo de efeitos atípicos } \\
\hline ID & c & $\begin{array}{l}\mathrm{N}^{0} \text { máximo } \\
\text { de iterações }\end{array}$ & Único & Platô & Pulso & $\begin{array}{l}\text { C.D. } \\
\text { linear }\end{array}$ & $\begin{array}{c}\text { C.D. } \\
\text { exponencial }\end{array}$ & $\begin{array}{c}\text { C.D. } \\
\text { logaritmico }\end{array}$ \\
\hline \multicolumn{9}{|c|}{ Todas as observações afetadas } \\
\hline out1 & 2 & 1 & 0,450 & 0,181 & 0,156 & 0,176 & 0,188 & 0,167 \\
\hline out 2 & 3 & 1 & 0,200 & 0,050 & 0,071 & 0,079 & 0,090 & 0,073 \\
\hline out3 & 4 & 1 & 0,133 & 0,010 & 0,034 & 0,022 & 0,041 & 0,021 \\
\hline out4 & 5 & 1 & 0,067 & 0,000 & 0,010 & 0,010 & 0,021 & 0,006 \\
\hline out 5 & 2 & 3 & 0,467 & 0,210 & 0,166 & 0,185 & 0,199 & 0,179 \\
\hline out 6 & 3 & 3 & 0,233 & 0,053 & 0,077 & 0,081 & 0,095 & 0,079 \\
\hline out 7 & 4 & 3 & 0,133 & 0,013 & 0,036 & 0,024 & 0,044 & 0,022 \\
\hline out 8 & 5 & 3 & 0,067 & 0,000 & 0,012 & 0,012 & 0,021 & 0,006 \\
\hline out9 & 2 & 5 & 0,467 & 0,210 & 0,166 & 0,185 & 0,199 & 0,179 \\
\hline out10 & 3 & 5 & 0,233 & 0,053 & 0,077 & 0,081 & 0,095 & 0,079 \\
\hline out11 & 4 & 5 & 0,133 & 0,013 & 0,036 & 0,024 & 0,044 & 0,022 \\
\hline out12 & 5 & 5 & 0,067 & 0,000 & 0,012 & 0,012 & 0,021 & 0,006 \\
\hline Total & - & - & 1,000 & 1,000 & 1,000 & 1,000 & 1,000 & 1,000 \\
\hline \multicolumn{9}{|c|}{ Somente observações mais afetadas } \\
\hline out1 & 2 & 1 & 0,450 & 0,181 & 0,550 & 0,419 & 0,514 & 0,381 \\
\hline out 2 & 3 & 1 & 0,200 & 0,050 & 0,350 & 0,267 & 0,333 & 0,229 \\
\hline out3 & 4 & 1 & 0,133 & 0,010 & 0,200 & 0,105 & 0,210 & 0,095 \\
\hline out 4 & 5 & 1 & 0,067 & 0,000 & 0,067 & 0,067 & 0,133 & 0,038 \\
\hline out 5 & 2 & 3 & 0,467 & 0,210 & 0,583 & 0,419 & 0,533 & 0,381 \\
\hline out6 & 3 & 3 & 0,233 & 0,053 & 0,367 & 0,276 & 0,352 & 0,229 \\
\hline out7 & 4 & 3 & 0,133 & 0,013 & 0,200 & 0,105 & 0,219 & 0,095 \\
\hline out8 & 5 & 3 & 0,067 & 0,000 & 0,067 & 0,076 & 0,133 & 0,038 \\
\hline out9 & 2 & 5 & 0,467 & 0,210 & 0,583 & 0,419 & 0,533 & 0,381 \\
\hline out10 & 3 & 5 & 0,233 & 0,053 & 0,367 & 0,276 & 0,352 & 0,229 \\
\hline out11 & 4 & 5 & 0,133 & 0,013 & 0,200 & 0,105 & 0,219 & 0,095 \\
\hline out12 & 5 & 5 & 0,067 & 0,000 & 0,067 & 0,076 & 0,133 & 0,038 \\
\hline Total & - & - & 1,000 & 1,000 & 1,000 & 1,000 & 1,000 & 1,000 \\
\hline
\end{tabular}

tal efeito (gráficos (C) e (B)).

A Tabela 3.15 apresenta a quantidade de anomalias detectadas em cada fase do tratamento dado a série de nível do reservatório Peruíbe. Nota-se que a maior parte das observações anômalas foram detectadas durante a fase de limpeza primária, o que dá a quantidade de 931 observações ou 5,3\% do total. Durante todo o processo, foram detectadas 1139 (6,5\%) observações anormais.

\subsubsection{Previsão}

A Tabela 3.16 traz os resultados de acurácia dos experimentos de previsão de acordo com RMSE. Ela é dividida em duas partes: a parte superior é dedicada a mostrar os resultados que usaram rolling windows de tamanho 336 horas (14 dias) e a parte inferior mostra os resultados referentes ao uso de rolling windows de tamanho 720 horas (30 dias). Os experimentos estão agrupados por tipo de modelos. A partir dessa tabela, verifica-se que:

- O melhor procedimento de previsão com modelos SARIMA, de acordo com o RMSE total, foi o que usou estratégia do tipo 1 e rolling windows de tamanho 720, apresentando RMSE total de 1,261. Um ponto a se observar é que a estratégia de tipo 2 teve um desempenho bem melhor do que a de tipo 1 no uso rolling window de tamanho 336, o que é um resultado um tanto inusitado, já que o esperado era que o desempenho de um modelo identificado usando as observações da própria rolling window fosse superior àquele que usasse as observações de uma outra rolling window para identicar o modelo.

- O melhor procedimento de regressão com erros autocorrelacionados, de acordo com o RMSE 
Tabela 3.14: RMSE do tratamento dos outliers de acordo com o procedimento que apresentou melhor desempenho em preencher valores omissos. O procedimento foi o de ajuste de curvas de regressão com polinômio de grau 5 modelando a tendência, com interpolação de $R_{t}$, sem sazonalidade semanal, janela de tamanho 336 e valor de corte $c=5$. Variou-se o valor de corte $c$ e a quantidade de iterações máxima com o objetivo de verificar se a mudança desses parâmetros causam algum impacto na detecção dos outliers. A linha total é o RMSE das observações ouliers em relação ao seu valor original. A aplicação se refere a série de nivel do reservatório Peruíbe.

\begin{tabular}{|c|c|c|c|c|c|c|c|c|}
\hline \multicolumn{3}{|c|}{ Experimentos } & \multicolumn{6}{|c|}{ Tipo de efeitos atípicos } \\
\hline ID & c & $\begin{array}{l}\mathrm{N}^{0} \text { máximo } \\
\text { de iterações }\end{array}$ & Único & Platô & Pulso & $\begin{array}{l}\text { C.D. } \\
\text { linear }\end{array}$ & $\begin{array}{c}\text { C.D. } \\
\text { exponencial }\end{array}$ & $\begin{array}{c}\text { C.D. } \\
\text { logaritmico }\end{array}$ \\
\hline \multicolumn{9}{|c|}{ Todas as observações afetadas } \\
\hline out1 & 2 & 1 & 1,12 & 1,37 & 1,07 & 1,26 & 1,23 & 1,28 \\
\hline out 2 & 3 & 1 & 1,74 & 1,54 & 1,26 & 1,45 & 1,43 & 1,45 \\
\hline out3 & 4 & 1 & 1,90 & 1,61 & 1,38 & 1,56 & 1,56 & 1,55 \\
\hline out 4 & 5 & 1 & 2,13 & 1,64 & 1,47 & 1,60 & 1,63 & 1,59 \\
\hline out5 & 2 & 3 & 1,09 & 1,35 & 1,06 & 1,25 & 1,21 & 1,27 \\
\hline out 6 & 3 & 3 & 1,66 & 1,53 & 1,25 & 1,44 & 1,43 & 1,45 \\
\hline out7 & 4 & 3 & 1,90 & 1,61 & 1,38 & 1,56 & 1,55 & 1,55 \\
\hline out 8 & 5 & 3 & 2,13 & 1,64 & 1,47 & 1,60 & 1,63 & 1,59 \\
\hline out 9 & 2 & 5 & 1,09 & 1,35 & 1,06 & 1,25 & 1,21 & 1,27 \\
\hline out10 & 3 & 5 & 1,66 & 1,53 & 1,25 & 1,44 & 1,43 & 1,45 \\
\hline out11 & 4 & 5 & 1,90 & 1,61 & 1,38 & 1,56 & 1,55 & 1,55 \\
\hline out12 & 5 & 5 & 2,13 & 1,64 & 1,47 & 1,60 & 1,63 & 1,59 \\
\hline Total & - & - & 2,37 & 1,64 & 1,53 & 1,65 & 1,77 & 1,61 \\
\hline \multicolumn{9}{|c|}{ Somente observações mais afetadas } \\
\hline out1 & 2 & 1 & 1,12 & 1,37 & 1,26 & 1,67 & 1,72 & 1,64 \\
\hline out 2 & 3 & 1 & 1,74 & 1,54 & 1,77 & 2,01 & 2,13 & 1,94 \\
\hline out3 & 4 & 1 & 1,90 & 1,61 & 2,17 & 2,31 & 2,38 & 2,16 \\
\hline out 4 & 5 & 1 & 2,13 & 1,64 & 2,51 & 2,42 & 2,61 & 2,29 \\
\hline out 5 & 2 & 3 & 1,09 & 1,35 & 1,21 & 1,67 & 1,70 & 1,63 \\
\hline out 6 & 3 & 3 & 1,66 & 1,53 & 1,74 & 2,00 & 2,12 & 1,94 \\
\hline out7 & 4 & 3 & 1,90 & 1,61 & 2,17 & 2,31 & 2,37 & 2,16 \\
\hline out 8 & 5 & 3 & 2,13 & 1,64 & 2,51 & 2,41 & 2,61 & 2,29 \\
\hline out 9 & 2 & 5 & 1,09 & 1,35 & 1,21 & 1,67 & 1,70 & 1,63 \\
\hline out10 & 3 & 5 & 1,66 & 1,53 & 1,74 & 2,00 & 2,12 & 1,94 \\
\hline out11 & 4 & 5 & 1,90 & 1,61 & 2,17 & 2,31 & 2,37 & 2,16 \\
\hline out12 & 5 & 5 & 2,13 & 1,64 & 2,51 & 2,41 & 2,61 & 2,29 \\
\hline Total & - & - & 2,37 & 1,64 & 2,82 & 2,62 & 3,17 & 2,38 \\
\hline
\end{tabular}

Tabela 3.15: Quantidade de valores detectados como anomalias em cada estágio de tratamento da série de nível do reservatório Peruíbe. A primeira linha da tabela se refere a quantidade de valores classificados pelo sistema da Sabesp como bad e que, portanto, eram omissos na série original. A segunda linha se refere aos valores detectados como anomalias pela limpeza primária. A terceira linha se refere a quantidade de valores detectados como outliers pela aplicação do algoritmo proposto.

\begin{tabular}{|c|c|c|c|c|}
\hline Fase de detecção de anomalias & Frequência absoluta & Frequência relativa & Acumulado absoluto & Acumulado relativo \\
\hline Originalmente & 205 & $1,2 \%$ & 205 & $1,2 \%$ \\
\hline Limpeza primária & 931 & $5,3 \%$ & 1.136 & $6,5 \%$ \\
\hline Algoritmo de detecção de outliers & 3 & $0 \%$ & 1.139 & $6,5 \%$ \\
\hline Tamanho da série & 17.519 & $100 \%$ & 18.658 & $100 \%$ \\
\hline
\end{tabular}

total, foi o que usou polinômio de grau 0 modelando a tendência, com sazonalidade semanal, com o uso da estratégia do tipo 1 para os erros SARIMA e rolling windows de tamanho 336, apresentando RMSE total de 0,959. É importante notar que nem todos os experimentos do tipo 2 conseguiram ajustar determinado modelo em todas as rollings windows, o que pode ser um empecilho a mais na hora de fazer comparações.

- Dentre os procedimentos BATS e TBATS, o que teve melhor desempenho de acordo com o RMSE total foi o que usou modelos BATS sem sazonalidade semanal e com rolling windows de tamanho 336, apresentando RMSE total de 0,922. Na maioria dos casos, o uso de sazonalidade semanal não melhorou o desempenho dos modelos, a exceção dos modelos com BATS com rollings windows de tamanho 720, no qual houve uma pequena melhora.

- Com exceção dos procedimentos que usaram modelos SARIMA, não houve uma diferença 
(A) Único

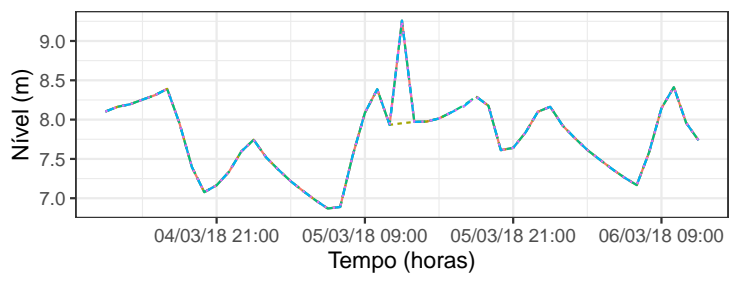

(C) Pulso

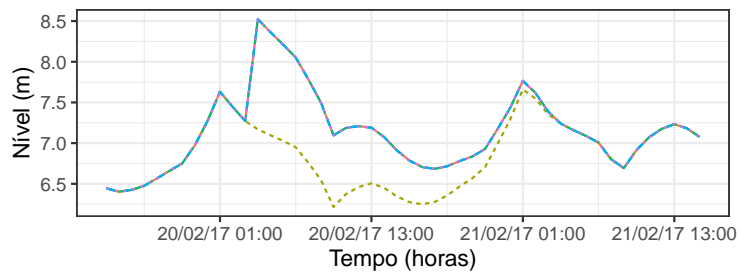

(E) C.D. Exponencial

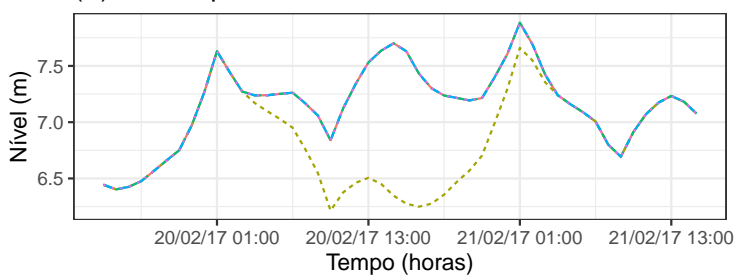

(B) Platô

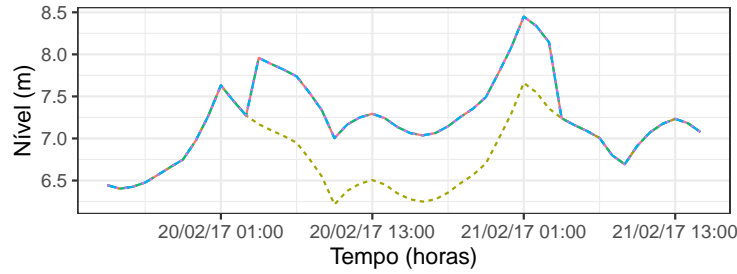

(D) C.D. Linear

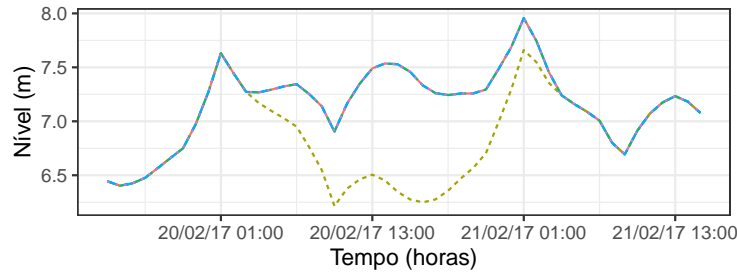

(F) C.D. Logaritmico

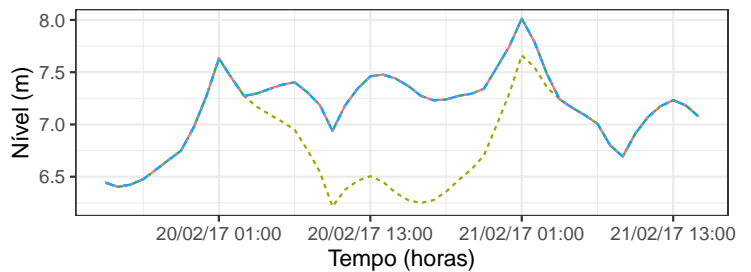

- Série com Outlier …. Original --- Corte $=2--$ Corte $=3 \cdots$ Corte $=5$

Figura 3.7: Exemplos de deteç̧ão e tratamento dos outliers inseridos na série de nivel do reservatório Peruibe. Os trechos mostrados possuem tamanho 48 e são centrados nas observações afetadas pelo efeito atípico. Os gráficos de (A) a (F) exemplificam cada tipo de efeito atípico na série. A quantidade de iteração máxima dos experimentos selecionados é 3.

notável de desempenho entre usar rolling windows de tamanho 336 ou 720.

- Alguns experimentos que empregaram a estratégia do tipo 2 tiveraram um valor de $N<30$. Isso é explicado pelo fato da estratégia consistir em identificar o modelo usando as observações de apenas de uma rolling windows e depois só reestimar os parâmetros nas damais, visto que, ao se fazer esse procedimento, corre-se o risco do modelo não ser "estimátivel"(raízes próximas do polinomio autoregressivo ou de médias móveis bem próximas ou dentro do circulo unitário). Assim, mesmo nas situações em que procedimento do tipo 2 teve um desempenho melhor, é preferivel escolher o do tipo 1, já que a diferença de desempenho entre eles não é muito discrepante.

- Os métodos de previsão propostos não tiveram desempenhos tão superiores aos métodos benchmark, sendo que alguns deles apresentaram desempenho inferior. Isso evidência que os métodos propostos provavelmente não sejam tão eficientes para fazer previsão da série de nível do reservatório Peruíbe.

- Dentre todos os procedimentos de previsão propostos, o melhor foi o que usou modelos BATS sem sazonalidade semanal e com rolling windows de tamanho 336, apresentando o valor de RMSE total de 0,922.

Os resultados não tão bons podem ser explicados pelo comportamento irregular que a série apresenta em vários de seus trechos, sendo, na maioria das vezes, uma sazonalidade não muito bem 
Tabela 3.16: RMSE dos experimentos de previsão aplicados a série de nível do reservatório Peruíbe. As estratégias de tipo 1 se referem a aplicação do algoritmo de seleção de modelo em cada uma das rollings windows, enquanto que as de tipo 2 se referem a aplicação do algoritmo somente na primeira rolling window $e$ do ajuste modelo selecionado nas demais rolling windows, reestimando os parâmetros. O RMSE "Todos"é calculado usando todos os valores preditos de horizonte $h=1, \ldots, 168$, incluido aqueles que não aparecem na tabela.

\begin{tabular}{|c|c|c|c|c|c|c|c|c|c|c|c|c|c|c|}
\hline \multicolumn{4}{|c|}{ Experimentos } & \multicolumn{11}{|c|}{ Horizonte de previsão } \\
\hline Modelos & $\begin{array}{c}\text { Grau do } \\
\text { polinô- } \\
\text { mio }\end{array}$ & $\begin{array}{l}\text { Sazonalidade } \\
\text { semanal }\end{array}$ & $\begin{array}{c}\text { Estratégia } \\
\text { de ajuste }\end{array}$ & $\mathrm{N}$ & 1 & 2 & 3 & 6 & 12 & 18 & 24 & 48 & 168 & Todos \\
\hline \multicolumn{15}{|c|}{ Rolling windows de tamanho 336} \\
\hline \multirow{2}{*}{ SARIMA } & - & - & Tipo 1 & 30 & 0,124 & 0,274 & 0,456 & 0,653 & 0,861 & 1,139 & 1,405 & 2,213 & 9,21 & 5,000 \\
\hline & - & - & Tipo 2 & 26 & 0,121 & 0,302 & 0,531 & 0,930 & 1,138 & 1,289 & 1,352 & 1,684 & 2,84 & 2,119 \\
\hline \multirow{8}{*}{$\begin{array}{c}\text { Regressão } \\
\text { com erros } \\
\text { SARIMA }\end{array}$} & 0 & $\operatorname{Sim}$ & Tipo 1 & 30 & 0,133 & 0,415 & 0,652 & 0,938 & 0,473 & 0,492 & 0,767 & 1,011 & 1,18 & 0,959 \\
\hline & 0 & $\operatorname{Sim}$ & Tipo 2 & 27 & 0,122 & 0,320 & 0,556 & 0,956 & 1,184 & 1,230 & 1,116 & 1,056 & 1,56 & 1,277 \\
\hline & 1 & $\operatorname{Sim}$ & Tipo 1 & 30 & 0,118 & 0,359 & 0,571 & 0,850 & 0,531 & 0,646 & 0,871 & 1,034 & 1,47 & 1,041 \\
\hline & 1 & $\operatorname{Sim}$ & Tipo 2 & 17 & 0,099 & 0,289 & 0,489 & 0,688 & 0,481 & 0,524 & 0,962 & 1,273 & 1,49 & 1,086 \\
\hline & 0 & Não & Tipo 1 & 30 & 0,329 & 0,590 & 0,747 & 0,935 & 0,518 & 0,469 & 0,801 & 1,039 & 1,21 & 0,969 \\
\hline & 0 & Não & Tipo 2 & 26 & 0,126 & 0,330 & 0,573 & 0,956 & 1,202 & 1,240 & 1,127 & 1,067 & 1,56 & 1,275 \\
\hline & 1 & Não & Tipo 1 & 30 & 0,208 & 0,483 & 0,647 & 0,847 & 0,492 & 0,659 & 0,898 & 1,057 & 1,46 & 1,038 \\
\hline & 1 & Não & Tipo 2 & 29 & 0,100 & 0,280 & 0,455 & 0,686 & 0,491 & 0,628 & 0,919 & 1,060 & 1,38 & 0,973 \\
\hline \multirow{2}{*}{ BATS } & - & Não & Tipo 1 & 30 & 0,139 & 0,268 & 0,448 & 0,673 & 0,522 & 0,652 & 0,808 & 0,775 & 1,23 & 0,922 \\
\hline & - & $\mathrm{Sim}$ & Tipo 1 & 30 & 0,111 & 0,261 & 0,450 & 0,681 & 0,520 & 0,583 & 0,784 & 0,750 & 1,25 & 0,931 \\
\hline \multirow{2}{*}{ TBATS } & - & Não & Tipo 1 & 30 & 0,106 & 0,267 & 0,455 & 0,691 & 0,697 & 0,771 & 0,970 & 0,981 & 1,36 & 1,050 \\
\hline & - & $\mathrm{Sim}$ & Tipo 1 & 30 & 0,108 & 0,273 & 0,458 & 0,668 & 0,992 & 1,423 & 1,556 & 1,974 & 1,80 & 2,080 \\
\hline \multirow{3}{*}{ Benchmark } & - & - & Média & 30 & 1,369 & 1,348 & 1,321 & 1,381 & 1,159 & 0,804 & 0,969 & 0,962 & 1,19 & 1,104 \\
\hline & - & - & Mediana & 30 & 1,429 & 1,404 & 1,378 & 1,422 & 1,163 & 0,818 & 1,023 & 1,017 & 1,26 & 1,113 \\
\hline & - & - & Ûlt. Obs. & 30 & 0,179 & 0,364 & 0,596 & 1,057 & 1,377 & 1,175 & 1,081 & 1,063 & 1,47 & 1,356 \\
\hline \multicolumn{15}{|c|}{ Rolling windows de tamanho 720} \\
\hline \multirow[b]{2}{*}{ SARIMA } & - & - & Tipo 1 & 30 & 0,206 & 0,386 & 0,624 & 0,986 & 0,976 & 1,127 & 1,063 & 1,164 & 2,14 & 1,261 \\
\hline & - & - & Tipo 2 & 29 & 0,208 & 0,378 & 0,610 & 0,990 & 0,893 & 1,105 & 1,017 & 1,077 & 1,72 & 1,267 \\
\hline \multirow{8}{*}{$\begin{array}{c}\text { Regressão } \\
\text { com erros } \\
\text { SARIMA }\end{array}$} & 0 & $\operatorname{Sim}$ & Tipo 1 & 30 & 0,186 & 0,337 & 0,554 & 0,926 & 0,780 & 0,966 & 1,038 & 1,022 & 1,34 & 1,003 \\
\hline & 0 & $\operatorname{Sim}$ & Tipo 2 & 30 & 0,215 & 0,394 & 0,601 & 0,877 & 1,028 & 1,127 & 1,133 & 1,472 & 1,97 & 1,425 \\
\hline & 1 & $\operatorname{Sim}$ & Tipo 1 & 30 & 0,197 & 0,331 & 0,534 & 0,908 & 0,850 & 0,936 & 0,924 & 0,868 & 1,60 & 1,014 \\
\hline & 1 & Sim & Tipo 2 & 30 & 0,186 & 0,329 & 0,534 & 0,898 & 0,853 & 0,896 & 0,873 & 0,833 & 1,58 & 0,997 \\
\hline & 0 & Não & Tipo 1 & 30 & 0,186 & 0,340 & 0,559 & 0,929 & 0,792 & 0,958 & 1,018 & 1,007 & 1,34 & 1,008 \\
\hline & 0 & Não & Tipo 2 & 30 & 0,215 & 0,394 & 0,600 & 0,854 & 1,002 & 1,089 & 1,087 & 1,451 & 1,97 & 1,413 \\
\hline & 1 & Não & Tipo 1 & 30 & 0,184 & 0,325 & 0,534 & 0,907 & 0,823 & 0,904 & 0,875 & 0,831 & 1,52 & 0,982 \\
\hline & 1 & Não & Tipo 2 & 29 & 0,186 & 0,327 & 0,526 & 0,882 & 0,897 & 1,072 & 1,030 & 0,939 & 1,55 & 1,049 \\
\hline \multirow{2}{*}{ BATS } & - & Não & Tipo 1 & 30 & 0,197 & 0,325 & 0,530 & 0,828 & 0,852 & 0,961 & 1,064 & 1,171 & 1,46 & 1,114 \\
\hline & - & Sim & Tipo 1 & 30 & 0,206 & 0,353 & 0,575 & 0,899 & 0,790 & 0,980 & 1,062 & 1,068 & 1,63 & 1,085 \\
\hline \multirow{2}{*}{ TBATS } & - & Não & Tipo 1 & 30 & 0,200 & 0,346 & 0,552 & 0,844 & 0,810 & 0,949 & 0,983 & 1,042 & 1,60 & 1,079 \\
\hline & - & Sim & Tipo 1 & 30 & 0,202 & 0,360 & 0,584 & 0,900 & 0,906 & 1,005 & 1,002 & 1,144 & 1,50 & 1,090 \\
\hline \multirow{3}{*}{ Benchmark } & - & - & Média & 30 & 1,250 & 1,295 & 1,394 & 1,412 & 0,961 & 1,097 & 1,391 & 1,273 & 1,27 & 1,141 \\
\hline & - & - & Mediana & 30 & 1,324 & 1,358 & 1,443 & 1,443 & 1,001 & 1,178 & 1,484 & 1,338 & 1,32 & 1,198 \\
\hline & - & - & Últ. Obs. & 30 & 0,240 & 0,419 & 0,628 & 0,900 & 1,178 & 1,115 & 1,035 & 1,309 & 1,75 & 1,416 \\
\hline
\end{tabular}

definida, o que prejudica demasiadamente a escolha de um modelo preditivo. Tal constatação pode ser observada na Figura 3.8, na qual são mostrados alguns exemplos de previsões para cada tipo de modelo que reforçam as observações realizadas.

Para a elaboração dos gráficos da Figura 3.8, decidiu-se não selecionar as previsões que usaram a estratégia do tipo 2, por tal método nem sempre conseguir estimar os parâmetros dos modelos, o que acaba resultando no uso de uma quantidade menor de rolling windows. Assim, as previsões SARIMA se referem ao uso de estratégia do tipo 1 e rolling windows de tamanho 720; as de regressão com erros autocorrelacionados se referem ao uso de polinômio de grau 0 modelando a tendência, com sazonalidade semanal, com o uso da estratégia do tipo 1 para os erros SARIMA e rolling windows de tamanho 336; as previsões BATS se referem ao uso de modelos sem sazonalidade semanal e rolling windows de tamanho 336; as previsões TBATS se referem ao uso de modelos sem sazonalidade semanal e rolling windows de tamanho 336 e as previsões benchmark se referem ao uso da média e rolling windows de tamanho 336. 
(A)

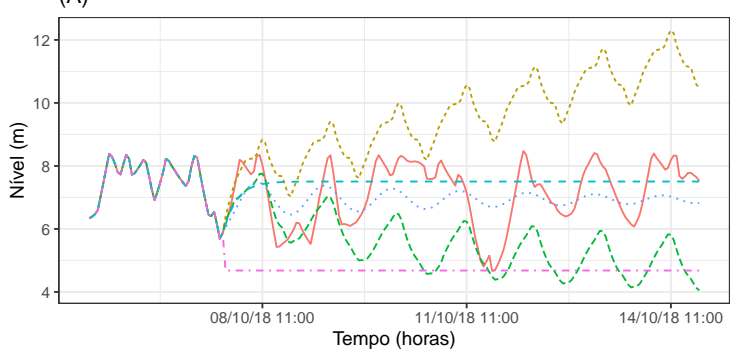

(C)

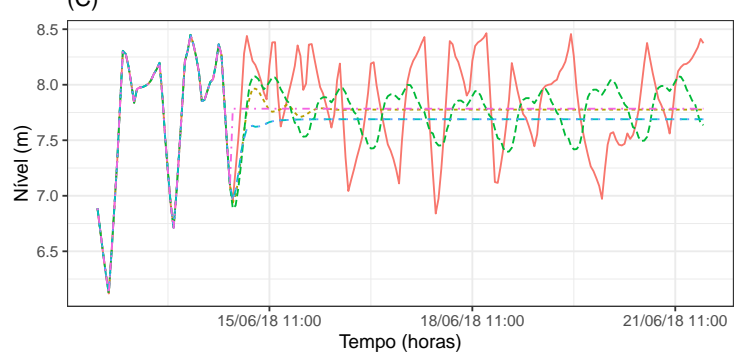

(B)

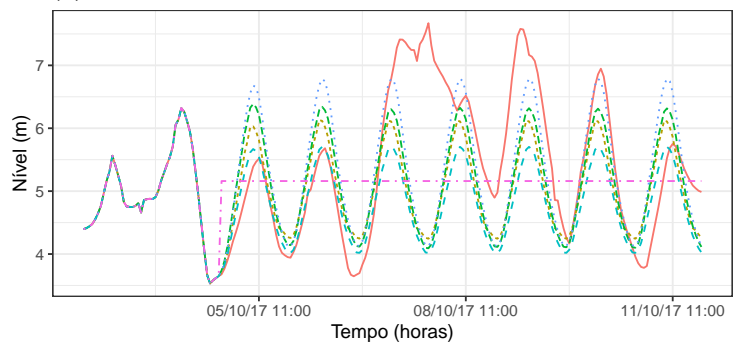

(D)

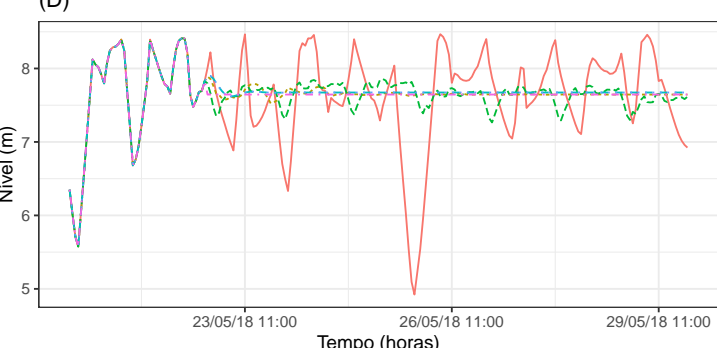

$\begin{array}{llll}\text { — Original } & \text {--- Melhor estratégia regressão } & \text { com erros SARIMA do tipo } 1 & \cdots\end{array}$

Figura 3.8: Alguns trechos da série de nivel do reservatório Peruibe que exemplificam a aplicação dos modelos de previsão. São apresentados o melhor procedimento de ajuste de cada familia de modelos, de acordo com o melhor RMSE de previsão, para os dois tamanhos de rolling window descritos na tabela 3.16. Para a seleção dos procedimentos, exluiu-se os que utilizaram a estratégia de tipo 2. Os gráficos exibem 48 horas da série seguidas de 168 horas de previsão. Os gráficos da esquerda se referem aos ajustes que usaram rolling windows de tamanho 336, já os da direita, de tamanho 720

\subsection{Consumo do reservatório Peruíbe}

Nesta seção é apresentado e discutido os resultados das aplicações dos procedimentos de imputação de valores omissos e detecção de outliers e dos métodos de previsão relacionados a série de consumo demandado do reservatório Peruíbe. A Figura 3.9 exibe um trecho da série que exemplifica seu comportamento. O gráfico (A) se refere a série original, enquanto que o gráfico (B) é mesmo trecho após limpeza e aplicação do métodos de detecção de outlier e preenchimento de valores omissos.

O método escolhido para a detecção de outliers e preenchimentos dos valores omissos, por possuir o menor RMSE total entre todos os experimentos realizados, com o valor de 93,16, foi o decomposição clássica sem interpolação de $R_{t}$, janela de tamanho 168 e valor de corte $c=$ 2. O total de valores classificados como anomalias após aplicação do método selecionado foi de 6443 (36,8 \%), vis-à-vis à quantidade de 4576 (26,1 \%) após a limpeza primária e à quantidade original de 207 (1,18 \%). Em relação a previsão, o método que apresentou melhor desempenho nos experimentos foi o que usou modelos SARIMA do tipo 2 e com rolling windows de tamanho 336, apresentando o valor de RMSE total de 96,239. Se excluírmos os procedimentos de previsão que usaram a estratégia do tipo 2, temos que o melhor procedimento foi o que usou modelos de regressão com erros autocorrelacionados, com polinômio de grau 0 modelando a tendência, sem sazonalidade semanal e com rolling windows de tamanho 336, apresentando um RMSE total de 97,113. De modo geral, os resultados mostram uma boa adequabilidade dos métodos propostos a série temporal de consumo demandado do reservatório Peruíbe.

As próximas subseções apresentam e discutem os resultados de forma mais detalhada. 
(A) Trecho da série original

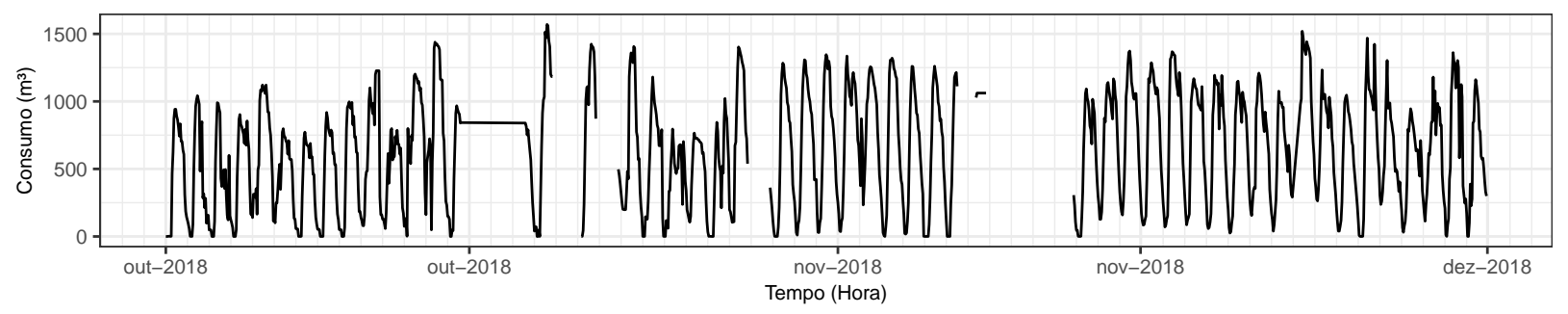

(B) Trecho da série após limpeza e preenchimento de valores omissos

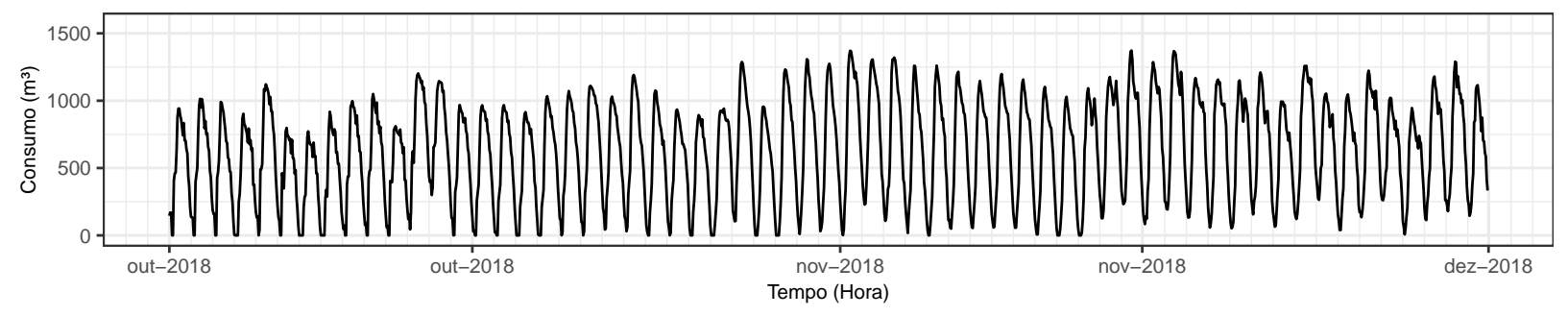

Figura 3.9: Trecho da série de consumo demandado do reservatório Peruỉe que exemplificam seu comportamento. O gráfico (A) é referente a série original e o gráfico (B) mostra a série após as limpezas, tratamento dos outliers detectados e preenchimento dos valores omissos de acordo com o método escolhido.

\subsubsection{Preenchimento de valores omissos}

As tabelas 3.17 à 3.19 mostram os resultados dos 12 melhores experimentos de cada tipo de procedimento de preenchimento de valores omissos, usando como medida de avaliação o RMSE. Em todas as tabelas os experimentos são apresentados em ordem decrescente de RMSE. Já a tabela 3.20 apresenta os resultados dos procedimentos de preenchimento de valores omissos usados como benchmark. Nesta, os experimentos são ordenados pelo ID.

Tabela 3.17: RMSE dos 12 melhores métodos de preenchimento de dados omissos baseados no ajuste de modelos de regressão, selecionados de acordo com menor RMSE. Os resultados se referem a aplicação dos métodos a série de consumo demandado do reservatório Peruíbe.

\begin{tabular}{|c|c|c|c|c|c|c|c|c|c|c|c|c|c|}
\hline \multicolumn{6}{|c|}{ Experimentos de regressão } & \multicolumn{8}{|c|}{ Quantidade de valores omissos em sequência } \\
\hline ID & $\begin{array}{l}\text { Interpolação } \\
\quad \text { de } R_{t}\end{array}$ & $\begin{array}{l}\text { Dia da } \\
\text { semana }\end{array}$ & $\begin{array}{l}\text { Grau do } \\
\text { polinômio }\end{array}$ & Janela & $c$ & 1 & 3 & 6 & 12 & 18 & 24 & 48 & Total \\
\hline reg33 & Sim & Sim & 2 & 720 & 2 & 103,8 & 89,8 & 93,6 & 77,9 & 117 & 90,2 & 89,9 & 94,6 \\
\hline reg72 & Sim & Sim & 5 & 720 & 3 & 95,7 & 86,4 & 101,9 & 80,2 & 118 & 89,0 & 92,4 & 94,7 \\
\hline reg30 & Sim & Sim & 1 & 720 & 2 & 104,6 & 89,0 & 94,5 & 83,2 & 115 & 90,1 & 88,1 & 94,9 \\
\hline reg60 & Sim & $\mathrm{Sim}$ & 2 & 720 & 3 & 97,6 & 86,5 & 110,8 & 81,6 & 117 & 87,4 & 86,4 & 95,4 \\
\hline reg69 & Sim & Sim & 2 & 720 & 3 & 95,5 & 86,3 & 108,5 & 84,7 & 115 & 88,8 & 88,7 & 95,4 \\
\hline reg36 & Sim & $\mathrm{Sim}$ & 5 & 720 & 2 & 104,4 & 95,9 & 99,1 & 80,1 & 112 & 90,3 & 89,8 & 95,9 \\
\hline reg24 & $\operatorname{Sim}$ & $\mathrm{Sim}$ & 2 & 720 & 2 & 106,0 & 95,3 & 99,1 & 81,2 & 112 & 88,6 & 88,8 & 95,9 \\
\hline $\operatorname{reg} 27$ & Sim & $\mathrm{Sim}$ & 5 & 720 & 2 & 108,9 & 96,5 & 97,5 & 79,9 & 114 & 88,9 & 88,3 & 96,3 \\
\hline reg99 & Sim & $\mathrm{Sim}$ & 5 & 720 & 5 & 76,3 & 78,4 & 103,5 & 81,3 & 128 & 113,0 & 93,3 & 96,3 \\
\hline reg108 & $\operatorname{Sim}$ & $\operatorname{Sim}$ & 5 & 720 & 5 & 76,2 & 78,1 & 103,1 & 82,9 & 125 & 115,0 & 96,3 & 96,7 \\
\hline reg96 & Sim & Sim & 2 & 720 & 5 & 76,7 & 78,6 & 104,6 & 81,5 & 129 & 113,6 & 93,2 & 96,7 \\
\hline reg105 & Sim & Sim & 2 & 720 & 5 & 76,9 & 78,7 & 103,0 & 82,8 & 126 & 114,3 & 95,8 & 96,9 \\
\hline
\end{tabular}

De acordo com as informações apresentadas nas tabelas 3.17 à 3.20 podemos verificar que, em geral:

- Os melhores procedimentos de regressão, de acordo com o RMSE total, foram aqueles que usaram interpolação nos resíduos $R_{t}$, que consideraram a sazonalidade semanal e que usaram uma janela de tamanho 720, sendo que o melhor procedimento de regressão para imputação de valores omissos foi o que usou polinômio de grau 2 modelando a tendência, com interpolação 
Tabela 3.18: RMSE dos 12 melhores métodos de preenchimento de dados omissos baseados no ajuste de modelo de regressão acompanhado de decomposições clássica, selecionados de acordo com menor RMSE. O modelo de regressão usado em conjundo com a decomposição clássica, por apresentar menor RMSE, foi o que possui polinômio de grau 2, com interpolação dos resíduos, com sazonalidade semanal e janela de tamanho 720. Os resultados se referem a aplicação dos métodos a série de consumo demandado do reservatório Peruibe.

\begin{tabular}{|c|c|c|c|c|c|c|c|c|c|c|c|}
\hline \multicolumn{4}{|c|}{ Experimentos de decomposição clássica } & \multicolumn{8}{|c|}{ Quantidade de valores omissos em sequência } \\
\hline ID & $\begin{array}{l}\text { Interpolação } \\
\text { de } R_{t}\end{array}$ & Janela & $c$ & 1 & 3 & 6 & 12 & 18 & 24 & 48 & Total \\
\hline $\operatorname{dec} 1$ & Não & 168 & 2 & 118,0 & 96,7 & 93,8 & 75,0 & 112 & 75,9 & 80,4 & 93,2 \\
\hline $\operatorname{dec} 4$ & $\operatorname{Sim}$ & 168 & 2 & 105,2 & 90,2 & 91,0 & 79,0 & 126 & 78,7 & 85,4 & 93,6 \\
\hline $\operatorname{dec} 10$ & $\operatorname{Sim}$ & 168 & 3 & 95,8 & 84,9 & 106,9 & 86,2 & 123 & 77,7 & 87,1 & 94,5 \\
\hline $\operatorname{dec} 7$ & Não & 168 & 3 & 115,4 & 95,6 & 104,8 & 81,2 & 111 & 75,5 & 78,8 & 94,7 \\
\hline $\operatorname{dec} 5$ & Sim & 336 & 2 & 104,2 & 88,5 & 89,6 & 78,3 & 129 & 87,3 & 89,3 & 95,1 \\
\hline $\operatorname{dec} 11$ & $\operatorname{Sim}$ & 336 & 3 & 96,2 & 83,9 & 105,4 & 85,1 & 124 & 86,8 & 91,7 & 96,2 \\
\hline $\operatorname{dec} 2$ & Não & 336 & 2 & 121,5 & 98,4 & 100,5 & 76,7 & 115 & 79,4 & 84,2 & 96,5 \\
\hline $\operatorname{dec} 8$ & Não & 336 & 3 & 119,2 & 98,1 & 107,9 & 82,9 & 113 & 79,4 & 83,1 & 97,7 \\
\hline $\operatorname{dec} 13$ & Não & 168 & 5 & 110,7 & 91,8 & 103,9 & 81,3 & 120 & 96,5 & 87,0 & 98,7 \\
\hline $\operatorname{dec} 6$ & Sim & 720 & 2 & 105,7 & 89,5 & 92,8 & 78,7 & 134 & 101,7 & 97,0 & 99,9 \\
\hline $\operatorname{dec} 3$ & Não & 720 & 2 & 125,9 & 101,5 & 104,0 & 80,8 & 120 & 85,3 & 90,1 & 101,1 \\
\hline $\operatorname{dec} 16$ & Sim & 168 & 5 & 85,1 & 77,7 & 106,8 & 88,2 & 138 & 112,0 & 100,2 & 101,1 \\
\hline
\end{tabular}

Tabela 3.19: RMSE dos 12 melhores métodos de preenchimento de dados omissos baseados em decomposição STL, selecionados de acordo com menor RMSE. Os resultados se referem a aplicação dos métodos a série de consumo demandado do reservatório Peruíbe.

\begin{tabular}{|c|c|c|c|c|c|c|c|c|c|c|c|c|c|}
\hline \multicolumn{6}{|c|}{ Experimentos de decomposição STL } & \multicolumn{8}{|c|}{ Quantidade de valores omissos em sequência } \\
\hline ID & $\begin{array}{l}\text { Interpolação } \\
\text { de } R_{t}\end{array}$ & $n_{(i)}$ & $n_{(e)}$ & $n_{(s)}$ & $c$ & 1 & 3 & 6 & 12 & 18 & 24 & 48 & Total \\
\hline st110 & $\operatorname{Sim}$ & 2 & 0 & 25 & 2 & 102,9 & 89,3 & 94,5 & 86,1 & 121 & 73,7 & 86,7 & 93,5 \\
\hline st149 & $\operatorname{Sim}$ & 1 & 5 & 25 & 5 & 108,6 & 94,6 & 91,6 & 83,3 & 116 & 75,1 & 89,0 & 94,1 \\
\hline st146 & Sim & 2 & 0 & 25 & 5 & 81,3 & 78,2 & 104,7 & 80,2 & 128 & 96,7 & 93,0 & 94,5 \\
\hline st128 & Sim & 2 & 0 & 25 & 3 & 99,9 & 88,3 & 96,1 & 82,6 & 123 & 86,6 & 89,9 & 95,1 \\
\hline st152 & Sim & 1 & 10 & 25 & 5 & 110,1 & 97,5 & 94,9 & 84,2 & 114 & 75,6 & 91,0 & 95,4 \\
\hline st111 & Sim & 2 & 0 & 37 & 2 & 106,7 & 92,4 & 96,6 & 88,1 & 111 & 79,4 & 95,8 & 95,7 \\
\hline st11 & Não & 2 & 0 & 25 & 2 & 122,2 & 99,9 & 100,4 & 84,7 & 116 & 67,4 & 80,2 & 95,8 \\
\hline st131 & Sim & 1 & 5 & 25 & 3 & 116,7 & 102,4 & 96,1 & 82,9 & 116 & 75,3 & 83,9 & 96,2 \\
\hline st147 & Sim & 2 & 0 & 37 & 5 & 87,1 & 78,4 & 105,8 & 80,2 & 125 & 102,3 & 99,2 & 96,8 \\
\hline st119 & Não & 2 & 0 & 25 & 3 & 121,3 & 101,0 & 98,4 & 84,4 & 118 & 68,7 & 86,9 & 96,9 \\
\hline stl13 & Sim & 1 & 5 & 25 & 2 & 122,1 & 112,0 & 100,4 & 82,9 & 113 & 72,3 & 82,1 & 97,9 \\
\hline st12 & Não & 2 & 0 & 37 & 2 & 126,0 & 102,9 & 103,9 & 87,4 & 108 & 70,8 & 85,7 & 97,9 \\
\hline
\end{tabular}

Tabela 3.20: RMSE dos métodos benchmark de preenchimento de dados omissos. Os resultados se referem a aplicação dos métodos a série de consumo demandado do reservatório Peruíbe.

\begin{tabular}{|c|c|c|c|c|c|c|c|c|c|c|}
\hline \multicolumn{3}{|c|}{ Experimentos emphbenchmark } & \multicolumn{8}{|c|}{ Quantidade de valores omissos em sequência } \\
\hline ID & $\begin{array}{c}\text { Forma de } \\
\text { benchmark }\end{array}$ & Janela & 1 & 3 & 6 & 12 & 18 & 24 & 48 & Total \\
\hline ben1 & Média & 168 & 267,4 & 239 & 253 & 251 & 271 & 264 & 276 & 260 \\
\hline ben 2 & Média & 336 & 270,8 & 240 & 254 & 250 & 273 & 268 & 277 & 262 \\
\hline ben 3 & Média & 720 & 272,5 & 245 & 257 & 259 & 279 & 279 & 283 & 268 \\
\hline ben 4 & Mediana & 168 & 271,1 & 235 & 249 & 248 & 276 & 268 & 278 & 261 \\
\hline ben 5 & Mediana & 336 & 273,6 & 237 & 250 & 248 & 273 & 270 & 279 & 261 \\
\hline ben 6 & Mediana & 720 & 274,7 & 243 & 254 & 256 & 279 & 282 & 286 & 268 \\
\hline ben 7 & Interpolação & - & 92,6 & 107 & 174 & 254 & 334 & 345 & 338 & 235 \\
\hline
\end{tabular}

de $R_{t}$, com sazonalidade semanal, janela de tamanho 720 e valor de corte $c=2$, apresentando um RMSE total igual a 94,637. Os parâmetros desse modelo de regressão foram os usados na aplicação do método de decomposição clássica.

- Aparentemente, os procedimentos de decomposição clássica que tiveram melhor desempenho, de acordo com o RMSE total, foram aqueles que usaram janelas de tamanho menores (168 e 
336) e valores de cortes baixo ( $c=2$ e 3 ). O melhor procedimento foi aquele que usou decomposição sem interpolação de $R_{t}$, janela de tamanho 168 e valor de corte $c=2$, apresentando um RMSE total igual a 93,16.

- Os tipos de decomposição STL que tiveram melhores resultados, de acordo com o RMSE total, foram os que possuem interpolação nos resíduos $R_{t}$, possui $n_{(s)}=24$ e que, aparentemente, usaram decomposição STL não robusta $\left(n_{(i)}=2\right.$ e $\left.n_{(e)}=0\right)$. O melhor procedimento foi o de decomposição não robusta $\left(n_{(i)}=2\right.$ e $\left.n_{(e)}=0\right)$, com interpolação de $R_{t}, n_{(s)}=25$ e valor de corte $c=2$, apresentando um RMSE total igual a 93,452.

- Dentre os métodos de benchmark, o que teve melhor desempenho foi o que interpola linearmente os valores da série, apresentando um RMSE total igual a 234,915. Verifica-se que os procedimentos propostos tiveram desempenhos bem superiores aos benchmarks.

- Dentre todos os experimentos, o que apresentou melhor resultado foi o procedimento de decomposição clássica sem interpolação de $R_{t}$, janela de tamanho 168 e valor de corte $c=2$, apresentando um valor de RMSE total de 93,16. Este é o procedimento para o qual é apresentado uma análise de outliers na próxima subseção e que é usado oficialmente para preencher os valores omissos da série.

A Figura 3.10 exemplifica alguns experimentos de preenchimento de valores omissos. Cada gráfico representa um trecho da série temporal de consumo demandado do reservatório Peruíbe no qual propositalmente foi removido uma sequência de valores. Todos os gráficos se referem a uma lacuna de tamanho 48 horas acompanhado de 12 valores anteriores e posteriores à lacuna principal. Os procedimentos de preenchimento adotados para ilustrar os gráficos são o melhor experimento, de acordo com o RMSE total, de cada tipo de procedimento apresentados nas tabelas 3.17 à 3.20.

Verifica-se que os procedimentos propostos conseguiram fazer uma boa estimativa dos valores omissos, sendo essas bem superiores às do método de interpolação. Esses resultados já eram esperados, pois a série de consumo demandado do reservatório Peruíbe apresenta um comportamento sazonal bem característico, mesmo que esse comportamento tenha alguns momentos de notáveis diferenças entre o valor real e o estimado pelos métodos propostos, como nos gráfico (A).

\subsubsection{Detecção e tratamento de outliers}

As tabelas 3.21 e 3.22 mostram os resultados dos experimentos elaborados para avaliar o desempenho em detectar e tratar os outliers do melhor procedimento selecionado para a imputação dos valores omissos. A Tabela 3.21 apresenta as taxas de detecção dos outliers, sendo dividida em duas partes: na parte superior o cálculo das taxas considera todas as observações afetadas pelo efeito atípico, enquanto que na parte inferior é considerado apenas a observação mais afetada pelo efeito atípico. Vale lembrar que no caso do efeito atípico do tipo platô todas as observações foram consideradas como sendo as mais afetadas devido ao efeito se distribuir igualmente entre elas. Já a tabela 3.22 é destinada a verificar a acurácia do procedimento ao corrigir os valores dos outliers. Sua estrutura é análoga à da tabela 3.21, sendo que a linha total é o RMSE do efeito atípico nas observações.

A partir das tabelas, podemos verificar que:

- De modo geral, as taxas de deteç̧ão dos outliers foram altas para o tipo único e para os demais tipos de efeitos a taxa de detecção depende dos parâmetros do experimento. Quando 
(A)

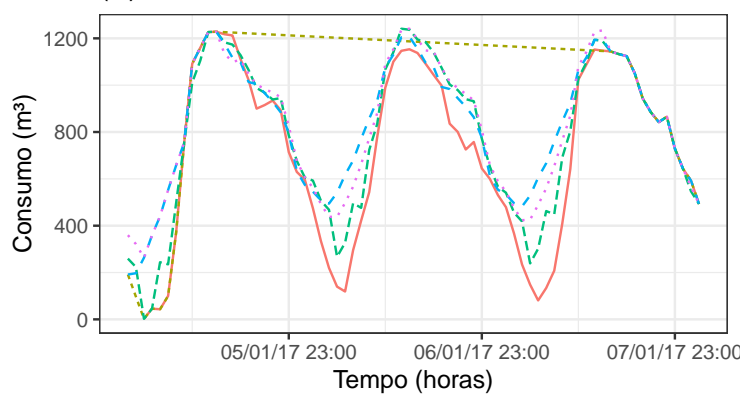

(C)

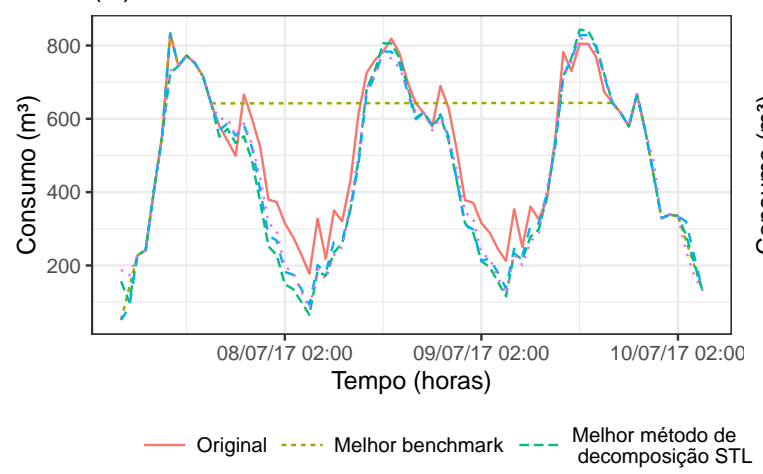

(B)

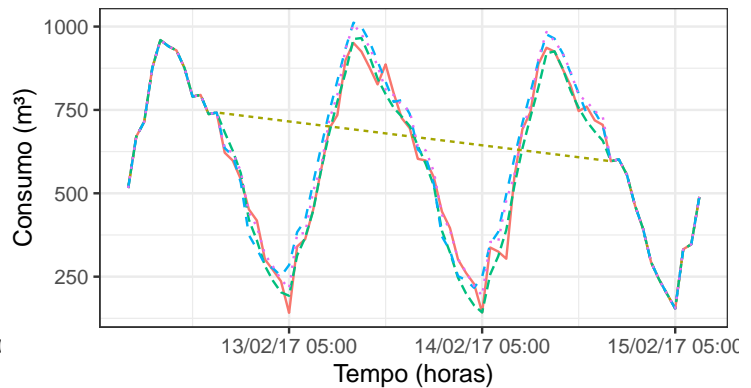

(D)

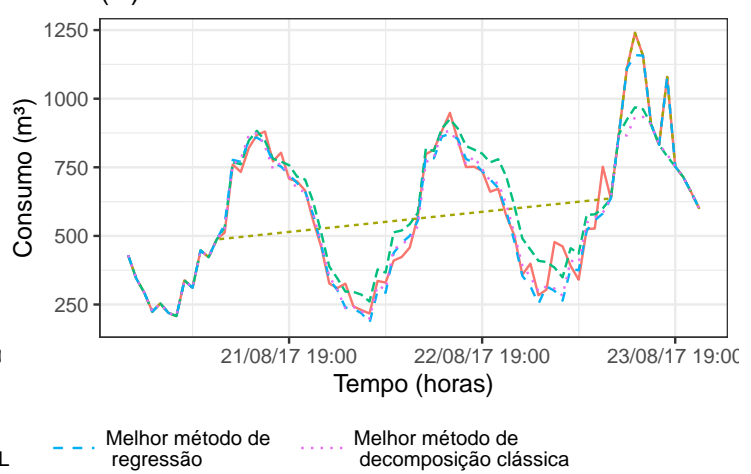

Figura 3.10: Alguns trechos da série de consumo demandado do reservatório Peruıbe que exemplificam a aplicação dos procedimentos de preenchimento de valores omissos. É apresentado o melhor experimento de imputação de valores omissos de cada tipo de procedimento de acordo com o RMSE, descritos nas tabelas 3.17 à 3.20. A lacuna principal de valores omissos usada em cada gráfico foi inserida artificialmente na série temporal a fim de avaliar a performance dos procedimentos de preenchimento de valores omissos. $O$ tamanho da lacuna principal é de 48 horas, sendo precedida e sucedida de 12 horas de valores originais.

se considera apenas as obsevações mais afetadas, as taxa de detecção foram bem altas, com exceção dos efeitos atípicos do tipo platô. Esses resultados são uma evidência da possível adequação do procedimento em detectar os outliers da série. Nota-se também que as altas taxas de detecção resultaram em um RMSE relativamente bom, conseguindo fazer uma redução expressiva em relação ao RMSE total.

- É possível ver que a quantidade de iterações tem pouca interferência na taxa de detecção dos outliers e também não melhora de forma significativa a acurácia ao corrigir os valores atípicos.

- Como o esperado, percebe-se claramente que o valor de corte $c$ influencia na taxa de detecção, sendo que quanto menor for valor de corte $c$, melhor é a taxa de detecção. Também verifica-se um melhor valor de RMSE para os valores mais baixos de $c$. Lembramos que, embora um valor de corte baixo aumente a taxa de detecção de outliers, ele também aumenta a taxa de detecção de valores que possivelmente não seriam outliers.

- Em todos os experimentos, o RMSE foi bem superior do que o RMSE total. Isso indica uma adequabilidade relativamente boa do método em tratar os outliers encontrados.

A Figura 3.11 exemplifica as constatações realizadas. É possível observar que os procedimentos conseguiram dar um tratamento relativamente bom aos outliers nos casos de efeito atípicos do tipo único. No caso do efeito atípico do tipo platô, a eficiência da correção depende do valor de corte $c$ (gráfico (B)). Nos demais casos o método proposto só conseguiu detectar e dar tratamento aos valores mais afetados pelo efeito atípico. 
Tabela 3.21: Taxa de deteç̧ão de outliers de acordo com o procedimento que apresentou melhor desempenho em preencher valores omissos. O procedimento foi o de decomposição clássica sem interpolação de $R_{t}$, janela de tamanho 168 e valor de corte $c=2$. Variou-se o valor de corte c e a quantidade de iterações máxima com o objetivo de verificar se a mudança desses parâmetros causam algum impacto na detecção dos outliers. A aplicação se refere a série de consumo demandado do reservatório Peruíbe.

\begin{tabular}{|c|c|c|c|c|c|c|c|c|}
\hline \multicolumn{3}{|c|}{ Experimentos } & \multicolumn{6}{|c|}{ Tipo de efeitos atípicos } \\
\hline ID & c & $\begin{array}{l}\mathrm{N}^{0} \text { máximo } \\
\text { de iterações }\end{array}$ & Único & Platô & Pulso & $\begin{array}{l}\text { C.D. } \\
\text { linear }\end{array}$ & $\begin{array}{c}\text { C.D. } \\
\text { exponencial }\end{array}$ & $\begin{array}{c}\text { C.D. } \\
\text { logaritmico }\end{array}$ \\
\hline \multicolumn{9}{|c|}{ Todas as observações afetadas } \\
\hline out1 & 2 & 1 & 0,833 & 0,858 & 0,658 & 0,726 & 0,676 & 0,748 \\
\hline out 2 & 3 & 1 & 0,833 & 0,659 & 0,505 & 0,560 & 0,550 & 0,581 \\
\hline out 3 & 4 & 1 & 0,833 & 0,370 & 0,393 & 0,428 & 0,428 & 0,430 \\
\hline out 4 & 5 & 1 & 0,833 & 0,228 & 0,308 & 0,308 & 0,324 & 0,283 \\
\hline out5 & 2 & 3 & 1,000 & 0,917 & 0,704 & 0,779 & 0,736 & 0,807 \\
\hline out 6 & 3 & 3 & 1,000 & 0,720 & 0,544 & 0,604 & 0,588 & 0,639 \\
\hline out 7 & 4 & 3 & 0,983 & 0,401 & 0,424 & 0,470 & 0,470 & 0,468 \\
\hline out 8 & 5 & 3 & 0,967 & 0,252 & 0,339 & 0,324 & 0,347 & 0,307 \\
\hline out9 & 2 & 5 & 1,000 & 0,920 & 0,707 & 0,782 & 0,744 & 0,810 \\
\hline out10 & 3 & 5 & 1,000 & 0,729 & 0,544 & 0,606 & 0,591 & 0,641 \\
\hline out11 & 4 & 5 & 0,983 & 0,403 & 0,425 & 0,470 & 0,471 & 0,468 \\
\hline out12 & 5 & 5 & 0,967 & 0,258 & 0,339 & 0,326 & 0,348 & 0,307 \\
\hline Total & - & - & 1,000 & 1,000 & 1,000 & 1,000 & 1,000 & 1,000 \\
\hline \multicolumn{9}{|c|}{ Somente observações mais afetadas } \\
\hline out1 & 2 & 1 & 0,833 & 0,858 & 0,933 & 0,933 & 0,933 & 0,933 \\
\hline out 2 & 3 & 1 & 0,833 & 0,659 & 0,917 & 0,924 & 0,933 & 0,895 \\
\hline out3 & 4 & 1 & 0,833 & 0,370 & 0,917 & 0,886 & 0,914 & 0,867 \\
\hline out4 & 5 & 1 & 0,833 & 0,228 & 0,917 & 0,848 & 0,886 & 0,714 \\
\hline out 5 & 2 & 3 & 1,000 & 0,917 & 1,000 & 1,000 & 1,000 & 1,000 \\
\hline out 6 & 3 & 3 & 1,000 & 0,720 & 0,983 & 0,990 & 1,000 & 0,981 \\
\hline out7 & 4 & 3 & 0,983 & 0,401 & 0,983 & 0,962 & 0,990 & 0,924 \\
\hline out 8 & 5 & 3 & 0,967 & 0,252 & 0,967 & 0,886 & 0,962 & 0,733 \\
\hline out9 & 2 & 5 & 1,000 & 0,920 & 1,000 & 1,000 & 1,000 & 1,000 \\
\hline out10 & 3 & 5 & 1,000 & 0,729 & 0,983 & 0,990 & 1,000 & 0,981 \\
\hline out11 & 4 & 5 & 0,983 & 0,403 & 0,983 & 0,962 & 0,990 & 0,924 \\
\hline out12 & 5 & 5 & 0,967 & 0,258 & 0,967 & 0,886 & 0,962 & 0,733 \\
\hline Total & - & - & 1,000 & 1,000 & 1,000 & 1,000 & 1,000 & 1,000 \\
\hline
\end{tabular}

A Tabela 3.23 apresenta a quantidade de anomalias detectadas em cada fase do tratamento dado a série de consumo demandado do reservatório Peruíbe. Nota-se que a maior parte das observações anômalas foram detectadas durante a fase de limpeza primária, o que dá a quantidade de 4369 observações ou 24,9 \% do total. Durante todo o processo, foram detectadas 6443 (36,8 \%) observações anormais.

\subsubsection{Previsão}

A Tabela 3.24 traz os resultados de acurácia dos experimentos de previsão de acordo com RMSE. Ela é dividida em duas partes: a parte superior é dedicada a mostrar os resultados que usaram rolling windows de tamanho 336 horas (14 dias) e a parte inferior mostra os resultados referentes ao uso de rolling windows de tamanho 720 horas (30 dias). Os experimentos estão agrupados por tipo de modelos. A partir dessa tabela, verifica-se que:

- O melhor procedimento de previsão com modelos SARIMA, de acordo com o RMSE total, foi o que usou estratégia do tipo 2 e rolling windows de tamanho 336, apresentando RMSE total de 96,239. Vale notar que a estratégia do tipo 2 não conseguiu se ajustar em todas as rolling windows testadas, o que pode ser um empecilho para se fazer comparações. Outro ponto a se observar é que a estratégia de tipo 2 teve um desempenho bem melhor do que a de tipo 1 no uso de rolling window de tamanho 336, o que é um resultado um tanto inusitado, já que o esperado era que o desempenho de um modelo identificado usando as observações da própria rolling window fosse superior àquele que usasse as observações de uma outra rolling window para se fazer tal identificação. 
Tabela 3.22: RMSE do tratamento dos outliers de acordo com o procedimento que apresentou melhor desempenho em preencher valores omissos. O procedimento foi o de decomposição clássica sem interpolação de $R_{t}$, janela de tamanho 168 e valor de corte $c=2$. Variou-se o valor de corte $c$ e a quantidade de iterações máxima com o objetivo de verificar se a mudança desses parâmetros causam algum impacto na detecção dos outliers. A linha total é o RMSE das observações ouliers em relação ao seu valor original. A aplicação se refere a série de consumo demandado do reservatório Peruíbe.

\begin{tabular}{|c|c|c|c|c|c|c|c|c|}
\hline \multicolumn{3}{|c|}{ Experimentos } & \multicolumn{6}{|c|}{ Tipo de efeitos atípicos } \\
\hline ID & c & $\begin{array}{l}\mathrm{N}^{0} \text { máximo } \\
\text { de iterações }\end{array}$ & Único & Platô & Pulso & $\begin{array}{l}\text { C.D. } \\
\text { linear }\end{array}$ & $\begin{array}{c}\text { C.D. } \\
\text { exponencial }\end{array}$ & $\begin{array}{c}\text { C.D. } \\
\text { logaritmico }\end{array}$ \\
\hline \multicolumn{9}{|c|}{ Todas as observações afetadas } \\
\hline out1 & 2 & 1 & 258,4 & 298 & 223 & 300 & 293 & 308 \\
\hline out 2 & 3 & 1 & 254,5 & 416 & 283 & 373 & 343 & 377 \\
\hline out 3 & 4 & 1 & 254,1 & 504 & 325 & 427 & 408 & 446 \\
\hline out 4 & 5 & 1 & 253,3 & 543 & 377 & 492 & 468 & 498 \\
\hline out 5 & 2 & 3 & 86,1 & 286 & 210 & 285 & 279 & 292 \\
\hline out 6 & 3 & 3 & 70,3 & 405 & 272 & 365 & 332 & 364 \\
\hline out7 & 4 & 3 & 79,9 & 497 & 318 & 420 & 400 & 439 \\
\hline out 8 & 5 & 3 & 85,0 & 539 & 369 & 489 & 463 & 494 \\
\hline out 9 & 2 & 5 & 86,1 & 286 & 210 & 284 & 278 & 291 \\
\hline out 10 & 3 & 5 & 70,3 & 403 & 272 & 364 & 332 & 363 \\
\hline out11 & 4 & 5 & 79,9 & 497 & 317 & 420 & 399 & 438 \\
\hline out12 & 5 & 5 & 85,0 & 538 & 369 & 489 & 463 & 494 \\
\hline Total & - & - & 773,3 & 724 & 644 & 726 & 779 & 708 \\
\hline \multicolumn{9}{|c|}{ Somente observações mais afetadas } \\
\hline out1 & 2 & 1 & 258,4 & 298 & 231 & 317 & 320 & 317 \\
\hline out 2 & 3 & 1 & 254,5 & 416 & 251 & 398 & 384 & 396 \\
\hline out3 & 4 & 1 & 254,1 & 504 & 286 & 471 & 469 & 484 \\
\hline out4 & 5 & 1 & 253,3 & 543 & 323 & 574 & 566 & 575 \\
\hline out5 & 2 & 3 & 86,1 & 286 & 186 & 284 & 281 & 290 \\
\hline out 6 & 3 & 3 & 70,3 & 405 & 213 & 377 & 351 & 371 \\
\hline out 7 & 4 & 3 & 79,9 & 497 & 254 & 454 & 445 & 470 \\
\hline out 8 & 5 & 3 & 85,0 & 539 & 300 & 564 & 546 & 567 \\
\hline out9 & 2 & 5 & 86,1 & 286 & 186 & 284 & 279 & 289 \\
\hline out10 & 3 & 5 & 70,3 & 403 & 213 & 377 & 351 & 370 \\
\hline out11 & 4 & 5 & 79,9 & 497 & 254 & 454 & 444 & 469 \\
\hline out12 & 5 & 5 & 85,0 & 538 & 300 & 564 & 544 & 567 \\
\hline Total & - & - & 773,3 & 724 & 1.040 & 1.058 & 1.269 & 965 \\
\hline
\end{tabular}

Tabela 3.23: Quantidade de valores detectados como anomalias em cada estágio de tratamento da série de consumo demandado do reservatório Peru々be. A primeira linha da tabela se refere a quantidade de valores classificados pelo sistema da Sabesp como bad e que, portanto, eram omissos na série original. A segunda linha se refere aos valores detectados como anomalias pela limpeza primária. A terceira linha se refere a quantidade de valores detectados como outliers pela aplicação do algoritmo proposto.

\begin{tabular}{|c|c|c|c|c|}
\hline Fase de detecção de anomalias & Frequência absoluta & Frequência relativa & Acumulado absoluto & Acumulado relativo \\
\hline Originalmente & 207 & $1,2 \%$ & 207 & $1,2 \%$ \\
\hline Limpeza primária & 4.369 & $24,9 \%$ & 4.576 & $26,1 \%$ \\
\hline Algoritmo de detecção de outliers & 1.867 & $10,7 \%$ & 6.443 & $36,8 \%$ \\
\hline Tamanho da série & 17.519 & $100 \%$ & 23.962 & $100 \%$ \\
\hline
\end{tabular}

- O melhor procedimento de regressão com erros autocorrelacionados, de acordo com o RMSE total, foi o que usou polinômio de grau 0 modelando a tendência, sem sazonalidade semanal, com o uso da estratégia do tipo 1 para os erros SARIMA e rolling windows de tamanho 336, apresentando RMSE total de 97,113. É importante notar, novamente, que nem todos os experimentos conseguiram ajustar determinado modelo em todas as rollings windows, o que pode ser um empecilho a mais na hora de fazer comparações.

- Dentre os procedimentos BATS e TBATS, o que teve melhor desempenho de acordo com o RMSE total foi o que usou modelos BATS com sazonalidade semanal e com rolling windows de tamanho 336, apresentando RMSE total de 107,678. Nota-se que os modelos TBATS com uso de rolling windows de tamanho 720 tiveram desempenho piores do que os procedimentos benchmark.

- O uso de rolling windows de tamanho 336 aparenta ser um pouco melhor do que usar as de 
(A) Único

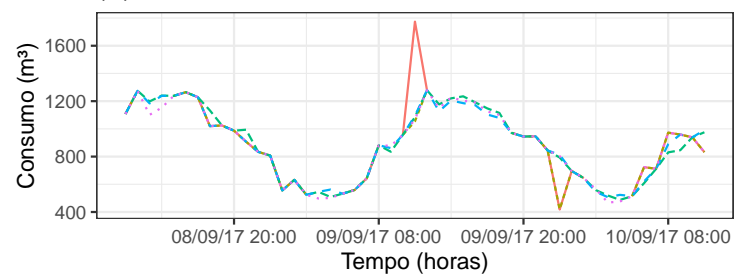

(C) Pulso

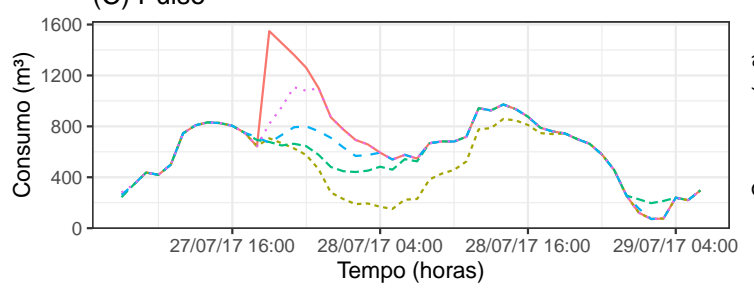

(E) C.D. Exponencial

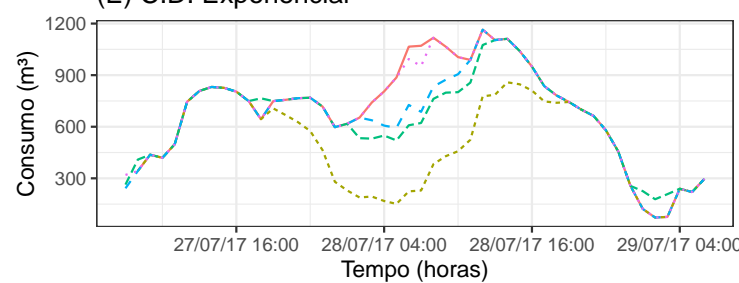

(B) Platô

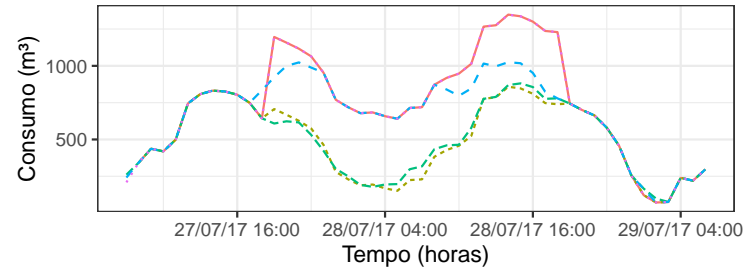

(D) C.D. Linear

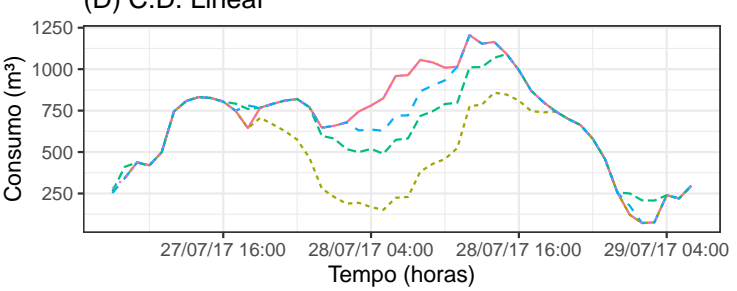

(F) C.D. Logaritmico

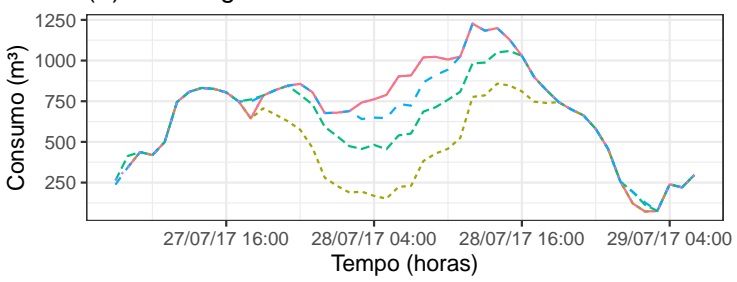

— Série com Outlier $\quad \cdots$ Original --- Corte $=2-\cdots$ Corte $=3 \cdots$ Corte $=5$

Figura 3.11: Exemplos de detecção e tratamento dos outliers inseridos na série de consumo demandado do reservatório Perußbe. Os trechos mostrados possuem tamanho 48 e são centrados nas observações afetadas pelo efeito atípico. Os gráficos de $(A)$ a $(F)$ exemplificam cada tipo de efeito atípico na série. A quantidade de iteração máxima dos experimentos selecionados é 3.

tamanho 720 .

- Alguns experimentos que empregaram a estratégia do tipo 2 tiveraram um valor de $N<30$. Isso é explicado pelo fato da estratégia consistir em identificar o modelo usando as observações de apenas de uma rolling windows e depois só reestimar os parâmetros nas damais, visto que, ao se fazer esse procedimento, corre-se o risco do modelo não ser "estimátivel"(raízes próximas do polinomio autoregressivo ou de médias móveis bem próximas ou dentro do circulo unitário). Assim, mesmo nas situações em que procedimento do tipo 2 teve um desempenho melhor, é preferivel escolher o do tipo 1 , já que a diferença de desempenho entre eles não é muito discrepante.

- Com exceção dos procedimentos TBATS com uso de rolling windows de tamanho 720, os métodos de previsão propostos tiveram desempenhos bem superiores aos métodos benchmark, mostrando, assim, uma possível adequabilidade dos modelos propostos.

- Dentre todos os procedimentos de previsão propostos, o melhor foi o que usou modelos SARIMA do tipo 2 e com rolling windows de tamanho 336, apresentando o valor de RMSE total de 96,239 . Se excluírmos os procedimentos de previsão que usaram a estratégia do tipo 2, temos que o melhor procedimento foi o que usou modelos de regressão com erros autocorrelacionados, com polinômio de grau 0 modelando a tendência, sem sazonalidade semanal e com rolling windows de tamanho 336, apresentando um RMSE total de 97,113.

Os bons resultados de previsão podem ser explicados por um comportamento regular que a série 
Tabela 3.24: RMSE dos experimentos de previsão aplicados a série de consumo demandado do reservatório Peruibe. As estratégias de tipo 1 se referem a aplicação do algoritmo de seleção de modelo em cada uma das rollings windows, enquanto que as de tipo 2 se referem a aplicação do algoritmo somente na primeira rolling window e do ajuste modelo selecionado nas demais rolling windows, reestimando os parâmetros. O RMSE "Todos"é calculado usando todos os valores preditos de horizonte $h=1, \ldots ., 168$, incluido aqueles que não aparecem na tabela.

\begin{tabular}{|c|c|c|c|c|c|c|c|c|c|c|c|c|c|c|}
\hline \multicolumn{4}{|c|}{ Experimentos } & \multicolumn{11}{|c|}{ Horizonte de previsão } \\
\hline Modelos & $\begin{array}{c}\text { Grau do } \\
\text { polinô- } \\
\text { mio }\end{array}$ & $\begin{array}{l}\text { Sazonalidade } \\
\text { semanal }\end{array}$ & $\begin{array}{c}\text { Estratégia } \\
\text { de ajuste }\end{array}$ & $\mathrm{N}$ & 1 & 2 & 3 & 6 & 12 & 18 & 24 & 48 & 168 & Todos \\
\hline \multicolumn{15}{|c|}{ Rolling windows de tamanho 336} \\
\hline \multirow{2}{*}{ SARIMA } & - & - & Tipo 1 & 30 & 31,0 & 33,8 & 48,1 & 45,5 & 67,3 & 80,5 & 70,9 & 142,3 & 214 & 167,6 \\
\hline & - & - & Tipo 2 & 19 & 30,6 & 26,0 & 32,0 & 43,4 & 62,3 & 92,4 & 70,3 & 123,0 & 117 & 96,2 \\
\hline \multirow{8}{*}{$\begin{array}{c}\text { Regressão } \\
\text { com erros } \\
\text { SARIMA }\end{array}$} & 0 & $\operatorname{Sim}$ & Tipo 1 & 30 & 34,0 & 37,6 & 40,9 & 47,8 & 64,9 & 85,3 & 69,1 & 104,6 & 134 & 98,6 \\
\hline & 0 & $\operatorname{Sim}$ & Tipo 2 & 25 & 28,2 & 30,2 & 45,8 & 50,4 & 75,2 & 89,5 & 82,6 & 130,3 & 119 & 117,0 \\
\hline & 1 & $\operatorname{Sim}$ & Tipo 1 & 30 & 34,5 & 39,0 & 43,5 & 49,3 & 68,4 & 83,7 & 70,6 & 99,3 & 167 & 124,1 \\
\hline & 1 & Sim & Tipo 2 & 21 & 32,6 & 41,0 & 39,1 & 49,4 & 73,7 & 83,8 & 64,7 & 113,5 & 123 & 137,1 \\
\hline & 0 & Não & Tipo 1 & 30 & 33,2 & 37,4 & 39,6 & 44,9 & 59,9 & 82,0 & 67,7 & 102,1 & 133 & 97,1 \\
\hline & 0 & Não & Tipo 2 & 24 & 29,1 & 30,5 & 46,3 & 45,6 & 65,3 & 58,0 & 58,4 & 94,0 & 118 & 103,9 \\
\hline & 1 & Não & Tipo 1 & 30 & 34,0 & 38,8 & 43,7 & 46,2 & 65,2 & 80,3 & 69,2 & 96,0 & 165 & 123,2 \\
\hline & 1 & Não & Tipo 2 & 21 & 30,6 & 42,4 & 41,5 & 48,0 & 73,5 & 97,3 & 76,1 & 132,0 & 144 & 140,2 \\
\hline \multirow{2}{*}{ BATS } & - & Não & Tipo 1 & 30 & 40,3 & 46,2 & 57,5 & 51,7 & 75,9 & 78,4 & 74,4 & 122,4 & 133 & 108,4 \\
\hline & - & Sim & Tipo 1 & 30 & 120,5 & 83,1 & 99,6 & 93,3 & 85,7 & 116,6 & 98,7 & 118,5 & 116 & 107,7 \\
\hline \multirow{2}{*}{ TBATS } & - & Não & Tipo 1 & 30 & 42,7 & 49,7 & 61,2 & 53,9 & 74,8 & 85,7 & 75,9 & 115,1 & 120 & 109,6 \\
\hline & - & $\mathrm{Sim}$ & Tipo 1 & 30 & 47,8 & 56,4 & 74,8 & 72,2 & 75,1 & 95,8 & 89,1 & 127,1 & 124 & 117,3 \\
\hline \multirow{3}{*}{ Benchmark } & - & _- & Média & 30 & 132,1 & 140,0 & 206,1 & 310,1 & 238,6 & 326,5 & 146,1 & 158,5 & 171 & 261,0 \\
\hline & - & - & Mediana & 30 & 117,4 & 125,9 & 211,2 & 322,2 & 255,4 & 312,9 & 137,0 & 151,0 & 162 & 262,8 \\
\hline & - & - & Ûlt. Obs. & 30 & 95,2 & 158,8 & 273,0 & 401,7 & 313,2 & 230,0 & 71,1 & 121,0 & 114 & 287,3 \\
\hline \multicolumn{15}{|c|}{ Rolling windows de tamanho 720} \\
\hline \multirow{2}{*}{ SARIMA } & - & - & Tipo 1 & 30 & 32,7 & 42,8 & 48,7 & 41,3 & 64,3 & 82,8 & 71,3 & 105,9 & 165 & 114,6 \\
\hline & - & - & Tipo 2 & 18 & 29,6 & 49,4 & 59,8 & 51,1 & 71,8 & 90,4 & 69,9 & 97,2 & 163 & 114,2 \\
\hline \multirow{8}{*}{$\begin{array}{c}\text { Regressão } \\
\text { com erros } \\
\text { SARIMA }\end{array}$} & 0 & $\operatorname{Sim}$ & Tipo 1 & 30 & 35,2 & 50,8 & 61,0 & 57,7 & 66,5 & 78,8 & 75,9 & 101,9 & 162 & 115,7 \\
\hline & 0 & $\operatorname{Sim}$ & Tipo 2 & 21 & 36,1 & 52,2 & 59,8 & 58,5 & 65,0 & 75,6 & 69,1 & 83,8 & 154 & 117,1 \\
\hline & 1 & $\operatorname{Sim}$ & Tipo 1 & 30 & 34,2 & 51,5 & 63,9 & 60,0 & 68,8 & 76,1 & 73,0 & 117,4 & 174 & 132,7 \\
\hline & 1 & Sim & Tipo 2 & 30 & 33,8 & 47,1 & 58,4 & 52,5 & 62,7 & 72,7 & 70,1 & 104,7 & 165 & 117,0 \\
\hline & 0 & Não & Tipo 1 & 30 & 35,5 & 50,5 & 60,6 & 54,4 & 65,4 & 83,3 & 79,0 & 107,2 & 161 & 116,4 \\
\hline & 0 & Não & Tipo 2 & 16 & 36,9 & 53,0 & 64,3 & 58,2 & 68,1 & 76,3 & 76,4 & 80,9 & 162 & 112,9 \\
\hline & 1 & Não & Tipo 1 & 30 & 34,4 & 51,2 & 62,6 & 56,4 & 66,2 & 81,1 & 75,9 & 119,8 & 169 & 130,2 \\
\hline & 1 & Não & Tipo 2 & 30 & 34,0 & 47,5 & 59,2 & 50,4 & 63,4 & 82,2 & 73,5 & 115,7 & 166 & 121,9 \\
\hline \multirow{2}{*}{ BATS } & - & Não & Tipo 1 & 30 & 39,1 & 47,4 & 59,6 & 49,3 & 77,0 & 95,1 & 91,8 & 135,4 & 274 & 176,3 \\
\hline & - & $\mathrm{Sim}$ & Tipo 1 & 30 & 59,8 & 72,1 & 86,0 & 70,0 & 82,2 & 87,9 & 89,6 & 104,5 & 156 & 118,8 \\
\hline \multirow{2}{*}{ TBATS } & - & Não & Tipo 1 & 30 & 48,6 & 68,8 & 84,6 & 108,5 & 99,1 & 136,0 & 151,7 & 285,0 & 903 & 539,6 \\
\hline & - & $\mathrm{Sim}$ & Tipo 1 & 30 & 50,5 & 69,2 & 85,2 & 116,7 & 87,4 & 115,0 & 128,8 & 239,8 & 734 & 447,1 \\
\hline \multirow{3}{*}{ Benchmark } & - & - & Média & 30 & 173,6 & 184,6 & 217,1 & 325,7 & 244,2 & 358,8 & 191,4 & 193,1 & 239 & 282,9 \\
\hline & - & - & Mediana & 30 & 168,8 & 177,0 & 222,2 & 332,0 & 259,7 & 349,2 & 183,9 & 186,9 & 231 & 282,4 \\
\hline & - & - & Últ. Obs. & 30 & 108,3 & 170,7 & 297,9 & 425,2 & 339,2 & 220,4 & 100,2 & 157,2 & 241 & 313,2 \\
\hline
\end{tabular}

apresenta em quase toda a sua extensão, sendo, muitas vezes, uma sazonalidade bem definida. Tal constatação pode ser observada na Figura 3.12, na qual são mostrados alguns exemplos de previsão para cada tipo de modelo que reforçam as constatações realizadas.

Para a elaboração dos gráficos da Figura 3.12, decidiu-se não selecionar as previsões que usaram a estratégia do tipo 2, por tal método nem sempre conseguir estimar os parâmetros dos modelos, o que acaba resultando no uso de uma quantidade menor de rolling windows. Assim, as previsões SARIMA se referem ao uso de estratégia do tipo 1 e rolling windows de tamanho 720; as de regressão com erros autocorrelacionados se referem ao uso de polinômio de grau 0 modelando a tendência, sem sazonalidade semanal, com o uso da estratégia do tipo 1 para os erros SARIMA e rolling windows de tamanho 336; as previsões BATS se referem ao uso de modelos com sazonalidade semanal e rolling windows de tamanho 336; as previsões TBATS se referem ao uso de modelos sem sazonalidade semanal e rolling windows de tamanho 336 e as previsões benchmark se referem ao uso da média e rolling windows de tamanho 336. 
(A)
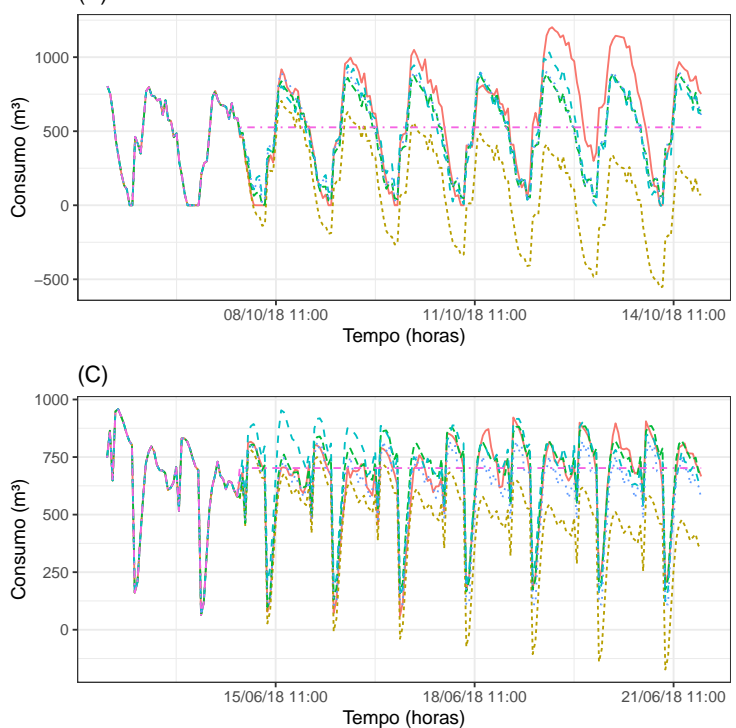

$\begin{array}{lll}\text { - Original } & -- \text { Melhor estratégia regressão } \\ \text { com erros SARIMA do tipo }\end{array}$
(B)

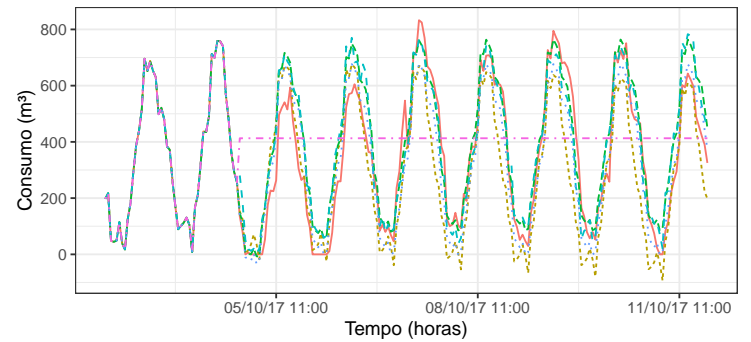

(D)

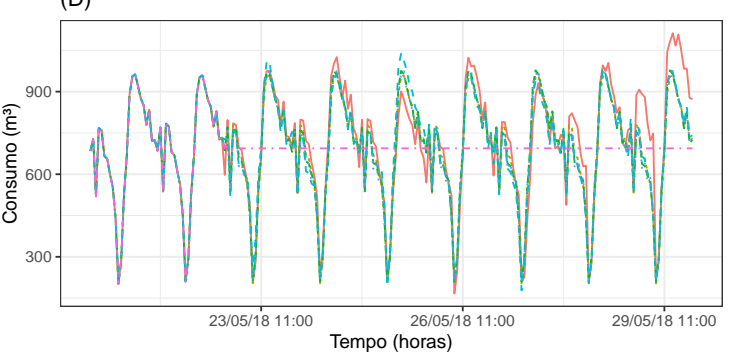

Figura 3.12: Alguns trechos da série de consumo demandado do reservatório Perů́be que exemplificam a aplicação dos modelos de previsão. São apresentados o melhor procedimento de ajuste de cada família de modelos, de acordo com o melhor RMSE de previsão, para os dois tamanhos de rolling window descritos na tabela 3.24. Para a seleção dos procedimentos, exluiu-se os que utilizaram a estratégia de tipo 2. Os gráficos exibem 48 horas da série seguidas de 168 horas de previsão. Os gráficos da esquerda se referem aos ajustes que usaram rolling windows de tamanho 336, já os da direita, de tamanho 720

\subsection{Vazão de saída do reservatório para o Norte de Peruíbe}

Nesta seção é apresentado e discutido os resultados das aplicações dos procedimentos de imputação de valores omissos e detecção de outliers e dos métodos de previsão relacionados a série de vazão de saída para o Norte de Peruíbe. A Figura 3.13 exibe um trecho da série que exemplifica seu comportamento. O gráfico (A) se refere a série original, enquanto que o gráfico (B) é mesmo trecho após limpeza e aplicação do métodos de detecção de outlier e preenchimento de valores omissos.

O método escolhido para a detecção de outliers e preenchimentos dos valores omissos, por possuir o menor RMSE total entre todos os experimentos realizados, com o valor de 14,883, foi o decomposição STL não robusta $\left(n_{(i)}=2\right.$ e $\left.n_{(e)}=0\right)$, com interpolação de $R_{t}, n_{(s)}=25$ e valor de corte $c=5$. O total de valores classificados como anomalias após aplicação do método selecionado foi de 2708 (15,5\%), vis-à-vis à quantidade de 2224 (12,7\%) após a limpeza primária e à quantidade original de 206 (1,18\%). Em relação a previsão, o método que apresentou melhor desempenho nos experimentos foi o que usou modelos de regressão com erros autocorrelacionados, com polinômio de grau 1 modelando a tendência, sem sazonalidade semanal, com o uso da estratégia do tipo 2 para os erros SARIMA e com rolling windows de tamanho 336, apresentando o valor de RMSE total de 20,033. Se excluírmos os procedimentos de previsão que usaram a estratégia do tipo 2, temos que o melhor procedimento foi o que usou modelos de regressão com erros autocorrelacionados, com polinômio de grau 1 modelando a tendência, sem sazonalidade semanal e com rolling windows de tamanho 336, apresentando um RMSE total de 20,417. De modo geral, os resultados mostram uma boa adequabilidade dos métodos propostos a série temporal de vazão de saída para o Norte de Peruíbe. 
(A) Trecho da série original

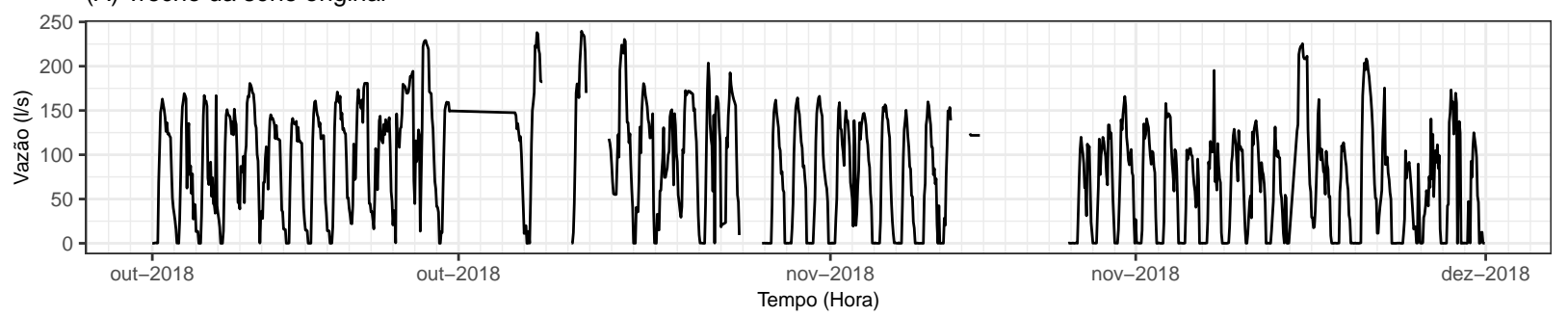

(B) Trecho da série após limpeza e preenchimento de valores omissos

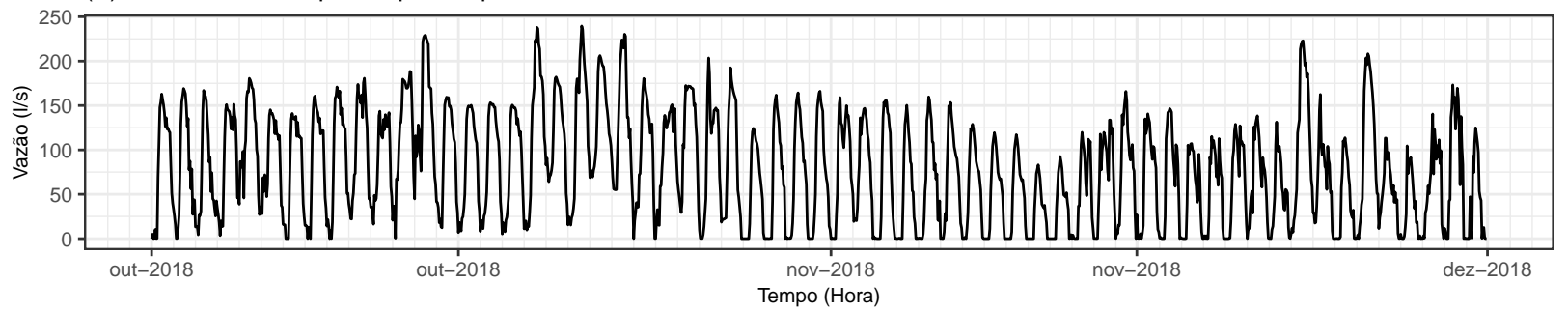

Figura 3.13: Trecho da série de vazão de saída para o Norte de Peruibe que exemplificam seu comportamento. O gráfico (A) é referente a série original e o gráfico (B) mostra a série após as limpezas, tratamento dos outliers detectados e preenchimento dos valores omissos de acordo com o método escolhido.

As próximas subseções apresentam e discutem os resultados de forma mais detalhada.

\subsubsection{Preenchimento de valores omissos}

As tabelas 3.25 à 3.27 mostram os resultados dos 12 melhores experimentos de cada tipo de procedimento de preenchimento de valores omissos, usando como medida de avaliação o RMSE. Em todas as tabelas os experimentos são apresentados em ordem decrescente de RMSE. Já a tabela 3.28 apresenta os resultados dos procedimentos de preenchimento de valores omissos usados como benchmark. Nesta, os experimentos são ordenados pelo ID.

Tabela 3.25: RMSE dos 12 melhores métodos de preenchimento de dados omissos baseados no ajuste de modelos de regressão, selecionados de acordo com menor RMSE. Os resultados se referem a aplicação dos métodos a série de vazão de saída para o Norte de Peruıbe.

\begin{tabular}{|c|c|c|c|c|c|c|c|c|c|c|c|c|c|}
\hline \multicolumn{6}{|c|}{ Experimentos de regressão } & \multicolumn{8}{|c|}{ Quantidade de valores omissos em sequência } \\
\hline ID & $\begin{array}{l}\text { Interpolação } \\
\text { de } R_{t}\end{array}$ & $\begin{array}{c}\text { Dia da } \\
\text { semana }\end{array}$ & $\begin{array}{l}\text { Grau do } \\
\text { polinômio }\end{array}$ & Janela & $c$ & 1 & 3 & 6 & 12 & 18 & 24 & 48 & Total \\
\hline reg97 & Sim & $\operatorname{Sim}$ & 5 & 168 & 5 & 15,8 & 22,6 & 17,6 & 17,5 & 16,1 & 8,76 & 8,28 & 15,2 \\
\hline reg61 & Sim & Sim & 5 & 168 & 3 & 18,1 & 23,3 & 17,4 & 17,4 & 15,3 & 7,84 & 7,95 & 15,3 \\
\hline $\operatorname{reg} 98$ & Sim & Sim & 5 & 336 & 5 & 16,0 & 24,7 & 18,8 & 17,1 & 15,7 & 9,03 & 9,23 & 15,8 \\
\hline reg91 & $\mathrm{Sim}$ & Sim & 1 & 168 & 5 & 17,4 & 23,8 & 19,5 & 17,7 & 15,5 & 8,70 & 8,13 & 15,8 \\
\hline $\operatorname{reg} 25$ & Sim & Sim & 5 & 168 & 2 & 19,6 & 23,6 & 19,7 & 17,4 & 15,0 & 7,51 & 7,92 & 15,8 \\
\hline $\operatorname{reg} 62$ & Sim & Sim & 5 & 336 & 3 & 17,5 & 24,4 & 19,2 & 16,6 & 15,4 & 8,80 & 9,06 & 15,8 \\
\hline reg104 & $\operatorname{Sim}$ & Sim & 2 & 336 & 5 & 15,6 & 24,3 & 18,5 & 17,4 & 15,4 & 9,58 & 10,35 & 15,9 \\
\hline reg92 & Sim & Sim & 1 & 336 & 5 & 15,3 & 24,1 & 20,5 & 17,6 & 15,3 & 9,04 & 9,29 & 15,9 \\
\hline reg 94 & Sim & Sim & 2 & 168 & 5 & 17,2 & 24,1 & 19,1 & 17,9 & 16,1 & 8,67 & 8,24 & 15,9 \\
\hline reg 26 & Sim & Sim & 5 & 336 & 2 & 19,0 & 24,3 & 19,9 & 16,4 & 14,3 & 8,58 & 9,11 & 15,9 \\
\hline reg 101 & Sim & Sim & 1 & 336 & 5 & 15,3 & 24,4 & 18,9 & 17,5 & 16,0 & 9,47 & 10,42 & 16,0 \\
\hline reg108 & $\operatorname{Sim}$ & Sim & 5 & 720 & 5 & 15,2 & 23,2 & 19,7 & 17,7 & 14,8 & 10,18 & 11,27 & 16,0 \\
\hline
\end{tabular}

De acordo com as informações apresentadas nas tabelas 3.25 à 3.28 podemos verificar que, em geral:

- Os melhores procedimentos de regressão, de acordo com o RMSE total, foram aqueles que usaram interpolação nos resíduos $R_{t}$, que consideraram a sazonalidade semanal e que, apa- 
Tabela 3.26: RMSE dos 12 melhores métodos de preenchimento de dados omissos baseados no ajuste de modelo de regressão acompanhado de decomposições clássica, selecionados de acordo com menor RMSE. $O$ modelo de regressão usado em conjundo com a decomposição clássica, por apresentar menor RMSE, foi o que possui polinômio de grau 5, com interpolação dos resíduos, sem sazonalidade semanal e janela de tamanho 168. Os resultados se referem a aplicação dos métodos a série de vazão de saída para o Norte de Peruíbe.

\begin{tabular}{|c|c|c|c|c|c|c|c|c|c|c|c|}
\hline \multicolumn{4}{|c|}{ Experimentos de decomposição clássica } & \multicolumn{8}{|c|}{ Quantidade de valores omissos em sequência } \\
\hline ID & $\begin{array}{l}\text { Interpolação } \\
\text { de } R_{t}\end{array}$ & Janela & $c$ & 1 & 3 & 6 & 12 & 18 & 24 & 48 & Total \\
\hline $\operatorname{dec} 7$ & Não & 168 & 3 & 19,4 & 23,5 & 17,8 & 17,3 & 14,5 & 7,60 & 7,97 & 15,4 \\
\hline $\operatorname{dec} 11$ & Sim & 336 & 3 & 17,7 & 22,9 & 17,6 & 18,0 & 15,2 & 9,15 & 8,95 & 15,6 \\
\hline $\operatorname{dec} 10$ & Sim & 168 & 3 & 17,8 & 22,9 & 17,5 & 17,8 & 15,7 & 8,63 & 9,36 & 15,6 \\
\hline $\operatorname{dec} 8$ & Não & 336 & 3 & 19,7 & 23,8 & 17,9 & 17,7 & 14,0 & 8,15 & 8,68 & 15,7 \\
\hline $\operatorname{dec} 17$ & Sim & 336 & 5 & 15,0 & 22,6 & 17,9 & 18,6 & 16,1 & 10,27 & 9,48 & 15,7 \\
\hline $\operatorname{dec} 1$ & Não & 168 & 2 & 20,2 & 23,5 & 19,3 & 17,4 & 14,6 & 7,40 & 7,89 & 15,8 \\
\hline $\operatorname{dec} 16$ & Sim & 168 & 5 & 15,4 & 22,6 & 17,9 & 18,4 & 16,9 & 9,62 & 9,53 & 15,8 \\
\hline $\operatorname{dec} 13$ & Não & 168 & 5 & 18,3 & 24,1 & 18,1 & 17,4 & 15,5 & 8,60 & 8,38 & 15,8 \\
\hline $\operatorname{dec} 2$ & Não & 336 & 2 & 20,3 & 23,6 & 19,2 & 17,7 & 14,1 & 8,04 & 8,57 & 15,9 \\
\hline $\operatorname{dec} 14$ & Não & 336 & 5 & 18,6 & 24,7 & 17,9 & 17,7 & 15,0 & 9,01 & 9,08 & 16,0 \\
\hline $\operatorname{dec} 5$ & Sim & 336 & 2 & 19,2 & 22,9 & 19,5 & 17,8 & 15,3 & 8,99 & 8,95 & 16,1 \\
\hline $\operatorname{dec} 4$ & $\operatorname{Sim}$ & 168 & 2 & 19,2 & 23,1 & 19,8 & 17,7 & 15,7 & 8,28 & 9,09 & 16,1 \\
\hline
\end{tabular}

Tabela 3.27: RMSE dos 12 melhores métodos de preenchimento de dados omissos baseados em decomposição STL, selecionados de acordo com menor RMSE. Os resultados se referem a aplicação dos métodos a série de vazão de saída para o Norte de Peruibe.

\begin{tabular}{|c|c|c|c|c|c|c|c|c|c|c|c|c|c|}
\hline \multicolumn{6}{|c|}{ Experimentos de decomposição STL } & \multicolumn{8}{|c|}{ Quantidade de valores omissos em sequência } \\
\hline ID & $\begin{array}{l}\text { Interpolação } \\
\text { de } R_{t}\end{array}$ & $n_{(i)}$ & $n_{(e)}$ & $n_{(s)}$ & $c$ & 1 & 3 & 6 & 12 & 18 & 24 & 48 & Total \\
\hline st146 & $\mathrm{Sim}$ & 2 & 0 & 25 & 5 & 14,2 & 21,8 & 17,3 & 17,2 & 14,4 & 9,51 & 9,81 & 14,9 \\
\hline st147 & Sim & 2 & 0 & 37 & 5 & 14,6 & 20,1 & 18,2 & 17,3 & 14,9 & 10,44 & 11,33 & 15,3 \\
\hline st148 & Sim & 2 & 0 & 49 & 5 & 14,7 & 20,0 & 18,4 & 17,6 & 15,3 & 11,07 & 12,57 & 15,7 \\
\hline st128 & Sim & 2 & 0 & 25 & 3 & 16,1 & 23,9 & 20,0 & 17,2 & 14,2 & 9,37 & 9,24 & 15,7 \\
\hline st129 & $\mathrm{Sim}$ & 2 & 0 & 37 & 3 & 16,4 & 22,2 & 21,8 & 17,3 & 14,2 & 10,18 & 10,78 & 16,1 \\
\hline st137 & Não & 2 & 0 & 25 & 5 & 18,5 & 24,8 & 20,2 & 17,4 & 14,0 & 8,91 & 10,21 & 16,3 \\
\hline st119 & Não & 2 & 0 & 25 & 3 & 19,6 & 25,1 & 21,4 & 16,7 & 13,8 & 8,74 & 9,63 & 16,4 \\
\hline st110 & Sim & 2 & 0 & 25 & 2 & 18,1 & 23,7 & 21,5 & 17,2 & 16,3 & 9,28 & 9,08 & 16,4 \\
\hline st138 & Não & 2 & 0 & 37 & 5 & 18,5 & 23,9 & 20,3 & 17,5 & 14,0 & 9,73 & 11,76 & 16,5 \\
\hline st11 & Não & 2 & 0 & 25 & 2 & 20,3 & 24,9 & 22,1 & 16,5 & 14,2 & 8,36 & 9,36 & 16,5 \\
\hline st130 & $\mathrm{Sim}$ & 2 & 0 & 49 & 3 & 16,6 & 21,9 & 22,1 & 17,7 & 14,7 & 10,93 & 12,13 & 16,6 \\
\hline st152 & $\mathrm{Sim}$ & 1 & 10 & 25 & 5 & 19,2 & 25,5 & 20,2 & 17,5 & 14,5 & 9,64 & 10,48 & 16,7 \\
\hline
\end{tabular}

Tabela 3.28: RMSE dos métodos benchmark de preenchimento de dados omissos. Os resultados se referem a aplicação dos métodos a série de vazão de saída para o Norte de Peruíbe.

\begin{tabular}{|c|c|c|c|c|c|c|c|c|c|c|}
\hline \multicolumn{3}{|c|}{ Experimentos emphbenchmark } & \multicolumn{8}{|c|}{ Quantidade de valores omissos em sequência } \\
\hline ID & $\begin{array}{c}\text { Forma de } \\
\text { benchmark }\end{array}$ & Janela & 1 & 3 & 6 & 12 & 18 & 24 & 48 & Tota \\
\hline ben1 & Média & 168 & 38,1 & 40,6 & 41,3 & 37,8 & 35,6 & 29,9 & 31,3 & 36,4 \\
\hline ben 2 & Média & 336 & 37,8 & 40,4 & 40,9 & 38,4 & 35,4 & 30,1 & 31,3 & 36,3 \\
\hline ben 3 & Média & 720 & 38,3 & 40,2 & 40,9 & 39,3 & 35,4 & 30,7 & 31,8 & 36,6 \\
\hline ben 4 & Mediana & 168 & 38,9 & 42,2 & 42,3 & 38,6 & 36,6 & 30,9 & 31,9 & 37,4 \\
\hline ben 5 & Mediana & 336 & 38,8 & 42,1 & 41,7 & 38,7 & 36,4 & 30,9 & 32,0 & 37,2 \\
\hline ben6 & Mediana & 720 & 39,4 & 41,7 & 40,7 & 39,2 & 35,3 & 30,9 & 32,0 & 37,0 \\
\hline ben 7 & Interpolação & - & 14,6 & 23,1 & 26,4 & 46,7 & 42,9 & 41,2 & 36,9 & 33,1 \\
\hline
\end{tabular}

rentemente, usaram janela de tamanho menores e grau de polinômio igual a 5, sendo que o melhor procedimento de regressão para imputação de valores omissos foi o que usou polinômio de grau 5 modelando a tendência, com interpolação de $R_{t}$, sem sazonalidade semanal, janela de tamanho 168 e valor de corte $c=5$, apresentando um RMSE total igual a 15,222. Os parâmetros desse modelo de regressão foram os usados na aplicação do método de decomposição clássica. 
- Não se observa um padrão muito claro nos parâmetros dos melhores procedimentos de decomposição clássica de acordo com o RMSE total. O melhor procedimento foi aquele que usou decomposição sem interpolação de $R_{t}$, janela de tamanho 168 e valor de corte $c=3$, apresentando um RMSE total igual a 15,43 .

- Os tipos de decomposição STL que tiveram melhores resultados, de acordo com o RMSE total, foram os que possuem interpolação nos resíduos $R_{t}$, e que usaram decomposição STL não robusta $\left(n_{(i)}=2\right.$ e $\left.n_{(e)}=0\right)$. O melhor procedimento foi o de decomposição não robusta $\left(n_{(i)}=2\right.$ e $\left.n_{(e)}=0\right)$, com interpolação de $R_{t}, n_{(s)}=25$ e valor de corte $c=5$, apresentando um RMSE total igual a 14,883 .

- Dentre os métodos de benchmark, o que teve melhor desempenho foi o que interpola linearmente os valores da série, apresentando um RMSE total igual a 33,119. Verifica-se que os procedimentos propostos tiveram desempenhos bem superiores aos benchmarks.

- Dentre todos os experimentos, o que apresentou melhor resultado foi o procedimento de decomposição STL não robusta $\left(n_{(i)}=2\right.$ e $\left.n_{(e)}=0\right)$, com interpolação de $R_{t}, n_{(s)}=25$ e valor de corte $c=5$, apresentando um valor de RMSE total de 14,883. Este é o procedimento para o qual é apresentado uma análise de outliers na próxima subseção e que é usado oficialmente para preencher os valores omissos da série.

A Figura 3.14 exemplifica alguns experimentos de preenchimento de valores omissos. Cada gráfico representa um trecho da série temporal de vazão de saída para o Norte de Peruíbe no qual propositalmente foi removido uma sequência de valores. Todos os gráficos se referem a uma lacuna de tamanho 48 horas acompanhado de 12 valores anteriores e posteriores à lacuna principal. Os procedimentos de preenchimento adotados para ilustrar os gráficos são o melhor experimento, de acordo com o RMSE total, de cada tipo de procedimento apresentados nas tabelas 3.25 à 3.28.

Verifica-se que os procedimentos propostos conseguiram fazer uma boa estimativa dos valores omissos, sendo estas bem superiores às do método de interpolação. Esses resultados já eram esperados, pois a série de vazão de saída para o Norte de Peruíbe apresenta um comportamento sazonal bem característico, mesmo que esse comportamento tenha alguns momentos de notáveis diferenças entre o valor real e o estimado pelos métodos propostos. Vale observar no gráfico (C) que o método STL, além de preencher os valores omissos, conseguiu detectar e tratar o outlier que aparece no começo do dia $07 / 08 / 2017$.

\subsubsection{Detecção e tratamento de outliers}

As tabelas 3.29 e 3.30 mostram os resultados dos experimentos elaborados para avaliar o desempenho em detectar e tratar os outliers do melhor procedimento selecionado para a imputação dos valores omissos. A Tabela 3.29 apresenta as taxas de detecção dos outliers, sendo dividida em duas partes: na parte superior o cálculo das taxas considera todas as observações afetadas pelo efeito atípico, enquanto que na parte inferior é considerado apenas a observação mais afetada pelo efeito atípico. Vale lembrar que no caso do efeito atípico do tipo platô todas as observações foram consideradas como sendo as mais afetadas devido ao efeito se distribuir igualmente entre elas. Já a tabela 3.30 é destinada a verificar a acurácia do procedimento ao corrigir os valores dos outliers. Sua estrutura é análoga à da tabela 3.29, sendo que a linha total é o RMSE do efeito atípico nas observações. 
(A)

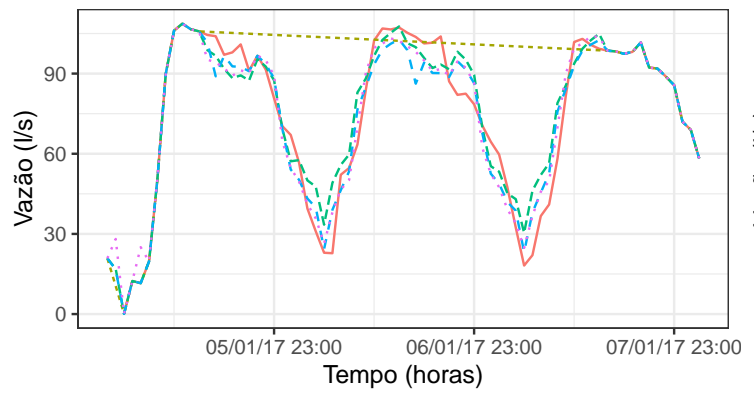

(C)

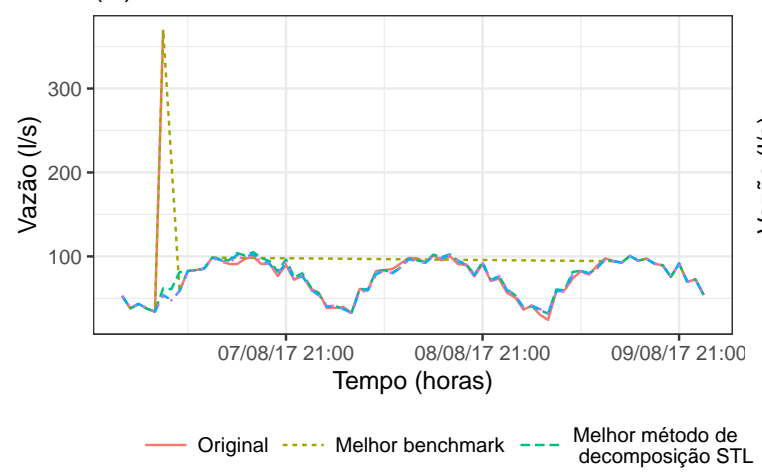

(B)

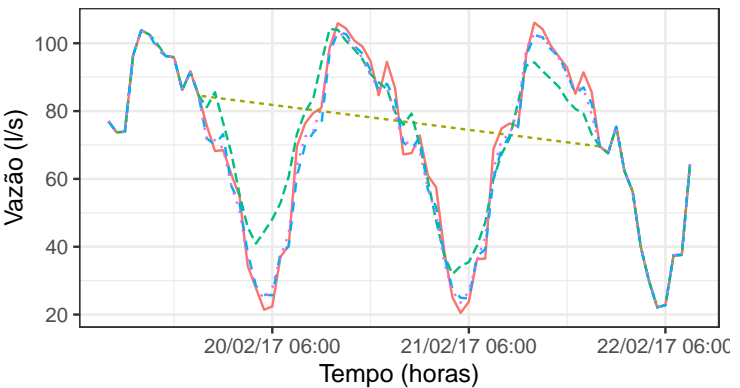

(D)

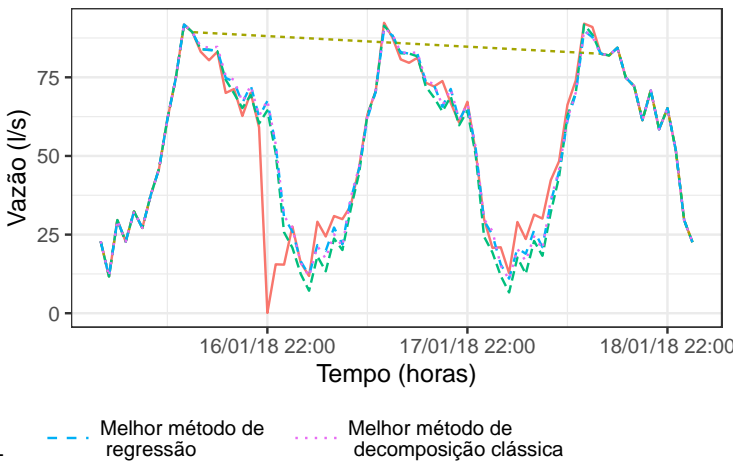

Figura 3.14: Alguns trechos da série de vazão de saída para o Norte de Peruíbe que exemplificam a aplicação dos procedimentos de preenchimento de valores omissos. É apresentado o melhor experimento de imputação de valores omissos de cada tipo de procedimento de acordo com o RMSE, descritos nas tabelas 3.25 à 3.28. A lacuna principal de valores omissos usada em cada gráfico foi inserida artificialmente na série temporal a fim de avaliar a performance dos procedimentos de preenchimento de valores omissos. O tamanho da lacuna principal é de 48 horas, sendo precedida e sucedida de 12 horas de valores originais.

A partir das tabelas, podemos verificar que:

- De modo geral, as taxas de detecção dos outliers foram altas para o tipo único e para os demais tipos de efeitos a taxa de detecção depende dos parâmetros do experimento. Quando se considera apenas as obsevações mais afetadas, as taxa de detecção foram bem altas, com exceção dos efeitos atípicos do tipo platô. Esses resultados são uma evidência da possível adequação do procedimento em detectar os outliers da série. Nota-se também que, para as observações mais afetadas, as altas taxas de detecção resultaram em um RMSE relativamente bom, conseguindo fazer uma redução expressiva em relação ao RMSE total, porém, o mesmo não pode ser dito quando se considera todas as observações afetadas pelos efeitos atípicos.

- O número de máximo de iterações possui, em geral, uma considerável influencia nos resultados. Com exceção do efeito do tipo único, a taxa de detecção dos experimentos que tiveram apenas uma iteração foi menor do que quando usadas iterações máximas iguais a 3 ou 5 . Porém, não há muita diferança entre usar um número máximo de iterações igual a 3 ou igual a 5 . Algo semelhante pode ser observado pelos valores de RMSE: o RMSE dos experimentos que usaram apenas uma iteração máxima foram maiores do aqueles que tiveram iterações máximas iguais a 3 ou 5. A semelhança dos resultados do uso de 3 e 5 iterações máximas pode ser explicado pelo algoritmo conseguir encontrar grande parte dos outliers antes de atingir número máximo de iterações, sendo necessário apenas uma baixa quantidade de iterações, isto é, um número menor ou igual a 3 , porém maior que 1 . 
Tabela 3.29: Taxa de deteç̧ão de outliers de acordo com o procedimento que apresentou melhor desempenho em preencher valores omissos. O procedimento foi o de decomposição $S T L$ não robusta $\left(n_{(i)}=2\right.$ e $\left.n_{(e)}=0\right)$, com interpolação de $R_{t}, n_{(s)}=25$ e valor de corte $c=5$. Variou-se o valor de corte $c$ e a quantidade de iterações máxima com o objetivo de verificar se a mudança desses parâmetros causam algum impacto na detecção dos outliers. A aplicação se refere a série de vazão de saída para o Norte de Peruíbe.

\begin{tabular}{|c|c|c|c|c|c|c|c|c|}
\hline \multicolumn{3}{|c|}{ Experimentos } & \multicolumn{6}{|c|}{ Tipo de efeitos atípicos } \\
\hline ID & c & $\begin{array}{l}\mathrm{N}^{\mathrm{O}} \text { máximo } \\
\text { de iterações }\end{array}$ & Único & Platô & Pulso & $\begin{array}{l}\text { C.D. } \\
\text { linear }\end{array}$ & $\begin{array}{c}\text { C.D. } \\
\text { exponencial }\end{array}$ & $\begin{array}{c}\text { C.D. } \\
\text { logaritmico }\end{array}$ \\
\hline \multicolumn{9}{|c|}{ Todas as observações afetadas } \\
\hline out1 & 2 & 1 & 1,000 & 0,409 & 0,370 & 0,399 & 0,400 & 0,390 \\
\hline out 2 & 3 & 1 & 1,000 & 0,216 & 0,280 & 0,277 & 0,276 & 0,258 \\
\hline out 3 & 4 & 1 & 0,967 & 0,107 & 0,193 & 0,175 & 0,204 & 0,160 \\
\hline out 4 & 5 & 1 & 0,867 & 0,065 & 0,139 & 0,114 & 0,133 & 0,104 \\
\hline out 5 & 2 & 3 & 1,000 & 0,665 & 0,573 & 0,604 & 0,618 & 0,604 \\
\hline out 6 & 3 & 3 & 1,000 & 0,443 & 0,446 & 0,443 & 0,455 & 0,433 \\
\hline out 7 & 4 & 3 & 1,000 & 0,228 & 0,327 & 0,301 & 0,321 & 0,258 \\
\hline out8 & 5 & 3 & 0,983 & 0,119 & 0,241 & 0,185 & 0,230 & 0,163 \\
\hline out9 & 2 & 5 & 1,000 & 0,673 & 0,575 & 0,613 & 0,628 & 0,615 \\
\hline out10 & 3 & 5 & 1,000 & 0,462 & 0,446 & 0,453 & 0,470 & 0,441 \\
\hline out11 & 4 & 5 & 1,000 & 0,241 & 0,329 & 0,304 & 0,324 & 0,267 \\
\hline out12 & 5 & 5 & 0,983 & 0,123 & 0,243 & 0,187 & 0,234 & 0,166 \\
\hline Total & - & - & 1,000 & 1,000 & 1,000 & 1,000 & 1,000 & 1,000 \\
\hline \multicolumn{9}{|c|}{ Somente observações mais afetadas } \\
\hline out1 & 2 & 1 & 1,000 & 0,409 & 1,000 & 0,895 & 0,962 & 0,829 \\
\hline out 2 & 3 & 1 & 1,000 & 0,216 & 1,000 & 0,790 & 0,867 & 0,714 \\
\hline out3 & 4 & 1 & 0,967 & 0,107 & 0,867 & 0,600 & 0,762 & 0,514 \\
\hline out 4 & 5 & 1 & 0,867 & 0,065 & 0,700 & 0,495 & 0,581 & 0,400 \\
\hline out 5 & 2 & 3 & 1,000 & 0,665 & 1,000 & 0,981 & 1,000 & 0,924 \\
\hline out 6 & 3 & 3 & 1,000 & 0,443 & 1,000 & 0,895 & 0,981 & 0,848 \\
\hline out 7 & 4 & 3 & 1,000 & 0,228 & 1,000 & 0,800 & 0,895 & 0,657 \\
\hline out 8 & 5 & 3 & 0,983 & 0,119 & 0,867 & 0,571 & 0,762 & 0,486 \\
\hline out 9 & 2 & 5 & 1,000 & 0,673 & 1,000 & 0,981 & 1,000 & 0,924 \\
\hline out10 & 3 & 5 & 1,000 & 0,462 & 1,000 & 0,895 & 0,981 & 0,848 \\
\hline out11 & 4 & 5 & 1,000 & 0,241 & 1,000 & 0,810 & 0,895 & 0,676 \\
\hline out12 & 5 & 5 & 0,983 & 0,123 & 0,867 & 0,571 & 0,762 & 0,486 \\
\hline Total & - & - & 1,000 & 1,000 & 1,000 & 1,000 & 1,000 & 1,000 \\
\hline
\end{tabular}

- Como o esperado, percebe-se claramente que o valor de corte $c$ influencia na taxa de deteç̧ão, sendo que quanto menor for valor de corte $c$, melhor é a taxa de detecção. Também verifica-se um melhor valor de RMSE para os valores mais baixos de $c$. Lembramos que, embora um valor de corte baixo aumente a taxa de detecção de outliers, ele também aumenta a taxa de detecção de valores que possivelmente não seriam outliers.

A Figura 3.15 exemplifica as constatações realizadas. É possível observar que os procedimentos conseguiram detectar e tratar somente as observações mais afetadas pelos efeitos atípicos.

A Tabela 3.31 apresenta a quantidade de anomalias detectadas em cada fase do tratamento dado a série de vazão de saída para o Norte de Peruíbe. Nota-se que a maior parte das observações anômalas foram detectadas durante a fase de limpeza primária, o que dá a quantidade de 2018 observações ou $11,5 \%$ do total. Durante todo o processo, foram detectadas 2708 (15,5 \%) observações anormais.

\subsubsection{Previsão}

A Tabela 3.32 traz os resultados de acurácia dos experimentos de previsão de acordo com RMSE. Ela é dividida em duas partes: a parte superior é dedicada a mostrar os resultados que usaram rolling windows de tamanho 336 horas (14 dias) e a parte inferior mostra os resultados referentes ao uso de rolling windows de tamanho 720 horas (30 dias). Os experimentos estão agrupados por tipo de modelos. A partir dessa tabela, verifica-se que:

- O melhor procedimento de previsão com modelos SARIMA, de acordo com o RMSE total, foi o que usou estratégia do tipo 2 e rolling windows de tamanho 336, apresentando RMSE total 
Tabela 3.30: RMSE do tratamento dos outliers de acordo com o procedimento que apresentou melhor desempenho em preencher valores omissos. O procedimento foi o de decomposição STL não robusta $\left(n_{(i)}=2\right.$ e $\left.n_{(e)}=0\right)$, com interpolação de $R_{t}, n_{(s)}=25$ e valor de corte $c=5$. Variou-se o valor de corte $c$ e a quantidade de iterações máxima com o objetivo de verificar se a mudança desses parâmetros causam algum impacto na detecção dos outliers. A linha total é o RMSE das observações ouliers em relação ao seu valor original. A aplicação se refere a série de vazão de saída para o Norte de Peruibe.

\begin{tabular}{|c|c|c|c|c|c|c|c|c|}
\hline \multicolumn{3}{|c|}{ Experimentos } & \multicolumn{6}{|c|}{ Tipo de efeitos atípicos } \\
\hline ID & c & $\begin{array}{l}\mathrm{N}^{0} \text { máximo } \\
\text { de iterações }\end{array}$ & Único & Platô & Pulso & $\begin{array}{l}\text { C.D. } \\
\text { linear }\end{array}$ & $\begin{array}{c}\text { C.D. } \\
\text { exponencial }\end{array}$ & $\begin{array}{c}\text { C.D. } \\
\text { logaritmico }\end{array}$ \\
\hline \multicolumn{9}{|c|}{ Todas as observações afetadas } \\
\hline out1 & 2 & 1 & 13,9 & 61,5 & 46,9 & 54,6 & 53,1 & 56,2 \\
\hline out2 & 3 & 1 & 13,6 & 69,2 & 49,0 & 59,9 & 59,5 & 62,1 \\
\hline out3 & 4 & 1 & 16,3 & 73,0 & 54,7 & 65,2 & 63,2 & 65,9 \\
\hline out4 & 5 & 1 & 25,7 & 75,3 & 58,7 & 67,7 & 66,5 & 68,4 \\
\hline out5 & 2 & 3 & 13,9 & 55,7 & 40,1 & 45,3 & 42,8 & 46,8 \\
\hline out6 & 3 & 3 & 13,6 & 63,0 & 43,7 & 53,1 & 50,0 & 54,5 \\
\hline out7 & 4 & 3 & 10,6 & 69,2 & 49,3 & 60,7 & 57,5 & 62,7 \\
\hline out8 & 5 & 3 & 12,9 & 73,3 & 53,6 & 64,9 & 62,3 & 66,3 \\
\hline out9 & 2 & 5 & 13,9 & 55,2 & 39,9 & 44,4 & 41,7 & 46,4 \\
\hline out 10 & 3 & 5 & 13,6 & 62,6 & 43,6 & 52,7 & 49,0 & 54,1 \\
\hline out11 & 4 & 5 & 10,6 & 69,0 & 49,2 & 60,6 & 57,3 & 62,4 \\
\hline out12 & 5 & 5 & 12,9 & 73,1 & 53,4 & 64,8 & 62,0 & 66,2 \\
\hline Total & - & - & 118,3 & 78,9 & 74,1 & 77,8 & 83,5 & 76,1 \\
\hline \multicolumn{9}{|c|}{ Somente observações mais afetadas } \\
\hline out1 & 2 & 1 & 13,9 & 61,5 & 32,5 & 61,6 & 61,0 & 61,8 \\
\hline out 2 & 3 & 1 & 13,6 & 69,2 & 34,8 & 70,1 & 73,1 & 71,5 \\
\hline out3 & 4 & 1 & 16,3 & 73,0 & 48,5 & 81,1 & 80,1 & 79,8 \\
\hline out4 & 5 & 1 & 25,7 & 75,3 & 60,6 & 87,6 & 90,0 & 85,7 \\
\hline out 5 & 2 & 3 & 13,9 & 55,7 & 30,3 & 50,5 & 47,7 & 50,5 \\
\hline out 6 & 3 & 3 & 13,6 & 63,0 & 33,9 & 61,0 & 59,4 & 61,5 \\
\hline out7 & 4 & 3 & 10,6 & 69,2 & 39,6 & 73,2 & 71,7 & 74,7 \\
\hline out 8 & 5 & 3 & 12,9 & 73,3 & 51,4 & 82,8 & 81,9 & 83,0 \\
\hline out9 & 2 & 5 & 13,9 & 55,2 & 30,3 & 49,4 & 46,4 & 50,3 \\
\hline out10 & 3 & 5 & 13,6 & 62,6 & 33,9 & 60,9 & 58,3 & 61,0 \\
\hline out11 & 4 & 5 & 10,6 & 69,0 & 39,6 & 72,9 & 71,3 & 74,2 \\
\hline out12 & 5 & 5 & 12,9 & 73,1 & 51,4 & 82,7 & 81,3 & 82,7 \\
\hline Total & - & - & 118,3 & 78,9 & 130,3 & 121,9 & 147,4 & 110,8 \\
\hline
\end{tabular}

Tabela 3.31: Quantidade de valores detectados como anomalias em cada estágio de tratamento da série de vazão de saída para o Norte de Peruibe. A primeira linha da tabela se refere a quantidade de valores classificados pelo sistema da Sabesp como bad e que, portanto, eram omissos na série original. A segunda linha se refere aos valores detectados como anomalias pela limpeza primária. A terceira linha se refere a quantidade de valores detectados como outliers pela aplicação do algoritmo proposto.

\begin{tabular}{rrrrr}
\hline Fase de deteção de anomalias & Frequência absoluta & Frequência relativa & Acumulado absoluto & Acumulado relativo \\
\hline Originalmente & 206 & $1,2 \%$ & 206 & $1,2 \%$ \\
Limpeza primária & 2.018 & $11,5 \%$ & 2.224 & $12,7 \%$ \\
Algoritmo de deteção de outliers & 484 & $2,8 \%$ & 2.708 & $15,5 \%$ \\
Tamanho da série & 17.519 & $100 \%$ & 20.227 & $100 \%$ \\
\hline
\end{tabular}

de 22,503. Vale notar que a estratégia de tipo 2 teve um desempenho bem superior do que a de tipo 1 no uso de rolling window de tamanho 336, o que é um resultado um tanto inusitado, já que o esperado era que o desempenho de um modelo identificado usando as observações da própria rolling window fosse superior àquele que usasse as observações de uma outra rolling window para se fazer tal identificação.

- O melhor procedimento de regressão com erros autocorrelacionados, de acordo com o RMSE total, foi o que usou polinômio de grau 1 modelando a tendência, sem sazonalidade semanal, com o uso da estratégia do tipo 2 para os erros SARIMA e rolling windows de tamanho 336, apresentando RMSE total de 20,033. É importante notar que nem todos os experimentos conseguiram ajustar determinado modelo em todas as rollings windows, o que pode ser um empecilho a mais na hora de fazer comparações.

- Dentre os procedimentos BATS e TBATS, o que teve melhor desempenho de acordo com o 
(A) Único

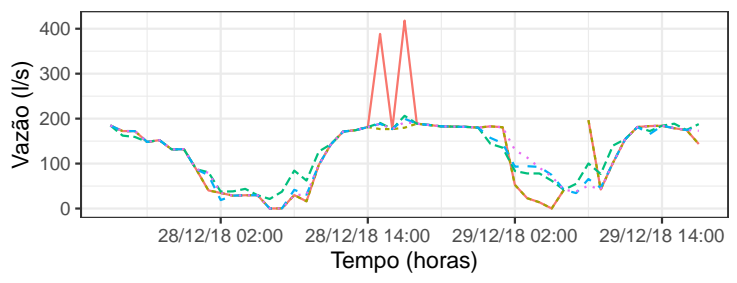

(C) Pulso

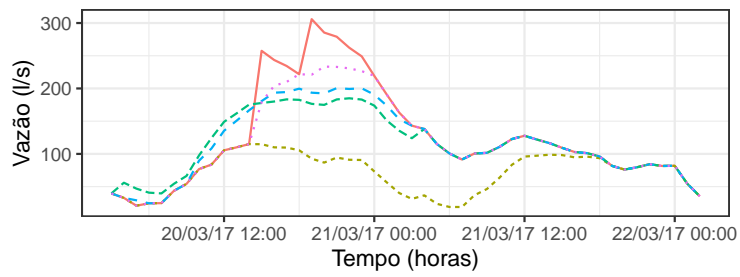

(E) C.D. Exponencial

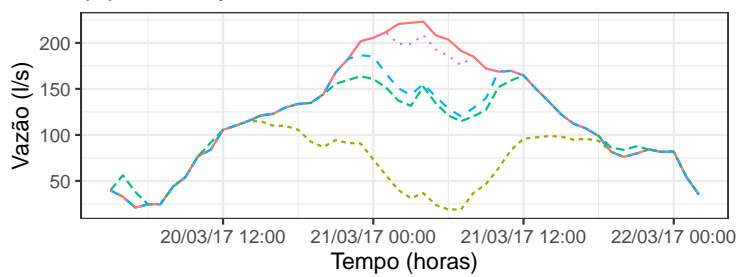

(B) Platô

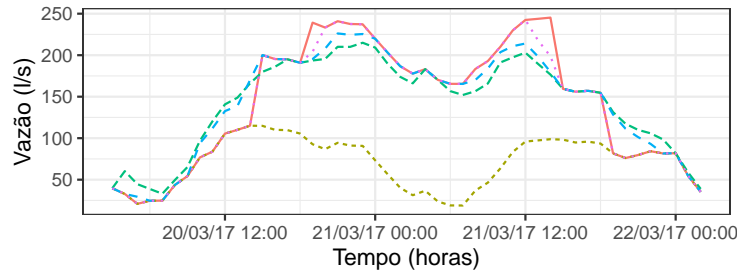

(D) C.D. Linear

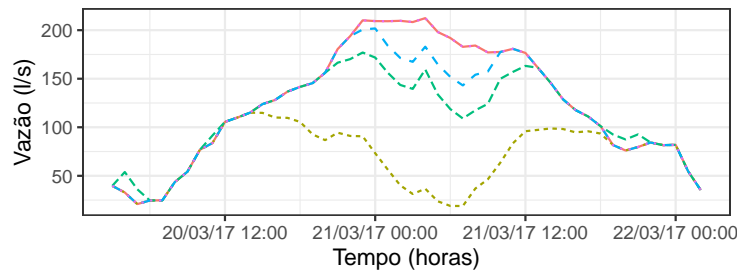

(F) C.D. Logaritmico

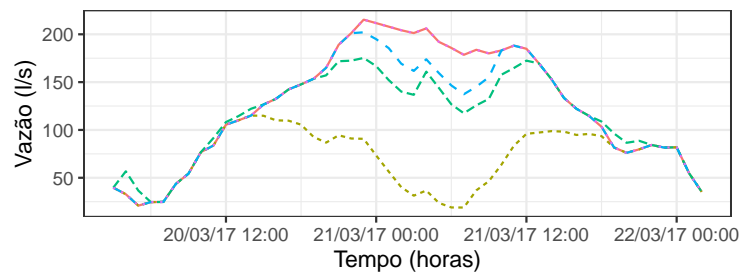

- Série com Outlier $\quad \ldots$.... Original --- Corte $=2-\ldots$ Corte $=3 \cdots$ Corte $=5$

Figura 3.15: Exemplos de detecção e tratamento dos outliers inseridos na série de vazão de saída para o Norte de Peruibe. Os trechos mostrados possuem tamanho 48 e são centrados nas observações afetadas pelo efeito atipico. Os gráficos de $(A)$ a $(F)$ exemplificam cada tipo de efeito atípico na série. A quantidade de iteração máxima dos experimentos selecionados é 3.

RMSE total foi o que usou modelos BATS sem sazonalidade semanal e com rolling windows de tamanho 720, apresentando RMSE total de 26,14. Para ambos os procedimentos BATS e TBATS o uso de sazonalidade semanal não melhorou significativamente o desempenho dos modelos.

- Aparentemente não há muita diferença de desempenho entre usar rolling windows de tamanho 336 ou 720, pois alguns experimentos que tiveram bom resultado usando rolling windows de tamanho 336 foram piores com as de tamanho 720 (em geral, os de regresão tiveram pior desempenho), enquanto que outros que tiveram mau resultado usando rolling windows de tamanho 336 foram melhores com as de tamanho 720 .

- Alguns experimentos que empregaram a estratégia do tipo 2 tiveraram um valor de $N<30$. Isso é explicado pelo fato da estratégia consistir em identificar o modelo usando as observações de apenas de uma rolling windows e depois só reestimar os parâmetros nas damais, visto que, ao se fazer esse procedimento, corre-se o risco do modelo não ser "estimátivel"(raízes próximas do polinomio autoregressivo ou de médias móveis bem próximas ou dentro do circulo unitário). Assim, mesmo nas situações em que procedimento do tipo 2 teve um desempenho melhor, é preferivel escolher o do tipo 1, já que a diferença de desempenho entre eles não é muito discrepante.

- De modo geral, os métodos de previsão propostos tiveram desempenhos bem superiores aos métodos benchmark, mostrando, assim, uma possível adequabilidade dos modelos propostos. 
Tabela 3.32: RMSE dos experimentos de previsão aplicados a série de vazão de saída para o Norte de Peruíbe. As estratégias de tipo 1 se referem a aplicação do algoritmo de seleção de modelo em cada uma das rollings windows, enquanto que as de tipo 2 se referem a aplicação do algoritmo somente na primeira rolling window e do ajuste modelo selecionado nas demais rolling windows, reestimando os parâmetros. $O R M S E$ "Todos"é calculado usando todos os valores preditos de horizonte $h=1, \ldots ., 168$, incluido aqueles que não aparecem na tabela.

\begin{tabular}{|c|c|c|c|c|c|c|c|c|c|c|c|c|c|c|}
\hline \multicolumn{4}{|c|}{ Experimentos } & \multicolumn{11}{|c|}{ Horizonte de previsão } \\
\hline Modelos & $\begin{array}{c}\text { Grau do } \\
\text { polinô- } \\
\text { mio }\end{array}$ & $\begin{array}{l}\text { Sazonalidade } \\
\text { semanal }\end{array}$ & $\begin{array}{c}\text { Estratégia } \\
\text { de ajuste }\end{array}$ & $\mathrm{N}$ & 1 & 2 & 3 & 6 & 12 & 18 & 24 & 48 & 168 & Todos \\
\hline \multicolumn{15}{|c|}{ Rolling windows de tamanho 336} \\
\hline \multirow{2}{*}{ SARIMA } & - & - & Tipo 1 & 30 & 12,21 & 14,9 & 13,4 & 16,3 & 25,5 & 18,91 & 21,2 & 32,9 & 53,8 & 35,4 \\
\hline & - & - & Tipo 2 & 30 & 12,22 & 14,7 & 12,4 & 15,9 & 25,8 & 16,54 & 18,3 & 27,9 & 21,7 & 22,5 \\
\hline \multirow{8}{*}{$\begin{array}{c}\text { Regressão } \\
\text { com erros } \\
\text { SARIMA }\end{array}$} & 0 & $\operatorname{Sim}$ & Tipo 1 & 30 & 12,46 & 14,3 & 12,0 & 19,1 & 24,3 & 14,25 & 18,4 & 19,2 & 23,5 & 22,4 \\
\hline & 0 & $\operatorname{Sim}$ & Tipo 2 & 19 & 13,65 & 15,0 & 12,4 & 23,2 & 28,4 & 12,23 & 20,9 & 27,4 & 31,0 & 31,5 \\
\hline & 1 & $\operatorname{Sim}$ & Tipo 1 & 30 & 12,63 & 14,7 & 12,4 & 17,7 & 23,8 & 16,00 & 16,0 & 22,3 & 20,4 & 21,6 \\
\hline & 1 & $\operatorname{Sim}$ & Tipo 2 & 24 & 9,32 & 11,6 & 12,5 & 17,5 & 16,8 & 18,50 & 19,2 & 23,6 & 20,4 & 22,5 \\
\hline & 0 & Não & Tipo 1 & 30 & 12,44 & 13,6 & 11,3 & 14,8 & 22,9 & 12,82 & 13,4 & 14,9 & 20,1 & 20,7 \\
\hline & 0 & Não & Tipo 2 & 14 & 13,74 & 14,4 & 10,9 & 20,0 & 23,6 & 9,51 & 17,7 & 23,9 & 32,2 & 27,8 \\
\hline & 1 & Não & Tipo 1 & 30 & 12,70 & 13,8 & 11,6 & 15,9 & 23,8 & 14,37 & 12,5 & 20,5 & 19,6 & 20,4 \\
\hline & 1 & Não & Tipo 2 & 27 & 13,61 & 14,8 & 13,5 & 18,1 & 18,5 & 18,15 & 16,2 & 21,4 & 18,0 & 20,0 \\
\hline \multirow{2}{*}{ BATS } & - & Não & Tipo 1 & 30 & 12,49 & 16,1 & 15,0 & 20,4 & 21,1 & 25,76 & 23,6 & 34,1 & 25,3 & 27,6 \\
\hline & - & $\mathrm{Sim}$ & Tipo 1 & 30 & 35,44 & 28,4 & 28,2 & 17,1 & 33,2 & 25,65 & 18,7 & 19,9 & 29,9 & 27,3 \\
\hline \multirow[b]{2}{*}{ TBATS } & - & Não & Tipo 1 & 30 & 12,97 & 16,4 & 16,3 & 20,4 & 26,3 & 24,71 & 21,9 & 33,1 & 21,3 & 27,1 \\
\hline & - & Sim & Tipo 1 & 30 & 12,49 & 18,5 & 20,5 & 24,3 & 29,6 & 39,42 & 36,7 & 47,7 & 53,3 & 47,7 \\
\hline \multirow{3}{*}{ Benchmark } & - & - & Média & 30 & 38,13 & 41,7 & 29,8 & 46,3 & 37,1 & 44,87 & 24,0 & 24,4 & 28,4 & 41,0 \\
\hline & - & - & Mediana & 30 & 37,85 & 41,1 & 32,6 & 52,3 & 40,0 & 41,66 & 23,7 & 21,9 & 28,0 & 42,4 \\
\hline & - & - & Ûlt. Obs. & 30 & 18,56 & 30,4 & 36,9 & 66,2 & 55,4 & 34,64 & 27,0 & 37,7 & 26,3 & 51,3 \\
\hline \multicolumn{15}{|c|}{ Rolling windows de tamanho 720} \\
\hline \multirow{2}{*}{ SARIMA } & - & - & Tipo 1 & 30 & 9,07 & 12,1 & 11,8 & 15,1 & 24,6 & 25,08 & 18,5 & 36,6 & 43,0 & 27,3 \\
\hline & - & - & Tipo 2 & 29 & 10,37 & 11,4 & 11,3 & 15,3 & 23,5 & 23,35 & 15,7 & 31,0 & 38,2 & 24,5 \\
\hline \multirow{8}{*}{$\begin{array}{c}\text { Regressão } \\
\text { com erros } \\
\text { SARIMA }\end{array}$} & 0 & $\operatorname{Sim}$ & Tipo 1 & 30 & 10,45 & 11,8 & 11,7 & 18,1 & 24,5 & 19,87 & 15,5 & 26,8 & 34,4 & 23,6 \\
\hline & 0 & $\operatorname{Sim}$ & Tipo 2 & 25 & 9,12 & 12,2 & 11,3 & 17,3 & 18,5 & 17,20 & 14,3 & 28,1 & 37,9 & 25,1 \\
\hline & 1 & $\operatorname{Sim}$ & Tipo 1 & 30 & 10,62 & 12,5 & 12,4 & 18,5 & 26,3 & 24,08 & 18,2 & 26,8 & 44,5 & 27,5 \\
\hline & 1 & $\operatorname{Sim}$ & Tipo 2 & 22 & 7,21 & 13,2 & 13,3 & 20,2 & 29,5 & 27,65 & 19,4 & 33,4 & 40,9 & 28,8 \\
\hline & 0 & Não & Tipo 1 & 30 & 10,38 & 11,7 & 11,9 & 18,3 & 24,3 & 20,35 & 15,6 & 29,0 & 33,9 & 23,7 \\
\hline & 0 & Não & Tipo 2 & 24 & 10,48 & 12,2 & 11,5 & 18,3 & 18,2 & 18,31 & 14,7 & 30,3 & 38,5 & 24,8 \\
\hline & 1 & Não & Tipo 1 & 30 & 10,72 & 12,5 & 12,6 & 19,0 & 26,4 & 24,85 & 18,5 & 28,6 & 45,5 & 27,7 \\
\hline & 1 & Não & Tipo 2 & 21 & 7,60 & 13,4 & 13,7 & 20,7 & 30,1 & 29,04 & 20,3 & 36,0 & 41,9 & 29,0 \\
\hline \multirow{2}{*}{ BATS } & - & Não & Tipo 1 & 30 & 11,60 & 11,8 & 11,7 & 17,0 & 27,0 & 23,43 & 16,9 & 29,4 & 40,9 & 26,1 \\
\hline & - & $\operatorname{Sim}$ & Tipo 1 & 30 & 14,75 & 19,3 & 19,3 & 21,4 & 29,3 & 22,91 & 18,1 & 28,5 & 37,6 & 27,2 \\
\hline \multirow{2}{*}{ TBATS } & - & Não & Tipo 1 & 30 & 12,04 & 14,7 & 17,2 & 22,8 & 27,8 & 22,83 & 15,8 & 30,3 & 40,0 & 26,8 \\
\hline & - & $\mathrm{Sim}$ & Tipo 1 & 30 & 13,15 & 15,0 & 17,0 & 21,5 & 29,0 & 20,59 & 14,0 & 29,8 & 40,4 & 28,4 \\
\hline \multirow{3}{*}{ Benchmark } & - & - & Média & 30 & 28,13 & 36,4 & 33,1 & 49,4 & 36,1 & 44,41 & 28,6 & 34,1 & 36,8 & 40,9 \\
\hline & - & - & Mediana & 30 & 25,94 & 32,9 & 32,3 & 53,7 & 38,3 & 41,03 & 24,9 & 32,4 & 36,4 & 41,8 \\
\hline & - & - & Últ. Obs. & 30 & 17,41 & 24,7 & 33,0 & 66,7 & 48,9 & 37,50 & 19,5 & 34,4 & 43,3 & 47,7 \\
\hline
\end{tabular}

- Dentre todos os procedimentos de previsão propostos, o melhor foi o que usou modelos de regressão com erros autocorrelacionados, com polinômio de grau 1 modelando a tendência, sem sazonalidade semanal, com o uso da estratégia do tipo 2 para os erros SARIMA e com rolling windows de tamanho 336, apresentando o valor de RMSE total de 20,033. Se excluírmos os procedimentos de previsão que usaram a estratégia do tipo 2 , temos que o melhor procedimento foi o que usou modelos de regressão com erros autocorrelacionados, com polinômio de grau 1 modelando a tendência, sem sazonalidade semanal e com rolling windows de tamanho 336, apresentando um RMSE total de 20,417.

Os bons resultados de previsão podem ser explicados por um comportamento regular que a série apresenta em quase toda a sua extensão, sendo, muitas vezes, uma sazonalidade bem definida. Tal constatação pode ser observada na Figura 3.16, na qual são mostrados alguns exemplos de previsão para cada tipo de modelo que reforçam as constatações realizadas.

Para a elaboração dos gráficos da Figura 3.16, decidiu-se não selecionar as previsões que usaram a estratégia do tipo 2, por tal método nem sempre conseguir estimar os parâmetros dos modelos, o que acaba resultando no uso de uma quantidade menor de rolling windows. Assim, as previsões SARIMA se referem ao uso de estratégia do tipo 1 e rolling windows de tamanho 720; as de regressão 
(A)

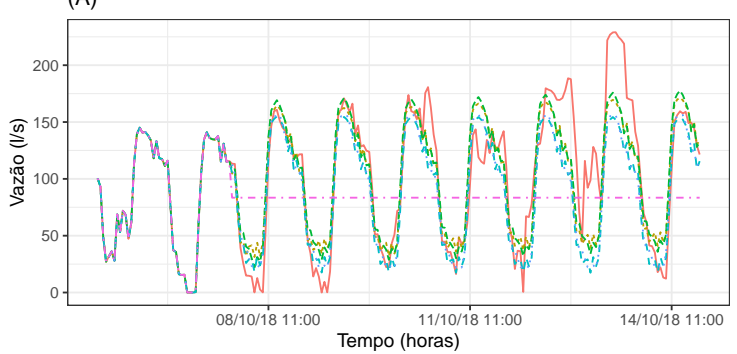

(C)

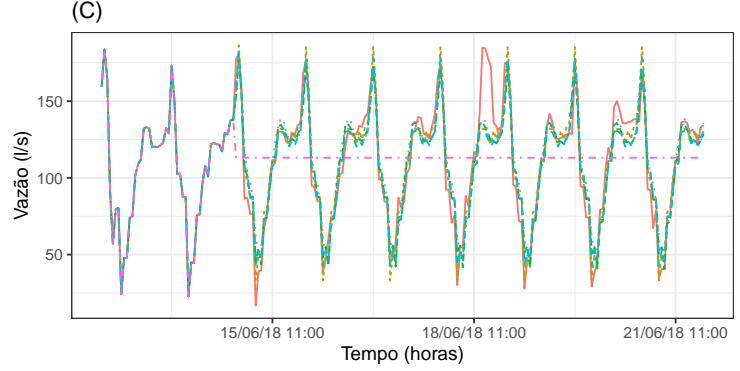

(B)

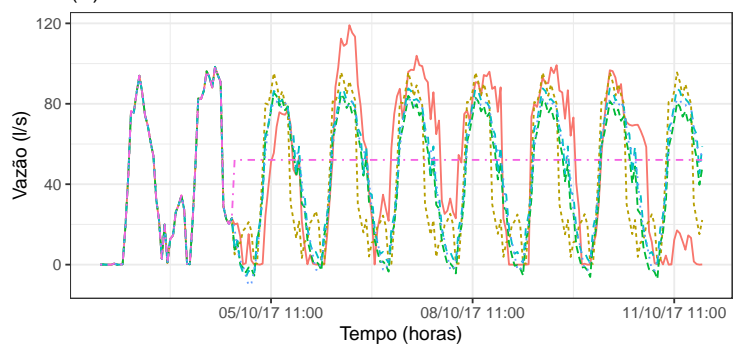

(D)

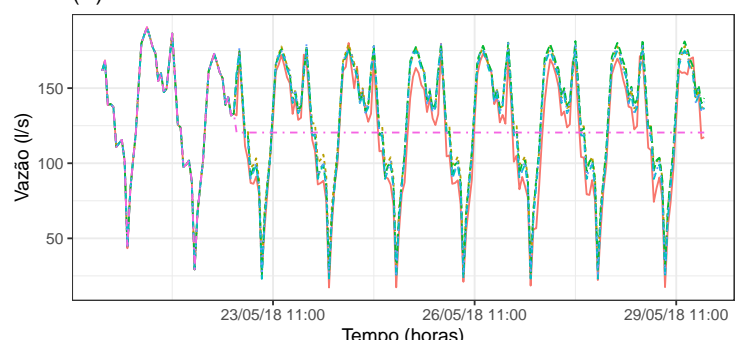

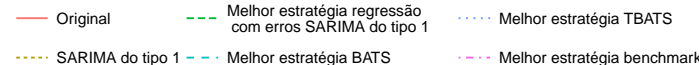

Figura 3.16: Alguns trechos da série de vazão de saída para o Norte de Peruíbe que exemplificam a aplicação dos modelos de previsão. São apresentados o melhor procedimento de ajuste de cada família de modelos, de acordo com o melhor RMSE de previsão, para os dois tamanhos de rolling window descritos na tabela 3.32. Para a seleção dos procedimentos, exluiu-se os que utilizaram a estratégia de tipo 2. Os gráficos exibem 48 horas da série seguidas de 168 horas de previsão. Os gráficos da esquerda se referem aos ajustes que usaram rolling windows de tamanho 336, já os da direita, de tamanho 720

com erros autocorrelacionados se referem ao uso de polinômio de grau 1 modelando a tendência, sem sazonalidade semanal, com o uso da estratégia do tipo 1 para os erros SARIMA e rolling windows de tamanho 336; as previsões BATS se referem ao uso de modelos sem sazonalidade semanal e rolling windows de tamanho 720; as previsões TBATS se referem ao uso de modelos sem sazonalidade semanal e rolling windows de tamanho 720 e as previsões benchmark se referem ao uso da média e rolling windows de tamanho 720.

\subsection{Vazão de saída do reservatório para o Sul de Peruíbe}

Nesta seção é apresentado e discutido os resultados das aplicações dos procedimentos de imputação de valores omissos e detecção de outliers e dos métodos de previsão relacionados a série de vazão de saída para o Sul de Peruíbe. A Figura 3.17 exibe um trecho da série que exemplifica seu comportamento. O gráfico (A) se refere a série original, enquanto que o gráfico (B) é mesmo trecho após limpeza e aplicação do métodos de deteç̧ão de outlier e preenchimento de valores omissos.

O método escolhido para a detecção de outliers e preenchimentos dos valores omissos, por possuir o menor RMSE total entre todos os experimentos realizados, com o valor de 18,483, foi o ajuste de curvas de regressão com polinômio de grau 5 modelando a tendência, com interpolação de $R_{t}$, sem sazonalidade semanal, janela de tamanho 336 e valor de corte $c=5$. O total de valores classificados como anomalias após aplicação do método selecionado foi de 4278 (24,4 \%), vis-à-vis à quantidade de $4182(23,9 \%)$ após a limpeza primária e à quantidade original de $207(1,18 \%)$. Em relação a previsão, o método que apresentou melhor desempenho nos experimentos foi o que 
(A) Trecho da série original

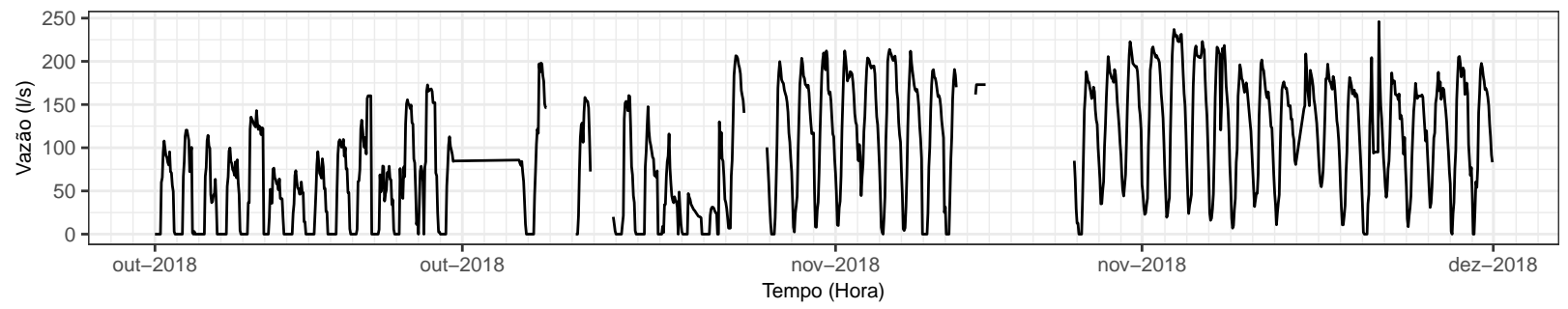

(B) Trecho da série após limpeza e preenchimento de valores omissos

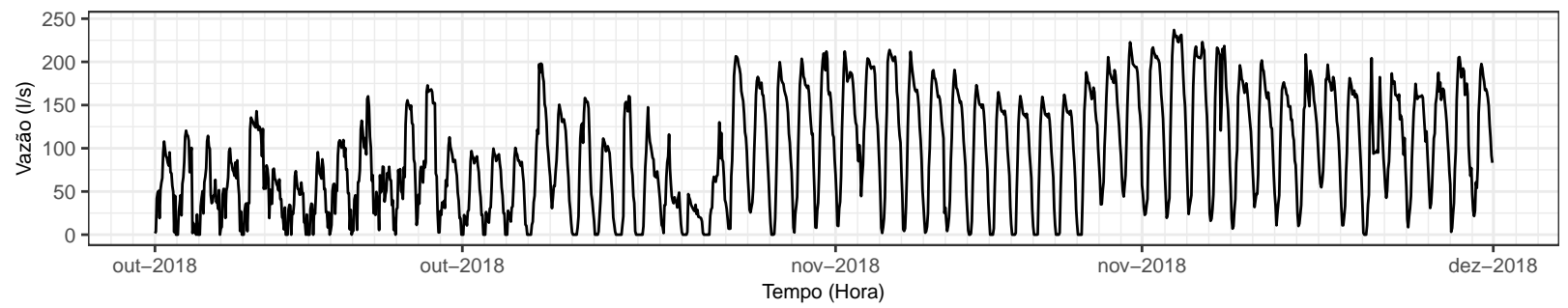

Figura 3.17: Trecho da série de vazão de saída para o Sul de Peruibe que exemplificam seu comportamento. O gráfico (A) é referente a série original e o gráfico (B) mostra a série após as limpezas, tratamento dos outliers detectados e preenchimento dos valores omissos de acordo com o método escolhido.

usou modelos de regressão com erros autocorrelacionados, com polinômio de grau 0 modelando a tendência, sem sazonalidade semanal, com o uso da estratégia do tipo 1 para os erros SARIMA e com rolling windows de tamanho 336, apresentando o valor de RMSE total de 25,156. De modo geral, os resultados mostram uma boa adequabilidade dos métodos propostos a série temporal de vazão de saída para o Sul de Peruíbe.

As próximas subseções apresentam e discutem os resultados de forma mais detalhada.

\subsubsection{Preenchimento de valores omissos}

As tabelas 3.33 à 3.35 mostram os resultados dos 12 melhores experimentos de cada tipo de procedimento de preenchimento de valores omissos, usando como medida de avaliação o RMSE. Em todas as tabelas os experimentos são apresentados em ordem decrescente de RMSE. Já a tabela 3.36 apresenta os resultados dos procedimentos de preenchimento de valores omissos usados como benchmark. Nesta, os experimentos são ordenados pelo ID.

Tabela 3.33: RMSE dos 12 melhores métodos de preenchimento de dados omissos baseados no ajuste de modelos de regressão, selecionados de acordo com menor RMSE. Os resultados se referem a aplicação dos métodos a série de vazão de saída para o Sul de Peruíbe.

\begin{tabular}{|c|c|c|c|c|c|c|c|c|c|c|c|c|c|}
\hline \multicolumn{6}{|c|}{ Experimentos de regressão } & \multicolumn{8}{|c|}{ Quantidade de valores omissos em sequência } \\
\hline ID & $\begin{array}{l}\text { Interpolação } \\
\text { de } R_{t}\end{array}$ & $\begin{array}{c}\text { Dia da } \\
\text { semana }\end{array}$ & $\begin{array}{l}\text { Grau do } \\
\text { polinômio }\end{array}$ & Janela & $c$ & 1 & 3 & 6 & 12 & 18 & 24 & 48 & Total \\
\hline reg98 & Sim & Sim & 5 & 336 & 5 & 13,8 & 10,7 & 16,7 & 21,4 & 20,6 & 22,4 & 23,8 & 18,5 \\
\hline reg62 & Sim & Sim & 5 & 336 & 3 & 16,1 & 11,1 & 16,8 & 21,2 & 20,6 & 19,9 & 23,9 & 18,5 \\
\hline reg95 & $\operatorname{Sim}$ & Sim & 2 & 336 & 5 & 13,1 & 10,7 & 17,2 & 22,1 & 21,1 & 22,2 & 23,5 & 18,6 \\
\hline reg92 & Sim & Sim & 1 & 336 & 5 & 13,0 & 11,0 & 17,3 & 21,8 & 20,8 & 22,3 & 23,6 & 18,6 \\
\hline $\operatorname{reg} 59$ & Sim & Sim & 2 & 336 & 3 & 16,7 & 11,6 & 16,8 & 21,1 & 20,5 & 20,1 & 23,2 & 18,6 \\
\hline reg107 & Sim & Sim & 5 & 336 & 5 & 13,0 & 11,0 & 16,7 & 21,5 & 20,6 & 23,3 & 25,5 & 18,8 \\
\hline reg104 & $\operatorname{Sim}$ & Sim & 2 & 336 & 5 & 13,0 & 10,9 & 16,6 & 22,3 & 20,7 & 23,0 & 24,8 & 18,8 \\
\hline reg68 & $\mathrm{Sim}$ & Sim & 2 & 336 & 3 & 16,5 & 13,0 & 16,8 & 21,3 & 21,3 & 20,1 & 23,1 & 18,9 \\
\hline $\operatorname{reg} 56$ & Sim & Sim & 1 & 336 & 3 & 16,1 & 11,6 & 18,2 & 21,5 & 20,4 & 20,1 & 24,4 & 18,9 \\
\hline reg 65 & Sim & $\mathrm{Sim}$ & 1 & 336 & 3 & 14,8 & 12,8 & 17,4 & 21,3 & 21,0 & 20,6 & 24,6 & 18,9 \\
\hline reg71 & Sim & $\mathrm{Sim}$ & 5 & 336 & 3 & 17,0 & 13,3 & 17,1 & 21,3 & 20,9 & 20,0 & 23,8 & 19,1 \\
\hline reg32 & Sim & Sim & 2 & 336 & 2 & 17,0 & 13,3 & 18,0 & 21,3 & 20,9 & 20,6 & 22,7 & 19,1 \\
\hline
\end{tabular}


Tabela 3.34: RMSE dos 12 melhores métodos de preenchimento de dados omissos baseados no ajuste de modelo de regressão acompanhado de decomposições clássica, selecionados de acordo com menor RMSE. O modelo de regressão usado em conjundo com a decomposição clássica, por apresentar menor RMSE, foi o que possui polinômio de grau 5, com interpolação dos resíduos, sem sazonalidade semanal e janela de tamanho 336. Os resultados se referem a aplicação dos métodos a série de vazão de saída para o Sul de Peruibe.

\begin{tabular}{|c|c|c|c|c|c|c|c|c|c|c|c|}
\hline \multicolumn{4}{|c|}{ Experimentos de decomposição clássica } & \multicolumn{8}{|c|}{ Quantidade de valores omissos em sequência } \\
\hline ID & $\begin{array}{l}\text { Interpolação } \\
\text { de } R_{t}\end{array}$ & Janela & $c$ & 1 & 3 & 6 & 12 & 18 & 24 & 48 & Total \\
\hline $\operatorname{dec} 16$ & Sim & 168 & 5 & 13,6 & 10,9 & 17,7 & 21,7 & 19,7 & 23,4 & 24,5 & 18,8 \\
\hline $\operatorname{dec} 7$ & Não & 168 & 3 & 17,9 & 13,1 & 18,6 & 21,1 & 19,7 & 19,0 & 23,4 & 19,0 \\
\hline $\operatorname{dec} 13$ & Não & 168 & 5 & 17,0 & 13,3 & 18,4 & 21,2 & 19,7 & 20,9 & 23,2 & 19,1 \\
\hline $\operatorname{dec} 10$ & Sim & 168 & 3 & 15,9 & 12,3 & 17,4 & 21,5 & 20,4 & 21,0 & 25,3 & 19,1 \\
\hline $\operatorname{dec} 4$ & Sim & 168 & 2 & 17,3 & 12,4 & 17,8 & 20,3 & 18,8 & 20,1 & 27,5 & 19,2 \\
\hline $\operatorname{dec} 17$ & Sim & 336 & 5 & 13,5 & 10,7 & 16,9 & 22,0 & 21,8 & 25,6 & 25,7 & 19,5 \\
\hline $\operatorname{dec} 11$ & Sim & 336 & 3 & 15,9 & 12,2 & 16,9 & 21,6 & 21,7 & 22,7 & 25,6 & 19,5 \\
\hline $\operatorname{dec} 1$ & Não & 168 & 2 & 18,7 & 13,8 & 18,7 & 20,6 & 19,0 & 19,3 & 26,8 & 19,6 \\
\hline $\operatorname{dec} 8$ & Não & 336 & 3 & 18,6 & 13,4 & 19,1 & 21,7 & 20,6 & 19,8 & 24,0 & 19,6 \\
\hline $\operatorname{dec} 14$ & Não & 336 & 5 & 17,8 & 13,6 & 18,6 & 21,9 & 20,8 & 21,7 & 23,8 & 19,7 \\
\hline $\operatorname{dec} 5$ & Sim & 336 & 2 & 17,4 & 12,2 & 17,4 & 20,7 & 20,4 & 22,1 & 28,0 & 19,7 \\
\hline $\operatorname{dec} 2$ & Não & 336 & 2 & 19,1 & 14,1 & 19,3 & 21,3 & 19,9 & 20,1 & 27,4 & 20,2 \\
\hline
\end{tabular}

Tabela 3.35: RMSE dos 12 melhores métodos de preenchimento de dados omissos baseados em decomposição STL, selecionados de acordo com menor RMSE. Os resultados se referem a aplicação dos métodos a série de vazão de saída para o Sul de Peruíbe.

\begin{tabular}{|c|c|c|c|c|c|c|c|c|c|c|c|c|c|}
\hline \multicolumn{6}{|c|}{ Experimentos de decomposição STL } & \multicolumn{8}{|c|}{ Quantidade de valores omissos em sequência } \\
\hline ID & $\begin{array}{l}\text { Interpolação } \\
\text { de } R_{t}\end{array}$ & $n_{(i)}$ & $n_{(e)}$ & $n_{(s)}$ & $c$ & 1 & 3 & 6 & 12 & 18 & 24 & 48 & Total \\
\hline st146 & $\operatorname{Sim}$ & 2 & 0 & 25 & 5 & 14,3 & 11,3 & 16,7 & 22,0 & 19,3 & 23,7 & 26,8 & 19,2 \\
\hline st110 & $\mathrm{Sim}$ & 2 & 0 & 25 & 2 & 17,2 & 13,8 & 18,2 & 21,3 & 19,8 & 19,9 & 24,4 & 19,2 \\
\hline st128 & Sim & 2 & 0 & 25 & 3 & 17,3 & 13,4 & 17,7 & 20,7 & 19,7 & 22,0 & 24,2 & 19,3 \\
\hline st149 & Sim & 1 & 5 & 25 & 5 & 18,4 & 13,1 & 18,0 & 20,8 & 20,4 & 19,9 & 25,2 & 19,4 \\
\hline st131 & Sim & 1 & 5 & 25 & 3 & 19,0 & 13,9 & 18,8 & 20,8 & 21,0 & 20,0 & 22,7 & 19,5 \\
\hline st153 & Sim & 1 & 10 & 37 & 5 & 18,5 & 12,8 & 18,3 & 21,7 & 21,0 & 19,6 & 24,7 & 19,5 \\
\hline st152 & $\operatorname{Sim}$ & 1 & 10 & 25 & 5 & 18,4 & 13,1 & 18,4 & 21,2 & 20,8 & 20,9 & 24,3 & 19,6 \\
\hline st129 & Sim & 2 & 0 & 37 & 3 & 17,1 & 13,4 & 17,5 & 20,9 & 20,1 & 22,4 & 26,9 & 19,7 \\
\hline st134 & Sim & 1 & 10 & 25 & 3 & 19,6 & 13,7 & 20,6 & 21,5 & 21,2 & 20,5 & 21,8 & 19,8 \\
\hline stl11 & Sim & 2 & 0 & 37 & 2 & 17,3 & 13,9 & 17,9 & 22,2 & 20,4 & 20,5 & 26,9 & 19,9 \\
\hline st147 & $\mathrm{Sim}$ & 2 & 0 & 37 & 5 & 14,4 & 11,6 & 16,6 & 22,1 & 19,9 & 25,3 & 29,5 & 19,9 \\
\hline st119 & Não & 2 & 0 & 25 & 3 & 19,5 & 15,1 & 21,4 & 22,2 & 19,7 & 18,3 & 23,2 & 19,9 \\
\hline
\end{tabular}

Tabela 3.36: RMSE dos métodos benchmark de preenchimento de dados omissos. Os resultados se referem a aplicação dos métodos a série de vazão de saída para o Sul de Peruíbe.

\begin{tabular}{|c|c|c|c|c|c|c|c|c|c|c|}
\hline \multicolumn{3}{|c|}{ Experimentos emphbenchmark } & \multicolumn{8}{|c|}{ Quantidade de valores omissos em sequência } \\
\hline ID & $\begin{array}{c}\text { Forma de } \\
\text { benchmark }\end{array}$ & Janela & 1 & 3 & 6 & 12 & 18 & 24 & 48 & Total \\
\hline ben1 & Média & 168 & 46,8 & 44,4 & 50,4 & 52,3 & 53,6 & 54,3 & 56,6 & 51,2 \\
\hline ben 2 & Média & 336 & 47,6 & 46,5 & 49,8 & 53,7 & 54,4 & 55,1 & 56,4 & 51,9 \\
\hline ben 3 & Média & 720 & 49,0 & 48,6 & 50,6 & 56,3 & 57,1 & 57,7 & 57,3 & 53,8 \\
\hline ben 4 & Mediana & 168 & 48,2 & 44,6 & 53,2 & 55,1 & 54,6 & 54,9 & 56,9 & 52,5 \\
\hline ben 5 & Mediana & 336 & 48,5 & 46,6 & 51,4 & 56,0 & 55,4 & 55,9 & 56,3 & 52,9 \\
\hline ben 6 & Mediana & 720 & 49,5 & 48,2 & 51,3 & 57,9 & 57,7 & 58,4 & 57,4 & 54,3 \\
\hline ben 7 & Interpolação & - & 15,9 & 17,6 & 27,4 & 46,9 & 61,4 & 71,3 & 71,5 & 44,6 \\
\hline
\end{tabular}

De acordo com as informações apresentadas nas tabelas 3.33 à 3.36 podemos verificar que, em geral:

- Os melhores procedimentos de regressão, de acordo com o RMSE total, foram aqueles que usaram interpolação nos resíduos $R_{t}$, que consideraram a sazonalidade semanal e que usaram janela de tamanho 336, sendo que o melhor procedimento de regressão para imputação de valores omissos foi o que usou polinômio de grau 5 modelando a tendência, com interpolação 
de $R_{t}$, sem sazonalidade semanal, janela de tamanho 336 e valor de corte $c=5$, apresentando um RMSE total igual a 18,483. Os parâmetros desse modelo de regressão foram os usados na aplicação do método de decomposição clássica.

- Aparentemente, os procedimentos de decomposição clássica que tiveram melhor desempenho, de acordo com o RMSE total, foram aqueles que usaram janela de tamanho menores (168 e 336). O melhor procedimento foi aquele que usou decomposição com interpolação de $R_{t}$, janela de tamanho 168 e valor de corte $c=5$, apresentando um RMSE total igual a 18,799.

- Os tipos de decomposição STL que tiveram melhores resultados, de acordo com o RMSE total, foram os que possuem interpolação nos resíduos $R_{t}$, e que, aparentemente, usaram $n_{(s)}=24$ e decomposição STL não robusta $\left(n_{(i)}=2\right.$ e $\left.n_{(e)}=0\right)$. O melhor procedimento foi o de decomposição não robusta $\left(n_{(i)}=2\right.$ e $\left.n_{(e)}=0\right)$, com interpolação de $R_{t}, n_{(s)}=25$ e valor de corte $c=5$, apresentando um RMSE total igual a 19,171 .

- Dentre os métodos de benchmark, o que teve melhor desempenho foi o que interpola linearmente os valores da série, apresentando um RMSE total igual a 44,57. Verifica-se que os procedimentos propostos tiveram desempenhos bem superiores aos benchmarks.

- Dentre todos os experimentos, o que apresentou melhor resultado foi o procedimento de ajuste de curvas de regressão com polinômio de grau 5 modelando a tendência, com interpolação de $R_{t}$, sem sazonalidade semanal, janela de tamanho 336 e valor de corte $c=5$, apresentando um valor de RMSE total de 18,483. Este é o procedimento para o qual é apresentado uma análise de outliers na próxima subseção e que é usado oficialmente para preencher os valores omissos da série.

A Figura 3.18 exemplifica alguns experimentos de preenchimento de valores omissos. Cada gráfico representa um trecho da série temporal de vazão de saída para o Sul de Peruíbe no qual propositalmente foi removido uma sequência de valores. Todos os gráficos se referem a uma lacuna de tamanho 48 horas acompanhado de 12 valores anteriores e posteriores à lacuna principal. Os procedimentos de preenchimento adotados para ilustrar os gráficos são o melhor experimento, de acordo com o RMSE total, de cada tipo de procedimento apresentados nas tabelas 3.33 à 3.36.

Verifica-se que os procedimentos propostos conseguiram fazer uma boa estimativa dos valores omissos, sendo estas bem superiores às do método de interpolação. Esses resultados já eram esperados, pois a série de vazão de saída para o Sul de Peruíbe apresenta um comportamento sazonal bem característico, mesmo que esse comportamento tenha alguns momentos de notáveis diferenças entre o valor real e o estimado pelos métodos propostos.

\subsubsection{Detecção e tratamento de outliers}

As tabelas 3.37 e 3.38 mostram os resultados dos experimentos elaborados para avaliar o desempenho em detectar e tratar os outliers do melhor procedimento selecionado para a imputação dos valores omissos. A Tabela 3.37 apresenta as taxas de detecção dos outliers, sendo dividida em duas partes: na parte superior o cálculo das taxas considera todas as observações afetadas pelo efeito atípico, enquanto que na parte inferior é considerado apenas a observação mais afetada pelo efeito atípico. Vale lembrar que no caso do efeito atípico do tipo platô todas as observações foram consideradas 
(A)

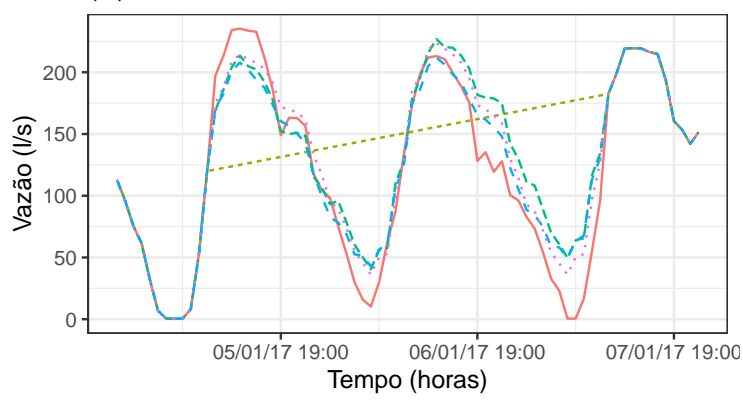

(C)

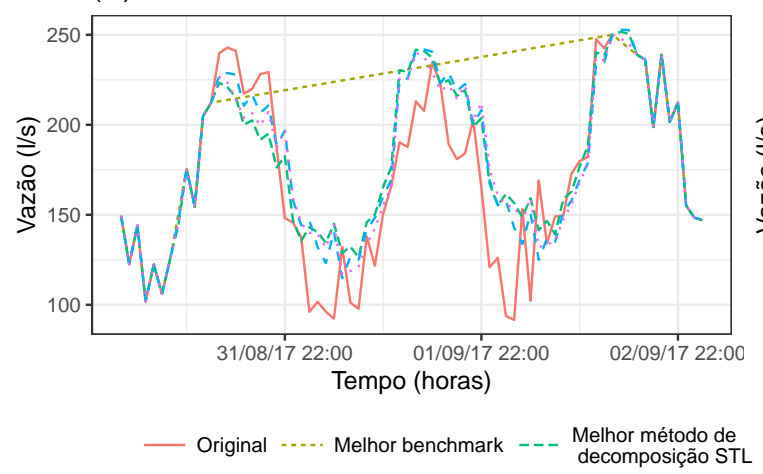

(B)

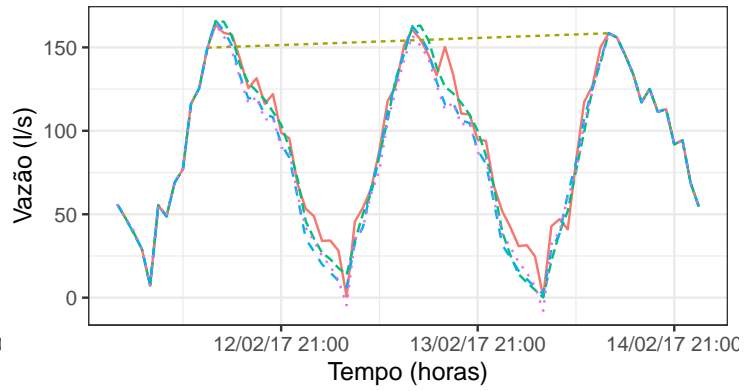

(D)

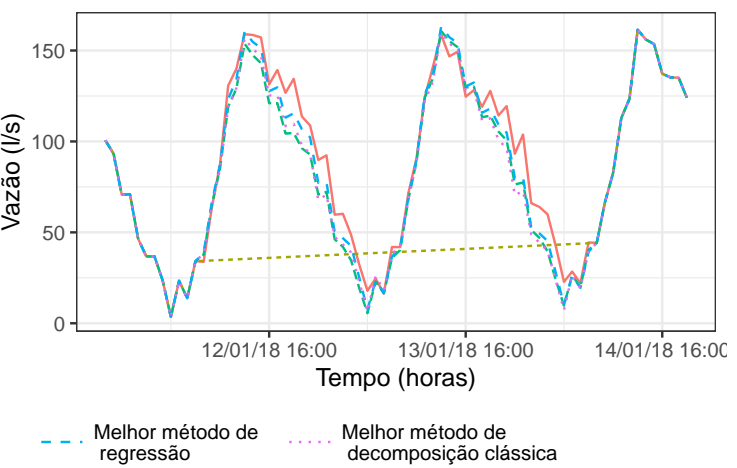

Figura 3.18: Alguns trechos da série de vazão de saída para o Sul de Peruıbe que exemplificam a aplicação dos procedimentos de preenchimento de valores omissos. É apresentado o melhor experimento de imputação de valores omissos de cada tipo de procedimento de acordo com o RMSE, descritos nas tabelas 3.33 à 3.36. A lacuna principal de valores omissos usada em cada gráfico foi inserida artificialmente na série temporal a fim de avaliar a performance dos procedimentos de preenchimento de valores omissos. O tamanho da lacuna principal é de 48 horas, sendo precedida e sucedida de 12 horas de valores originais.

como sendo as mais afetadas devido ao efeito se distribuir igualmente entre elas. Já a tabela 3.38 é destinada a verificar a acurácia do procedimento ao corrigir os valores dos outliers. Sua estrutura é análoga à da tabela 3.37, sendo que a linha total é o RMSE do efeito atípico nas observações.

A partir das tabelas, podemos verificar que:

- De modo geral, as taxas de detecção dos outliers foram altas para o tipo único e para os demais tipos de efeitos a taxa de detecção depende dos parâmetros do experimento. Quando se considera apenas as obsevações mais afetadas, as taxa de deteç̧ão foram bem altas, com exceção dos efeitos atípicos do tipo platô. Esses resultados são uma evidência da possível adequação do procedimento em detectar os outliers da série. Nota-se também que, para as observações mais afetadas, as altas taxas de detecção resultaram em um RMSE relativamente bom, conseguindo fazer uma redução expressiva em relação ao RMSE total, porém, o mesmo não pode ser dito quando se considera todas as observações afetadas pelos efeitos atípicos.

- O número de máximo de iterações possui, em geral, uma considerável influencia nos resultados. Com exceção do efeito do tipo único, a taxa de detecção dos experimentos que tiveram apenas uma iteração foi menor do que quando usadas iterações máximas iguais a 3 ou 5 . Porém, não há muita diferança entre usar um número máximo de iterações igual a 3 ou igual a 5 . Algo semelhante pode ser observado pelos valores de RMSE: o RMSE dos experimentos que usaram apenas uma iteração máxima foram maiores do aqueles que tiveram iterações máximas iguais a 3 ou 5. A semelhança dos resultados do uso de 3 e 5 iterações máximas pode ser explicado 
Tabela 3.37: Taxa de deteç̧ão de outliers de acordo com o procedimento que apresentou melhor desempenho em preencher valores omissos. O procedimento foi o de ajuste de curvas de regressão com polinômio de grau 5 modelando a tendência, com interpolação de $R_{t}$, sem sazonalidade semanal, janela de tamanho 336 e valor de corte $c=5$. Variou-se o valor de corte $c$ e a quantidade de iterações máxima com o objetivo de verificar se a mudança desses parâmetros causam algum impacto na detecção dos outliers. A aplicação se refere a série de vazão de saída para o Sul de Peruibe.

\begin{tabular}{|c|c|c|c|c|c|c|c|c|}
\hline \multicolumn{3}{|c|}{ Experimentos } & \multicolumn{6}{|c|}{ Tipo de efeitos atípicos } \\
\hline ID & c & $\begin{array}{l}\text { № máximo } \\
\text { de iterações }\end{array}$ & Único & Platô & Pulso & $\begin{array}{l}\text { C.D. } \\
\text { linear }\end{array}$ & $\begin{array}{c}\text { C.D. } \\
\text { exponencial }\end{array}$ & $\begin{array}{c}\text { C.D. } \\
\text { logaritmico }\end{array}$ \\
\hline \multicolumn{9}{|c|}{ Todas as observações afetadas } \\
\hline out1 & 2 & 1 & 0,783 & 0,705 & 0,479 & - & - & - \\
\hline out 2 & 3 & 1 & 0,783 & - & 0,367 & 0,403 & 0,381 & 0,397 \\
\hline out3 & 4 & 1 & 0,767 & 0,150 & 0,261 & 0,249 & 0,271 & 0,230 \\
\hline out4 & 5 & 1 & 0,700 & 0,090 & 0,178 & 0,156 & 0,190 & 0,135 \\
\hline out5 & 2 & 3 & 1,000 & 0,981 & 0,671 & 0,754 & 0,710 & 0,790 \\
\hline out6 & 3 & 3 & 0,983 & 0,732 & 0,532 & 0,591 & 0,561 & 0,612 \\
\hline out7 & 4 & 3 & 0,967 & 0,367 & 0,399 & 0,418 & 0,422 & 0,401 \\
\hline out 8 & 5 & 3 & 0,867 & 0,167 & 0,276 & 0,264 & 0,301 & 0,225 \\
\hline out9 & 2 & 5 & 1,000 & 0,984 & 0,671 & 0,757 & 0,717 & 0,799 \\
\hline out10 & 3 & 5 & 0,983 & 0,763 & 0,536 & 0,599 & 0,570 & 0,618 \\
\hline out11 & 4 & 5 & 0,967 & 0,376 & 0,400 & 0,419 & 0,427 & 0,409 \\
\hline out12 & 5 & 5 & 0,867 & 0,169 & 0,277 & 0,264 & 0,301 & 0,228 \\
\hline Total & - & - & 1,000 & 1,000 & 1,000 & 1,000 & 1,000 & 1,000 \\
\hline \multicolumn{9}{|c|}{ Somente observações mais afetadas } \\
\hline out1 & 2 & 1 & 0,783 & 0,705 & 0,867 & - & - & - \\
\hline out 2 & 3 & 1 & 0,783 & - & 0,867 & 0,857 & 0,857 & 0,848 \\
\hline out 3 & 4 & 1 & 0,767 & 0,150 & 0,850 & 0,724 & 0,857 & 0,600 \\
\hline out4 & 5 & 1 & 0,700 & 0,090 & 0,717 & 0,486 & 0,676 & 0,390 \\
\hline out 5 & 2 & 3 & 1,000 & 0,981 & 1,000 & 1,000 & 1,000 & 0,990 \\
\hline out6 & 3 & 3 & 0,983 & 0,732 & 1,000 & 0,990 & 0,990 & 0,981 \\
\hline out 7 & 4 & 3 & 0,967 & 0,367 & 0,967 & 0,952 & 0,971 & 0,905 \\
\hline out 8 & 5 & 3 & 0,867 & 0,167 & 0,900 & 0,752 & 0,943 & 0,590 \\
\hline out 9 & 2 & 5 & 1,000 & 0,984 & 1,000 & 1,000 & 1,000 & 0,990 \\
\hline out10 & 3 & 5 & 0,983 & 0,763 & 1,000 & 0,990 & 0,990 & 0,990 \\
\hline out11 & 4 & 5 & 0,967 & 0,376 & 0,967 & 0,952 & 0,971 & 0,933 \\
\hline out12 & 5 & 5 & 0,867 & 0,169 & 0,900 & 0,752 & 0,943 & 0,600 \\
\hline Total & - & - & 1,000 & 1,000 & 1,000 & 1,000 & 1,000 & 1,000 \\
\hline
\end{tabular}

pelo algoritmo conseguir encontrar grande parte dos outliers antes de atingir número máximo de iterações, sendo necessário apenas uma baixa quantidade de iterações, isto é, um número menor ou igual a 3 , porém maior que 1 .

- Como o esperado, percebe-se claramente que o valor de corte $c$ influencia na taxa de deteç̧ão, sendo que quanto menor for valor de corte $c$, melhor é a taxa de detecção. Também verifica-se um melhor valor de RMSE para os valores mais baixos de $c$. Lembramos que, embora um valor de corte baixo aumente a taxa de deteç̧ão de outliers, ele também aumenta a taxa de detecção de valores que possivelmente não seriam outliers.

A Figura 3.19 exemplifica as constatações realizadas. É possível observar que os procedimentos conseguiram detectar e tratar somente as observações mais afetadas pelos efeitos atípicos.

A Tabela 3.39 apresenta a quantidade de anomalias detectadas em cada fase do tratamento dado a série de vazão de saída para o Sul de Peruíbe. Nota-se que a maior parte das observações anômalas foram detectadas durante a fase de limpeza primária, o que dá a quantidade de 3975 observações ou $22,7 \%$ do total. Durante todo o processo, foram detectadas 4278 (24,4 \%) observações anormais.

\subsubsection{Previsão}

A Tabela 3.40 traz os resultados de acurácia dos experimentos de previsão de acordo com RMSE. Ela é dividida em duas partes: a parte superior é dedicada a mostrar os resultados que usaram rolling windows de tamanho 336 horas (14 dias) e a parte inferior mostra os resultados referentes 
Tabela 3.38: RMSE do tratamento dos outliers de acordo com o procedimento que apresentou melhor desempenho em preencher valores omissos. O procedimento foi o de ajuste de curvas de regressão com polinômio de grau 5 modelando a tendência, com interpolação de $R_{t}$, sem sazonalidade semanal, janela de tamanho 336 e valor de corte $c=5$. Variou-se o valor de corte $c$ e a quantidade de iterações máxima com o objetivo de verificar se a mudança desses parâmetros causam algum impacto na detecção dos outliers. A linha total é o RMSE das observações ouliers em relação ao seu valor original. A aplicação se refere a série de vazão de saída para o Sul de Peruíbe.

\begin{tabular}{|c|c|c|c|c|c|c|c|c|}
\hline \multicolumn{3}{|c|}{ Experimentos } & \multicolumn{6}{|c|}{ Tipo de efeitos atípicos } \\
\hline ID & c & $\begin{array}{l}\mathrm{N}^{0} \text { máximo } \\
\text { de iterações }\end{array}$ & Único & Platô & Pulso & $\begin{array}{l}\text { C.D. } \\
\text { linear }\end{array}$ & $\begin{array}{c}\text { C.D. } \\
\text { exponencial }\end{array}$ & $\begin{array}{c}\text { C.D. } \\
\text { logaritmico }\end{array}$ \\
\hline \multicolumn{9}{|c|}{ Todas as observações afetadas } \\
\hline out1 & 2 & 1 & 46,9 & 63,7 & 45,9 & - & - & - \\
\hline out 2 & 3 & 1 & 46,8 & - & 53,9 & 72,7 & 70,3 & 75,7 \\
\hline out3 & 4 & 1 & 48,5 & 102,1 & 64,5 & 83,9 & 81,0 & 86,5 \\
\hline out4 & 5 & 1 & 56,6 & 105,5 & 74,7 & 91,2 & 88,8 & 92,2 \\
\hline out 5 & 2 & 3 & 14,1 & 43,0 & 36,4 & 41,1 & 39,5 & 42,6 \\
\hline out6 & 3 & 3 & 14,1 & 69,7 & 45,1 & 59,7 & 54,8 & 61,4 \\
\hline out7 & 4 & 3 & 16,5 & 86,4 & 57,0 & 73,6 & 68,5 & 76,5 \\
\hline out 8 & 5 & 3 & 36,0 & 98,7 & 67,8 & 84,3 & 79,5 & 87,7 \\
\hline out9 & 2 & 5 & 14,1 & 42,2 & 36,2 & 40,5 & 39,0 & 41,9 \\
\hline out10 & 3 & 5 & 14,1 & 68,8 & 45,1 & 59,2 & 54,3 & 60,9 \\
\hline out11 & 4 & 5 & 16,5 & 85,4 & 57,0 & 73,3 & 68,3 & 76,1 \\
\hline out12 & 5 & 5 & 36,0 & 98,6 & 67,7 & 84,3 & 79,4 & 87,5 \\
\hline Total & - & - & 137,1 & 122,5 & 111,7 & 121,0 & 130,4 & 118,1 \\
\hline \multicolumn{9}{|c|}{ Somente observações mais afetadas } \\
\hline out1 & 2 & 1 & 46,9 & 63,7 & 52,9 & - & - & - \\
\hline out2 & 3 & 1 & 46,8 & - & 51,6 & 81,7 & 84,4 & 82,7 \\
\hline out3 & 4 & 1 & 48,5 & 102,1 & 58,3 & 101,3 & 100,2 & 102,3 \\
\hline out4 & 5 & 1 & 56,6 & 105,5 & 79,4 & 117,3 & 117,6 & 115,3 \\
\hline out 5 & 2 & 3 & 14,1 & 43,0 & 33,3 & 39,9 & 39,2 & 39,5 \\
\hline out6 & 3 & 3 & 14,1 & 69,7 & 34,3 & 62,7 & 58,9 & 63,2 \\
\hline out7 & 4 & 3 & 16,5 & 86,4 & 44,2 & 82,7 & 79,8 & 84,2 \\
\hline out8 & 5 & 3 & 36,0 & 98,7 & 58,9 & 102,4 & 98,2 & 105,9 \\
\hline out9 & 2 & 5 & 14,1 & 42,2 & 32,5 & 39,1 & 38,5 & 39,1 \\
\hline out10 & 3 & 5 & 14,1 & 68,8 & 34,3 & 62,1 & 58,6 & 62,5 \\
\hline out11 & 4 & 5 & 16,5 & 85,4 & 44,2 & 82,1 & 79,4 & 83,2 \\
\hline out12 & 5 & 5 & 36,0 & 98,6 & 58,9 & 102,4 & 98,0 & 105,1 \\
\hline Total & - & - & 137,1 & 122,5 & 187,3 & 182,0 & 219,8 & 165,5 \\
\hline
\end{tabular}

Tabela 3.39: Quantidade de valores detectados como anomalias em cada estágio de tratamento da série de vazão de saída para o Sul de Peruibe. A primeira linha da tabela se refere a quantidade de valores classificados pelo sistema da Sabesp como bad e que, portanto, eram omissos na série original. A segunda linha se refere aos valores detectados como anomalias pela limpeza primária. A terceira linha se refere a quantidade de valores detectados como outliers pela aplicação do algoritmo proposto.

\begin{tabular}{rrrrr}
\hline Fase de deteção de anomalias & Frequência absoluta & Frequência relativa & Acumulado absoluto & Acumulado relativo \\
\hline Originalmente & 207 & $1,2 \%$ & 207 & $1,2 \%$ \\
Limpeza primária & 3.975 & $22,7 \%$ & 4.182 & 4.278 \\
Algoritmo de detecção de outliers & 96 & $0,5 \%$ & $21.9 \%$ \\
Tamanho da série & 17.519 & $100 \%$ & $24,4 \%$ \\
\hline
\end{tabular}

ao uso de rolling windows de tamanho 720 horas (30 dias). Os experimentos estão agrupados por tipo de modelos. A partir dessa tabela, verifica-se que:

- O melhor procedimento de previsão com modelos SARIMA, de acordo com o RMSE total, foi o que usou estratégia do tipo 2 e rolling windows de tamanho 336, apresentando RMSE total de 25,291 . Vale notar que a estratégia de tipo 2 teve um desempenho bem superior do que a de tipo 1 no uso de rolling window de tamanho 336, o que é um resultado um tanto inusitado, já que o esperado era que o desempenho de um modelo identificado usando as observações da própria rolling window fosse superior àquele que usasse as observações de uma outra rolling window para se fazer tal identificação.

- O melhor procedimento de regressão com erros autocorrelacionados, de acordo com o RMSE total, foi o que usou polinômio de grau 0 modelando a tendência, sem sazonalidade semanal, 


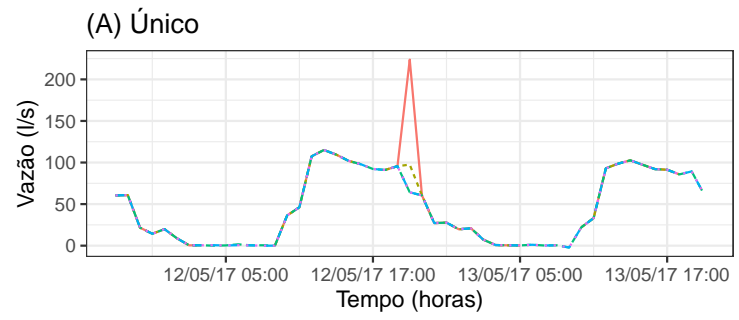

(C) Pulso

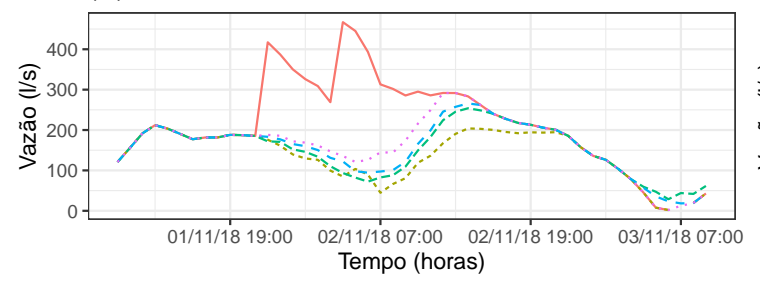

(E) C.D. Exponencial

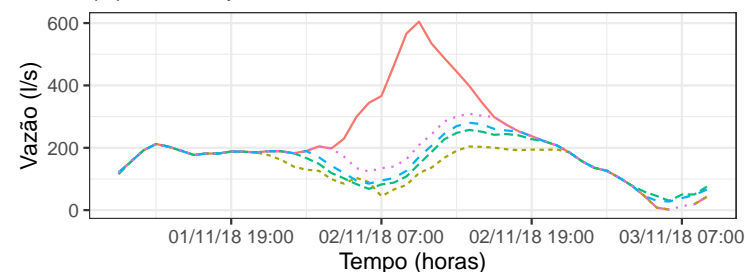

— Série com Outlier
(B) Platô

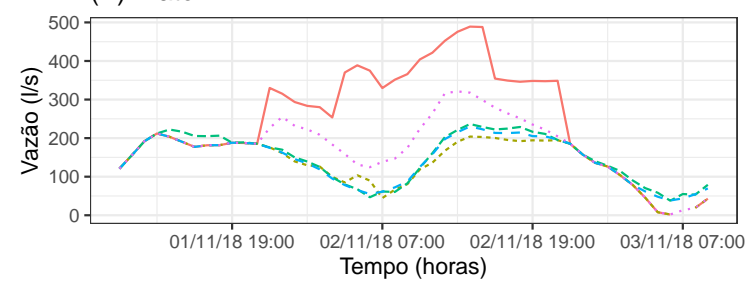

(D) C.D. Linear

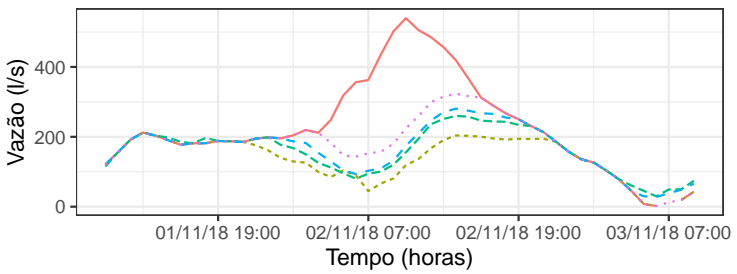

(F) C.D. Logaritmico

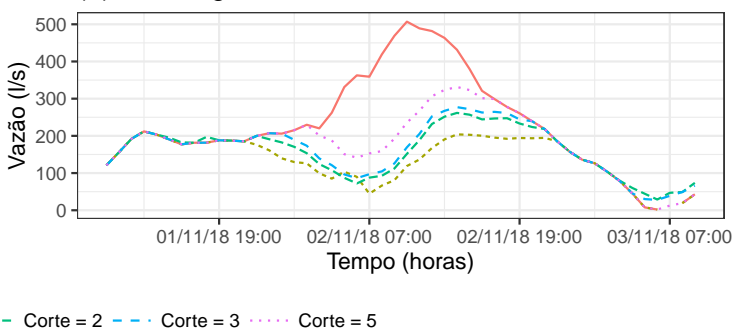

Figura 3.19: Exemplos de detecção e tratamento dos outliers inseridos na série de vazão de saída para o Sul de Peruíbe. Os trechos mostrados possuem tamanho 48 e são centrados nas observações afetadas pelo efeito atípico. Os gráficos de $(A)$ a $(F)$ exemplificam cada tipo de efeito atípico na série. A quantidade de iteração máxima dos experimentos selecionados é 3.

com o uso da estratégia do tipo 1 para os erros SARIMA e rolling windows de tamanho 336, apresentando RMSE total de 25,156. É importante notar que nem todos os experimentos conseguiram ajustar determinado modelo em todas as rollings windows, o que pode ser um empecilho a mais na hora de fazer comparações.

- Dentre os procedimentos BATS e TBATS, o que teve melhor desempenho de acordo com o RMSE total foi o que usou modelos BATS com sazonalidade semanal e com rolling windows de tamanho 720, apresentando RMSE total de 27,659. Para ambos os procedimentos BATS e TBATS o uso de sazonalidade semanal não melhorou significativamente o desempenho dos modelos.

- Aparentemente não há muita diferença de desempenho entre usar rolling windows de tamanho 336 ou 720, pois alguns experimentos que tiveram bom resultado usando rolling windows de tamanho 336 foram piores com as de tamanho 720 (em geral, os de regresão tiveram pior desempenho), enquanto que outros que tiveram mau resultado usando rolling windows de tamanho 336 foram melhores com as de tamanho 720 .

- Alguns experimentos que empregaram a estratégia do tipo 2 tiveraram um valor de $N<30$. Isso é explicado pelo fato da estratégia consistir em identificar o modelo usando as observações de apenas de uma rolling windows e depois só reestimar os parâmetros nas damais, visto que, ao se fazer esse procedimento, corre-se o risco do modelo não ser "estimátivel"(raízes próximas do polinomio autoregressivo ou de médias móveis bem próximas ou dentro do circulo unitário). 
Tabela 3.40: RMSE dos experimentos de previsão aplicados a série de vazão de saída para o Sul de Peruíbe. As estratégias de tipo 1 se referem a aplicação do algoritmo de seleção de modelo em cada uma das rollings windows, enquanto que as de tipo 2 se referem a aplicação do algoritmo somente na primeira rolling window $e$ do ajuste modelo selecionado nas demais rolling windows, reestimando os parâmetros. O RMSE "Todos"é calculado usando todos os valores preditos de horizonte $h=1, \ldots, 168$, incluido aqueles que não aparecem na tabela.

\begin{tabular}{|c|c|c|c|c|c|c|c|c|c|c|c|c|c|c|}
\hline \multicolumn{4}{|c|}{ Experimentos } & \multicolumn{11}{|c|}{ Horizonte de previsão } \\
\hline Modelos & $\begin{array}{c}\text { Grau do } \\
\text { polinô- } \\
\text { mio }\end{array}$ & $\begin{array}{l}\text { Sazonalidade } \\
\text { semanal }\end{array}$ & $\begin{array}{c}\text { Estratégia } \\
\text { de ajuste }\end{array}$ & $\mathrm{N}$ & 1 & 2 & 3 & 6 & 12 & 18 & 24 & 48 & 168 & Todos \\
\hline \multicolumn{15}{|c|}{ Rolling windows de tamanho 336} \\
\hline \multirow{2}{*}{ SARIMA } & - & - & Tipo 1 & 30 & 8,25 & 8,66 & 10,21 & 24,1 & 21,3 & 13,8 & 22,4 & 48,0 & 107,1 & 72,0 \\
\hline & - & - & Tipo 2 & 29 & 8,39 & 8,39 & 10,48 & 16,7 & 17,1 & 26,1 & 23,3 & 24,9 & 28,3 & 25,3 \\
\hline \multirow{8}{*}{$\begin{array}{c}\text { Regressão } \\
\text { com erros } \\
\text { SARIMA }\end{array}$} & 0 & $\operatorname{Sim}$ & Tipo 1 & 30 & 9,35 & 9,30 & 11,85 & 19,7 & 19,0 & 30,0 & 25,4 & 24,7 & 27,7 & 25,8 \\
\hline & 0 & $\operatorname{Sim}$ & Tipo 2 & 26 & 8,46 & 10,51 & 11,82 & 22,1 & 17,7 & 17,2 & 20,4 & 26,9 & 30,0 & 28,3 \\
\hline & 1 & $\mathrm{Sim}$ & Tipo 1 & 30 & 9,06 & 8,94 & 12,21 & 18,6 & 18,7 & 25,8 & 22,9 & 23,0 & 36,2 & 30,0 \\
\hline & 1 & Sim & Tipo 2 & 22 & 8,03 & 8,70 & 11,45 & 24,1 & 18,8 & 20,2 & 19,1 & 28,4 & 37,7 & 30,2 \\
\hline & 0 & Não & Tipo 1 & 30 & 9,19 & 9,74 & 11,12 & 19,2 & 13,5 & 22,6 & 19,6 & 25,2 & 28,0 & 25,2 \\
\hline & 0 & Não & Tipo 2 & 25 & 8,39 & 8,72 & 9,46 & 17,8 & 14,9 & 14,6 & 17,5 & 26,4 & 34,1 & 28,8 \\
\hline & 1 & Não & Tipo 1 & 30 & 8,94 & 9,38 & 11,78 & 18,7 & 14,0 & 19,0 & 16,6 & 21,5 & 34,6 & 29,1 \\
\hline & 1 & Não & Tipo 2 & 30 & 9,46 & 10,97 & 14,44 & 17,5 & 17,7 & 25,7 & 21,6 & 20,7 & 34,4 & 29,0 \\
\hline \multirow{2}{*}{ BATS } & - & Não & Tipo 1 & 30 & 11,26 & 10,77 & 13,02 & 23,9 & 15,7 & 16,2 & 16,2 & 26,4 & 32,7 & 29,7 \\
\hline & - & $\operatorname{Sim}$ & Tipo 1 & 30 & 47,20 & 32,75 & 32,52 & 25,7 & 19,7 & 27,4 & 20,9 & 27,3 & 36,0 & 29,2 \\
\hline \multirow{2}{*}{ TBATS } & - & Não & Tipo 1 & 30 & 11,67 & 11,57 & 12,68 & 26,2 & 18,0 & 17,1 & 13,5 & 28,3 & 33,7 & 32,0 \\
\hline & - & $\operatorname{Sim}$ & Tipo 1 & 30 & 10,87 & 12,01 & 16,29 & 27,7 & 21,7 & 25,9 & 25,5 & 40,2 & 37,3 & 34,8 \\
\hline \multirow{3}{*}{ Benchmark } & - & - & Média & 30 & 41,24 & 42,24 & 49,71 & 48,7 & 42,0 & 58,3 & 31,8 & 30,9 & 32,6 & 47,1 \\
\hline & - & - & Mediana & 30 & 41,35 & 40,85 & 48,43 & 46,4 & 41,2 & 61,1 & 34,0 & 33,5 & 35,8 & 48,4 \\
\hline & - & - & Últ. Obs. & 30 & 23,05 & 31,65 & 49,86 & 63,6 & 59,7 & 37,1 & 19,6 & 34,6 & 40,8 & 57,4 \\
\hline \multicolumn{15}{|c|}{ Rolling windows de tamanho 720} \\
\hline \multirow{2}{*}{ SARIMA } & - & - & Tipo 1 & 30 & 10,30 & 12,82 & 16,93 & 17,3 & 12,5 & 23,3 & 23,3 & 31,8 & 45,0 & 28,7 \\
\hline & - & - & Tipo 2 & 28 & 9,22 & 12,34 & 16,21 & 17,0 & 14,8 & 24,4 & 22,6 & 30,8 & 48,7 & 27,6 \\
\hline \multirow{8}{*}{$\begin{array}{c}\text { Regressão } \\
\text { com erros } \\
\text { SARIMA }\end{array}$} & 0 & $\operatorname{Sim}$ & Tipo 1 & 30 & 10,31 & 13,80 & 17,03 & 21,6 & 13,3 & 24,9 & 23,8 & 32,7 & 43,3 & 31,4 \\
\hline & 0 & $\operatorname{Sim}$ & Tipo 2 & 17 & 6,72 & 12,25 & 11,41 & 16,9 & 27,1 & 28,9 & 29,1 & 48,3 & 90,6 & 58,5 \\
\hline & 1 & $\operatorname{Sim}$ & Tipo 1 & 30 & 10,24 & 13,43 & 16,58 & 21,3 & 13,5 & 22,0 & 20,7 & 29,8 & 47,5 & 28,0 \\
\hline & 1 & $\operatorname{Sim}$ & Tipo 2 & 23 & 10,78 & 14,19 & 18,15 & 22,0 & 15,1 & 24,0 & 21,7 & 31,7 & 38,7 & 27,7 \\
\hline & 0 & Não & Tipo 1 & 30 & 10,28 & 13,96 & 17,03 & 20,7 & 12,9 & 24,6 & 23,8 & 33,5 & 42,2 & 31,0 \\
\hline & 0 & Não & Tipo 2 & 18 & 9,71 & 14,34 & 17,88 & 21,6 & 27,6 & 29,4 & 29,4 & 48,3 & 93,0 & 59,2 \\
\hline & 1 & Não & Tipo 1 & 30 & 10,22 & 13,71 & 16,61 & 20,1 & 13,5 & 21,8 & 20,7 & 29,8 & 46,5 & 28,0 \\
\hline & 1 & Não & Tipo 2 & 22 & 10,68 & 14,66 & 18,93 & 14,2 & 13,7 & 21,2 & 25,3 & 31,3 & 39,2 & 27,4 \\
\hline \multirow{2}{*}{ BATS } & - & Não & Tipo 1 & 30 & 10,96 & 12,87 & 17,65 & 18,3 & 15,4 & 24,9 & 25,5 & 33,2 & 41,4 & 28,4 \\
\hline & - & Sim & Tipo 1 & 29 & 17,53 & 17,73 & 20,18 & 26,9 & 19,1 & 22,6 & 25,0 & 28,8 & 47,0 & 27,7 \\
\hline \multirow{2}{*}{ TBATS } & - & Não & Tipo 1 & 30 & 12,37 & 14,88 & 19,42 & 30,0 & 17,1 & 23,1 & 22,9 & 30,0 & 43,8 & 31,4 \\
\hline & - & Sim & Tipo 1 & 30 & 13,54 & 14,78 & 18,05 & 33,9 & 25,8 & 27,6 & 27,5 & 41,8 & 74,9 & 52,4 \\
\hline \multirow{3}{*}{ Benchmark } & - & - & Média & 30 & 40,41 & 39,75 & 52,27 & 52,5 & 48,2 & 62,8 & 42,5 & 46,6 & 49,1 & 53,7 \\
\hline & - & - & Mediana & 30 & 41,30 & 38,87 & 51,55 & 51,0 & 47,9 & 65,0 & 43,3 & 47,5 & 49,4 & 54,3 \\
\hline & - & - & Ûlt. Obs. & 30 & 21,19 & 31,65 & 54,25 & 63,8 & 59,7 & 40,6 & 23,5 & 32,6 & 49,2 & 53,2 \\
\hline
\end{tabular}

Assim, mesmo nas situações em que procedimento do tipo 2 teve um desempenho melhor, é preferivel escolher o do tipo 1 , já que a diferença de desempenho entre eles não é muito discrepante.

- De modo geral, os métodos de previsão propostos tiveram desempenhos bem superiores aos métodos benchmark, mostrando, assim, uma possível adequabilidade dos modelos propostos.

- Dentre todos os procedimentos de previsão propostos, o melhor foi o que usou modelos de regressão com erros autocorrelacionados, com polinômio de grau 0 modelando a tendência, sem sazonalidade semanal, com o uso da estratégia do tipo 1 para os erros SARIMA e com rolling windows de tamanho 336, apresentando o valor de RMSE total de 25,156.

Os resultados de previsão relativamente bons podem ser explicados por um comportamento frequentemente regular da série, sendo, muitas vezes, uma sazonalidade bem definida. Tal constatação pode ser observada na Figura 3.20, na qual são mostrados alguns exemplos de previsão para cada tipo de modelo que reforçam as constatações realizadas. É possível observar que existem momentos em que há mudanças de comportamentos (Graficos (A) e (D)), mas que estes ou ocorrem poucas 
vezes ou são mudanças suaves ao longo do tempo, o que permitem com que os métodos de previsão ainda performem bem.
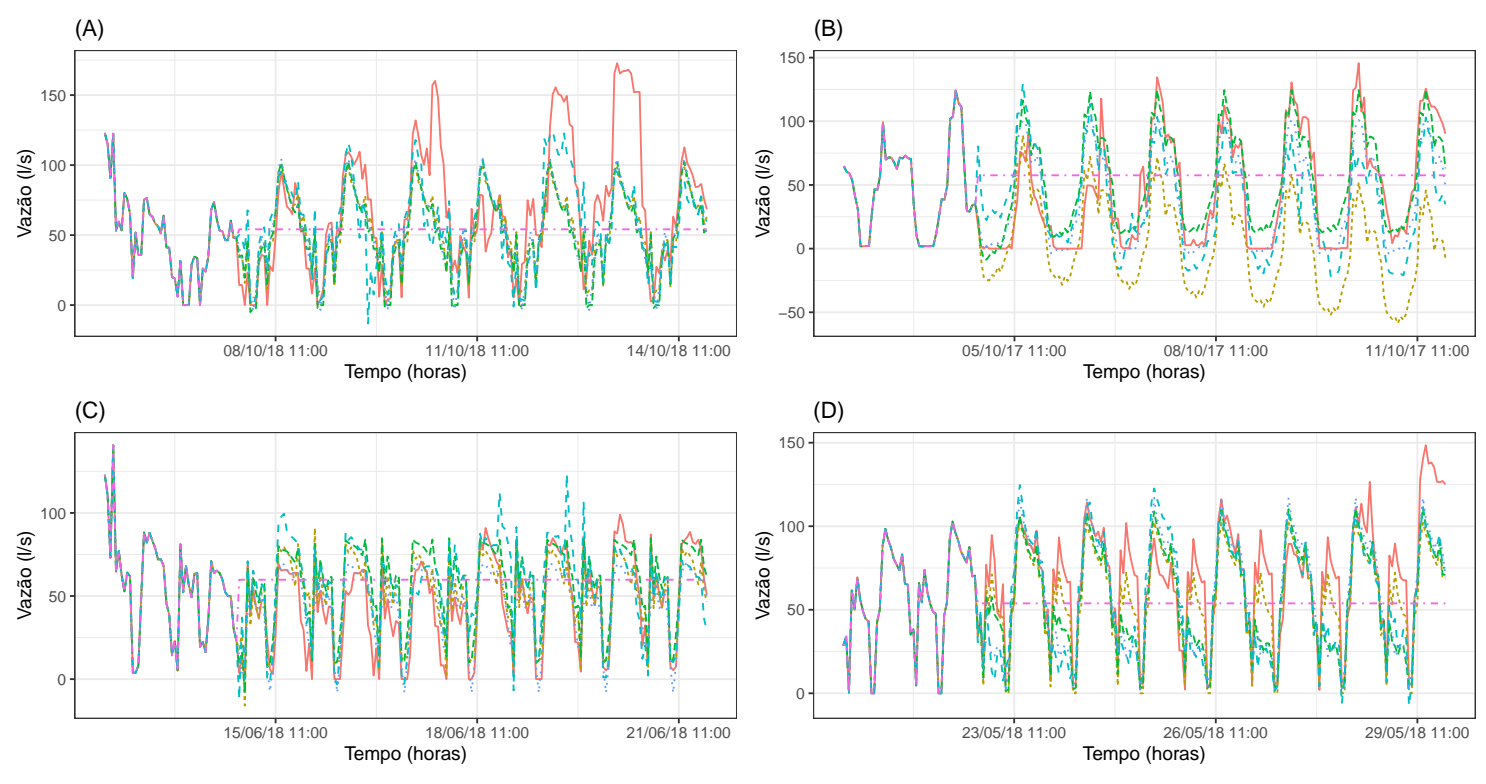

$\begin{array}{lll}\text { - Original } & -- \text { Melhor estratégia regressão } \\ \text { com erros SARIMA do tipo }\end{array}$

.. Melhor estratégia TBATS

-... Melhor estratégia benchmark

Figura 3.20: Alguns trechos da série de vazão de saída para o Sul de Peruibe que exemplificam a aplicação dos modelos de previsão. São apresentados o melhor procedimento de ajuste de cada família de modelos, de acordo com o melhor RMSE de previsão, para os dois tamanhos de rolling window descritos na tabela 3.40. Para a seleção dos procedimentos, exluiu-se os que utilizaram a estratégia de tipo 2. Os gráficos exibem 48 horas da série seguidas de 168 horas de previsão. Os gráficos da esquerda se referem aos ajustes que usaram rolling windows de tamanho 336, já os da direita, de tamanho 720

Para a elaboração dos gráficos da Figura 3.20, decidiu-se não selecionar as previsões que usaram a estratégia do tipo 2, por tal método nem sempre conseguir estimar os parâmetros dos modelos, o que acaba resultando no uso de uma quantidade menor de rolling windows. Assim, as previsões SARIMA se referem ao uso de estratégia do tipo 1 e rolling windows de tamanho 720; as de regressão com erros autocorrelacionados se referem ao uso de polinômio de grau 0 modelando a tendência, sem sazonalidade semanal, com o uso da estratégia do tipo 1 para os erros SARIMA e rolling windows de tamanho 336; as previsões BATS se referem ao uso de modelos com sazonalidade semanal e rolling windows de tamanho 720; as previsões TBATS se referem ao uso de modelos sem sazonalidade semanal e rolling windows de tamanho 720 e as previsões benchmark se referem ao uso da média e rolling windows de tamanho 336.

\subsection{Pressão a montante no Norte de Peruíbe}

Nesta seção é apresentado e discutido os resultados das aplicações dos procedimentos de imputação de valores omissos e detecção de outliers e dos métodos de previsão relacionados a série de pressão a montante ao Norte de Peruíbe. A Figura 3.21 exibe um trecho da série que exemplifica seu comportamento. O gráfico (A) se refere a série original, enquanto que o gráfico (B) é mesmo trecho após limpeza e aplicação do métodos de detecção de outlier e preenchimento de valores omissos.

O método escolhido para a deteç̧ão de outliers e preenchimentos dos valores omissos, por possuir 
(A) Trecho da série original

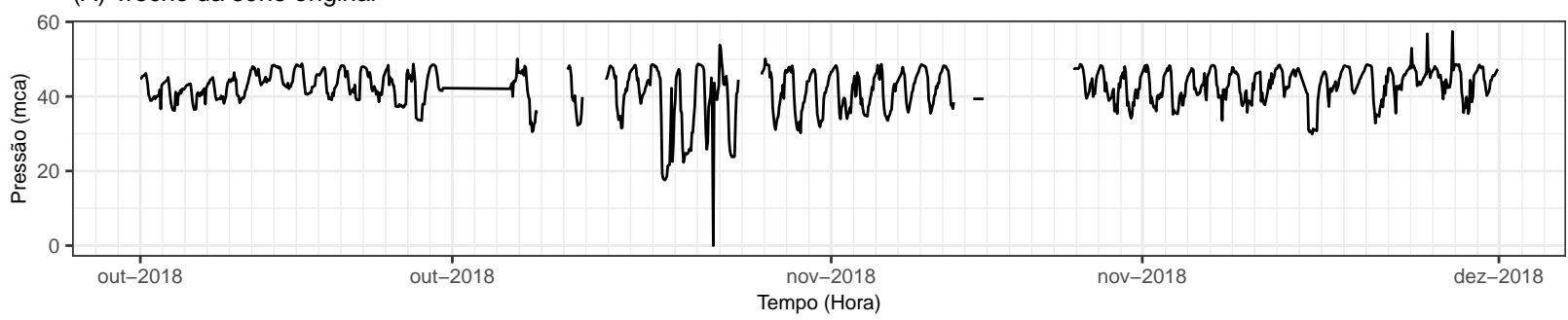

(B) Trecho da série após limpeza e preenchimento de valores omissos

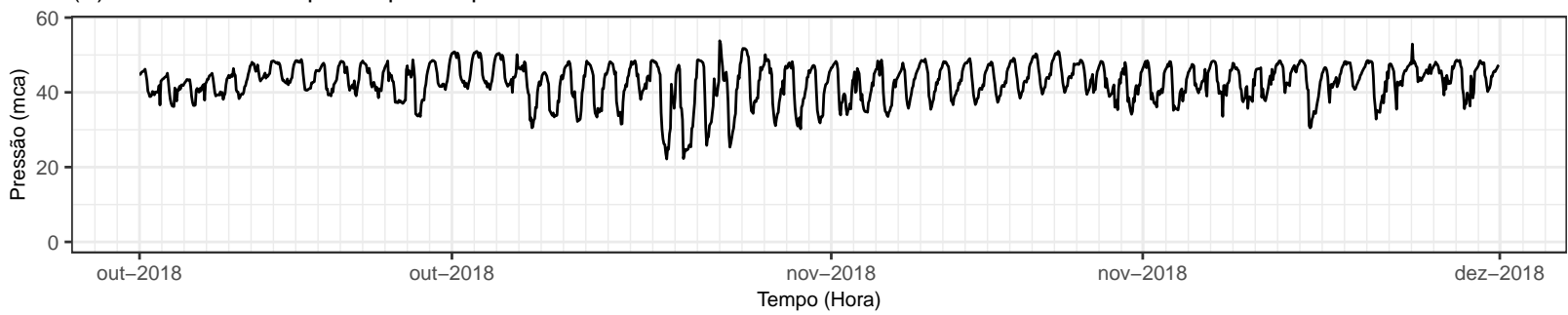

Figura 3.21: Trecho da série de pressão a montante ao Norte de Peruíbe que exemplificam seu comportamento. O gráfico (A) é referente a série original e o gráfico (B) mostra a série após as limpezas, tratamento dos outliers detectados e preenchimento dos valores omissos de acordo com o método escolhido.

o menor RMSE total entre todos os experimentos realizados, com o valor de 1,925, foi o ajuste de curvas de regressão com polinômio de grau 5 modelando a tendência, com interpolação de $R_{t}$, sem sazonalidade semanal, janela de tamanho 168 e valor de corte $c=5$. O total de valores classificados como anomalias após aplicação do método selecionado foi de 2018 (11,5\%), vis-à-vis à quantidade de $1804(10,3 \%)$ após a limpeza primária e à quantidade original de 206 (1,18 \%). Em relação a previsão, o método que apresentou melhor desempenho nos experimentos foi o que usou modelos SARIMA do tipo 2 e com rolling windows de tamanho 720, apresentando o valor de RMSE total de 1,627. Se excluírmos os procedimentos de previsão que usaram a estratégia do tipo 2, temos que o melhor procedimento foi o que usou modelos BATS sem sazonalidade semanal e com rolling windows de tamanho 336, apresentando um RMSE total de 2,249. De modo geral, os resultados mostram uma boa adequabilidade dos métodos propostos a série temporal de pressão a montante ao Norte de Peruíbe.

As próximas subseções apresentam e discutem os resultados de forma mais detalhada.

\subsubsection{Preenchimento de valores omissos}

As tabelas 3.41 à 3.43 mostram os resultados dos 12 melhores experimentos de cada tipo de procedimento de preenchimento de valores omissos, usando como medida de avaliação o RMSE. Em todas as tabelas os experimentos são apresentados em ordem decrescente de RMSE. Já a tabela 3.44 apresenta os resultados dos procedimentos de preenchimento de valores omissos usados como benchmark. Nesta, os experimentos são ordenados pelo ID.

De acordo com as informações apresentadas nas tabelas 3.41 à 3.44 podemos verificar que, em geral:

- Os melhores procedimentos de regressão, de acordo com o RMSE total, foram aqueles que usaram interpolação nos resíduos $R_{t}$, que consideraram a sazonalidade semanal e que, aparentemente, usaram janelas menores (de tamanho 168 e 336) e valor de corte $c=5$, sendo que o melhor procedimento de regressão para imputação de valores omissos foi o que usou 
Tabela 3.41: RMSE dos 12 melhores métodos de preenchimento de dados omissos baseados no ajuste de modelos de regressão, selecionados de acordo com menor RMSE. Os resultados se referem a aplicação dos métodos a série de pressão a montante ao Norte de Peruỉe.

\begin{tabular}{|c|c|c|c|c|c|c|c|c|c|c|c|c|c|}
\hline \multicolumn{6}{|c|}{ Experimentos de regressão } & \multicolumn{8}{|c|}{ Quantidade de valores omissos em sequência } \\
\hline ID & $\begin{array}{l}\text { Interpolação } \\
\quad \text { de } R_{t}\end{array}$ & $\begin{array}{c}\text { Dia da } \\
\text { semana }\end{array}$ & $\begin{array}{l}\text { Grau do } \\
\text { polinômio }\end{array}$ & Janela & $c$ & 1 & 3 & 6 & 12 & 18 & 24 & 48 & Total \\
\hline reg97 & Sim & Sim & 5 & 168 & 5 & 1,22 & 1,42 & 2,09 & 2,35 & 2,33 & 1,78 & 2,27 & 1,92 \\
\hline reg98 & $\operatorname{Sim}$ & Sim & 5 & 336 & 5 & 1,18 & 1,37 & 1,92 & 2,63 & 2,48 & 1,88 & 2,28 & 1,96 \\
\hline reg94 & Sim & Sim & 2 & 168 & 5 & 1,28 & 1,48 & 2,02 & 2,90 & 2,32 & 1,78 & 2,21 & 2,00 \\
\hline $\operatorname{reg} 25$ & Sim & Sim & 5 & 168 & 2 & 1,64 & 1,60 & 2,24 & 2,52 & 2,35 & 1,72 & 2,14 & 2,03 \\
\hline reg61 & Sim & Sim & 5 & 168 & 3 & 1,39 & 1,61 & 2,32 & 2,65 & 2,37 & 1,69 & 2,18 & 2,03 \\
\hline reg104 & Sim & $\operatorname{Sim}$ & 2 & 336 & 5 & 1,18 & 1,49 & 2,13 & 2,28 & 2,54 & 2,21 & 2,54 & 2,05 \\
\hline reg107 & Sim & Sim & 5 & 336 & 5 & 1,14 & 1,53 & 2,11 & 2,53 & 2,55 & 2,03 & 2,50 & 2,06 \\
\hline reg62 & Sim & Sim & 5 & 336 & 3 & 1,43 & 1,67 & 2,48 & 2,50 & 2,49 & 1,75 & 2,21 & 2,08 \\
\hline reg91 & Sim & Sim & 1 & 168 & 5 & 1,37 & 1,52 & 2,65 & 2,81 & 2,35 & 1,81 & 2,19 & 2,10 \\
\hline reg108 & Sim & Sim & 5 & 720 & 5 & 1,24 & 1,50 & 2,74 & 2,25 & 2,56 & 2,01 & 2,52 & 2,12 \\
\hline reg71 & Sim & $\mathrm{Sim}$ & 5 & 336 & 3 & 1,31 & 1,60 & 2,41 & 2,52 & 2,61 & 1,97 & 2,39 & 2,12 \\
\hline $\operatorname{reg} 58$ & Sim & Sim & 2 & 168 & 3 & 1,52 & 1,65 & 2,74 & 2,64 & 2,38 & 1,70 & 2,20 & 2,12 \\
\hline
\end{tabular}

Tabela 3.42: RMSE dos 12 melhores métodos de preenchimento de dados omissos baseados no ajuste de modelo de regressão acompanhado de decomposições clássica, selecionados de acordo com menor RMSE. $O$ modelo de regressão usado em conjundo com a decomposição clássica, por apresentar menor RMSE, foi o que possui polinômio de grau 5, com interpolação dos resíduos, sem sazonalidade semanal e janela de tamanho 168. Os resultados se referem a aplicação dos métodos a série de pressão a montante ao Norte de Peruíbe.

\begin{tabular}{|c|c|c|c|c|c|c|c|c|c|c|c|}
\hline \multicolumn{4}{|c|}{ Experimentos de decomposição clássica } & \multicolumn{8}{|c|}{ Quantidade de valores omissos em sequência } \\
\hline ID & $\begin{array}{l}\text { Interpolação } \\
\quad \text { de } R_{t}\end{array}$ & Janela & $c$ & 1 & 3 & 6 & 12 & 18 & 24 & 48 & Total \\
\hline $\operatorname{dec} 17$ & Sim & 336 & 5 & 1,13 & 1,39 & 2,04 & 2,27 & 2,58 & 2,10 & 2,49 & 2,00 \\
\hline $\operatorname{dec} 16$ & Sim & 168 & 5 & 1,18 & 1,43 & 2,09 & 2,36 & 2,46 & 2,02 & 2,50 & 2,01 \\
\hline $\operatorname{dec} 13$ & Não & 168 & 5 & 1,62 & 1,62 & 2,35 & 2,37 & 2,32 & 1,78 & 2,23 & 2,04 \\
\hline $\operatorname{dec} 18$ & $\mathrm{Sim}$ & 720 & 5 & 1,14 & 1,39 & 2,06 & 2,26 & 2,62 & 2,23 & 2,61 & 2,04 \\
\hline $\operatorname{dec} 4$ & Sim & 168 & 2 & 1,58 & 1,60 & 2,21 & 2,48 & 2,40 & 1,82 & 2,38 & 2,07 \\
\hline $\operatorname{dec} 14$ & Não & 336 & 5 & 1,66 & 1,66 & 2,34 & 2,38 & 2,34 & 1,83 & 2,29 & 2,07 \\
\hline $\operatorname{dec} 1$ & Não & 168 & 2 & 1,84 & 1,73 & 2,36 & 2,55 & 2,33 & 1,69 & 2,07 & 2,08 \\
\hline $\operatorname{dec} 10$ & Sim & 168 & 3 & 1,38 & 1,62 & 2,29 & 2,57 & 2,46 & 1,83 & 2,43 & 2,08 \\
\hline $\operatorname{dec} 5$ & Sim & 336 & 2 & 1,57 & 1,59 & 2,16 & 2,47 & 2,50 & 1,89 & 2,42 & 2,08 \\
\hline $\operatorname{dec} 11$ & Sim & 336 & 3 & 1,34 & 1,57 & 2,24 & 2,55 & 2,55 & 1,91 & 2,47 & 2,09 \\
\hline $\operatorname{dec} 7$ & Não & 168 & 3 & 1,71 & 1,73 & 2,43 & 2,68 & 2,33 & 1,68 & 2,14 & 2,10 \\
\hline $\operatorname{dec} 2$ & Não & 336 & 2 & 1,87 & 1,75 & 2,36 & 2,57 & 2,38 & 1,73 & 2,14 & 2,12 \\
\hline
\end{tabular}

Tabela 3.43: RMSE dos 12 melhores métodos de preenchimento de dados omissos baseados em decomposição STL, selecionados de acordo com menor RMSE. Os resultados se referem a aplicação dos métodos a série de pressão a montante ao Norte de Peruibe.

\begin{tabular}{|c|c|c|c|c|c|c|c|c|c|c|c|c|c|}
\hline \multicolumn{6}{|c|}{ Experimentos de decomposição STL } & \multicolumn{8}{|c|}{ Quantidade de valores omissos em sequência } \\
\hline ID & $\begin{array}{l}\text { Interpolação } \\
\text { de } R_{t}\end{array}$ & $n_{(i)}$ & $n_{(e)}$ & $n_{(s)}$ & $c$ & 1 & 3 & 6 & 12 & 18 & 24 & 48 & Total \\
\hline st146 & $\operatorname{Sim}$ & 2 & 0 & 25 & 5 & 1,15 & 1,39 & 2,02 & 2,59 & 2,35 & 1,83 & 2,57 & 1,99 \\
\hline st147 & $\mathrm{Sim}$ & 2 & 0 & 37 & 5 & 1,10 & 1,38 & 1,97 & 2,64 & 2,34 & 1,88 & 2,77 & 2,01 \\
\hline st148 & $\operatorname{Sim}$ & 2 & 0 & 49 & 5 & 1,09 & 1,38 & 1,96 & 2,67 & 2,39 & 1,92 & 2,98 & 2,06 \\
\hline st128 & $\mathrm{Sim}$ & 2 & 0 & 25 & 3 & 1,40 & 1,48 & 2,17 & 2,34 & 2,39 & 1,91 & 2,76 & 2,06 \\
\hline stl10 & $\mathrm{Sim}$ & 2 & 0 & 25 & 2 & 1,46 & 1,53 & 2,20 & 2,41 & 2,45 & 1,80 & 2,62 & 2,07 \\
\hline st149 & $\mathrm{Sim}$ & 1 & 5 & 25 & 5 & 1,46 & 1,47 & 2,48 & 2,36 & 2,35 & 1,86 & 2,56 & 2,08 \\
\hline st152 & $\operatorname{Sim}$ & 1 & 10 & 25 & 5 & 1,55 & 1,46 & 2,43 & 2,29 & 2,35 & 1,97 & 2,52 & 2,08 \\
\hline st129 & $\operatorname{Sim}$ & 2 & 0 & 37 & 3 & 1,34 & 1,48 & 2,18 & 2,73 & 2,40 & 1,81 & 2,64 & 2,08 \\
\hline st150 & $\operatorname{Sim}$ & 1 & 5 & 37 & 5 & 1,42 & 1,54 & 2,39 & 2,36 & 2,50 & 1,88 & 2,69 & 2,11 \\
\hline st153 & $\mathrm{Sim}$ & 1 & 10 & 37 & 5 & 1,47 & 1,55 & 2,35 & 2,30 & 2,60 & 1,93 & 2,66 & 2,12 \\
\hline st131 & $\mathrm{Sim}$ & 1 & 5 & 25 & 3 & 1,66 & 1,48 & 2,46 & 2,33 & 2,32 & 1,97 & 2,68 & 2,13 \\
\hline st130 & $\operatorname{Sim}$ & 2 & 0 & 49 & 3 & 1,33 & 1,50 & 2,16 & 2,75 & 2,48 & 1,87 & 2,85 & 2,13 \\
\hline
\end{tabular}

polinômio de grau 5 modelando a tendência, com interpolação de $R_{t}$, sem sazonalidade semanal, janela de tamanho 168 e valor de corte $c=5$, apresentando um RMSE total igual a 1,925. Os parâmetros desse modelo de regressão foram os usados na aplicação do método de 
Tabela 3.44: RMSE dos métodos benchmark de preenchimento de dados omissos. Os resultados se referem a aplicação dos métodos a série de pressão a montante ao Norte de Peruíbe.

\begin{tabular}{|c|c|c|c|c|c|c|c|c|c|c|}
\hline \multicolumn{3}{|c|}{ Experimentos emphbenchmark } & \multicolumn{8}{|c|}{ Quantidade de valores omissos em sequência } \\
\hline ID & $\begin{array}{c}\text { Forma de } \\
\text { benchmark }\end{array}$ & Janela & 1 & 3 & 6 & 12 & 18 & 24 & 48 & Total \\
\hline ben1 & Média & 168 & 4,21 & 3,98 & 4,83 & 4,79 & 4,37 & 3,79 & 4,26 & 4,32 \\
\hline ben 2 & Média & 336 & 4,39 & 4,11 & 5,12 & 4,63 & 4,46 & 3,92 & 4,31 & 4,42 \\
\hline ben3 & Média & 720 & 4,60 & 4,07 & 5,39 & 4,72 & 4,50 & 4,03 & 4,53 & 4,55 \\
\hline ben 4 & Mediana & 168 & 4,42 & 3,98 & 5,21 & 4,50 & 4,24 & 3,79 & 4,34 & 4,35 \\
\hline ben 5 & Mediana & 336 & 4,53 & 3,93 & 5,34 & 4,55 & 4,28 & 3,85 & 4,39 & 4,41 \\
\hline ben 6 & Mediana & 720 & 4,68 & 3,95 & 5,50 & 4,68 & 4,43 & 3,95 & 4,41 & 4,52 \\
\hline ben 7 & Interpolação & - & 1,47 & 1,66 & 3,14 & 4,11 & 4,71 & 5,84 & 5,36 & 3,75 \\
\hline
\end{tabular}

decomposição clássica.

- Não se observa um padrão muito claro nos parâmetros dos melhores procedimentos de decomposição clássica de acordo com o RMSE total. O melhor procedimento foi aquele que usou decomposição com interpolação de $R_{t}$, janela de tamanho 336 e valor de corte $c=5$, apresentando um RMSE total igual a 2.

- Os tipos de decomposição STL que tiveram melhores resultados, de acordo com o RMSE total, foram os que possuem interpolação nos resíduos $R_{t}$, e que, aparentemente, usaram $n_{(s)}=24$ e decomposição STL não robusta $\left(n_{(i)}=2\right.$ e $\left.n_{(e)}=0\right)$. O melhor procedimento foi o de decomposição não robusta $\left(n_{(i)}=2\right.$ e $\left.n_{(e)}=0\right)$, com interpolação de $R_{t}, n_{(s)}=25$ e valor de corte $c=5$, apresentando um RMSE total igual a 1,986 .

- Dentre os métodos de benchmark, o que teve melhor desempenho foi o que interpola linearmente os valores da série, apresentando um RMSE total igual a 3,755. Verifica-se que os procedimentos propostos tiveram desempenhos bem superiores aos benchmarks.

- Dentre todos os experimentos, o que apresentou melhor resultado foi o procedimento de ajuste de curvas de regressão com polinômio de grau 5 modelando a tendência, com interpolação de $R_{t}$, sem sazonalidade semanal, janela de tamanho 168 e valor de corte $c=5$, apresentando um valor de RMSE total de 1,925. Este é o procedimento para o qual é apresentado uma análise de outliers na próxima subseção e que é usado oficialmente para preencher os valores omissos da série.

A Figura 3.22 exemplifica alguns experimentos de preenchimento de valores omissos. Cada gráfico representa um trecho da série temporal de pressão a montante ao Norte de Peruíbe no qual propositalmente foi removido uma sequência de valores. Todos os gráficos se referem a uma lacuna de tamanho 48 horas acompanhado de 12 valores anteriores e posteriores à lacuna principal. Os procedimentos de preenchimento adotados para ilustrar os gráficos são o melhor experimento, de acordo com o RMSE total, de cada tipo de procedimento apresentados nas tabelas 3.41 à 3.44.

Verifica-se que os procedimentos propostos conseguiram fazer uma boa estimativa dos valores omissos, sendo estas bem superiores às do método de interpolação. Esses resultados já eram esperados, pois a série de pressão a montante ao Norte de Peruíbe apresenta um comportamento sazonal bem característico, mesmo que esse comportamento tenha alguns momentos de notáveis diferenças entre o valor real e o estimado pelos métodos propostos. 
(A)

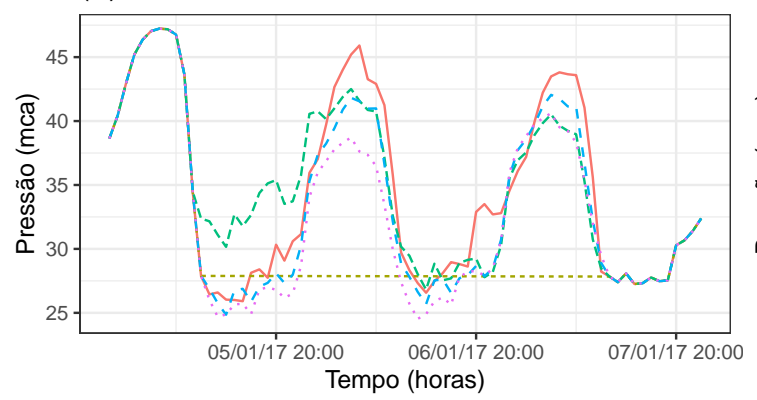

(C)

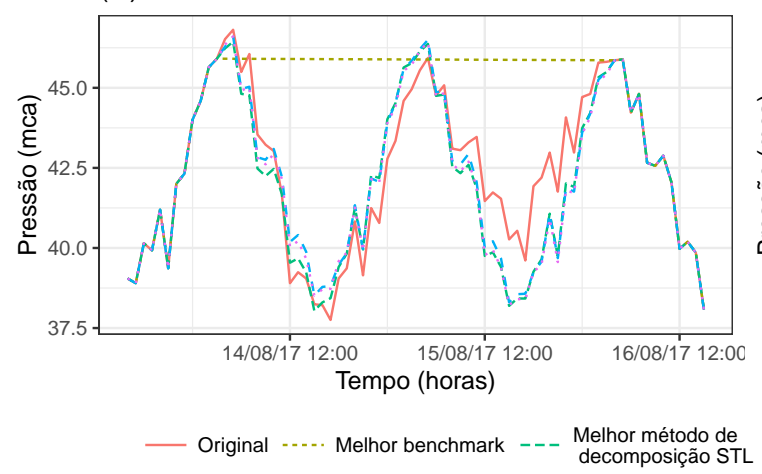

(B)

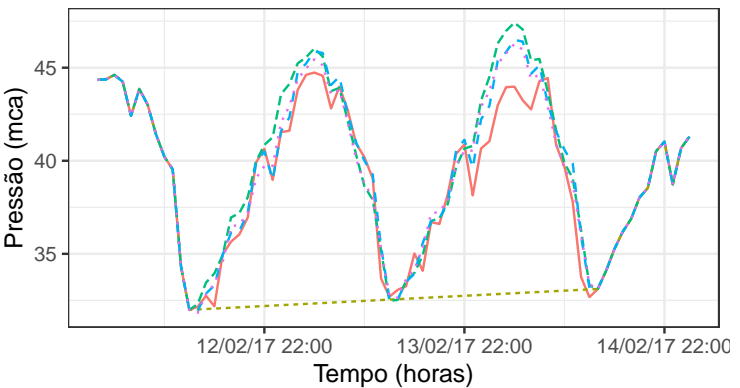

(D)

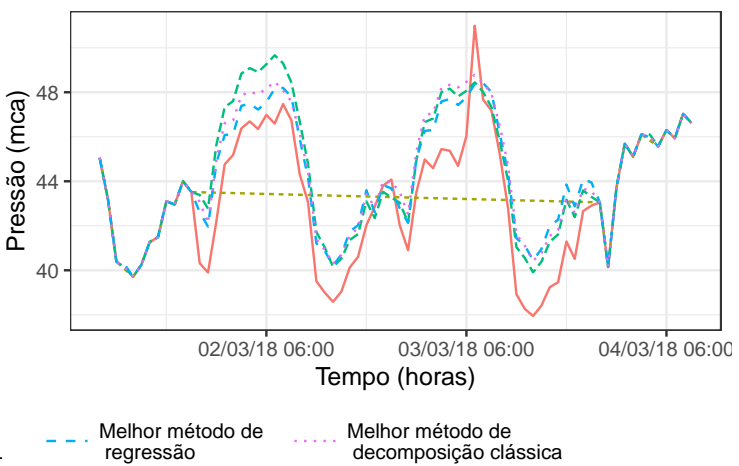

Figura 3.22: Alguns trechos da série de pressão a montante ao Norte de Peruíbe que exemplificam a aplicação dos procedimentos de preenchimento de valores omissos. É apresentado o melhor experimento de imputação de valores omissos de cada tipo de procedimento de acordo com o RMSE, descritos nas tabelas 3.41 à 3.44. A lacuna principal de valores omissos usada em cada gráfico foi inserida artificialmente na série temporal a fim de avaliar a performance dos procedimentos de preenchimento de valores omissos. $O$ tamanho da lacuna principal é de 48 horas, sendo precedida e sucedida de 12 horas de valores originais.

\subsubsection{Detecção e tratamento de outliers}

As tabelas 3.45 e 3.46 mostram os resultados dos experimentos elaborados para avaliar o desempenho em detectar e tratar os outliers do melhor procedimento selecionado para a imputação dos valores omissos. A Tabela 3.45 apresenta as taxas de deteç̧ão dos outliers, sendo dividida em duas partes: na parte superior o cálculo das taxas considera todas as observações afetadas pelo efeito atípico, enquanto que na parte inferior é considerado apenas a observação mais afetada pelo efeito atípico. Vale lembrar que no caso do efeito atípico do tipo platô todas as observações foram consideradas como sendo as mais afetadas devido ao efeito se distribuir igualmente entre elas. Já a tabela 3.46 é destinada a verificar a acurácia do procedimento ao corrigir os valores dos outliers. Sua estrutura é análoga à da tabela 3.45, sendo que a linha total é o RMSE do efeito atípico nas observações.

A partir das tabelas, podemos verificar que:

- De modo geral, as taxas de deteção dos outliers foram altas para o tipo único e para os demais tipos de efeitos a taxa de detecção depende dos parâmetros do experimento. Quando se considera apenas as obsevações mais afetadas, as taxa de detecção foram bem altas, com exceção dos efeitos atípicos do tipo platô. Esses resultados são uma evidência da possível adequação do procedimento em detectar os outliers da série. Nota-se também que, para as observações mais afetadas, as altas taxas de deteç̧ão resultaram em um RMSE relativamente bom, conseguindo fazer uma redução expressiva em relação ao RMSE total, porém, o mesmo não pode ser dito quando se considera todas as observações afetadas pelos efeitos atípicos. 
Tabela 3.45: Taxa de deteç̧̃̃o de outliers de acordo com o procedimento que apresentou melhor desempenho em preencher valores omissos. O procedimento foi o de ajuste de curvas de regressão com polinômio de grau 5 modelando a tendência, com interpolação de $R_{t}$, sem sazonalidade semanal, janela de tamanho 168 e valor de corte $c=5$. Variou-se o valor de corte $c$ e a quantidade de iterações máxima com o objetivo de verificar se a mudança desses parâmetros causam algum impacto na deteç̧ão dos outliers. A aplicação se refere a série de pressão a montante ao Norte de Peruíbe.

\begin{tabular}{|c|c|c|c|c|c|c|c|c|}
\hline \multicolumn{3}{|c|}{ Experimentos } & \multicolumn{6}{|c|}{ Tipo de efeitos atípicos } \\
\hline ID & c & $\begin{array}{l}\mathrm{N}^{0} \text { máximo } \\
\text { de iterações }\end{array}$ & Único & Platô & Pulso & $\begin{array}{l}\text { C.D. } \\
\text { linear }\end{array}$ & $\begin{array}{c}\text { C.D. } \\
\text { exponencial }\end{array}$ & $\begin{array}{c}\text { C.D. } \\
\text { logaritmico }\end{array}$ \\
\hline \multicolumn{9}{|c|}{ Todas as observações afetadas } \\
\hline out1 & 2 & 1 & - & 0,439 & 0,413 & 0,441 & 0,425 & 0,440 \\
\hline out 2 & 3 & 1 & 0,950 & 0,193 & 0,298 & 0,277 & 0,293 & 0,264 \\
\hline out3 & 4 & 1 & 0,833 & 0,142 & 0,176 & 0,166 & 0,193 & 0,156 \\
\hline out 4 & 5 & 1 & 0,583 & 0,093 & 0,110 & 0,105 & 0,124 & 0,099 \\
\hline out 5 & 2 & 3 & 1,000 & 0,724 & 0,563 & 0,579 & 0,556 & 0,588 \\
\hline out 6 & 3 & 3 & 0,967 & 0,316 & 0,409 & 0,391 & 0,412 & 0,375 \\
\hline out 7 & 4 & 3 & 0,950 & 0,164 & 0,273 & 0,243 & 0,283 & 0,213 \\
\hline out 8 & 5 & 3 & 0,767 & 0,120 & 0,169 & 0,148 & 0,173 & 0,135 \\
\hline out9 & 2 & 5 & 1,000 & 0,733 & 0,563 & 0,587 & 0,561 & 0,600 \\
\hline out10 & 3 & 5 & 0,967 & 0,324 & 0,409 & 0,393 & 0,413 & 0,378 \\
\hline out11 & 4 & 5 & 0,950 & 0,164 & 0,276 & 0,246 & 0,284 & 0,213 \\
\hline out12 & 5 & 5 & 0,767 & 0,120 & 0,169 & 0,153 & 0,173 & 0,135 \\
\hline Total & - & - & 1,000 & 1,000 & 1,000 & 1,000 & 1,000 & 1,000 \\
\hline \multicolumn{9}{|c|}{ Somente observações mais afetadas } \\
\hline out1 & 2 & 1 & - & 0,439 & 1,000 & 0,924 & 0,952 & 0,876 \\
\hline out 2 & 3 & 1 & 0,950 & 0,193 & 0,967 & 0,762 & 0,886 & 0,648 \\
\hline out3 & 4 & 1 & 0,833 & 0,142 & 0,750 & 0,505 & 0,657 & 0,390 \\
\hline out 4 & 5 & 1 & 0,583 & 0,093 & 0,483 & 0,333 & 0,476 & 0,276 \\
\hline out 5 & 2 & 3 & 1,000 & 0,724 & 1,000 & 0,971 & 0,971 & 0,971 \\
\hline out 6 & 3 & 3 & 0,967 & 0,316 & 1,000 & 0,914 & 0,971 & 0,857 \\
\hline out 7 & 4 & 3 & 0,950 & 0,164 & 0,950 & 0,657 & 0,876 & 0,533 \\
\hline out 8 & 5 & 3 & 0,767 & 0,120 & 0,667 & 0,429 & 0,610 & 0,333 \\
\hline out9 & 2 & 5 & 1,000 & 0,733 & 1,000 & 0,971 & 0,971 & 0,971 \\
\hline out10 & 3 & 5 & 0,967 & 0,324 & 1,000 & 0,914 & 0,971 & 0,867 \\
\hline out11 & 4 & 5 & 0,950 & 0,164 & 0,950 & 0,657 & 0,886 & 0,533 \\
\hline out12 & 5 & 5 & 0,767 & 0,120 & 0,667 & 0,429 & 0,610 & 0,333 \\
\hline Total & - & - & 1,000 & 1,000 & 1,000 & 1,000 & 1,000 & 1,000 \\
\hline
\end{tabular}

- O número de máximo de iterações possui, em geral, uma considerável influencia nos resultados. Com exceção do efeito do tipo único, a taxa de deteç̧ão dos experimentos que tiveram apenas uma iteração foi menor do que quando usadas iterações máximas iguais a 3 ou 5. Porém, não há muita diferança entre usar um número máximo de iterações igual a 3 ou igual a 5 . Algo semelhante pode ser observado pelos valores de RMSE: o RMSE dos experimentos que usaram apenas uma iteração máxima foram maiores do aqueles que tiveram iterações máximas iguais a 3 ou 5. A semelhança dos resultados do uso de 3 e 5 iterações máximas pode ser explicado pelo algoritmo conseguir encontrar grande parte dos outliers antes de atingir número máximo de iterações, sendo necessário apenas uma baixa quantidade de iterações, isto é, um número menor ou igual a 3 , porém maior que 1 .

- Como o esperado, percebe-se claramente que o valor de corte $c$ influencia na taxa de detecção, sendo que quanto menor for valor de corte $c$, melhor é a taxa de deteç̧ão. Também verifica-se um melhor valor de RMSE para os valores mais baixos de $c$. Lembramos que, embora um valor de corte baixo aumente a taxa de detecção de outliers, ele também aumenta a taxa de detecção de valores que possivelmente não seriam outliers.

A Figura 3.23 exemplifica as constatações realizadas. É possível observar que os procedimentos conseguiram detectar e tratar somente as observações mais afetadas pelos efeitos atípicos. No caso do efeito atípico do tipo platô, o tratamento foi quase nulo (gráfico (B)).

A Tabela 3.47 apresenta a quantidade de anomalias detectadas em cada fase do tratamento dado a série de pressão a montante ao Norte de Peruíbe. Nota-se que a maior parte das observações 
Tabela 3.46: RMSE do tratamento dos outliers de acordo com o procedimento que apresentou melhor desempenho em preencher valores omissos. O procedimento foi o de ajuste de curvas de regressão com polinômio de grau 5 modelando a tendência, com interpolação de $R_{t}$, sem sazonalidade semanal, janela de tamanho 168 e valor de corte $c=5$. Variou-se o valor de corte $c$ e a quantidade de iterações máxima com o objetivo de verificar se a mudança desses parâmetros causam algum impacto na detecção dos outliers. A linha total é o RMSE das observações ouliers em relação ao seu valor original. A aplicação se refere a série de pressão a montante ao Norte de Peruibe.

\begin{tabular}{|c|c|c|c|c|c|c|c|c|}
\hline \multicolumn{3}{|c|}{ Experimentos } & \multicolumn{6}{|c|}{ Tipo de efeitos atípicos } \\
\hline ID & $\mathrm{c}$ & $\begin{array}{l}\text { No máximo } \\
\text { de iterações }\end{array}$ & Único & Platô & Pulso & $\begin{array}{l}\text { C.D. } \\
\text { linear }\end{array}$ & $\begin{array}{c}\text { C.D. } \\
\text { exponencial }\end{array}$ & $\begin{array}{c}\text { C.D. } \\
\text { logaritmico }\end{array}$ \\
\hline \multicolumn{9}{|c|}{ Todas as observações afetadas } \\
\hline out1 & 2 & 1 & - & 5,94 & 4,17 & 5,16 & 5,25 & 5,43 \\
\hline out 2 & 3 & 1 & 1,75 & 6,74 & 4,71 & 6,26 & 6,15 & 6,11 \\
\hline out3 & 4 & 1 & 3,36 & 7,03 & 5,63 & 6,96 & 6,65 & 6,90 \\
\hline out 4 & 5 & 1 & 5,45 & 7,39 & 6,10 & 7,40 & 7,29 & 7,53 \\
\hline out 5 & 2 & 3 & 1,20 & 5,02 & 3,72 & 4,40 & 4,14 & 4,60 \\
\hline out 6 & 3 & 3 & 1,55 & 6,40 & 4,25 & 5,47 & 5,12 & 5,70 \\
\hline out7 & 4 & 3 & 1,87 & 6,89 & 5,02 & 6,15 & 6,05 & 6,42 \\
\hline out 8 & 5 & 3 & 3,82 & 7,16 & 5,66 & 6,88 & 6,74 & 6,99 \\
\hline out 9 & 2 & 5 & 1,20 & 5,00 & 3,71 & 4,39 & 4,12 & 4,55 \\
\hline out10 & 3 & 5 & 1,55 & 6,38 & 4,25 & 5,46 & 5,10 & 5,68 \\
\hline out11 & 4 & 5 & 1,87 & 6,89 & 5,01 & 6,13 & 6,03 & 6,42 \\
\hline out12 & 5 & 5 & 3,82 & 7,16 & 5,66 & 6,84 & 6,74 & 6,99 \\
\hline Total & - & - & 11,92 & 9,51 & 8,76 & 9,69 & 10,34 & 9,46 \\
\hline \multicolumn{9}{|c|}{ Somente observações mais afetadas } \\
\hline out1 & 2 & 1 & - & 5,94 & 2,41 & 5,67 & 5,94 & 5,79 \\
\hline out 2 & 3 & 1 & 1,75 & 6,74 & 2,90 & 7,28 & 7,33 & 7,13 \\
\hline out 3 & 4 & 1 & 3,36 & 7,03 & 5,43 & 8,54 & 8,62 & 8,40 \\
\hline out 4 & 5 & 1 & 5,45 & 7,39 & 7,42 & 9,75 & 9,89 & 9,47 \\
\hline out 5 & 2 & 3 & 1,20 & 5,02 & 2,41 & 4,84 & 4,77 & 4,98 \\
\hline out 6 & 3 & 3 & 1,55 & 6,40 & 2,52 & 6,40 & 6,33 & 6,49 \\
\hline out 7 & 4 & 3 & 1,87 & 6,89 & 3,75 & 7,73 & 7,61 & 7,82 \\
\hline out 8 & 5 & 3 & 3,82 & 7,16 & 6,12 & 9,10 & 9,19 & 8,86 \\
\hline out 9 & 2 & 5 & 1,20 & 5,00 & 2,41 & 4,84 & 4,75 & 4,94 \\
\hline out10 & 3 & 5 & 1,55 & 6,38 & 2,52 & 6,40 & 6,29 & 6,47 \\
\hline out11 & 4 & 5 & 1,87 & 6,89 & 3,75 & 7,70 & 7,53 & 7,82 \\
\hline out12 & 5 & 5 & 3,82 & 7,16 & 6,12 & 9,10 & 9,19 & 8,86 \\
\hline Total & - & - & 11,92 & 9,51 & 14,66 & 14,27 & 16,95 & 13,06 \\
\hline
\end{tabular}

anômalas foram detectadas durante a fase de limpeza primária, o que dá a quantidade de 1598 observações ou 9,1 \% do total. Durante todo o processo, foram detectadas 2018 (11,5 \%) observações anormais.

Tabela 3.47: Quantidade de valores detectados como anomalias em cada estágio de tratamento da série de pressão a montante ao Norte de Peruibe. A primeira linha da tabela se refere a quantidade de valores classificados pelo sistema da Sabesp como bad e que, portanto, eram omissos na série original. A segunda linha se refere aos valores detectados como anomalias pela limpeza primária. A terceira linha se refere a quantidade de valores detectados como outliers pela aplicação do algoritmo proposto.

\begin{tabular}{rrrrr}
\hline Fase de deteção de anomalias & Frequência absoluta & Frequência relativa & Acumulado absoluto & Acumulado relativo \\
\hline Originalmente & 206 & $1,2 \%$ & 206 & $1,2 \%$ \\
Limpeza primária & 1.598 & $9,1 \%$ & 1.804 & $10,3 \%$ \\
Algoritmo de deteção de outliers & 214 & $1,2 \%$ & 2.018 & $11,5 \%$ \\
Tamanho da série & 17.519 & $100 \%$ & 19.537 & $100 \%$ \\
\hline
\end{tabular}

\subsubsection{Previsão}

A Tabela 3.48 traz os resultados de acurácia dos experimentos de previsão de acordo com RMSE. Ela é dividida em duas partes: a parte superior é dedicada a mostrar os resultados que usaram rolling windows de tamanho 336 horas (14 dias) e a parte inferior mostra os resultados referentes ao uso de rolling windows de tamanho 720 horas (30 dias). Os experimentos estão agrupados por tipo de modelos. A partir dessa tabela, verifica-se que:

- O melhor procedimento de previsão com modelos SARIMA, de acordo com o RMSE total, foi 
(A) Único

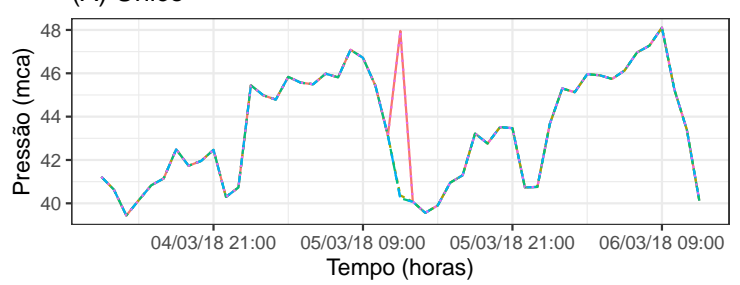

(C) Pulso

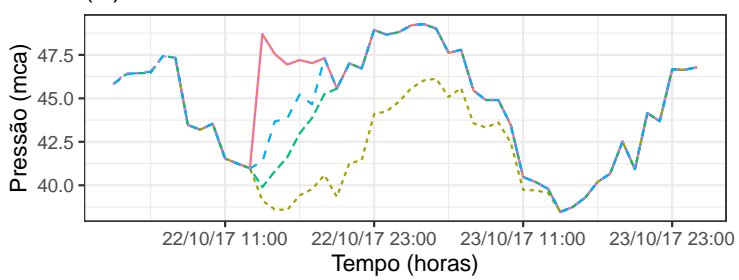

(E) C.D. Exponencial

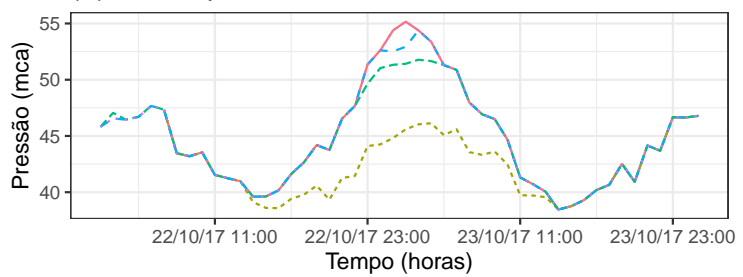

(B) Platô

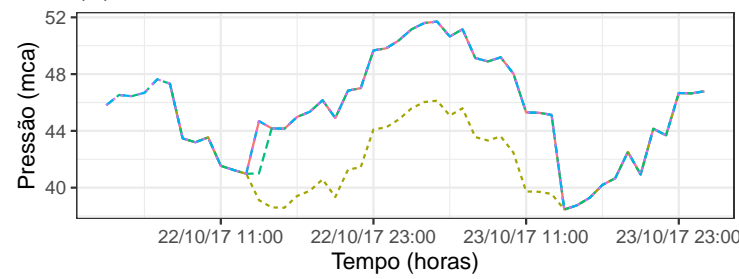

(D) C.D. Linear

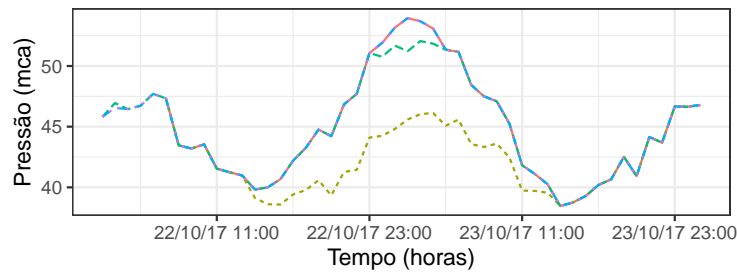

(F) C.D. Logaritmico

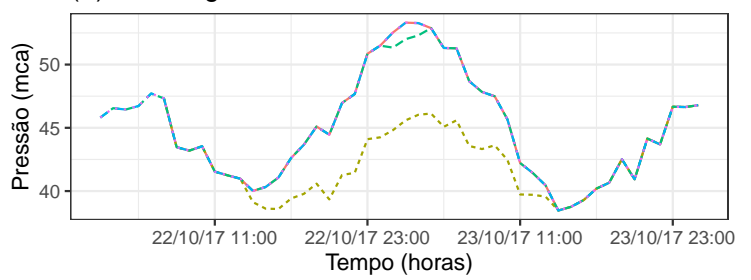

Corte $=5$

Figura 3.23: Exemplos de detecção e tratamento dos outliers inseridos na série de pressão a montante ao Norte de Peruibe. Os trechos mostrados possuem tamanho 48 e são centrados nas observações afetadas pelo efeito atípico. Os gráficos de (A) a (F) exemplificam cada tipo de efeito atípico na série. A quantidade de iteração máxima dos experimentos selecionados é 3.

o que usou estratégia do tipo 2 e rolling windows de tamanho 720, apresentando RMSE total de 1,627. Vale notar que a estratégia do tipo 2 não conseguiu se ajustar em todas as rolling windows de tamanho 720 testadas, o que pode ser um empecilho para se fazer comparações. Outro ponto a se observar é que a estratégia de tipo 2 teve um desempenho bem superior do que a de tipo 1 no uso de rolling window de ambos tamanhos, o que é um resultado um tanto inusitado, já que o esperado era que o desempenho de um modelo identificado usando as observações da própria rolling window fosse superior àquele que usasse as observações de uma outra rolling window para se fazer tal identificação.

- O melhor procedimento de regressão com erros autocorrelacionados, de acordo com o RMSE total, foi o que usou polinômio de grau 1 modelando a tendência, com sazonalidade semanal, com o uso da estratégia do tipo 2 para os erros SARIMA e rolling windows de tamanho 336, apresentando RMSE total de 1,952. É importante notar que nem todos os experimentos conseguiram ajustar determinado modelo em todas as rollings windows, o que pode ser um empecilho a mais na hora de fazer comparações.

- Dentre os procedimentos BATS e TBATS, o que teve melhor desempenho de acordo com o RMSE total foi o que usou modelos BATS sem sazonalidade semanal e com rolling windows de tamanho 336, apresentando RMSE total de 2,249. Na maioria dos casos, os procedimentos BATS e TBATS o uso de sazonalidade semanal não melhorou significativamente o desempenho dos modelos. 
Tabela 3.48: RMSE dos experimentos de previsão aplicados a série de pressão a montante ao Norte de Peruíbe. As estratégias de tipo 1 se referem a aplicação do algoritmo de seleção de modelo em cada uma das rollings windows, enquanto que as de tipo 2 se referem a aplicação do algoritmo somente na primeira rolling window e do ajuste modelo selecionado nas demais rolling windows, reestimando os parâmetros. $O R M S E$ "Todos"é calculado usando todos os valores preditos de horizonte $h=1, \ldots ., 168$, incluido aqueles que não aparecem na tabela.

\begin{tabular}{|c|c|c|c|c|c|c|c|c|c|c|c|c|c|c|}
\hline \multicolumn{4}{|c|}{ Experimentos } & \multicolumn{11}{|c|}{ Horizonte de previsão } \\
\hline Modelos & $\begin{array}{l}\text { Grau do } \\
\text { polinô- } \\
\text { mio }\end{array}$ & $\begin{array}{l}\text { Sazonalidade } \\
\text { semanal }\end{array}$ & $\begin{array}{c}\text { Estratégia } \\
\text { de ajuste }\end{array}$ & $\mathrm{N}$ & 1 & 2 & 3 & 6 & 12 & 18 & 24 & 48 & 168 & Todos \\
\hline \multicolumn{15}{|c|}{ Rolling windows de tamanho 336} \\
\hline \multirow{2}{*}{ SARIMA } & - & - & Tipo 1 & 30 & 1,010 & 1,651 & 1,906 & 1,275 & 1,565 & 1,95 & 1,67 & 2,31 & 4,74 & 3,40 \\
\hline & - & - & Tipo 2 & 30 & 1,046 & 1,592 & 1,873 & 1,423 & 1,446 & 1,67 & 1,39 & 1,90 & 2,06 & 1,98 \\
\hline \multirow{8}{*}{$\begin{array}{c}\text { Regressão } \\
\text { com erros } \\
\text { SARIMA }\end{array}$} & 0 & $\operatorname{Sim}$ & Tipo 1 & 30 & 1,135 & 1,699 & 2,029 & 1,695 & 1,715 & 1,57 & 1,58 & 2,13 & 2,36 & 2,52 \\
\hline & 0 & $\operatorname{Sim}$ & Tipo 2 & 28 & 1,174 & 1,686 & 1,916 & 2,154 & 2,125 & 2,41 & 2,22 & 2,77 & 2,34 & 2,91 \\
\hline & 1 & $\operatorname{Sim}$ & Tipo 1 & 30 & 1,152 & 1,921 & 2,305 & 3,199 & 2,624 & 2,71 & 3,06 & 3,06 & 3,28 & 2,97 \\
\hline & 1 & $\operatorname{Sim}$ & Tipo 2 & 21 & 0,905 & 1,483 & 1,703 & 1,479 & 1,492 & 1,30 & 1,18 & 1,96 & 2,50 & 1,95 \\
\hline & 0 & Não & Tipo 1 & 30 & 1,122 & 1,684 & 2,010 & 1,437 & 1,596 & 1,80 & 1,55 & 2,22 & 2,39 & 2,30 \\
\hline & 0 & Não & Tipo 2 & 30 & 1,108 & 1,628 & 1,813 & 1,793 & 1,681 & 2,25 & 1,97 & 2,34 & 2,28 & 2,58 \\
\hline & 1 & Não & Tipo 1 & 30 & 1,260 & 1,648 & 2,024 & 1,520 & 1,421 & 1,83 & 1,60 & 2,00 & 2,88 & 2,46 \\
\hline & 1 & Não & Tipo 2 & 16 & 0,943 & 1,314 & 1,725 & 1,302 & 1,263 & 1,38 & 1,37 & 1,99 & 2,93 & 2,38 \\
\hline \multirow{2}{*}{ BATS } & - & Não & Tipo 1 & 30 & 1,302 & 1,752 & 2,091 & 1,292 & 1,615 & 1,74 & 1,74 & 2,26 & 2,47 & 2,25 \\
\hline & - & $\mathrm{Sim}$ & Tipo 1 & 30 & 3,240 & 2,421 & 2,846 & 2,072 & 2,373 & 2,47 & 2,89 & 2,95 & 3,26 & 3,27 \\
\hline \multirow[b]{2}{*}{ TBATS } & - & Não & Tipo 1 & 30 & 1,219 & 1,849 & 2,202 & 1,561 & 1,523 & 2,08 & 1,74 & 2,24 & 2,15 & 2,39 \\
\hline & - & $\mathrm{Sim}$ & Tipo 1 & 30 & 1,149 & 1,756 & 2,120 & 1,699 & 1,439 & 1,88 & 2,03 & 2,43 & 2,46 & 3,63 \\
\hline \multirow{3}{*}{ Benchmark } & - & - & Média & 30 & 3,048 & 3,589 & 4,272 & 4,961 & 4,191 & 4,02 & 1,91 & 2,40 & 2,70 & 4,00 \\
\hline & - & - & Mediana & 30 & 2,705 & 3,252 & 3,955 & 4,728 & 3,618 & 3,98 & 1,30 & 2,15 & 2,26 & 3,67 \\
\hline & - & - & Ûlt. Obs. & 30 & 1,790 & 2,625 & 3,859 & 5,846 & 4,830 & 3,49 & 2,00 & 2,35 & 2,40 & 4,41 \\
\hline \multicolumn{15}{|c|}{ Rolling windows de tamanho 720} \\
\hline \multirow{2}{*}{ SARIMA } & - & - & Tipo 1 & 30 & 0,529 & 0,674 & 0,753 & 0,813 & 0,904 & 2,31 & 2,63 & 4,10 & 3,54 & 2,90 \\
\hline & - & - & Tipo 2 & 21 & 0,461 & 0,646 & 0,719 & 0,593 & 0,678 & 1,31 & 1,28 & 1,49 & 2,16 & 1,63 \\
\hline \multirow{8}{*}{$\begin{array}{c}\text { Regressão } \\
\text { com erros } \\
\text { SARIMA }\end{array}$} & 0 & $\operatorname{Sim}$ & Tipo 1 & 30 & 1,394 & 2,199 & 3,058 & 4,550 & 4,438 & 4,12 & 3,20 & 3,06 & 2,28 & 3,34 \\
\hline & 0 & $\mathrm{Sim}$ & Tipo 2 & 20 & 1,182 & 1,461 & 1,952 & 2,202 & 2,577 & 2,26 & 2,32 & 2,65 & 3,54 & 3,10 \\
\hline & 1 & $\operatorname{Sim}$ & Tipo 1 & 30 & 1,266 & 1,884 & 2,121 & 1,947 & 2,307 & 3,23 & 3,28 & 3,14 & 3,13 & 3,14 \\
\hline & 1 & $\operatorname{Sim}$ & Tipo 2 & 27 & 1,202 & 1,804 & 1,889 & 1,914 & 2,198 & 3,19 & 3,15 & 3,24 & 3,16 & 3,16 \\
\hline & 0 & Não & Tipo 1 & 30 & 1,634 & 2,823 & 4,004 & 4,975 & 4,760 & 4,22 & 3,05 & 3,23 & 2,48 & 3,58 \\
\hline & 0 & Não & Tipo 2 & 10 & 1,639 & 2,870 & 1,583 & 1,677 & 2,880 & 2,40 & 3,00 & 3,98 & 4,31 & 3,50 \\
\hline & 1 & Não & Tipo 1 & 30 & 1,337 & 1,982 & 2,185 & 1,885 & 2,242 & 3,23 & 3,29 & 3,26 & 3,19 & 3,13 \\
\hline & 1 & Não & Tipo 2 & 27 & 1,298 & 1,950 & 2,070 & 1,910 & 2,365 & 3,53 & 3,49 & 3,60 & 3,48 & 3,46 \\
\hline \multirow{2}{*}{ BATS } & - & Não & Tipo 1 & 30 & 1,329 & 1,819 & 1,849 & 1,561 & 1,470 & 2,90 & 2,84 & 4,49 & 6,01 & 4,61 \\
\hline & - & $\operatorname{Sim}$ & Tipo 1 & 30 & 1,304 & 1,857 & 2,123 & 1,879 & 2,481 & 3,53 & 3,84 & 3,50 & 3,27 & 3,31 \\
\hline \multirow{2}{*}{ TBATS } & - & Não & Tipo 1 & 30 & 1,242 & 1,960 & 2,120 & 1,833 & 2,367 & 3,68 & 3,68 & 3,75 & 3,00 & 3,30 \\
\hline & - & $\operatorname{Sim}$ & Tipo 1 & 30 & 1,253 & 1,923 & 2,089 & 1,694 & 2,488 & 3,61 & 3,58 & 3,96 & 3,33 & 3,60 \\
\hline \multirow{3}{*}{ Benchmark } & - & - & Média & 30 & 2,469 & 2,581 & 2,816 & 4,149 & 3,427 & 5,52 & 3,74 & 3,87 & 2,66 & 4,12 \\
\hline & - & - & Mediana & 30 & 2,795 & 2,757 & 2,854 & 4,101 & 3,170 & 5,65 & 3,81 & 3,86 & 2,56 & 4,06 \\
\hline & - & - & Últ. Obs. & 30 & 2,123 & 2,668 & 3,458 & 5,727 & 5,137 & 5,18 & 3,87 & 4,04 & 3,73 & 5,09 \\
\hline
\end{tabular}

- Com exceção dos procedimentos que usaram modelos SARIMA, o uso de rolling windows de tamanho 336 aparenta ser um pouco melhor do que usar as de tamanho 720.

- Alguns experimentos que empregaram a estratégia do tipo 2 tiveraram um valor de $N<30$. Isso é explicado pelo fato da estratégia consistir em identificar o modelo usando as observações de apenas de uma rolling windows e depois só reestimar os parâmetros nas damais, visto que, ao se fazer esse procedimento, corre-se o risco do modelo não ser "estimátivel"(raízes próximas do polinomio autoregressivo ou de médias móveis bem próximas ou dentro do circulo unitário). Assim, mesmo nas situações em que procedimento do tipo 2 teve um desempenho melhor, é preferivel escolher o do tipo 1, já que a diferença de desempenho entre eles não é muito discrepante.

- De modo geral, os métodos de previsão propostos tiveram desempenhos bem superiores aos métodos benchmark, mostrando, assim, uma possível adequabilidade dos modelos propostos.

- Dentre todos os procedimentos de previsão propostos, o melhor foi o que usou modelos SARIMA do tipo 2 e com rolling windows de tamanho 720, apresentando o valor de RMSE total de 1,627. Se excluírmos os procedimentos de previsão que usaram a estratégia do tipo 2, temos 
que o melhor procedimento foi o que usou modelos BATS sem sazonalidade semanal e com rolling windows de tamanho 336, apresentando um RMSE total de 2,249.

Os resultados de previsão relativamente bons podem ser explicados por um comportamento frequentemente regular da série, sendo, muitas vezes, uma sazonalidade bem definida. Tal constatação pode ser observada na Figura 3.24, na qual são mostrados alguns exemplos de previsão para cada tipo de modelo que reforçam as constatações realizadas. É possível observar que existem momentos em que há mudanças de comportamentos, mas que estes ou ocorrem poucas vezes ou são mudanças suaves ao longo do tempo, o que permitem com que os métodos de previsão ainda performem bem. Vale observar também a previsão discrepante realizada pelo método SARIMA no gráfico (A).
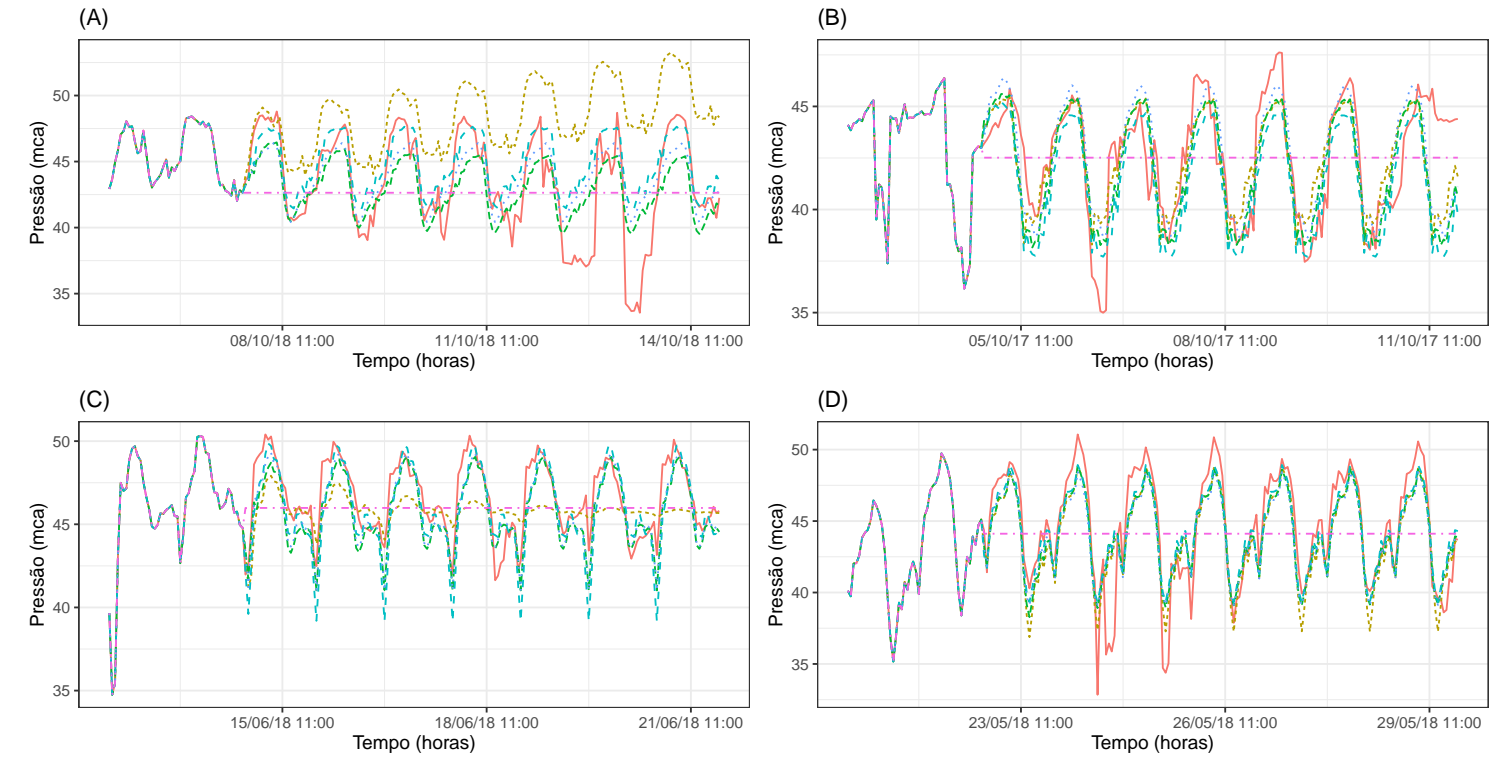

(D)
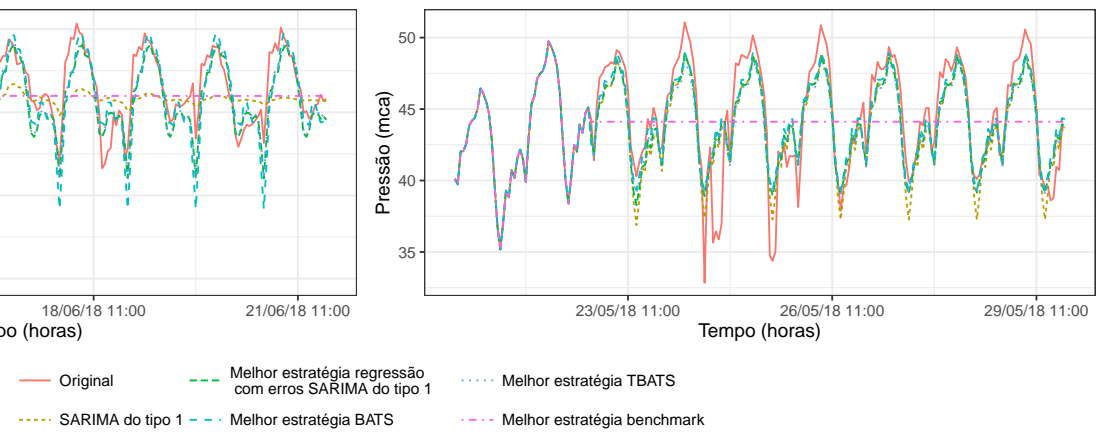

.. Melhor estratégia TBATS

Melhor estratégia benchmark

Figura 3.24: Alguns trechos da série de pressão a montante ao Norte de Peruíbe que exemplificam a aplicação dos modelos de previsão. São apresentados o melhor procedimento de ajuste de cada família de modelos, de acordo com o melhor RMSE de previsão, para os dois tamanhos de rolling window descritos na tabela 3.48. Para a seleção dos procedimentos, exluiu-se os que utilizaram a estratégia de tipo 2. Os gráficos exibem 48 horas da série seguidas de 168 horas de previsão. Os gráficos da esquerda se referem aos ajustes que usaram rolling windows de tamanho 336, já os da direita, de tamanho 720

Para a elaboração dos gráficos da Figura 3.24, decidiu-se não selecionar as previsões que usaram a estratégia do tipo 2, por tal método nem sempre conseguir estimar os parâmetros dos modelos, o que acaba resultando no uso de uma quantidade menor de rolling windows. Assim, as previsões SARIMA se referem ao uso de estratégia do tipo 1 e rolling windows de tamanho 720; as de regressão com erros autocorrelacionados se referem ao uso de polinômio de grau 0 modelando a tendência, sem sazonalidade semanal, com o uso da estratégia do tipo 1 para os erros SARIMA e rolling windows de tamanho 336; as previsões BATS se referem ao uso de modelos sem sazonalidade semanal e rolling windows de tamanho 336; as previsões TBATS se referem ao uso de modelos sem sazonalidade semanal e rolling windows de tamanho 336 e as previsões benchmark se referem ao uso da mediana e rolling windows de tamanho 336. 


\subsection{Pressão a montante no Sul de Peruíbe}

Nesta seção é apresentado e discutido os resultados das aplicações dos procedimentos de imputação de valores omissos e detecção de outliers e dos métodos de previsão relacionados a série de pressão a montante ao Sul de Peruíbe. A Figura 3.25 exibe um trecho da série que exemplifica seu comportamento. O gráfico (A) se refere a série original, enquanto que o gráfico (B) é mesmo trecho após limpeza e aplicação do métodos de deteç̧ão de outlier e preenchimento de valores omissos.

(A) Trecho da série original

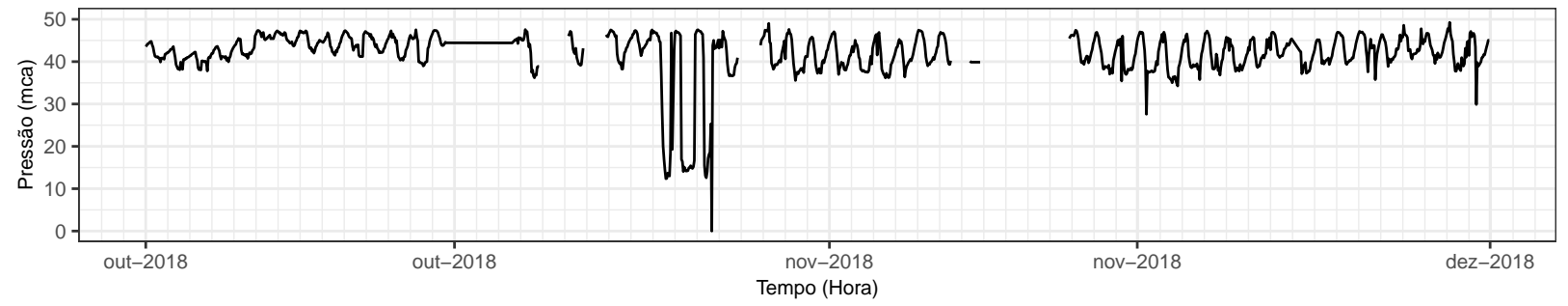

(B) Trecho da série após limpeza e preenchimento de valores omissos

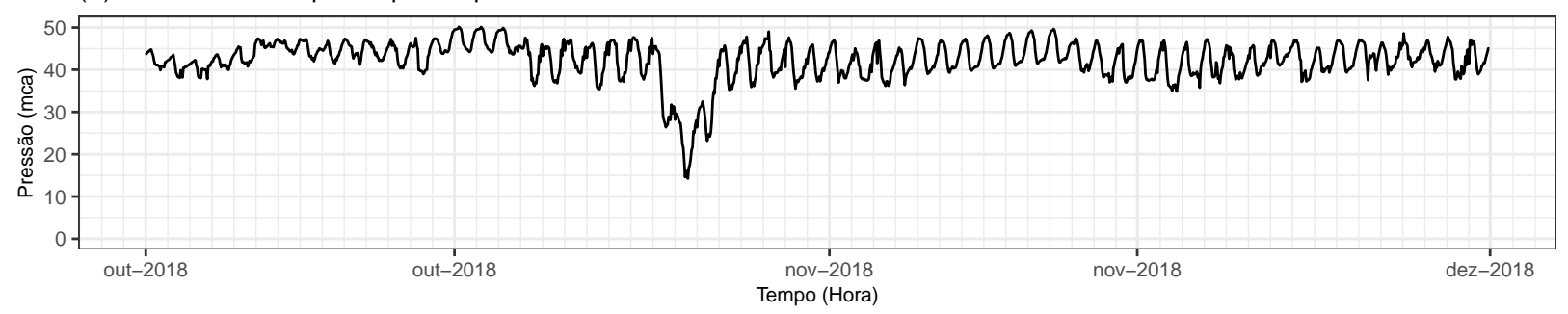

Figura 3.25: Trecho da série de pressão a montante ao Sul de Peruíbe que exemplificam seu comportamento. O gráfico (A) é referente a série original e o gráfico (B) mostra a série após as limpezas, tratamento dos outliers detectados e preenchimento dos valores omissos de acordo com o método escolhido.

O método escolhido para a deteç̧ão de outliers e preenchimentos dos valores omissos, por possuir o menor RMSE total entre todos os experimentos realizados, com o valor de 2,167 , foi o ajuste de curvas de regressão com polinômio de grau 5 modelando a tendência, com interpolação de $R_{t}$, sem sazonalidade semanal, janela de tamanho 168 e valor de corte $c=3$. O total de valores classificados como anomalias após aplicação do método selecionado foi de 2652 (15,1 \%), vis-à-vis à quantidade de 2209 (12,6 \%) após a limpeza primária e à quantidade original de $207(1,18 \%)$. Em relação a previsão, o método que apresentou melhor desempenho nos experimentos foi o que usou modelos de regressão com erros autocorrelacionados, com polinômio de grau 0 modelando a tendência, sem sazonalidade semanal, com o uso da estratégia do tipo 1 para os erros SARIMA e com rolling windows de tamanho 336, apresentando o valor de RMSE total de 1,598. De modo geral, os resultados mostram uma boa adequabilidade dos métodos propostos a série temporal de pressão a montante ao Sul de Peruíbe.

As próximas subseções apresentam e discutem os resultados de forma mais detalhada.

\subsubsection{Preenchimento de valores omissos}

As tabelas 3.49 à 3.51 mostram os resultados dos 12 melhores experimentos de cada tipo de procedimento de preenchimento de valores omissos, usando como medida de avaliação o RMSE. Em todas as tabelas os experimentos são apresentados em ordem decrescente de RMSE. Já a tabela 3.52 apresenta os resultados dos procedimentos de preenchimento de valores omissos usados como 
benchmark. Nesta, os experimentos são ordenados pelo ID.

Tabela 3.49: RMSE dos 12 melhores métodos de preenchimento de dados omissos baseados no ajuste de modelos de regressãa, selecionados de acordo com menor RMSE. Os resultados se referem a aplicação dos métodos a série de pressão a montante ao Sul de Peruíbe.

\begin{tabular}{|c|c|c|c|c|c|c|c|c|c|c|c|c|c|}
\hline \multicolumn{6}{|c|}{ Experimentos de regressão } & \multicolumn{8}{|c|}{ Quantidade de valores omissos em sequência } \\
\hline ID & $\begin{array}{l}\text { Interpolação } \\
\quad \text { de } R_{t}\end{array}$ & $\begin{array}{c}\text { Dia da } \\
\text { semana }\end{array}$ & $\begin{array}{l}\text { Grau do } \\
\text { polinômio }\end{array}$ & Janela & $c$ & 1 & 3 & 6 & 12 & 18 & 24 & 48 & Total \\
\hline reg61 & Sim & $\mathrm{Sim}$ & 5 & 168 & 3 & 1,23 & 1,78 & 2,88 & 2,90 & 2,40 & 1,98 & 1,99 & 2,17 \\
\hline reg97 & Sim & Sim & 5 & 168 & 5 & 1,22 & 1,86 & 2,96 & 2,83 & 2,34 & 1,92 & 2,04 & 2,17 \\
\hline $\operatorname{reg} 25$ & Sim & Sim & 5 & 168 & 2 & 1,27 & 1,89 & 2,81 & 2,89 & 2,41 & 1,98 & 1,97 & 2,18 \\
\hline reg 26 & $\operatorname{Sim}$ & $\operatorname{Sim}$ & 5 & 336 & 2 & 1,39 & 2,18 & 2,48 & 3,22 & 2,76 & 2,00 & 1,93 & 2,28 \\
\hline reg 43 & Não & Sim & 5 & 168 & 3 & 1,79 & 2,42 & 2,63 & 3,09 & 2,53 & 1,85 & 1,70 & 2,29 \\
\hline $\operatorname{reg} 62$ & Sim & $\operatorname{Sim}$ & 5 & 336 & 3 & 1,45 & 2,15 & 2,49 & 3,18 & 2,77 & 2,00 & 2,01 & 2,29 \\
\hline $\operatorname{reg} 79$ & Não & Sim & 5 & 168 & 5 & 1,81 & 2,52 & 2,57 & 2,90 & 2,75 & 1,83 & 1,69 & 2,30 \\
\hline reg 58 & Sim & $\mathrm{Sim}$ & 2 & 168 & 3 & 1,49 & 2,31 & 2,48 & 3,32 & 2,67 & 2,02 & 1,97 & 2,32 \\
\hline $\operatorname{reg} 7$ & Não & Sim & 5 & 168 & 2 & 1,85 & 2,42 & 2,62 & 3,20 & 2,59 & 1,85 & 1,72 & 2,32 \\
\hline reg89 & Não & Sim & 5 & 336 & 5 & 1,68 & 2,56 & 2,67 & 3,49 & 2,44 & 1,91 & 1,56 & 2,33 \\
\hline reg 22 & Sim & Sim & 2 & 168 & 2 & 1,53 & 2,25 & 2,52 & 3,23 & 2,86 & 2,03 & 1,90 & 2,33 \\
\hline reg91 & Sim & Sim & 1 & 168 & 5 & 1,46 & 2,66 & 2,56 & 3,38 & 2,31 & 1,96 & 2,00 & 2,33 \\
\hline
\end{tabular}

Tabela 3.50: RMSE dos 12 melhores métodos de preenchimento de dados omissos baseados no ajuste de modelo de regressão acompanhado de decomposiçôes clássica, selecionados de acordo com menor RMSE. O modelo de regressão usado em conjundo com a decomposição clássica, por apresentar menor RMSE, foi o que possui polinômio de grau 5, com interpolação dos resíduos, sem sazonalidade semanal e janela de tamanho 168. Os resultados se referem a aplicação dos métodos a série de pressão a montante ao Sul de Peruıbe.

\begin{tabular}{|c|c|c|c|c|c|c|c|c|c|c|c|}
\hline \multicolumn{4}{|c|}{ Experimentos de decomposição clássica } & \multicolumn{8}{|c|}{ Quantidade de valores omissos em sequência } \\
\hline ID & $\begin{array}{l}\text { Interpolação } \\
\quad \text { de } R_{t}\end{array}$ & Janela & $c$ & 1 & 3 & 6 & 12 & 18 & 24 & 48 & Total \\
\hline $\operatorname{dec} 7$ & Não & 168 & 3 & 1,36 & 1,90 & 2,89 & 2,88 & 2,34 & 1,96 & 1,96 & 2,18 \\
\hline $\operatorname{dec} 1$ & Não & 168 & 2 & 1,37 & 1,91 & 2,83 & 2,94 & 2,35 & 1,97 & 1,94 & 2,19 \\
\hline $\operatorname{dec} 13$ & Não & 168 & 5 & 1,36 & 2,01 & 3,00 & 2,81 & 2,32 & 1,90 & 2,00 & 2,20 \\
\hline $\operatorname{dec} 4$ & Sim & 168 & 2 & 1,24 & 1,80 & 2,86 & 2,98 & 2,40 & 2,04 & 2,13 & 2,21 \\
\hline dec10 & Sim & 168 & 3 & 1,20 & 1,77 & 2,92 & 2,95 & 2,43 & 2,07 & 2,16 & 2,21 \\
\hline $\operatorname{dec} 8$ & Não & 336 & 3 & 1,38 & 1,89 & 2,97 & 2,98 & 2,36 & 1,98 & 1,96 & 2,22 \\
\hline $\operatorname{dec} 2$ & Não & 336 & 2 & 1,38 & 1,93 & 2,92 & 3,03 & 2,39 & 1,99 & 1,94 & 2,23 \\
\hline $\operatorname{dec} 16$ & $\mathrm{Sim}$ & 168 & 5 & 1,17 & 1,83 & 3,04 & 2,88 & 2,51 & 2,03 & 2,23 & 2,24 \\
\hline $\operatorname{dec} 14$ & Não & 336 & 5 & 1,39 & 2,01 & 3,12 & 2,93 & 2,33 & 1,93 & 2,00 & 2,24 \\
\hline dec11 & Sim & 336 & 3 & 1,18 & 1,73 & 2,99 & 3,05 & 2,48 & 2,10 & 2,20 & 2,25 \\
\hline $\operatorname{dec} 5$ & Sim & 336 & 2 & 1,23 & 1,77 & 2,95 & 3,08 & 2,49 & 2,08 & 2,17 & 2,25 \\
\hline $\operatorname{dec} 9$ & Não & 720 & 3 & 1,43 & 1,93 & 3,04 & 3,02 & 2,41 & 2,00 & 1,97 & 2,26 \\
\hline
\end{tabular}

Tabela 3.51: RMSE dos 12 melhores métodos de preenchimento de dados omissos baseados em decomposição STL, selecionados de acordo com menor RMSE. Os resultados se referem a aplicação dos métodos a série de pressão a montante ao Sul de Peruíbe.

\begin{tabular}{|c|c|c|c|c|c|c|c|c|c|c|c|c|c|}
\hline \multicolumn{6}{|c|}{ Experimentos de decomposição STL } & \multicolumn{8}{|c|}{ Quantidade de valores omissos em sequência } \\
\hline ID & $\begin{array}{l}\text { Interpolação } \\
\text { de } R_{t}\end{array}$ & $n_{(i)}$ & $n_{(e)}$ & $n_{(s)}$ & $c$ & 1 & 3 & 6 & 12 & 18 & 24 & 48 & Total \\
\hline st131 & $\operatorname{Sim}$ & 1 & 5 & 25 & 3 & 1,24 & 2,41 & 2,52 & 3,47 & 2,27 & 2,04 & 2,09 & 2,29 \\
\hline st12 & Não & 2 & 0 & 37 & 2 & 1,52 & 2,45 & 2,69 & 3,21 & 2,35 & 1,96 & 1,94 & 2,30 \\
\hline st116 & $\operatorname{Sim}$ & 1 & 10 & 25 & 2 & 1,34 & 2,31 & 2,65 & 3,50 & 2,31 & 1,97 & 2,06 & 2,30 \\
\hline st11 & Não & 2 & 0 & 25 & 2 & 1,57 & 2,62 & 2,62 & 3,15 & 2,36 & 1,93 & 1,88 & 2,31 \\
\hline st113 & Sim & 1 & 5 & 25 & 2 & 1,36 & 2,42 & 2,53 & 3,47 & 2,27 & 1,97 & 2,13 & 2,31 \\
\hline st119 & Não & 2 & 0 & 25 & 3 & 1,51 & 2,44 & 2,87 & 3,18 & 2,33 & 1,95 & 1,91 & 2,31 \\
\hline st146 & Sim & 2 & 0 & 25 & 5 & 1,02 & 2,13 & 3,46 & 3,25 & 2,35 & 1,93 & 2,04 & 2,31 \\
\hline st137 & Não & 2 & 0 & 25 & 5 & 1,43 & 2,37 & 2,93 & 3,20 & 2,47 & 1,91 & 1,95 & 2,32 \\
\hline st13 & Não & 2 & 0 & 49 & 2 & 1,54 & 2,46 & 2,74 & 3,24 & 2,38 & 1,97 & 1,95 & 2,33 \\
\hline st128 & Sim & 2 & 0 & 25 & 3 & 1,15 & 2,20 & 3,30 & 3,21 & 2,37 & 2,06 & 2,04 & 2,33 \\
\hline stl10 & $\operatorname{Sim}$ & 2 & 0 & 25 & 2 & 1,20 & 2,27 & 3,44 & 3,10 & 2,29 & 2,05 & 2,00 & 2,34 \\
\hline st134 & Sim & 1 & 10 & 25 & 3 & 1,24 & 2,48 & 2,58 & 3,50 & 2,41 & 2,02 & 2,20 & 2,35 \\
\hline
\end{tabular}


Tabela 3.52: RMSE dos métodos benchmark de preenchimento de dados omissos. Os resultados se referem a aplicação dos métodos a série de pressão a montante ao Sul de Peruíbe.

\begin{tabular}{|c|c|c|c|c|c|c|c|c|c|c|}
\hline \multicolumn{3}{|c|}{ Experimentos emphbenchmark } & \multicolumn{8}{|c|}{ Quantidade de valores omissos em sequência } \\
\hline ID & $\begin{array}{c}\text { Forma de } \\
\text { benchmark }\end{array}$ & Janela & 1 & 3 & 6 & 12 & 18 & 24 & 48 & Total \\
\hline ben1 & Média & 168 & 2,664 & 3,33 & 3,25 & 3,97 & 3,28 & 2,85 & 2,49 & 3,12 \\
\hline ben 2 & Média & 336 & 2,702 & 3,39 & 3,36 & 4,12 & 3,33 & 2,91 & 2,51 & 3,19 \\
\hline ben3 & Média & 720 & 2,805 & 3,50 & 3,54 & 4,33 & 3,42 & 2,94 & 2,71 & 3,32 \\
\hline ben 4 & Mediana & 168 & 2,637 & 3,50 & 3,42 & 4,26 & 3,32 & 2,92 & 2,57 & 3,23 \\
\hline ben 5 & Mediana & 336 & 2,714 & 3,46 & 3,50 & 4,32 & 3,42 & 2,98 & 2,54 & 3,27 \\
\hline ben 6 & Mediana & 720 & 2,841 & 3,57 & 3,69 & 4,49 & 3,54 & 3,03 & 2,71 & 3,41 \\
\hline ben 7 & Interpolação & - & 0,905 & 2,03 & 4,20 & 4,12 & 3,70 & 3,53 & 3,26 & 3,11 \\
\hline
\end{tabular}

De acordo com as informações apresentadas nas tabelas 3.49 à 3.52 podemos verificar que, em geral:

- Os melhores procedimentos de regressão, de acordo com o RMSE total, foram aqueles que usaram interpolação nos resíduos $R_{t}$, que consideraram a sazonalidade semanal, valor de corte $c=5$ e que, aparentemente, usaram janelas menores (de tamanho 168 e 336), sendo que o melhor procedimento de regressão para imputação de valores omissos foi o que usou polinômio de grau 5 modelando a tendência, com interpolação de $R_{t}$, sem sazonalidade semanal, janela de tamanho 168 e valor de corte $c=3$, apresentando um RMSE total igual a 2,167. Os parâmetros desse modelo de regressão foram os usados na aplicação do método de decomposição clássica.

- Aparentemente, os procedimentos de decomposição clássica que tiveram melhor desempenho, de acordo com o RMSE total, foram aqueles que usaram janela de tamanho menores (168 e 336). O melhor procedimento foi aquele que usou decomposição sem interpolação de $R_{t}$, janela de tamanho 168 e valor de corte $c=3$, apresentando um RMSE total igual a 2,184.

- Aparentemente, os tipos de decomposição STL que tiveram melhores resultados, de acordo com o RMSE total, usaram $n_{(s)}=24$ e decomposição STL não robusta $\left(n_{(i)}=2\right.$ e $\left.n_{(e)}=0\right)$. O melhor procedimento foi o de decomposição robusta $\left(n_{(i)}=1\right.$ e $\left.n_{(e)}=5\right)$, com interpolação de $R_{t}, n_{(s)}=25$ e valor de corte $c=3$, apresentando um RMSE total igual a 2,288.

- Dentre os métodos de benchmark, o que teve melhor desempenho foi o que interpola linearmente os valores da série, apresentando um RMSE total igual a 3,107. Verifica-se que os procedimentos propostos tiveram desempenhos bem superiores aos benchmarks.

- Dentre todos os experimentos, o que apresentou melhor resultado foi o procedimento de ajuste de curvas de regressão com polinômio de grau 5 modelando a tendência, com interpolação de $R_{t}$, sem sazonalidade semanal, janela de tamanho 168 e valor de corte $c=3$, apresentando um valor de RMSE total de 2,167. Este é o procedimento para o qual é apresentado uma análise de outliers na próxima subseção e que é usado oficialmente para preencher os valores omissos da série.

A Figura 3.26 exemplifica alguns experimentos de preenchimento de valores omissos. Cada gráfico representa um trecho da série temporal de pressão a montante ao Sul de Peruíbe no qual propositalmente foi removido uma sequência de valores. Todos os gráficos se referem a uma lacuna de tamanho 48 horas acompanhado de 12 valores anteriores e posteriores à lacuna principal. Os 
procedimentos de preenchimento adotados para ilustrar os gráficos são o melhor experimento, de acordo com o RMSE total, de cada tipo de procedimento apresentados nas tabelas 3.49 à 3.52.

(A)

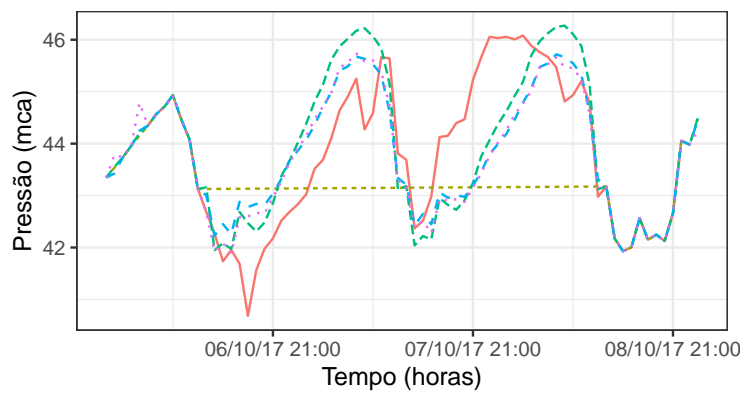

(C)

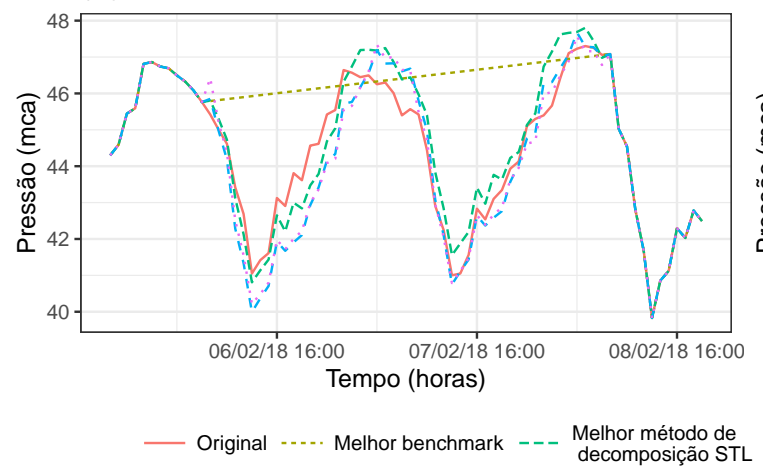

(B)

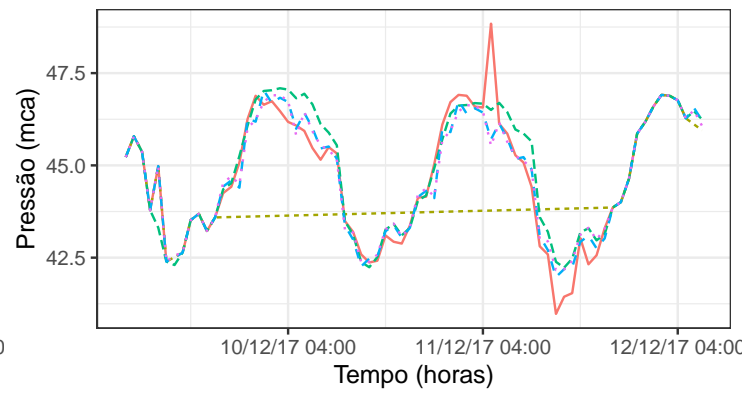

(D)

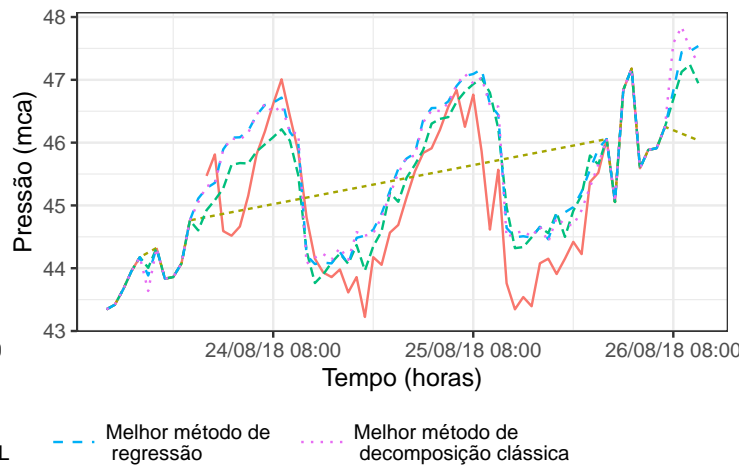

Figura 3.26: Alguns trechos da série de pressão a montante ao Sul de Peruíbe que exemplificam a aplicação dos procedimentos de preenchimento de valores omissos. É apresentado o melhor experimento de imputação de valores omissos de cada tipo de procedimento de acordo com o RMSE, descritos nas tabelas 3.49 à 3.52 . A lacuna principal de valores omissos usada em cada gráfico foi inserida artificialmente na série temporal a fim de avaliar a performance dos procedimentos de preenchimento de valores omissos. O tamanho da lacuna principal é de 48 horas, sendo precedida e sucedida de 12 horas de valores originais.

Verifica-se que os procedimentos propostos conseguiram fazer uma boa estimativa dos valores omissos, sendo estas bem superiores às do método de interpolação. Esses resultados já eram esperados, pois a série de pressão a montante ao Sul de Peruíbe apresenta um comportamento sazonal bem característico, mesmo que esse comportamento tenha alguns momentos de notáveis diferenças entre o valor real e o estimado pelos métodos propostos.

\subsubsection{Detecção e tratamento de outliers}

As tabelas 3.53 e 3.54 mostram os resultados dos experimentos elaborados para avaliar o desempenho em detectar e tratar os outliers do melhor procedimento selecionado para a imputação dos valores omissos. A Tabela 3.53 apresenta as taxas de detecção dos outliers, sendo dividida em duas partes: na parte superior o cálculo das taxas considera todas as observações afetadas pelo efeito atípico, enquanto que na parte inferior é considerado apenas a observação mais afetada pelo efeito atípico. Vale lembrar que no caso do efeito atípico do tipo platô todas as observações foram consideradas como sendo as mais afetadas devido ao efeito se distribuir igualmente entre elas. Já a tabela 3.54 é destinada a verificar a acurácia do procedimento ao corrigir os valores dos outliers. Sua estrutura é análoga à da tabela 3.53, sendo que a linha total é o RMSE do efeito atípico nas observações.

A partir das tabelas, podemos verificar que: 
Tabela 3.53: Taxa de deteç̧ão de outliers de acordo com o procedimento que apresentou melhor desempenho em preencher valores omissos. O procedimento foi o de ajuste de curvas de regressão com polinômio de grau 5 modelando a tendência, com interpolação de $R_{t}$, sem sazonalidade semanal, janela de tamanho 168 e valor de corte $c=3$. Variou-se o valor de corte $c$ e a quantidade de iterações máxima com o objetivo de verificar se a mudança desses parâmetros causam algum impacto na deteç̧ão dos outliers. A aplicação se refere a série de pressão a montante ao Sul de Peruß̉e.

\begin{tabular}{|c|c|c|c|c|c|c|c|c|}
\hline \multicolumn{3}{|c|}{ Experimentos } & \multicolumn{6}{|c|}{ Tipo de efeitos atípicos } \\
\hline ID & c & $\begin{array}{l}\text { № máximo } \\
\text { de iterações }\end{array}$ & Único & Platô & Pulso & $\begin{array}{l}\text { C.D. } \\
\text { linear }\end{array}$ & $\begin{array}{c}\text { C.D. } \\
\text { exponencial }\end{array}$ & $\begin{array}{c}\text { C.D. } \\
\text { logaritmico }\end{array}$ \\
\hline \multicolumn{9}{|c|}{ Todas as observações afetadas } \\
\hline out1 & 2 & 1 & 0,950 & 0,213 & 0,256 & 0,283 & 0,293 & 0,273 \\
\hline out2 & 3 & 1 & 0,750 & 0,099 & 0,136 & 0,129 & 0,164 & 0,114 \\
\hline out3 & 4 & 1 & 0,467 & 0,043 & 0,068 & 0,076 & 0,093 & 0,070 \\
\hline out4 & 5 & 1 & 0,300 & 0,013 & 0,036 & 0,039 & 0,062 & 0,034 \\
\hline out5 & 2 & 3 & 0,983 & 0,384 & 0,370 & 0,406 & 0,412 & 0,410 \\
\hline out6 & 3 & 3 & 0,883 & 0,169 & 0,227 & 0,228 & 0,250 & 0,203 \\
\hline out7 & 4 & 3 & 0,567 & 0,076 & 0,116 & 0,104 & 0,139 & 0,093 \\
\hline out8 & 5 & 3 & 0,433 & 0,024 & 0,058 & 0,061 & 0,084 & 0,050 \\
\hline out9 & 2 & 5 & 0,983 & 0,387 & 0,372 & 0,413 & 0,412 & 0,418 \\
\hline out 10 & 3 & 5 & 0,883 & 0,172 & 0,228 & 0,228 & 0,250 & 0,203 \\
\hline out11 & 4 & 5 & 0,567 & 0,076 & 0,116 & 0,104 & 0,141 & 0,093 \\
\hline out12 & 5 & 5 & 0,433 & 0,024 & 0,058 & 0,064 & 0,084 & 0,052 \\
\hline Total & - & - & 1,000 & 1,000 & 1,000 & 1,000 & 1,000 & 1,000 \\
\hline \multicolumn{9}{|c|}{ Somente observações mais afetadas } \\
\hline out1 & 2 & 1 & 0,950 & 0,213 & 0,933 & 0,790 & 0,857 & 0,752 \\
\hline out 2 & 3 & 1 & 0,750 & 0,099 & 0,650 & 0,476 & 0,629 & 0,371 \\
\hline out 3 & 4 & 1 & 0,467 & 0,043 & 0,400 & 0,314 & 0,429 & 0,276 \\
\hline out4 & 5 & 1 & 0,300 & 0,013 & 0,250 & 0,171 & 0,314 & 0,133 \\
\hline out 5 & 2 & 3 & 0,983 & 0,384 & 0,950 & 0,886 & 0,933 & 0,848 \\
\hline out 6 & 3 & 3 & 0,883 & 0,169 & 0,833 & 0,657 & 0,819 & 0,524 \\
\hline out7 & 4 & 3 & 0,567 & 0,076 & 0,517 & 0,390 & 0,571 & 0,343 \\
\hline out8 & 5 & 3 & 0,433 & 0,024 & 0,367 & 0,257 & 0,400 & 0,171 \\
\hline out9 & 2 & 5 & 0,983 & 0,387 & 0,950 & 0,886 & 0,933 & 0,857 \\
\hline out10 & 3 & 5 & 0,883 & 0,172 & 0,850 & 0,657 & 0,819 & 0,524 \\
\hline out11 & 4 & 5 & 0,567 & 0,076 & 0,517 & 0,390 & 0,571 & 0,343 \\
\hline out12 & 5 & 5 & 0,433 & 0,024 & 0,367 & 0,257 & 0,400 & 0,181 \\
\hline Total & - & - & 1,000 & 1,000 & 1,000 & 1,000 & 1,000 & 1,000 \\
\hline
\end{tabular}

- As taxas de deteç̧ão dos outliers foram, em geral, baixas. Os motivos mais prováveis para essa baixa taxa de detecção é termos usado uma contante $\omega$ relativamente baixo para a produção dos outliers. Nota-se que a taxa de detecção foram altas somente quando se considera as observações mais afetadas e valores baixo de $c$. A baixa taxa de detecção reflete nos valores de acurácia não tão bons.

- O número de máximo de iterações possui, em geral, uma pequena influencia nos resultados. A taxa de deteç̧ão dos experimentos que tiveram apenas uma iteração foi menor do que quando usadas iterações máximas iguais a 3 ou 5 . Porém, não há muita diferança entre usar um número máximo de iterações igual a 3 ou igual a 5 . Algo semelhante pode ser observado pelos valores de RMSE: o RMSE dos experimentos que usaram apenas uma iteração máxima foram maiores do aqueles que tiveram iterações máximas iguais a 3 ou 5 . A semelhança dos resultados do uso de 3 e 5 iterações máximas pode ser explicado pelo algoritmo conseguir encontrar grande parte dos outliers antes de atingir número máximo de iterações, sendo necessário apenas uma baixa quantidade de iterações, isto é, um número menor ou igual a 3, porém maior que 1.

- Como o esperado, percebe-se claramente que o valor de corte $c$ influencia na taxa de detecção, sendo que quanto menor for valor de corte $c$, melhor é a taxa de detecção. Também verifica-se um melhor valor de RMSE para os valores mais baixos de $c$. Lembramos que, embora um valor de corte baixo aumente a taxa de detecção de outliers, ele também aumenta a taxa de detecção de valores que possivelmente não seriam outliers.

A Figura 3.27 exemplifica as constatações realizadas. É possível observar que os procedimentos 
Tabela 3.54: RMSE do tratamento dos outliers de acordo com o procedimento que apresentou melhor desempenho em preencher valores omissos. O procedimento foi o de ajuste de curvas de regressã̃o com polinômio de grau 5 modelando a tendência, com interpolação de $R_{t}$, sem sazonalidade semanal, janela de tamanho 168 e valor de corte $c=3$. Variou-se o valor de corte $c$ e a quantidade de iterações máxima com o objetivo de verificar se a mudança desses parâmetros causam algum impacto na detecção dos outliers. A linha total é o RMSE das observações ouliers em relação ao seu valor original. A aplicação se refere a série de pressão a montante ao Sul de Peruíbe.

\begin{tabular}{|c|c|c|c|c|c|c|c|c|}
\hline \multicolumn{3}{|c|}{ Experimentos } & \multicolumn{6}{|c|}{ Tipo de efeitos atípicos } \\
\hline ID & c & $\begin{array}{l}\text { № máximo } \\
\text { de iterações }\end{array}$ & Único & Platô & Pulso & $\begin{array}{l}\text { C.D. } \\
\text { linear }\end{array}$ & $\begin{array}{c}\text { C.D. } \\
\text { exponencial }\end{array}$ & $\begin{array}{c}\text { C.D. } \\
\text { logaritmico }\end{array}$ \\
\hline \multicolumn{9}{|c|}{ Todas as observações afetadas } \\
\hline out1 & 2 & 1 & 1,016 & 3,40 & 2,58 & 3,07 & 3,01 & 3,15 \\
\hline out 2 & 3 & 1 & 2,005 & 3,64 & 3,02 & 3,49 & 3,39 & 3,53 \\
\hline out3 & 4 & 1 & 3,357 & 3,92 & 3,41 & 3,71 & 3,71 & 3,72 \\
\hline out 4 & 5 & 1 & 4,099 & 4,13 & 3,61 & 3,92 & 3,94 & 3,88 \\
\hline out 5 & 2 & 3 & 0,819 & 3,10 & 2,31 & 2,72 & 2,62 & 2,79 \\
\hline out 6 & 3 & 3 & 1,442 & 3,50 & 2,73 & 3,24 & 3,12 & 3,31 \\
\hline out 7 & 4 & 3 & 2,878 & 3,77 & 3,18 & 3,60 & 3,50 & 3,62 \\
\hline out 8 & 5 & 3 & 3,503 & 4,04 & 3,47 & 3,81 & 3,81 & 3,80 \\
\hline out9 & 2 & 5 & 0,819 & 3,09 & 2,30 & 2,69 & 2,60 & 2,77 \\
\hline out 10 & 3 & 5 & 1,442 & 3,49 & 2,72 & 3,24 & 3,11 & 3,30 \\
\hline out11 & 4 & 5 & 2,878 & 3,77 & 3,18 & 3,60 & 3,50 & 3,62 \\
\hline out12 & 5 & 5 & 3,503 & 4,04 & 3,47 & 3,79 & 3,81 & 3,80 \\
\hline Total & - & - & 7,022 & 4,20 & 4,07 & 4,35 & 4,77 & 4,21 \\
\hline \multicolumn{9}{|c|}{ Somente observações mais afetadas } \\
\hline out1 & 2 & 1 & 1,016 & 3,40 & 1,98 & 3,57 & 3,70 & 3,56 \\
\hline out 2 & 3 & 1 & 2,005 & 3,64 & 3,35 & 4,53 & 4,55 & 4,45 \\
\hline out 3 & 4 & 1 & 3,357 & 3,92 & 4,57 & 5,08 & 5,31 & 4,87 \\
\hline out 4 & 5 & 1 & 4,099 & 4,13 & 5,26 & 5,74 & 5,89 & 5,44 \\
\hline out 5 & 2 & 3 & 0,819 & 3,10 & 1,80 & 3,13 & 3,11 & 3,17 \\
\hline out6 & 3 & 3 & 1,442 & 3,50 & 2,63 & 4,09 & 3,99 & 4,11 \\
\hline out7 & 4 & 3 & 2,878 & 3,77 & 4,00 & 4,88 & 4,81 & 4,68 \\
\hline out 8 & 5 & 3 & 3,503 & 4,04 & 4,66 & 5,50 & 5,56 & 5,34 \\
\hline out9 & 2 & 5 & 0,819 & 3,09 & 1,80 & 3,09 & 3,11 & 3,14 \\
\hline out10 & 3 & 5 & 1,442 & 3,49 & 2,55 & 4,09 & 3,99 & 4,09 \\
\hline out11 & 4 & 5 & 2,878 & 3,77 & 4,00 & 4,88 & 4,81 & 4,68 \\
\hline out12 & 5 & 5 & 3,503 & 4,04 & 4,66 & 5,50 & 5,56 & 5,31 \\
\hline Total & - & - & 7,022 & 4,20 & 7,83 & 7,27 & 8,96 & 6,54 \\
\hline
\end{tabular}

conseguiram detectar e tratar somente as observações mais afetadas pelos efeitos atípicos.

A Tabela 3.55 apresenta a quantidade de anomalias detectadas em cada fase do tratamento dado a série de pressão a montante ao Sul de Peruíbe. Nota-se que a maior parte das observações anômalas foram detectadas durante a fase de limpeza primária, o que dá a quantidade de 2002 observações ou $11,4 \%$ do total. Durante todo o processo, foram detectadas $2652(15,1 \%)$ observações anormais.

Tabela 3.55: Quantidade de valores detectados como anomalias em cada estágio de tratamento da série de pressão a montante ao Sul de Peruíbe. A primeira linha da tabela se refere a quantidade de valores classificados pelo sistema da Sabesp como bad e que, portanto, eram omissos na série original. A segunda linha se refere aos valores detectados como anomalias pela limpeza primária. A terceira linha se refere a quantidade de valores detectados como outliers pela aplicação do algoritmo proposto.

\begin{tabular}{|c|c|c|c|c|}
\hline Fase de detecção de anomalias & Frequência absoluta & Frequência relativa & Acumulado absoluto & Acumulado relativo \\
\hline Originalmente & 207 & $1,2 \%$ & 207 & $1,2 \%$ \\
\hline Limpeza primária & 2.002 & $11,4 \%$ & 2.209 & $12,6 \%$ \\
\hline Algoritmo de detecção de outliers & 443 & $2,5 \%$ & 2.652 & $15,1 \%$ \\
\hline Tamanho da série & 17.519 & $100 \%$ & 20.171 & $100 \%$ \\
\hline
\end{tabular}

\subsubsection{Previsão}

A Tabela 3.56 traz os resultados de acurácia dos experimentos de previsão de acordo com RMSE. Ela é dividida em duas partes: a parte superior é dedicada a mostrar os resultados que usaram rolling windows de tamanho 336 horas (14 dias) e a parte inferior mostra os resultados referentes ao uso de rolling windows de tamanho 720 horas (30 dias). Os experimentos estão agrupados por 
(A) Único

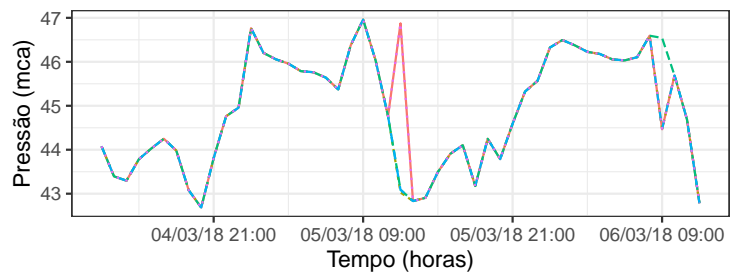

(C) Pulso

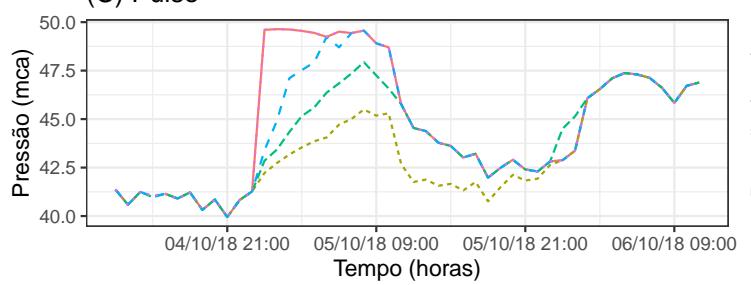

(E) C.D. Exponencial

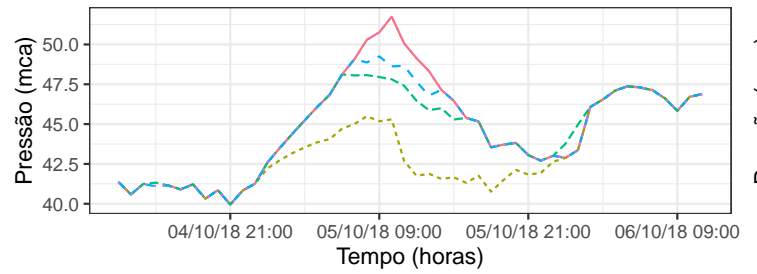

(B) Platô

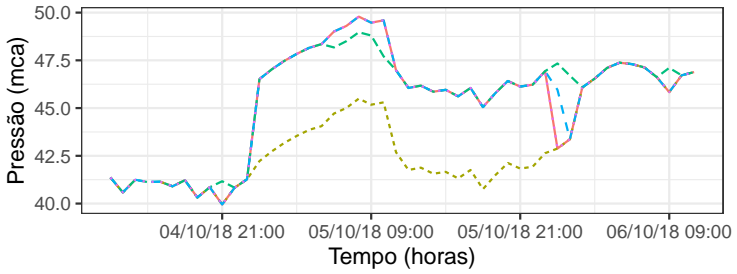

(D) C.D. Linear

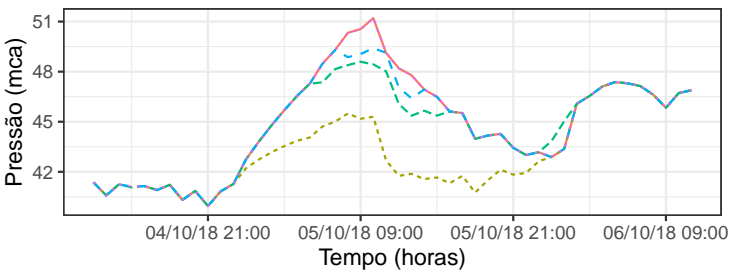

(F) C.D. Logaritmico

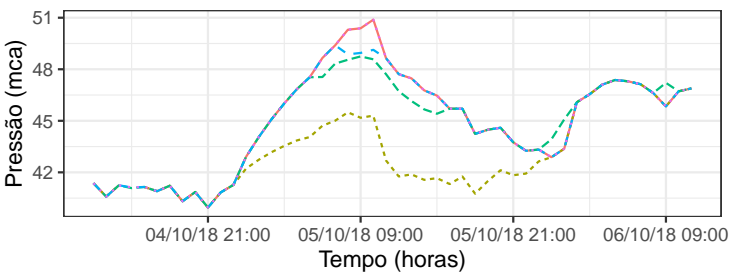

— Série com Outlier $\quad \cdots$ O... Original --- Corte $=2-\cdots$ Corte $=3 \cdots$ Corte $=5$

Figura 3.27: Exemplos de deteç̧ão e tratamento dos outliers inseridos na série de pressão a montante ao Sul de Peruíbe. Os trechos mostrados possuem tamanho 48 e são centrados nas observações afetadas pelo efeito atípico. Os gráficos de (A) a (F) exemplificam cada tipo de efeito atípico na série. A quantidade de iteração máxima dos experimentos selecionados é 3.

tipo de modelos. A partir dessa tabela, verifica-se que:

- O melhor procedimento de previsão com modelos SARIMA, de acordo com o RMSE total, foi o que usou estratégia do tipo 2 e rolling windows de tamanho 720, apresentando RMSE total de 1,627. Vale notar que a estratégia do tipo 2 não conseguiu se ajustar em todas as rolling windows testadas, o que pode ser um empecilho para se fazer comparações. Outro ponto a se observar é que a estratégia de tipo 2 teve um desempenho bem superior do que a de tipo 1 no uso de rolling window de ambos tamanhos, o que é um resultado um tanto inusitado, já que o esperado era que o desempenho de um modelo identificado usando as observações da própria rolling window fosse superior àquele que usasse as observações de uma outra rolling window para se fazer tal identificação.

- O melhor procedimento de regressão com erros autocorrelacionados, de acordo com o RMSE total, foi o que usou polinômio de grau 0 modelando a tendência, sem sazonalidade semanal, com o uso da estratégia do tipo 1 para os erros SARIMA e rolling windows de tamanho 336, apresentando RMSE total de 1,598. É importante notar que nem todos os experimentos conseguiram ajustar determinado modelo em todas as rollings windows, o que pode ser um empecilho a mais na hora de fazer comparações.

- Dentre os procedimentos BATS e TBATS, o que teve melhor desempenho de acordo com o RMSE total foi o que usou modelos TBATS sem sazonalidade semanal e com rolling windows de tamanho 336, apresentando RMSE total de 1,885. Na maioria dos casos, os procedimentos 
Tabela 3.56: RMSE dos experimentos de previsão aplicados a série de pressão a montante ao Sul de Peruıbe. As estratégias de tipo 1 se referem a aplicação do algoritmo de seleção de modelo em cada uma das rollings windows, enquanto que as de tipo 2 se referem a aplicação do algoritmo somente na primeira rolling window e do ajuste modelo selecionado nas demais rolling windows, reestimando os parâmetros. $O R M S E$ "Todos"é calculado usando todos os valores preditos de horizonte $h=1, \ldots ., 168$, incluido aqueles que não aparecem na tabela.

\begin{tabular}{|c|c|c|c|c|c|c|c|c|c|c|c|c|c|c|}
\hline \multicolumn{4}{|c|}{ Experimentos } & \multicolumn{11}{|c|}{ Horizonte de previsão } \\
\hline Modelos & $\begin{array}{c}\text { Grau do } \\
\text { polinô- } \\
\text { mio }\end{array}$ & $\begin{array}{l}\text { Sazonalidade } \\
\text { semanal }\end{array}$ & $\begin{array}{l}\text { Estratégia } \\
\text { de ajuste }\end{array}$ & $\mathrm{N}$ & 1 & 2 & 3 & 6 & 12 & 18 & 24 & 48 & 168 & Todos \\
\hline \multicolumn{15}{|c|}{ Rolling windows de tamanho 336} \\
\hline \multirow{2}{*}{ SARIMA } & - & - & Tipo 1 & 30 & 0,374 & 0,480 & 0,791 & 1,247 & 1,138 & 1,625 & 1,72 & 2,28 & 6,84 & 4,34 \\
\hline & - & - & Tipo 2 & 26 & 0,397 & 0,581 & 0,838 & 1,134 & 0,813 & 1,241 & 1,22 & 1,14 & 1,83 & 1,86 \\
\hline \multirow{8}{*}{$\begin{array}{c}\text { Regressão } \\
\text { com erros } \\
\text { SARIMA }\end{array}$} & 0 & $\operatorname{Sim}$ & Tipo 1 & 30 & 0,321 & 0,566 & 0,814 & 1,128 & 0,919 & 1,197 & 1,03 & 1,47 & 1,55 & 1,61 \\
\hline & 0 & $\operatorname{Sim}$ & Tipo 2 & 18 & 0,292 & 0,625 & 0,723 & 1,421 & 1,594 & 1,291 & 1,20 & 1,63 & 1,95 & 2,18 \\
\hline & 1 & $\operatorname{Sim}$ & Tipo 1 & 30 & 0,326 & 0,562 & 0,825 & 1,149 & 1,066 & 1,287 & 1,21 & 1,48 & 2,80 & 2,19 \\
\hline & 1 & $\operatorname{Sim}$ & Tipo 2 & 24 & 0,319 & 0,586 & 0,829 & 1,045 & 1,038 & 1,329 & 1,33 & 1,54 & 3,02 & 2,11 \\
\hline & 0 & Não & Tipo 1 & 30 & 0,307 & 0,562 & 0,816 & 1,121 & 0,899 & 1,223 & 1,04 & 1,36 & 1,55 & 1,60 \\
\hline & 0 & Não & Tipo 2 & 20 & 0,329 & 0,537 & 0,673 & 1,408 & 1,484 & 1,322 & 1,23 & 1,29 & 1,92 & 2,12 \\
\hline & 1 & Não & Tipo 1 & 30 & 0,304 & 0,560 & 0,822 & 1,153 & 1,080 & 1,383 & 1,26 & 1,44 & 2,81 & 2,27 \\
\hline & 1 & Não & Tipo 2 & 8 & 0,262 & 0,539 & 0,463 & 0,978 & 0,784 & 1,314 & 1,70 & 1,87 & 2,01 & 1,77 \\
\hline \multirow{2}{*}{ BATS } & - & Não & Tipo 1 & 30 & 0,419 & 0,580 & 0,770 & 1,104 & 1,260 & 1,377 & 1,39 & 1,48 & 2,16 & 2,01 \\
\hline & - & Sim & Tipo 1 & 30 & 1,669 & 1,547 & 1,676 & 1,888 & 2,102 & 2,306 & 2,75 & 3,98 & 4,05 & 3,52 \\
\hline \multirow{2}{*}{ TBATS } & - & Não & Tipo 1 & 30 & 0,414 & 0,596 & 0,843 & 1,175 & 1,193 & 1,164 & 1,15 & 1,44 & 1,91 & 1,88 \\
\hline & - & Sim & Tipo 1 & 30 & 0,356 & 0,499 & 0,800 & 1,404 & 1,706 & 2,039 & 2,31 & 3,00 & 2,08 & 2,56 \\
\hline \multirow{3}{*}{ Benchmark } & - & - & Média & 30 & 1,965 & 1,948 & 2,208 & 2,415 & 2,362 & 2,234 & 1,21 & 1,50 & 1,64 & 2,28 \\
\hline & - & - & Mediana & 30 & 2,055 & 1,926 & 2,128 & 2,263 & 2,131 & 2,486 & 1,34 & 1,67 & 1,73 & 2,27 \\
\hline & - & - & Ûlt. Obs. & 30 & 0,744 & 1,253 & 1,887 & 2,985 & 3,284 & 1,808 & 1,35 & 1,34 & 1,97 & 2,86 \\
\hline \multicolumn{15}{|c|}{ Rolling windows de tamanho 720} \\
\hline \multirow{2}{*}{ SARIMA } & - & - & Tipo 1 & 30 & 0,529 & 0,674 & 0,753 & 0,813 & 0,904 & 2,309 & 2,63 & 4,10 & 3,54 & 2,90 \\
\hline & - & - & Tipo 2 & 21 & 0,461 & 0,646 & 0,719 & 0,593 & 0,678 & 1,307 & 1,28 & 1,49 & 2,16 & 1,63 \\
\hline \multirow{8}{*}{$\begin{array}{c}\text { Regressão } \\
\text { com erros } \\
\text { SARIMA }\end{array}$} & 0 & $\operatorname{Sim}$ & Tipo 1 & 30 & 0,451 & 0,662 & 0,728 & 0,887 & 0,837 & 2,609 & 2,78 & 4,10 & 2,05 & 2,49 \\
\hline & 0 & $\operatorname{Sim}$ & Tipo 2 & 22 & 0,397 & 0,576 & 0,693 & 0,904 & 1,022 & 1,113 & 1,28 & 1,77 & 2,67 & 1,94 \\
\hline & 1 & Sim & Tipo 1 & 30 & 0,436 & 0,635 & 0,681 & 0,910 & 0,934 & 2,568 & 2,77 & 4,21 & 2,31 & 2,58 \\
\hline & 1 & $\mathrm{Sim}$ & Tipo 2 & 23 & 0,481 & 0,667 & 0,755 & 0,973 & 1,098 & 2,800 & 3,05 & 4,65 & 2,37 & 2,81 \\
\hline & 0 & Não & Tipo 1 & 30 & 0,442 & 0,672 & 0,724 & 0,801 & 0,793 & 2,531 & 2,71 & 4,02 & 2,08 & 2,46 \\
\hline & 0 & Não & Tipo 2 & 21 & 0,400 & 0,578 & 0,693 & 0,871 & 1,021 & 0,981 & 1,23 & 1,78 & 2,75 & 1,99 \\
\hline & 1 & Não & Tipo 1 & 30 & 0,426 & 0,645 & 0,694 & 0,846 & 0,914 & 2,517 & 2,74 & 4,15 & 2,39 & 2,56 \\
\hline & 1 & Não & Tipo 2 & 20 & 0,392 & 0,660 & 0,762 & 0,880 & 0,847 & 1,305 & 1,34 & 1,58 & 1,87 & 1,72 \\
\hline \multirow{2}{*}{ BATS } & - & Não & Tipo 1 & 30 & 0,523 & 0,681 & 0,768 & 0,727 & 0,808 & 2,516 & 2,71 & 4,08 & 2,41 & 2,53 \\
\hline & - & $\operatorname{Sim}$ & Tipo 1 & 30 & 0,902 & 0,921 & 1,025 & 1,082 & 1,197 & 2,779 & 2,97 & 3,80 & 2,50 & 2,54 \\
\hline \multirow{2}{*}{ TBATS } & - & Não & Tipo 1 & 30 & 0,488 & 0,682 & 0,706 & 0,894 & 1,032 & 2,626 & 2,79 & 4,21 & 3,00 & 2,80 \\
\hline & - & $\mathrm{Sim}$ & Tipo 1 & 30 & 0,512 & 0,709 & 0,723 & 0,904 & 1,127 & 2,613 & 2,73 & 3,95 & 2,43 & 2,56 \\
\hline \multirow{3}{*}{ Benchmark } & - & - & Média & 30 & 1,824 & 1,809 & 1,994 & 2,002 & 1,908 & 4,186 & 3,55 & 4,55 & 2,34 & 3,04 \\
\hline & - & - & Mediana & 30 & 1,895 & 1,824 & 1,929 & 1,801 & 1,722 & 4,363 & 3,65 & 4,61 & 2,46 & 3,06 \\
\hline & - & - & Últ. Obs. & 30 & 0,746 & 1,325 & 1,831 & 2,617 & 2,884 & 3,092 & 2,67 & 4,06 & 2,54 & 3,11 \\
\hline
\end{tabular}

BATS e TBATS o uso de sazonalidade semanal não melhorou significativamente o desempenho dos modelos.

- Com exceção dos procedimentos que usaram modelos SARIMA, não houve uma diferença notável de desempenho entre usar rolling windows de tamanho 336 ou 720.

- Alguns experimentos que empregaram a estratégia do tipo 2 tiveraram um valor de $N<30$. Isso é explicado pelo fato da estratégia consistir em identificar o modelo usando as observações de apenas de uma rolling windows e depois só reestimar os parâmetros nas damais, visto que, ao se fazer esse procedimento, corre-se o risco do modelo não ser "estimátivel"(raízes próximas do polinomio autoregressivo ou de médias móveis bem próximas ou dentro do circulo unitário). Assim, mesmo nas situações em que procedimento do tipo 2 teve um desempenho melhor, é preferivel escolher o do tipo 1 , já que a diferença de desempenho entre eles não é muito discrepante.

- De modo geral, mesmo os métodos de previsão propostos tendo desempenhos pouco superiores aos métodos benchmark, eles se mostram possivelmente adequados à série, sobretudo quando se consideram horizontes mais curtos de previsão. 
- Dentre todos os procedimentos de previsão propostos, o melhor foi o que usou modelos de regressão com erros autocorrelacionados, com polinômio de grau 0 modelando a tendência, sem sazonalidade semanal, com o uso da estratégia do tipo 1 para os erros SARIMA e com rolling windows de tamanho 336, apresentando o valor de RMSE total de 1,598.

Os resultados de previsão relativamente bons podem ser explicados por um comportamento frequentemente regular da série, sendo, muitas vezes, uma sazonalidade bem definida. Tal constatação pode ser observada na Figura 3.28, na qual são mostrados alguns exemplos de previsão para cada tipo de modelo que reforçam as constatações realizadas. É possível observar que existem momentos em que há mudanças de comportamentos, mas que estes ou ocorrem poucas vezes (gráfico (B)) ou são mudanças suaves ao longo do tempo (gráfico (A)), o que permitem com que os métodos de previsão ainda consiga performar bem mediante a algumas dessas situações.
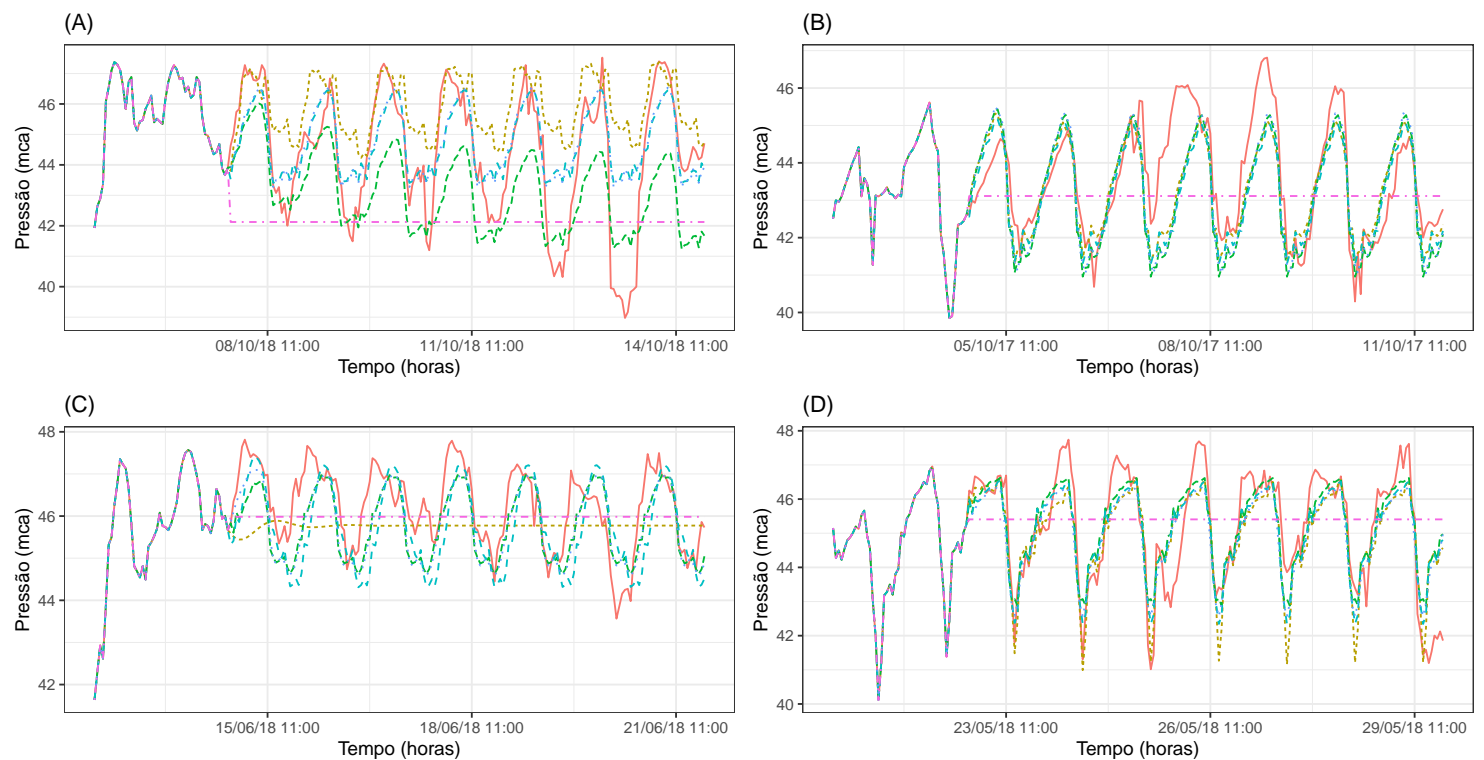

(D)

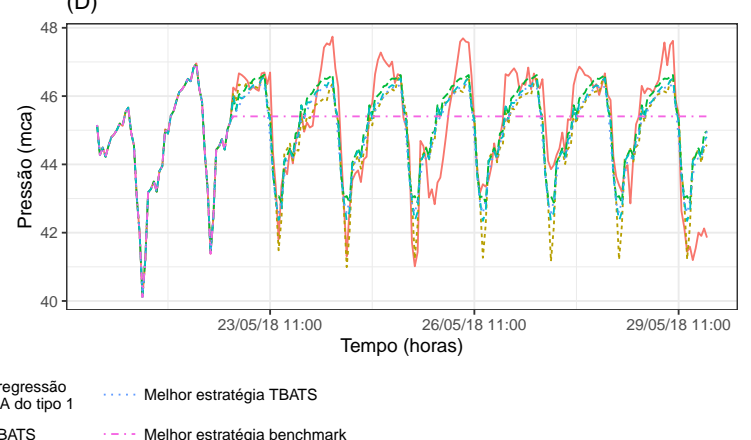

Figura 3.28: Alguns trechos da série de pressão a montante ao Sul de Perußbe que exemplificam a aplicação dos modelos de previsão. São apresentados o melhor procedimento de ajuste de cada família de modelos, de acordo com o melhor RMSE de previsão, para os dois tamanhos de rolling window descritos na tabela 3.56 . Para a seleção dos procedimentos, exluiu-se os que utilizaram a estratégia de tipo 2. Os gráficos exibem 48 horas da série seguidas de 168 horas de previsão. Os gráficos da esquerda se referem aos ajustes que usaram rolling windows de tamanho 336, já os da direita, de tamanho 720

Para a elaboração dos gráficos da Figura 3.28, decidiu-se não selecionar as previsões que usaram a estratégia do tipo 2, por tal método nem sempre conseguir estimar os parâmetros dos modelos, o que acaba resultando no uso de uma quantidade menor de rolling windows. Assim, as previsões SARIMA se referem ao uso de estratégia do tipo 1 e rolling windows de tamanho 720; as de regressão com erros autocorrelacionados se referem ao uso de polinômio de grau 0 modelando a tendência, sem sazonalidade semanal, com o uso da estratégia do tipo 1 para os erros SARIMA e rolling windows de tamanho 336; as previsões BATS se referem ao uso de modelos sem sazonalidade semanal e rolling windows de tamanho 336; as previsões TBATS se referem ao uso de modelos sem sazonalidade semanal e rolling windows de tamanho 336 e as previsões benchmark se referem ao uso da mediana e rolling windows de tamanho 336 . 


\subsection{Pressão a jusante no Norte de Peruíbe}

Nesta seção é apresentado e discutido os resultados das aplicações dos procedimentos de imputação de valores omissos e deteç̧ão de outliers e dos métodos de previsão relacionados a série de pressão a jusante ao Norte de Peruíbe. A Figura 3.29 exibe um trecho da série que exemplifica seu comportamento. O gráfico (A) se refere a série original, enquanto que o gráfico (B) é mesmo trecho após limpeza e aplicação do métodos de detecção de outlier e preenchimento de valores omissos.

(A) Trecho da série original

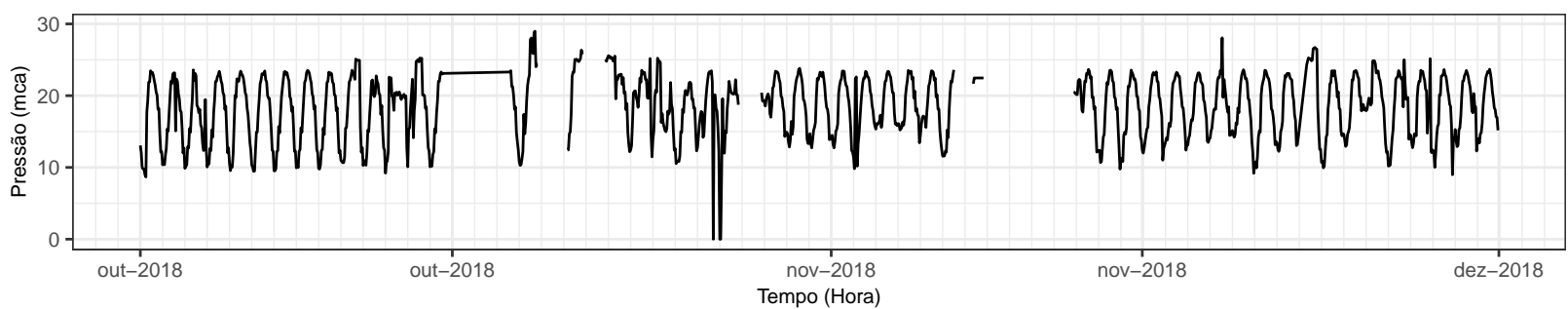

(B) Trecho da série após limpeza e preenchimento de valores omissos

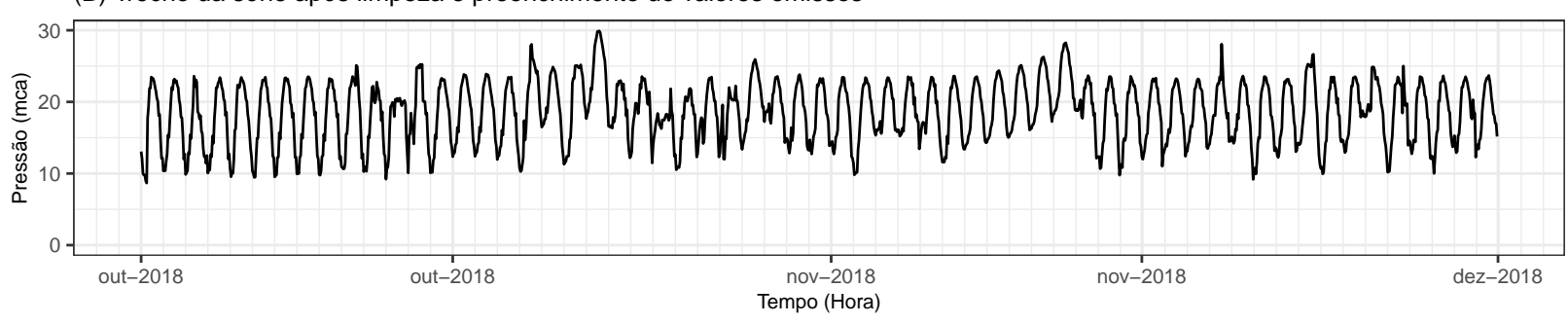

Figura 3.29: Trecho da série de pressão a jusante ao Norte de Peruíbe que exemplificam seu comportamento. O gráfico (A) é referente a série original e o gráfico (B) mostra a série após as limpezas, tratamento dos outliers detectados e preenchimento dos valores omissos de acordo com o método escolhido.

O método escolhido para a detecção de outliers e preenchimentos dos valores omissos, por possuir o menor RMSE total entre todos os experimentos realizados, com o valor de 1,79 , foi o ajuste de curvas de regressão com polinômio de grau 2 modelando a tendência, com interpolação de $R_{t}$, com sazonalidade semanal, janela de tamanho 720 e valor de corte $c=5$. O total de valores classificados como anomalias após aplicação do método selecionado foi de 2352 (13,4 \%), vis-à-vis à quantidade de $1772(10,1 \%)$ após a limpeza primária e à quantidade original de $206(1,18 \%)$. Em relação a previsão, o método que apresentou melhor desempenho nos experimentos foi o que usou modelos de regressão com erros autocorrelacionados, com polinômio de grau 0 modelando a tendência, sem sazonalidade semanal, com o uso da estratégia do tipo 1 para os erros SARIMA e com rolling windows de tamanho 336, apresentando o valor de RMSE total de 1,408. De modo geral, os resultados mostram uma boa adequabilidade dos métodos propostos a série temporal de pressão a jusante ao Norte de Peruíbe.

As próximas subseções apresentam e discutem os resultados de forma mais detalhada.

\subsubsection{Preenchimento de valores omissos}

As tabelas 3.57 à 3.59 mostram os resultados dos 12 melhores experimentos de cada tipo de procedimento de preenchimento de valores omissos, usando como medida de avaliação o RMSE. Em todas as tabelas os experimentos são apresentados em ordem decrescente de RMSE. Já a tabela 3.60 apresenta os resultados dos procedimentos de preenchimento de valores omissos usados como 
benchmark. Nesta, os experimentos são ordenados pelo ID.

Tabela 3.57: RMSE dos 12 melhores métodos de preenchimento de dados omissos baseados no ajuste de modelos de regressão, selecionados de acordo com menor RMSE. Os resultados se referem a aplicação dos métodos a série de pressão a jusante ao Norte de Peruíbe.

\begin{tabular}{|c|c|c|c|c|c|c|c|c|c|c|c|c|c|}
\hline \multicolumn{6}{|c|}{ Experimentos de regressão } & \multicolumn{8}{|c|}{ Quantidade de valores omissos em sequência } \\
\hline ID & $\begin{array}{l}\text { Interpolação } \\
\quad \text { de } R_{t}\end{array}$ & $\begin{array}{c}\text { Dia da } \\
\text { semana }\end{array}$ & $\begin{array}{l}\text { Grau do } \\
\text { polinômio }\end{array}$ & Janela & $c$ & 1 & 3 & 6 & 12 & 18 & 24 & 48 & Total \\
\hline reg105 & Sim & $\mathrm{Sim}$ & 2 & 720 & 5 & 1,32 & 1,25 & 1,89 & 2,09 & 2,07 & 1,43 & 2,48 & 1,79 \\
\hline reg93 & Sim & Sim & 1 & 720 & 5 & 1,39 & 1,26 & 1,93 & 2,22 & 2,06 & 1,39 & 2,41 & 1,81 \\
\hline reg96 & Sim & Sim & 2 & 720 & 5 & 1,38 & 1,23 & 1,99 & 2,21 & 2,07 & 1,40 & 2,39 & 1,81 \\
\hline reg108 & Sim & Sim & 5 & 720 & 5 & 1,32 & 1,26 & 2,07 & 2,09 & 2,08 & 1,42 & 2,52 & 1,82 \\
\hline reg101 & Sim & Sim & 1 & 336 & 5 & 1,30 & 1,16 & 1,98 & 2,04 & 2,27 & 1,54 & 2,60 & 1,84 \\
\hline reg102 & $\mathrm{Sim}$ & $\mathrm{Sim}$ & 1 & 720 & 5 & 1,31 & 1,30 & 1,89 & 2,09 & 2,16 & 1,66 & 2,51 & 1,85 \\
\hline reg104 & Sim & $\mathrm{Sim}$ & 2 & 336 & 5 & 1,26 & 1,19 & 2,01 & 2,01 & 2,31 & 1,54 & 2,66 & 1,85 \\
\hline reg99 & Sim & Sim & 5 & 720 & 5 & 1,41 & 1,26 & 2,02 & 2,13 & 2,12 & 1,40 & 2,69 & 1,86 \\
\hline reg92 & Sim & Sim & 1 & 336 & 5 & 1,47 & 1,24 & 2,09 & 2,37 & 2,04 & 1,41 & 2,42 & 1,86 \\
\hline reg94 & Sim & Sim & 2 & 168 & 5 & 1,47 & 1,19 & 2,12 & 2,28 & 2,16 & 1,39 & 2,47 & 1,87 \\
\hline reg97 & $\mathrm{Sim}$ & $\mathrm{Sim}$ & 5 & 168 & 5 & 1,37 & 1,21 & 1,83 & 2,05 & 2,25 & 1,79 & 2,60 & 1,87 \\
\hline reg98 & Sim & Sim & 5 & 336 & 5 & 1,34 & 1,26 & 2,06 & 2,07 & 2,31 & 1,50 & 2,55 & 1,87 \\
\hline
\end{tabular}

Tabela 3.58: RMSE dos 12 melhores métodos de preenchimento de dados omissos baseados no ajuste de modelo de regressão acompanhado de decomposiçôes clássica, selecionados de acordo com menor RMSE. O modelo de regressão usado em conjundo com a decomposição clássica, por apresentar menor RMSE, foi o que possui polinômio de grau 2, com interpolação dos resíduos, com sazonalidade semanal e janela de tamanho 720. Os resultados se referem a aplicação dos métodos a série de pressão a jusante ao Norte de Peruibe.

\begin{tabular}{|c|c|c|c|c|c|c|c|c|c|c|c|}
\hline \multicolumn{4}{|c|}{ Experimentos de decomposição clássica } & \multicolumn{8}{|c|}{ Quantidade de valores omissos em sequência } \\
\hline ID & $\begin{array}{l}\text { Interpolação } \\
\text { de } R_{t}\end{array}$ & Janela & $c$ & 1 & 3 & 6 & 12 & 18 & 24 & 48 & Total \\
\hline $\operatorname{dec} 16$ & $\operatorname{Sim}$ & 168 & 5 & 1,31 & 1,25 & 1,89 & 1,94 & 2,09 & 1,51 & 2,65 & 1,81 \\
\hline $\operatorname{dec} 13$ & Não & 168 & 5 & 1,55 & 1,26 & 1,92 & 2,13 & 2,00 & 1,47 & 2,47 & 1,83 \\
\hline $\operatorname{dec} 17$ & Sim & 336 & 5 & 1,34 & 1,24 & 1,89 & 2,01 & 2,10 & 1,55 & 2,75 & 1,84 \\
\hline $\operatorname{dec} 18$ & Sim & 720 & 5 & 1,31 & 1,25 & 1,90 & 2,02 & 2,14 & 1,56 & 2,72 & 1,84 \\
\hline $\operatorname{dec} 14$ & Não & 336 & 5 & 1,61 & 1,31 & 1,95 & 2,18 & 2,02 & 1,48 & 2,50 & 1,86 \\
\hline $\operatorname{dec} 15$ & Não & 720 & 5 & 1,63 & 1,36 & 1,97 & 2,21 & 2,05 & 1,48 & 2,50 & 1,89 \\
\hline $\operatorname{dec} 7$ & Não & 168 & 3 & 1,64 & 1,28 & 2,10 & 2,40 & 1,94 & 1,39 & 2,52 & 1,90 \\
\hline $\operatorname{dec} 10$ & Sim & 168 & 3 & 1,53 & 1,30 & 2,12 & 2,33 & 2,00 & 1,38 & 2,60 & 1,90 \\
\hline $\operatorname{dec} 8$ & Não & 336 & 3 & 1,69 & 1,32 & 2,13 & 2,43 & 1,96 & 1,42 & 2,54 & 1,92 \\
\hline $\operatorname{dec} 11$ & Sim & 336 & 3 & 1,56 & 1,31 & 2,13 & 2,40 & 2,01 & 1,43 & 2,63 & 1,93 \\
\hline $\operatorname{dec} 12$ & Sim & 720 & 3 & 1,55 & 1,33 & 2,14 & 2,40 & 2,04 & 1,50 & 2,68 & 1,95 \\
\hline $\operatorname{dec} 9$ & Não & 720 & 3 & 1,71 & 1,37 & 2,13 & 2,45 & 1,99 & 1,45 & 2,56 & 1,95 \\
\hline
\end{tabular}

Tabela 3.59: RMSE dos 12 melhores métodos de preenchimento de dados omissos baseados em decomposição STL, selecionados de acordo com menor RMSE. Os resultados se referem a aplicação dos métodos a série de pressão a jusante ao Norte de Peruíbe.

\begin{tabular}{|c|c|c|c|c|c|c|c|c|c|c|c|c|c|}
\hline \multicolumn{6}{|c|}{ Experimentos de decomposição STL } & \multicolumn{8}{|c|}{ Quantidade de valores omissos em sequência } \\
\hline ID & $\begin{array}{l}\text { Interpolação } \\
\quad \text { de } R_{t}\end{array}$ & $n_{(i)}$ & $n_{(e)}$ & $n_{(s)}$ & $c$ & 1 & 3 & 6 & 12 & 18 & 24 & 48 & Total \\
\hline st146 & Sim & 2 & 0 & 25 & 5 & 1,24 & 1,30 & 1,92 & 1,88 & 2,34 & 1,68 & 2,77 & 1,88 \\
\hline st128 & Sim & 2 & 0 & 25 & 3 & 1,45 & 1,26 & 2,07 & 2,02 & 2,24 & 1,58 & 2,57 & 1,88 \\
\hline st147 & Sim & 2 & 0 & 37 & 5 & 1,25 & 1,31 & 1,85 & 1,87 & 2,35 & 1,68 & 2,90 & 1,89 \\
\hline st129 & Sim & 2 & 0 & 37 & 3 & 1,41 & 1,27 & 2,07 & 1,94 & 2,26 & 1,56 & 2,72 & 1,89 \\
\hline st148 & Sim & 2 & 0 & 49 & 5 & 1,23 & 1,30 & 1,85 & 1,86 & 2,36 & 1,69 & 2,98 & 1,90 \\
\hline st130 & $\mathrm{Sim}$ & 2 & 0 & 49 & 3 & 1,40 & 1,32 & 2,08 & 1,95 & 2,25 & 1,57 & 2,80 & 1,91 \\
\hline st111 & $\operatorname{Sim}$ & 2 & 0 & 37 & 2 & 1,48 & 1,36 & 2,14 & 2,17 & 2,29 & 1,69 & 2,61 & 1,96 \\
\hline st112 & Sim & 2 & 0 & 49 & 2 & 1,50 & 1,39 & 2,17 & 2,19 & 2,28 & 1,64 & 2,66 & 1,98 \\
\hline st110 & Sim & 2 & 0 & 25 & 2 & 1,50 & 1,35 & 2,23 & 2,17 & 2,28 & 1,74 & 2,62 & 1,98 \\
\hline st14 & Não & 1 & 5 & 25 & 2 & 1,91 & 1,40 & 2,20 & 2,63 & 2,01 & 1,60 & 2,16 & 1,99 \\
\hline stl22 & Não & 1 & 5 & 25 & 3 & 1,88 & 1,40 & 2,21 & 2,65 & 2,02 & 1,70 & 2,14 & 2,00 \\
\hline st17 & Não & 1 & 10 & 25 & 2 & 1,94 & 1,41 & 2,24 & 2,65 & 2,03 & 1,60 & 2,15 & 2,00 \\
\hline
\end{tabular}


Tabela 3.60: RMSE dos métodos benchmark de preenchimento de dados omissos. Os resultados se referem a aplicação dos métodos a série de pressão a jusante ao Norte de Peruíbe.

\begin{tabular}{|c|c|c|c|c|c|c|c|c|c|c|}
\hline \multicolumn{3}{|c|}{ Experimentos emphbenchmark } & \multicolumn{8}{|c|}{ Quantidade de valores omissos em sequência } \\
\hline ID & $\begin{array}{c}\text { Forma de } \\
\text { benchmark }\end{array}$ & Janela & 1 & 3 & 6 & 12 & 18 & 24 & 48 & Total \\
\hline ben 1 & Média & 168 & 4,65 & 4,47 & 4,36 & 4,54 & 4,30 & 4,31 & 4,38 & 4,43 \\
\hline ben 2 & Média & 336 & 4,56 & 4,37 & 4,27 & 4,52 & 4,31 & 4,33 & 4,41 & 4,39 \\
\hline ben 3 & Média & 720 & 4,60 & 4,39 & 4,26 & 4,50 & 4,31 & 4,36 & 4,42 & 4,41 \\
\hline ben 4 & Mediana & 168 & 4,82 & 4,59 & 4,53 & 4,65 & 4,43 & 4,38 & 4,51 & 4,56 \\
\hline ben 5 & Mediana & 336 & 4,66 & 4,51 & 4,41 & 4,61 & 4,45 & 4,42 & 4,52 & 4,51 \\
\hline ben 6 & Mediana & 720 & 4,69 & 4,53 & 4,37 & 4,58 & 4,48 & 4,42 & 4,53 & 4,51 \\
\hline ben 7 & Interpolação & - & 1,28 & 1,49 & 2,42 & 3,75 & 5,46 & 6,07 & 5,78 & 3,75 \\
\hline
\end{tabular}

De acordo com as informações apresentadas nas tabelas 3.57 à 3.60 podemos verificar que, em geral:

- Os melhores procedimentos de regressão, de acordo com o RMSE total, foram aqueles que usaram interpolação nos resíduos $R_{t}$, que consideraram a sazonalidade semanal, valor de corte $c=5$ e que, aparentemente, usaram janelas de tamanho 720 , sendo que o melhor procedimento de regressão para imputação de valores omissos foi o que usou polinômio de grau 2 modelando a tendência, com interpolação de $R_{t}$, com sazonalidade semanal, janela de tamanho 720 e valor de corte $c=5$, apresentando um RMSE total igual a 1,79. Os parâmetros desse modelo de regressão foram os usados na aplicação do método de decomposição clássica.

- Aparentemente, os procedimentos de decomposição clássica que tiveram melhor desempenho, de acordo com o RMSE total, foram aqueles que usaram valor de corte $c=5$. O melhor procedimento foi aquele que usou decomposição com interpolação de $R_{t}$, janela de tamanho 168 e valor de corte $c=5$, apresentando um RMSE total igual a 1,806.

- Os tipos de decomposição STL que tiveram melhores resultados, de acordo com o RMSE total, possuem interpolação nos resíduos $R_{t}$ e usaram decomposição STL não robusta $\left(n_{(i)}=2 \mathrm{e}\right.$ $\left.n_{(e)}=0\right)$. O melhor procedimento foi o de decomposição não robusta $\left(n_{(i)}=2\right.$ e $\left.n_{(e)}=0\right)$, com interpolação de $R_{t}, n_{(s)}=25$ e valor de corte $c=5$, apresentando um RMSE total igual a 1,875 .

- Dentre os métodos de benchmark, o que teve melhor desempenho foi o que interpola linearmente os valores da série, apresentando um RMSE total igual a 3,749. Verifica-se que os procedimentos propostos tiveram desempenhos bem superiores aos benchmarks.

- Dentre todos os experimentos, o que apresentou melhor resultado foi o procedimento de ajuste de curvas de regressão com polinômio de grau 2 modelando a tendência, com interpolação de $R_{t}$, com sazonalidade semanal, janela de tamanho 720 e valor de corte $c=5$, apresentando um valor de RMSE total de 1,79. Este é o procedimento para o qual é apresentado uma análise de outliers na próxima subseção e que é usado oficialmente para preencher os valores omissos da série.

A Figura 3.30 exemplifica alguns experimentos de preenchimento de valores omissos. Cada gráfico representa um trecho da série temporal de pressão a jusante ao Norte de Peruíbe no qual propositalmente foi removido uma sequência de valores. Todos os gráficos se referem a uma lacuna 
de tamanho 48 horas acompanhado de 12 valores anteriores e posteriores à lacuna principal. Os procedimentos de preenchimento adotados para ilustrar os gráficos são o melhor experimento, de acordo com o RMSE total, de cada tipo de procedimento apresentados nas tabelas 3.57 à 3.60.

(A)

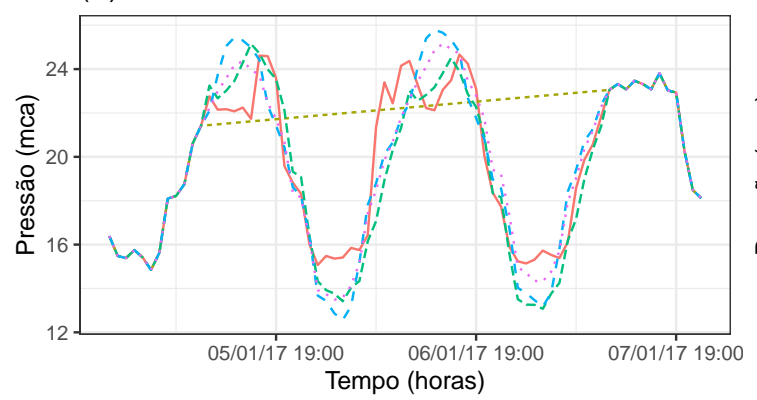

(C)

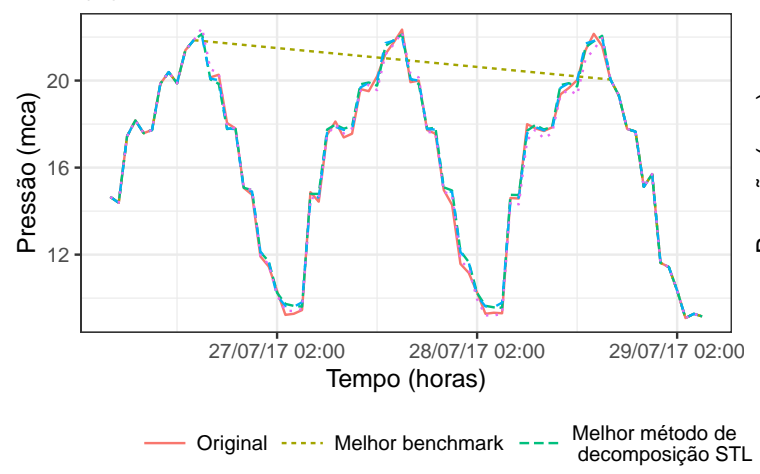

(B)

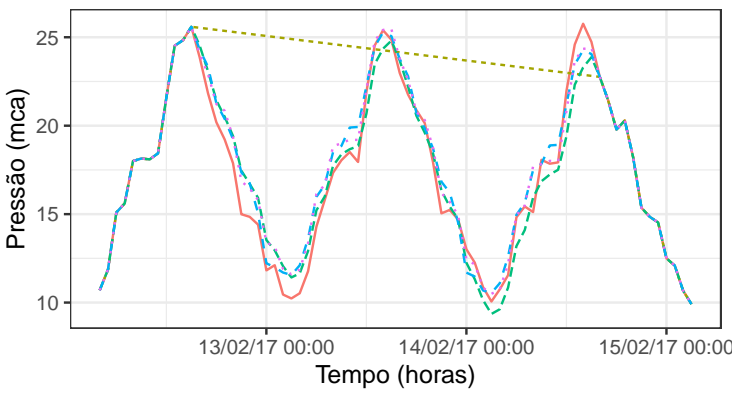

(D)

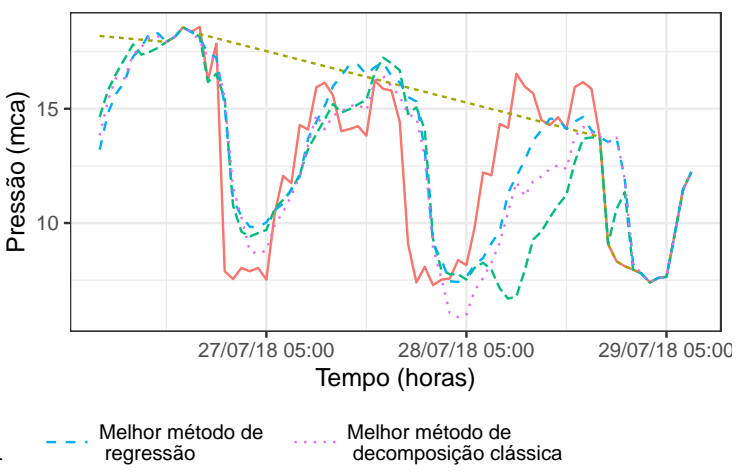

Figura 3.30: Alguns trechos da série de pressão a jusante ao Norte de Peru々be que exemplificam a aplicação dos procedimentos de preenchimento de valores omissos. É apresentado o melhor experimento de imputação de valores omissos de cada tipo de procedimento de acordo com o RMSE, descritos nas tabelas 3.57 à 3.60. A lacuna principal de valores omissos usada em cada gráfico foi inserida artificialmente na série temporal a fim de avaliar a performance dos procedimentos de preenchimento de valores omissos. O tamanho da lacuna principal é de 48 horas, sendo precedida e sucedida de 12 horas de valores originais.

Verifica-se que os procedimentos propostos conseguiram fazer uma boa estimativa dos valores omissos, sendo estas bem superiores às do método de interpolação. Esses resultados já eram esperados, pois a série de pressão a jusante ao Norte de Peruíbe apresenta um comportamento sazonal bem característico, mesmo que esse comportamento tenha alguns momentos de notáveis diferenças entre o valor real e o estimado pelos métodos propostos.

\subsubsection{Detecção e tratamento de outliers}

As tabelas 3.61 e 3.62 mostram os resultados dos experimentos elaborados para avaliar o desempenho em detectar e tratar os outliers do melhor procedimento selecionado para a imputação dos valores omissos. A Tabela 3.61 apresenta as taxas de deteç̧ão dos outliers, sendo dividida em duas partes: na parte superior o cálculo das taxas considera todas as observações afetadas pelo efeito atípico, enquanto que na parte inferior é considerado apenas a observação mais afetada pelo efeito atípico. Vale lembrar que no caso do efeito atípico do tipo platô todas as observações foram consideradas como sendo as mais afetadas devido ao efeito se distribuir igualmente entre elas. Já a tabela 3.62 é destinada a verificar a acurácia do procedimento ao corrigir os valores dos outliers. Sua estrutura é análoga à da tabela 3.61, sendo que a linha total é o RMSE do efeito atípico nas observações.

A partir das tabelas, podemos verificar que: 
Tabela 3.61: Taxa de deteç̧ão de outliers de acordo com o procedimento que apresentou melhor desempenho em preencher valores omissos. O procedimento foi o de ajuste de curvas de regressão com polinômio de grau 2 modelando a tendência, com interpolação de $R_{t}$, com sazonalidade semanal, janela de tamanho 720 e valor de corte $c=5$. Variou-se o valor de corte c e a quantidade de iterações máxima com o objetivo de verificar se a mudança desses parâmetros causam algum impacto na deteç̧ão dos outliers. A aplicação se refere a série de pressão a jusante ao Norte de Peruíbe.

\begin{tabular}{|c|c|c|c|c|c|c|c|c|}
\hline \multicolumn{3}{|c|}{ Experimentos } & \multicolumn{6}{|c|}{ Tipo de efeitos atípicos } \\
\hline ID & c & $\begin{array}{l}\mathrm{N}^{0} \text { máximo } \\
\text { de iterações }\end{array}$ & Único & Platô & Pulso & $\begin{array}{l}\text { C.D. } \\
\text { linear }\end{array}$ & $\begin{array}{c}\text { C.D. } \\
\text { exponencial }\end{array}$ & $\begin{array}{c}\text { C.D. } \\
\text { logaritmico }\end{array}$ \\
\hline \multicolumn{9}{|c|}{ Todas as observações afetadas } \\
\hline out1 & 2 & 1 & 1 & 0,964 & 0,641 & 0,745 & 0,680 & 0,781 \\
\hline out 2 & 3 & 1 & 1 & 0,890 & 0,527 & 0,607 & 0,567 & 0,656 \\
\hline out3 & 4 & 1 & 1 & 0,683 & 0,433 & 0,514 & 0,470 & 0,541 \\
\hline out 4 & 5 & 1 & 1 & 0,344 & 0,338 & 0,394 & 0,364 & 0,404 \\
\hline out 5 & 2 & 3 & 1 & 0,988 & 0,807 & 0,883 & 0,846 & 0,914 \\
\hline out 6 & 3 & 3 & 1 & 0,982 & 0,680 & 0,781 & 0,719 & 0,819 \\
\hline out 7 & 4 & 3 & 1 & 0,938 & 0,569 & 0,650 & 0,606 & 0,676 \\
\hline out 8 & 5 & 3 & 1 & 0,631 & 0,452 & 0,511 & 0,486 & 0,530 \\
\hline out9 & 2 & 5 & 1 & 0,991 & 0,809 & 0,893 & 0,850 & 0,929 \\
\hline out10 & 3 & 5 & 1 & 0,982 & 0,689 & 0,793 & 0,726 & 0,822 \\
\hline out11 & 4 & 5 & 1 & 0,951 & 0,569 & 0,656 & 0,613 & 0,696 \\
\hline out12 & 5 & 5 & 1 & 0,686 & 0,455 & 0,516 & 0,490 & 0,533 \\
\hline Total & - & - & 1 & 1,000 & 1,000 & 1,000 & 1,000 & 1,000 \\
\hline \multicolumn{9}{|c|}{ Somente observações mais afetadas } \\
\hline out1 & 2 & 1 & 1 & 0,964 & 1,000 & 0,990 & 0,990 & 0,990 \\
\hline out 2 & 3 & 1 & 1 & 0,890 & 1,000 & 0,990 & 0,990 & 0,990 \\
\hline out3 & 4 & 1 & 1 & 0,683 & 1,000 & 0,990 & 0,990 & 0,971 \\
\hline out 4 & 5 & 1 & 1 & 0,344 & 0,983 & 0,971 & 0,990 & 0,933 \\
\hline out 5 & 2 & 3 & 1 & 0,988 & 1,000 & 0,990 & 0,990 & 0,990 \\
\hline out 6 & 3 & 3 & 1 & 0,982 & 1,000 & 0,990 & 0,990 & 0,990 \\
\hline out 7 & 4 & 3 & 1 & 0,938 & 1,000 & 0,990 & 0,990 & 0,990 \\
\hline out 8 & 5 & 3 & 1 & 0,631 & 1,000 & 0,990 & 0,990 & 0,971 \\
\hline out9 & 2 & 5 & 1 & 0,991 & 1,000 & 0,990 & 0,990 & 0,990 \\
\hline out10 & 3 & 5 & 1 & 0,982 & 1,000 & 0,990 & 0,990 & 0,990 \\
\hline out11 & 4 & 5 & 1 & 0,951 & 1,000 & 0,990 & 0,990 & 0,990 \\
\hline out12 & 5 & 5 & 1 & 0,686 & 1,000 & 0,990 & 0,990 & 0,971 \\
\hline Total & - & - & 1 & 1,000 & 1,000 & 1,000 & 1,000 & 1,000 \\
\hline
\end{tabular}

- De modo geral, as taxas de deteç̧ão dos outliers foram altas, principalmente quando se considera apenas as obsevações mais afetadas. Um ponto de destaque é que os efeitos atípicos do tipo único tiveram todos os seus outliers detectados pelo método. Esses resultados são uma evidência da possível adequação do procedimento em detectar os outliers da série. Nota-se também que as altas taxas de detecção resultaram em um RMSE relativamente bom.

- O número de máximo de iterações possui, em geral, uma considerável influencia nos resultados. Com exceção do efeito do tipo único, a taxa de detecção dos experimentos que tiveram apenas uma iteração foi menor do que quando usadas iterações máximas iguais a 3 ou 5 . Porém, não há muita diferança entre usar um número máximo de iterações igual a 3 ou igual a 5 . Algo semelhante pode ser observado pelos valores de RMSE: o RMSE dos experimentos que usaram apenas uma iteração máxima foram maiores do aqueles que tiveram iterações máximas iguais a 3 ou 5. A semelhança dos resultados do uso de 3 e 5 iterações máximas pode ser explicado pelo algoritmo conseguir encontrar grande parte dos outliers antes de atingir número máximo de iterações, sendo necessário apenas uma baixa quantidade de iterações, isto é, um número menor ou igual a 3 , porém maior que 1 .

- Como o esperado, percebe-se claramente que o valor de corte $c$ influencia na taxa de detecção, sendo que quanto menor for valor de corte $c$, melhor é a taxa de deteç̧ão. Também verifica-se um melhor valor de RMSE para os valores mais baixos de $c$. Lembramos que, embora um valor de corte baixo aumente a taxa de detecção de outliers, ele também aumenta a taxa de detecção de valores que possivelmente não seriam outliers. 
Tabela 3.62: RMSE do tratamento dos outliers de acordo com o procedimento que apresentou melhor desempenho em preencher valores omissos. O procedimento foi o de ajuste de curvas de regressão com polinômio de grau 2 modelando a tendência, com interpolação de $R_{t}$, com sazonalidade semanal, janela de tamanho 720 e valor de corte $c=5$. Variou-se o valor de corte $c$ e a quantidade de iterações máxima com o objetivo de verificar se a mudança desses parâmetros causam algum impacto na detecção dos outliers. A linha total é o RMSE das observações ouliers em relação ao seu valor original. A aplicação se refere a série de pressão a jusante ao Norte de Peruíbe.

\begin{tabular}{|c|c|c|c|c|c|c|c|c|}
\hline \multicolumn{3}{|c|}{ Experimentos } & \multicolumn{6}{|c|}{ Tipo de efeitos atípicos } \\
\hline ID & c & $\begin{array}{l}\mathrm{N}^{0} \text { máximo } \\
\text { de iterações }\end{array}$ & Único & Platô & Pulso & $\begin{array}{l}\text { C.D. } \\
\text { linear }\end{array}$ & $\begin{array}{c}\text { C.D. } \\
\text { exponencial }\end{array}$ & $\begin{array}{c}\text { C.D. } \\
\text { logaritmico }\end{array}$ \\
\hline \multicolumn{9}{|c|}{ Todas as observações afetadas } \\
\hline out1 & 2 & 1 & 1,301 & 2,54 & 2,99 & 3,81 & 3,73 & 3,86 \\
\hline out 2 & 3 & 1 & 1,289 & 3,46 & 3,52 & 4,81 & 4,56 & 4,80 \\
\hline out 3 & 4 & 1 & 1,227 & 5,72 & 4,21 & 5,61 & 5,39 & 5,78 \\
\hline out 4 & 5 & 1 & 0,989 & 7,63 & 4,86 & 6,42 & 6,22 & 6,60 \\
\hline out 5 & 2 & 3 & 1,437 & 2,24 & 2,49 & 2,76 & 2,67 & 2,66 \\
\hline out6 & 3 & 3 & 1,289 & 2,54 & 3,07 & 3,60 & 3,50 & 3,65 \\
\hline out7 & 4 & 3 & 1,227 & 3,93 & 3,84 & 4,75 & 4,58 & 4,94 \\
\hline out 8 & 5 & 3 & 0,989 & 6,63 & 4,51 & 5,85 & 5,49 & 6,12 \\
\hline out9 & 2 & 5 & 1,437 & 2,23 & 2,48 & 2,72 & 2,64 & 2,62 \\
\hline out10 & 3 & 5 & 1,289 & 2,53 & 3,05 & 3,57 & 3,48 & 3,62 \\
\hline out11 & 4 & 5 & 1,227 & 3,91 & 3,84 & 4,72 & 4,54 & 4,87 \\
\hline out12 & 5 & 5 & 0,989 & 6,49 & 4,51 & 5,83 & 5,47 & 6,10 \\
\hline Total & - & - & 13,127 & 9,07 & 8,61 & 9,11 & 9,73 & 8,89 \\
\hline \multicolumn{9}{|c|}{ Somente observações mais afetadas } \\
\hline out1 & 2 & 1 & 1,301 & 2,54 & 1,98 & 3,88 & 4,05 & 3,79 \\
\hline out 2 & 3 & 1 & 1,289 & 3,46 & 1,93 & 5,12 & 5,03 & 4,81 \\
\hline out3 & 4 & 1 & 1,227 & 5,72 & 2,05 & 6,11 & 6,19 & 6,22 \\
\hline out 4 & 5 & 1 & 0,989 & 7,63 & 3,16 & 7,37 & 7,42 & 7,49 \\
\hline out 5 & 2 & 3 & 1,437 & 2,24 & 1,98 & 3,06 & 3,09 & 2,95 \\
\hline out6 & 3 & 3 & 1,289 & 2,54 & 1,93 & 3,87 & 3,96 & 3,76 \\
\hline out7 & 4 & 3 & 1,227 & 3,93 & 2,05 & 5,24 & 5,26 & 5,27 \\
\hline out 8 & 5 & 3 & 0,989 & 6,63 & 2,78 & 6,62 & 6,49 & 6,91 \\
\hline out 9 & 2 & 5 & 1,437 & 2,23 & 1,98 & 3,04 & 3,07 & 2,93 \\
\hline out10 & 3 & 5 & 1,289 & 2,53 & 1,93 & 3,86 & 3,95 & 3,74 \\
\hline out11 & 4 & 5 & 1,227 & 3,91 & 2,06 & 5,21 & 5,24 & 5,22 \\
\hline out12 & 5 & 5 & 0,989 & 6,49 & 2,78 & 6,61 & 6,42 & 6,88 \\
\hline Total & - & - & 13,127 & 9,07 & 15,43 & 14,61 & 17,46 & 13,32 \\
\hline
\end{tabular}

- Em todos os experimentos, o RMSE foi bem superior do que o RMSE total. Isso indica a boa adequabilidade do método em tratar os outliers encontrados.

A Figura 3.31 exemplifica as constatações realizadas. É possível observar que os procedimentos conseguiram dar uma bom tratamentos aos outliers.

A Tabela 3.63 apresenta a quantidade de anomalias detectadas em cada fase do tratamento dado a série de pressão a jusante ao Norte de Peruíbe. Nota-se que a maior parte das observações anômalas foram detectadas durante a fase de limpeza primária, o que dá a quantidade de 1566 observações ou $8,9 \%$ do total. Durante todo o processo, foram detectadas $2352(13,4 \%)$ observações anormais.

Tabela 3.63: Quantidade de valores detectados como anomalias em cada estágio de tratamento da série de pressão a jusante ao Norte de Peruíbe. A primeira linha da tabela se refere a quantidade de valores classificados pelo sistema da Sabesp como bad e que, portanto, eram omissos na série original. A segunda linha se refere aos valores detectados como anomalias pela limpeza primária. A terceira linha se refere a quantidade de valores detectados como outliers pela aplicação do algoritmo proposto.

\begin{tabular}{|c|c|c|c|c|}
\hline Fase de detecção de anomalias & Frequência absoluta & Frequência relativa & Acumulado absoluto & Acumulado relativo \\
\hline Originalmente & 206 & $1,2 \%$ & 206 & $1,2 \%$ \\
\hline Limpeza primária & 1.566 & $8,9 \%$ & 1.772 & $10,1 \%$ \\
\hline Algoritmo de detecção de outliers & 580 & $3,3 \%$ & 2.352 & $13,4 \%$ \\
\hline Tamanho da série & 17.519 & $100 \%$ & 19.871 & $100 \%$ \\
\hline
\end{tabular}


(A) Único

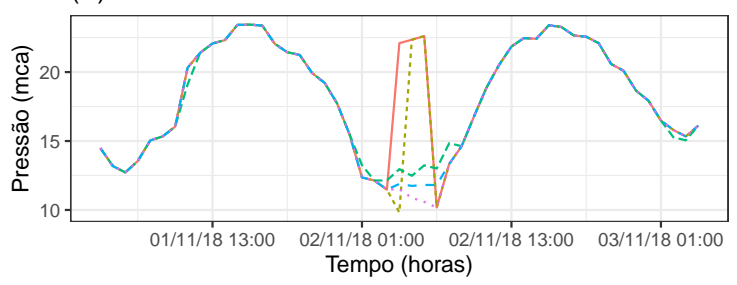

(C) Pulso

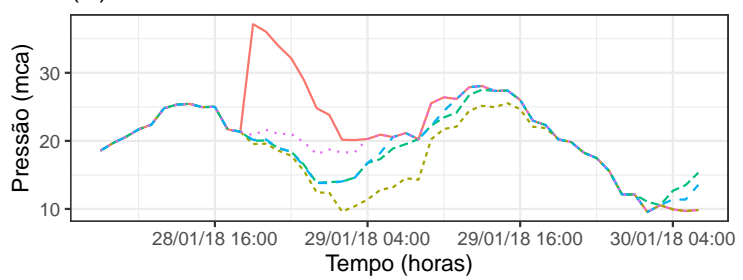

(E) C.D. Exponencial

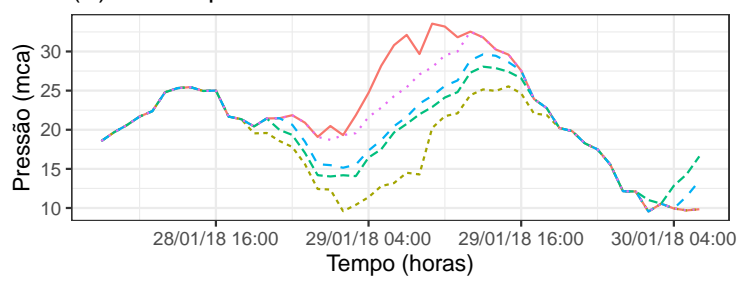

(B) Platô

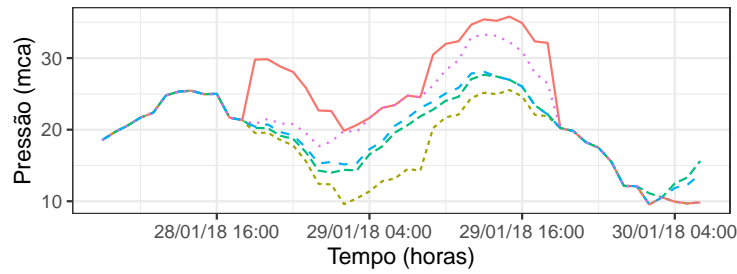

(D) C.D. Linear

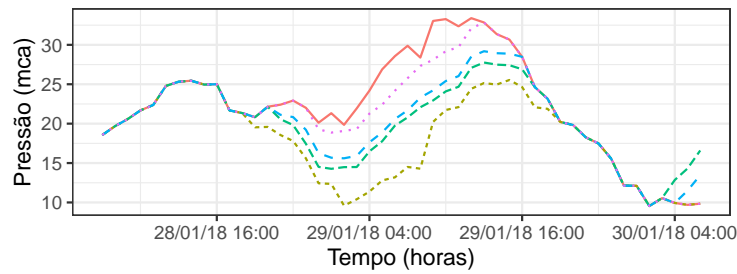

(F) C.D. Logaritmico

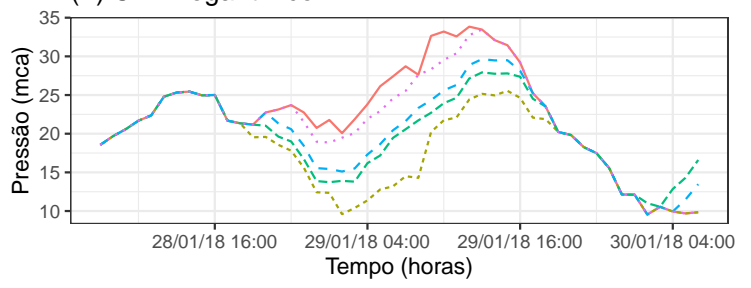

- Série com Outlier $\quad \ldots$.... Original --- Corte $=2-\ldots$ Corte $=3 \cdots$ Corte $=5$

Figura 3.31: Exemplos de detecção e tratamento dos outliers inseridos na série de pressão a jusante ao Norte de Peruibe. Os trechos mostrados possuem tamanho 48 e são centrados nas observações afetadas pelo efeito atípico. Os gráficos de $(A)$ a (F) exemplificam cada tipo de efeito atípico na série. A quantidade de iteração máxima dos experimentos selecionados é 3.

\subsubsection{Previsão}

A Tabela 3.64 traz os resultados de acurácia dos experimentos de previsão de acordo com RMSE. Ela é dividida em duas partes: a parte superior é dedicada a mostrar os resultados que usaram rolling windows de tamanho 336 horas (14 dias) e a parte inferior mostra os resultados referentes ao uso de rolling windows de tamanho 720 horas (30 dias). Os experimentos estão agrupados por tipo de modelos. A partir dessa tabela, verifica-se que:

- O melhor procedimento de previsão com modelos SARIMA, de acordo com o RMSE total, foi o que usou estratégia do tipo 2 e rolling windows de tamanho 336, apresentando RMSE total de 1,63 . Vale notar que a estratégia de tipo 2 teve um desempenho superior do que a de tipo 1 no uso de rolling window de ambos tamanhos, o que é um resultado um tanto inusitado, já que o esperado era que o desempenho de um modelo identificado usando as observações da própria rolling window fosse superior àquele que usasse as observações de uma outra rolling window para se fazer tal identificação.

- O melhor procedimento de regressão com erros autocorrelacionados, de acordo com o RMSE total, foi o que usou polinômio de grau 0 modelando a tendência, sem sazonalidade semanal, com o uso da estratégia do tipo 1 para os erros SARIMA e rolling windows de tamanho 336, apresentando RMSE total de 1,408. É importante notar que nem todos os experimentos conseguiram ajustar determinado modelo em todas as rollings windows, o que pode ser um empecilho a mais na hora de fazer comparações. 
Tabela 3.64: RMSE dos experimentos de previsão aplicados a série de pressão a jusante ao Norte de Peruíbe. As estratégias de tipo 1 se referem a aplicação do algoritmo de seleção de modelo em cada uma das rollings windows, enquanto que as de tipo 2 se referem a aplicação do algoritmo somente na primeira rolling window e do ajuste modelo selecionado nas demais rolling windows, reestimando os parâmetros. $O R M S E$ "Todos"é calculado usando todos os valores preditos de horizonte $h=1, \ldots ., 168$, incluido aqueles que não aparecem na tabela.

\begin{tabular}{|c|c|c|c|c|c|c|c|c|c|c|c|c|c|c|}
\hline \multicolumn{4}{|c|}{ Experimentos } & \multicolumn{11}{|c|}{ Horizonte de previsão } \\
\hline Modelos & $\begin{array}{c}\text { Grau do } \\
\text { polinô- } \\
\text { mio }\end{array}$ & $\begin{array}{l}\text { Sazonalidade } \\
\text { semanal }\end{array}$ & $\begin{array}{l}\text { Estratégia } \\
\text { de ajuste }\end{array}$ & $\mathrm{N}$ & 1 & 2 & 3 & 6 & 12 & 18 & 24 & 48 & 168 & Todos \\
\hline \multicolumn{15}{|c|}{ Rolling windows de tamanho 336} \\
\hline \multirow{2}{*}{ SARIMA } & - & - & Tipo 1 & 30 & 0,839 & 1,21 & 1,291 & 1,57 & 1,34 & 1,047 & 1,787 & 1,649 & 3,20 & 2,21 \\
\hline & - & - & Tipo 2 & 30 & 0,993 & 1,26 & 1,242 & 1,73 & 1,25 & 0,830 & 1,617 & 1,242 & 1,88 & 1,63 \\
\hline \multirow{8}{*}{$\begin{array}{c}\text { Regressão } \\
\text { com erros } \\
\text { SARIMA }\end{array}$} & 0 & $\operatorname{Sim}$ & Tipo 1 & 30 & 0,748 & 1,19 & 1,013 & 1,47 & 1,43 & 1,089 & 0,994 & 1,087 & 1,48 & 1,42 \\
\hline & 0 & $\operatorname{Sim}$ & Tipo 2 & 30 & 0,850 & 1,39 & 1,443 & 2,07 & 1,91 & 1,399 & 1,751 & 1,859 & 1,88 & 2,06 \\
\hline & 1 & Sim & Tipo 1 & 30 & 0,758 & 1,16 & 1,111 & 1,53 & 1,41 & 0,980 & 1,432 & 1,320 & 1,82 & 1,79 \\
\hline & 1 & Sim & Tipo 2 & 19 & 0,584 & 1,12 & 0,723 & 1,51 & 1,43 & 0,619 & 1,423 & 1,196 & 1,97 & 1,72 \\
\hline & 0 & Não & Tipo 1 & 30 & 0,743 & 1,20 & 1,058 & 1,52 & 1,40 & 1,174 & 0,972 & 1,065 & 1,53 & 1,41 \\
\hline & 0 & Não & Tipo 2 & 25 & 0,729 & 1,31 & 1,125 & 1,63 & 1,66 & 1,159 & 1,356 & 1,099 & 1,62 & 1,47 \\
\hline & 1 & Não & Tipo 1 & 30 & 0,781 & 1,20 & 1,180 & 1,57 & 1,22 & 0,806 & 1,203 & 0,882 & 1,78 & 1,66 \\
\hline & 1 & Não & Tipo 2 & 21 & 0,532 & 1,11 & 0,769 & 1,09 & 1,13 & 0,610 & 1,174 & 0,826 & 1,88 & 1,63 \\
\hline \multirow{2}{*}{ BATS } & - & Não & Tipo 1 & 30 & 0,896 & 1,23 & 1,288 & 1,82 & 1,56 & 1,013 & 1,295 & 1,163 & 2,06 & 1,78 \\
\hline & - & $\operatorname{Sim}$ & Tipo 1 & 30 & 3,119 & 2,08 & 1,985 & 1,80 & 2,12 & 2,078 & 2,434 & 2,296 & 2,01 & 2,12 \\
\hline \multirow{2}{*}{ TBATS } & - & Não & Tipo 1 & 30 & 0,865 & 1,32 & 1,393 & 1,87 & 1,62 & 1,045 & 1,205 & 0,934 & 1,66 & 1,61 \\
\hline & - & $\operatorname{Sim}$ & Tipo 1 & 30 & 0,916 & 1,30 & 1,480 & 1,58 & 1,68 & 1,346 & 1,489 & 1,469 & 1,69 & 1,68 \\
\hline \multirow{3}{*}{ Benchmark } & - & - & Média & 30 & 1,495 & 2,70 & 4,004 & 6,74 & 2,25 & 5,523 & 2,205 & 2,220 & 2,38 & 4,33 \\
\hline & - & - & Mediana & 30 & 2,000 & 3,31 & 4,794 & 7,53 & 2,46 & 4,837 & 2,053 & 2,030 & 2,16 & 4,43 \\
\hline & - & - & Ült. Obs. & 30 & 2,077 & 3,10 & 5,172 & 8,35 & 4,00 & 4,580 & 1,576 & 1,315 & 1,97 & 4,84 \\
\hline \multicolumn{15}{|c|}{ Rolling windows de tamanho 720} \\
\hline \multirow{2}{*}{ SARIMA } & - & - & Tipo 1 & 30 & 0,868 & 1,20 & 0,913 & 1,35 & 1,86 & 2,302 & 1,834 & 2,513 & 2,51 & 1,93 \\
\hline & - & - & Tipo 2 & 28 & 0,822 & 1,20 & 1,041 & 1,29 & 1,87 & 2,206 & 1,463 & 2,081 & 2,12 & 1,78 \\
\hline \multirow{8}{*}{$\begin{array}{c}\text { Regressão } \\
\text { com erros } \\
\text { SARIMA }\end{array}$} & 0 & $\mathrm{Sim}$ & Tipo 1 & 30 & 0,862 & 1,26 & 1,010 & 1,50 & 1,86 & 1,869 & 1,157 & 1,848 & 2,05 & 1,73 \\
\hline & 0 & $\operatorname{Sim}$ & Tipo 2 & 25 & 0,836 & 1,25 & 1,151 & 1,50 & 2,32 & 2,136 & 1,330 & 2,046 & 1,78 & 1,85 \\
\hline & 1 & $\operatorname{Sim}$ & Tipo 1 & 30 & 0,840 & 1,21 & 1,002 & 1,27 & 1,78 & 2,235 & 1,433 & 2,214 & 2,51 & 1,97 \\
\hline & 1 & Sim & Tipo 2 & 23 & 0,927 & 1,38 & 1,134 & 1,41 & 2,03 & 2,542 & 1,577 & 2,526 & 2,86 & 2,20 \\
\hline & 0 & Não & Tipo 1 & 30 & 0,860 & 1,24 & 1,005 & 1,36 & 1,83 & 1,937 & 1,214 & 1,907 & 2,00 & 1,71 \\
\hline & 0 & Não & Tipo 2 & 25 & 0,827 & 1,25 & 1,153 & 1,33 & 2,25 & 2,285 & 1,442 & 1,987 & 1,75 & 1,81 \\
\hline & 1 & Não & Tipo 1 & 30 & 0,834 & 1,20 & 0,990 & 1,17 & 1,82 & 2,351 & 1,542 & 2,284 & 2,41 & 1,97 \\
\hline & 1 & Não & Tipo 2 & 23 & 0,926 & 1,36 & 1,116 & 1,28 & 2,05 & 2,653 & 1,715 & 2,635 & 2,76 & 2,20 \\
\hline \multirow{2}{*}{ BATS } & - & Não & Tipo 1 & 30 & 0,782 & 1,16 & 1,189 & 1,16 & 1,81 & 2,296 & 1,542 & 2,215 & 2,23 & 1,90 \\
\hline & - & $\operatorname{Sim}$ & Tipo 1 & 30 & 1,157 & 1,31 & 1,305 & 1,43 & 2,08 & 2,005 & 1,222 & 2,124 & 2,23 & 1,87 \\
\hline \multirow{2}{*}{ TBATS } & - & Não & Tipo 1 & 30 & 0,872 & 1,32 & 1,254 & 1,24 & 2,09 & 2,251 & 1,438 & 2,083 & 2,14 & 1,91 \\
\hline & - & Sim & Tipo 1 & 30 & 0,982 & 1,37 & 1,356 & 1,42 & 2,56 & 2,221 & 1,220 & 2,010 & 2,22 & 1,95 \\
\hline \multirow{3}{*}{ Benchmark } & - & - & Média & 30 & 2,152 & 2,68 & 4,306 & 6,74 & 2,80 & 5,573 & 2,244 & 2,706 & 2,51 & 4,45 \\
\hline & - & - & Mediana & 30 & 2,389 & 3,04 & 4,953 & 7,49 & 3,01 & 4,957 & 1,963 & 2,435 & 2,31 & 4,58 \\
\hline & - & - & Últ. Obs. & 30 & 2,058 & 2,56 & 5,041 & 8,21 & 4,55 & 5,247 & 1,865 & 2,398 & 2,65 & 5,23 \\
\hline
\end{tabular}

- Dentre os procedimentos BATS e TBATS, o que teve melhor desempenho de acordo com o RMSE total foi o que usou modelos TBATS sem sazonalidade semanal e com rolling windows de tamanho 336, apresentando RMSE total de 1,606. Na maioria dos casos, os procedimentos BATS e TBATS o uso de sazonalidade semanal não melhorou significativamente o desempenho dos modelos.

- Não houve uma diferença notável de desempenho entre usar rolling windows de tamanho 336 ou 720 .

- Alguns experimentos que empregaram a estratégia do tipo 2 tiveraram um valor de $N<30$. Isso é explicado pelo fato da estratégia consistir em identificar o modelo usando as observações de apenas de uma rolling windows e depois só reestimar os parâmetros nas damais, visto que, ao se fazer esse procedimento, corre-se o risco do modelo não ser "estimátivel"(raízes próximas do polinomio autoregressivo ou de médias móveis bem próximas ou dentro do circulo unitário). Assim, mesmo nas situações em que procedimento do tipo 2 teve um desempenho melhor, é preferivel escolher o do tipo 1 , já que a diferença de desempenho entre eles não é muito discrepante. 
- Os métodos de previsão propostos tiveram desempenhos bem superiores aos métodos benchmark, o que demonstra uma boa adequabilidade dos métodos de previsão propostos.

- Dentre todos os procedimentos de previsão propostos, o melhor foi o que usou modelos de regressão com erros autocorrelacionados, com polinômio de grau 0 modelando a tendência, sem sazonalidade semanal, com o uso da estratégia do tipo 1 para os erros SARIMA e com rolling windows de tamanho 336, apresentando o valor de RMSE total de 1,408.

Os bons resultados de previsão podem ser explicados por um comportamento regular que a série apresenta em quase toda a sua extensão, sendo, muitas vezes, uma sazonalidade bem definida. Tal constatação pode ser observada na Figura 3.32, na qual são mostrados alguns exemplos de previsão para cada tipo de modelo que reforçam as constatações realizadas.
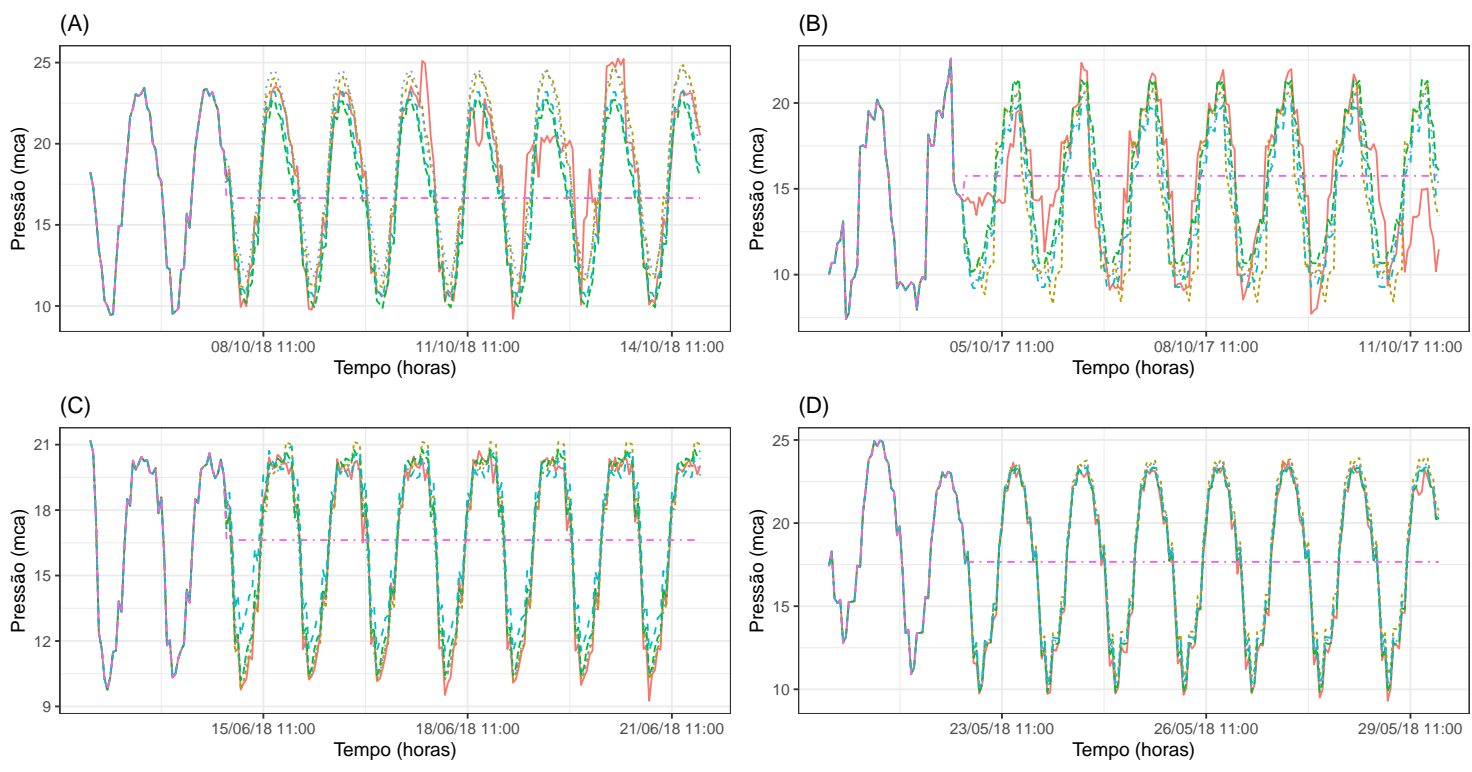

(D)

$\begin{array}{lll}\text { - Original } & \text {--- Melhor estratégia regres } \\ \text { com erros SARIMA do }\end{array}$

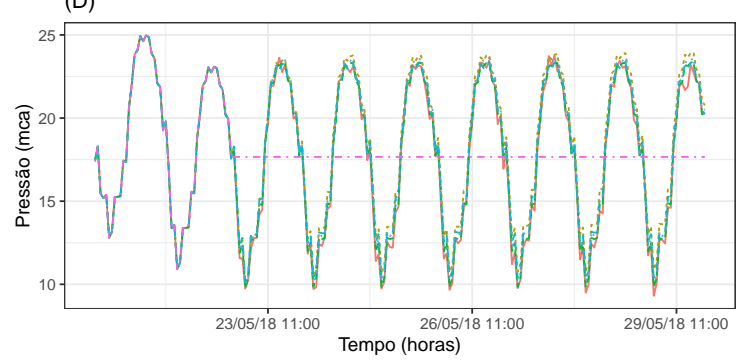

Figura 3.32: Alguns trechos da série de pressão a jusante ao Norte de Peruibe que exemplificam a aplicação dos modelos de previsão. São apresentados o melhor procedimento de ajuste de cada familia de modelos, de acordo com o melhor RMSE de previsão, para os dois tamanhos de rolling window descritos na tabela 3.64. Para a seleção dos procedimentos, exluiu-se os que utilizaram a estratégia de tipo 2. Os gráficos exibem 48 horas da série seguidas de 168 horas de previsão. Os gráficos da esquerda se referem aos ajustes que usaram rolling windows de tamanho 336, já os da direita, de tamanho 720

Para a elaboração dos gráficos da Figura 3.32, decidiu-se não selecionar as previsões que usaram a estratégia do tipo 2, por tal método nem sempre conseguir estimar os parâmetros dos modelos, o que acaba resultando no uso de uma quantidade menor de rolling windows. Assim, as previsões SARIMA se referem ao uso de estratégia do tipo 1 e rolling windows de tamanho 720; as de regressão com erros autocorrelacionados se referem ao uso de polinômio de grau 0 modelando a tendência, sem sazonalidade semanal, com o uso da estratégia do tipo 1 para os erros SARIMA e rolling windows de tamanho 336; as previsões BATS se referem ao uso de modelos sem sazonalidade semanal e rolling windows de tamanho 336; as previsões TBATS se referem ao uso de modelos sem sazonalidade semanal e rolling windows de tamanho 336 e as previsões benchmark se referem ao uso da média e rolling windows de tamanho 336. 


\subsection{Pressão a jusante no Sul de Peruíbe}

Nesta seção é apresentado e discutido os resultados das aplicações dos procedimentos de imputação de valores omissos e detecção de outliers e dos métodos de previsão relacionados a série de pressão a jusante ao Sul de Peruíbe. A Figura 3.33 exibe um trecho da série que exemplifica seu comportamento. O gráfico (A) se refere a série original, enquanto que o gráfico (B) é mesmo trecho após limpeza e aplicação do métodos de deteç̧ão de outlier e preenchimento de valores omissos.

(A) Trecho da série original

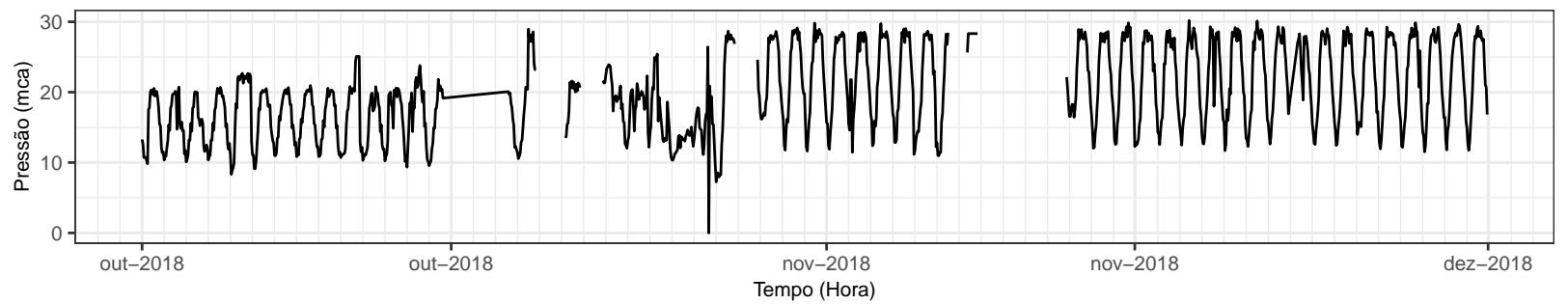

(B) Trecho da série após limpeza e preenchimento de valores omissos

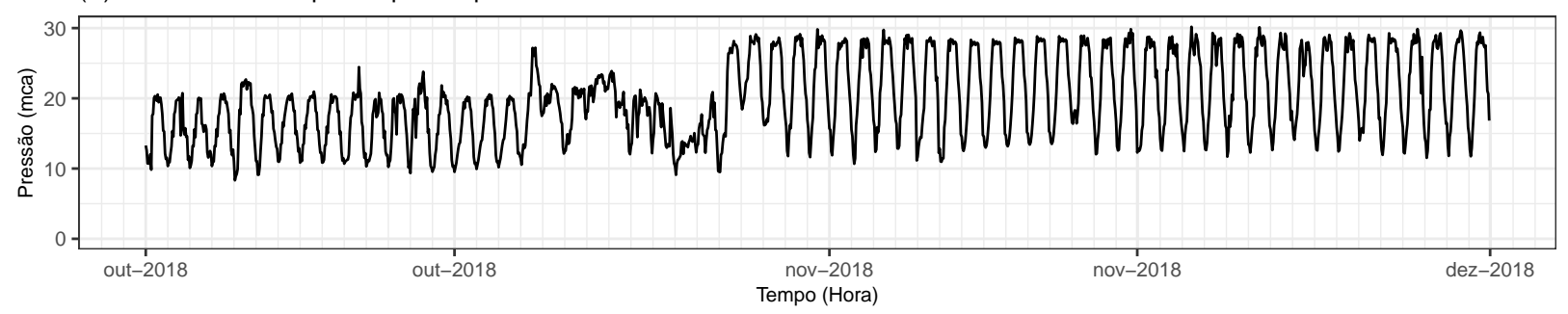

Figura 3.33: Trecho da série de pressão a jusante ao Sul de Peruíbe que exemplificam seu comportamento. O gráfico (A) é referente a série original e o gráfico (B) mostra a série após as limpezas, tratamento dos outliers detectados e preenchimento dos valores omissos de acordo com o método escolhido.

O método escolhido para a deteç̧ão de outliers e preenchimentos dos valores omissos, por possuir o menor RMSE total entre todos os experimentos realizados, com o valor de 1,952, foi o ajuste de curvas de regressão com polinômio de grau 5 modelando a tendência, com interpolação de $R_{t}$, sem sazonalidade semanal, janela de tamanho 168 e valor de corte $c=5$. O total de valores classificados como anomalias após aplicação do método selecionado foi de 2142 (12,2\%), vis-à-vis à quantidade de $1743(9,95 \%)$ após a limpeza primária e à quantidade original de 207 (1,18\%). Em relação a previsão, o método que apresentou melhor desempenho nos experimentos foi o que usou modelos SARIMA do tipo 2 e com rolling windows de tamanho 720, apresentando o valor de RMSE total de 1,376. Se excluírmos os procedimentos de previsão que usaram a estratégia do tipo 2, temos que o melhor procedimento foi o que usou modelos de regressão com erros autocorrelacionados, com polinômio de grau 0 modelando a tendência, sem sazonalidade semanal e com rolling windows de tamanho 336, apresentando um RMSE total de 1,78. De modo geral, os resultados mostram uma boa adequabilidade dos métodos propostos a série temporal de pressão a jusante ao Sul de Peruíbe.

As próximas subseções apresentam e discutem os resultados de forma mais detalhada.

\subsubsection{Preenchimento de valores omissos}

As tabelas 3.65 à 3.67 mostram os resultados dos 12 melhores experimentos de cada tipo de procedimento de preenchimento de valores omissos, usando como medida de avaliação o RMSE. Em todas as tabelas os experimentos são apresentados em ordem decrescente de RMSE. Já a tabela 
3.68 apresenta os resultados dos procedimentos de preenchimento de valores omissos usados como benchmark. Nesta, os experimentos são ordenados pelo ID.

Tabela 3.65: $R M S E$ dos 12 melhores métodos de preenchimento de dados omissos baseados no ajuste de modelos de regressão, selecionados de acordo com menor RMSE. Os resultados se referem a aplicação dos métodos a série de pressão a jusante ao Sul de Peruíbe.

\begin{tabular}{|c|c|c|c|c|c|c|c|c|c|c|c|c|c|}
\hline \multicolumn{6}{|c|}{ Experimentos de regressão } & \multicolumn{8}{|c|}{ Quantidade de valores omissos em sequência } \\
\hline ID & $\begin{array}{l}\text { Interpolação } \\
\text { de } R_{t}\end{array}$ & $\begin{array}{c}\text { Dia da } \\
\text { semana }\end{array}$ & $\begin{array}{l}\text { Grau do } \\
\text { polinômio }\end{array}$ & Janela & $c$ & 1 & 3 & 6 & 12 & 18 & 24 & 48 & Total \\
\hline reg97 & Sim & Sim & 5 & 168 & 5 & 1,73 & 1,32 & 2,77 & 1,80 & 2,18 & 2,32 & 1,54 & 1,95 \\
\hline $\operatorname{reg} 79$ & Não & $\mathrm{Sim}$ & 5 & 168 & 5 & 2,08 & 1,77 & 2,64 & 1,55 & 2,14 & 2,24 & 1,42 & 1,98 \\
\hline reg61 & $\operatorname{Sim}$ & $\operatorname{Sim}$ & 5 & 168 & 3 & 1,90 & 1,66 & 2,58 & 1,71 & 2,29 & 2,24 & 1,53 & 1,99 \\
\hline reg96 & Sim & Sim & 2 & 720 & 5 & 1,94 & 1,42 & 2,64 & 1,90 & 2,24 & 2,39 & 1,52 & 2,01 \\
\hline reg7 & Não & $\mathrm{Sim}$ & 5 & 168 & 2 & 2,14 & 1,85 & 2,67 & 1,55 & 2,19 & 2,31 & 1,36 & 2,01 \\
\hline $\operatorname{reg} 43$ & Não & Sim & 5 & 168 & 3 & 2,13 & 1,83 & 2,66 & 1,56 & 2,21 & 2,29 & 1,39 & 2,01 \\
\hline reg93 & Sim & Sim & 1 & 720 & 5 & 1,93 & 1,42 & 2,65 & 1,89 & 2,23 & 2,44 & 1,52 & 2,01 \\
\hline $\operatorname{reg} 25$ & Sim & Sim & 5 & 168 & 2 & 2,00 & 1,75 & 2,62 & 1,67 & 2,27 & 2,25 & 1,54 & 2,01 \\
\hline reg102 & Sim & Sim & 1 & 720 & 5 & 1,86 & 1,42 & 2,59 & 1,99 & 2,30 & 2,45 & 1,50 & 2,02 \\
\hline reg105 & Sim & $\mathrm{Sim}$ & 2 & 720 & 5 & 1,86 & 1,41 & 2,59 & 2,00 & 2,32 & 2,45 & 1,49 & 2,02 \\
\hline reg 40 & Não & Sim & 2 & 168 & 3 & 2,14 & 1,82 & 2,73 & 1,52 & 2,20 & 2,30 & 1,42 & 2,02 \\
\hline reg60 & Sim & Sim & 2 & 720 & 3 & 1,96 & 1,70 & 2,82 & 1,63 & 2,29 & 2,28 & 1,51 & 2,03 \\
\hline
\end{tabular}

Tabela 3.66: $R M S E$ dos 12 melhores métodos de preenchimento de dados omissos baseados no ajuste de modelo de regressão acompanhado de decomposições clássica, selecionados de acordo com menor RMSE. O modelo de regressão usado em conjundo com a decomposição clássica, por apresentar menor RMSE, foi o que possui polinômio de grau 5, com interpolação dos resíduos, sem sazonalidade semanal e janela de tamanho 168. Os resultados se referem a aplicação dos métodos a série de pressão a jusante ao Sul de Peruíbe.

\begin{tabular}{|c|c|c|c|c|c|c|c|c|c|c|c|}
\hline \multicolumn{4}{|c|}{ Experimentos de decomposição clássica } & \multicolumn{8}{|c|}{ Quantidade de valores omissos em sequência } \\
\hline ID & $\begin{array}{l}\text { Interpolação } \\
\quad \text { de } R_{t}\end{array}$ & Janela & $c$ & 1 & 3 & 6 & 12 & 18 & 24 & 48 & Total \\
\hline $\operatorname{dec} 13$ & Não & 168 & 5 & 1,87 & 1,59 & 2,66 & 1,69 & 2,16 & 2,34 & 1,51 & 1,97 \\
\hline $\operatorname{dec} 7$ & Não & 168 & 3 & 1,97 & 1,76 & 2,54 & 1,62 & 2,27 & 2,28 & 1,52 & 2,00 \\
\hline $\operatorname{dec} 1$ & Não & 168 & 2 & 2,02 & 1,76 & 2,59 & 1,59 & 2,25 & 2,32 & 1,51 & 2,01 \\
\hline $\operatorname{dec} 16$ & Sim & 168 & 5 & 1,69 & 1,30 & 2,77 & 1,87 & 2,30 & 2,46 & 1,72 & 2,02 \\
\hline $\operatorname{dec} 14$ & Não & 336 & 5 & 1,94 & 1,66 & 2,67 & 1,81 & 2,21 & 2,38 & 1,54 & 2,03 \\
\hline $\operatorname{dec} 10$ & Sim & 168 & 3 & 1,89 & 1,66 & 2,59 & 1,70 & 2,40 & 2,28 & 1,72 & 2,04 \\
\hline $\operatorname{dec} 15$ & Não & 720 & 5 & 1,93 & 1,72 & 2,73 & 1,81 & 2,21 & 2,39 & 1,48 & 2,04 \\
\hline $\operatorname{dec} 8$ & Não & 336 & 3 & 2,01 & 1,83 & 2,58 & 1,75 & 2,29 & 2,31 & 1,54 & 2,04 \\
\hline $\operatorname{dec} 4$ & Sim & 168 & 2 & 1,99 & 1,72 & 2,60 & 1,63 & 2,37 & 2,38 & 1,69 & 2,05 \\
\hline $\operatorname{dec} 2$ & Não & 336 & 2 & 2,04 & 1,84 & 2,61 & 1,72 & 2,27 & 2,34 & 1,54 & 2,05 \\
\hline $\operatorname{dec} 9$ & Não & 720 & 3 & 2,01 & 1,89 & 2,63 & 1,78 & 2,29 & 2,31 & 1,50 & 2,06 \\
\hline $\operatorname{dec} 3$ & Não & 720 & 2 & 2,03 & 1,89 & 2,67 & 1,76 & 2,26 & 2,33 & 1,50 & 2,06 \\
\hline
\end{tabular}

Tabela 3.67: RMSE dos 12 melhores métodos de preenchimento de dados omissos baseados em decomposição STL, selecionados de acordo com menor RMSE. Os resultados se referem a aplicação dos métodos a série de pressão a jusante ao Sul de Peruíbe.

\begin{tabular}{|c|c|c|c|c|c|c|c|c|c|c|c|c|c|}
\hline \multicolumn{6}{|c|}{ Experimentos de decomposição STL } & \multicolumn{8}{|c|}{ Quantidade de valores omissos em sequência } \\
\hline ID & $\begin{array}{l}\text { Interpolação } \\
\text { de } R_{t}\end{array}$ & $n_{(i)}$ & $n_{(e)}$ & $n_{(s)}$ & $c$ & 1 & 3 & 6 & 12 & 18 & 24 & 48 & Total \\
\hline st148 & Sim & 2 & 0 & 49 & 5 & 1,65 & 1,25 & 2,54 & 2,00 & 2,33 & 2,44 & 1,82 & 2,00 \\
\hline st147 & $\operatorname{Sim}$ & 2 & 0 & 37 & 5 & 1,66 & 1,28 & 2,54 & 2,00 & 2,32 & 2,46 & 1,86 & 2,02 \\
\hline st146 & Sim & 2 & 0 & 25 & 5 & 1,65 & 1,32 & 2,65 & 1,96 & 2,32 & 2,46 & 1,87 & 2,03 \\
\hline st11 & Não & 2 & 0 & 25 & 2 & 2,01 & 1,94 & 2,61 & 1,81 & 2,19 & 2,35 & 1,49 & 2,06 \\
\hline st130 & Sim & 2 & 0 & 49 & 3 & 1,81 & 1,61 & 2,53 & 1,97 & 2,34 & 2,43 & 1,76 & 2,06 \\
\hline st129 & $\operatorname{Sim}$ & 2 & 0 & 37 & 3 & 1,81 & 1,63 & 2,54 & 1,95 & 2,31 & 2,44 & 1,80 & 2,07 \\
\hline st14 & Não & 1 & 5 & 25 & 2 & 2,12 & 1,92 & 2,73 & 1,72 & 2,29 & 2,32 & 1,39 & 2,07 \\
\hline st119 & Não & 2 & 0 & 25 & 3 & 2,02 & 1,89 & 2,64 & 1,90 & 2,17 & 2,35 & 1,53 & 2,07 \\
\hline st 128 & Sim & 2 & 0 & 25 & 3 & 1,83 & 1,62 & 2,64 & 1,93 & 2,29 & 2,39 & 1,80 & 2,07 \\
\hline st110 & Sim & 2 & 0 & 25 & 2 & 1,91 & 1,70 & 2,52 & 1,89 & 2,29 & 2,53 & 1,68 & 2,07 \\
\hline st17 & Não & 1 & 10 & 25 & 2 & 2,15 & 1,92 & 2,73 & 1,74 & 2,27 & 2,31 & 1,41 & 2,08 \\
\hline st120 & Não & 2 & 0 & 37 & 3 & 1,99 & 1,90 & 2,62 & 1,91 & 2,18 & 2,37 & 1,56 & 2,08 \\
\hline
\end{tabular}


Tabela 3.68: RMSE dos métodos benchmark de preenchimento de dados omissos. Os resultados se referem a aplicação dos métodos a série de pressão a jusante ao Sul de Peruibe.

\begin{tabular}{|c|c|c|c|c|c|c|c|c|c|c|}
\hline \multicolumn{3}{|c|}{ Experimentos emphbenchmark } & \multicolumn{8}{|c|}{ Quantidade de valores omissos em sequência } \\
\hline ID & $\begin{array}{c}\text { Forma de } \\
\text { benchmark }\end{array}$ & Janela & 1 & 3 & 6 & 12 & 18 & 24 & 48 & Total \\
\hline ben1 & Média & 168 & 4,33 & 4,21 & 4,36 & 4,35 & 4,16 & 4,09 & 3,84 & 4,19 \\
\hline ben 2 & Média & 336 & 4,26 & 4,19 & 4,32 & 4,31 & 4,16 & 4,15 & 3,83 & 4,18 \\
\hline ben 3 & Média & 720 & 4,32 & 4,25 & 4,36 & 4,35 & 4,19 & 4,17 & 3,82 & 4,21 \\
\hline ben 4 & Mediana & 168 & 4,47 & 4,33 & 4,55 & 4,57 & 4,23 & 4,14 & 3,97 & 4,32 \\
\hline ben 5 & Mediana & 336 & 4,33 & 4,26 & 4,44 & 4,50 & 4,21 & 4,17 & 3,86 & 4,25 \\
\hline ben 6 & Mediana & 720 & 4,36 & 4,32 & 4,45 & 4,59 & 4,24 & 4,17 & 3,84 & 4,28 \\
\hline ben 7 & Interpolação & - & 1,40 & 1,44 & 2,45 & 3,88 & 5,16 & 5,20 & 5,25 & 3,54 \\
\hline
\end{tabular}

De acordo com as informações apresentadas nas tabelas 3.65 à 3.68 podemos verificar que, em geral:

- Os melhores procedimentos de regressão, de acordo com o RMSE total, foram aqueles que consideraram a sazonalidade semanal e que, aparentemente, usaram interpolação nos resíduos $R_{t}$ e janela de ajuste de tamanho 168, sendo que o melhor procedimento de regressão para imputação de valores omissos foi o que usou polinômio de grau 5 modelando a tendência, com interpolação de $R_{t}$, sem sazonalidade semanal, janela de tamanho 168 e valor de corte $c=5$, apresentando um RMSE total igual a 1,952. Os parâmetros desse modelo de regressão foram os usados na aplicação do método de decomposição clássica.

- Aparentemente, os procedimentos de decomposição clássica que tiveram melhor desempenho, de acordo com o RMSE total, foram aqueles que não aplicaram interpolações nos resíduos $R_{t} \mathrm{e}$ que possuem janela de tamanho 168. O melhor procedimento foi aquele que usou decomposição sem interpolação de $R_{t}$, janela de tamanho 168 e valor de corte $c=5$, apresentando um RMSE total igual a 1,974 .

- Os tipos de decomposição STL que tiveram melhores resultados, de acordo com o RMSE total, foram os que usaram decomposição STL não robusta $\left(n_{(i)}=2\right.$ e $\left.n_{(e)}=0\right)$. O melhor procedimento foi o de decomposição não robusta $\left(n_{(i)}=2\right.$ e $\left.n_{(e)}=0\right)$, com interpolação de $R_{t}, n_{(s)}=49$ e valor de corte $c=5$, apresentando um RMSE total igual a 2,003.

- Dentre os métodos de benchmark, o que teve melhor desempenho foi o que interpola linearmente os valores da série. Percebe-se que os procedimentos propostos tiveram desempenhos bem superiores aos benchmarks.

- Dentre todos os experimentos, o que apresentou melhor resultado foi o procedimento de ajuste de curvas de regressão com polinômio de grau 5 modelando a tendência, com interpolação de $R_{t}$, sem sazonalidade semanal, janela de tamanho 168 e valor de corte $c=5$, apresentando um valor de RMSE total de 1,952. Este é o procedimento para o qual é apresentado uma análise de outliers na próxima subseção e que é usado oficialmente para preencher os valores omissos da série.

A Figura 3.34 exemplifica alguns experimentos de preenchimento de valores omissos. Cada gráfico representa um trecho da série temporal de pressão a jusante ao Sul de Peruíbe no qual propositalmente foi removido uma sequência de valores. Todos os gráficos se referem a uma lacuna 
de tamanho 48 horas acompanhado de 12 valores anteriores e posteriores à lacuna principal. Os procedimentos de preenchimento adotados para ilustrar os gráficos são o melhor experimento, de acordo com o RMSE total, de cada tipo de procedimento apresentados nas tabelas 3.65 à 3.68

(A)

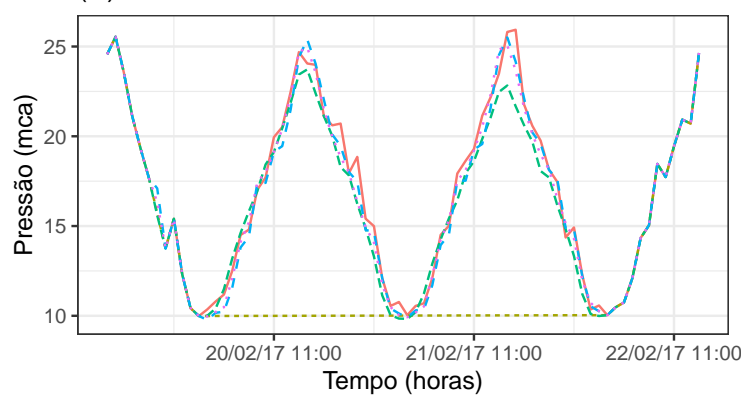

(C)

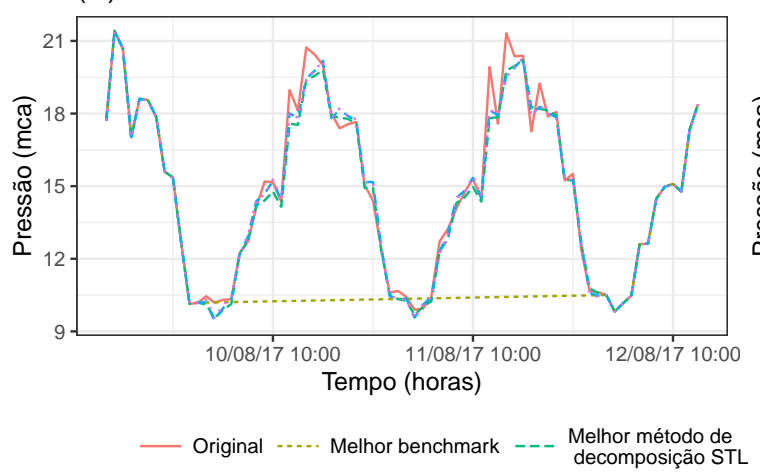

(B)

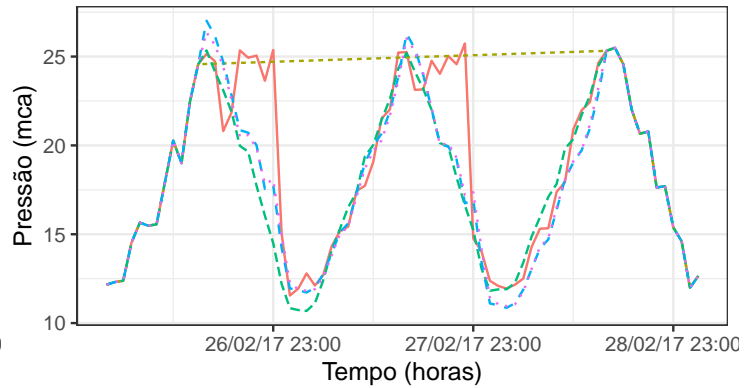

(D)

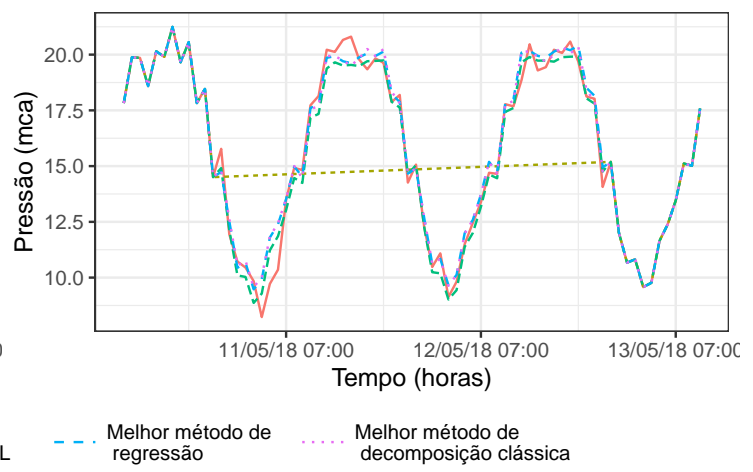

Figura 3.34: Alguns trechos da série de pressão a jusante ao Sul de Peruỉbe que exemplificam a aplicação dos procedimentos de preenchimento de valores omissos. É apresentado o melhor experimento de imputação de valores omissos de cada tipo de procedimento de acordo com o RMSE, descritos nas tabelas 3.65 à 3.68 . A lacuna principal de valores omissos usada em cada gráfico foi inserida artificialmente na série temporal a fim de avaliar a performance dos procedimentos de preenchimento de valores omissos. O tamanho da lacuna principal é de 48 horas, sendo precedida e sucedida de 12 horas de valores originais.

Verifica-se que os procedimentos propostos conseguiram fazer uma boa estimativa dos valores omissos, sendo essas bem superiores às do método de interpolação. Esses resultados já eram esperados, pois a série de pressão a jusante ao Sul de Peruíbe apresenta um comportamento sazonal bem característico, mesmo que esse comportamento tenha alguns momentos de notáveis diferenças entre o valor real e o estimado pelos métodos propostos, como nos gráfico (B).

\subsubsection{Detecção e tratamento de outliers}

As tabelas 3.69 e 3.70 mostram os resultados dos experimentos elaborados para avaliar o desempenho em detectar e tratar os outliers do melhor procedimento selecionado para a imputação dos valores omissos. A Tabela 3.69 apresenta as taxas de detecção dos outliers, sendo dividida em duas partes: na parte superior o cálculo das taxas considera todas as observações afetadas pelo efeito atípico, enquanto que na parte inferior é considerado apenas a observação mais afetada pelo efeito atípico. Vale lembrar que no caso do efeito atípico do tipo platô todas as observações foram consideradas como sendo as mais afetadas devido ao efeito se distribuir igualmente entre elas. Já a tabela 3.70 é destinada a verificar a acurácia do procedimento ao corrigir os valores dos outliers. Sua estrutura é análoga à da tabela 3.69, sendo que a linha total é o RMSE do efeito atípico nas observações.

A partir das tabelas, podemos verificar que: 
Tabela 3.69: Taxa de deteç̧ão de outliers de acordo com o procedimento que apresentou melhor desempenho em preencher valores omissos. O procedimento foi o de ajuste de curvas de regressão com polinômio de grau 5 modelando a tendência, com interpolação de $R_{t}$, sem sazonalidade semanal, janela de tamanho 168 e valor de corte $c=5$. Variou-se o valor de corte $c$ e a quantidade de iterações máxima com o objetivo de verificar se a mudança desses parâmetros causam algum impacto na deteç̧ão dos outliers. A aplicação se refere a série de pressão a jusante ao Sul de Peruíbe.

\begin{tabular}{|c|c|c|c|c|c|c|c|c|}
\hline \multicolumn{3}{|c|}{ Experimentos } & \multicolumn{6}{|c|}{ Tipo de efeitos atípicos } \\
\hline ID & c & $\begin{array}{l}\mathrm{N}^{0} \text { máximo } \\
\text { de iterações }\end{array}$ & Único & Platô & Pulso & $\begin{array}{l}\text { C.D. } \\
\text { linear }\end{array}$ & $\begin{array}{c}\text { C.D. } \\
\text { exponencial }\end{array}$ & $\begin{array}{c}\text { C.D. } \\
\text { logaritmico }\end{array}$ \\
\hline \multicolumn{9}{|c|}{ Todas as observações afetadas } \\
\hline out1 & 2 & 1 & 1 & 0,701 & 0,504 & 0,566 & 0,529 & 0,587 \\
\hline out2 & 3 & 1 & 1 & 0,369 & 0,394 & 0,418 & 0,412 & 0,416 \\
\hline out3 & 4 & 1 & 1 & 0,185 & 0,284 & 0,271 & 0,279 & 0,265 \\
\hline out 4 & 5 & 1 & 1 & 0,121 & 0,190 & 0,179 & 0,222 & 0,148 \\
\hline out5 & 2 & 3 & 1 & 0,975 & 0,710 & 0,776 & 0,727 & 0,816 \\
\hline out 6 & 3 & 3 & 1 & 0,767 & 0,563 & 0,610 & 0,591 & 0,627 \\
\hline out7 & 4 & 3 & 1 & 0,360 & 0,459 & 0,452 & 0,455 & 0,450 \\
\hline out8 & 5 & 3 & 1 & 0,175 & 0,338 & 0,287 & 0,317 & 0,265 \\
\hline out9 & 2 & 5 & 1 & 0,981 & 0,716 & 0,788 & 0,745 & 0,827 \\
\hline out10 & 3 & 5 & 1 & 0,799 & 0,575 & 0,628 & 0,600 & 0,644 \\
\hline out11 & 4 & 5 & 1 & 0,396 & 0,459 & 0,465 & 0,456 & 0,458 \\
\hline out12 & 5 & 5 & 1 & 0,179 & 0,347 & 0,293 & 0,326 & 0,280 \\
\hline Total & - & - & 1 & 1,000 & 1,000 & 1,000 & 1,000 & 1,000 \\
\hline \multicolumn{9}{|c|}{ Somente observações mais afetadas } \\
\hline out1 & 2 & 1 & 1 & 0,701 & 1,000 & 1,000 & 1,000 & 1,000 \\
\hline out2 & 3 & 1 & 1 & 0,369 & 1,000 & 0,971 & 1,000 & 0,933 \\
\hline out3 & 4 & 1 & 1 & 0,185 & 1,000 & 0,886 & 0,943 & 0,790 \\
\hline out4 & 5 & 1 & 1 & 0,121 & 0,917 & 0,600 & 0,895 & 0,467 \\
\hline out 5 & 2 & 3 & 1 & 0,975 & 1,000 & 1,000 & 1,000 & 1,000 \\
\hline out 6 & 3 & 3 & 1 & 0,767 & 1,000 & 1,000 & 1,000 & 0,990 \\
\hline out7 & 4 & 3 & 1 & 0,360 & 1,000 & 0,962 & 1,000 & 0,933 \\
\hline out 8 & 5 & 3 & 1 & 0,175 & 1,000 & 0,895 & 0,943 & 0,771 \\
\hline out9 & 2 & 5 & 1 & 0,981 & 1,000 & 1,000 & 1,000 & 1,000 \\
\hline out10 & 3 & 5 & 1 & 0,799 & 1,000 & 1,000 & 1,000 & 0,990 \\
\hline out11 & 4 & 5 & 1 & 0,396 & 1,000 & 0,971 & 1,000 & 0,943 \\
\hline out12 & 5 & 5 & 1 & 0,179 & 1,000 & 0,895 & 0,943 & 0,810 \\
\hline Total & - & - & 1 & 1,000 & 1,000 & 1,000 & 1,000 & 1,000 \\
\hline
\end{tabular}

- De modo geral, as taxas de detecção dos outliers foram altas, principalmente quando se considera apenas as obsevações mais afetadas. Um ponto de destaque é que os efeitos atípicos do tipo único tiveram todos os seus outliers detectados pelo método. Esses resultados são uma evidência da possível adequação do procedimento em detectar os outliers da série. Nota-se também que as altas taxas de detecção resultaram em um RMSE relativamente bom.

- O número de máximo de iterações possui, em geral, uma considerável influencia nos resultados. Com exceção do efeito do tipo único, a taxa de detecção dos experimentos que tiveram apenas uma iteração foi menor do que quando usadas iterações máximas iguais a 3 ou 5 . Porém, não há muita diferança entre usar um número máximo de iterações igual a 3 ou igual a 5 . Algo semelhante pode ser observado pelos valores de RMSE: o RMSE dos experimentos que usaram apenas uma iteração máxima foram maiores do aqueles que tiveram iterações máximas iguais a 3 ou 5. A semelhança dos resultados do uso de 3 e 5 iterações máximas pode ser explicado pelo algoritmo conseguir encontrar grande parte dos outliers antes de atingir número máximo de iterações, sendo necessário apenas uma baixa quantidade de iterações, isto é, um número menor ou igual a 3 , porém maior que 1 .

- Como o esperado, percebe-se claramente que o valor de corte $c$ influencia na taxa de detecção, sendo que quanto menor for valor de corte $c$, melhor é a taxa de detecção. Também verifica-se um melhor valor de RMSE para os valores mais baixos de $c$. Lembramos que, embora um valor de corte baixo aumente a taxa de detecção de outliers, ele também aumenta a taxa de deteç̧ão de valores que possivelmente não seriam outliers. 
Tabela 3.70: RMSE do tratamento dos outliers de acordo com o procedimento que apresentou melhor desempenho em preencher valores omissos. O procedimento foi o de ajuste de curvas de regressã̃o com polinômio de grau 5 modelando a tendência, com interpolação de $R_{t}$, sem sazonalidade semanal, janela de tamanho 168 e valor de corte $c=5$. Variou-se o valor de corte $c$ e a quantidade de iterações máxima com o objetivo de verificar se a mudança desses parâmetros causam algum impacto na detecção dos outliers. A linha total é o RMSE das observações ouliers em relação ao seu valor original. A aplicação se refere a série de pressão a jusante ao Sul de Peruíbe.

\begin{tabular}{|c|c|c|c|c|c|c|c|c|}
\hline \multicolumn{3}{|c|}{ Experimentos } & \multicolumn{6}{|c|}{ Tipo de efeitos atípicos } \\
\hline ID & c & $\begin{array}{l}\mathrm{N}^{0} \text { máximo } \\
\text { de iterações }\end{array}$ & Único & Platô & Pulso & $\begin{array}{l}\text { C.D. } \\
\text { linear }\end{array}$ & $\begin{array}{c}\text { C.D. } \\
\text { exponencial }\end{array}$ & $\begin{array}{c}\text { C.D. } \\
\text { logaritmico }\end{array}$ \\
\hline \multicolumn{9}{|c|}{ Todas as observações afetadas } \\
\hline out1 & 2 & 1 & 1,20 & 5,24 & 3,49 & 4,69 & 4,38 & 4,90 \\
\hline out 2 & 3 & 1 & 1,21 & 6,56 & 4,25 & 5,65 & 5,29 & 5,75 \\
\hline out3 & 4 & 1 & 1,28 & 7,65 & 5,06 & 6,53 & 6,27 & 6,67 \\
\hline out 4 & 5 & 1 & 1,07 & 8,15 & 6,06 & 7,06 & 6,68 & 7,31 \\
\hline out 5 & 2 & 3 & 1,31 & 3,92 & 2,68 & 3,29 & 3,11 & 3,39 \\
\hline out6 & 3 & 3 & 1,32 & 5,00 & 3,50 & 4,60 & 4,25 & 4,71 \\
\hline out7 & 4 & 3 & 1,28 & 7,00 & 4,27 & 5,57 & 5,19 & 5,83 \\
\hline out 8 & 5 & 3 & 1,07 & 7,76 & 5,10 & 6,60 & 6,21 & 6,82 \\
\hline out9 & 2 & 5 & 1,31 & 3,86 & 2,64 & 3,21 & 3,02 & 3,30 \\
\hline out10 & 3 & 5 & 1,32 & 4,88 & 3,47 & 4,47 & 4,18 & 4,64 \\
\hline out11 & 4 & 5 & 1,28 & 6,90 & 4,26 & 5,51 & 5,17 & 5,79 \\
\hline out12 & 5 & 5 & 1,07 & 7,75 & 5,07 & 6,55 & 6,17 & 6,71 \\
\hline Total & - & - & 11,82 & 9,09 & 8,29 & 8,96 & 9,60 & 8,76 \\
\hline \multicolumn{9}{|c|}{ Somente observações mais afetadas } \\
\hline out1 & 2 & 1 & 1,20 & 5,24 & 1,57 & 4,76 & 4,57 & 4,85 \\
\hline out 2 & 3 & 1 & 1,21 & 6,56 & 1,86 & 6,00 & 5,75 & 6,01 \\
\hline out3 & 4 & 1 & 1,28 & 7,65 & 2,62 & 7,42 & 7,36 & 7,52 \\
\hline out 4 & 5 & 1 & 1,07 & 8,15 & 4,87 & 8,86 & 8,11 & 9,01 \\
\hline out 5 & 2 & 3 & 1,31 & 3,92 & 1,43 & 3,51 & 3,50 & 3,50 \\
\hline out 6 & 3 & 3 & 1,32 & 5,00 & 1,86 & 5,01 & 4,72 & 5,01 \\
\hline out7 & 4 & 3 & 1,28 & 7,00 & 2,62 & 6,30 & 6,07 & 6,50 \\
\hline out 8 & 5 & 3 & 1,07 & 7,76 & 3,53 & 7,77 & 7,68 & 8,03 \\
\hline out9 & 2 & 5 & 1,31 & 3,86 & 1,43 & 3,41 & 3,40 & 3,41 \\
\hline out10 & 3 & 5 & 1,32 & 4,88 & 1,86 & 4,87 & 4,63 & 4,95 \\
\hline out11 & 4 & 5 & 1,28 & 6,90 & 2,62 & 6,21 & 6,00 & 6,45 \\
\hline out12 & 5 & 5 & 1,07 & 7,75 & 3,53 & 7,73 & 7,66 & 7,85 \\
\hline Total & - & - & 11,82 & 9,09 & 14,04 & 13,62 & 16,37 & 12,42 \\
\hline
\end{tabular}

- Em todos os experimentos, o RMSE foi bem superior do que o RMSE total. Isso indica a boa adequabilidade do método em tratar os outliers encontrados.

A Figura 3.35 exemplifica as constatações realizadas. É possível observar que os procedimentos conseguiram dar uma bom tratamentos aos outliers.

A Tabela 3.71 apresenta a quantidade de anomalias detectadas em cada fase do tratamento dado a série de pressão a jusante ao Sul de Peruíbe. Nota-se que a maior parte das observações anômalas foram detectadas durante a fase de limpeza primária, o que dá a quantidade de 1536 observações ou $8,8 \%$ do total. Durante todo o processo, foram detectadas 2142 (12,2 \%) observações anormais.

Tabela 3.71: Quantidade de valores detectados como anomalias em cada estágio de tratamento da série de pressão a jusante ao Sul de Peruíbe. A primeira linha da tabela se refere a quantidade de valores classificados pelo sistema da Sabesp como bad e que, portanto, eram omissos na série original. A segunda linha se refere aos valores detectados como anomalias pela limpeza primária. A terceira linha se refere a quantidade de valores detectados como outliers pela aplicação do algoritmo proposto.

\begin{tabular}{rrrrr}
\hline Fase de deteç̧ão de anomalias & Frequência absoluta & Frequência relativa & Acumulado absoluto & Acumulado relativo \\
\hline Originalmente & 207 & $1,2 \%$ & 207 & $1,2 \%$ \\
Limpeza primária & 1.536 & $8,8 \%$ & 1.743 & $9,9 \%$ \\
Algoritmo de deteção de outliers & 399 & $2,3 \%$ & 2.142 & $12,2 \%$ \\
Tamanho da série & 17.519 & $100 \%$ & 19.661 & $100 \%$ \\
\hline
\end{tabular}


(A) Único

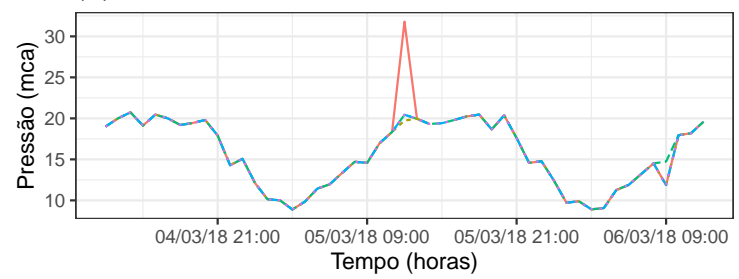

(C) Pulso

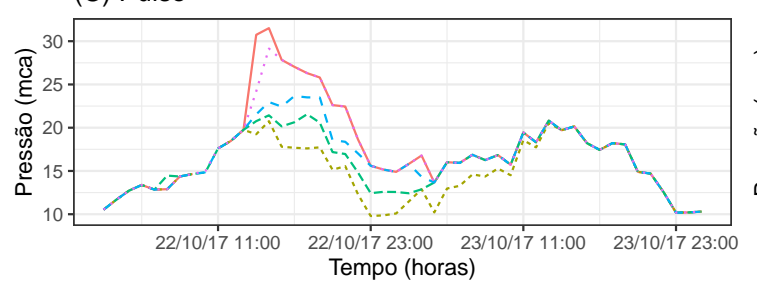

(E) C.D. Exponencial

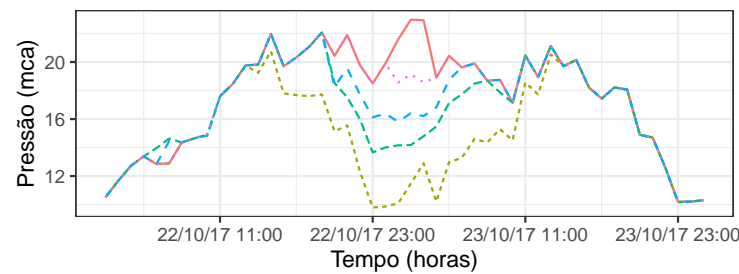

— Série com Outlier $\quad \cdots$ Original --- Corte $=2-\cdots$ Corte $=3 \cdots$ Corte $=5$
(B) Platô

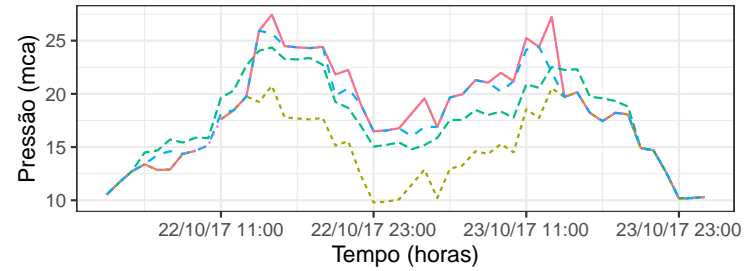

(D) C.D. Linear

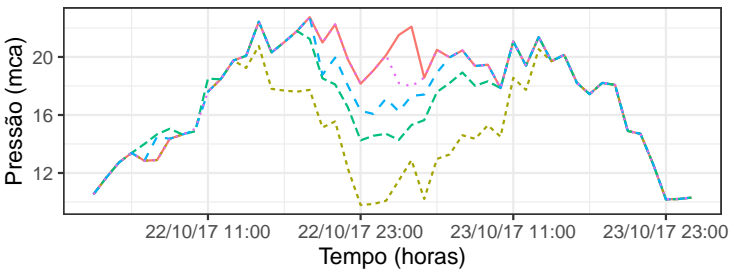

(F) C.D. Logaritmico

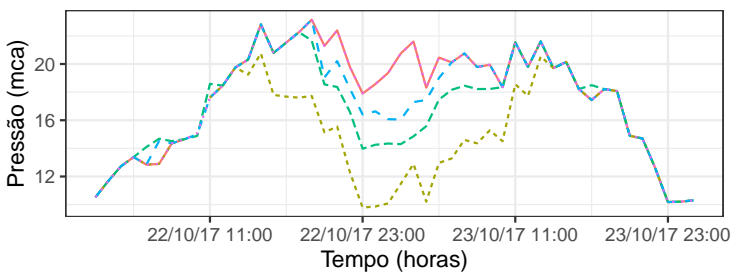

Figura 3.35: Exemplos de detecção e tratamento dos outliers inseridos na série de pressão a jusante ao Sul de Perußbe. Os trechos mostrados possuem tamanho 48 e são centrados nas observações afetadas pelo efeito atípico. Os gráficos de $(A)$ a (F) exemplificam cada tipo de efeito atípico na série. A quantidade de iteração máxima dos experimentos selecionados é 3.

\subsubsection{Previsão}

A Tabela 3.72 traz os resultados de acurácia dos experimentos de previsão de acordo com RMSE. Ela é dividida em duas partes: a parte superior é dedicada a mostrar os resultados que usaram rolling windows de tamanho 336 horas (14 dias) e a parte inferior mostra os resultados referentes ao uso de rolling windows de tamanho 720 horas (30 dias). Os experimentos estão agrupados por tipo de modelos. A partir dessa tabela, verifica-se que:

- O melhor procedimento de previsão com modelos SARIMA, de acordo com o RMSE total, foi o que usou estratégia do tipo 2 e rolling windows de tamanho 720, apresentando RMSE total de 1,376 . Vale notar que no caso do uso de rolling window, a estratégia do tipo 2 conseguiu se ajustar em apenas 8 das 30 rolling windows testadas, o que pode ser um empecilho para se fazer comparações. Outro ponto a se observar é que a estratégia de Tipo 2 teve um desempenho bem melhor do que a de Tipo 1 no uso de ambos os tamanhos de rolling window. Estes resultados são um tanto inusitados, já que o esperado era que o desempenho de um modelo identificado usando as observações da própria rolling window fosse superior àquele que usasse as observações de uma outra rolling window para identicar o modelo.

- O melhor procedimento de regressão com erros autocorrelacionados, de acordo com o RMSE total, foi o que usou polinômio de grau 0 modelando a tendência, sem sazonalidade semanal, com o uso da estratégia do tipo 1 para os erros SARIMA e rolling windows de tamanho 336, apresentando RMSE total de 1,78. É importante notar que nem todos os experimentos 
Tabela 3.72: RMSE dos experimentos de previsão aplicados a série de pressão a jusante ao Sul de Peruíbe. As estratégias de tipo 1 se referem a aplicação do algoritmo de seleção de modelo em cada uma das rollings windows, enquanto que as de tipo 2 se referem a aplicação do algoritmo somente na primeira rolling window $e$ do ajuste modelo selecionado nas demais rolling windows, reestimando os parâmetros. O RMSE "Todos"é calculado usando todos os valores preditos de horizonte $h=1, \ldots ., 168$, incluido aqueles que não aparecem na tabela.

\begin{tabular}{|c|c|c|c|c|c|c|c|c|c|c|c|c|c|c|}
\hline \multicolumn{4}{|c|}{ Experimentos } & \multicolumn{11}{|c|}{ Horizonte de previsão } \\
\hline Modelos & $\begin{array}{c}\text { Grau do } \\
\text { polinô- } \\
\text { mio }\end{array}$ & $\begin{array}{l}\text { Sazonalidade } \\
\text { semanal }\end{array}$ & $\begin{array}{c}\text { Estratégia } \\
\text { de ajuste }\end{array}$ & $\mathrm{N}$ & 1 & 2 & 3 & 6 & 12 & 18 & 24 & 48 & 168 & Todos \\
\hline \multicolumn{15}{|c|}{ Rolling windows de tamanho 336} \\
\hline \multirow{2}{*}{ SARIMA } & - & - & Tipo 1 & 30 & 0,722 & 0,843 & 1,338 & 2,09 & 1,298 & 1,764 & 2,536 & 2,886 & 5,34 & 3,67 \\
\hline & - & - & Tipo 2 & 29 & 0,632 & 0,821 & 1,024 & 1,47 & 0,759 & 1,537 & 1,731 & 1,627 & 1,93 & 1,67 \\
\hline \multirow{8}{*}{$\begin{array}{r}\text { Regressão } \\
\text { com erros } \\
\text { SARIMA }\end{array}$} & 0 & $\operatorname{Sim}$ & Tipo 1 & 30 & 0,883 & 1,151 & 1,174 & 1,64 & 1,008 & 1,836 & 1,766 & 1,985 & 2,03 & 1,82 \\
\hline & 0 & $\operatorname{Sim}$ & Tipo 2 & 23 & 0,977 & 1,233 & 1,552 & 2,41 & 2,026 & 2,192 & 2,414 & 2,518 & 2,78 & 2,86 \\
\hline & 1 & $\operatorname{Sim}$ & Tipo 1 & 30 & 0,898 & 1,120 & 1,286 & 1,86 & 1,229 & 1,502 & 2,150 & 2,220 & 2,66 & 2,41 \\
\hline & 1 & $\operatorname{Sim}$ & Tipo 2 & 25 & 1,195 & 1,569 & 1,480 & 1,80 & 1,439 & 1,732 & 2,152 & 2,161 & 2,81 & 2,59 \\
\hline & 0 & Não & Tipo 1 & 30 & 0,894 & 1,135 & 1,146 & 1,74 & 1,023 & 1,795 & 1,744 & 1,828 & 2,09 & 1,78 \\
\hline & 0 & Não & Tipo 2 & 23 & 0,973 & 1,415 & 1,667 & 2,31 & 1,856 & 2,001 & 2,496 & 2,453 & 2,67 & 2,76 \\
\hline & 1 & Não & Tipo 1 & 30 & 0,923 & 1,128 & 1,310 & 1,90 & 1,245 & 1,515 & 2,077 & 1,988 & 2,69 & 2,36 \\
\hline & 1 & Não & Tipo 2 & 16 & 0,920 & 1,198 & 1,563 & 2,32 & 1,418 & 1,628 & 1,756 & 1,851 & 2,61 & 2,29 \\
\hline \multirow{2}{*}{ BATS } & - & Não & Tipo 1 & 30 & 1,118 & 1,256 & 1,304 & 1,73 & 1,343 & 2,090 & 2,536 & 2,614 & 3,02 & 2,44 \\
\hline & - & $\operatorname{Sim}$ & Tipo 1 & 30 & 3,202 & 2,442 & 2,088 & 2,61 & 2,784 & 1,814 & 2,461 & 2,694 & 2,71 & 2,93 \\
\hline \multirow{2}{*}{ TBATS } & - & Não & Tipo 1 & 30 & 1,272 & 1,324 & 1,199 & 1,47 & 1,374 & 1,901 & 2,146 & 2,146 & 2,50 & 2,10 \\
\hline & - & Sim & Tipo 1 & 30 & 1,220 & 1,235 & 1,407 & 1,76 & 1,942 & 2,161 & 2,414 & 2,330 & 2,67 & 2,49 \\
\hline \multirow{3}{*}{ Benchmark } & - & - & Média & 30 & 2,870 & 3,266 & 3,876 & 5,28 & 1,569 & 5,107 & 2,668 & 2,677 & 2,70 & 3,97 \\
\hline & - & - & Mediana & 30 & 2,754 & 3,192 & 3,953 & 5,54 & 1,881 & 4,952 & 2,542 & 2,575 & 2,54 & 4,02 \\
\hline & - & - & Últ. Obs. & 30 & 2,269 & 2,943 & 5,020 & 7,27 & 3,834 & 4,049 & 2,236 & 2,077 & 2,50 & 4,73 \\
\hline \multicolumn{15}{|c|}{ Rolling windows de tamanho 720} \\
\hline \multirow{2}{*}{ SARIMA } & - & - & Tipo 1 & 30 & 0,664 & 1,042 & 0,771 & 1,34 & 1,865 & 2,211 & 1,975 & 2,637 & 2,71 & 2,22 \\
\hline & - & - & Tipo 2 & 8 & 0,676 & 0,363 & 0,365 & 1,11 & 0,945 & 0,651 & 0,833 & 0,689 & 3,21 & 1,38 \\
\hline \multirow{8}{*}{$\begin{array}{r}\text { Regressão } \\
\text { com erros } \\
\text { SARIMA }\end{array}$} & 0 & $\operatorname{Sim}$ & Tipo 1 & 30 & 0,641 & 1,128 & 0,844 & 1,29 & 1,671 & 1,948 & 1,628 & 2,262 & 2,92 & 2,19 \\
\hline & 0 & $\operatorname{Sim}$ & Tipo 2 & 30 & 0,647 & 1,086 & 0,920 & 1,37 & 1,847 & 2,201 & 2,042 & 2,850 & 3,10 & 2,54 \\
\hline & 1 & Sim & Tipo 1 & 30 & 0,666 & 1,116 & 0,834 & 1,28 & 1,646 & 2,061 & 1,822 & 2,588 & 2,83 & 2,23 \\
\hline & 1 & $\operatorname{Sim}$ & Tipo 2 & 30 & 0,652 & 1,119 & 0,821 & 1,24 & 1,619 & 2,050 & 1,812 & 2,585 & 2,81 & 2,22 \\
\hline & 0 & Não & Tipo 1 & 30 & 0,632 & 1,135 & 0,844 & 1,19 & 1,590 & 1,895 & 1,615 & 2,233 & 2,93 & 2,18 \\
\hline & 0 & Não & Tipo 2 & 30 & 0,683 & 1,075 & 0,835 & 1,19 & 1,583 & 2,014 & 1,826 & 2,482 & 2,74 & 2,20 \\
\hline & 1 & Não & Tipo 1 & 30 & 0,649 & 1,119 & 0,837 & 1,10 & 1,538 & 2,012 & 1,800 & 2,532 & 2,82 & 2,22 \\
\hline & 1 & Não & Tipo 2 & 30 & 0,644 & 1,118 & 0,817 & 1,14 & 1,557 & 2,006 & 1,802 & 2,534 & 2,81 & 2,21 \\
\hline \multirow{2}{*}{ BATS } & - & Não & Tipo 1 & 30 & 0,866 & 1,032 & 0,877 & 1,25 & 1,659 & 1,989 & 1,978 & 2,586 & 2,56 & 2,15 \\
\hline & - & $\operatorname{Sim}$ & Tipo 1 & 30 & 1,143 & 1,072 & 0,794 & 1,60 & 1,959 & 2,317 & 1,972 & 2,636 & 3,01 & 2,27 \\
\hline \multirow{2}{*}{ TBATS } & - & Não & Tipo 1 & 30 & 0,943 & 1,114 & 0,909 & 1,44 & 1,742 & 2,105 & 1,794 & 2,487 & 2,82 & 2,23 \\
\hline & - & $\mathrm{Sim}$ & Tipo 1 & 30 & 0,929 & 1,049 & 0,953 & 1,38 & 1,767 & 2,304 & 1,914 & 2,632 & 2,81 & 2,32 \\
\hline \multirow{3}{*}{ Benchmark } & - & - & Média & 30 & 2,177 & 2,894 & 4,388 & 5,59 & 2,141 & 5,374 & 2,301 & 2,613 & 3,63 & 4,28 \\
\hline & - & - & Mediana & 30 & 2,237 & 2,950 & 4,481 & 5,82 & 2,355 & 5,231 & 2,228 & 2,487 & 3,42 & 4,31 \\
\hline & - & - & Últ. Obs. & 30 & 2,210 & 2,849 & 4,840 & 6,75 & 3,836 & 5,082 & 2,229 & 2,816 & 3,42 & 4,88 \\
\hline
\end{tabular}

conseguiram ajustar determinado modelo em todas as rollings windows, o que pode ser um empecilho a mais na hora de fazer comparações.

- Dentre os procedimentos BATS e TBATS, o que teve melhor desempenho de acordo com o RMSE total foi o que usou modelos TBATS sem sazonalidade semanal e com rolling windows de tamanho 336, apresentando RMSE total de 2,102. Para ambos os procedimentos BATS e TBATS o uso de sazonalidade semanal não melhorou o desempenho dos modelos.

- Com exceção dos procedimentos que usaram modelos SARIMA, não houve uma diferença notável de desempenho entre usar rolling windows de tamanho 336 ou 720.

- Alguns experimentos que empregaram a estratégia do tipo 2 tiveraram um valor de $N<30$. Isso é explicado pelo fato da estratégia consistir em identificar o modelo usando as observações de apenas de uma rolling windows e depois só reestimar os parâmetros nas damais, visto que, ao se fazer esse procedimento, corre-se o risco do modelo não ser "estimátivel"(raízes próximas do polinomio autoregressivo ou de médias móveis bem próximas ou dentro do circulo unitário). Assim, mesmo nas situações em que procedimento do tipo 2 teve um desempenho melhor, é 
preferivel escolher o do tipo 1 , já que a diferença de desempenho entre eles não é muito discrepante.

- Os métodos de previsão propostos tiveram desempenhos bem superiores aos métodos benchmark, mostrando, assim, uma possível adequabilidade dos modelos propostos.

- Dentre todos os procedimentos de previsão propostos, o melhor foi o que usou modelos SARIMA do tipo 2 e com rolling windows de tamanho 720, apresentando o valor de RMSE total de 1,376. Se excluírmos os procedimentos de previsão que usaram a estratégia do tipo 2, temos que o melhor procedimento foi o que usou modelos de regressão com erros autocorrelacionados, com polinômio de grau 0 modelando a tendência, sem sazonalidade semanal e com rolling windows de tamanho 336, apresentando um RMSE total de 1,78.

Os bons resultados de previsão podem ser explicados por um comportamento regular que a série apresenta em quase toda a sua extensão, sendo, muitas vezes, uma sazonalidade bem definida. Tal constatação pode ser observada na Figura 3.36, na qual são mostrados alguns exemplos de previsão para cada tipo de modelo que reforçam as constatações realizadas.
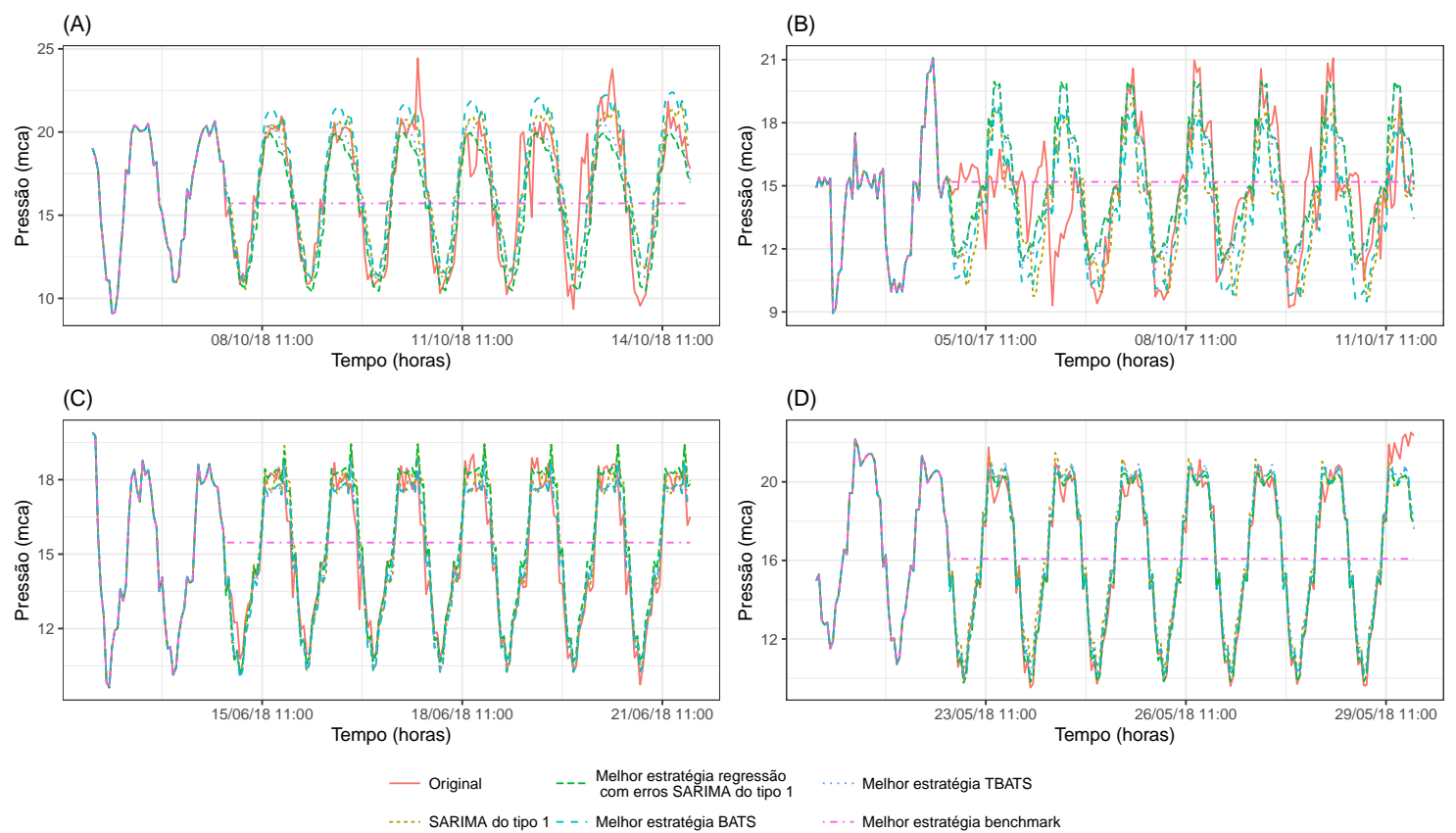

Figura 3.36: Alguns trechos da série de pressão a jusante ao Sul de Peruỉe que exemplificam a aplicação dos modelos de previsão. São apresentados o melhor procedimento de ajuste de cada família de modelos, de acordo com o melhor RMSE de previsão, para os dois tamanhos de rolling window descritos na tabela 3.72. Para a seleção dos procedimentos, exluiu-se os que utilizaram a estratégia de tipo 2. Os gráficos exibem 48 horas da série seguidas de 168 horas de previsão. Os gráficos da esquerda se referem aos ajustes que usaram rolling windows de tamanho 336, já os da direita, de tamanho 720

Para a elaboração dos gráficos da Figura 3.36, decidiu-se não selecionar as previsões que usaram a estratégia do tipo 2, por tal método nem sempre conseguir estimar os parâmetros dos modelos, o que acaba resultando no uso de uma quantidade menor de rolling windows. Assim, as previsões SARIMA se referem ao uso de estratégia do tipo 1 e rolling windows de tamanho 720; as de regressão com erros autocorrelacionados se referem ao uso de polinômio de grau 0 modelando a tendência, sem sazonalidade semanal, com o uso da estratégia do tipo 1 para os erros SARIMA e rolling windows de 
tamanho 336; as previsões BATS se referem ao uso de modelos sem sazonalidade semanal e rolling windows de tamanho 720; as previsões TBATS se referem ao uso de modelos sem sazonalidade semanal e rolling windows de tamanho 336 e as previsões benchmark se referem ao uso da média e rolling windows de tamanho 336 . 


\subsection{Discussão geral}

Fazemos aqui uma discussão geral sobre os resultados e também comentamos sobre possíveis perspectivas futuras de métodos e análises.

Quanto aos procedimentos de detecção de outliers e preenchimento de valores omissos, temos que os métodos propostos geraram resultados próximos entre si. A qualidade da imputação depende muito do comportamento da série na qual os métodos são aplicados. De fato, para as séries que são influenciadas mais diretamente pela vontade do CCO, ou seja, as séries de vazão de entrada e de nível de reservatório, os resultados foram poucos satisfatórios devido ao comportamento pouco regular ao longo do tempo. Já para as demais séries os resultados foram bem satisfatórios devido às suas variações e comportamentos estarem intimamente ligados às características de demanda de água da população.

A Tabela 3.73 mostra um resumo dos procedimentos selecionados para cada série de acordo com o menor RMSE total. Embora a escolha desses procedimentos tenha se baseado apenas na acurácia, também seria interessante considerar outros aspectos no caso de aplicação em tempo real, como o custo computacional de execução do procedimento. Por exemplo, os procedimentos de imputação de valores omissos e de detecção e tratamento de outliers que usaram a decomposição STL tiveram, em geral, um tempo de execução bem menor do que os demais quando este utiliza uma decomposição com poucas iterações $n_{(e)}$ e $n_{(i)}$. Tal diferença de tempo pode ser explicado pelo fato do STL usar, basicamente, operações simples de cálculo, enquanto que os de regressão (e consequentemente o procedimento de decomposição clássica + regressão) envolve operações mais complexas, com inversão de matrizes. Logo, o tempo de execução é algo que também pode ser considerado na hora de escolher o método de preenchimento de valores omissos, já que as diferenças de performance entre os tipos de experimentos não foram tão destoantes. Deixa-se claro que não chegamos a controlar rigidamente o tempo de execução computacional devido a dificuldade de se manter constantes, em cada experimento, todas as variáveis exógenas que poderiam influenciar nesse tempo, como, por exemplo, aplicações secundárias que viriam a ser executadas concomitantemente à execução dos experimentos.

Tabela 3.73: Procedimentos de detecção de outliers e preenchimento de valores omissos selecionados de acordo com o menor RMSE total. Para a seleção dos modelos foram excluídos aqueles que usaram estratégia do tipo 2 de ajuste.

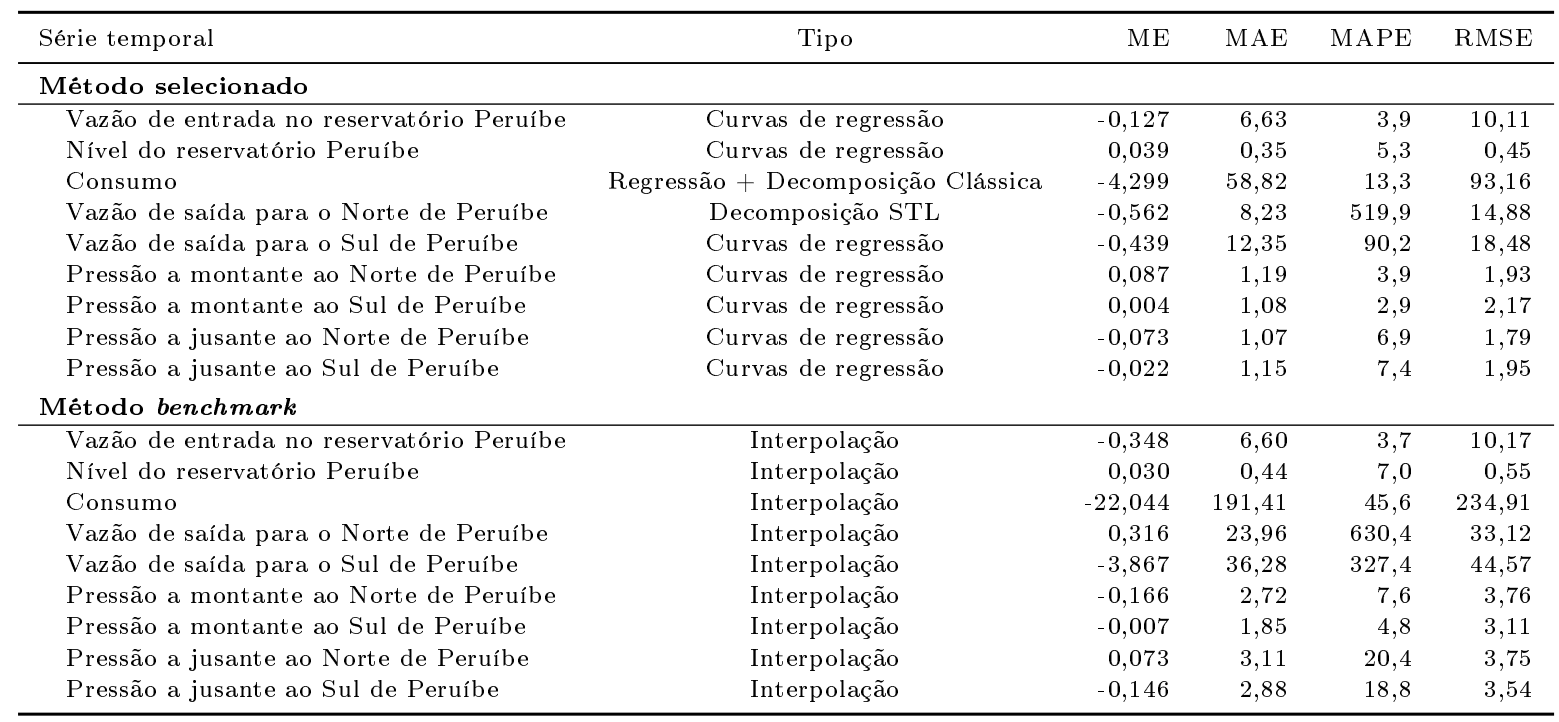


Vale constatar que o método que combinava regressão e decomposição clássica não teve um desempenho significativamente superior aos que apenas aplicavam regressão, no quesito de acurácia de imputação dos valores omissos, a ponto de justificar o seu uso. Apesar de ter utilizado apenas um tipo de modelo de regressão em combinação com a decomposição clássica devido a uma restrição computacional, acredita-se que outras combinações não trariam uma melhora nas previsões.

Os métodos propostos de imputação de valores omissos podem ser aperfeiçoados por uma mistura dos métodos de acordo com o tamanho da sequência de valores omissos. Assim, por exemplo, poderíamos usar uma simples interpolação linear para preencher sequências de tamanho até 3, regressão para sequências de tamanho entre 4 e 24 e STL para sequências de valores omissos maiores que 24. Mas, para isso seriam necessários fazer análises mais profundas que visem avaliar se tal método é realmente efetivo e, caso o seja, quais seriam as combinações que trariam bons resultados.

Outra ideia seria usar os métodos de previsão como procedimentos de imputação quando se tem sequências muito longas de valores omissos. Neste caso, poderia se usar a abordagem de imputação descrita por Barrela (2015) [Bar15], na qual os valores passados em relação à sequência de valores omissos são usados para fazer forescasting e as observações futuras em relação à lacuna são usada para fazer backcasting e, então, as estimativas das observações omissas seria uma ponderação entre os forescasting e backcasting de acordo com a distância euclidiana do índice de cada observação omissa em relação a última observação não omissa sucessora e antecessora a lacuna omissa. Ou seja, se $\hat{Z}_{t+1}^{f}, \hat{Z}_{t+2}^{f}, \ldots, \hat{Z}_{t+k}^{f}$ são previsões forescasting e $\hat{Z}_{t+1}^{b}, \hat{Z}_{t+2}^{b}, \ldots, \hat{Z}_{t+k}^{b}$ são previsões backcasting, então a estimativa dos valores omissos $\hat{Z}_{t+1}, \hat{Z}_{t+2}, \ldots, \hat{Z}_{t+k}$, é

$$
\hat{Z}_{t+i}=(1-p) \hat{Z}_{t+i}^{f}+p \hat{Z}_{t+i}^{b}
$$

em que

$$
p=\frac{i}{k+1} \text {. }
$$

Porém, vale ressaltar que tal método se torna ineficiente do ponto de vista computacional quando a série possui muitas sequências de valores omissos, sendo que em situações em que a série possui muitos valores omissos próximos um dos outros o ajuste de modelos previsionais propostos se torna praticamente inviável.

Embora tivéssemos propostos alguns experimentos para se analisar a qualidade da detecção e tratamento dos outliers, temos que salientar que tais experimentações foram realizadas mais por uma questão de averiguação do que para propor de fato um procedimento de escolha de parâmetros, visto que, por exemplo, uma alta taxa de detecção de outliers gera, frequentemente, o problema de detecção excessiva, ou seja, classificar como outliers aqueles valores que não seriam necessariamente de fato. Assim a escolha dos parâmetros de corte $c$ e a quantidade máxima de iterações do algoritmo teriam que ser realizadas de modo mais subjetivo, respeitando as características de cada série, do que de forma automática como consequência de alguma medida de detecção ou de acurácia.

Quanto aos métodos de previsões, nota-se que, semelhantemente aos métodos de imputação de valores omisso, tiveram bons desempenhos nas séries com comportamento sazonal mais bem definido, cuja geração advém do comportamento de consumo da população. Enquanto que para as séries geradas diretamente pelo comportamento do CCO (nível e vazão de entrada) as previsões não foram boas, sendo as previsões benchmark por vezes melhores. Logo, podemos concluir que o comportamento do CCO, em relação ao abastecimento do reservatório, não possui muita previssibilidade de 
acordo com os métodos previsionais aqui propostos, sendo necessária abordagem diferente no trato dessas séries, que pode ser desde o uso de modelos mais sofisticados ou a inclusão de covariáveis das quais não dispomos.

A Tabela 3.74 mostra um resumo dos procedimentos de previsão selecionados por terem melhores resultados nos experimentos realizados de acordo com o RMSE total de 168 horas. Porém, ainda que essa escolha tenha sido baseada somente na melhor acurácia de previsão, um fator que se deve levar em consideração na escolha do modelo é o tempo total de identificação e ajuste do modelo, pois estes variaram bastante, dependendo tanto dos dados, como também do tipo de modelo. Em geral os modelos BATS com duas sazonalidades tiveram tempo de identificação e ajuste bem superiores aos demais. Notou-se que uma boa parte do tempo gasto é devido a identificação da parte SARIMA dos modelos. Assim como no caso dos métodos de imputação dos valores omissos, as constatações aqui realizadas sobre o tempo de identificação e ajuste dos modelos de previsão são baseadas em observações sem muita precisão, pois não foi realizado nenhum controle rigoroso dos tempos de execução das previsões.

Tabela 3.74: Procedimentos de previsão selecionados de acordo com o menor RMSE total de 168 horas de previsão. Para a seleção dos modelos foram excluídos aqueles que usaram estratégia do tipo 2 de ajuste. Algumas medidas de MAPE não foi possivel calcular devido ao valor original da série ser igual a 0.

\begin{tabular}{|c|c|c|c|c|c|}
\hline Série temporal & Tipo de procedimento de previsão & $\mathrm{ME}$ & MAE & MAPE & RMSE \\
\hline \multicolumn{6}{|l|}{ Método selecionado } \\
\hline Vazão de entrada no reservatório Peruíbe & TBATS & 0,517 & 15,06 & 9,3 & 23,07 \\
\hline Nível do reservatório Peruíbe & BATS & $-0,056$ & 0,67 & 10,7 & 0,92 \\
\hline Consumo & Regressão com erros SARIMA & $-3,366$ & 70,74 & - & 97,11 \\
\hline Vazão de saída para o Norte de Peruíbe & Regressão com erros SARIMA & 2,237 & 13,41 & - & 20,42 \\
\hline Vazão de saída para o Sul de Peruíbe & Regressão com erros SARIMA & $-0,010$ & 17,69 & - & 25,16 \\
\hline Pressão a montante ao Norte de Peruíbe & BATS & $-0,247$ & 1,65 & 4,0 & 2,25 \\
\hline Pressão a montante ao Sul de Peruíbe & Regressão com erros SARIMA & $-0,320$ & 1,09 & 2,5 & 1,60 \\
\hline Pressão a jusante ao Norte de Peruíbe & Regressão com erros SARIMA & $-0,061$ & 0,91 & 5,8 & 1,41 \\
\hline Pressão a jusante ao Sul de Peruíbe & Regressão com erros SARIMA & $-0,055$ & 1,15 & 7,2 & 1,78 \\
\hline \multicolumn{6}{|l|}{ Método benchmark } \\
\hline Vazão de entrada no reservatório Peruíbe & Ült. Obs. & $-1,927$ & 15,79 & 9,6 & 24,31 \\
\hline Nível do reservatório Peruíbe & Média & $-0,278$ & 0,81 & 12,3 & 1,10 \\
\hline Consumo & Média & 2,005 & 216,29 & - & 261,01 \\
\hline Vazão de saída para o Norte de Peruíbe & Média & $-2,195$ & 32,70 & $1.278,7$ & 40,86 \\
\hline Vazão de saída para o Sul de Peruíbe & Média & 0,541 & 39,21 & - & 47,10 \\
\hline Pressão a montante ao Norte de Peruíbe & Mediana & $-0,714$ & 3,01 & 7,1 & 3,67 \\
\hline Pressão a montante ao Sul de Peruíbe & Mediana & $-0,193$ & 1,78 & 4,1 & 2,27 \\
\hline Pressão a jusante ao Norte de Peruíbe & Média & $-0,051$ & 3,76 & 25,3 & 4,33 \\
\hline Pressão a jusante ao Sul de Peruíbe & Média & $-0,161$ & 3,32 & 22,4 & 3,97 \\
\hline
\end{tabular}

Um último comentário sobre as previsões é que seu uso em tempo real, além de auxiliar o operador a tomar decisões sobre a demanda de água, também pode servir para detecção de valores outliers gerados, ora por algum erro de transmissão de dados pelo sistema, ora por um consumo atípico da população. Essa constatação pode ser realizada facilmente através do estabelecimento de bandas de variação máxima para a previsão, que podem ser, por exemplo, os intervalos de confianças de previsão (neste caso há a necessidade de se verificar as hipóteses sobre a distribuição dos erros são de fato são cumpridas) ou por algum método mais robusto, como os intervalos via boostrap.

Uma discussão a parte é sobre a estrutura das séries temporais e sua influência nos resultados. Como já mencionado anteriormente, as séries são formadas por amostragens que ocorrem a cada uma hora de valores medidos instantaneamente, com exceção a série de consumo, cujo valores foram calculados de acordo com as observações das duas séries de vazão de saída. Para a série de vazão de entrada (e em menor escala para a série de nível), os valores amostrados podem não ser representativos para o período de uma hora, visto que durante uma hora podem ocorrer algumas variações 
bruscas nessa vazão. Este problema fica explícito ao se calcular o balanço hídrico (volume de água que sai do reservatório usando as séries de nível e vazão de entrada do reservatório) e obter valores negativos na quantidade de água demandada em alguns períodos. A falta de representatividade, ou seja, considerar o valor medido no início de cada hora como sendo um valor constante ao longo da respectiva hora, também pode ser um dos motivos pelo mau desempenho dos métodos de imputação de valores omissos e de previsão para a série de vazão de entrada e, em menor intensidade, para a série de nível.

Pode surgir a ideia que as análises aqui elaboradas poderiam ser melhoradas ao se coniderar modelos multivariados, como, por exemplo os modelos VAR. No entanto, análises prévias constataram que o uso de tais modelos não melhorariam as previsões, visto que as autocorrelações cruzadas, ou não eram significativas, ou variavam demasiadamente ao longo do tempo. Também chegou a ser cogitado o uso de outros modelos univariados mais complexos, como os ARFIMA sazonais, porém análises prévias demonstraram que tais modelos eram ineficientes tanto do ponto de vista de qualidade de previsão como também do ponto de vista computacional. 


\section{Capítulo 4}

\section{Conclusões}

Os métodos propostos, tanto para deteç̧ão de outliers e preenchimento de valores omissos, como para previsão, tiveram bons desempenhos para a maioria das séries e cumprem com as metas e objetivos propostos de deteç̧ão de anomalias, qualidades de imputação e de previsão.

A primeira meta deste trabalho, que era desenvolver um procedimento para indicar a qualidade dos dados enviados ao CCO, foi alcançada com sucesso. Inicialmente, a taxa de erros encontrada era em torno de $1,0 \%$ a 1,5\% em todos os equipamentos, e com a metodologia proposta as taxas de erros identificadas aumentaram para 8,94 \%, 6,5\%,36,8 \%, 15,5\%, 24,4 \%, 11,5 \%, 15,1 \%, 13,4\% e 12,2 \% para respectivamente as seguintes séries temporais: vazão de entrada no reservatório Peruíbe, nível do reservatório Peruíbe, consumo demandado do reservatório Peruíbe, vazão de saída para o Norte de Peruíbe, vazão de saída para o Sul de Peruíbe, pressão a montante ao Norte de Peruíbe, pressão a montante ao Sul de Peruíbe, pressão a jusante ao Norte de Peruíbe e pressão a jusante ao Sul de Peruíbe. Outro resultado importante foi a verificação de que as anomalias encontradas na limpeza primária foi bem mais frequêntes do que os outliers, ou seja, a limpeza primária proposta identificou um tipo de erro que possui muito significado para a área de manutenção da companhia, e também para a digitalização da prestação de serviços de manutenção de equipamentos e telemetria, que são os erros gerados por alguma falha no sistema.

A segunda meta, que era preencher os valores omissos das séries, também foi obtida com relativo sucesso. Foi proposto um algoritmo que detectava os outliers e que ao mesmo estimava os valores omissos usando um conjunto de modelos para se fazer essas detecções e estimativas. Os métodos propostos conseguiram preencher os vazios das séries de forma bem satisfatória, sendo que nos experimentos realizados, a maioria das estimativas para os valores omissso foram bem próximas aos valores originais. Mesmo para a séries mais problemáticas (vazão de entrada do reservatório e nível do reservatório) os procedimentos ainda se mostraram resilientes, conseguindo performar igual ou um pouco melhor aos métodos benchmarks. A Tabela 3.73 resume os procedimentos de detecção de outliers e preenchimento de valores omissos selecionados por apresentar melhor acurácia.

A terceira e última meta, que era desenvolver e indicar modelos previsionais com boa acurácia e que antecipem a demanda em tempo real das próximas horas, foi alcançada com bons resultados. Foi testado uma gama de possibilidades de modelos previsionais devidamente parametrizadas que convergiu para um conjunto de modelos previsionais adequados para o domínio deste estudo que são as séries temporais associadas a equipamentos e telemetria do sistema de abastecimento de água em Peruíbe. Apenas para as séries de vazão de entrada do reservatório e nível do reservatório que os procedimentos não performaram tão bem, mas, certa forma, conseguiram ser resilientes. A Tabela 
3.74 resume os procedimentos de previsão selecionados para cada série temporal por apresentar melhor acurácia.

As metodologias abordadas neste trabalho, tanto para detecção de outliers e preenchimento de valores omisso, como para a elaboração de previsão, podem ser aplicadas em qualquer sistema de distribuição de água de outros municípios do país, podendo ainda ser extrapoladas para outras áreas de aplicação que envolvam análises de séries temporais.

Este trabalho também cumpre seu objetivo de contribuir para a digitalização e automatização das operações na Indústria da Água. Há tempos que o problema de erros em séries temporais já criava obstáculos para a automação das operações dos reservatórios e distribuição. A detecção de anomalias em séries temporais é um tema de pesquisa muito ativo na área de Aprendizado de Máquina (Machine Learning) e Internet das Coisas na Indústria (IIoT - Industrial Internet of Things).

O próximo passo seria partir para uma abordagem multivariada e modelar o consumo demandado de todos os reservatórios do sistema da Sabesp da Baixada Santista de forma conjunta e incluir nas análises outras séries como covariáveis (como por exemplo, séries de índices pluviométricos e de temperatura). Dessa foram, haveria a necessidade de calcular o balanço hídrico, visto que nos demais reservatórios não existe medições de saída de água. Isso só é possível se as séries temporais de vazão de entrada e de nível sejam, de fato, uma medida representativa do período e não apenas uma amostragem que pode muitas vezes não ser o valor adequado para o período, como é o caso das séries de vazão de entrada com as quais trabalhamos. 


\section{Apêndice A}

\section{Informações descritivas das séries originais}

A seguir são apresentadas um conjunto de tabelas e gráficos descritivos para cada série temporal, sendo organizados da seguinte maneira:

- A Tabela A.1 e a Figura A.1 se referem a série de nível do reservatório de Peruíbe;

- A Tabela A.2 e a Figura A.2 se referem a série de consumo demandado do reservatório de Peruíbe;

- A Tabela A.3 e a Figura A.3 se referem a série de vazão de entrada do reservatório de Peruíbe;

- A Tabela A.4 e a Figura A.4 se referem a série de vazão de saída do reservatório para o Norte de Peruíbe;

- A Tabela A.5 e a Figura A.5 se referem a série de vazão de saída do reservatório para o Sul de Peruíbe;

- A Tabela A.6 e a Figura A.6 se referem a série de pressão a montante no Norte de Peruíbe;

- A Tabela A.7 e a Figura A.7 se referem a série de pressão a montante no Sul de Peruíbe;

- A Tabela A.8 e a Figura A.8 se referem a série de pressão a jusante no Norte de Peruíbe;

- A Tabela A.9 e a Figura A.9 se referem a série de pressão a jusante no Sul de Peruíbe. 
Tabela A.1: Medidas descritivas da série original de nível do reservatório de Peruíbe. As informações descritivas são apresentadas para a série em sua totalidade e desagregada por períodos mensais, por dias da semana e por horários do dia.

\begin{tabular}{|c|c|c|c|c|c|c|c|c|c|}
\hline Descritiva & Média & Desvio padrão & Mínimo & $1^{\mathrm{O}}$ Quartil & Mediana & $3^{\mathcal{O}}$ Quartil & Máximo & Omissos & Total \\
\hline \multicolumn{10}{|l|}{ Geral } \\
\hline Geral & 6,72 & 1,29 & 0,00 & 6,21 & 7,04 & 7,60 & 10,00 & 205 & 17519 \\
\hline \multicolumn{10}{|l|}{ Por ano e mês } \\
\hline 2017 jan & 6,26 & 1,27 & 0,00 & 5,58 & 6,63 & 7,24 & 8,28 & 2 & 743 \\
\hline $2017 \mathrm{fev}$ & 6,78 & 0,69 & 3,39 & 6,46 & 6,99 & 7,23 & 7,99 & 0 & 673 \\
\hline 2017 mar & 6,61 & 0,85 & 3,40 & 6,31 & 6,80 & 7,18 & 7,95 & 0 & 744 \\
\hline 2017 abr & 6,79 & 0,57 & 5,21 & 6,40 & 6,85 & 7,23 & 8,06 & 1 & 720 \\
\hline 2017 mai & 6,76 & 0,70 & 3,79 & 6,43 & 6,85 & 7,26 & 8,00 & 0 & 744 \\
\hline 2017 jun & 6,87 & 0,55 & 4,60 & 6,51 & 6,93 & 7,29 & 8,01 & 0 & 720 \\
\hline 2017 jul & 6,67 & 0,75 & 4,00 & 6,19 & 6,82 & 7,23 & 10,00 & 0 & 744 \\
\hline 2017 ago & 6,49 & 0,96 & 2,23 & 6,00 & 6,71 & 7,19 & 8,00 & 0 & 744 \\
\hline 2017 set & 5,56 & 1,21 & 2,80 & 4,59 & 5,57 & 6,61 & 7,88 & 0 & 720 \\
\hline 2017 out & 5,75 & 1,35 & 2,52 & 4,78 & 5,84 & 6,95 & 8,47 & 4 & 743 \\
\hline 2017 nov & 7,36 & 0,81 & 4,40 & 6,97 & 7,50 & 7,95 & 8,52 & 0 & 720 \\
\hline 2017 dez & 6,91 & 1,06 & 3,71 & 6,46 & 7,17 & 7,66 & 8,52 & 0 & 744 \\
\hline 2018 jan & 7,11 & 1,11 & 2,81 & 6,77 & 7,39 & 7,85 & 8,49 & 0 & 744 \\
\hline 2018 fev & 7,36 & 0,87 & 2,57 & 7,11 & 7,53 & 7,91 & 8,51 & 1 & 673 \\
\hline 2018 mar & 7,61 & 0,66 & 4,50 & 7,34 & 7,76 & 8,09 & 8,51 & 0 & 744 \\
\hline 2018 abr & 7,51 & 0,72 & 3,37 & 7,24 & 7,63 & 7,97 & 8,53 & 0 & 720 \\
\hline 2018 mai & 7,35 & 1,56 & 0,00 & 7,29 & 7,71 & 8,02 & 8,55 & 0 & 744 \\
\hline 2018 jun & 7,81 & 0,41 & 6,12 & 7,57 & 7,85 & 8,12 & 8,55 & 0 & 720 \\
\hline 2018 jul & 6,64 & 1,31 & 0,00 & 5,86 & 6,86 & 7,73 & 8,49 & 1 & 744 \\
\hline 2018 ago & 6,74 & 1,50 & 1,95 & 6,18 & 7,20 & 7,88 & 8,50 & 1 & 744 \\
\hline 2018 set & 4,40 & 1,50 & 0,00 & 3,20 & 4,11 & 5,34 & 8,34 & 0 & 720 \\
\hline 2018 out & 6,60 & 1,59 & 0,00 & 5,97 & 7,11 & 7,74 & 8,51 & 79 & 744 \\
\hline 2018 nov & 7,06 & 0,86 & 3,96 & 6,54 & 7,20 & 7,73 & 8,47 & 116 & 719 \\
\hline $2018 \mathrm{dez}$ & 6,32 & 1,47 & 1,48 & 5,54 & 6,60 & 7,38 & 8,53 & 0 & 744 \\
\hline \multicolumn{10}{|c|}{ Por dia da semana } \\
\hline segunda-feira & 6,66 & 1,32 & 1,48 & 6,17 & 6,96 & 7,57 & 8,53 & 1 & 2520 \\
\hline terça-feira & 6,67 & 1,37 & 0,00 & 6,07 & 7,08 & 7,62 & 8,55 & 11 & 2496 \\
\hline quarta-feira & 6,74 & 1,31 & 0,00 & 6,16 & 7,09 & 7,69 & 8,52 & 17 & 2496 \\
\hline quinta-feira & 6,73 & 1,29 & 0,00 & 6,24 & 7,08 & 7,60 & 10,00 & 27 & 2496 \\
\hline sexta-feira & 6,74 & 1,16 & 0,00 & 6,20 & 6,98 & 7,55 & 8,51 & 48 & 2496 \\
\hline sábado & 6,80 & 1,24 & 0,00 & 6,38 & 7,05 & 7,64 & 8,51 & 34 & 2498 \\
\hline domingo & 6,69 & 1,34 & 0,00 & 6,26 & 7,02 & 7,56 & 8,53 & 67 & 2517 \\
\hline \multicolumn{10}{|c|}{ Por horário do dia } \\
\hline $0: 00$ & 6,72 & 1,38 & 0,00 & 6,14 & 7,05 & 7,73 & 8,51 & 9 & 727 \\
\hline $1: 00$ & 6,82 & 1,33 & 0,00 & 6,31 & 7,11 & 7,79 & 8,50 & 9 & 730 \\
\hline $2: 00$ & 6,91 & 1,25 & 0,00 & 6,43 & 7,21 & 7,80 & 8,53 & 9 & 730 \\
\hline $3: 00$ & 6,98 & 1,18 & 0,00 & 6,52 & 7,24 & 7,83 & 8,55 & 9 & 730 \\
\hline $4: 00$ & 7,01 & 1,10 & 0,00 & 6,58 & 7,25 & 7,76 & 8,53 & 8 & 730 \\
\hline $5: 00$ & 7,04 & 1,03 & 0,00 & 6,61 & 7,27 & 7,73 & 8,46 & 9 & 730 \\
\hline $6: 00$ & 7,06 & 0,96 & 0,00 & 6,63 & 7,24 & 7,70 & 8,49 & 9 & 730 \\
\hline $7: 00$ & 7,12 & 0,93 & 0,00 & 6,79 & 7,27 & 7,73 & 8,50 & 8 & 730 \\
\hline $8: 00$ & 7,16 & 0,94 & 0,00 & 6,83 & 7,33 & 7,76 & 8,47 & 8 & 730 \\
\hline $9: 00$ & 7,12 & 1,01 & 0,00 & 6,77 & 7,32 & 7,77 & 8,45 & 8 & 730 \\
\hline $10: 00$ & 7,00 & 1,03 & 0,00 & 6,57 & 7,23 & 7,68 & 8,47 & 8 & 730 \\
\hline $11: 00$ & 6,87 & 1,08 & 0,00 & 6,45 & 7,12 & 7,57 & 8,48 & 8 & 730 \\
\hline $12: 00$ & 6,74 & 1,16 & 0,00 & 6,25 & 7,00 & 7,53 & 8,45 & 9 & 730 \\
\hline $13: 00$ & 6,63 & 1,22 & 0,00 & 6,06 & 6,92 & 7,46 & 8,50 & 8 & 730 \\
\hline $14: 00$ & 6,52 & 1,31 & 0,00 & 5,90 & 6,81 & 7,40 & 8,49 & 8 & 730 \\
\hline $15: 00$ & 6,47 & 1,35 & 0,00 & 5,87 & 6,77 & 7,40 & 8,49 & 8 & 730 \\
\hline $16: 00$ & 6,42 & 1,38 & 0,00 & 5,78 & 6,73 & 7,40 & 8,50 & 8 & 730 \\
\hline $17: 00$ & 6,36 & 1,42 & 0,00 & 5,66 & 6,68 & 7,38 & 8,50 & 8 & 730 \\
\hline $18: 00$ & 6,33 & 1,43 & 0,00 & 5,53 & 6,69 & 7,34 & 8,50 & 8 & 730 \\
\hline $19: 00$ & 6,31 & 1,45 & 0,00 & 5,47 & 6,68 & 7,41 & 8,46 & 8 & 730 \\
\hline $20: 00$ & 6,31 & 1,47 & 0,00 & 5,46 & 6,68 & 7,41 & 8,45 & 8 & 730 \\
\hline $21: 00$ & 6,34 & 1,48 & 0,00 & 5,58 & 6,77 & 7,43 & 8,49 & 10 & 730 \\
\hline $22: 00$ & 6,44 & 1,49 & 0,00 & 5,68 & 6,84 & 7,51 & 10,00 & 10 & 730 \\
\hline $23: 00$ & 6,56 & 1,46 & 0,00 & 5,90 & 6,97 & 7,62 & 8,52 & 10 & 732 \\
\hline
\end{tabular}


(A) Nível do reservatório por hora de acordo com o mês

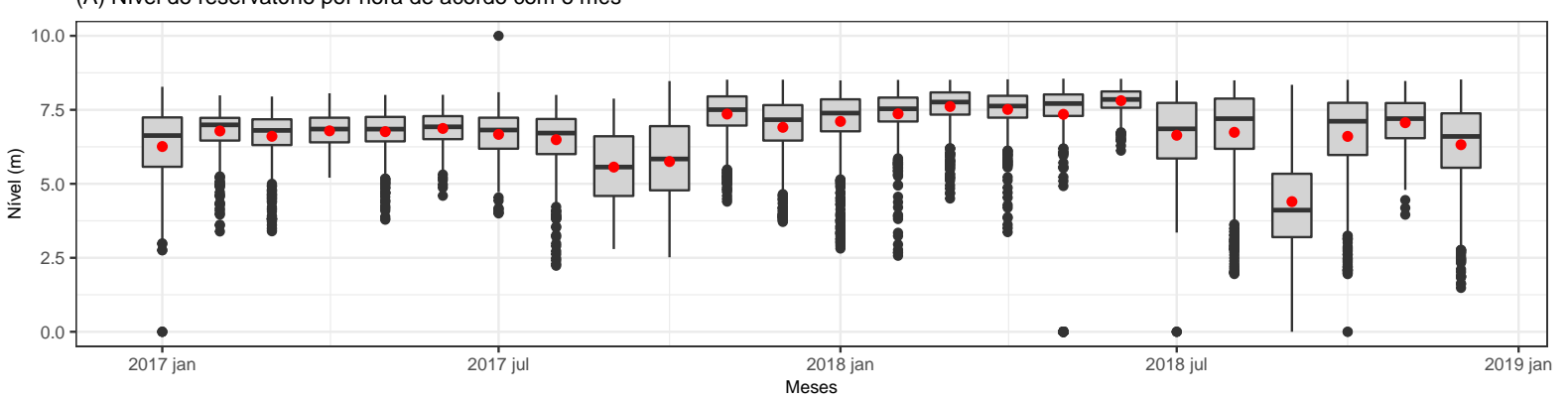

(B) Nível do reservatório por hora de acordo com o horário do dia

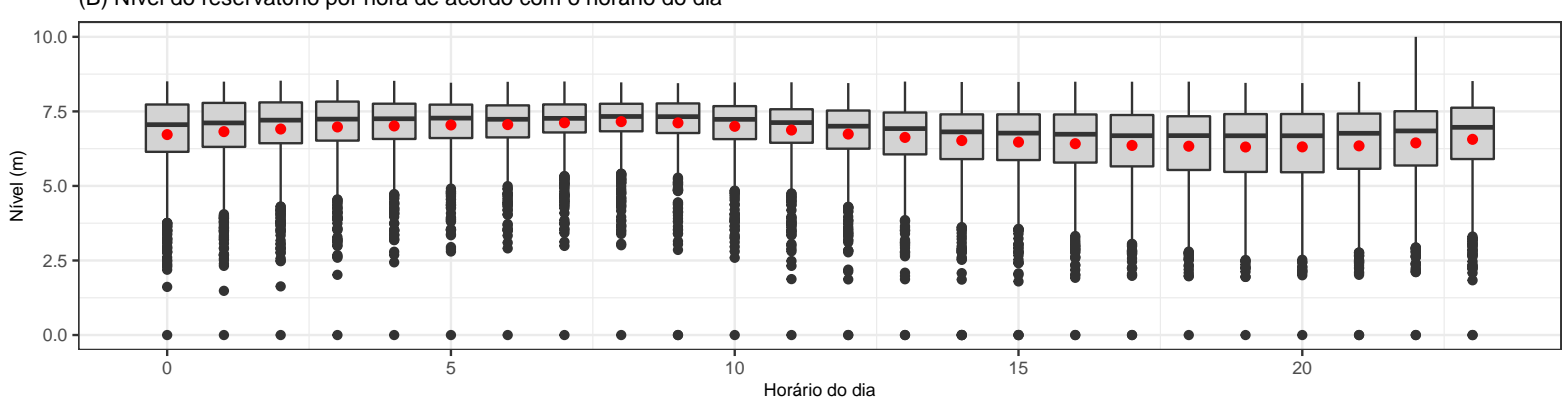

(C) Nível do reservatório por hora de acordo com dia da semana

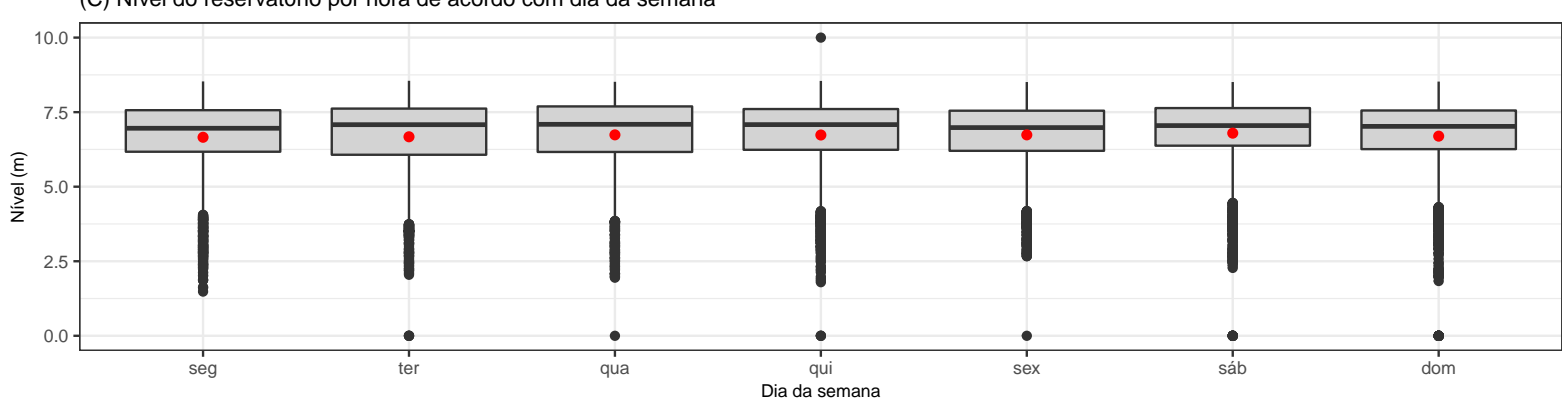

(D) Trecho da série de Nível De 1 1ํ a 31 de janeiro de 2017

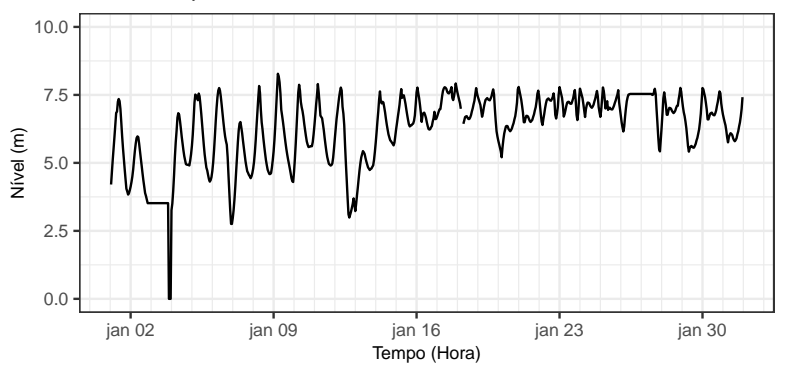

(E) Trecho da série de Nível

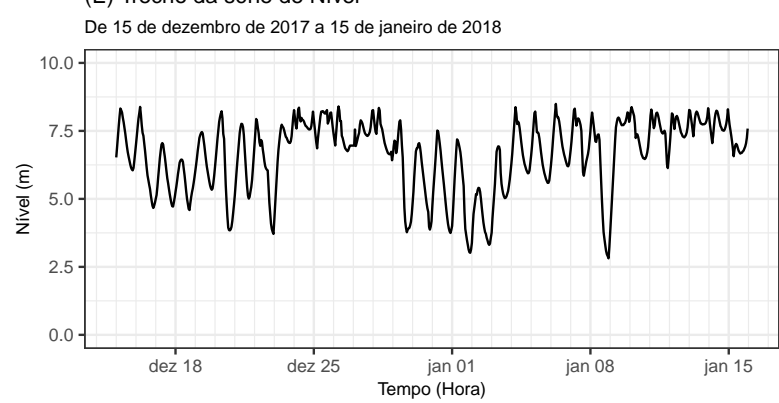

Figura A.1: Painel com alguns gráficos descritivos da série original de nível do reservatório de Peruibe. Os gráficos $(A),(B)$ e $(C)$ são boxplots série de nível em $m$ de acordo com mês, horário do dia e dia semana, respectivamente. Os pontos vermelhos são as médias de cada período. Já os gráficos (D) e (E) são trechos selecionados da série. 
Tabela A.2: Medidas descritivas da série original de consumo demandado do reservatório de Peruíbe. As informações descritivas são apresentadas para a série em sua totalidade e desagregada por períodos mensais, por dias da semana e por horários do dia.

\begin{tabular}{|c|c|c|c|c|c|c|c|c|c|}
\hline Descritiva & Média & Desvio padrão & Mínimo & $1^{\mathrm{O}}$ Quartil & Mediana & $3^{\mathcal{O}}$ Quartil & Máximo & Omissos & Total \\
\hline \multicolumn{10}{|l|}{ Geral } \\
\hline Geral & 552 & 325 & 0,00 & 278,2 & 570 & 779 & 1684 & 207 & 17519 \\
\hline \multicolumn{10}{|l|}{ Por ano e mês } \\
\hline 2017 jan & 666 & 297 & 0,00 & 460,2 & 684 & 853 & 1300 & 2 & 743 \\
\hline $2017 \mathrm{fev}$ & 587 & 291 & 75,38 & 320,4 & 586 & 808 & 1224 & 0 & 673 \\
\hline 2017 mar & 483 & 274 & 1,10 & 223,2 & 511 & 698 & 1102 & 0 & 744 \\
\hline 2017 abr & 425 & 253 & 0,33 & 190,9 & 421 & 650 & 1110 & 1 & 720 \\
\hline 2017 mai & 400 & 235 & 0,00 & 198,1 & 398 & 620 & 1007 & 0 & 744 \\
\hline 2017 jun & 421 & 228 & 0,33 & 202,7 & 394 & 626 & 988 & 0 & 720 \\
\hline 2017 jul & 458 & 253 & 0,33 & 229,4 & 455 & 661 & 1630 & 0 & 744 \\
\hline 2017 ago & 564 & 284 & 86,86 & 332,3 & 570 & 748 & 1445 & 0 & 744 \\
\hline 2017 set & 629 & 390 & 0,00 & 328,4 & 640 & 949 & 1290 & 0 & 720 \\
\hline 2017 out & 367 & 271 & 0,00 & 119,1 & 353 & 614 & 984 & 5 & 743 \\
\hline 2017 nov & 442 & 236 & 0,00 & 201,7 & 454 & 662 & 867 & 0 & 720 \\
\hline 2017 dez & 482 & 259 & 0,00 & 239,0 & 485 & 700 & 1169 & 0 & 744 \\
\hline 2018 jan & 568 & 314 & 0,00 & 287,5 & 604 & 826 & 1251 & 0 & 744 \\
\hline 2018 fev & 681 & 384 & 0,00 & 339,1 & 751 & 972 & 1645 & 1 & 673 \\
\hline 2018 mar & 658 & 308 & 0,00 & 362,8 & 745 & 904 & 1419 & 0 & 744 \\
\hline 2018 abr & 664 & 321 & 0,65 & 338,8 & 740 & 904 & 1443 & 0 & 720 \\
\hline 2018 mai & 591 & 294 & 0,00 & 317,3 & 648 & 832 & 1223 & 0 & 744 \\
\hline 2018 jun & 538 & 256 & 0,00 & 302,0 & 598 & 738 & 1324 & 0 & 720 \\
\hline 2018 jul & 638 & 241 & 0,00 & 609,0 & 712 & 712 & 1317 & 2 & 744 \\
\hline 2018 ago & 503 & 315 & 0,00 & 222,3 & 505 & 817 & 1130 & 1 & 744 \\
\hline 2018 set & 433 & 356 & 0,00 & 61,2 & 415 & 776 & 1183 & 0 & 720 \\
\hline 2018 out & 609 & 400 & 0,00 & 213,1 & 672 & 843 & 1570 & 79 & 744 \\
\hline 2018 nov & 699 & 411 & 0,00 & 322,0 & 776 & 1048 & 1519 & 116 & 719 \\
\hline $2018 \mathrm{dez}$ & 775 & 405 & 0,00 & 440,0 & 820 & 1110 & 1684 & 0 & 744 \\
\hline \multicolumn{10}{|c|}{ Por dia da semana } \\
\hline segunda-feira & 558 & 332 & 0,00 & 271,9 & 564 & 783 & 1645 & 1 & 2520 \\
\hline terça-feira & 526 & 317 & 0,00 & 245,8 & 544 & 752 & 1436 & 11 & 2496 \\
\hline quarta-feira & 541 & 326 & 0,00 & 267,4 & 554 & 783 & 1436 & 19 & 2496 \\
\hline quinta-feira & 550 & 331 & 0,00 & 280,3 & 576 & 774 & 1570 & 27 & 2496 \\
\hline sexta-feira & 562 & 326 & 0,00 & 290,3 & 588 & 795 & 1520 & 48 & 2496 \\
\hline sábado & 578 & 327 & 0,00 & 308,1 & 615 & 806 & 1510 & 34 & 2498 \\
\hline domingo & 546 & 316 & 0,00 & 285,0 & 561 & 755 & 1684 & 67 & 2517 \\
\hline \multicolumn{10}{|c|}{ Por horário do dia } \\
\hline $0: 00$ & 269 & 219 & 0,00 & 123,6 & 225 & 325 & 1635 & 9 & 727 \\
\hline $1: 00$ & 254 & 215 & 0,00 & 107,7 & 218 & 321 & 1262 & 9 & 730 \\
\hline $2: 00$ & 230 & 219 & 0,00 & 79,0 & 161 & 321 & 1190 & 9 & 730 \\
\hline $3: 00$ & 241 & 216 & 0,00 & 104,5 & 208 & 285 & 1332 & 9 & 730 \\
\hline $4: 00$ & 219 & 222 & 0,00 & 69,8 & 171 & 293 & 1354 & 8 & 730 \\
\hline $5: 00$ & 293 & 217 & 0,00 & 181,8 & 262 & 364 & 1131 & 9 & 730 \\
\hline $6: 00$ & 345 & 212 & 0,00 & 207,7 & 316 & 446 & 1131 & 9 & 730 \\
\hline $7: 00$ & 481 & 183 & 0,00 & 367,7 & 438 & 589 & 1377 & 8 & 730 \\
\hline $8: 00$ & 602 & 204 & 0,00 & 467,8 & 592 & 721 & 1404 & 8 & 730 \\
\hline $9: 00$ & 786 & 217 & 0,00 & 680,7 & 764 & 940 & 1394 & 8 & 730 \\
\hline $10: 00$ & 841 & 233 & 0,00 & 707,3 & 809 & 997 & 1510 & 9 & 730 \\
\hline $11: 00$ & 871 & 238 & 0,00 & 734,4 & 851 & 1014 & 1565 & 8 & 730 \\
\hline $12: 00$ & 863 & 236 & 0,00 & 736,3 & 847 & 995 & 1565 & 10 & 730 \\
\hline $13: 00$ & 839 & 224 & 0,00 & 714,9 & 818 & 954 & 1549 & 8 & 730 \\
\hline $14: 00$ & 794 & 231 & 0,00 & 668,6 & 764 & 917 & 1585 & 8 & 730 \\
\hline $15: 00$ & 763 & 227 & 0,00 & 654,2 & 738 & 855 & 1586 & 8 & 730 \\
\hline $16: 00$ & 758 & 227 & 0,00 & 636,9 & 726 & 871 & 1630 & 8 & 730 \\
\hline $17: 00$ & 718 & 222 & 0,00 & 602,1 & 694 & 818 & 1645 & 8 & 730 \\
\hline $18: 00$ & 689 & 217 & 0,00 & 552,3 & 670 & 785 & 1582 & 8 & 730 \\
\hline $19: 00$ & 639 & 237 & 0,00 & 495,2 & 605 & 765 & 1574 & 8 & 730 \\
\hline $20: 00$ & 602 & 254 & 0,00 & 415,7 & 565 & 784 & 1445 & 8 & 730 \\
\hline $21: 00$ & 469 & 256 & 0,00 & 273,3 & 452 & 600 & 1510 & 10 & 730 \\
\hline $22: 00$ & 362 & 238 & 0,00 & 196,0 & 318 & 417 & 1466 & 10 & 730 \\
\hline $23: 00$ & 309 & 235 & 0,00 & 143,8 & 260 & 396 & 1684 & 10 & 732 \\
\hline
\end{tabular}




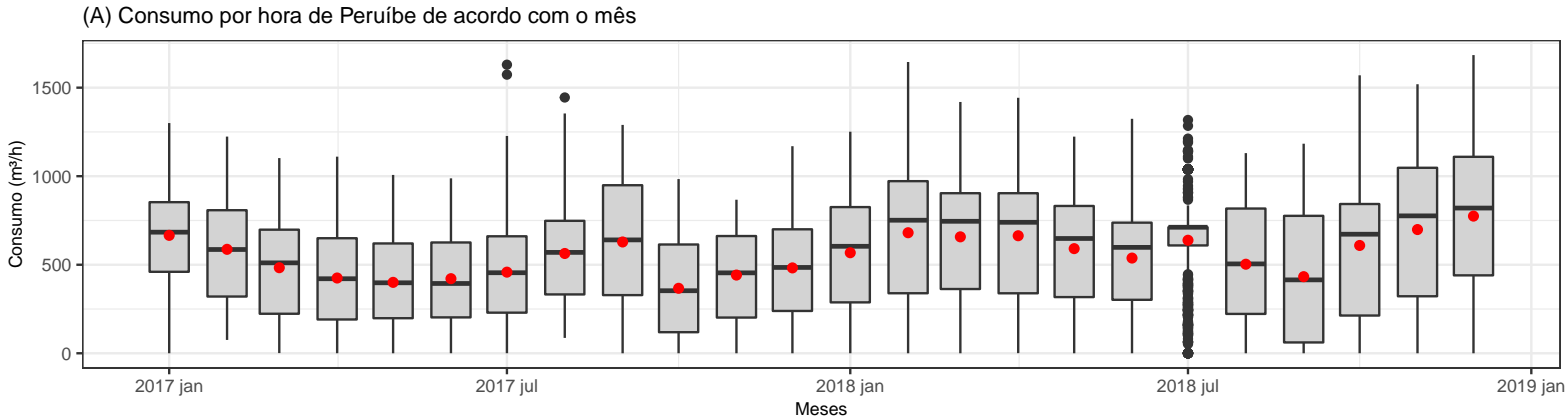

(B) Consumo por hora de Peruíbe de acordo com o horário do dia

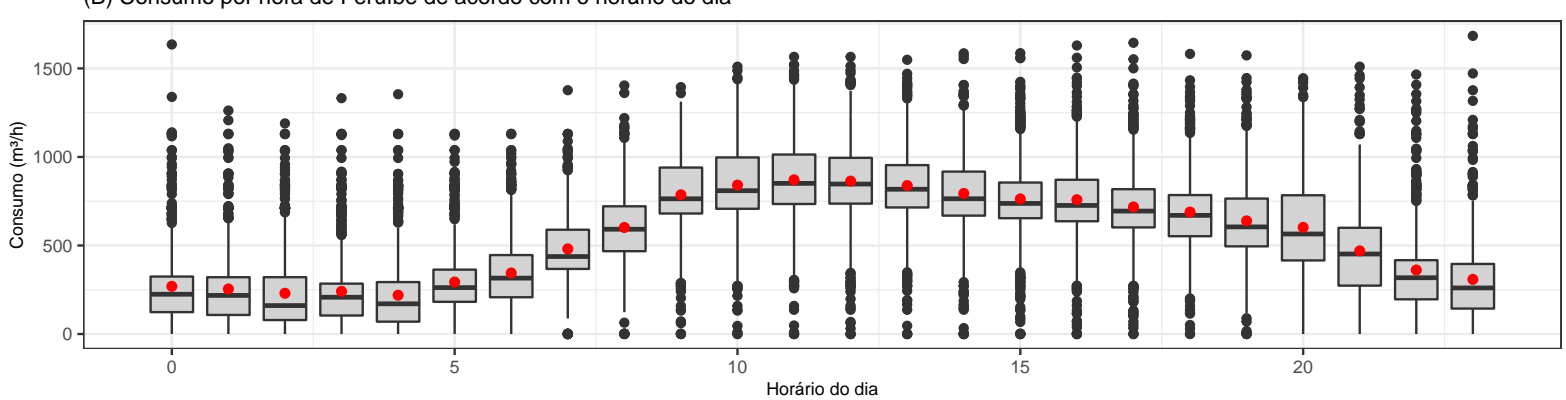

(C) Consumo por hora de Peruíbe de acordo com dia da semana

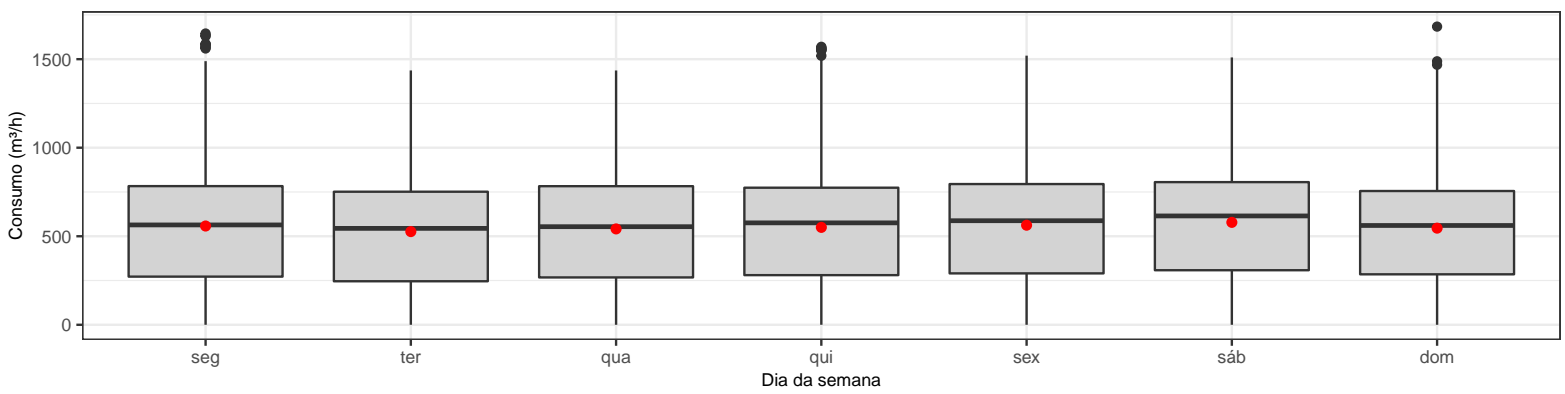

(D) Trecho da série de consumo de Peruíbe

(E) Trecho da série de consumo de Peruíbe De $1^{1}$ a 31 de Julho de 2017
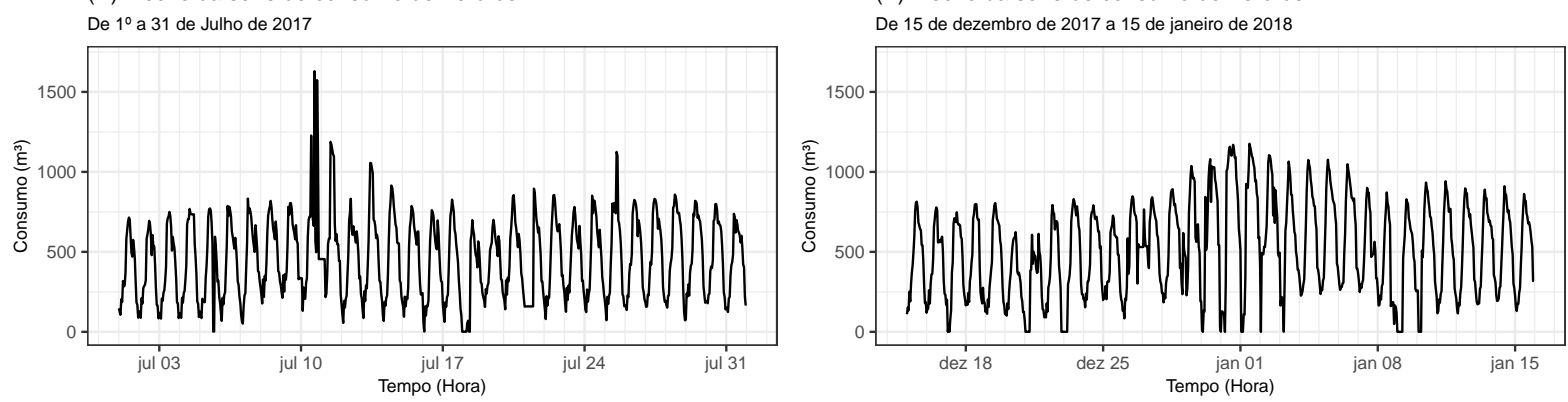

Figura A.2: Painel com alguns gráficos descritivos da série original de consumo demandado do reservatório de Peruíbe. Os gráficos $(A),(B)$ e $(C)$ são boxplots série de consumo em $\mathrm{m}^{3}$ de acordo com mês, horário do dia e dia semana, respectivamente. Os pontos vermelhos são as médias de cada perído. Já os gráficos (D) e (E) são trechos selecionados da série. 
Tabela A.3: Medidas descritivas da série original de vazão de entrada do reservatório de Peru々be. As informações descritivas são apresentadas para a série em sua totalidade e desagregada por periodos mensais, por dias da semana e por horários do dia.

\begin{tabular}{|c|c|c|c|c|c|c|c|c|c|}
\hline Descritiva & Média & Desvio padrão & Mínimo & $1^{\mathrm{O}}$ Quartil & Mediana & $3^{\mathcal{O}}$ Quartil & Máximo & Omissos & Total \\
\hline \multicolumn{10}{|l|}{ Geral } \\
\hline Geral & 194 & 52,37 & 0,0 & 165,0 & 216 & 233 & 350 & 205 & 17519 \\
\hline \multicolumn{10}{|l|}{ Por ano e mês } \\
\hline 2017 jan & 232 & 16,22 & 0,0 & 231,1 & 233 & 235 & 250 & 2 & 743 \\
\hline $2017 \mathrm{fev}$ & 226 & 13,01 & 199,7 & 217,7 & 219 & 232 & 270 & 0 & 673 \\
\hline 2017 mar & 224 & 8,64 & 203,7 & 219,1 & 221 & 234 & 248 & 0 & 744 \\
\hline 2017 abr & 225 & 8,30 & 213,8 & 217,7 & 219 & 233 & 247 & 1 & 720 \\
\hline 2017 mai & 212 & 32,91 & 0,0 & 208,6 & 215 & 226 & 244 & 0 & 744 \\
\hline 2017 jun & 216 & 18,78 & 0,0 & 208,8 & 218 & 223 & 238 & 0 & 720 \\
\hline 2017 jul & 175 & 31,49 & 0,0 & 161,1 & 177 & 190 & 350 & 0 & 744 \\
\hline 2017 ago & 153 & 30,20 & 116,8 & 131,0 & 141 & 166 & 234 & 0 & 744 \\
\hline 2017 set & 113 & 27,87 & 0,0 & 95,3 & 103 & 124 & 220 & 0 & 720 \\
\hline 2017 out & 123 & 49,99 & 0,0 & 80,6 & 108 & 172 & 228 & 4 & 743 \\
\hline 2017 nov & 191 & 37,59 & 0,0 & 162,5 & 209 & 216 & 231 & 0 & 720 \\
\hline 2017 dez & 204 & 35,56 & 0,0 & 195,0 & 208 & 225 & 249 & 0 & 744 \\
\hline 2018 jan & 244 & 5,90 & 234,6 & 240,1 & 242 & 244 & 261 & 0 & 744 \\
\hline 2018 fev & 228 & 14,81 & 197,7 & 215,8 & 229 & 238 & 257 & 1 & 673 \\
\hline 2018 mar & 243 & 7,95 & 231,0 & 235,9 & 239 & 250 & 276 & 0 & 744 \\
\hline 2018 abr & 240 & 12,72 & 191,6 & 235,7 & 239 & 250 & 260 & 0 & 720 \\
\hline 2018 mai & 222 & 45,77 & 0,0 & 223,6 & 232 & 238 & 256 & 0 & 744 \\
\hline 2018 jun & 207 & 18,69 & 165,6 & 191,9 & 204 & 221 & 245 & 0 & 720 \\
\hline 2018 jul & 135 & 32,86 & 0,0 & 109,9 & 126 & 160 & 220 & 1 & 744 \\
\hline 2018 ago & 144 & 40,44 & 0,0 & 116,3 & 141 & 174 & 243 & 1 & 744 \\
\hline 2018 set & 115 & 23,48 & 89,1 & 100,8 & 108 & 119 & 220 & 0 & 720 \\
\hline 2018 out & 203 & 44,09 & 87,8 & 206,2 & 219 & 222 & 255 & 79 & 744 \\
\hline 2018 nov & 218 & 15,27 & 96,3 & 211,7 & 217 & 219 & 251 & 116 & 719 \\
\hline $2018 \mathrm{dez}$ & 178 & 77,45 & 0,0 & 195,0 & 214 & 217 & 250 & 0 & 744 \\
\hline \multicolumn{10}{|c|}{ Por dia da semana } \\
\hline segunda-feira & 195 & 51,70 & 0,0 & 167,5 & 216 & 233 & 260 & 1 & 2520 \\
\hline terça-feira & 194 & 51,82 & 0,0 & 166,0 & 216 & 233 & 261 & 11 & 2496 \\
\hline quarta-feira & 193 & 53,76 & 0,0 & 154,4 & 216 & 233 & 276 & 17 & 2496 \\
\hline quinta-feira & 194 & 53,45 & 0,0 & 166,2 & 217 & 233 & 350 & 27 & 2496 \\
\hline sexta-feira & 195 & 49,70 & 0,0 & 174,8 & 216 & 232 & 350 & 48 & 2496 \\
\hline sábado & 194 & 51,71 & 0,0 & 167,7 & 216 & 232 & 259 & 34 & 2498 \\
\hline domingo & 193 & 54,30 & 0,0 & 162,4 & 215 & 233 & 260 & 67 & 2517 \\
\hline \multicolumn{10}{|c|}{ Por horário do dia } \\
\hline $0: 00$ & 198 & 51,55 & 0,0 & 171,3 & 218 & 234 & 258 & 9 & 727 \\
\hline $1: 00$ & 199 & 51,78 & 0,0 & 172,3 & 218 & 235 & 258 & 9 & 730 \\
\hline $2: 00$ & 200 & 52,26 & 0,0 & 176,2 & 219 & 236 & 350 & 9 & 730 \\
\hline $3: 00$ & 201 & 52,39 & 0,0 & 175,2 & 220 & 236 & 350 & 9 & 730 \\
\hline $4: 00$ & 201 & 52,22 & 0,0 & 173,5 & 222 & 237 & 274 & 8 & 730 \\
\hline $5: 00$ & 200 & 53,24 & 0,0 & 172,2 & 220 & 236 & 276 & 9 & 730 \\
\hline $6: 00$ & 199 & 51,35 & 0,0 & 172,0 & 219 & 235 & 274 & 9 & 730 \\
\hline $7: 00$ & 195 & 50,02 & 0,0 & 165,4 & 216 & 233 & 275 & 8 & 730 \\
\hline $8: 00$ & 194 & 49,98 & 0,0 & 166,7 & 215 & 232 & 275 & 8 & 730 \\
\hline $9: 00$ & 193 & 50,59 & 0,0 & 164,4 & 215 & 231 & 274 & 8 & 730 \\
\hline $10: 00$ & 191 & 51,50 & 0,0 & 160,9 & 214 & 230 & 273 & 8 & 730 \\
\hline $11: 00$ & 190 & 53,53 & 0,0 & 159,5 & 213 & 227 & 270 & 8 & 730 \\
\hline $12: 00$ & 190 & 53,42 & 0,0 & 162,2 & 213 & 228 & 269 & 9 & 730 \\
\hline $13: 00$ & 189 & 53,52 & 0,0 & 160,4 & 213 & 228 & 267 & 8 & 730 \\
\hline $14: 00$ & 189 & 53,89 & 0,0 & 160,8 & 213 & 226 & 269 & 8 & 730 \\
\hline $15: 00$ & 189 & 54,54 & 0,0 & 160,3 & 214 & 227 & 267 & 8 & 730 \\
\hline $16: 00$ & 190 & 53,15 & 0,0 & 161,5 & 214 & 229 & 269 & 8 & 730 \\
\hline $17: 00$ & 191 & 51,81 & 0,0 & 162,2 & 214 & 229 & 267 & 8 & 730 \\
\hline $18: 00$ & 191 & 51,23 & 0,0 & 162,9 & 214 & 229 & 256 & 8 & 730 \\
\hline $19: 00$ & 192 & 51,27 & 0,0 & 163,4 & 214 & 231 & 257 & 8 & 730 \\
\hline $20: 00$ & 193 & 51,71 & 0,0 & 164,3 & 215 & 232 & 256 & 8 & 730 \\
\hline $21: 00$ & 194 & 52,71 & 0,0 & 164,6 & 216 & 233 & 256 & 10 & 730 \\
\hline $22: 00$ & 195 & 53,21 & 0,0 & 164,5 & 216 & 233 & 350 & 10 & 730 \\
\hline $23: 00$ & 196 & 52,51 & 0,0 & 168,8 & 217 & 234 & 260 & 10 & 732 \\
\hline
\end{tabular}


(A) Vazão de entrada do reservatório por hora de acordo com o mês

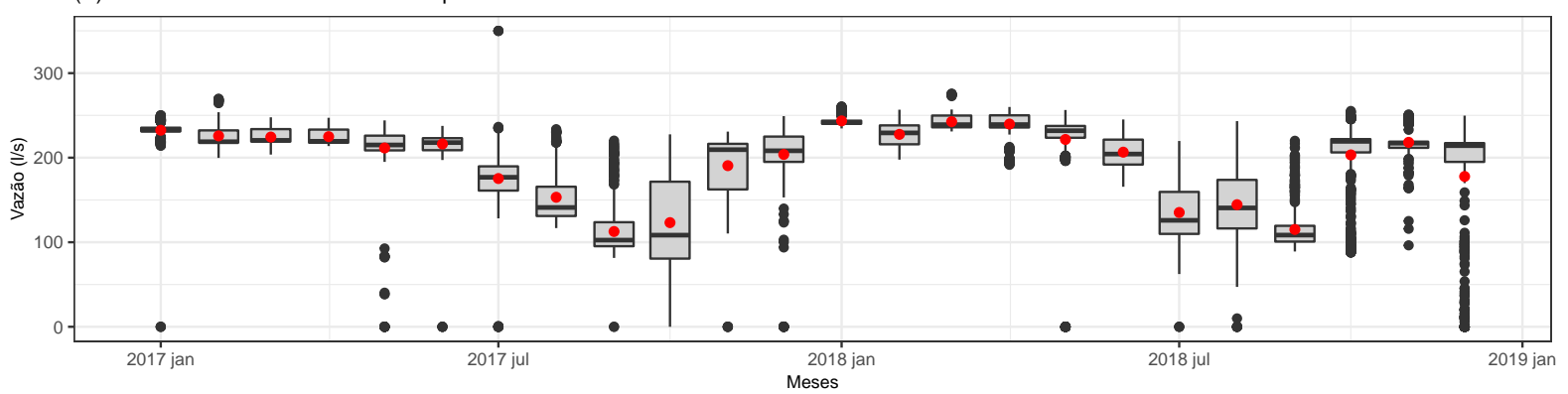

(B) Vazão de entrada do reservatório por hora de acordo com o horário do dia

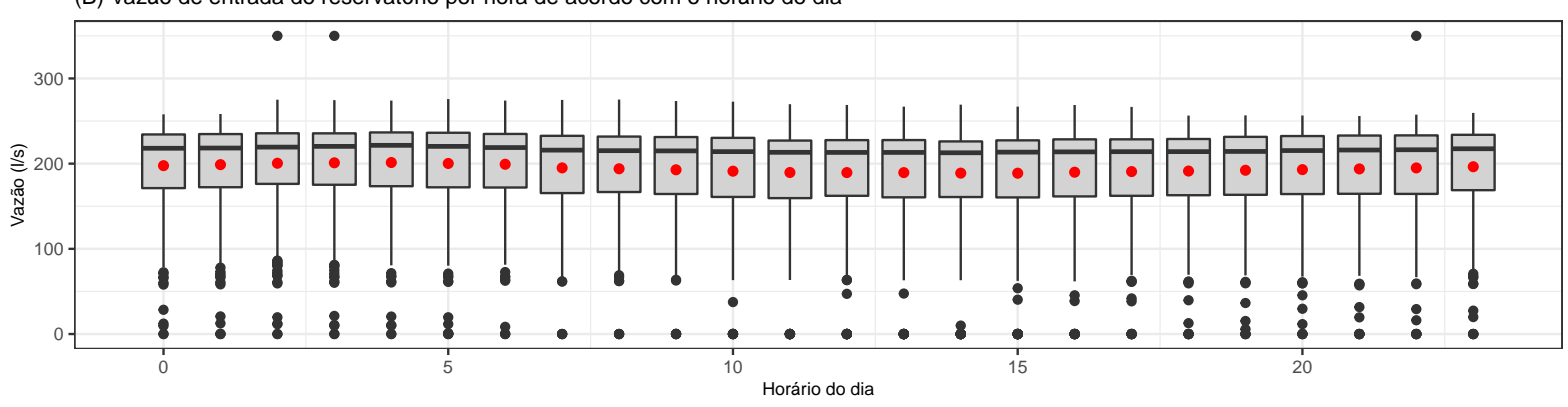

(C) Vazão de entrada do reservatório por hora de acordo com dia da semana

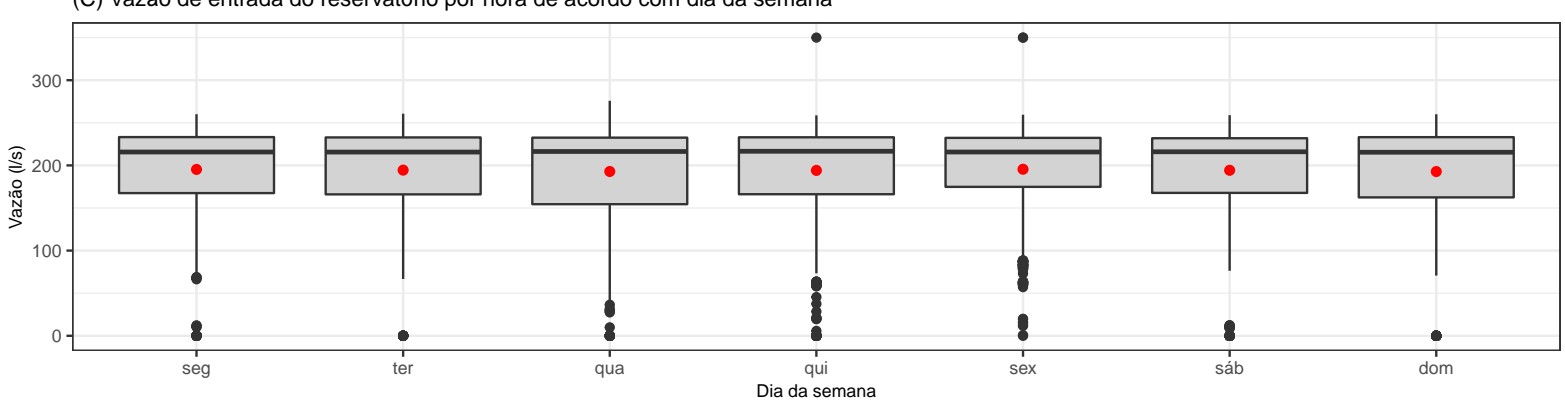

(D) Trecho da série de vazão de entrada De 1 1a 30 de Julho de 2017

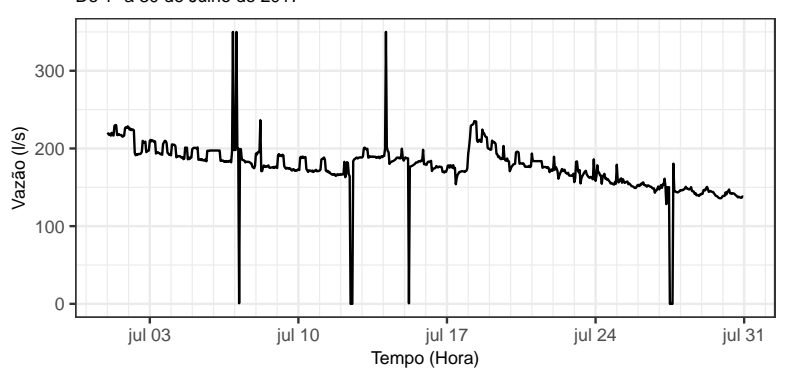

(E) Trecho da série de vazão de entrada De 15 de dezembro de 2017 a 15 de janeiro de 2018

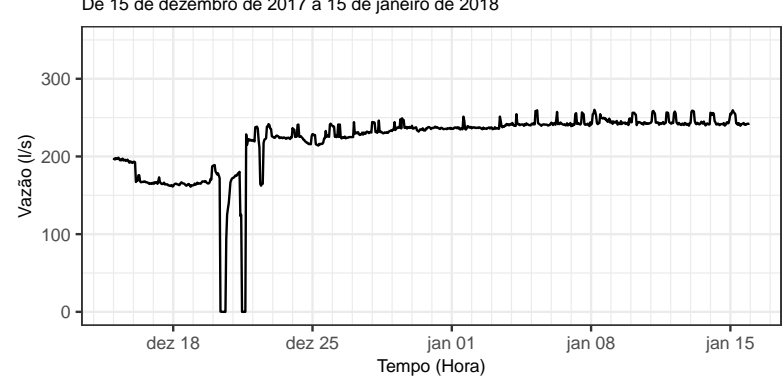

Figura A.3: Painel com alguns gráficos descritivos da série original de vazão de entrada do reservatório de Peruíbe. Os gráficos (A), (B) e (C) são boxplots série de vazão em l/s de acordo com mês, horário do dia e dia semana, respectivamente. Os pontos vermelhos são as médias de cada periodo. Já os gráficos (D) e (E) são trechos selecionados da série. 
Tabela A.4: Medidas descritivas da série original de vazão de saída do reservatório para o Norte de Peruíbe. As informações descritivas são apresentadas para a série em sua totalidade e desagregada por períodos mensais, por dias da semana e por horários do dia.

\begin{tabular}{|c|c|c|c|c|c|c|c|c|c|}
\hline Descritiva & Média & Desvio padrão & Mínimo & $1^{\mathrm{O}}$ Quartil & Mediana & $3^{\mathcal{O}}$ Quartil & Máximo & Omissos & Total \\
\hline \multicolumn{10}{|l|}{ Geral } \\
\hline Geral & 83,1 & 46,7 & 0,00 & 51,14 & 84,3 & 110,3 & 370 & 206 & 17519 \\
\hline \multicolumn{10}{|l|}{ Por ano e mês } \\
\hline 2017 jan & 75,2 & 25,4 & 0,00 & 59,36 & 84,2 & 95,0 & 111 & 2 & 743 \\
\hline $2017 \mathrm{fev}$ & 73,3 & 25,2 & 20,51 & 49,97 & 74,0 & 94,7 & 121 & 0 & 673 \\
\hline 2017 mar & 72,8 & 26,0 & 0,00 & 52,50 & 79,2 & 92,7 & 120 & 0 & 744 \\
\hline 2017 abr & 68,1 & 27,7 & 0,00 & 47,80 & 79,0 & 88,3 & 124 & 1 & 720 \\
\hline 2017 mai & 68,6 & 28,2 & 0,00 & 53,29 & 81,3 & 90,1 & 125 & 0 & 744 \\
\hline 2017 jun & 69,0 & 25,4 & 0,00 & 52,68 & 72,6 & 90,4 & 116 & 0 & 720 \\
\hline 2017 jul & 71,8 & 30,4 & 0,00 & 56,56 & 75,3 & 91,8 & 370 & 0 & 744 \\
\hline 2017 ago & 73,6 & 31,1 & 0,00 & 55,34 & 78,4 & 91,4 & 370 & 0 & 744 \\
\hline 2017 set & 58,2 & 37,0 & 0,00 & 25,10 & 73,3 & 90,0 & 108 & 0 & 720 \\
\hline 2017 out & 52,3 & 37,0 & 0,00 & 17,39 & 63,0 & 86,7 & 119 & 4 & 743 \\
\hline 2017 nov & 69,1 & 26,8 & 0,00 & 47,71 & 78,9 & 91,6 & 106 & 0 & 720 \\
\hline 2017 dez & 64,8 & 27,8 & 0,00 & 42,01 & 71,2 & 86,0 & 117 & 0 & 744 \\
\hline 2018 jan & 68,1 & 42,0 & 0,00 & 34,15 & 66,9 & 87,7 & 194 & 0 & 744 \\
\hline 2018 fev & 109,7 & 54,9 & 0,00 & 61,69 & 122,2 & 153,6 & 229 & 1 & 673 \\
\hline 2018 mar & 119,8 & 43,8 & 0,00 & 94,33 & 127,5 & 155,2 & 237 & 0 & 744 \\
\hline 2018 abr & 115,5 & 40,4 & 0,18 & 84,75 & 117,5 & 143,6 & 236 & 0 & 720 \\
\hline 2018 mai & 116,1 & 43,9 & 0,00 & 85,57 & 131,9 & 147,0 & 180 & 0 & 744 \\
\hline 2018 jun & 111,0 & 40,3 & 0,00 & 82,47 & 118,8 & 137,3 & 227 & 0 & 720 \\
\hline 2018 jul & 120,2 & 39,6 & 0,00 & 116,87 & 129,8 & 129,8 & 207 & 2 & 744 \\
\hline 2018 ago & 90,1 & 52,2 & 0,00 & 44,59 & 95,2 & 135,0 & 188 & 1 & 744 \\
\hline 2018 set & 74,8 & 60,9 & 0,00 & 0,45 & 74,8 & 133,0 & 191 & 0 & 720 \\
\hline 2018 out & 103,2 & 63,3 & 0,00 & 44,82 & 119,2 & 149,0 & 240 & 79 & 744 \\
\hline 2018 nov & 66,8 & 58,1 & 0,00 & 0,36 & 66,7 & 111,3 & 225 & 116 & 719 \\
\hline $2018 \mathrm{dez}$ & 83,2 & 68,7 & 0,00 & 8,34 & 83,1 & 132,8 & 261 & 0 & 744 \\
\hline \multicolumn{10}{|c|}{ Por dia da semana } \\
\hline segunda-feira & 84,2 & 48,0 & 0,00 & 52,09 & 84,4 & 113,6 & 370 & 1 & 2520 \\
\hline terça-feira & 80,3 & 45,9 & 0,00 & 47,26 & 82,4 & 105,6 & 237 & 11 & 2496 \\
\hline quarta-feira & 81,8 & 46,1 & 0,00 & 49,99 & 83,1 & 108,9 & 231 & 18 & 2496 \\
\hline quinta-feira & 84,7 & 47,6 & 0,00 & 53,40 & 85,6 & 115,8 & 370 & 27 & 2496 \\
\hline sexta-feira & 83,4 & 47,5 & 0,00 & 49,60 & 84,5 & 111,5 & 277 & 48 & 2496 \\
\hline sábado & 85,5 & 46,4 & 0,00 & 54,66 & 86,6 & 114,3 & 261 & 34 & 2498 \\
\hline domingo & 81,9 & 45,2 & 0,00 & 50,62 & 83,2 & 105,0 & 241 & 67 & 2517 \\
\hline \multicolumn{10}{|c|}{ Por horário do dia } \\
\hline $0: 00$ & 45,9 & 37,1 & 0,00 & 24,60 & 35,1 & 66,2 & 239 & 9 & 727 \\
\hline $1: 00$ & 44,3 & 38,5 & 0,00 & 19,34 & 32,3 & 72,2 & 239 & 9 & 730 \\
\hline $2: 00$ & 41,4 & 38,9 & 0,00 & 15,27 & 29,8 & 60,6 & 237 & 9 & 730 \\
\hline $3: 00$ & 46,0 & 38,1 & 0,00 & 22,86 & 43,4 & 61,6 & 370 & 9 & 730 \\
\hline $4: 00$ & 41,7 & 38,4 & 0,00 & 11,52 & 37,0 & 57,6 & 370 & 8 & 730 \\
\hline $5: 00$ & 54,2 & 36,5 & 0,00 & 34,15 & 55,4 & 74,1 & 277 & 9 & 730 \\
\hline $6: 00$ & 63,9 & 33,2 & 0,00 & 46,35 & 68,7 & 80,5 & 218 & 9 & 730 \\
\hline $7: 00$ & 77,5 & 29,0 & 0,00 & 70,77 & 78,5 & 91,4 & 225 & 8 & 730 \\
\hline $8: 00$ & 95,4 & 30,3 & 0,00 & 81,59 & 88,0 & 118,7 & 236 & 8 & 730 \\
\hline $9: 00$ & 108,7 & 35,6 & 0,00 & 90,72 & 97,7 & 139,5 & 228 & 8 & 730 \\
\hline $10: 00$ & 115,8 & 37,6 & 0,00 & 93,34 & 99,8 & 150,4 & 229 & 9 & 730 \\
\hline $11: 00$ & 116,0 & 39,0 & 0,00 & 90,72 & 100,6 & 153,8 & 229 & 8 & 730 \\
\hline $12: 00$ & 117,4 & 37,2 & 0,00 & 95,68 & 103,2 & 152,8 & 229 & 9 & 730 \\
\hline $13: 00$ & 114,7 & 35,8 & 0,00 & 93,36 & 101,1 & 147,2 & 225 & 8 & 730 \\
\hline $14: 00$ & 113,1 & 35,7 & 0,00 & 94,26 & 101,7 & 142,1 & 238 & 8 & 730 \\
\hline $15: 00$ & 104,9 & 33,6 & 0,00 & 87,76 & 95,6 & 129,7 & 240 & 8 & 730 \\
\hline $16: 00$ & 103,0 & 37,9 & 0,00 & 82,24 & 91,3 & 132,6 & 370 & 8 & 730 \\
\hline $17: 00$ & 96,4 & 36,4 & 0,00 & 74,66 & 86,4 & 122,4 & 244 & 8 & 730 \\
\hline $18: 00$ & 99,7 & 34,9 & 0,00 & 82,63 & 90,1 & 125,9 & 251 & 8 & 730 \\
\hline $19: 00$ & 96,5 & 42,1 & 0,00 & 69,23 & 84,8 & 124,7 & 370 & 8 & 730 \\
\hline $20: 00$ & 99,6 & 49,0 & 0,00 & 70,97 & 83,0 & 132,7 & 370 & 8 & 730 \\
\hline $21: 00$ & 83,1 & 44,6 & 0,00 & 55,52 & 75,5 & 114,7 & 240 & 10 & 730 \\
\hline $22: 00$ & 63,2 & 40,7 & 0,00 & 40,23 & 54,5 & 87,5 & 232 & 10 & 730 \\
\hline $23: 00$ & 52,6 & 41,7 & 0,00 & 25,05 & 41,1 & 74,2 & 237 & 10 & 732 \\
\hline
\end{tabular}


(A) Vazão de saída por hora para o Norte de Peruíbe de acordo com o mês

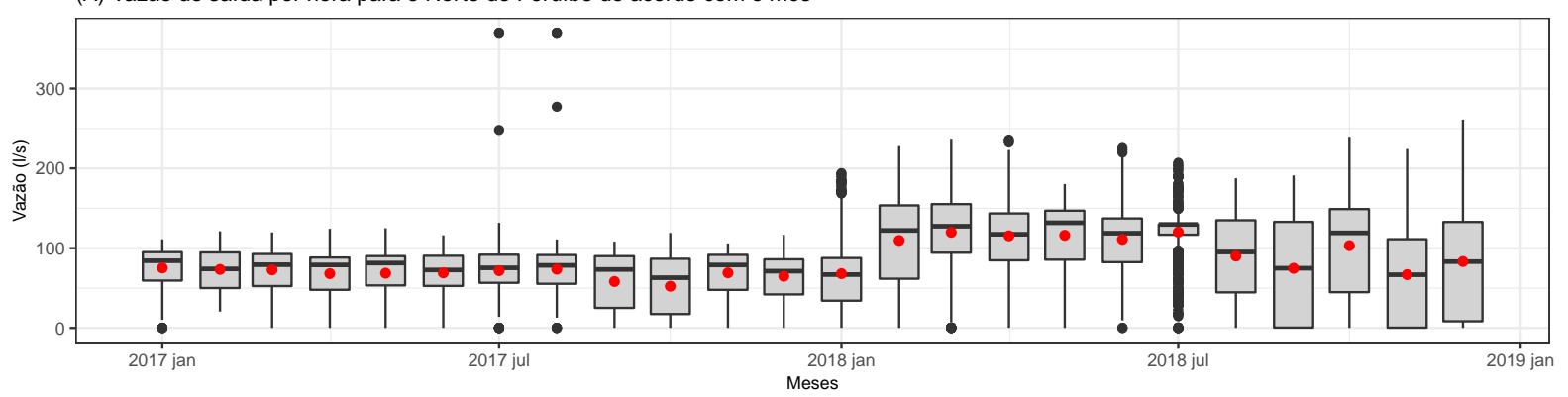

(B) Vazão de saída por hora para o Norte de Peruíbe de acordo com o horário do dia

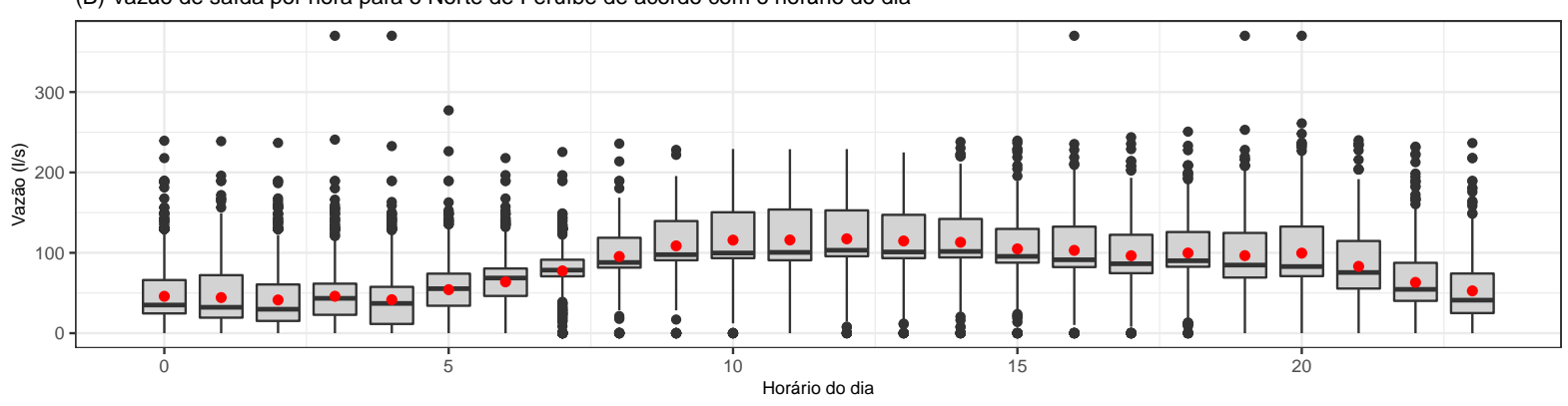

(C) Vazão de saída por hora para o Norte de Peruíbe de acordo com dia da semana

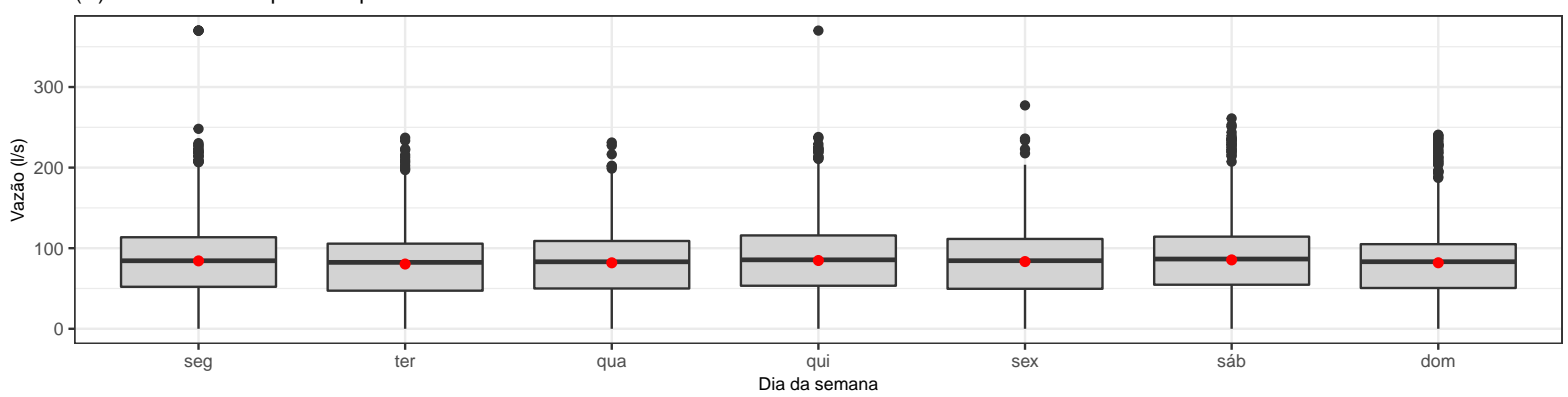

(D) Trecho da série de vazão de saída para o Norte de Peruíbe De $1^{\circ}$ a 31 de Julho de 2017

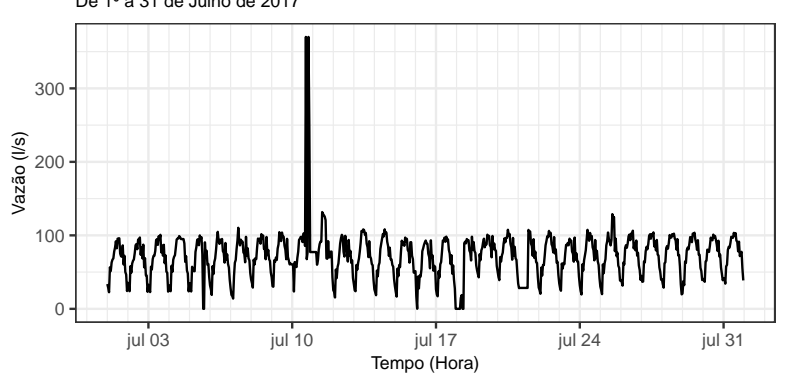

(E) Trecho da série de vazão de saída para o Norte de Peruíbe De 15 de dezembro de 2017 a 15 de janeiro de 2018

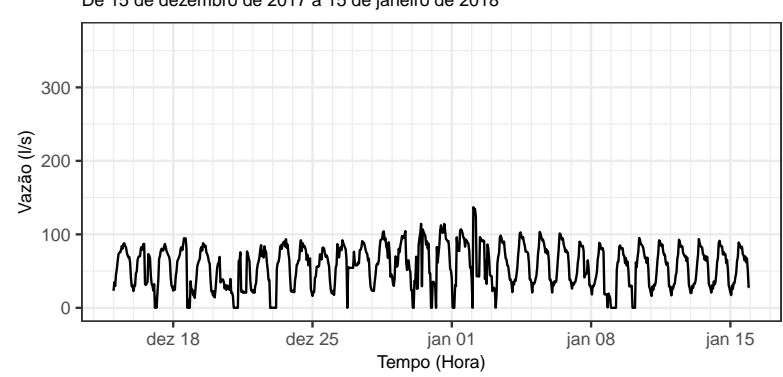

Figura A.4: Painel com alguns gráficos descritivos da série original de vazão de saída do reservatório para o Norte de Peruíbe. Os gráficos (A), (B) e (C) são boxplots série de vazão em l/s de acordo com mês, horário do dia e dia semana, respectivamente. Os pontos vermelhos são as médias de cada periodo. Já os gráficos (D) e (E) são trechos selecionados da série. 
Tabela A.5: Medidas descritivas da série original de vazão de saída do reservatório para o Sul de Peruíbe. As informações descritivas são apresentadas para a série em sua totalidade e desagregada por períodos mensais, por dias da semana e por horários do dia.

\begin{tabular}{|c|c|c|c|c|c|c|c|c|c|}
\hline Descritiva & Média & Desvio padrão & Mínimo & $1^{\mathrm{O}}$ Quartil & Mediana & $3^{\mathcal{O}}$ Quartil & Máximo & Omissos & Total \\
\hline \multicolumn{10}{|l|}{ Geral } \\
\hline Geral & 70,1 & 59,5 & 0 & 13,72 & 67,95 & 107,2 & 250 & 207 & 17519 \\
\hline \multicolumn{10}{|l|}{ Por ano e mês } \\
\hline 2017 jan & 109,8 & 60,8 & 0 & 63,98 & 107,26 & 144,3 & 250 & 2 & 743 \\
\hline $2017 \mathrm{fev}$ & 89,8 & 56,9 & 0 & 35,65 & 86,69 & 135,2 & 222 & 0 & 673 \\
\hline 2017 mar & 61,4 & 52,5 & 0 & 0,90 & 62,58 & 103,2 & 193 & 0 & 744 \\
\hline 2017 abr & 50,0 & 47,8 & 0 & 0,55 & 35,96 & 92,3 & 186 & 1 & 720 \\
\hline 2017 mai & 42,6 & 41,3 & 0 & 0,55 & 28,05 & 82,9 & 173 & 0 & 744 \\
\hline 2017 jun & 48,0 & 45,8 & 0 & 0,49 & 42,55 & 87,6 & 232 & 0 & 720 \\
\hline 2017 jul & 55,5 & 46,4 & 0 & 13,02 & 49,08 & 92,3 & 250 & 0 & 744 \\
\hline 2017 ago & 82,9 & 64,7 & 0 & 33,07 & 77,99 & 118,5 & 250 & 0 & 744 \\
\hline 2017 set & 116,4 & 86,8 & 0 & 29,85 & 121,46 & 186,2 & 250 & 0 & 720 \\
\hline 2017 out & 49,7 & 44,9 & 0 & 2,66 & 37,82 & 89,2 & 164 & 5 & 743 \\
\hline 2017 nov & 53,6 & 42,0 & 0 & 14,62 & 47,37 & 92,2 & 146 & 0 & 720 \\
\hline 2017 dez & 69,1 & 51,2 & 0 & 23,53 & 66,15 & 109,4 & 218 & 0 & 744 \\
\hline 2018 jan & 89,6 & 54,2 & 0 & 41,74 & 91,12 & 132,5 & 220 & 0 & 744 \\
\hline 2018 fev & 79,4 & 54,5 & 0 & 31,52 & 81,78 & 119,3 & 243 & 1 & 673 \\
\hline 2018 mar & 62,8 & 49,3 & 0 & 1,53 & 71,28 & 105,8 & 176 & 0 & 744 \\
\hline 2018 abr & 68,9 & 64,2 & 0 & 0,00 & 68,04 & 108,2 & 239 & 0 & 720 \\
\hline 2018 mai & 48,0 & 45,5 & 0 & 0,00 & 47,59 & 92,7 & 164 & 0 & 744 \\
\hline 2018 jun & 38,3 & 38,7 & 0 & 0,00 & 32,20 & 73,6 & 145 & 0 & 720 \\
\hline 2018 jul & 57,1 & 30,9 & 0 & 43,41 & 67,95 & 68,0 & 163 & 2 & 744 \\
\hline 2018 ago & 49,6 & 40,3 & 0 & 0,00 & 47,19 & 86,0 & 132 & 1 & 744 \\
\hline 2018 set & 45,4 & 43,5 & 0 & 0,00 & 46,21 & 81,4 & 160 & 0 & 720 \\
\hline 2018 out & 65,9 & 57,9 & 0 & 0,00 & 66,36 & 99,8 & 212 & 79 & 744 \\
\hline 2018 nov & 127,3 & 64,0 & 0 & 76,95 & 144,96 & 177,2 & 246 & 116 & 719 \\
\hline $2018 \mathrm{dez}$ & 131,9 & 68,3 & 0 & 76,98 & 146,21 & 184,8 & 250 & 0 & 744 \\
\hline \multicolumn{10}{|c|}{ Por dia da semana } \\
\hline segunda-feira & 70,7 & 59,8 & 0 & 16,36 & 67,95 & 105,9 & 250 & 1 & 2520 \\
\hline terça-feira & 65,8 & 57,2 & 0 & 6,47 & 65,81 & 102,5 & 250 & 11 & 2496 \\
\hline quarta-feira & 68,5 & 59,7 & 0 & 7,81 & 67,70 & 105,2 & 250 & 19 & 2496 \\
\hline quinta-feira & 68,1 & 58,9 & 0 & 10,01 & 67,95 & 105,0 & 250 & 27 & 2496 \\
\hline sexta-feira & 72,8 & 60,2 & 0 & 14,59 & 67,95 & 113,7 & 250 & 48 & 2496 \\
\hline sábado & 75,2 & 61,1 & 0 & 20,19 & 69,57 & 112,4 & 250 & 34 & 2498 \\
\hline domingo & 69,7 & 59,5 & 0 & 18,13 & 67,34 & 106,0 & 250 & 67 & 2517 \\
\hline \multicolumn{10}{|c|}{ Por horário do dia } \\
\hline 0:00 & 28,9 & 43,5 & 0 & 0,00 & 3,27 & 48,6 & 247 & 9 & 727 \\
\hline $1: 00$ & 26,3 & 40,8 & 0 & 0,00 & 3,60 & 41,6 & 246 & 9 & 730 \\
\hline $2: 00$ & 22,6 & 38,7 & 0 & 0,00 & 0,55 & 32,5 & 236 & 9 & 730 \\
\hline $3: 00$ & 20,9 & 36,9 & 0 & 0,00 & 0,49 & 27,3 & 229 & 9 & 730 \\
\hline $4: 00$ & 19,2 & 36,0 & 0 & 0,00 & 0,37 & 27,5 & 229 & 8 & 730 \\
\hline $5: 00$ & 27,3 & 37,3 & 0 & 0,00 & 17,28 & 40,0 & 229 & 9 & 730 \\
\hline $6: 00$ & 31,9 & 38,6 & 0 & 0,31 & 20,76 & 49,8 & 229 & 9 & 730 \\
\hline $7: 00$ & 56,1 & 40,2 & 0 & 28,48 & 51,43 & 74,3 & 229 & 8 & 730 \\
\hline $8: 00$ & 71,8 & 42,5 & 0 & 44,22 & 67,83 & 91,7 & 239 & 8 & 730 \\
\hline $9: 00$ & 109,7 & 43,5 & 0 & 89,21 & 106,50 & 126,2 & 250 & 8 & 730 \\
\hline 10:00 & 117,8 & 45,8 & 0 & 93,41 & 113,00 & 134,0 & 250 & 9 & 730 \\
\hline $11: 00$ & 125,9 & 49,9 & 0 & 98,55 & 120,27 & 152,5 & 250 & 8 & 730 \\
\hline $12: 00$ & 122,4 & 50,7 & 0 & 93,73 & 114,44 & 152,2 & 250 & 10 & 730 \\
\hline $13: 00$ & 118,2 & 49,5 & 0 & 88,95 & 108,85 & 145,6 & 250 & 8 & 730 \\
\hline $14: 00$ & 107,4 & 48,6 & 0 & 80,05 & 96,00 & 126,1 & 250 & 8 & 730 \\
\hline $15: 00$ & 107,1 & 47,9 & 0 & 80,77 & 96,89 & 126,8 & 250 & 8 & 730 \\
\hline $16: 00$ & 107,6 & 45,5 & 0 & 83,91 & 99,73 & 123,3 & 250 & 8 & 730 \\
\hline $17: 00$ & 103,0 & 47,3 & 0 & 71,76 & 98,14 & 120,5 & 250 & 8 & 730 \\
\hline $18: 00$ & 91,6 & 48,2 & 0 & 63,63 & 78,21 & 108,1 & 250 & 8 & 730 \\
\hline $19: 00$ & 81,0 & 52,8 & 0 & 44,81 & 67,95 & 101,2 & 250 & 8 & 730 \\
\hline $20: 00$ & 67,7 & 51,0 & 0 & 32,57 & 58,09 & 84,1 & 250 & 8 & 730 \\
\hline $21: 00$ & 47,2 & 53,3 & 0 & 4,15 & 26,01 & 72,9 & 249 & 10 & 730 \\
\hline $22: 00$ & 37,3 & 51,3 & 0 & 0,00 & 11,26 & 60,3 & 250 & 10 & 730 \\
\hline $23: 00$ & 33,1 & 48,5 & 0 & 0,00 & 8,21 & 50,5 & 250 & 10 & 732 \\
\hline
\end{tabular}


(A) Vazão de saída por hora para o Sul de Peruíbe de acordo com o mês

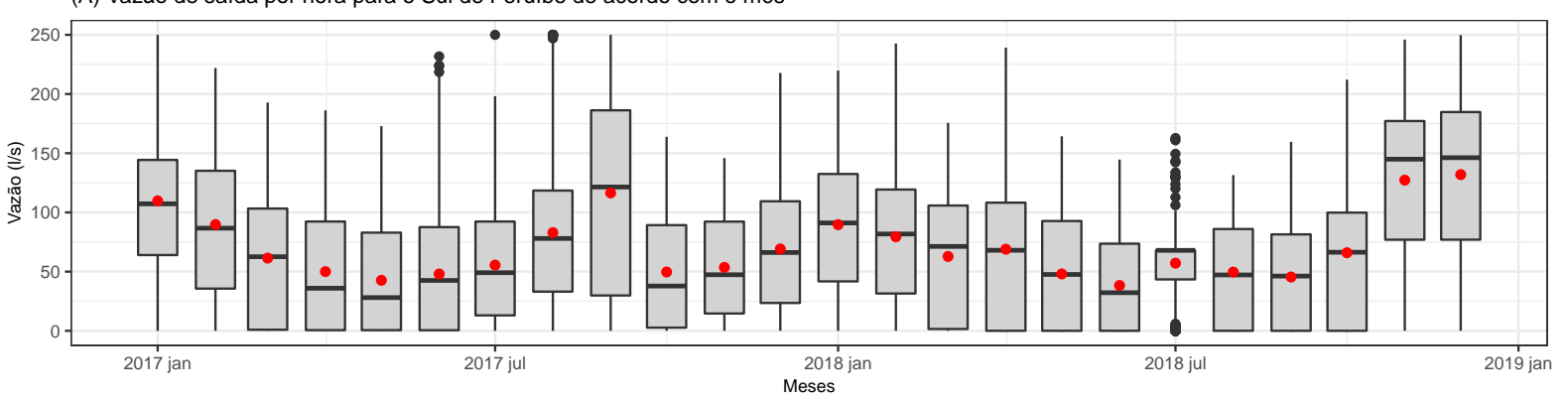

(B) Vazão de saída por hora para o Sul de Peruíbe de acordo com o horário do dia

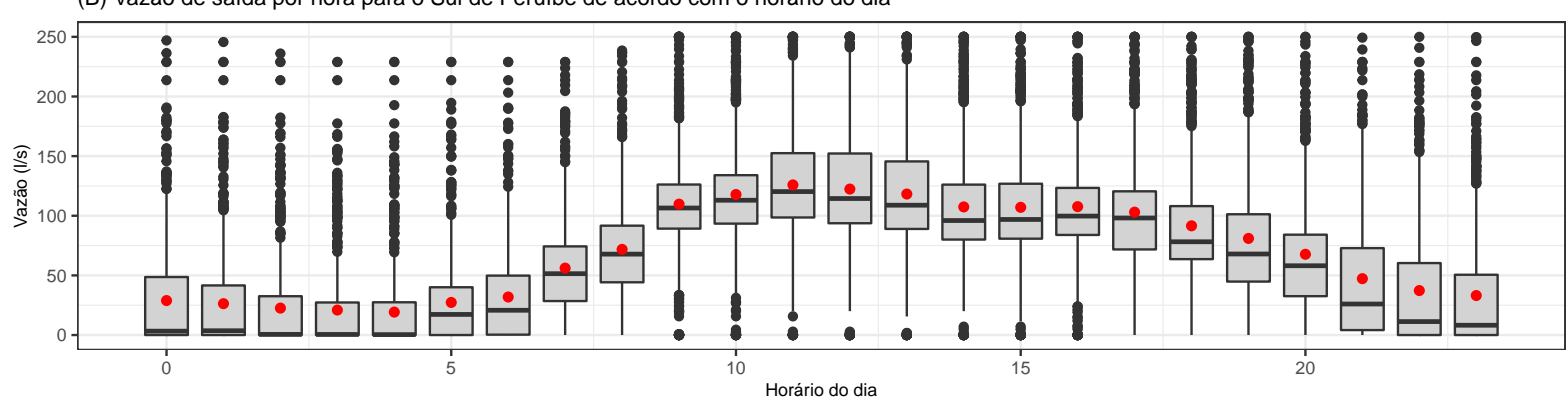

(C) Vazão de saída por hora para o Sul de Peruíbe de acordo com dia da semana

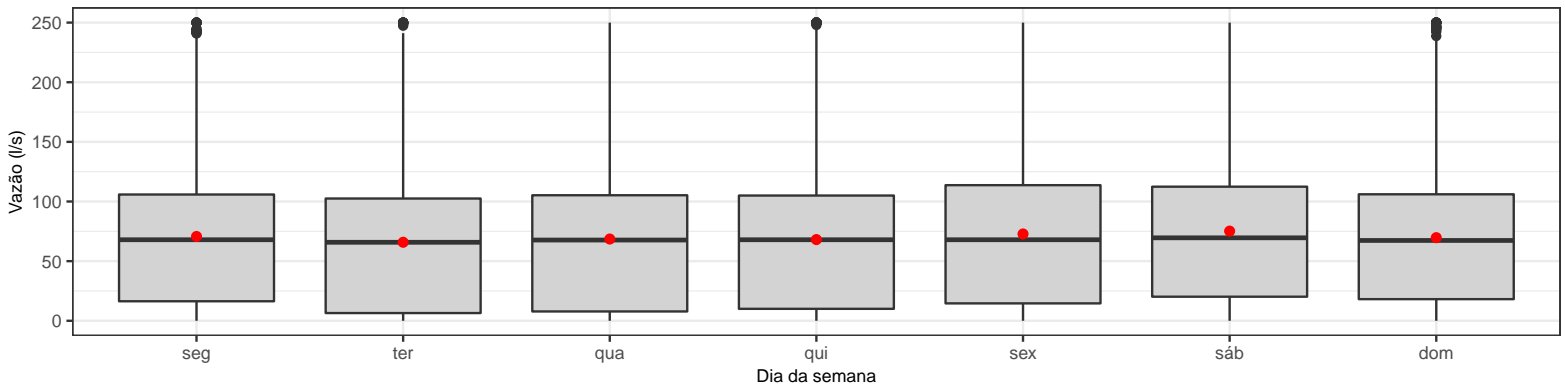

(D) Trecho da série de vazão de saída para o Sul de Peruíbe De $1^{\circ}$ a 31 de Julho de 2017

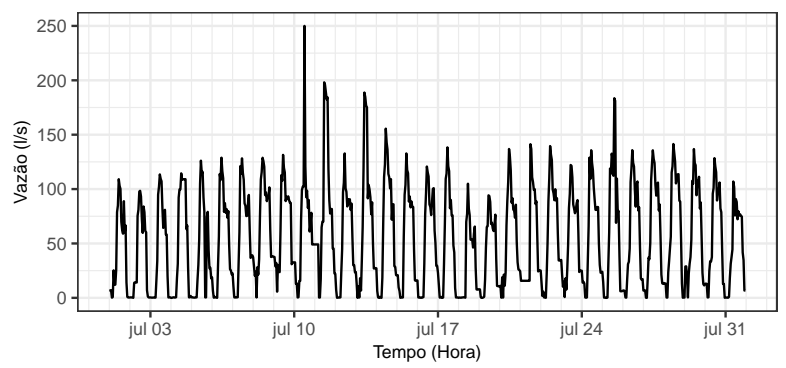

(E) Trecho da série de vazão de saída para o Sul de Peruíbe De 15 de dezembro de 2017 a 15 de janeiro de 2018

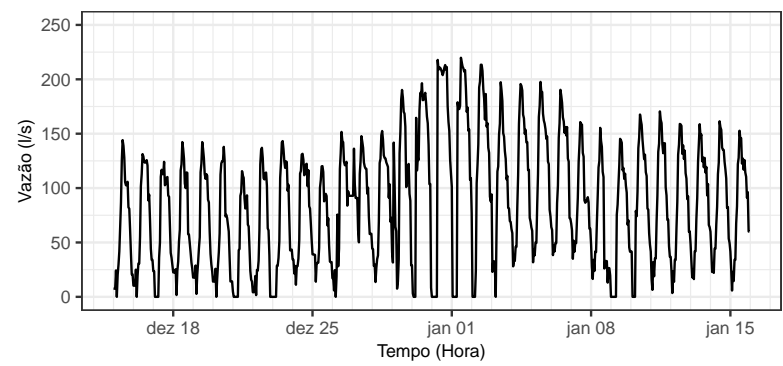

Figura A.5: Painel com alguns gráficos descritivos da série original de vazão de saída do reservatório para o Sul de Peruíbe. Os gráficos (A), (B) e (C) são boxplots série de vazão em l/s de acordo com mês, horário do dia e dia semana, respectivamente. Os pontos vermelhos são as médias de cada período. Já os gráficos (D) e (E) são trechos selecionados da série. 
Tabela A.6: Medidas descritivas da série original de pressão a montante ao Norte de Peruibe. As informações descritivas são apresentadas para a série em sua totalidade e desagregada por períodos mensais, por dias da semana e por horários do dia.

\begin{tabular}{|c|c|c|c|c|c|c|c|c|c|}
\hline Descritiva & Média & Desvio padrão & Mínimo & $1^{\mathrm{O}}$ Quartil & Mediana & $3^{\mathcal{O}}$ Quartil & Máximo & Omissos & Total \\
\hline \multicolumn{10}{|l|}{ Geral } \\
\hline Geral & 41,7 & 5,47 & 0,00 & 39,2 & 42,5 & 45,5 & 100,0 & 206 & 17519 \\
\hline \multicolumn{10}{|l|}{ Por ano e mês } \\
\hline 2017 jan & 35,6 & 6,46 & 0,00 & 32,1 & 34,3 & 40,6 & 50,4 & 2 & 743 \\
\hline $2017 \mathrm{fev}$ & 38,8 & 5,28 & 26,84 & 34,8 & 39,7 & 43,8 & 47,1 & 0 & 673 \\
\hline 2017 mar & 39,3 & 5,11 & 26,32 & 35,8 & 39,4 & 43,7 & 55,0 & 0 & 744 \\
\hline 2017 abr & 40,5 & 4,18 & 27,37 & 37,5 & 39,6 & 44,5 & 56,9 & 1 & 720 \\
\hline 2017 mai & 40,7 & 3,97 & 27,50 & 37,7 & 39,8 & 44,5 & 48,1 & 0 & 744 \\
\hline 2017 jun & 40,8 & 5,20 & 0,00 & 38,1 & 41,5 & 44,2 & 49,2 & 0 & 720 \\
\hline 2017 jul & 42,6 & 3,62 & 31,38 & 40,3 & 42,6 & 45,0 & 100,0 & 0 & 744 \\
\hline 2017 ago & 42,3 & 3,49 & 35,34 & 39,9 & 42,2 & 44,6 & 100,0 & 0 & 744 \\
\hline 2017 set & 41,6 & 3,21 & 35,02 & 38,5 & 41,9 & 44,6 & 47,6 & 0 & 720 \\
\hline 2017 out & 42,4 & 3,10 & 32,99 & 39,9 & 42,8 & 44,7 & 47,9 & 4 & 743 \\
\hline 2017 nov & 42,6 & 3,38 & 34,46 & 39,7 & 42,2 & 45,7 & 53,8 & 0 & 720 \\
\hline 2017 dez & 41,6 & 4,18 & 4,49 & 38,9 & 41,8 & 44,6 & 55,1 & 0 & 744 \\
\hline 2018 jan & 41,6 & 6,87 & 0,61 & 38,9 & 42,3 & 46,1 & 51,2 & 0 & 744 \\
\hline 2018 fev & 42,6 & 5,19 & 2,30 & 40,2 & 43,0 & 46,2 & 49,8 & 1 & 673 \\
\hline 2018 mar & 42,9 & 3,13 & 32,48 & 40,4 & 43,0 & 45,6 & 51,0 & 0 & 744 \\
\hline 2018 abr & 43,0 & 3,06 & 31,60 & 40,6 & 42,7 & 45,5 & 48,7 & 0 & 720 \\
\hline 2018 mai & 42,5 & 8,96 & 0,00 & 41,8 & 43,7 & 47,0 & 58,0 & 0 & 744 \\
\hline 2018 jun & 46,1 & 2,68 & 34,75 & 44,5 & 46,0 & 48,4 & 50,5 & 0 & 720 \\
\hline 2018 jul & 44,6 & 4,06 & 0,00 & 44,9 & 45,5 & 45,5 & 50,3 & 2 & 744 \\
\hline 2018 ago & 41,7 & 9,72 & 4,79 & 41,9 & 44,2 & 46,8 & 48,8 & 1 & 744 \\
\hline 2018 set & 42,2 & 3,47 & 4,57 & 40,2 & 42,5 & 44,3 & 48,4 & 0 & 720 \\
\hline 2018 out & 41,5 & 6,05 & 0,00 & 39,5 & 42,2 & 45,6 & 53,8 & 79 & 744 \\
\hline 2018 nov & 42,9 & 4,40 & 29,89 & 39,8 & 43,5 & 46,6 & 57,4 & 116 & 719 \\
\hline $2018 \mathrm{dez}$ & 40,9 & 5,92 & 7,33 & 38,2 & 42,2 & 45,3 & 48,7 & 0 & 744 \\
\hline \multicolumn{10}{|c|}{ Por dia da semana } \\
\hline segunda-feira & 41,6 & 5,35 & 9,60 & 39,1 & 42,2 & 45,5 & 100,0 & 1 & 2520 \\
\hline terça-feira & 41,6 & 6,59 & 0,00 & 39,3 & 42,5 & 45,5 & 100,0 & 11 & 2496 \\
\hline quarta-feira & 41,9 & 5,12 & 4,57 & 39,3 & 42,6 & 45,5 & 57,4 & 18 & 2496 \\
\hline quinta-feira & 41,7 & 5,28 & 0,00 & 39,1 & 42,5 & 45,4 & 55,0 & 27 & 2496 \\
\hline sexta-feira & 41,9 & 4,53 & 0,00 & 39,0 & 42,6 & 45,5 & 53,8 & 48 & 2496 \\
\hline sábado & 41,7 & 5,27 & 0,00 & 39,2 & 42,6 & 45,4 & 53,8 & 34 & 2498 \\
\hline domingo & 41,7 & 5,93 & 0,00 & 39,5 & 42,6 & 45,5 & 54,0 & 67 & 2517 \\
\hline \multicolumn{10}{|c|}{ Por horário do dia } \\
\hline $0: 00$ & 45,2 & 3,84 & 0,00 & 44,4 & 45,9 & 46,9 & 53,8 & 9 & 727 \\
\hline $1: 00$ & 45,4 & 3,75 & 0,00 & 44,6 & 46,1 & 47,2 & 52,9 & 9 & 730 \\
\hline $2: 00$ & 45,6 & 4,09 & 0,00 & 45,0 & 46,2 & 47,2 & 56,9 & 9 & 730 \\
\hline $3: 00$ & 45,4 & 3,95 & 0,00 & 44,7 & 45,7 & 47,0 & 51,2 & 9 & 730 \\
\hline $4: 00$ & 45,4 & 4,03 & 0,00 & 44,7 & 45,8 & 47,1 & 52,6 & 8 & 730 \\
\hline $5: 00$ & 44,8 & 4,05 & 0,00 & 43,5 & 45,1 & 47,0 & 50,6 & 9 & 730 \\
\hline $6: 00$ & 44,3 & 4,16 & 0,00 & 42,8 & 44,8 & 46,6 & 50,4 & 9 & 730 \\
\hline $7: 00$ & 43,0 & 4,51 & 0,00 & 41,5 & 43,4 & 45,5 & 50,5 & 8 & 730 \\
\hline $8: 00$ & 41,5 & 4,62 & 0,00 & 40,1 & 42,0 & 43,7 & 50,6 & 8 & 730 \\
\hline $9: 00$ & 39,4 & 4,91 & 0,00 & 37,6 & 39,7 & 41,8 & 50,1 & 8 & 730 \\
\hline $10: 00$ & 38,4 & 5,22 & 0,00 & 36,3 & 39,0 & 40,9 & 49,6 & 9 & 730 \\
\hline $11: 00$ & 38,0 & 5,42 & 0,00 & 36,1 & 38,6 & 40,6 & 48,0 & 8 & 730 \\
\hline $12: 00$ & 37,6 & 5,85 & 0,00 & 36,0 & 38,2 & 40,2 & 47,5 & 9 & 730 \\
\hline $13: 00$ & 38,0 & 5,37 & 0,00 & 36,4 & 38,4 & 40,8 & 49,9 & 8 & 730 \\
\hline $14: 00$ & 38,3 & 5,94 & 0,00 & 36,7 & 38,7 & 41,1 & 100,0 & 8 & 730 \\
\hline $15: 00$ & 39,0 & 5,47 & 0,00 & 37,1 & 39,7 & 42,3 & 50,3 & 8 & 730 \\
\hline $16: 00$ & 39,7 & 5,10 & 0,00 & 38,1 & 40,0 & 42,1 & 100,0 & 8 & 730 \\
\hline $17: 00$ & 40,1 & 4,95 & 0,00 & 38,7 & 40,7 & 42,9 & 50,2 & 8 & 730 \\
\hline $18: 00$ & 40,1 & 4,39 & 0,00 & 38,4 & 40,6 & 42,7 & 58,0 & 8 & 730 \\
\hline $19: 00$ & 40,8 & 4,37 & 0,00 & 39,5 & 41,6 & 43,1 & 56,8 & 8 & 730 \\
\hline $20: 00$ & 40,8 & 4,18 & 0,00 & 39,7 & 41,5 & 43,0 & 52,4 & 8 & 730 \\
\hline $21: 00$ & 42,1 & 4,62 & 0,00 & 41,1 & 43,1 & 44,6 & 53,8 & 10 & 730 \\
\hline $22: 00$ & 43,8 & 4,55 & 0,00 & 43,0 & 44,6 & 45,9 & 57,4 & 10 & 730 \\
\hline $23: 00$ & 44,6 & 4,26 & 0,00 & 44,0 & 45,4 & 46,5 & 49,2 & 10 & 732 \\
\hline
\end{tabular}


(A) Pressão a montante a cada hora no Norte de Peruíbe de acordo com o mês

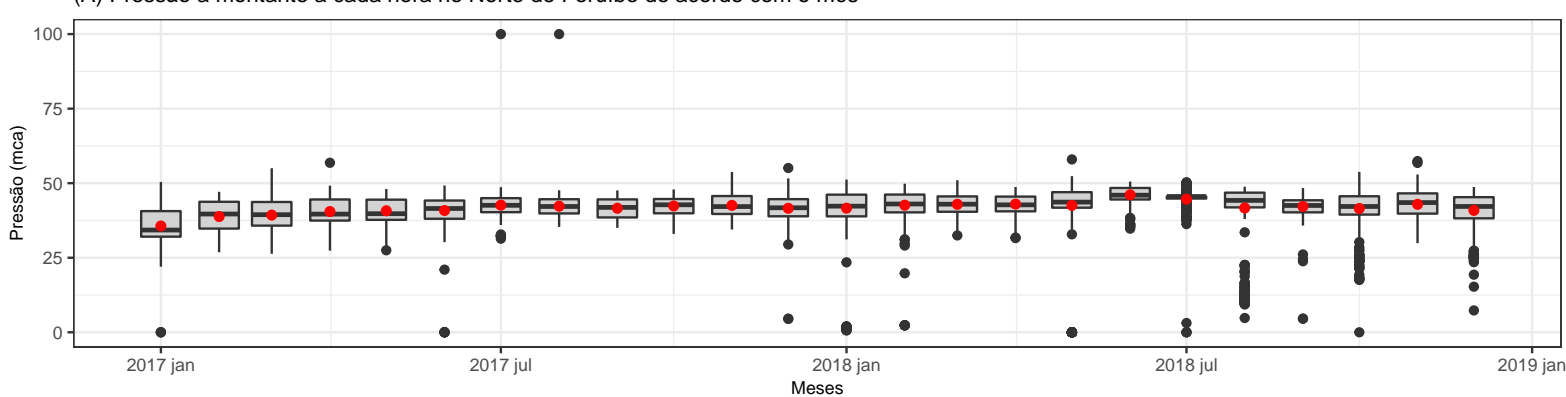

(B) Pressão a montante a cada hora no Norte de Peruíbe de acordo com o horário do dia

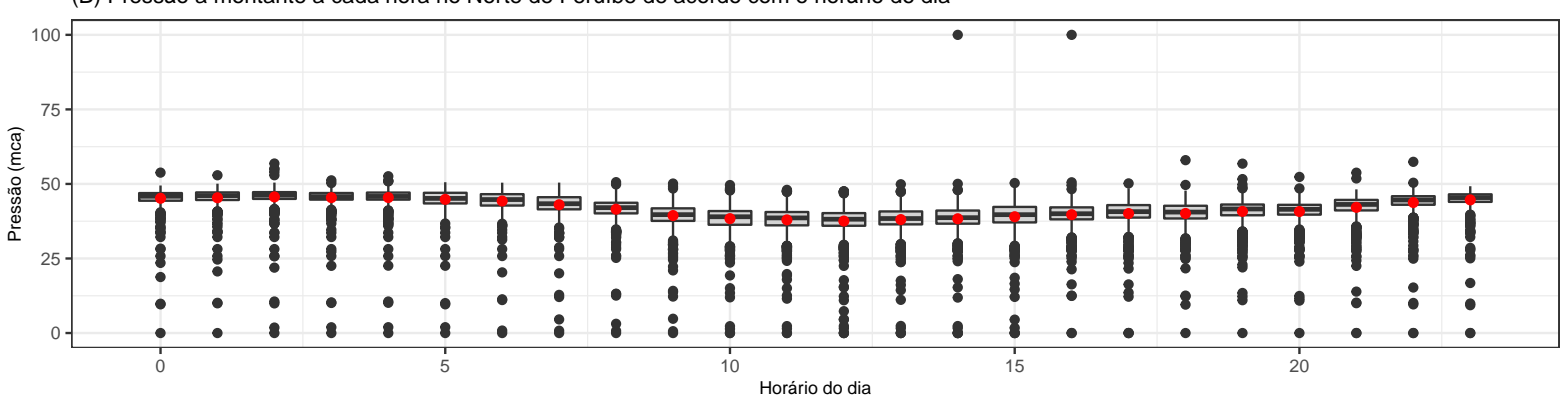

(C) Pressão a montante a cada hora no Norte de Peruíbe de acordo com dia da semana

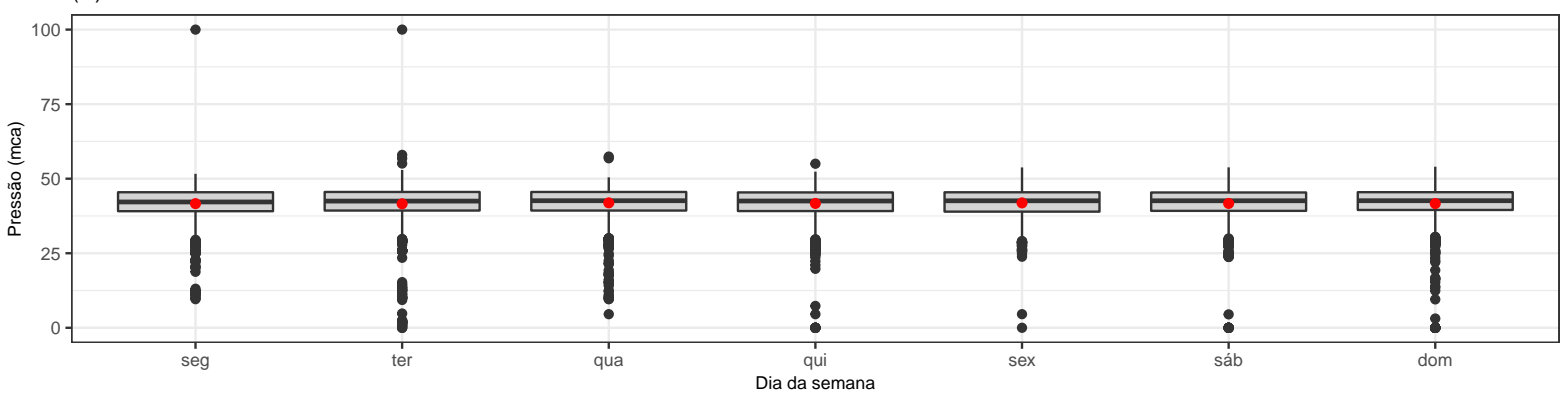

(D) Trecho da série de pressão a montante no Norte de Peruíbe De $1^{\circ}$ a 31 de Julho de 2017

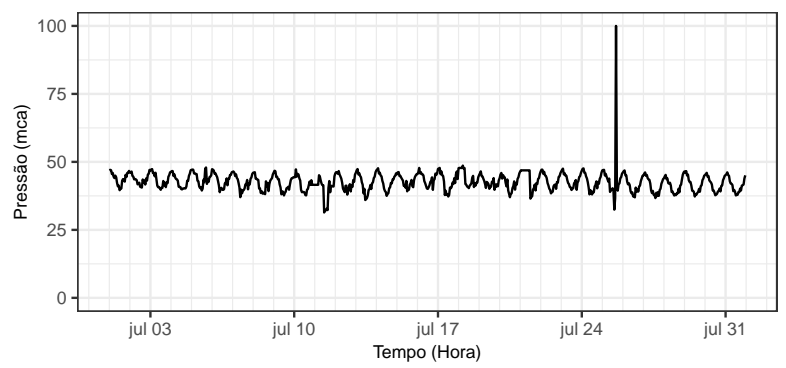

(E) Trecho da série de vazão de pressão a montante no Norte de Peruíb De 15 de dezembro de 2017 a 15 de janeiro de 2018

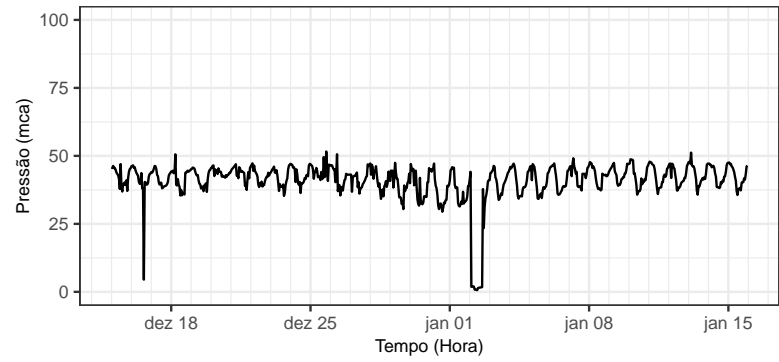

Figura A.6: Painel com alguns gráficos descritivos da série original de pressão a montante ao Norte de Peruibe. Os gráficos (A), (B) e (C) são boxplots série de vazão em l/s de acordo com mês, horário do dia e dia semana, respectivamente. Os pontos vermelhos são as médias de cada periodo. Já os gráficos (D) e (E) são trechos selecionados da série. 
Tabela A.7: Medidas descritivas da série original de pressão a montante ao Sul de Peruíbe. As informações descritivas são apresentadas para a série em sua totalidade e desagregada por períodos mensais, por dias da semana e por horários do dia.

\begin{tabular}{|c|c|c|c|c|c|c|c|c|c|}
\hline Descritiva & Média & Desvio padrão & Mínimo & $1^{\mathrm{O}}$ Quartil & Mediana & $3^{\mathcal{O}}$ Quartil & Máximo & Omissos & Total \\
\hline \multicolumn{10}{|l|}{ Geral } \\
\hline Geral & 43,5 & 4,54 & 0,0 & 42,4 & 44,3 & 45,8 & 100,0 & 207 & 17519 \\
\hline \multicolumn{10}{|l|}{ Por ano e mês } \\
\hline 2017 jan & 41,1 & 4,82 & 0,0 & 39,1 & 42,2 & 44,1 & 58,9 & 2 & 743 \\
\hline $2017 \mathrm{fev}$ & 43,0 & 2,85 & 32,9 & 41,2 & 43,6 & 45,4 & 47,3 & 0 & 673 \\
\hline 2017 mar & 43,8 & 2,35 & 36,0 & 42,7 & 44,4 & 45,7 & 47,0 & 0 & 744 \\
\hline 2017 abr & 44,5 & 1,80 & 35,8 & 43,3 & 45,0 & 45,8 & 47,4 & 1 & 720 \\
\hline 2017 mai & 44,8 & 1,55 & 39,0 & 43,7 & 45,0 & 45,9 & 48,7 & 0 & 744 \\
\hline 2017 jun & 43,6 & 6,28 & 0,0 & 43,5 & 45,1 & 46,0 & 48,7 & 0 & 720 \\
\hline 2017 jul & 44,7 & 2,70 & 37,5 & 43,2 & 44,9 & 46,1 & 100,0 & 0 & 744 \\
\hline 2017 ago & 44,5 & 1,91 & 27,5 & 43,2 & 44,9 & 45,9 & 47,3 & 0 & 744 \\
\hline 2017 set & 43,2 & 1,94 & 37,0 & 41,6 & 43,3 & 44,8 & 48,1 & 0 & 720 \\
\hline 2017 out & 43,6 & 1,96 & 37,3 & 42,4 & 43,6 & 45,2 & 47,3 & 5 & 743 \\
\hline 2017 nov & 45,0 & 1,93 & 33,9 & 43,6 & 45,3 & 46,6 & 48,8 & 0 & 720 \\
\hline 2017 dez & 41,9 & 9,80 & 0,0 & 42,2 & 44,0 & 45,8 & 48,8 & 0 & 744 \\
\hline 2018 jan & 42,1 & 7,08 & 0,0 & 41,0 & 43,2 & 45,5 & 47,4 & 0 & 744 \\
\hline 2018 fev & 43,9 & 2,44 & 32,4 & 42,5 & 44,1 & 45,9 & 47,5 & 1 & 673 \\
\hline 2018 mar & 44,6 & 1,75 & 38,8 & 43,2 & 44,7 & 46,2 & 48,5 & 0 & 744 \\
\hline 2018 abr & 44,0 & 3,29 & 33,1 & 42,9 & 44,7 & 46,2 & 47,5 & 0 & 720 \\
\hline 2018 mai & 43,3 & 8,73 & 0,0 & 43,9 & 45,1 & 46,3 & 47,7 & 0 & 744 \\
\hline 2018 jun & 45,8 & 1,47 & 36,8 & 45,0 & 46,1 & 46,9 & 47,8 & 0 & 720 \\
\hline 2018 jul & 44,7 & 3,43 & 0,0 & 44,6 & 45,7 & 45,7 & 47,6 & 2 & 744 \\
\hline 2018 ago & 44,6 & 1,98 & 39,5 & 43,4 & 44,8 & 46,3 & 55,8 & 1 & 744 \\
\hline 2018 set & 42,2 & 1,87 & 37,3 & 40,9 & 42,0 & 43,4 & 47,1 & 0 & 720 \\
\hline 2018 out & 42,0 & 6,89 & 0,0 & 41,0 & 44,0 & 45,5 & 49,0 & 79 & 744 \\
\hline 2018 nov & 42,0 & 3,26 & 27,6 & 39,5 & 41,8 & 44,9 & 49,3 & 116 & 719 \\
\hline $2018 \mathrm{dez}$ & 40,4 & 4,73 & 0,0 & 38,4 & 40,7 & 43,5 & 47,9 & 0 & 744 \\
\hline \multicolumn{10}{|c|}{ Por dia da semana } \\
\hline segunda-feira & 43,4 & 4,55 & 0,0 & 42,4 & 44,3 & 45,7 & 49,0 & 1 & 2520 \\
\hline terça-feira & 43,9 & 3,23 & 0,0 & 42,5 & 44,4 & 45,8 & 100,0 & 11 & 2496 \\
\hline quarta-feira & 43,6 & 3,95 & 0,0 & 42,4 & 44,4 & 45,8 & 50,0 & 19 & 2496 \\
\hline quinta-feira & 43,7 & 3,77 & 0,0 & 42,4 & 44,4 & 45,8 & 49,3 & 27 & 2496 \\
\hline sexta-feira & 43,6 & 3,22 & 0,0 & 42,2 & 44,1 & 45,7 & 55,8 & 48 & 2496 \\
\hline sábado & 43,1 & 5,58 & 0,0 & 42,1 & 44,2 & 45,8 & 48,1 & 34 & 2498 \\
\hline domingo & 43,0 & 6,43 & 0,0 & 42,5 & 44,4 & 45,8 & 48,8 & 67 & 2517 \\
\hline \multicolumn{10}{|c|}{ Por horário do dia } \\
\hline $0: 00$ & 45,0 & 3,85 & 0,0 & 44,5 & 45,8 & 46,6 & 48,2 & 9 & 727 \\
\hline $1: 00$ & 45,2 & 3,78 & 0,0 & 44,7 & 45,9 & 46,7 & 47,8 & 9 & 730 \\
\hline $2: 00$ & 45,4 & 3,74 & 0,0 & 45,0 & 46,1 & 46,8 & 48,6 & 9 & 730 \\
\hline $3: 00$ & 45,4 & 3,64 & 0,0 & 45,2 & 46,1 & 46,7 & 48,8 & 9 & 730 \\
\hline $4: 00$ & 45,5 & 3,59 & 0,0 & 45,3 & 46,0 & 46,7 & 49,3 & 8 & 730 \\
\hline $5: 00$ & 45,5 & 3,52 & 0,0 & 45,3 & 46,0 & 46,6 & 49,1 & 9 & 730 \\
\hline $6: 00$ & 45,3 & 3,50 & 0,0 & 45,0 & 45,8 & 46,4 & 49,0 & 9 & 730 \\
\hline $7: 00$ & 44,8 & 3,71 & 0,0 & 44,5 & 45,5 & 45,9 & 47,9 & 8 & 730 \\
\hline $8: 00$ & 44,2 & 3,85 & 0,0 & 43,7 & 44,9 & 45,6 & 48,2 & 8 & 730 \\
\hline $9: 00$ & 42,4 & 4,42 & 0,0 & 41,9 & 43,0 & 44,2 & 47,3 & 8 & 730 \\
\hline $10: 00$ & 41,9 & 4,35 & 0,0 & 41,1 & 42,6 & 43,8 & 48,1 & 9 & 730 \\
\hline $11: 00$ & 41,3 & 4,83 & 0,0 & 40,2 & 42,1 & 43,4 & 50,0 & 8 & 730 \\
\hline $12: 00$ & 41,1 & 5,13 & 0,0 & 40,2 & 42,1 & 43,4 & 47,7 & 10 & 730 \\
\hline $13: 00$ & 41,3 & 5,00 & 0,0 & 40,3 & 42,2 & 43,6 & 47,6 & 8 & 730 \\
\hline $14: 00$ & 41,6 & 5,20 & 0,0 & 40,8 & 42,7 & 43,9 & 47,4 & 8 & 730 \\
\hline $15: 00$ & 41,9 & 5,46 & 0,0 & 41,0 & 42,7 & 44,0 & 100,0 & 8 & 730 \\
\hline $16: 00$ & 41,9 & 4,81 & 0,0 & 41,0 & 42,8 & 43,9 & 55,8 & 8 & 730 \\
\hline $17: 00$ & 42,1 & 4,29 & 0,0 & 41,2 & 42,9 & 44,1 & 47,4 & 8 & 730 \\
\hline $18: 00$ & 42,5 & 4,06 & 0,0 & 41,7 & 43,4 & 44,6 & 47,3 & 8 & 730 \\
\hline $19: 00$ & 42,9 & 4,12 & 0,0 & 42,0 & 43,9 & 45,1 & 47,2 & 8 & 730 \\
\hline $20: 00$ & 43,3 & 4,02 & 0,0 & 42,5 & 44,3 & 45,4 & 47,0 & 8 & 730 \\
\hline $21: 00$ & 43,9 & 4,39 & 0,0 & 43,1 & 44,9 & 45,9 & 47,9 & 10 & 730 \\
\hline $22: 00$ & 44,4 & 4,13 & 0,0 & 43,7 & 45,4 & 46,2 & 48,6 & 10 & 730 \\
\hline $23: 00$ & 44,7 & 4,05 & 0,0 & 44,1 & 45,7 & 46,4 & 48,7 & 10 & 732 \\
\hline
\end{tabular}


(A) Pressão a montante a cada hora no Sul de Peruíbe de acordo com o mês

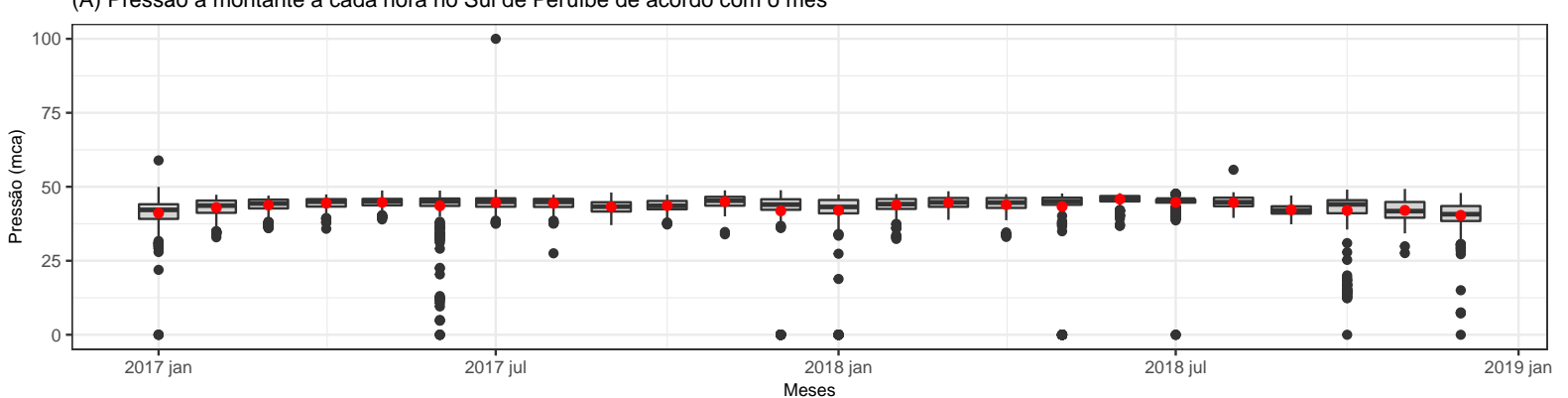

(B) Pressão a montante a cada hora no Sul de Peruíbe de acordo com o horário do dia

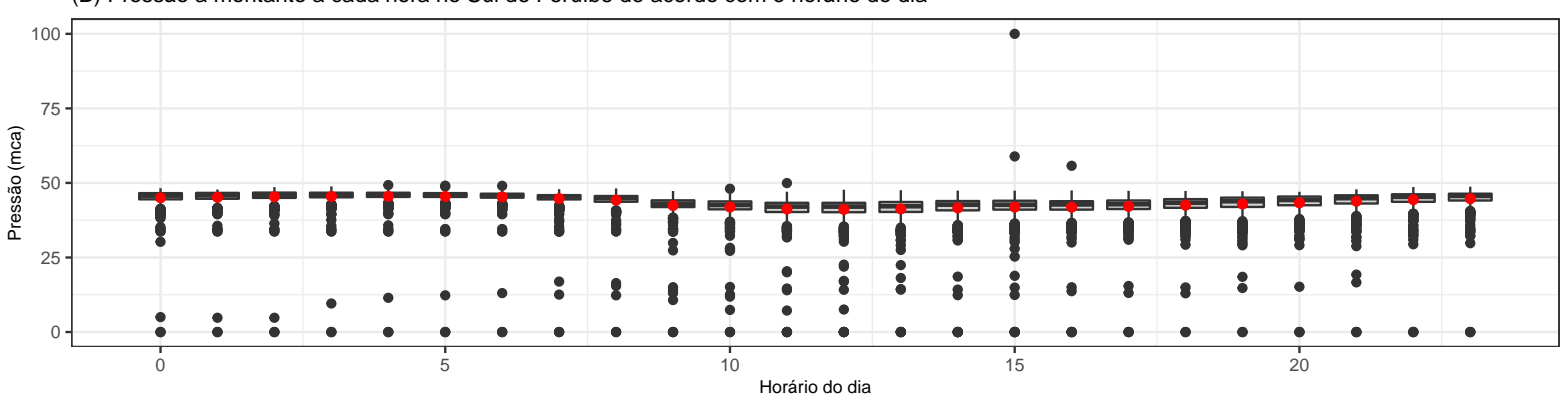

(C) Pressão a montante a cada hora no Sul de Peruíbe de acordo com dia da semana

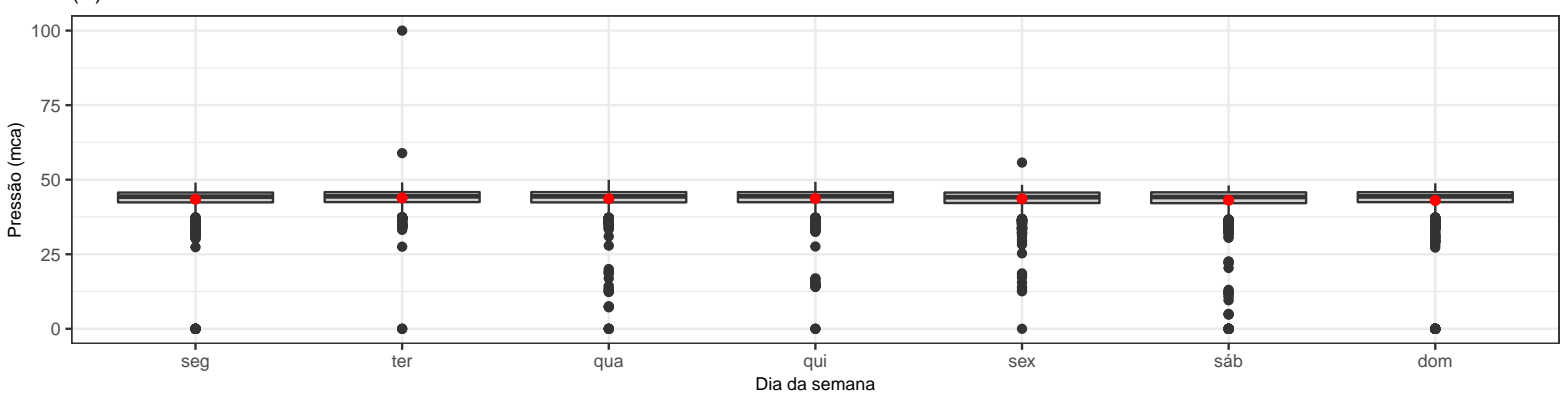

(D) Trecho da série de pressão a montante no Sul de Peruíbe De 1 a 31 de Julho de 2017

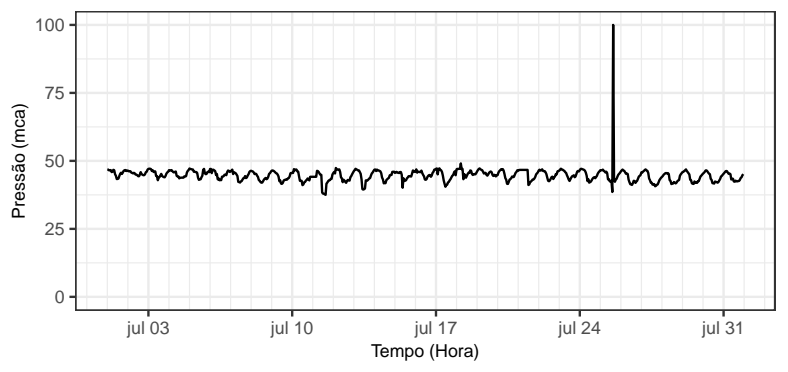

(E) Trecho da série de pressão a montante no Sul de Peruíbe De 15 de dezembro de 2017 a 15 de janeiro de 2018

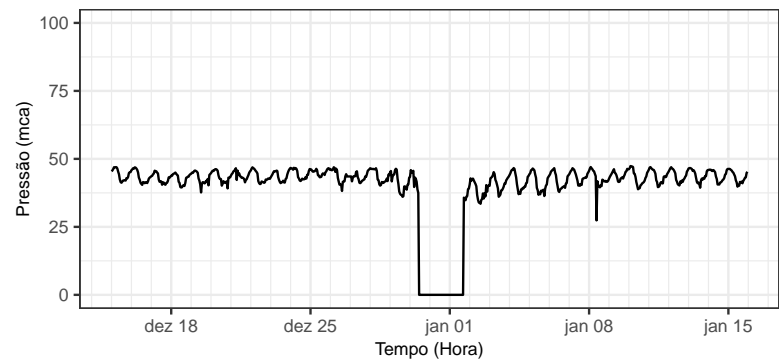

Figura A.7: Painel com alguns gráficos descritivos da série original de pressão a montante ao Sul de Peruíbe. Os gráficos (A), (B) e (C) são boxplots série de vazão em l/s de acordo com mês, horário do dia e dia semana, respectivamente. Os pontos vermelhos são as médias de cada periodo. Já os gráficos (D) e (E) são trechos selecionados da série. 
Tabela A.8: Medidas descritivas da série original de pressão a jusante ao Norte de Peruibe. As informações descritivas são apresentadas para a série em sua totalidade e desagregada por períodos mensais, por dias da semana e por horários do dia.

\begin{tabular}{|c|c|c|c|c|c|c|c|c|c|}
\hline Descritiva & Média & Desvio padrão & Mínimo & $1^{\mathrm{O}}$ Quartil & Mediana & $3^{\mathcal{O}}$ Quartil & Máximo & Omissos & Total \\
\hline \multicolumn{10}{|l|}{ Geral } \\
\hline Geral & 17,1 & 4,74 & 0,00 & 12,89 & 17,9 & 20,4 & 100,0 & 206 & 17519 \\
\hline \multicolumn{10}{|l|}{ Por ano e mês } \\
\hline 2017 jan & 19,6 & 4,53 & 0,00 & 16,21 & 20,3 & 23,1 & 33,8 & 2 & 743 \\
\hline $2017 \mathrm{fev}$ & 17,6 & 4,71 & 9,91 & 12,55 & 17,9 & 21,7 & 26,0 & 0 & 673 \\
\hline 2017 mar & 16,9 & 4,65 & 6,20 & 12,41 & 17,8 & 20,4 & 26,6 & 0 & 744 \\
\hline 2017 abr & 15,9 & 4,15 & 6,18 & 12,28 & 17,3 & 19,8 & 24,9 & 1 & 720 \\
\hline 2017 mai & 15,6 & 4,11 & 7,25 & 12,11 & 16,0 & 19,8 & 22,4 & 0 & 744 \\
\hline 2017 jun & 15,8 & 4,38 & 0,00 & 12,21 & 17,2 & 19,7 & 23,8 & 0 & 720 \\
\hline 2017 jul & 16,2 & 5,15 & 8,64 & 12,53 & 17,3 & 19,5 & 100,0 & 0 & 744 \\
\hline 2017 ago & 16,4 & 5,09 & 8,96 & 12,84 & 17,6 & 19,7 & 100,0 & 0 & 744 \\
\hline 2017 set & 16,1 & 3,91 & 7,25 & 13,06 & 17,3 & 19,5 & 22,4 & 0 & 720 \\
\hline 2017 out & 14,9 & 4,71 & 5,49 & 9,66 & 14,8 & 19,4 & 24,8 & 4 & 743 \\
\hline 2017 nov & 16,4 & 4,38 & 8,06 & 11,98 & 17,7 & 20,0 & 22,9 & 0 & 720 \\
\hline 2017 dez & 17,0 & 4,60 & 4,05 & 12,84 & 18,2 & 20,7 & 25,4 & 0 & 744 \\
\hline 2018 jan & 18,7 & 4,98 & 4,13 & 14,65 & 19,5 & 22,4 & 27,3 & 0 & 744 \\
\hline 2018 fev & 18,7 & 4,62 & 8,62 & 14,55 & 19,5 & 22,2 & 26,4 & 1 & 673 \\
\hline 2018 mar & 17,7 & 4,72 & 6,54 & 12,63 & 18,5 & 22,1 & 26,6 & 0 & 744 \\
\hline 2018 abr & 17,5 & 4,63 & 7,20 & 12,52 & 18,9 & 21,8 & 26,2 & 0 & 720 \\
\hline 2018 mai & 17,0 & 5,60 & 0,00 & 12,57 & 18,1 & 22,1 & 25,4 & 0 & 744 \\
\hline 2018 jun & 16,5 & 4,02 & 8,86 & 12,11 & 18,0 & 19,9 & 25,7 & 0 & 720 \\
\hline 2018 jul & 18,1 & 3,95 & 0,00 & 16,57 & 20,3 & 20,3 & 25,5 & 2 & 744 \\
\hline 2018 ago & 16,4 & 4,47 & 7,55 & 12,63 & 15,8 & 20,1 & 25,1 & 1 & 744 \\
\hline 2018 set & 16,8 & 4,49 & 6,52 & 13,16 & 16,2 & 21,7 & 23,7 & 0 & 720 \\
\hline 2018 out & 18,8 & 4,76 & 0,00 & 15,04 & 19,9 & 23,0 & 29,0 & 79 & 744 \\
\hline 2018 nov & 18,7 & 4,05 & 8,99 & 15,20 & 19,5 & 22,3 & 28,1 & 116 & 719 \\
\hline $2018 \mathrm{dez}$ & 18,2 & 4,96 & 4,30 & 14,43 & 18,4 & 22,4 & 28,6 & 0 & 744 \\
\hline \multicolumn{10}{|c|}{ Por dia da semana } \\
\hline segunda-feira & 17,3 & 4,86 & 4,13 & 13,57 & 17,9 & 20,5 & 100,0 & 1 & 2520 \\
\hline terça-feira & 17,1 & 4,87 & 0,00 & 12,72 & 17,8 & 20,3 & 100,0 & 11 & 2496 \\
\hline quarta-feira & 17,1 & 4,63 & 4,22 & 12,80 & 17,8 & 20,4 & 26,6 & 18 & 2496 \\
\hline quinta-feira & 17,1 & 4,65 & 0,00 & 12,72 & 17,9 & 20,3 & 29,0 & 27 & 2496 \\
\hline sexta-feira & 17,1 & 4,63 & 0,00 & 12,72 & 17,9 & 20,4 & 26,6 & 48 & 2496 \\
\hline sábado & 17,2 & 4,68 & 0,00 & 13,99 & 18,0 & 20,5 & 28,6 & 34 & 2498 \\
\hline domingo & 17,1 & 4,83 & 0,00 & 13,07 & 17,9 & 20,3 & 33,8 & 67 & 2517 \\
\hline \multicolumn{10}{|c|}{ Por horário do dia } \\
\hline $0: 00$ & 11,2 & 3,25 & 0,00 & 9,45 & 10,0 & 12,2 & 28,3 & 9 & 727 \\
\hline $1: 00$ & 11,3 & 3,26 & 0,00 & 9,50 & 10,2 & 12,2 & 28,4 & 9 & 730 \\
\hline $2: 00$ & 12,0 & 3,34 & 0,00 & 9,67 & 10,9 & 12,8 & 28,4 & 9 & 730 \\
\hline $3: 00$ & 13,4 & 3,04 & 0,00 & 11,65 & 12,6 & 14,8 & 28,2 & 9 & 730 \\
\hline $4: 00$ & 14,1 & 3,12 & 0,00 & 12,21 & 14,0 & 15,4 & 28,4 & 8 & 730 \\
\hline $5: 00$ & 15,8 & 3,00 & 0,00 & 14,31 & 15,2 & 17,9 & 28,2 & 9 & 730 \\
\hline $6: 00$ & 16,3 & 2,83 & 0,00 & 14,51 & 15,4 & 18,2 & 28,3 & 9 & 730 \\
\hline $7: 00$ & 17,8 & 2,29 & 0,00 & 17,31 & 17,8 & 18,6 & 27,6 & 8 & 730 \\
\hline $8: 00$ & 18,7 & 2,42 & 0,00 & 17,75 & 18,5 & 19,9 & 27,7 & 8 & 730 \\
\hline $9: 00$ & 20,1 & 2,58 & 0,00 & 19,56 & 20,2 & 21,9 & 27,5 & 8 & 730 \\
\hline $10: 00$ & 20,7 & 2,87 & 0,00 & 19,76 & 20,7 & 22,1 & 27,9 & 9 & 730 \\
\hline $11: 00$ & 21,1 & 3,12 & 0,00 & 19,83 & 20,6 & 23,2 & 28,5 & 8 & 730 \\
\hline $12: 00$ & 21,8 & 3,16 & 0,00 & 20,61 & 22,1 & 23,4 & 27,8 & 9 & 730 \\
\hline $13: 00$ & 21,9 & 3,09 & 0,00 & 20,86 & 22,3 & 23,3 & 33,8 & 8 & 730 \\
\hline $14: 00$ & 21,8 & 4,29 & 0,00 & 20,77 & 22,2 & 23,3 & 100,0 & 8 & 730 \\
\hline $15: 00$ & 20,9 & 4,13 & 0,00 & 19,84 & 21,5 & 22,4 & 100,0 & 8 & 730 \\
\hline $16: 00$ & 20,3 & 2,72 & 0,00 & 19,58 & 20,3 & 21,9 & 28,8 & 8 & 730 \\
\hline $17: 00$ & 19,3 & 2,72 & 0,00 & 17,88 & 19,7 & 20,3 & 29,0 & 8 & 730 \\
\hline $18: 00$ & 18,8 & 2,47 & 0,00 & 17,63 & 19,4 & 20,0 & 27,4 & 8 & 730 \\
\hline $19: 00$ & 17,2 & 2,82 & 0,00 & 15,32 & 17,5 & 18,4 & 27,2 & 8 & 730 \\
\hline $20: 00$ & 16,9 & 2,92 & 0,00 & 14,88 & 17,6 & 18,2 & 27,0 & 8 & 730 \\
\hline $21: 00$ & 14,7 & 3,44 & 0,00 & 12,16 & 14,9 & 15,8 & 28,0 & 10 & 730 \\
\hline $22: 00$ & 12,9 & 3,40 & 0,00 & 11,40 & 12,0 & 12,7 & 28,6 & 10 & 730 \\
\hline $23: 00$ & 12,0 & 3,25 & 0,00 & 9,82 & 12,0 & 12,4 & 27,9 & 10 & 732 \\
\hline
\end{tabular}


(A) Pressão a jusante a cada hora no Norte de Peruíbe de acordo com o mês

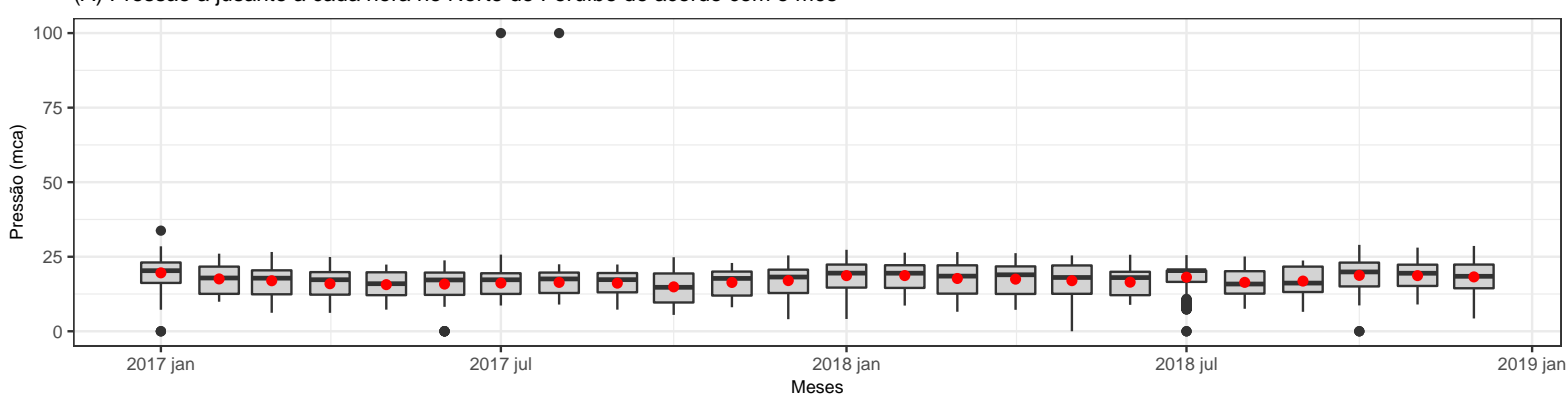

(B) Pressão a jusante a cada hora no Norte de Peruíbe de acordo com o horário do dia

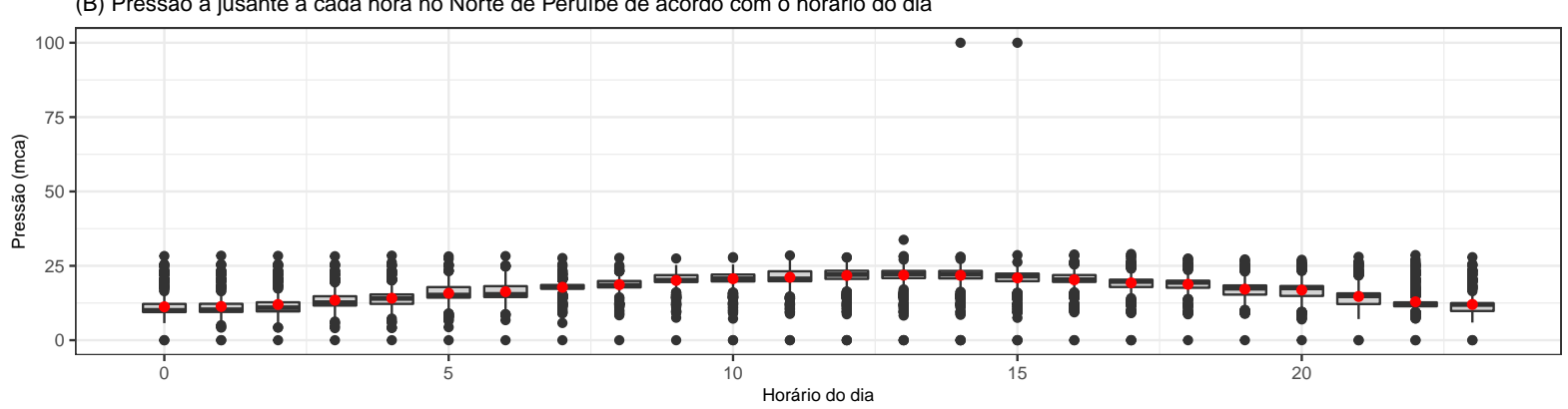

(C) Pressão a jusante a cada hora no Norte de Peruíbe de acordo com dia da semana

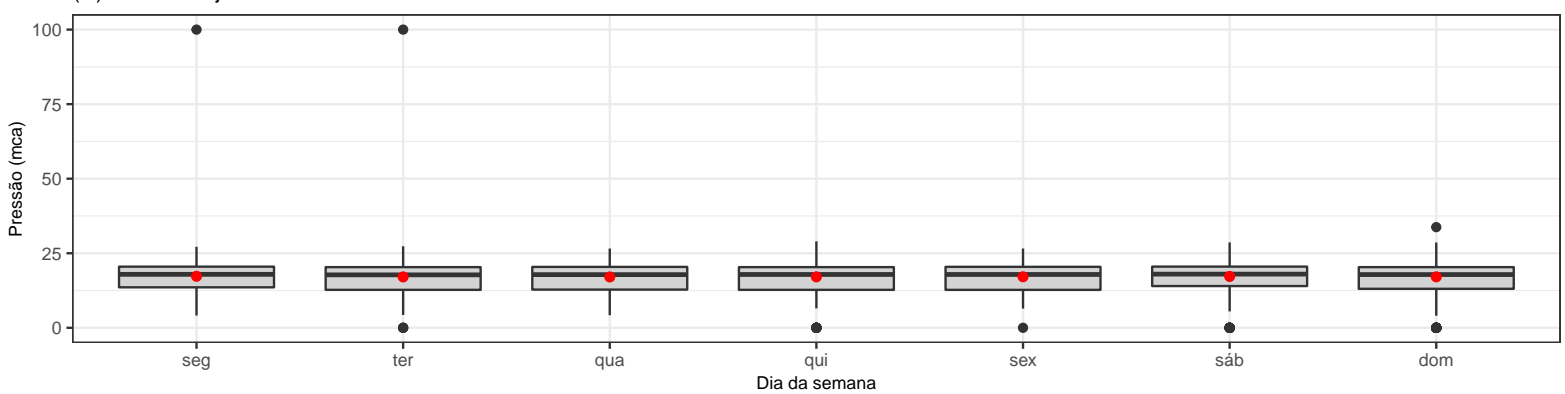

(D) Trecho da série de pressão a jusante no Norte de Peruíbe De $1^{\circ}$ a 31 de Julho de 2017

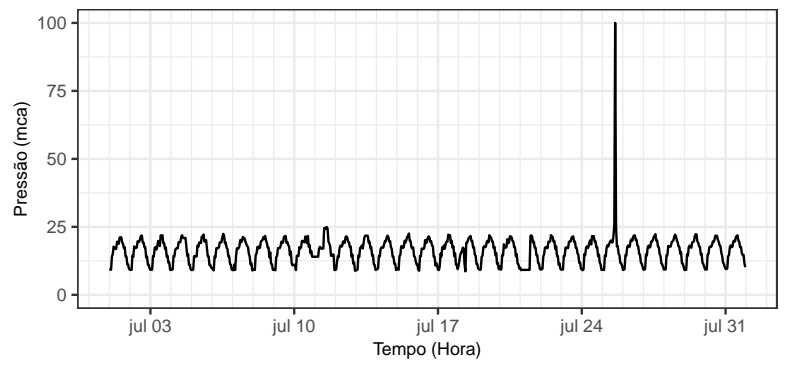

(E) Trecho da série de vazão de pressão a jusante no Norte de Peruíbe De 15 de dezembro de 2017 a 15 de janeiro de 2018

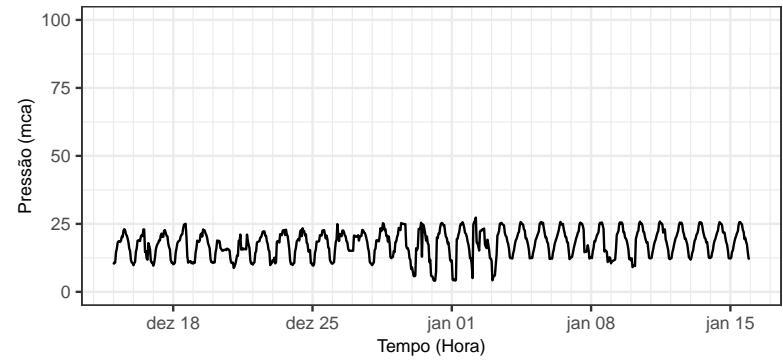

Figura A.8: Painel com alguns gráficos descritivos da série original de pressão a jusante ao Norte de Peruibe. Os gráficos (A), (B) e (C) são boxplots série de vazão em l/s de acordo com mês, horário do dia e dia semana, respectivamente. Os pontos vermelhos são as médias de cada periodo. Já os gráficos (D) e (E) são trechos selecionados da série. 
Tabela A.9: Medidas descritivas da série original de pressão a jusante ao Sul de Peruíbe. As informações descritivas são apresentadas para a série em sua totalidade e desagregada por períodos mensais, por dias da semana e por horários do dia.

\begin{tabular}{|c|c|c|c|c|c|c|c|c|c|}
\hline Descritiva & Média & Desvio padrão & Mínimo & $1^{\mathrm{O}}$ Quartil & Mediana & $3^{\mathcal{O}}$ Quartil & Máximo & Omissos & Total \\
\hline \multicolumn{10}{|l|}{ Geral } \\
\hline Geral & 16,4 & 4,87 & 0,00 & 12,60 & 15,9 & 19,4 & 100,0 & 207 & 17519 \\
\hline \multicolumn{10}{|l|}{ Por ano e mês } \\
\hline 2017 jan & 19,5 & 4,88 & 0,00 & 15,46 & 19,7 & 22,2 & 30,0 & 2 & 743 \\
\hline $2017 \mathrm{fev}$ & 17,2 & 4,81 & 9,67 & 12,31 & 17,5 & 20,8 & 26,8 & 0 & 673 \\
\hline 2017 mar & 15,6 & 4,50 & 6,28 & 12,03 & 15,1 & 19,0 & 26,2 & 0 & 744 \\
\hline 2017 abr & 14,7 & 3,92 & 6,25 & 11,18 & 14,5 & 17,9 & 26,3 & 1 & 720 \\
\hline 2017 mai & 14,3 & 3,35 & 8,69 & 11,39 & 14,0 & 17,7 & 26,2 & 0 & 744 \\
\hline 2017 jun & 14,7 & 4,07 & 0,00 & 11,18 & 14,6 & 17,9 & 37,2 & 0 & 720 \\
\hline 2017 jul & 15,2 & 4,88 & 9,18 & 11,98 & 14,9 & 18,1 & 100,0 & 0 & 744 \\
\hline 2017 ago & 15,2 & 3,68 & 9,13 & 12,23 & 14,9 & 18,1 & 26,8 & 0 & 744 \\
\hline 2017 set & 15,2 & 3,12 & 8,72 & 12,74 & 14,9 & 18,0 & 22,4 & 0 & 720 \\
\hline 2017 out & 14,4 & 3,63 & 6,62 & 10,65 & 14,6 & 17,6 & 26,0 & 5 & 743 \\
\hline 2017 nov & 14,9 & 3,43 & 8,99 & 11,73 & 14,8 & 18,0 & 21,8 & 0 & 720 \\
\hline 2017 dez & 15,1 & 3,88 & 3,49 & 12,11 & 14,9 & 18,1 & 28,5 & 0 & 744 \\
\hline 2018 jan & 17,8 & 4,86 & 3,57 & 13,41 & 18,2 & 21,6 & 27,4 & 0 & 744 \\
\hline 2018 fev & 17,7 & 4,49 & 7,91 & 14,09 & 18,1 & 20,9 & 29,8 & 1 & 673 \\
\hline 2018 mar & 16,2 & 4,31 & 7,06 & 12,33 & 17,6 & 19,8 & 27,0 & 0 & 744 \\
\hline 2018 abr & 17,1 & 6,24 & 8,23 & 12,45 & 17,7 & 19,9 & 35,7 & 0 & 720 \\
\hline 2018 mai & 15,5 & 4,90 & 0,00 & 12,45 & 15,3 & 19,8 & 25,6 & 0 & 744 \\
\hline 2018 jun & 15,2 & 3,18 & 9,01 & 12,50 & 14,7 & 17,9 & 25,1 & 0 & 720 \\
\hline 2018 jul & 16,2 & 3,20 & 0,00 & 14,36 & 17,9 & 17,9 & 25,6 & 2 & 744 \\
\hline 2018 ago & 15,8 & 3,59 & 8,25 & 12,54 & 15,5 & 19,5 & 23,8 & 1 & 744 \\
\hline 2018 set & 15,9 & 3,34 & 8,25 & 13,11 & 15,7 & 19,3 & 21,2 & 0 & 720 \\
\hline 2018 out & 17,8 & 4,81 & 0,00 & 13,77 & 18,4 & 20,2 & 29,8 & 79 & 744 \\
\hline 2018 nov & 22,5 & 5,70 & 10,96 & 17,28 & 24,0 & 27,9 & 30,2 & 116 & 719 \\
\hline $2018 \mathrm{dez}$ & 22,2 & 6,35 & 0,00 & 16,83 & 24,1 & 27,8 & 35,8 & 0 & 744 \\
\hline \multicolumn{10}{|c|}{ Por dia da semana } \\
\hline segunda-feira & 16,6 & 4,72 & 3,57 & 12,67 & 16,6 & 19,5 & 30,6 & 1 & 2520 \\
\hline terça-feira & 16,4 & 4,62 & 0,00 & 12,67 & 15,6 & 19,4 & 30,1 & 11 & 2496 \\
\hline quarta-feira & 16,4 & 4,79 & 0,00 & 12,60 & 15,7 & 19,4 & 42,4 & 19 & 2496 \\
\hline quinta-feira & 16,2 & 4,53 & 0,00 & 12,53 & 15,7 & 19,1 & 29,6 & 27 & 2496 \\
\hline sexta-feira & 16,5 & 4,89 & 0,00 & 12,53 & 16,1 & 19,5 & 37,2 & 48 & 2496 \\
\hline sábado & 16,6 & 5,14 & 0,00 & 12,65 & 16,7 & 19,5 & 35,8 & 34 & 2498 \\
\hline domingo & 16,4 & 5,36 & 0,00 & 12,53 & 15,9 & 19,4 & 100,0 & 67 & 2517 \\
\hline \multicolumn{10}{|c|}{ Por horário do dia } \\
\hline $0: 00$ & 11,7 & 3,57 & 0,00 & 9,79 & 10,3 & 12,3 & 35,0 & 9 & 727 \\
\hline $1: 00$ & 11,7 & 3,45 & 0,00 & 10,09 & 10,6 & 12,4 & 35,0 & 9 & 730 \\
\hline $2: 00$ & 12,2 & 3,24 & 0,00 & 10,50 & 11,4 & 12,7 & 35,0 & 9 & 730 \\
\hline $3: 00$ & 13,2 & 3,09 & 0,00 & 11,87 & 12,5 & 13,4 & 35,0 & 9 & 730 \\
\hline $4: 00$ & 13,8 & 2,91 & 0,00 & 12,67 & 13,2 & 14,8 & 35,0 & 8 & 730 \\
\hline $5: 00$ & 15,1 & 2,77 & 0,00 & 14,07 & 14,8 & 15,8 & 35,0 & 9 & 730 \\
\hline $6: 00$ & 15,4 & 2,63 & 0,00 & 14,26 & 14,8 & 16,2 & 35,0 & 9 & 730 \\
\hline $7: 00$ & 16,6 & 2,76 & 0,00 & 14,85 & 17,0 & 18,0 & 35,0 & 8 & 730 \\
\hline $8: 00$ & 17,0 & 3,12 & 0,00 & 14,60 & 17,3 & 18,8 & 35,0 & 8 & 730 \\
\hline $9: 00$ & 19,1 & 3,22 & 0,00 & 17,85 & 18,8 & 20,5 & 35,0 & 8 & 730 \\
\hline $10: 00$ & 19,5 & 3,47 & 0,00 & 17,85 & 18,9 & 20,8 & 35,0 & 9 & 730 \\
\hline $11: 00$ & 20,6 & 3,93 & 0,00 & 18,93 & 20,1 & 21,9 & 35,0 & 8 & 730 \\
\hline $12: 00$ & 20,9 & 5,00 & 0,00 & 18,97 & 20,1 & 23,5 & 100,0 & 10 & 730 \\
\hline $13: 00$ & 20,8 & 4,01 & 0,00 & 18,97 & 20,1 & 22,8 & 35,0 & 8 & 730 \\
\hline $14: 00$ & 19,8 & 3,98 & 0,00 & 17,95 & 19,1 & 21,4 & 35,0 & 8 & 730 \\
\hline $15: 00$ & 19,7 & 3,86 & 0,00 & 17,83 & 19,2 & 20,9 & 35,8 & 8 & 730 \\
\hline $16: 00$ & 19,6 & 3,84 & 0,00 & 17,90 & 19,1 & 20,4 & 42,4 & 8 & 730 \\
\hline $17: 00$ & 19,1 & 3,81 & 0,00 & 17,58 & 18,3 & 20,0 & 35,1 & 8 & 730 \\
\hline $18: 00$ & 17,7 & 4,11 & 0,00 & 15,12 & 17,4 & 18,3 & 35,7 & 8 & 730 \\
\hline $19: 00$ & 16,6 & 4,37 & 0,00 & 14,51 & 15,1 & 17,8 & 35,4 & 8 & 730 \\
\hline $20: 00$ & 15,5 & 4,26 & 0,00 & 12,60 & 14,9 & 15,6 & 35,6 & 8 & 730 \\
\hline $21: 00$ & 13,8 & 4,51 & 0,00 & 10,65 & 12,4 & 14,9 & 36,8 & 10 & 730 \\
\hline $22: 00$ & 12,8 & 4,44 & 0,00 & 10,26 & 10,9 & 12,6 & 36,2 & 10 & 730 \\
\hline $23: 00$ & 12,3 & 3,92 & 0,00 & 10,13 & 10,8 & 12,4 & 37,2 & 10 & 732 \\
\hline
\end{tabular}


(A) Pressão a jusante a cada hora no Sul de Peruíbe de acordo com o mês

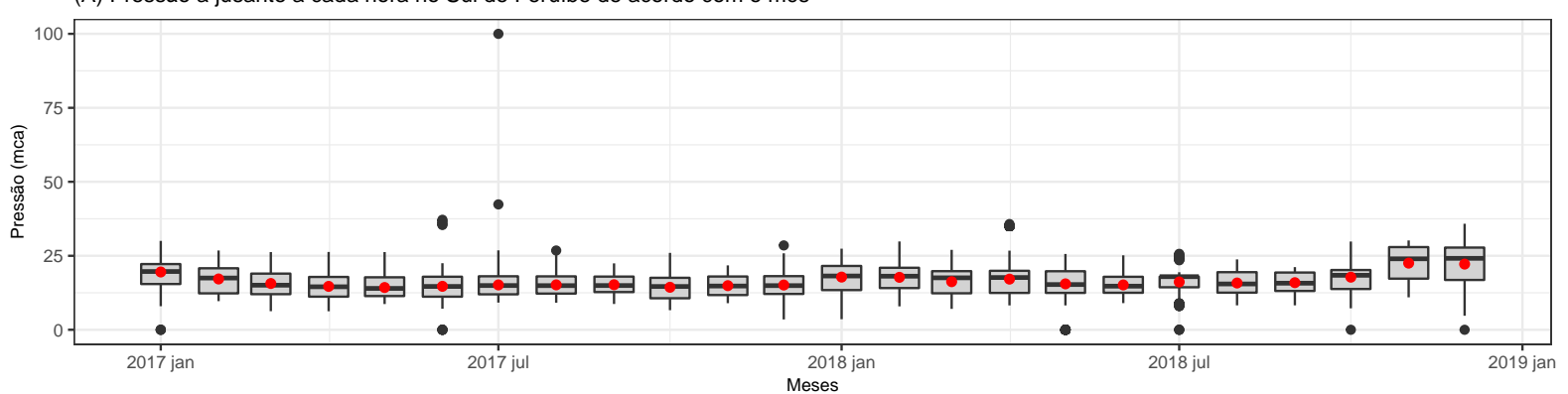

(B) Pressão a jusante a cada hora no Sul de Peruíbe de acordo com o horário do dia

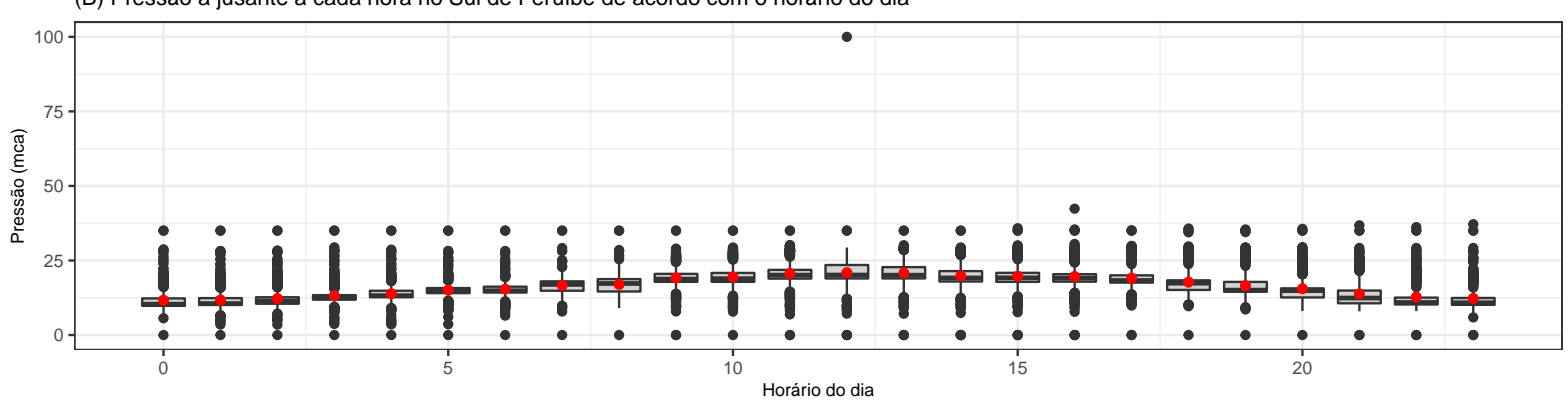

(C) Pressão a jusante a cada hora no Sul de Peruíbe de acordo com dia da semana

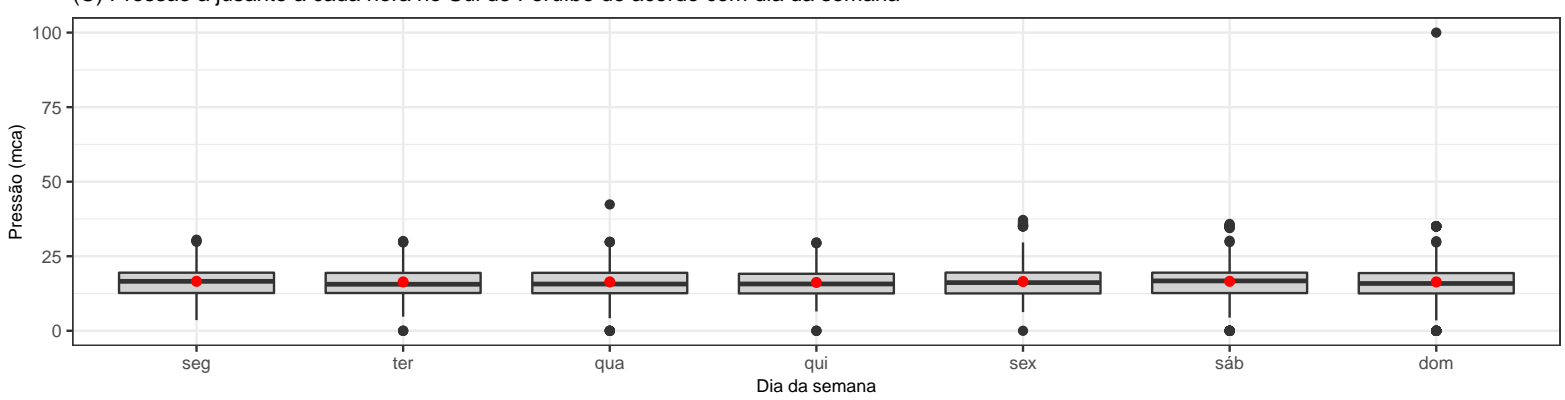

(D) Trecho da série de pressão a jusante no Sul de Peruíbe De $1^{\circ}$ a 31 de Julho de 2017

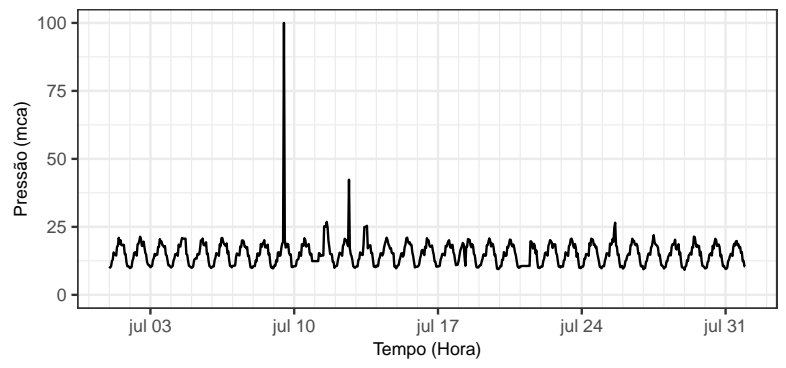

(E) Trecho da série de pressão a jusante no Sul de Peruíbe De 15 de dezembro de 2017 a 15 de janeiro de 2018

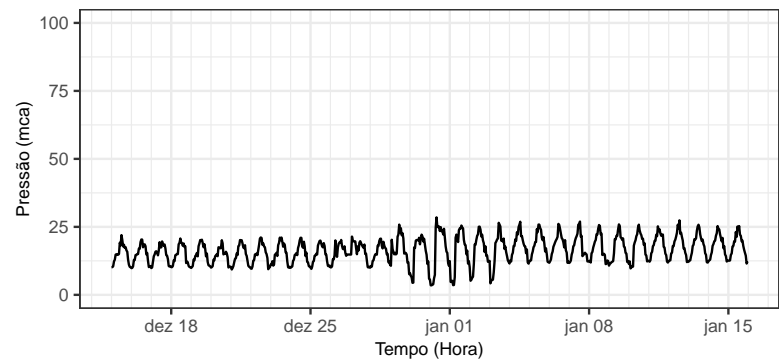

Figura A.9: Painel com alguns gráficos descritivos da série original de pressão a jusante ao Sul de Peruíbe. Os gráficos (A), (B) e (C) são boxplots série de vazão em l/s de acordo com mês, horário do dia e dia semana, respectivamente. Os pontos vermelhos são as médias de cada período. Já os gráficos (D) e (E) são trechos selecionados da série. 


\section{Apêndice B}

\section{Informações descritivas após a limpeza primária}

A seguir são apresentadas um conjunto de tabelas e gráficos descritivos para cada série temporal, sendo organizados da seguinte maneira:

- A Tabela B.1 e as figuras B.1 e B.2 se referem a série de nível do reservatório de Peruíbe;

- A Tabela B.2 e a figura B.3 e B.4 se referem a série de consumo demandado do reservatório de Peruíbe;

- A Tabela B.3 e a figura B.5 e B.6 se referem a série de vazão de entrada do reservatório de Peruíbe;

- A Tabela B.4 e a figura B.7 e B.8 se referem a série de vazão de saída do reservatório para o Norte de Peruíbe;

- A Tabela B.5 e a figura B.9 e B.10 se referem a série de vazão de saída do reservatório para o Sul de Peruíbe;

- A Tabela B.6 e a figura B.11 e B.12 se referem a série de pressão a montante no Norte de Peruíbe;

- A Tabela B.7 e a figura B.13 e B.14 se referem a série de pressão a montante no Sul de Peruíbe;

- A Tabela B.8 e a figura B.15 e B.16 se referem a série de pressão a jusante no Norte de Peruíbe;

- A Tabela B.9 e a figura B.17 e B.18 se referem a série de pressão a jusante no Sul de Peruíbe. 
Tabela B.1: Medidas descritivas da série após limpeza primária de nivel do reservatório de Peruibe. As informações descritivas são apresentadas para a série em sua totalidade e desagregada por períodos mensais, por dias da semana e por horários do dia.

\begin{tabular}{|c|c|c|c|c|c|c|c|c|c|}
\hline Descritiva & Média & Desvio padrão & Mínimo & $1^{\mathrm{O}}$ Quartil & Mediana & $3^{\mathcal{O}}$ Quartil & Máximo & Omissos & Total \\
\hline \multicolumn{10}{|l|}{ Geral } \\
\hline Geral & 6,74 & 1,25 & 1,48 & 6,23 & 7,04 & 7,61 & 8,50 & 1136 & 17519 \\
\hline \multicolumn{10}{|l|}{ Por ano e mês } \\
\hline 2017 jan & 6,33 & 1,11 & 2,75 & 5,64 & 6,63 & 7,20 & 8,28 & 69 & 743 \\
\hline $2017 \mathrm{fev}$ & 6,80 & 0,70 & 3,39 & 6,47 & 6,96 & 7,27 & 7,99 & 68 & 673 \\
\hline 2017 mar & 6,62 & 0,82 & 3,40 & 6,31 & 6,80 & 7,19 & 7,95 & 25 & 744 \\
\hline 2017 abr & 6,79 & 0,57 & 5,21 & 6,40 & 6,85 & 7,23 & 8,06 & 17 & 720 \\
\hline 2017 mai & 6,76 & 0,70 & 3,79 & 6,44 & 6,85 & 7,26 & 8,00 & 11 & 744 \\
\hline 2017 jun & 6,87 & 0,55 & 4,60 & 6,51 & 6,93 & 7,29 & 8,01 & 13 & 720 \\
\hline 2017 jul & 6,65 & 0,74 & 4,00 & 6,16 & 6,82 & 7,22 & 8,10 & 45 & 744 \\
\hline 2017 ago & 6,48 & 0,96 & 2,23 & 6,00 & 6,71 & 7,18 & 8,00 & 15 & 744 \\
\hline 2017 set & 5,51 & 1,20 & 2,80 & 4,56 & 5,53 & 6,47 & 7,88 & 72 & 720 \\
\hline 2017 out & 5,78 & 1,36 & 2,52 & 4,80 & 5,90 & 6,98 & 8,47 & 36 & 743 \\
\hline 2017 nov & 7,36 & 0,80 & 4,40 & 6,97 & 7,50 & 7,95 & 8,46 & 20 & 720 \\
\hline 2017 dez & 6,90 & 1,07 & 3,71 & 6,45 & 7,17 & 7,67 & 8,47 & 22 & 744 \\
\hline 2018 jan & 7,11 & 1,11 & 2,81 & 6,77 & 7,38 & 7,85 & 8,49 & 15 & 744 \\
\hline 2018 fev & 7,36 & 0,87 & 2,57 & 7,10 & 7,53 & 7,90 & 8,49 & 12 & 673 \\
\hline 2018 mar & 7,61 & 0,66 & 4,50 & 7,34 & 7,76 & 8,09 & 8,50 & 20 & 744 \\
\hline 2018 abr & 7,56 & 0,73 & 3,37 & 7,35 & 7,74 & 8,03 & 8,50 & 106 & 720 \\
\hline 2018 mai & 7,63 & 0,59 & 4,92 & 7,35 & 7,76 & 8,05 & 8,50 & 86 & 744 \\
\hline 2018 jun & 7,80 & 0,41 & 6,12 & 7,57 & 7,85 & 8,12 & 8,49 & 15 & 720 \\
\hline 2018 jul & 6,68 & 1,24 & 3,35 & 5,89 & 6,88 & 7,74 & 8,49 & 25 & 744 \\
\hline 2018 ago & 6,83 & 1,50 & 1,95 & 6,41 & 7,31 & 7,90 & 8,50 & 69 & 744 \\
\hline 2018 set & 4,41 & 1,50 & 1,80 & 3,21 & 4,10 & 5,35 & 8,34 & 27 & 720 \\
\hline 2018 out & 6,52 & 1,62 & 1,95 & 5,78 & 6,96 & 7,81 & 8,48 & 168 & 744 \\
\hline 2018 nov & 7,07 & 0,86 & 3,96 & 6,58 & 7,21 & 7,71 & 8,47 & 153 & 719 \\
\hline $2018 \mathrm{dez}$ & 6,31 & 1,48 & 1,48 & 5,53 & 6,60 & 7,35 & 8,49 & 27 & 744 \\
\hline \multicolumn{10}{|c|}{ Por dia da semana } \\
\hline segunda-feira & 6,64 & 1,32 & 1,48 & 6,15 & 6,92 & 7,56 & 8,49 & 125 & 2520 \\
\hline terça-feira & 6,71 & 1,33 & 2,05 & 6,12 & 7,07 & 7,63 & 8,50 & 137 & 2496 \\
\hline quarta-feira & 6,76 & 1,31 & 1,95 & 6,19 & 7,12 & 7,71 & 8,50 & 154 & 2496 \\
\hline quinta-feira & 6,73 & 1,27 & 1,80 & 6,23 & 7,07 & 7,61 & 8,48 & 154 & 2496 \\
\hline sexta-feira & 6,75 & 1,15 & 2,67 & 6,21 & 6,98 & 7,56 & 8,50 & 183 & 2496 \\
\hline sábado & 6,83 & 1,16 & 2,28 & 6,40 & 7,05 & 7,64 & 8,49 & 175 & 2498 \\
\hline domingo & 6,74 & 1,22 & 1,84 & 6,29 & 7,04 & 7,57 & 8,50 & 208 & 2517 \\
\hline \multicolumn{10}{|c|}{ Por horário do dia } \\
\hline $0: 00$ & 6,74 & 1,36 & 1,61 & 6,20 & 7,06 & 7,75 & 8,48 & 45 & 727 \\
\hline $1: 00$ & 6,86 & 1,30 & 1,48 & 6,40 & 7,15 & 7,81 & 8,50 & 60 & 730 \\
\hline $2: 00$ & 6,93 & 1,22 & 1,63 & 6,44 & 7,21 & 7,81 & 8,48 & 60 & 730 \\
\hline $3: 00$ & 7,01 & 1,14 & 2,02 & 6,55 & 7,26 & 7,83 & 8,49 & 55 & 730 \\
\hline $4: 00$ & 7,03 & 1,07 & 2,44 & 6,60 & 7,26 & 7,76 & 8,47 & 61 & 730 \\
\hline $5: 00$ & 7,06 & 0,99 & 2,80 & 6,61 & 7,29 & 7,73 & 8,46 & 40 & 730 \\
\hline $6: 00$ & 7,07 & 0,92 & 2,91 & 6,63 & 7,24 & 7,72 & 8,49 & 42 & 730 \\
\hline $7: 00$ & 7,14 & 0,89 & 2,99 & 6,80 & 7,27 & 7,75 & 8,49 & 37 & 730 \\
\hline $8: 00$ & 7,18 & 0,89 & 3,01 & 6,83 & 7,34 & 7,76 & 8,47 & 34 & 730 \\
\hline $9: 00$ & 7,14 & 0,94 & 2,85 & 6,78 & 7,33 & 7,78 & 8,45 & 33 & 730 \\
\hline $10: 00$ & 7,02 & 0,99 & 2,59 & 6,58 & 7,23 & 7,68 & 8,47 & 50 & 730 \\
\hline $11: 00$ & 6,88 & 1,06 & 1,88 & 6,44 & 7,12 & 7,58 & 8,48 & 50 & 730 \\
\hline $12: 00$ & 6,75 & 1,11 & 1,87 & 6,25 & 6,99 & 7,53 & 8,45 & 65 & 730 \\
\hline $13: 00$ & 6,64 & 1,16 & 1,87 & 6,06 & 6,90 & 7,45 & 8,46 & 51 & 730 \\
\hline $14: 00$ & 6,57 & 1,21 & 1,86 & 5,96 & 6,81 & 7,40 & 8,49 & 48 & 730 \\
\hline $15: 00$ & 6,49 & 1,30 & 1,80 & 5,86 & 6,76 & 7,41 & 8,49 & 65 & 730 \\
\hline $16: 00$ & 6,43 & 1,36 & 1,92 & 5,78 & 6,72 & 7,42 & 8,50 & 50 & 730 \\
\hline $17: 00$ & 6,38 & 1,38 & 1,99 & 5,66 & 6,68 & 7,37 & 8,48 & 41 & 730 \\
\hline $18: 00$ & 6,35 & 1,41 & 1,97 & 5,60 & 6,70 & 7,34 & 8,50 & 40 & 730 \\
\hline $19: 00$ & 6,31 & 1,44 & 1,95 & 5,46 & 6,67 & 7,41 & 8,46 & 34 & 730 \\
\hline $20: 00$ & 6,33 & 1,44 & 2,00 & 5,51 & 6,68 & 7,41 & 8,45 & 40 & 730 \\
\hline $21: 00$ & 6,36 & 1,45 & 2,02 & 5,58 & 6,77 & 7,43 & 8,49 & 38 & 730 \\
\hline $22: 00$ & 6,47 & 1,43 & 2,11 & 5,73 & 6,84 & 7,50 & 8,46 & 50 & 730 \\
\hline $23: 00$ & 6,58 & 1,42 & 1,84 & 5,92 & 6,95 & 7,62 & 8,49 & 47 & 732 \\
\hline
\end{tabular}


(A) Nível do reservatório por hora de acordo com o mês

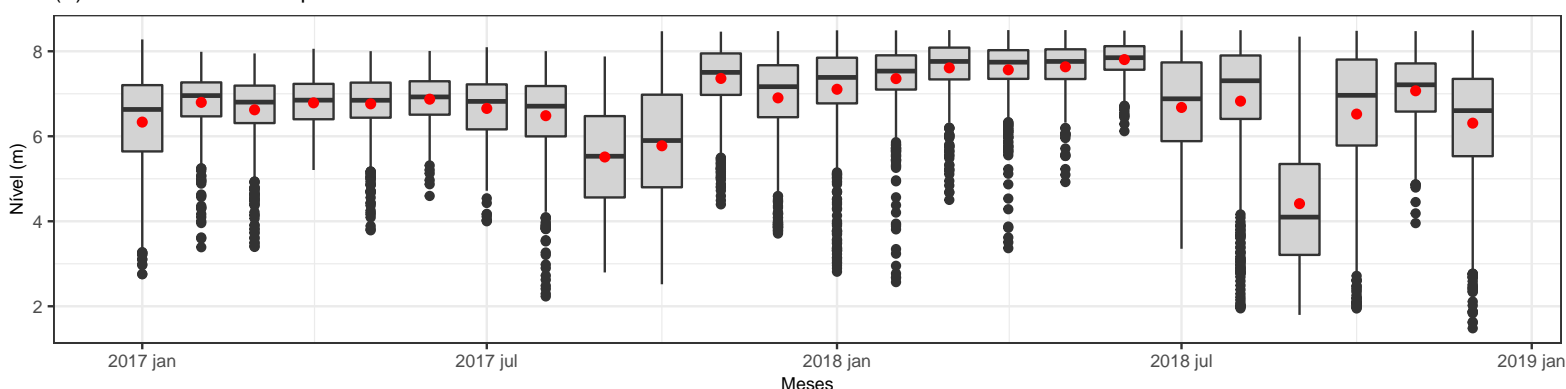

(B) Nível do reservatório por hora de acordo com o horário do dia

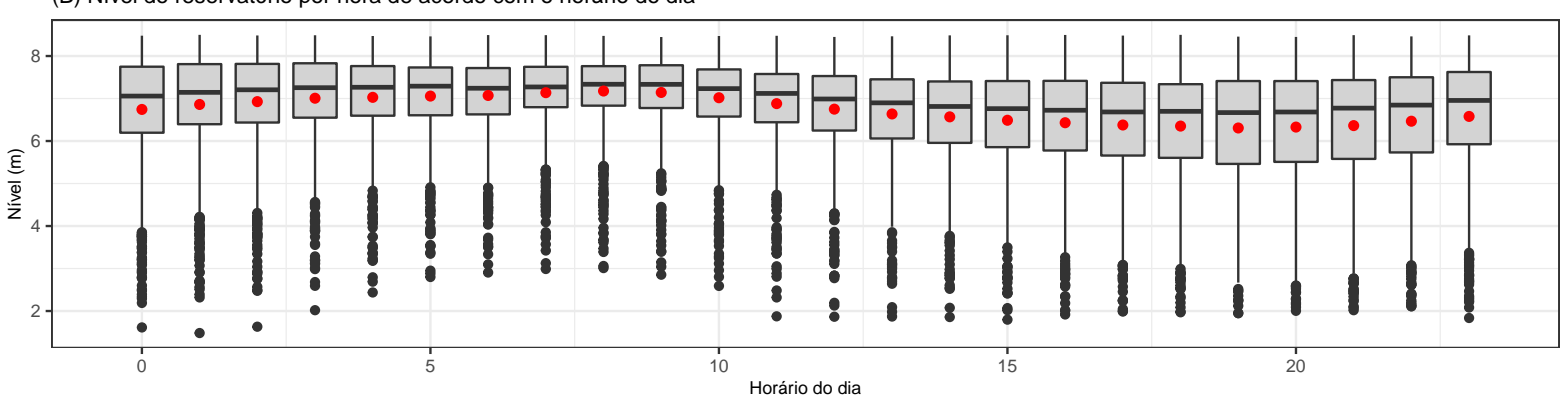

(C) Nível do reservatório por hora de acordo com dia da semana

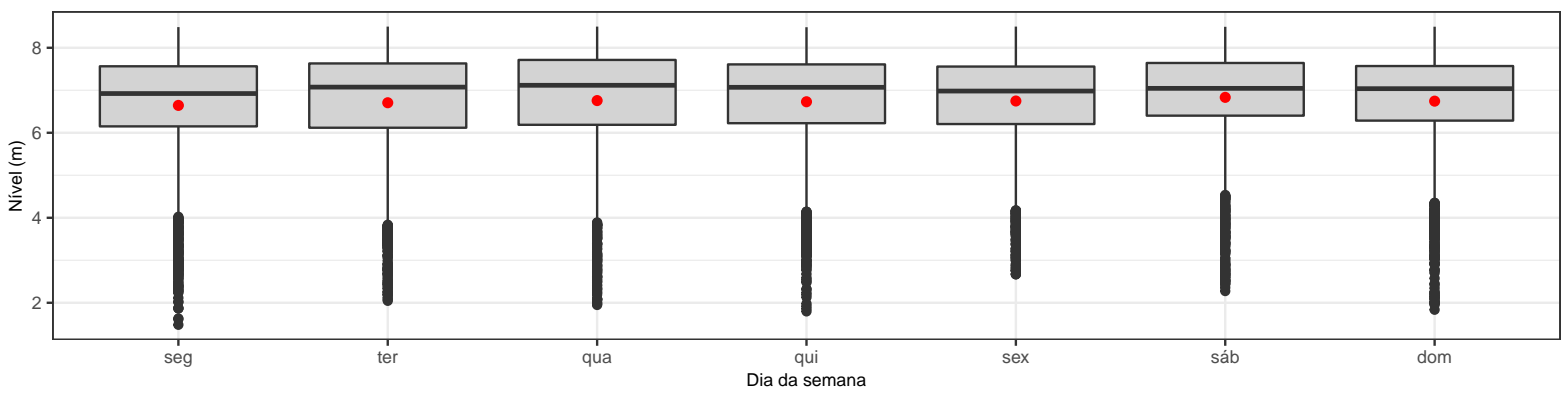

(D) Trecho da série de Nível De $1^{\circ}$ a 31 de janeiro de 2017

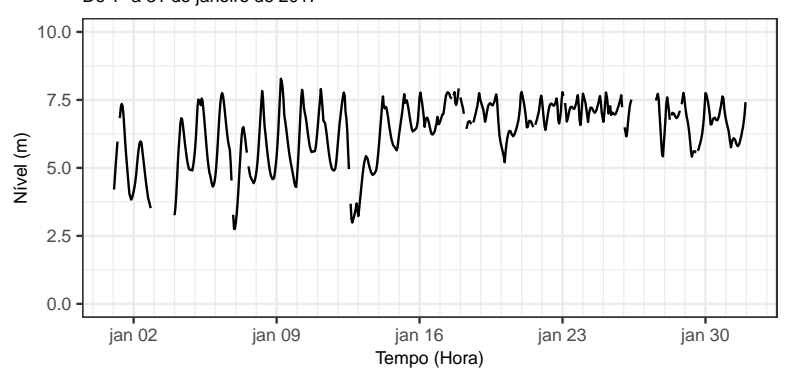

(E) Trecho da série de Nível

De 15 de dezembro de 2017 a 15 de janeiro de 2018

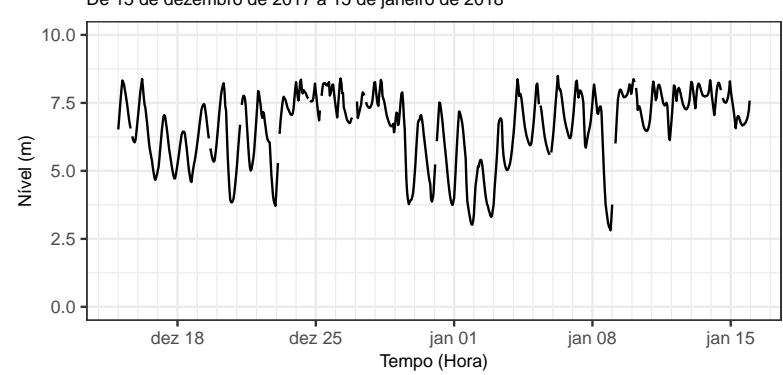

Figura B.1: Painel com alguns gráficos descritivos da série após limpeza primária de nível do reservatório de Peruı́be. Os gráficos $(A),(B)$ e $(C)$ são boxplots série de nível em $m$ de acordo com mês, horário do dia e dia semana, respectivamente. Os pontos vermelhos são as médias de cada período. Já os gráficos (D) e (E) são trechos selecionados da série. 
(A) Distribuição dos valores omissos do nível do reservatório de acordo com o mês

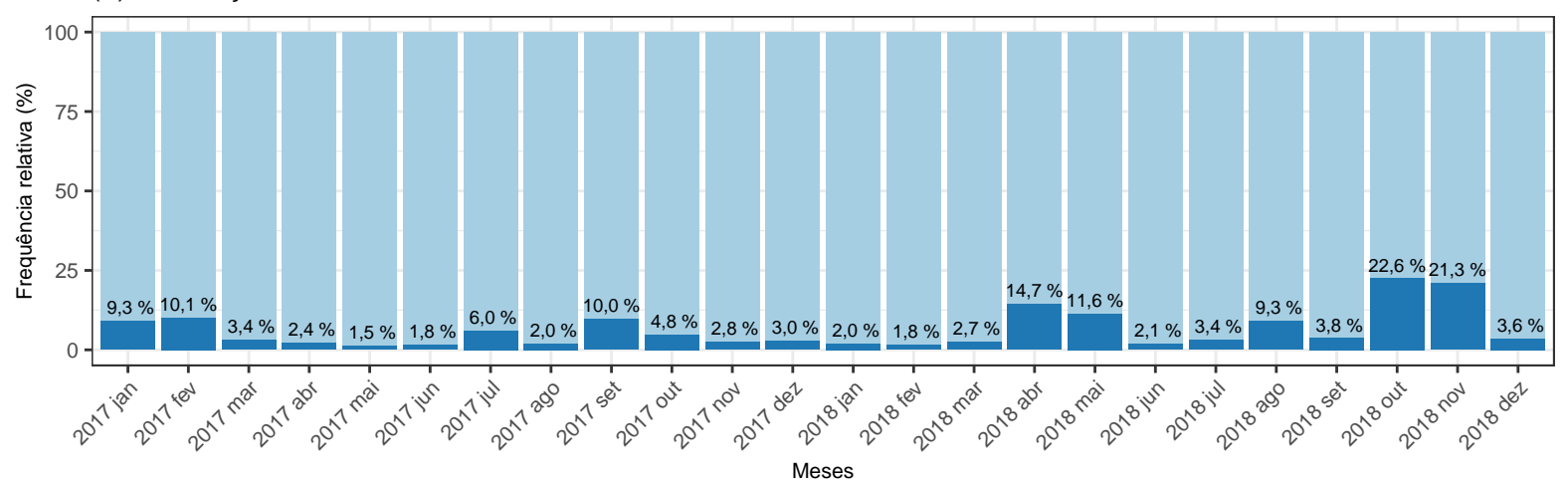

(B) Distribuição dos valores omissos do nível do reservatório de acordo com o dia da semana

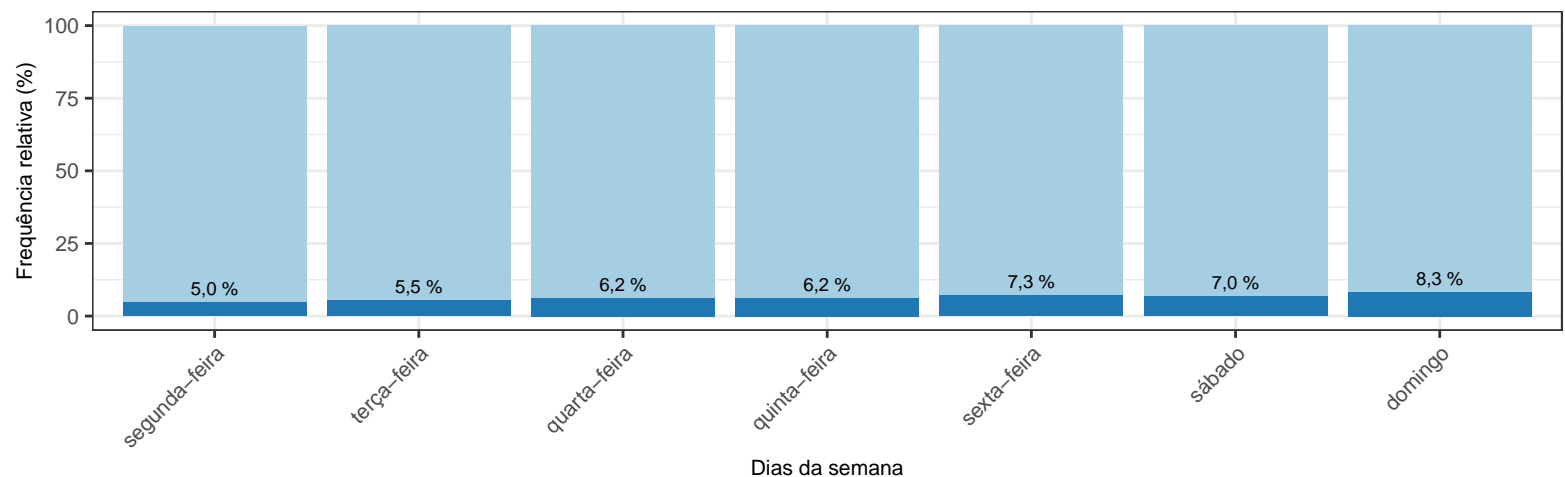

(C) Distribuição dos valores omissos do nível do reservatório de acordo com o horário do dia

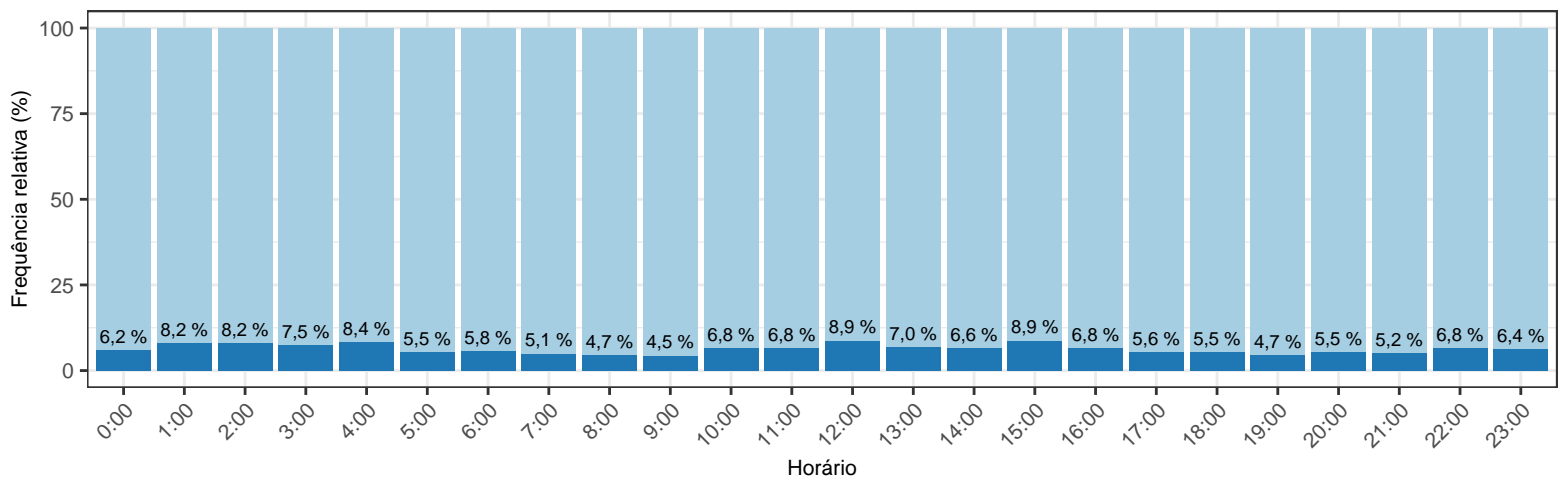

Figura B.2: Painel com alguns gráficos descritivos sobre a distribuição dos valores omissos presentes na série de nivel do reservatório de Peruíbe. O gráfico (A) é a distribuição os valores omissos ao longo dos meses da série; o gráfico (B) é a distribuição os valores omissos de acordo com o dias da semana e o gráfico (C) é a distribuição os valores omissos de acordo com os horários do dia. 
Tabela B.2: Medidas descritivas da série após limpeza primária de consumo demandado do reservatório de Peruíbe. As informações descritivas são apresentadas para a série em sua totalidade e desagregada por periodos mensais, por dias da semana e por horários do dia.

\begin{tabular}{|c|c|c|c|c|c|c|c|c|c|}
\hline Descritiva & Média & Desvio padrão & Mínimo & $1^{\mathcal{O}}$ Quartil & Mediana & $3^{\mathrm{O}}$ Quartil & Máximo & Omissos & Total \\
\hline \multicolumn{10}{|l|}{ Geral } \\
\hline Geral & 615 & 299 & 0,98 & 380 & 633 & 809 & 1684 & 4576 & 17519 \\
\hline \multicolumn{10}{|l|}{ Por ano e mês } \\
\hline 2017 jan & 631 & 297 & 2,30 & 393 & 630 & 844 & 1300 & 192 & 743 \\
\hline 2017 fev & 600 & 284 & 75,38 & 362 & 603 & 811 & 1224 & 71 & 673 \\
\hline 2017 mar & 511 & 269 & 34,61 & 258 & 557 & 706 & 1102 & 92 & 744 \\
\hline 2017 abr & 449 & 245 & 1,64 & 219 & 456 & 655 & 1110 & 76 & 720 \\
\hline 2017 mai & 433 & 221 & 1,42 & 222 & 430 & 629 & 1007 & 108 & 744 \\
\hline 2017 jun & 447 & 221 & 1,42 & 258 & 428 & 644 & 988 & 89 & 720 \\
\hline 2017 jul & 476 & 250 & 0,98 & 246 & 491 & 667 & 1630 & 72 & 744 \\
\hline 2017 ago & 566 & 270 & 86,86 & 345 & 574 & 746 & 1445 & 42 & 744 \\
\hline 2017 set & 736 & 291 & 6,92 & 556 & 720 & 964 & 1279 & 243 & 720 \\
\hline 2017 out & 475 & 234 & 1,86 & 270 & 506 & 673 & 984 & 211 & 743 \\
\hline 2017 nov & 487 & 218 & 12,19 & 313 & 520 & 677 & 867 & 110 & 720 \\
\hline 2017 dez & 518 & 244 & 11,96 & 306 & 535 & 714 & 1169 & 83 & 744 \\
\hline 2018 jan & 608 & 288 & 48,98 & 322 & 653 & 837 & 1251 & 60 & 744 \\
\hline $2018 \mathrm{fev}$ & 760 & 336 & 98,21 & 446 & 812 & 1003 & 1645 & 87 & 673 \\
\hline $2018 \mathrm{mar}$ & 781 & 240 & 168,23 & 649 & 824 & 945 & 1419 & 193 & 744 \\
\hline 2018 abr & 772 & 237 & 170,31 & 626 & 805 & 929 & 1443 & 321 & 720 \\
\hline 2018 mai & 757 & 209 & 170,86 & 664 & 785 & 911 & 1223 & 329 & 744 \\
\hline 2018 jun & 713 & 146 & 227,85 & 646 & 719 & 777 & 1324 & 299 & 720 \\
\hline 2018 jul & 660 & 206 & 215,76 & 556 & 663 & 733 & 1317 & 572 & 744 \\
\hline 2018 ago & 633 & 245 & 98,89 & 426 & 650 & 847 & 1130 & 265 & 744 \\
\hline 2018 set & 692 & 229 & 7,68 & 524 & 725 & 878 & 1183 & 319 & 720 \\
\hline 2018 out & 786 & 321 & 9,99 & 568 & 765 & 991 & 1570 & 342 & 744 \\
\hline 2018 nov & 803 & 365 & 17,44 & 512 & 884 & 1086 & 1519 & 243 & 719 \\
\hline $2018 \mathrm{dez}$ & 863 & 377 & 11,31 & 544 & 911 & 1174 & 1684 & 157 & 744 \\
\hline \multicolumn{10}{|c|}{ Por dia da semana } \\
\hline segunda-feira & 624 & 308 & 1,42 & 384 & 629 & 819 & 1645 & 630 & 2520 \\
\hline terça-feira & 593 & 293 & 0,98 & 361 & 620 & 785 & 1436 & 656 & 2496 \\
\hline quarta-feira & 603 & 293 & 1,42 & 368 & 625 & 804 & 1436 & 677 & 2496 \\
\hline quinta-feira & 622 & 304 & 2,30 & 385 & 640 & 806 & 1570 & 694 & 2496 \\
\hline sexta-feira & 633 & 298 & 30,73 & 404 & 652 & 840 & 1520 & 645 & 2496 \\
\hline sábado & 628 & 305 & 1,42 & 379 & 650 & 827 & 1510 & 591 & 2498 \\
\hline domingo & 603 & 286 & 1,86 & 374 & 613 & 779 & 1684 & 683 & 2517 \\
\hline \multicolumn{10}{|c|}{ Por horário do dia } \\
\hline $0: 00$ & 281 & 206 & 1,64 & 140 & 216 & 374 & 1635 & 356 & 727 \\
\hline $1: 00$ & 271 & 192 & 6,92 & 142 & 220 & 358 & 1262 & 388 & 730 \\
\hline $2: 00$ & 250 & 201 & 0,98 & 112 & 183 & 348 & 1190 & 390 & 730 \\
\hline $3: 00$ & 263 & 178 & 2,19 & 137 & 222 & 309 & 1124 & 367 & 730 \\
\hline $4: 00$ & 283 & 184 & 2,52 & 138 & 237 & 348 & 870 & 413 & 730 \\
\hline $5: 00$ & 331 & 170 & 43,17 & 213 & 304 & 379 & 1121 & 276 & 730 \\
\hline $6: 00$ & 382 & 167 & 69,64 & 269 & 361 & 467 & 1019 & 249 & 730 \\
\hline $7: 00$ & 492 & 153 & 1,86 & 387 & 444 & 585 & 1377 & 128 & 730 \\
\hline $8: 00$ & 615 & 182 & 2,84 & 478 & 594 & 722 & 1404 & 91 & 730 \\
\hline $9: 00$ & 807 & 194 & 67,58 & 686 & 772 & 949 & 1394 & 72 & 730 \\
\hline $10: 00$ & 859 & 213 & 45,78 & 714 & 830 & 1002 & 1510 & 89 & 730 \\
\hline $11: 00$ & 892 & 218 & 11,31 & 749 & 870 & 1020 & 1565 & 98 & 730 \\
\hline $12: 00$ & 885 & 215 & 30,27 & 752 & 859 & 1002 & 1565 & 106 & 730 \\
\hline $13: 00$ & 852 & 202 & 1,42 & 727 & 827 & 955 & 1549 & 105 & 730 \\
\hline $14: 00$ & 808 & 212 & 33,48 & 671 & 772 & 925 & 1585 & 96 & 730 \\
\hline $15: 00$ & 772 & 206 & 2,41 & 656 & 739 & 855 & 1586 & 91 & 730 \\
\hline $16: 00$ & 769 & 206 & 1,86 & 642 & 739 & 874 & 1630 & 93 & 730 \\
\hline $17: 00$ & 721 & 206 & 52,40 & 603 & 689 & 809 & 1645 & 93 & 730 \\
\hline $18: 00$ & 690 & 205 & 1,64 & 553 & 664 & 771 & 1582 & 87 & 730 \\
\hline $19: 00$ & 640 & 224 & 7,68 & 503 & 595 & 757 & 1574 & 85 & 730 \\
\hline $20: 00$ & 606 & 239 & 2,84 & 421 & 560 & 778 & 1445 & 109 & 730 \\
\hline $21: 00$ & 479 & 239 & 1,97 & 296 & 465 & 596 & 1510 & 162 & 730 \\
\hline $22: 00$ & 373 & 235 & 6,70 & 205 & 310 & 451 & 1466 & 297 & 730 \\
\hline $23: 00$ & 308 & 228 & 1,42 & 163 & 248 & 394 & 1684 & 335 & 732 \\
\hline
\end{tabular}




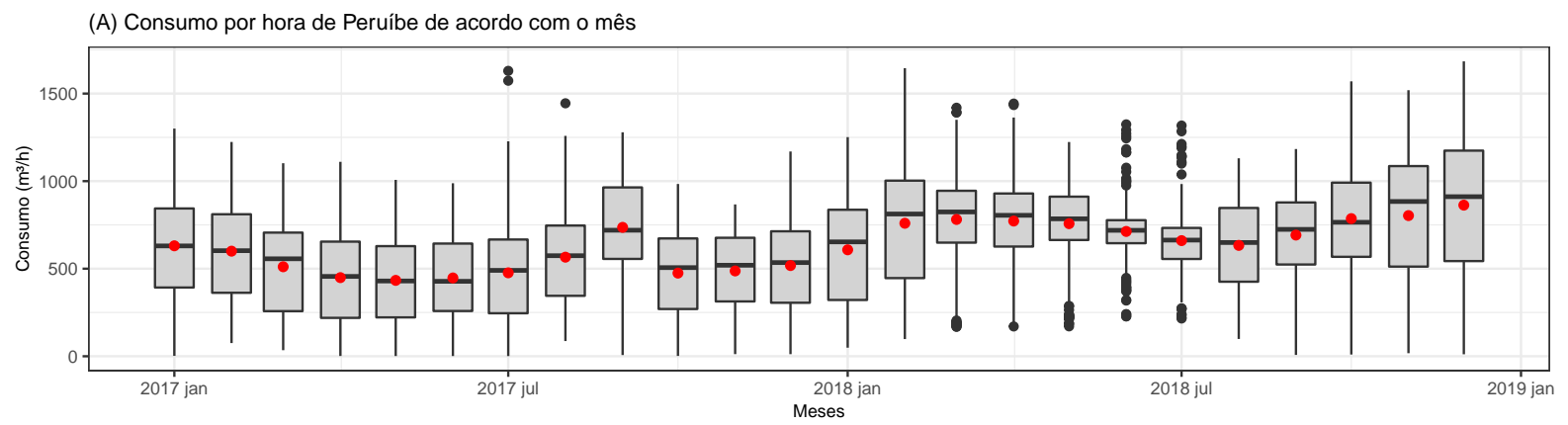

(B) Consumo por hora de Peruíbe de acordo com o horário do dia

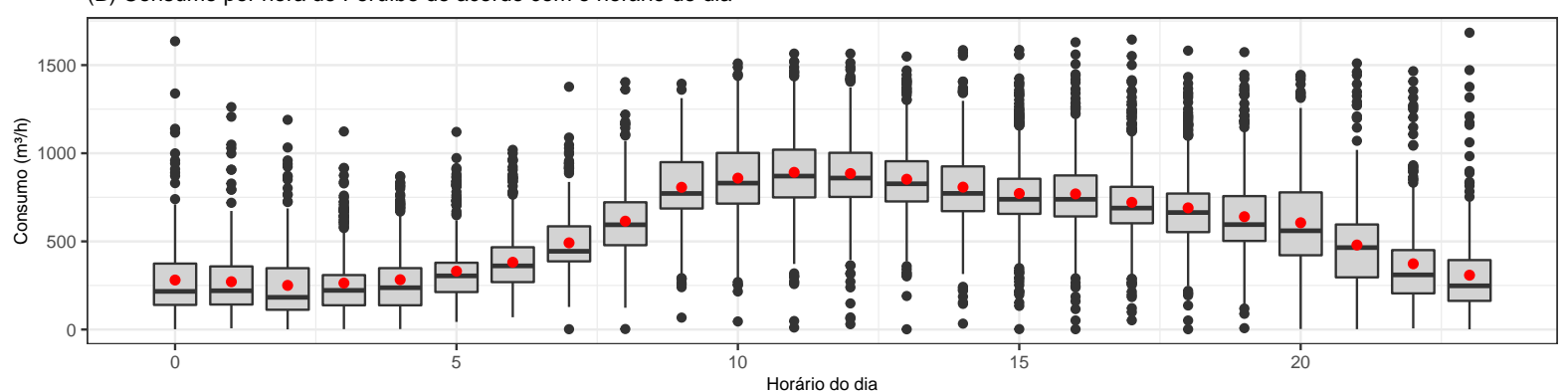

(C) Consumo por hora de Peruíbe de acordo com dia da semana

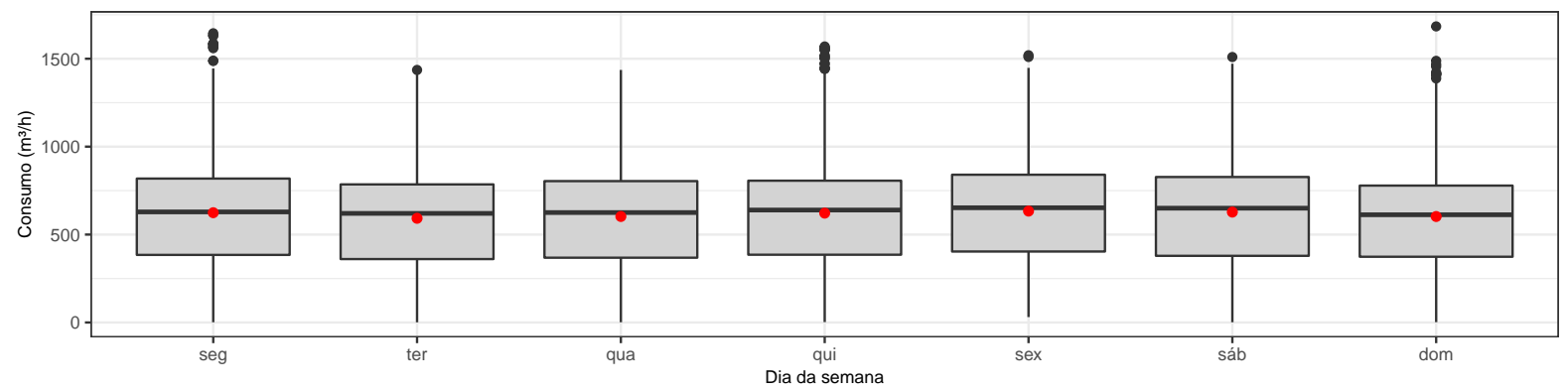

(D) Trecho da série de consumo de Peruíbe

(E) Trecho da série de consumo de Peruíbe
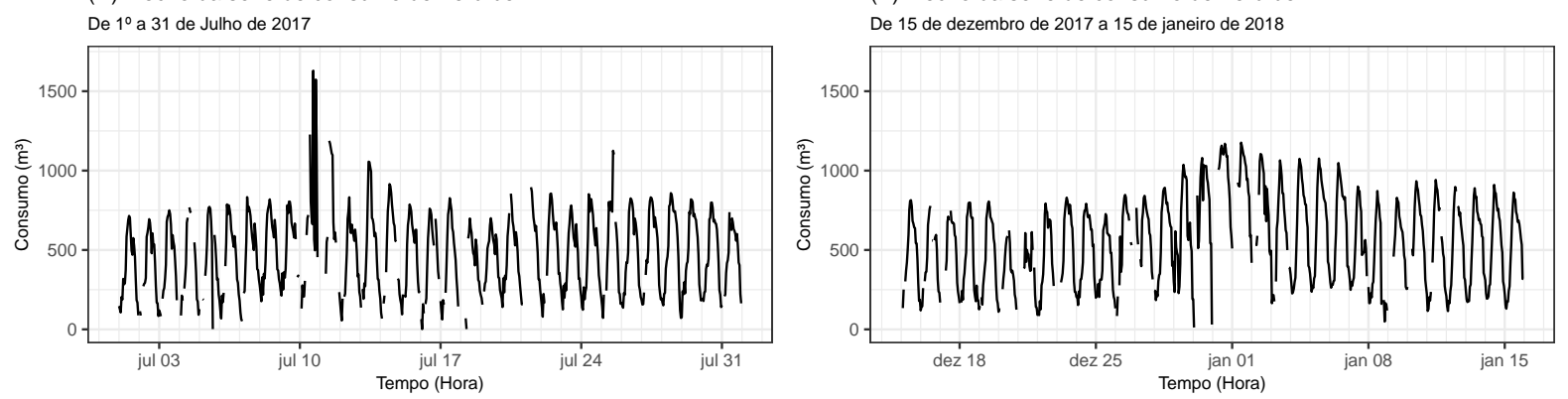

Figura B.3: Painel com alguns gráficos descritivos da série após limpeza primária de consumo demandado do reservatório de Peruibe. Os gráficos $(A),(B)$ e (C) são boxplots série de consumo em $\mathrm{m}^{3}$ de acordo com mês, horário do dia e dia semana, respectivamente. Os pontos vermelhos são as médias de cada período. Já os gráficos (D) e (E) são trechos selecionados da série. 
(A) Distribuição dos valores omissos do consumo do reservatório de acordo com o mês

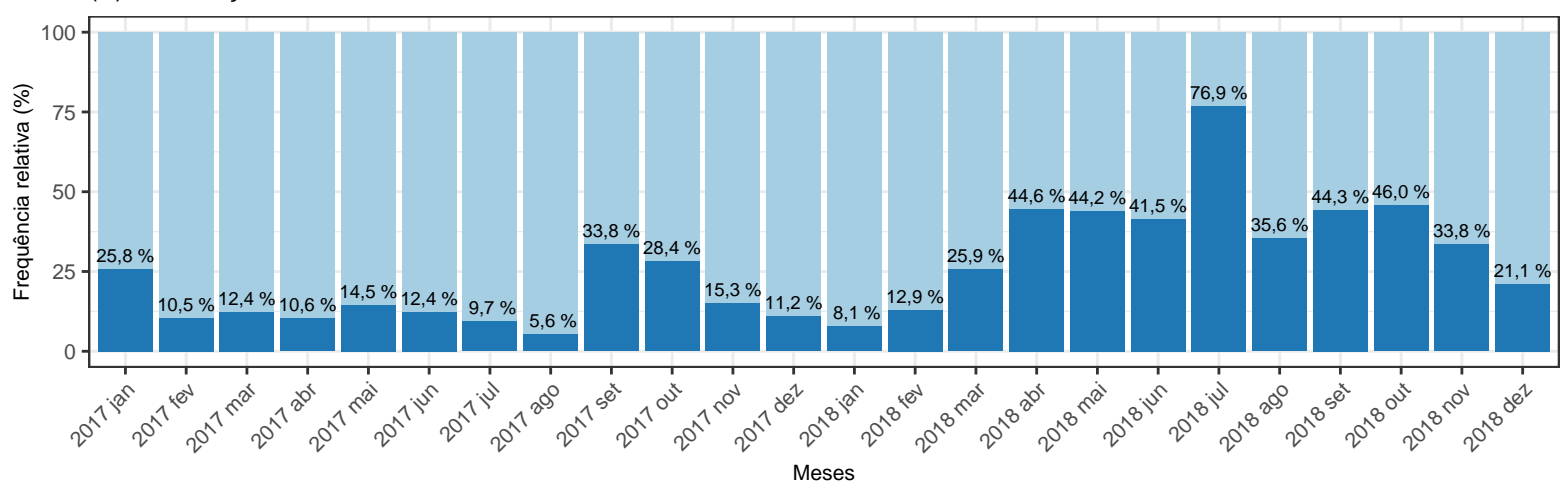

(B) Distribuição dos valores omissos do consumo do reservatório de acordo com o dia da semana

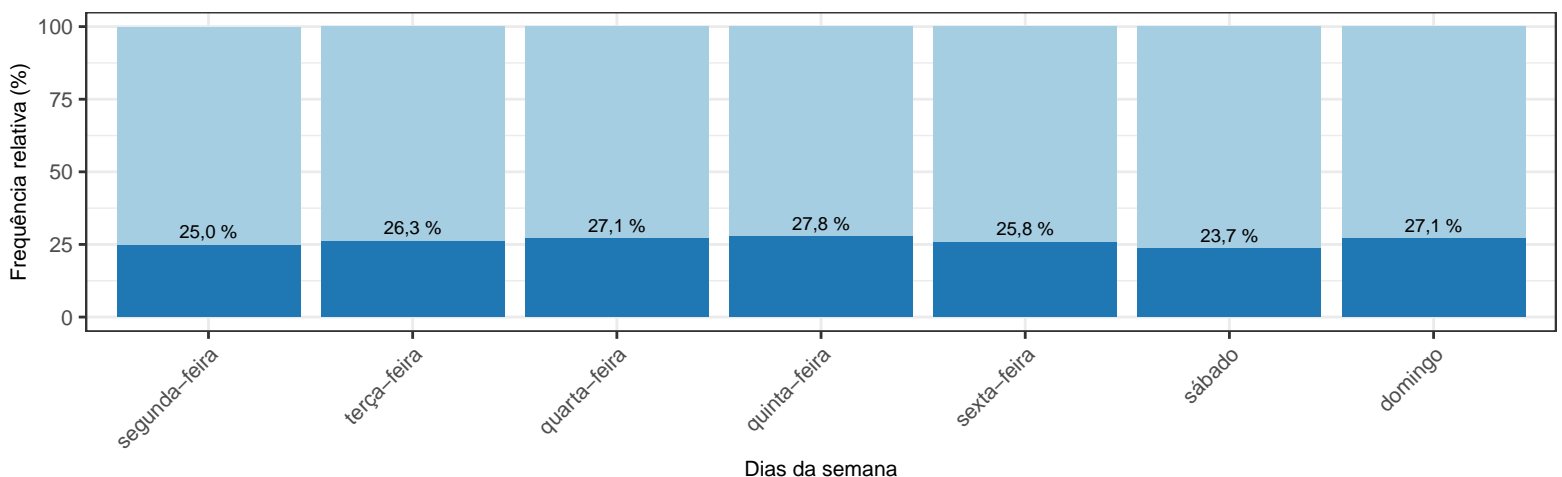

(C) Distribuição dos valores omissos do consumo do reservatório de acordo com o horário do dia

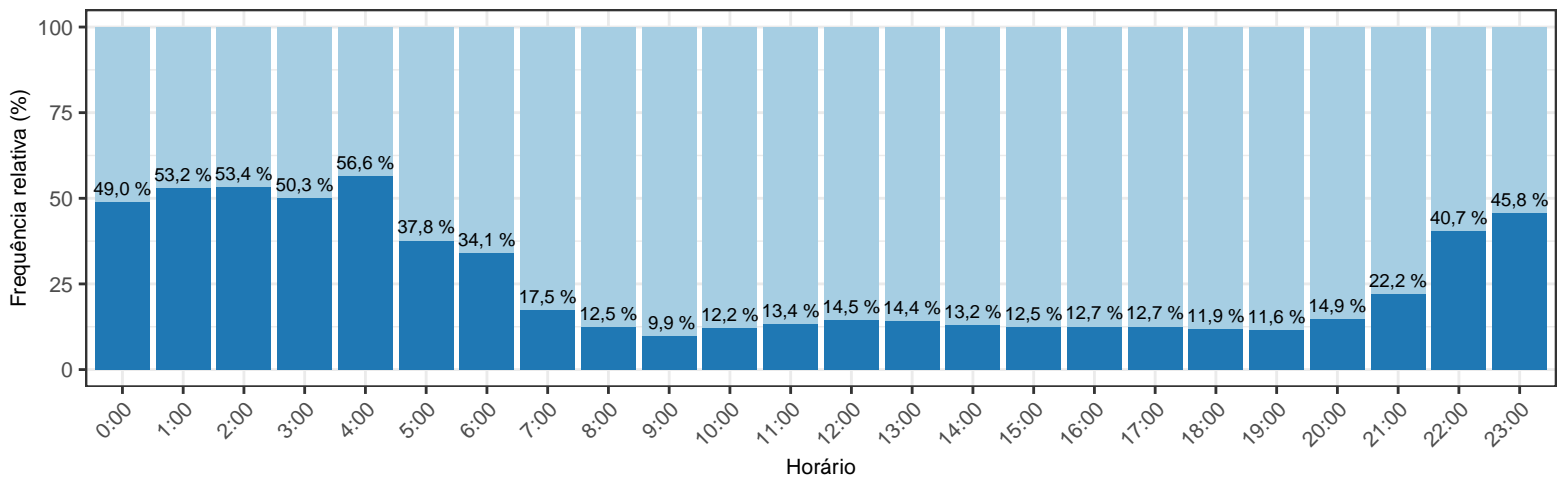

Figura B.4: Painel com alguns gráficos descritivos sobre a distribuição dos valores omissos presentes na série de consumo demandado do reservatório de Peruíbe. O gráfico (A) é a distribuição os valores omissos ao longo dos meses da série; o gráfico (B) é a distribuição os valores omissos de acordo com o dias da semana e o gráfico $(C)$ é a distribuição os valores omissos de acordo com os horários do dia. 
Tabela B.3: Medidas descritivas da série após limpeza primária de vazão de entrada do reservatório de Peruíbe. As informações descritivas são apresentadas para a série em sua totalidade e desagregada por periodos mensais, por dias da semana e por horários do dia.

\begin{tabular}{|c|c|c|c|c|c|c|c|c|c|}
\hline Descritiva & Média & Desvio padrão & Mínimo & $1^{\mathrm{O}}$ Quartil & Mediana & $3^{\mathcal{O}}$ Quartil & Máximo & Omissos & Total \\
\hline \multicolumn{10}{|l|}{ Geral } \\
\hline Geral & 196 & 48,60 & 20,5 & 166,5 & 216 & 233 & 276 & 1416 & 17519 \\
\hline \multicolumn{10}{|l|}{ Por ano e mês } \\
\hline 2017 jan & 233 & 6,72 & 214,2 & 230,9 & 233 & 235 & 250 & 80 & 743 \\
\hline $2017 \mathrm{fev}$ & 224 & 11,77 & 199,7 & 217,5 & 219 & 231 & 270 & 85 & 673 \\
\hline 2017 mar & 225 & 8,67 & 203,7 & 219,1 & 221 & 234 & 248 & 38 & 744 \\
\hline 2017 abr & 225 & 8,31 & 213,8 & 217,7 & 219 & 233 & 247 & 31 & 720 \\
\hline 2017 mai & 215 & 20,11 & 38,4 & 209,7 & 215 & 226 & 244 & 35 & 744 \\
\hline 2017 jun & 217 & 9,56 & 197,3 & 209,1 & 218 & 223 & 238 & 19 & 720 \\
\hline 2017 jul & 176 & 22,51 & 128,3 & 161,1 & 177 & 189 & 236 & 56 & 744 \\
\hline 2017 ago & 153 & 30,24 & 116,8 & 131,0 & 141 & 166 & 234 & 16 & 744 \\
\hline 2017 set & 113 & 27,93 & 81,5 & 95,0 & 102 & 121 & 220 & 55 & 720 \\
\hline 2017 out & 124 & 49,52 & 57,1 & 80,9 & 109 & 172 & 228 & 28 & 743 \\
\hline 2017 nov & 192 & 34,26 & 110,3 & 162,6 & 209 & 217 & 231 & 27 & 720 \\
\hline 2017 dez & 207 & 24,28 & 93,8 & 195,8 & 208 & 225 & 249 & 34 & 744 \\
\hline 2018 jan & 244 & 5,96 & 234,6 & 240,1 & 242 & 244 & 261 & 22 & 744 \\
\hline 2018 fev & 228 & 14,79 & 197,7 & 216,1 & 229 & 238 & 257 & 25 & 673 \\
\hline 2018 mar & 243 & 7,94 & 231,0 & 236,0 & 239 & 250 & 276 & 40 & 744 \\
\hline 2018 abr & 239 & 13,32 & 191,6 & 235,3 & 238 & 250 & 260 & 111 & 720 \\
\hline 2018 mai & 230 & 13,82 & 196,1 & 224,3 & 232 & 240 & 256 & 90 & 744 \\
\hline 2018 jun & 206 & 18,66 & 165,6 & 191,9 & 203 & 221 & 245 & 22 & 720 \\
\hline 2018 jul & 136 & 31,86 & 62,4 & 110,0 & 126 & 160 & 220 & 13 & 744 \\
\hline 2018 ago & 149 & 37,13 & 47,2 & 120,5 & 145 & 178 & 243 & 72 & 744 \\
\hline 2018 set & 115 & 23,47 & 89,1 & 100,8 & 108 & 119 & 220 & 42 & 720 \\
\hline 2018 out & 201 & 46,31 & 87,8 & 204,9 & 215 & 223 & 255 & 175 & 744 \\
\hline 2018 nov & 218 & 15,71 & 96,3 & 213,6 & 217 & 219 & 251 & 161 & 719 \\
\hline $2018 \mathrm{dez}$ & 204 & 40,91 & 20,5 & 200,7 & 215 & 218 & 250 & 139 & 744 \\
\hline \multicolumn{10}{|c|}{ Por dia da semana } \\
\hline segunda-feira & 196 & 48,17 & 66,3 & 168,7 & 215 & 233 & 260 & 185 & 2520 \\
\hline terça-feira & 196 & 48,71 & 66,7 & 166,8 & 216 & 233 & 261 & 170 & 2496 \\
\hline quarta-feira & 194 & 51,15 & 27,4 & 156,3 & 216 & 233 & 276 & 185 & 2496 \\
\hline quinta-feira & 195 & 49,72 & 20,5 & 165,4 & 216 & 233 & 259 & 203 & 2496 \\
\hline sexta-feira & 196 & 48,27 & 57,1 & 174,1 & 215 & 232 & 259 & 197 & 2496 \\
\hline sábado & 197 & 46,11 & 76,3 & 171,6 & 216 & 232 & 259 & 208 & 2498 \\
\hline domingo & 196 & 47,91 & 70,7 & 166,2 & 215 & 233 & 260 & 268 & 2517 \\
\hline \multicolumn{10}{|c|}{ Por horário do dia } \\
\hline $0: 00$ & 198 & 49,46 & 28,5 & 171,7 & 218 & 234 & 258 & 48 & 727 \\
\hline $1: 00$ & 200 & 49,36 & 20,7 & 172,9 & 218 & 235 & 258 & 53 & 730 \\
\hline $2: 00$ & 201 & 49,83 & 59,4 & 174,5 & 219 & 235 & 275 & 48 & 730 \\
\hline $3: 00$ & 201 & 50,40 & 21,3 & 174,7 & 220 & 235 & 260 & 54 & 730 \\
\hline $4: 00$ & 202 & 50,31 & 20,5 & 173,6 & 223 & 237 & 274 & 47 & 730 \\
\hline $5: 00$ & 202 & 50,13 & 61,2 & 175,0 & 220 & 236 & 276 & 53 & 730 \\
\hline $6: 00$ & 200 & 49,00 & 62,6 & 174,2 & 219 & 235 & 274 & 47 & 730 \\
\hline $7: 00$ & 196 & 47,73 & 61,6 & 168,0 & 216 & 233 & 275 & 52 & 730 \\
\hline $8: 00$ & 195 & 47,57 & 62,1 & 168,2 & 215 & 232 & 275 & 50 & 730 \\
\hline $9: 00$ & 193 & 47,70 & 62,8 & 164,4 & 214 & 230 & 274 & 58 & 730 \\
\hline $10: 00$ & 192 & 47,64 & 37,5 & 161,7 & 214 & 229 & 273 & 65 & 730 \\
\hline $11: 00$ & 193 & 46,20 & 63,4 & 165,0 & 213 & 226 & 270 & 81 & 730 \\
\hline $12: 00$ & 192 & 46,53 & 47,2 & 164,8 & 213 & 227 & 269 & 73 & 730 \\
\hline $13: 00$ & 192 & 46,94 & 47,5 & 163,5 & 212 & 225 & 267 & 75 & 730 \\
\hline $14: 00$ & 192 & 46,88 & 63,2 & 164,0 & 212 & 226 & 269 & 73 & 730 \\
\hline $15: 00$ & 192 & 46,98 & 40,3 & 164,8 & 213 & 226 & 267 & 74 & 730 \\
\hline $16: 00$ & 192 & 48,08 & 38,7 & 163,5 & 214 & 229 & 269 & 60 & 730 \\
\hline $17: 00$ & 192 & 48,00 & 38,4 & 164,9 & 214 & 228 & 267 & 59 & 730 \\
\hline $18: 00$ & 193 & 47,62 & 39,7 & 164,7 & 214 & 228 & 256 & 62 & 730 \\
\hline $19: 00$ & 193 & 49,01 & 36,4 & 163,9 & 214 & 232 & 257 & 61 & 730 \\
\hline $20: 00$ & 194 & 49,67 & 29,7 & 164,3 & 215 & 232 & 256 & 56 & 730 \\
\hline $21: 00$ & 195 & 49,56 & 31,6 & 165,2 & 216 & 233 & 256 & 50 & 730 \\
\hline $22: 00$ & 197 & 49,38 & 29,2 & 167,4 & 216 & 233 & 258 & 57 & 730 \\
\hline $23: 00$ & 198 & 49,36 & 27,4 & 170,7 & 218 & 234 & 260 & 60 & 732 \\
\hline
\end{tabular}


(A) Vazão de entrada do reservatório por hora de acordo com o mês

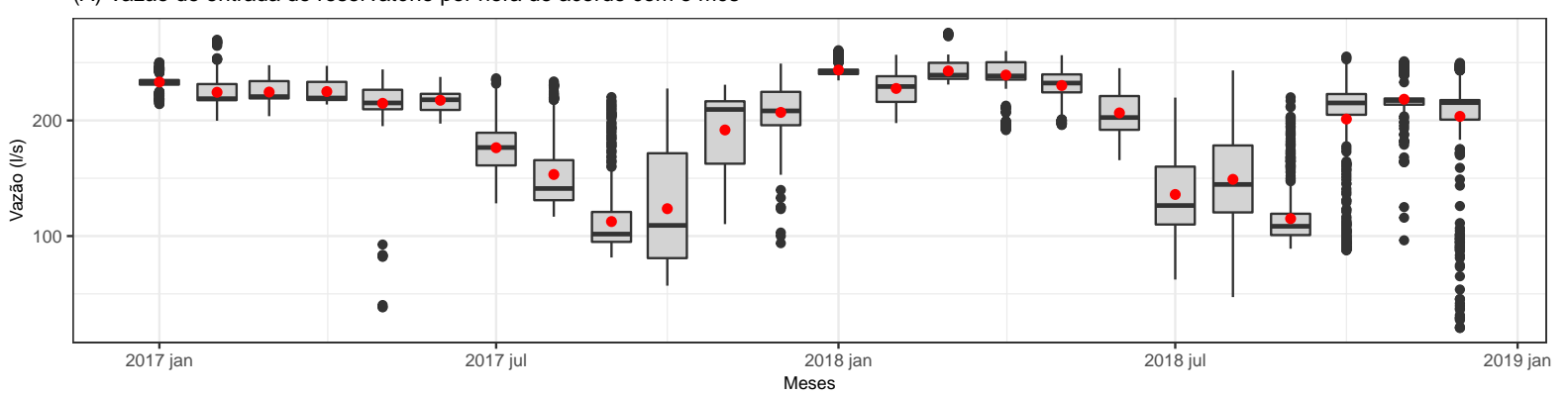

(B) Vazão de entrada do reservatório por hora de acordo com o horário do dia

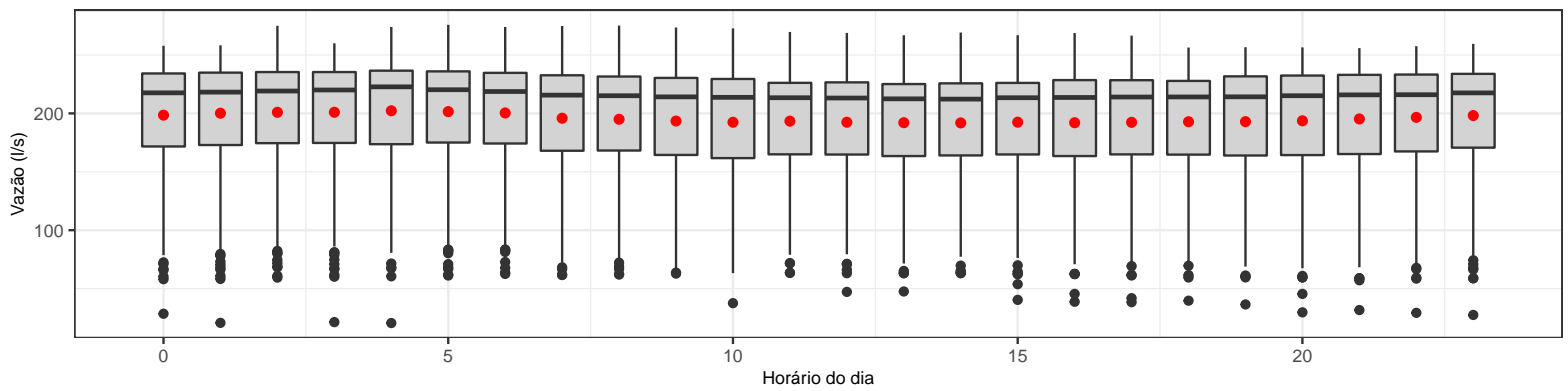

(C) Vazão de entrada do reservatório por hora de acordo com dia da semana

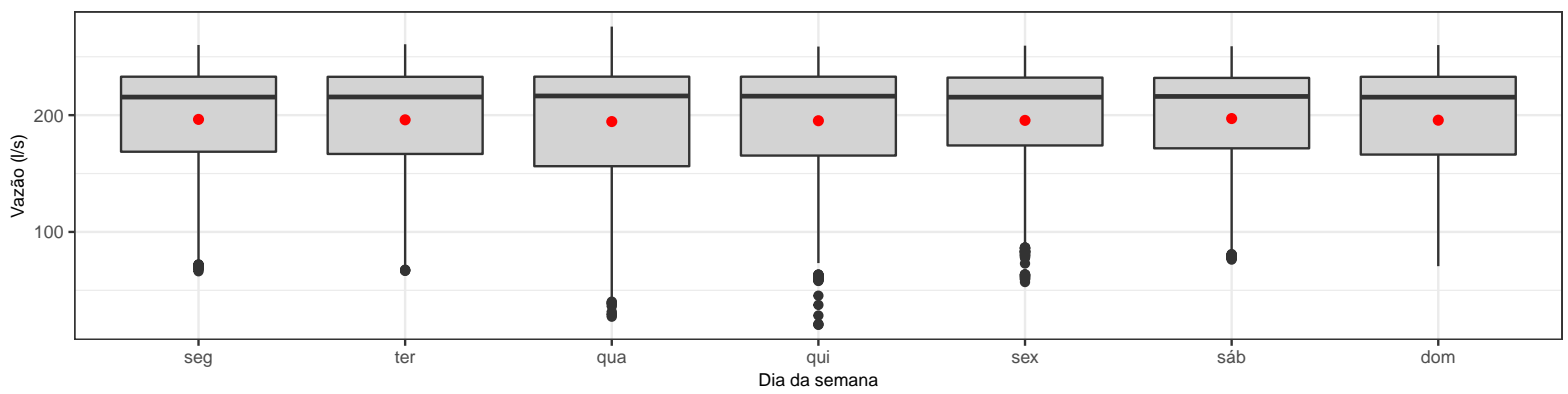

(D) Trecho da série de vazão de entrada

(E) Trecho da série de vazão de entrada De $1^{\circ}$ a 30 de Julho de 2017

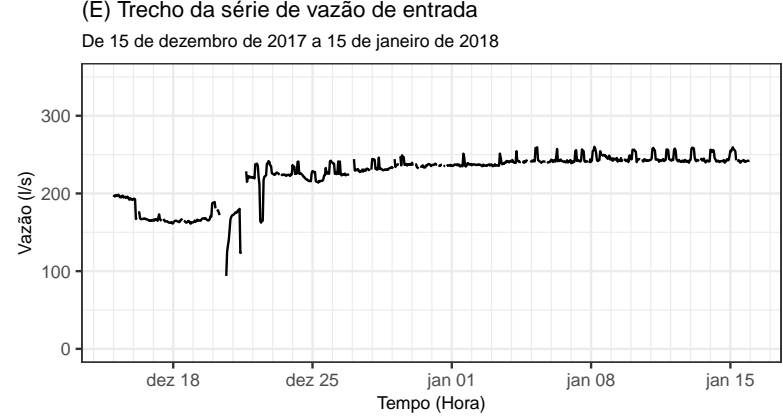

Figura B.5: Painel com alguns gráficos descritivos da série após limpeza primária de vazão de entrada do reservatório de Peruibe. Os gráficos $(A),(B)$ e (C) são boxplots série de vazão em l/s de acordo com mês, horário do dia e dia semana, respectivamente. Os pontos vermelhos são as médias de cada período. Já os gráficos (D) e (E) são trechos selecionados da série. 
(A) Distribuição dos valores omissos da vazão de entrada do reservatório de acordo com o mês

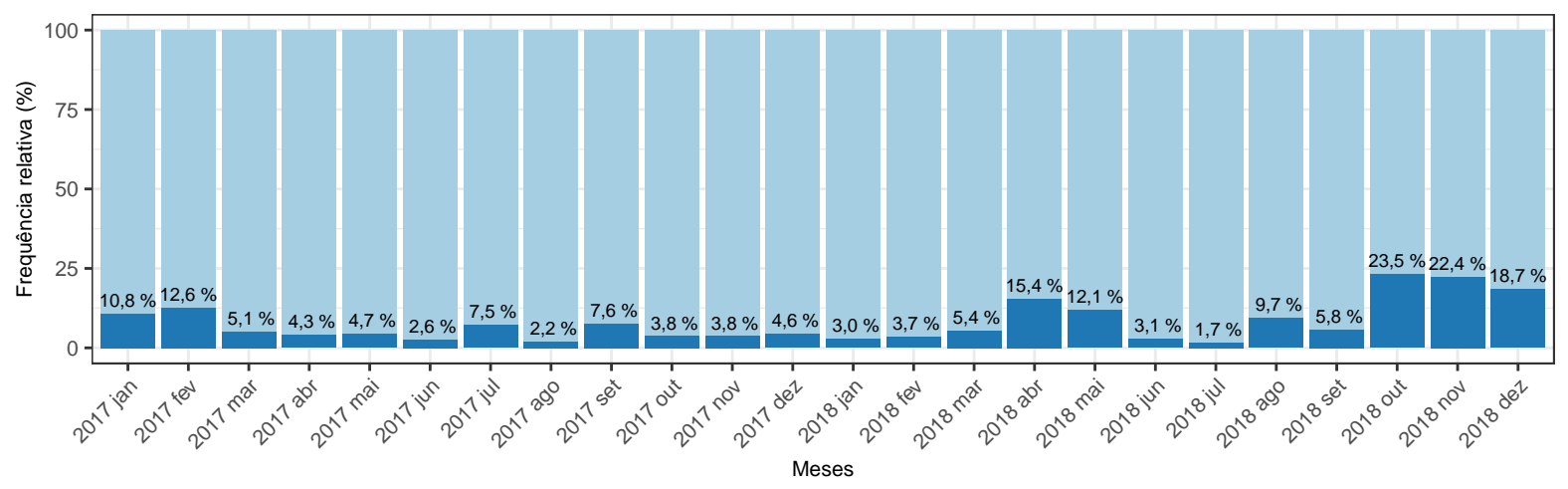

(B) Distribuição dos valores omissos da vazão de entrada do reservatório de acordo com o dia da semana

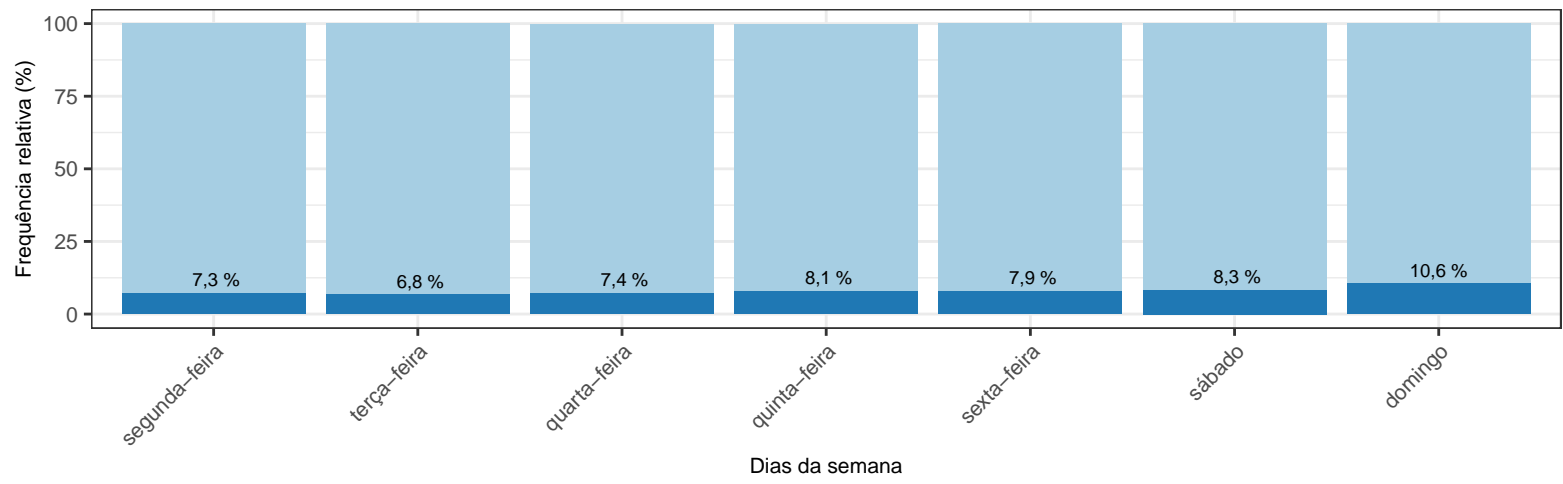

(C) Distribuição dos valores omissos da vazão de entrada do reservatório de acordo com o horário do dia

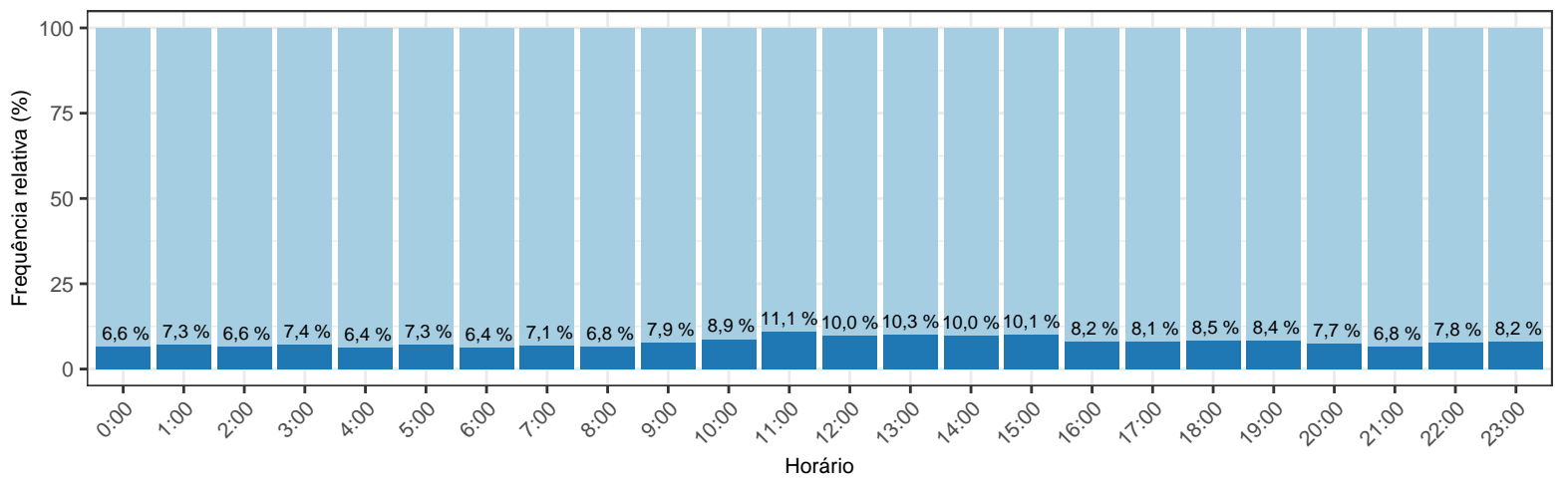

Figura B.6: Painel com alguns gráficos descritivos sobre a distribuição dos valores omissos presentes na série de vazão de entrada do reservatório de Perußbe. O gráfico (A) é a distribuição os valores omissos ao longo dos meses da série; o gráfico $(B)$ é a distribuição os valores omissos de acordo com o dias da semana e o gráfico $(C)$ é a distribuição os valores omissos de acordo com os horários do dia. 
Tabela B.4: Medidas descritivas da série após limpeza primária de vazão de saída do reservatório para o Norte de Peruíbe. As informações descritivas são apresentadas para a série em sua totalidade e desagregada por periodos mensais, por dias da semana e por horários do dia.

\begin{tabular}{|c|c|c|c|c|c|c|c|c|c|}
\hline Descritiva & Média & Desvio padrão & Mínimo & $1^{\mathcal{O}}$ Quartil & Mediana & $3^{\mathrm{O}}$ Quartil & Máximo & Omissos & Total \\
\hline \multicolumn{10}{|l|}{ Geral } \\
\hline Geral & 84,4 & 44,3 & 0,09 & 54,3 & 83,9 & 106,4 & 370 & 2224 & 17519 \\
\hline \multicolumn{10}{|l|}{ Por ano e mês } \\
\hline 2017 jan & 71,3 & 24,8 & 0,09 & 53,3 & 78,2 & 91,1 & 111 & 187 & 743 \\
\hline 2017 fev & 74,7 & 24,6 & 20,51 & 56,4 & 75,4 & 94,8 & 121 & 65 & 673 \\
\hline 2017 mar & 72,9 & 26,2 & 9,13 & 51,9 & 80,4 & 92,8 & 120 & 46 & 744 \\
\hline 2017 abr & 68,1 & 27,4 & 0,09 & 48,0 & 78,7 & 88,1 & 124 & 16 & 720 \\
\hline 2017 mai & 70,0 & 26,7 & 0,09 & 54,8 & 81,8 & 90,1 & 125 & 40 & 744 \\
\hline 2017 jun & 70,0 & 24,1 & 0,09 & 53,5 & 73,0 & 90,5 & 116 & 20 & 720 \\
\hline 2017 jul & 72,6 & 29,9 & 0,09 & 57,6 & 75,5 & 92,0 & 370 & 38 & 744 \\
\hline 2017 ago & 73,5 & 29,0 & 0,09 & 55,4 & 78,5 & 91,4 & 370 & 7 & 744 \\
\hline 2017 set & 65,5 & 32,4 & 0,09 & 47,0 & 77,3 & 91,3 & 108 & 87 & 720 \\
\hline 2017 out & 59,9 & 33,5 & 0,09 & 26,9 & 72,4 & 88,1 & 119 & 103 & 743 \\
\hline 2017 nov & 69,3 & 26,4 & 0,09 & 47,7 & 78,9 & 91,3 & 106 & 15 & 720 \\
\hline $2017 \mathrm{dez}$ & 66,1 & 26,8 & 0,09 & 42,6 & 71,8 & 86,4 & 117 & 29 & 744 \\
\hline 2018 jan & 69,8 & 41,2 & 0,09 & 35,4 & 67,9 & 88,6 & 194 & 24 & 744 \\
\hline 2018 fev & 111,8 & 53,2 & 0,09 & 65,3 & 122,6 & 154,2 & 229 & 18 & 673 \\
\hline 2018 mar & 120,5 & 43,0 & 0,09 & 95,0 & 127,7 & 155,2 & 237 & 15 & 744 \\
\hline 2018 abr & 116,4 & 42,4 & 0,18 & 85,6 & 121,3 & 150,9 & 236 & 144 & 720 \\
\hline 2018 mai & 118,8 & 40,0 & 0,09 & 85,8 & 128,2 & 153,6 & 180 & 137 & 744 \\
\hline 2018 jun & 111,3 & 39,8 & 0,18 & 82,6 & 118,7 & 136,8 & 227 & 11 & 720 \\
\hline 2018 jul & 100,0 & 45,7 & 0,09 & 67,5 & 104,4 & 129,6 & 207 & 464 & 744 \\
\hline 2018 ago & 93,4 & 50,7 & 0,09 & 45,1 & 97,1 & 138,7 & 188 & 97 & 744 \\
\hline 2018 set & 87,6 & 56,8 & 0,09 & 36,1 & 98,1 & 138,8 & 191 & 122 & 720 \\
\hline 2018 out & 105,6 & 60,9 & 0,09 & 50,4 & 116,3 & 151,0 & 240 & 194 & 744 \\
\hline 2018 nov & 78,5 & 55,6 & 0,09 & 28,9 & 82,4 & 118,3 & 225 & 230 & 719 \\
\hline $2018 \mathrm{dez}$ & 95,7 & 65,8 & 0,09 & 41,3 & 100,2 & 139,3 & 261 & 115 & 744 \\
\hline \multicolumn{10}{|c|}{ Por dia da semana } \\
\hline segunda-feira & 84,9 & 45,9 & 0,09 & 54,5 & 83,4 & 108,3 & 370 & 296 & 2520 \\
\hline terça-feira & 81,5 & 42,9 & 0,09 & 51,6 & 82,3 & 101,5 & 237 & 304 & 2496 \\
\hline quarta-feira & 82,4 & 42,4 & 0,09 & 53,3 & 82,7 & 103,4 & 231 & 301 & 2496 \\
\hline quinta-feira & 86,2 & 45,2 & 0,09 & 55,6 & 85,6 & 112,0 & 370 & 329 & 2496 \\
\hline sexta-feira & 85,3 & 45,5 & 0,09 & 54,3 & 84,8 & 108,2 & 277 & 320 & 2496 \\
\hline sábado & 86,5 & 44,9 & 0,09 & 55,5 & 86,3 & 107,8 & 261 & 307 & 2498 \\
\hline domingo & 83,8 & 43,1 & 0,09 & 54,5 & 83,1 & 103,2 & 241 & 367 & 2517 \\
\hline \multicolumn{10}{|c|}{ Por horário do dia } \\
\hline $0: 00$ & 44,5 & 31,2 & 0,09 & 26,8 & 35,1 & 63,1 & 239 & 110 & 727 \\
\hline $1: 00$ & 44,0 & 32,7 & 0,09 & 23,0 & 33,7 & 69,5 & 239 & 129 & 730 \\
\hline $2: 00$ & 40,6 & 33,2 & 0,09 & 19,6 & 31,2 & 56,6 & 237 & 134 & 730 \\
\hline $3: 00$ & 46,5 & 32,1 & 0,09 & 28,6 & 45,4 & 60,8 & 370 & 137 & 730 \\
\hline $4: 00$ & 41,5 & 29,3 & 0,09 & 22,0 & 41,7 & 56,1 & 233 & 150 & 730 \\
\hline $5: 00$ & 55,3 & 29,5 & 0,09 & 40,6 & 56,4 & 73,4 & 277 & 130 & 730 \\
\hline $6: 00$ & 64,2 & 27,0 & 0,09 & 49,0 & 68,7 & 79,8 & 218 & 103 & 730 \\
\hline $7: 00$ & 77,3 & 23,6 & 0,09 & 71,5 & 78,3 & 88,8 & 225 & 80 & 730 \\
\hline $8: 00$ & 95,6 & 27,4 & 0,09 & 81,9 & 88,0 & 116,7 & 236 & 72 & 730 \\
\hline $9: 00$ & 109,6 & 33,6 & 0,09 & 91,3 & 97,5 & 143,1 & 228 & 64 & 730 \\
\hline $10: 00$ & 117,5 & 35,9 & 0,18 & 93,5 & 99,4 & 153,7 & 229 & 73 & 730 \\
\hline $11: 00$ & 117,1 & 38,4 & 0,09 & 90,7 & 100,2 & 156,7 & 229 & 80 & 730 \\
\hline $12: 00$ & 118,7 & 36,1 & 0,09 & 96,2 & 103,0 & 154,0 & 229 & 80 & 730 \\
\hline $13: 00$ & 116,0 & 34,3 & 0,09 & 93,7 & 100,8 & 148,7 & 225 & 82 & 730 \\
\hline $14: 00$ & 114,3 & 34,2 & 0,18 & 94,7 & 101,7 & 143,3 & 238 & 80 & 730 \\
\hline $15: 00$ & 105,5 & 31,8 & 0,09 & 87,9 & 95,4 & 129,0 & 240 & 71 & 730 \\
\hline $16: 00$ & 103,4 & 36,9 & 0,09 & 82,1 & 90,5 & 133,2 & 370 & 74 & 730 \\
\hline $17: 00$ & 96,0 & 34,6 & 0,09 & 74,5 & 85,2 & 120,3 & 244 & 73 & 730 \\
\hline $18: 00$ & 98,7 & 33,9 & 0,09 & 82,0 & 89,5 & 124,3 & 251 & 67 & 730 \\
\hline $19: 00$ & 95,9 & 41,2 & 0,18 & 68,8 & 83,8 & 122,1 & 370 & 68 & 730 \\
\hline $20: 00$ & 99,5 & 48,5 & 0,09 & 70,9 & 81,6 & 133,6 & 370 & 74 & 730 \\
\hline $21: 00$ & 83,3 & 42,4 & 0,09 & 55,9 & 74,8 & 108,5 & 240 & 79 & 730 \\
\hline $22: 00$ & 62,5 & 37,0 & 0,09 & 42,7 & 54,3 & 79,1 & 232 & 88 & 730 \\
\hline $23: 00$ & 52,8 & 37,1 & 0,09 & 28,4 & 41,6 & 67,0 & 237 & 126 & 732 \\
\hline
\end{tabular}


(A) Vazão de saída por hora para o Norte de Peruíbe de acordo com o mês

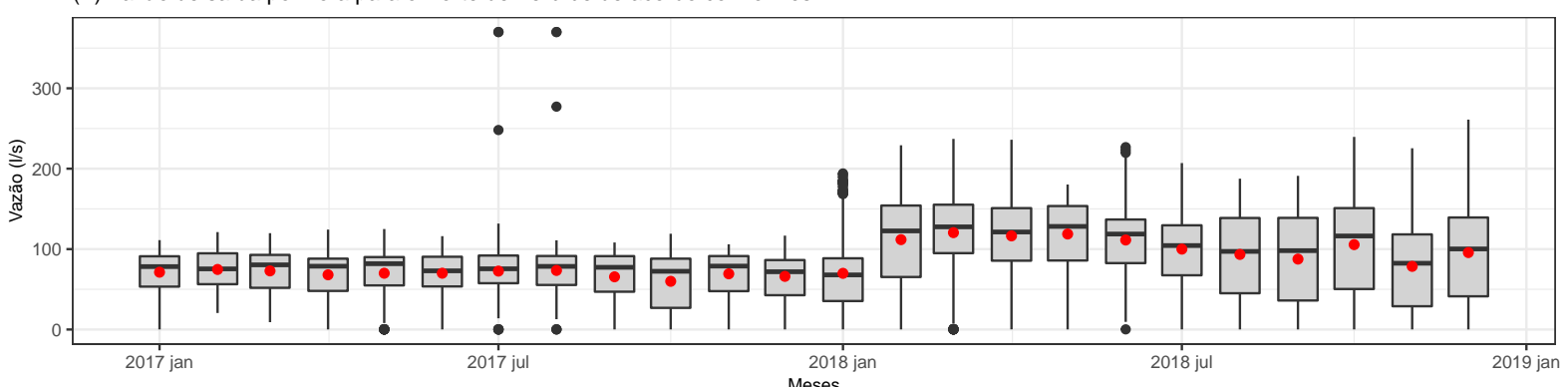

(B) Vazão de saída por hora para o Norte de Peruíbe de acordo com o horário do dia

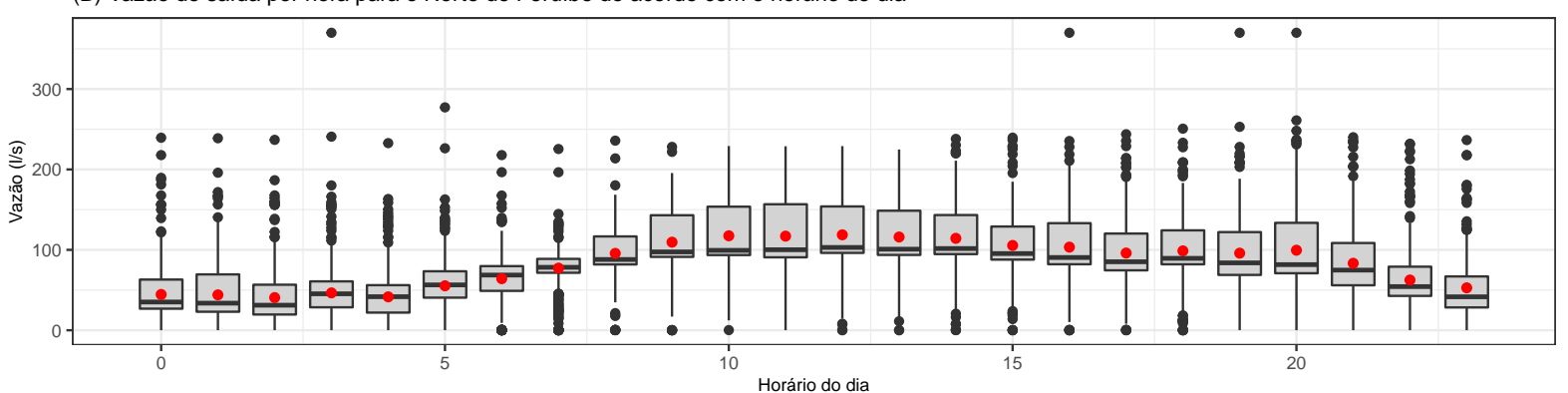

(C) Vazão de saída por hora para o Norte de Peruíbe de acordo com dia da semana

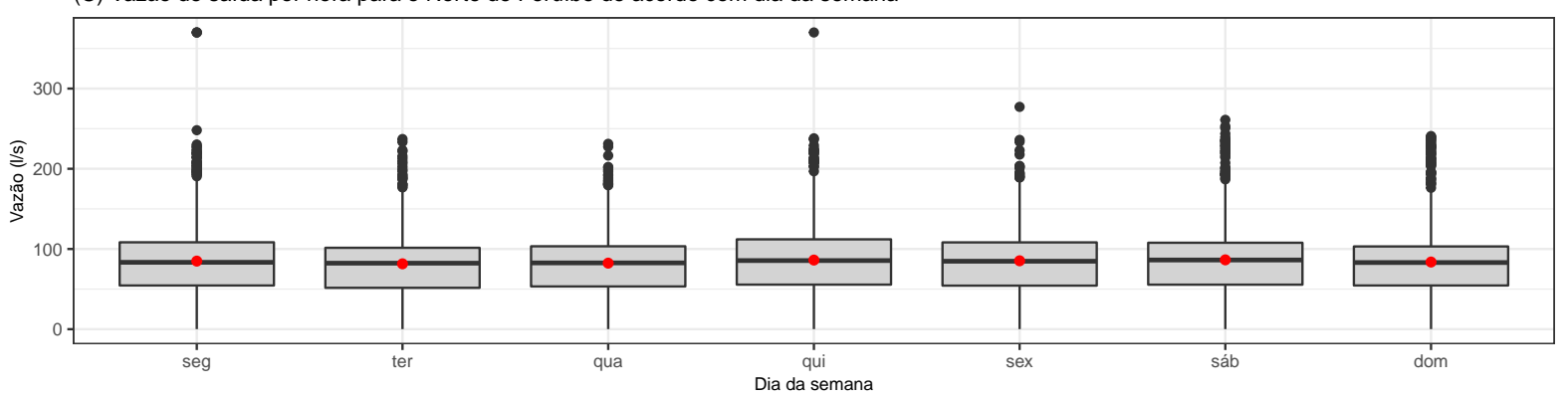

(D) Trecho da série de vazão de saída para o Norte de Peruíbe

(E) Trecho da série de vazão de saída para o Norte de Peruíbe

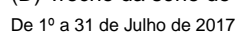
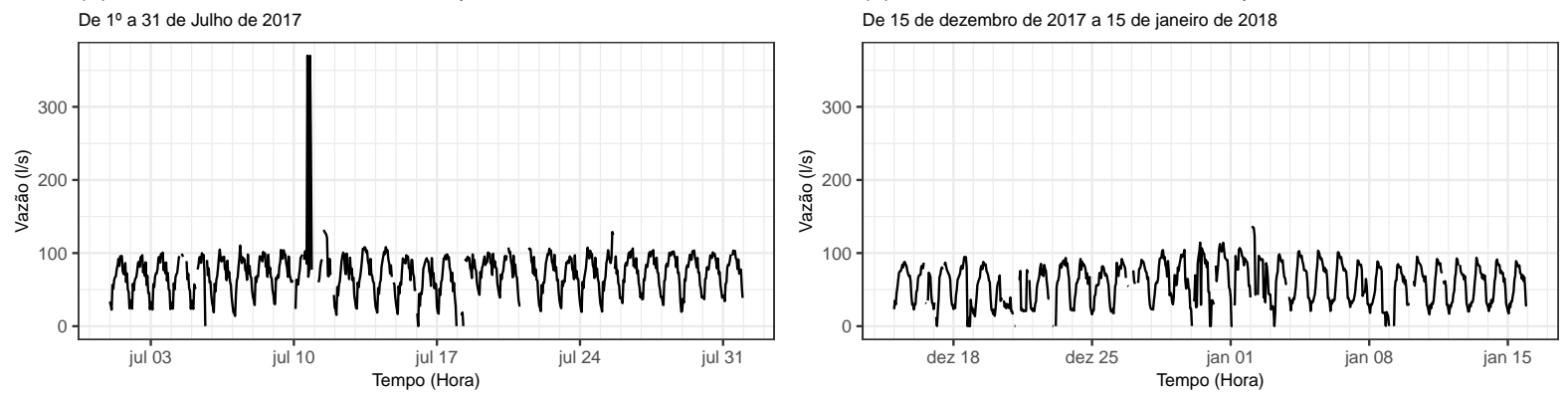

Figura B.7: Painel com alguns gráficos descritivos da série após limpeza primária de vazão de saída do reservatório para o Norte de Peruibe. Os gráficos $(A),(B)$ e $(C)$ são boxplots série de vazão em l/s de acordo com mês, horário do dia e dia semana, respectivamente. Os pontos vermelhos são as médias de cada periodo. Já os gráficos $(D)$ e (E) são trechos selecionados da série. 
(A) Distribuição dos valores omissos da vazão de saída para o Norte de Peruíbe de acordo com o mês

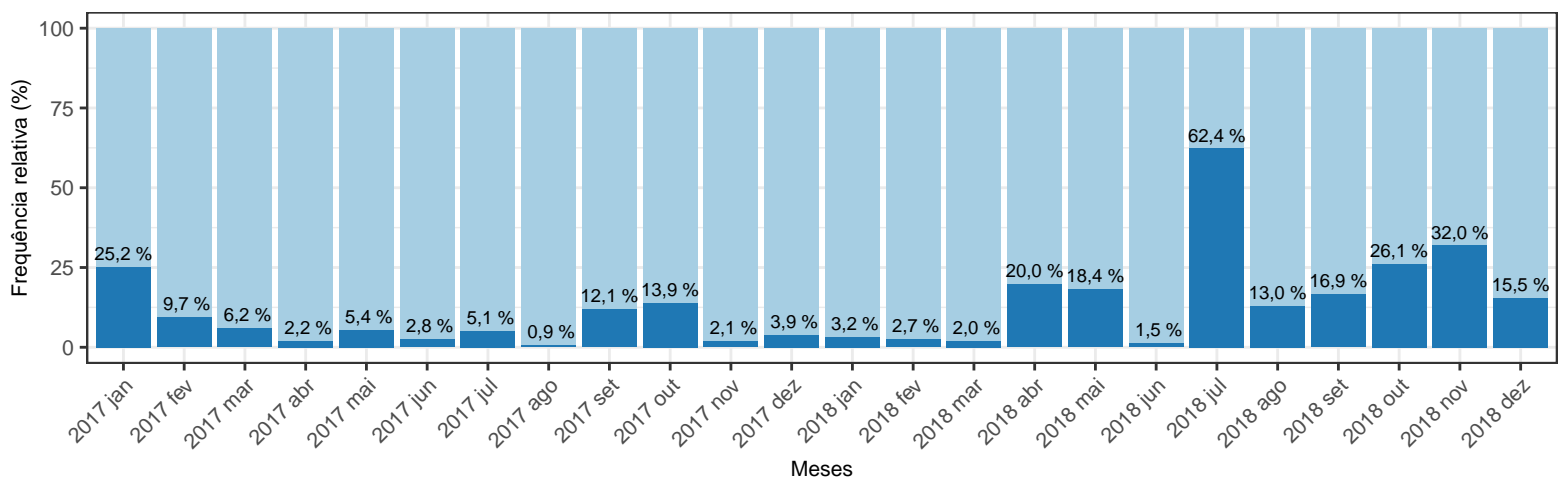

(B) Distribuição dos valores omissos da vazão de saída para o Norte de Peruíbe de acordo com o dia da semana

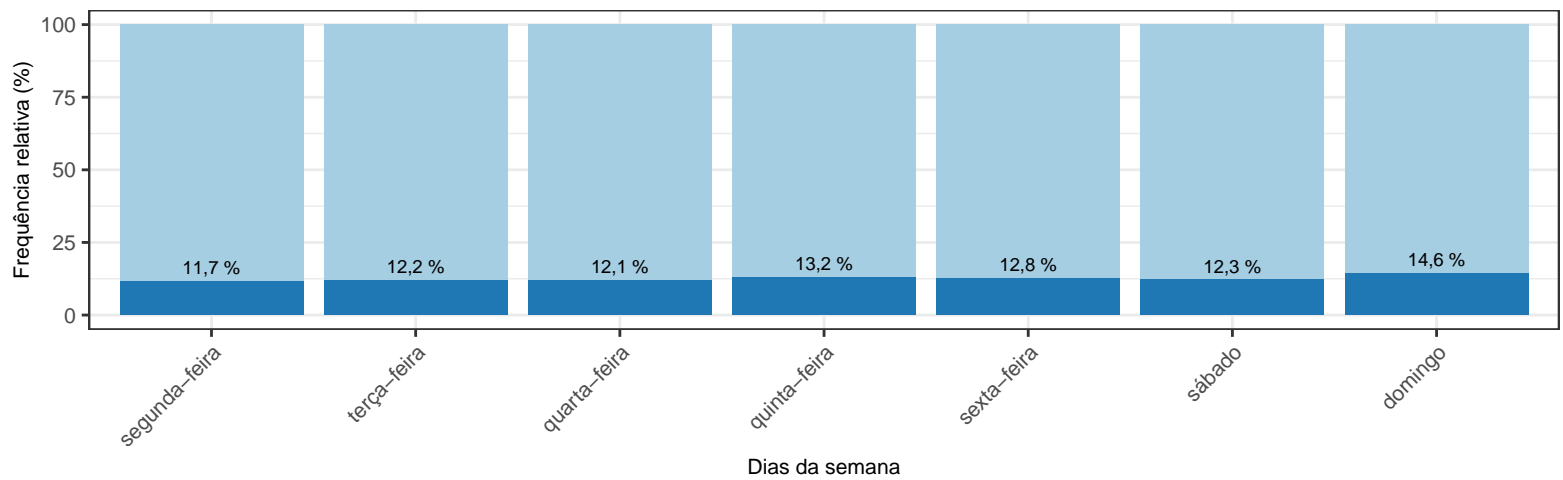

(C) Distribuição dos valores omissos da vazão de saída para o Norte de Peruíbe de acordo com o horário do dia

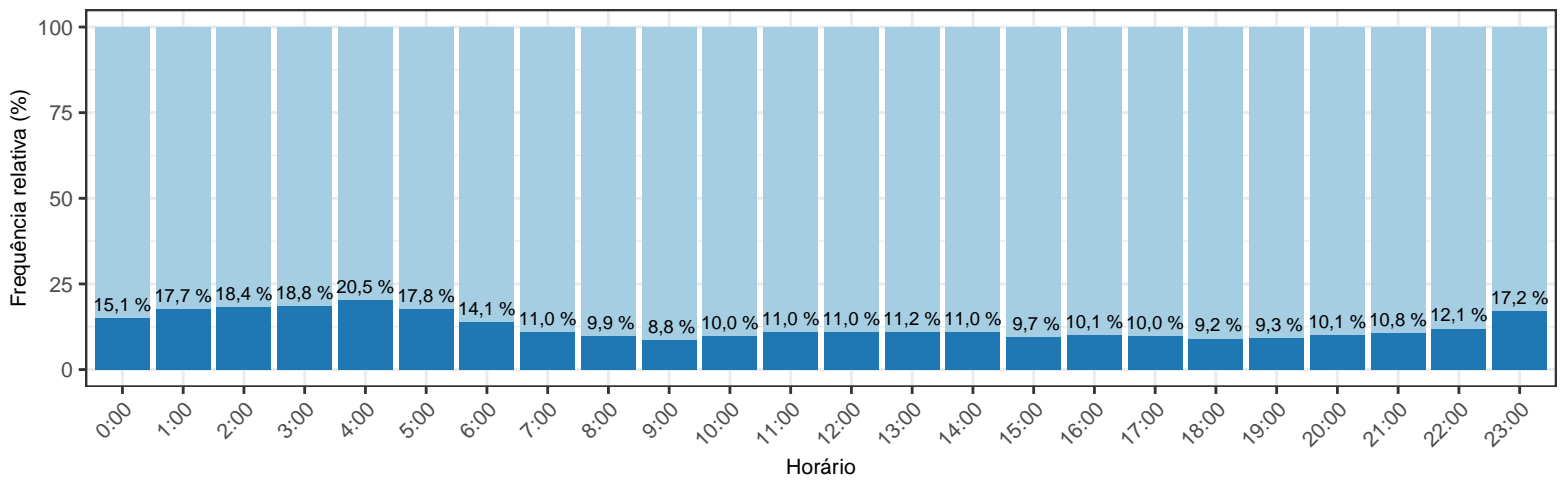

Figura B.8: Painel com alguns gráficos descritivos sobre a distribuição dos valores omissos presentes na série de vazão de saída do reservatório para o Norte de Peruibe. O gráfico (A) é a distribuição os valores omissos ao longo dos meses da série; o gráfico (B) é a distribuição os valores omissos de acordo com o dias da semana e o gráfico $(C)$ é a distribuição os valores omissos de acordo com os horários do dia. 
Tabela B.5: Medidas descritivas da série após limpeza primária de vazão de saída do reservatório para o Sul de Peruíbe. As informações descritivas são apresentadas para a série em sua totalidade e desagregada por periodos mensais, por dias da semana e por horários do dia.

\begin{tabular}{|c|c|c|c|c|c|c|c|c|c|}
\hline Descritiva & Média & Desvio padrão & Mínimo & $1^{\underline{O}}$ Quartil & Mediana & $3^{\underline{O}}$ Quartil & Máximo & Omissos & Total \\
\hline \multicolumn{10}{|l|}{ Geral } \\
\hline Geral & 81,3 & 55,5 & 0,06 & 35,10 & 79,2 & 114,0 & 250 & 4182 & 17519 \\
\hline \multicolumn{10}{|l|}{ Por ano e mês } \\
\hline 2017 jan & 103,6 & 62,0 & 0,06 & 56,90 & 97,2 & 142,6 & 250 & 184 & 743 \\
\hline 2017 fev & 92,0 & 56,1 & 0,06 & 43,13 & 91,2 & 134,0 & 222 & 67 & 673 \\
\hline 2017 mar & 66,8 & 51,8 & 0,06 & 16,48 & 69,0 & 105,9 & 193 & 88 & 744 \\
\hline 2017 abr & 54,1 & 47,3 & 0,06 & 0,85 & 45,3 & 94,0 & 186 & 66 & 720 \\
\hline 2017 mai & 46,2 & 40,6 & 0,06 & 0,85 & 37,7 & 85,6 & 173 & 93 & 744 \\
\hline 2017 jun & 52,9 & 45,5 & 0,06 & 1,08 & 53,3 & 89,6 & 232 & 76 & 720 \\
\hline 2017 jul & 58,5 & 46,4 & 0,06 & 14,77 & 56,5 & 94,3 & 250 & 65 & 744 \\
\hline 2017 ago & 83,7 & 61,7 & 0,06 & 34,65 & 82,2 & 118,4 & 250 & 37 & 744 \\
\hline 2017 set & 136,9 & 65,5 & 1,59 & 96,06 & 136,1 & 185,4 & 250 & 205 & 720 \\
\hline 2017 out & 63,9 & 41,6 & 0,12 & 26,01 & 66,3 & 99,2 & 164 & 175 & 743 \\
\hline 2017 nov & 61,4 & 39,5 & 1,47 & 22,68 & 64,6 & 96,0 & 146 & 105 & 720 \\
\hline 2017 dez & 75,3 & 49,3 & 1,59 & 29,49 & 75,5 & 112,9 & 218 & 76 & 744 \\
\hline 2018 jan & 96,4 & 50,2 & 3,48 & 49,69 & 101,1 & 134,1 & 220 & 55 & 744 \\
\hline 2018 fev & 89,9 & 49,4 & 1,28 & 47,54 & 95,0 & 125,3 & 243 & 85 & 673 \\
\hline 2018 mar & 82,6 & 39,5 & 1,47 & 62,23 & 90,5 & 110,2 & 176 & 186 & 744 \\
\hline 2018 abr & 81,0 & 39,5 & 1,77 & 56,75 & 86,0 & 107,0 & 239 & 321 & 720 \\
\hline 2018 mai & 73,3 & 35,3 & 2,01 & 50,18 & 76,5 & 98,8 & 164 & 327 & 744 \\
\hline 2018 jun & 63,1 & 30,0 & 2,20 & 40,28 & 67,8 & 83,1 & 145 & 294 & 720 \\
\hline 2018 jul & 59,7 & 32,8 & 2,69 & 35,53 & 63,5 & 78,1 & 163 & 571 & 744 \\
\hline 2018 ago & 64,5 & 30,8 & 1,59 & 39,80 & 66,5 & 90,2 & 132 & 255 & 744 \\
\hline 2018 set & 74,5 & 30,9 & 1,77 & 56,53 & 75,5 & 95,3 & 160 & 293 & 720 \\
\hline 2018 out & 88,6 & 53,8 & 1,83 & 45,79 & 79,6 & 126,1 & 212 & 327 & 744 \\
\hline 2018 nov & 131,7 & 60,6 & 1,95 & 83,27 & 148,8 & 180,0 & 246 & 162 & 719 \\
\hline $2018 \mathrm{dez}$ & 139,6 & 61,9 & 2,81 & 88,58 & 149,8 & 189,6 & 250 & 69 & 744 \\
\hline \multicolumn{10}{|c|}{ Por dia da semana } \\
\hline segunda-feira & 82,3 & 56,3 & 0,12 & 36,69 & 78,5 & 113,3 & 250 & 563 & 2520 \\
\hline terça-feira & 77,6 & 53,9 & 0,06 & 31,35 & 77,2 & 109,5 & 250 & 585 & 2496 \\
\hline quarta-feira & 79,1 & 54,8 & 0,06 & 34,89 & 78,3 & 111,1 & 250 & 620 & 2496 \\
\hline quinta-feira & 80,3 & 55,0 & 0,06 & 35,29 & 78,3 & 111,8 & 250 & 643 & 2496 \\
\hline sexta-feira & 85,8 & 56,0 & 0,06 & 36,75 & 87,3 & 122,4 & 250 & 587 & 2496 \\
\hline sábado & 84,0 & 56,9 & 0,06 & 35,99 & 82,9 & 119,5 & 250 & 551 & 2498 \\
\hline domingo & 79,8 & 54,9 & 0,06 & 34,98 & 75,7 & 111,4 & 250 & 633 & 2517 \\
\hline \multicolumn{10}{|c|}{ Por horário do dia } \\
\hline $0: 00$ & 41,9 & 44,7 & 0,06 & 5,80 & 28,1 & 63,0 & 247 & 330 & 727 \\
\hline $1: 00$ & 38,9 & 41,7 & 0,12 & 6,87 & 27,8 & 55,2 & 246 & 351 & 730 \\
\hline $2: 00$ & 32,6 & 39,9 & 0,06 & 1,89 & 18,9 & 44,9 & 236 & 357 & 730 \\
\hline $3: 00$ & 29,0 & 37,3 & 0,06 & 0,61 & 19,8 & 35,5 & 168 & 340 & 730 \\
\hline 4:00 & 29,5 & 37,5 & 0,06 & 0,55 & 17,3 & 41,9 & 193 & 386 & 730 \\
\hline $5: 00$ & 32,8 & 35,0 & 0,06 & 6,53 & 22,7 & 44,4 & 195 & 253 & 730 \\
\hline $6: 00$ & 38,3 & 35,7 & 0,06 & 13,49 & 31,2 & 55,4 & 203 & 238 & 730 \\
\hline $7: 00$ & 59,4 & 36,9 & 0,37 & 32,45 & 54,7 & 76,8 & 224 & 114 & 730 \\
\hline $8: 00$ & 73,8 & 40,2 & 0,12 & 45,45 & 67,8 & 92,9 & 239 & 79 & 730 \\
\hline $9: 00$ & 113,8 & 39,6 & 0,37 & 92,03 & 108,4 & 127,3 & 250 & 66 & 730 \\
\hline $10: 00$ & 120,7 & 40,2 & 0,43 & 97,01 & 114,5 & 134,7 & 250 & 80 & 730 \\
\hline $11: 00$ & 129,9 & 44,4 & 0,31 & 102,63 & 122,0 & 154,7 & 250 & 89 & 730 \\
\hline $12: 00$ & 126,5 & 44,3 & 0,37 & 98,93 & 116,4 & 153,7 & 250 & 98 & 730 \\
\hline $13: 00$ & 120,6 & 43,5 & 0,31 & 93,22 & 109,9 & 146,0 & 250 & 95 & 730 \\
\hline $14: 00$ & 109,5 & 44,5 & 0,43 & 81,88 & 96,4 & 126,5 & 250 & 90 & 730 \\
\hline $15: 00$ & 108,5 & 43,4 & 0,31 & 82,72 & 97,1 & 126,8 & 250 & 83 & 730 \\
\hline $16: 00$ & 109,3 & 40,8 & 0,37 & 85,70 & 100,5 & 123,4 & 250 & 84 & 730 \\
\hline $17: 00$ & 104,2 & 43,9 & 0,31 & 75,38 & 99,8 & 120,6 & 250 & 82 & 730 \\
\hline $18: 00$ & 92,1 & 45,9 & 0,37 & 63,61 & 78,5 & 108,0 & 250 & 77 & 730 \\
\hline $19: 00$ & 81,1 & 51,3 & 0,24 & 45,57 & 67,4 & 100,4 & 250 & 76 & 730 \\
\hline $20: 00$ & 68,0 & 49,4 & 0,18 & 33,90 & 56,4 & 81,6 & 250 & 96 & 730 \\
\hline $21: 00$ & 50,7 & 52,6 & 0,06 & 10,10 & 28,3 & 75,2 & 249 & 151 & 730 \\
\hline $22: 00$ & 49,5 & 53,0 & 0,12 & 5,04 & 32,0 & 80,0 & 250 & 274 & 730 \\
\hline $23: 00$ & 44,3 & 50,1 & 0,06 & 4,37 & 25,6 & 67,8 & 250 & 293 & 732 \\
\hline
\end{tabular}


(A) Vazão de saída por hora para o Sul de Peruíbe de acordo com o mês

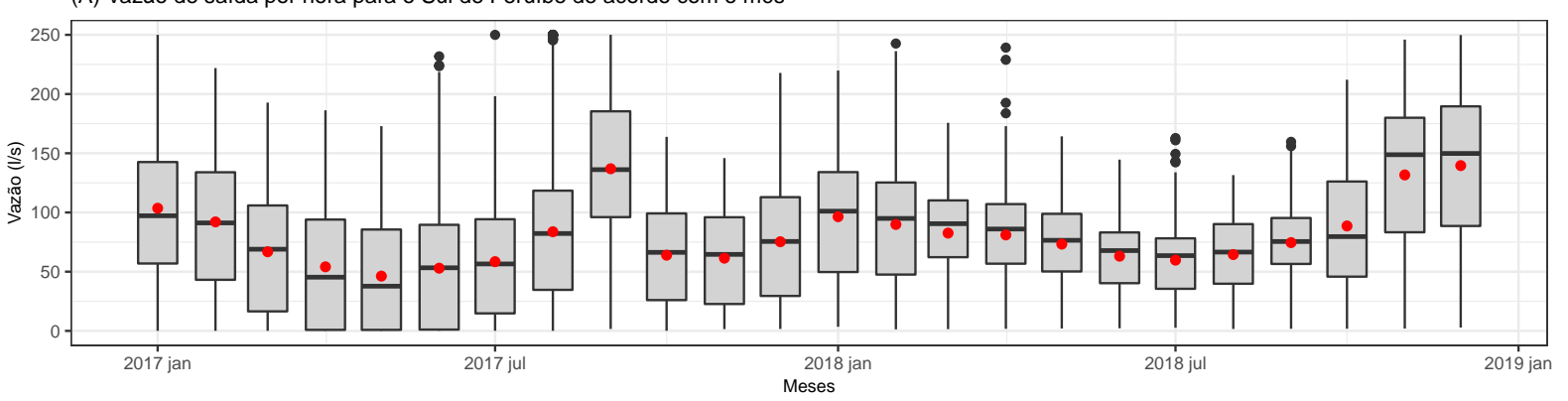

(B) Vazão de saída por hora para o Sul de Peruíbe de acordo com o horário do dia

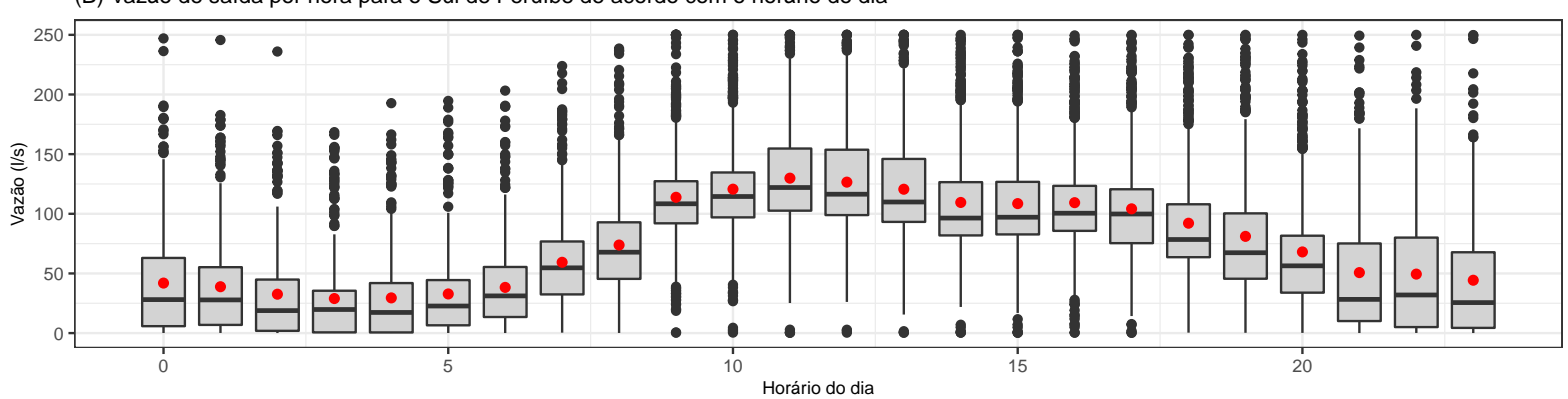

(C) Vazão de saída por hora para o Sul de Peruíbe de acordo com dia da semana

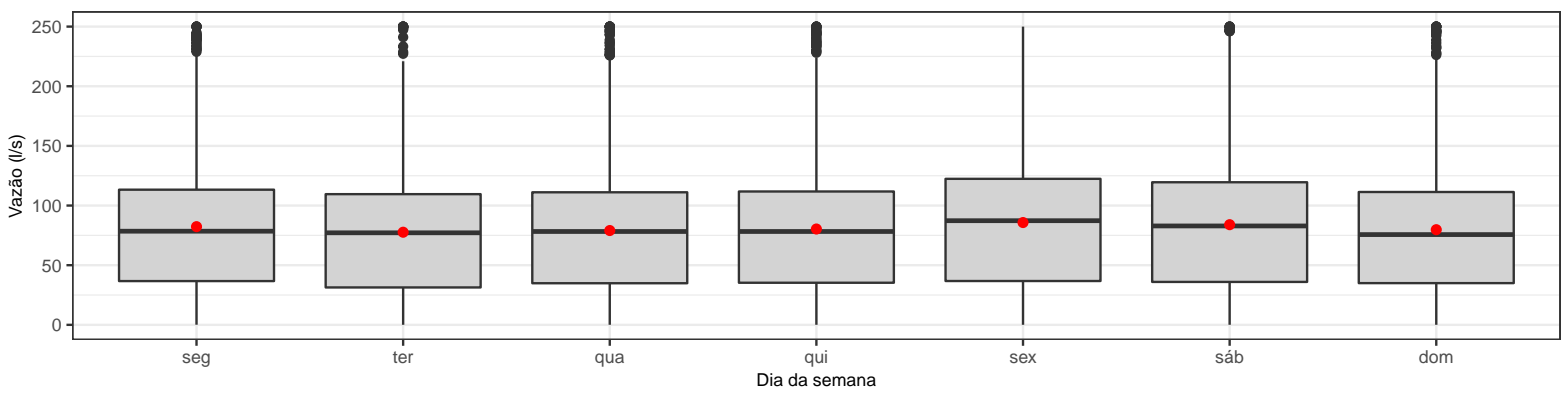

(D) Trecho da série de vazão de saída para o Sul de Peruíbe De $1^{\circ}$ a 31 de Julho de 2017

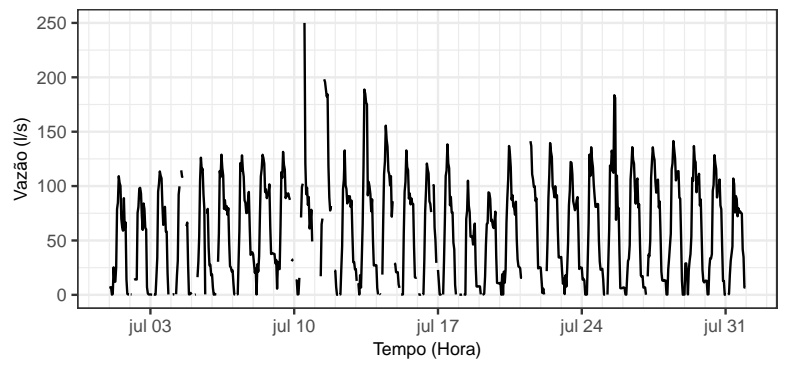

(E) Trecho da série de vazão de saída para o Sul de Peruíbe De 15 de dezembro de 2017 a 15 de janeiro de 2018

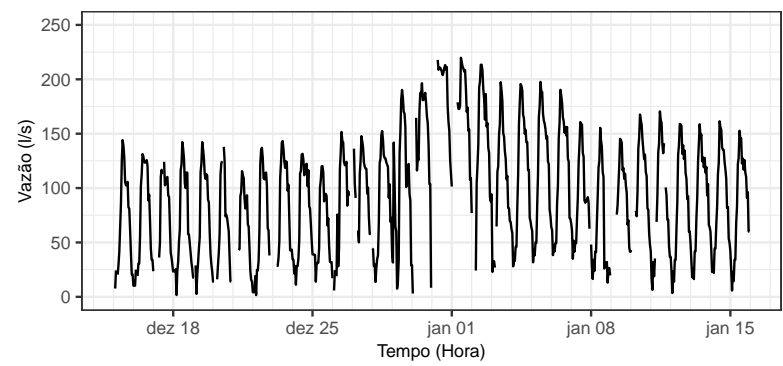

Figura B.9: Painel com alguns gráficos descritivos da série após limpeza primária de vazão de saída do reservatório para o Sul de Peruíbe. Os gráficos (A), (B) e (C) são boxplots série de vazão em l/s de acordo com mês, horário do dia e dia semana, respectivamente. Os pontos vermelhos são as médias de cada periodo. $J a ́$ os gráficos $(D)$ e (E) são trechos selecionados da série. 
(A) Distribuição dos valores omissos da vazão de saída para o Sul de Peruíbe de acordo com o mês

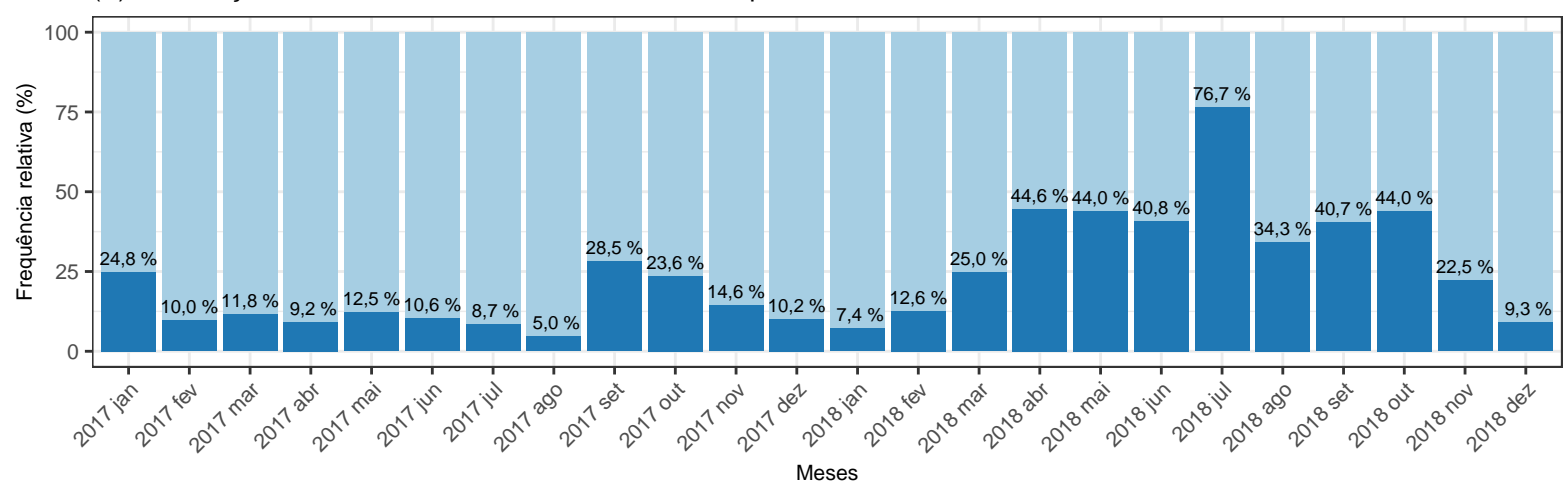

(B) Distribuição dos valores omissos da vazão de saída para o Sul de Peruíbe de acordo com o dia da semana

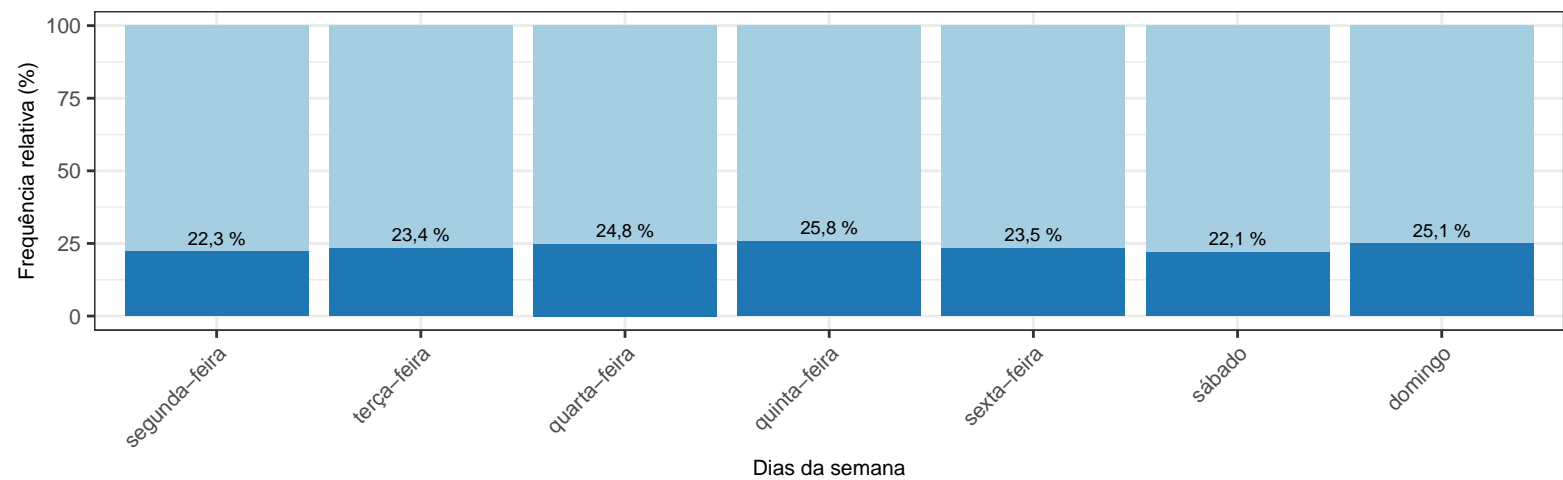

(C) Distribuição dos valores omissos da vazão de saída para o Sul de Peruíbe de acordo com o horário do dia

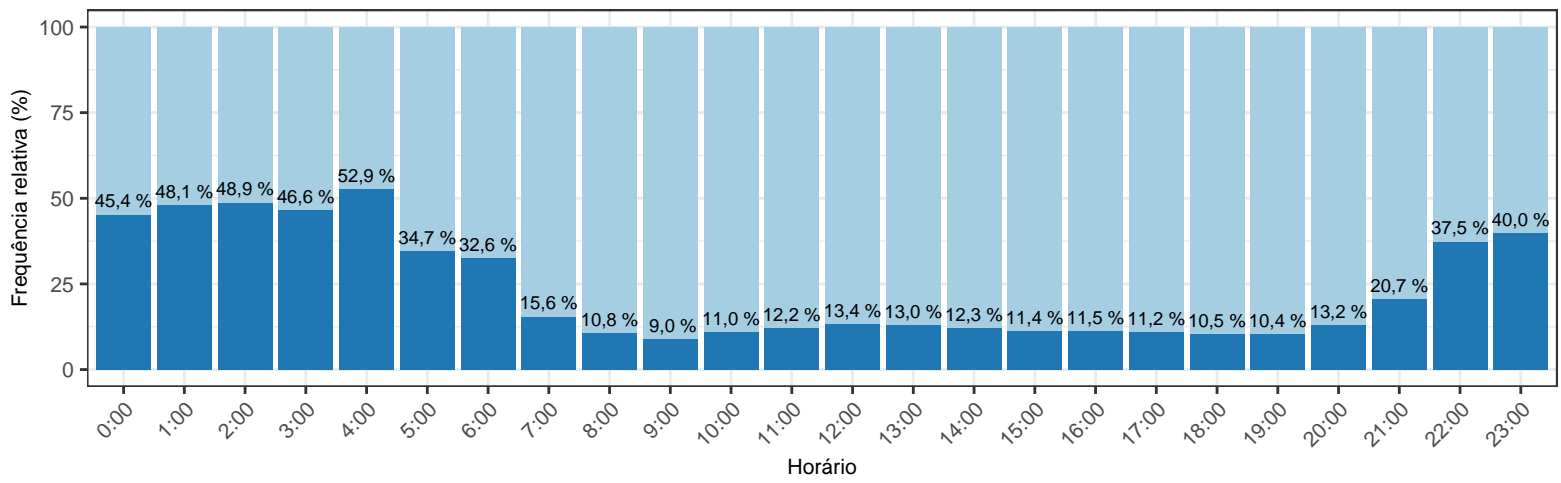

Figura B.10: Painel com alguns gráficos descritivos sobre a distribuição dos valores omissos presentes na série de vazão de saída do reservatório para o Sul de Peruibe. O gráfico (A) é a distribuição os valores omissos ao longo dos meses da série; o gráfico (B) é a distribuição os valores omissos de acordo com o dias da semana e o gráfico $(C)$ é a distribuição os valores omissos de acordo com os horários do dia. 
Tabela B.6: Medidas descritivas da série após limpeza primária de pressão a montante ao Norte de Peruíbe. As informações descritivas são apresentadas para a série em sua totalidade e desagregada por períodos mensais, por dias da semana e por horários do dia.

\begin{tabular}{|c|c|c|c|c|c|c|c|c|c|}
\hline Descritiva & Média & Desvio padrão & Mínimo & $1^{\mathcal{O}}$ Quartil & Mediana & $3^{\mathrm{O}}$ Quartil & Máximo & Omissos & Tota \\
\hline \multicolumn{10}{|l|}{ Geral } \\
\hline Geral & 41,8 & 4,99 & 0,61 & 39,2 & 42,5 & 45,4 & 58,0 & 1804 & 17519 \\
\hline \multicolumn{10}{|l|}{ Por ano e mês } \\
\hline 2017 jan & 36,9 & 6,06 & 22,00 & 32,4 & 36,6 & 42,3 & 50,4 & 185 & 743 \\
\hline 2017 fev & 38,6 & 5,10 & 26,84 & 34,6 & 39,5 & 42,8 & 47,1 & 66 & 673 \\
\hline 2017 mar & 39,2 & 5,07 & 26,32 & 35,7 & 39,1 & 43,7 & 55,0 & 46 & 744 \\
\hline 2017 abr & 40,5 & 4,18 & 27,37 & 37,5 & 39,6 & 44,5 & 56,9 & 14 & 720 \\
\hline 2017 mai & 40,7 & 3,90 & 27,50 & 37,7 & 39,7 & 44,2 & 48,1 & 36 & 744 \\
\hline 2017 jun & 41,2 & 3,63 & 21,00 & 38,1 & 41,5 & 44,2 & 49,2 & 20 & 720 \\
\hline 2017 jul & 42,5 & 2,95 & 31,38 & 40,2 & 42,5 & 44,9 & 48,6 & 39 & 744 \\
\hline 2017 ago & 42,2 & 2,76 & 35,34 & 39,8 & 42,1 & 44,6 & 47,6 & 9 & 744 \\
\hline 2017 set & 41,5 & 3,19 & 35,02 & 38,5 & 41,7 & 44,3 & 47,6 & 36 & 720 \\
\hline 2017 out & 42,2 & 3,11 & 32,99 & 39,8 & 42,5 & 44,6 & 47,9 & 46 & 743 \\
\hline 2017 nov & 42,5 & 3,37 & 34,46 & 39,7 & 42,1 & 45,7 & 53,8 & 15 & 720 \\
\hline 2017 dez & 41,6 & 4,21 & 4,49 & 38,8 & 41,7 & 44,7 & 55,1 & 20 & 744 \\
\hline 2018 jan & 41,8 & 6,42 & 0,61 & 39,0 & 42,4 & 46,1 & 51,2 & 18 & 744 \\
\hline $2018 \mathrm{fev}$ & 42,7 & 4,73 & 2,30 & 40,2 & 43,0 & 46,1 & 49,8 & 17 & 673 \\
\hline $2018 \mathrm{mar}$ & 42,9 & 3,14 & 32,48 & 40,4 & 43,0 & 45,6 & 51,0 & 19 & 744 \\
\hline 2018 abr & 43,1 & 3,22 & 31,60 & 40,5 & 43,1 & 46,0 & 48,7 & 153 & 720 \\
\hline 2018 mai & 44,5 & 3,26 & 32,84 & 41,8 & 44,4 & 47,3 & 58,0 & 141 & 744 \\
\hline 2018 jun & 46,1 & 2,67 & 34,75 & 44,6 & 46,1 & 48,4 & 50,5 & 22 & 720 \\
\hline 2018 jul & 45,0 & 3,61 & 3,10 & 43,7 & 45,1 & 46,9 & 50,3 & 457 & 744 \\
\hline 2018 ago & 41,6 & 10,05 & 4,79 & 42,4 & 44,6 & 46,9 & 48,8 & 76 & 744 \\
\hline 2018 set & 42,2 & 3,51 & 4,57 & 40,2 & 42,5 & 44,3 & 48,4 & 33 & 720 \\
\hline 2018 out & 41,5 & 6,18 & 17,56 & 39,2 & 42,8 & 45,9 & 53,8 & 167 & 744 \\
\hline 2018 nov & 42,9 & 4,44 & 29,89 & 39,9 & 43,5 & 46,6 & 57,4 & 142 & 719 \\
\hline $2018 \mathrm{dez}$ & 40,9 & 6,00 & 7,33 & 38,1 & 42,2 & 45,4 & 48,7 & 27 & 744 \\
\hline \multicolumn{10}{|c|}{ Por dia da semana } \\
\hline segunda-feira & 41,7 & 5,12 & 9,60 & 39,1 & 42,3 & 45,4 & 51,6 & 226 & 2520 \\
\hline terça-feira & 41,8 & 6,07 & 0,61 & 39,4 & 42,6 & 45,6 & 58,0 & 223 & 2496 \\
\hline quarta-feira & 42,0 & 5,05 & 4,57 & 39,4 & 42,6 & 45,5 & 57,4 & 236 & 2496 \\
\hline quinta-feira & 41,8 & 4,69 & 4,57 & 39,1 & 42,4 & 45,3 & 55,0 & 277 & 2496 \\
\hline sexta-feira & 41,8 & 4,47 & 4,57 & 38,8 & 42,4 & 45,2 & 53,8 & 254 & 2496 \\
\hline sábado & 41,8 & 4,64 & 4,49 & 39,0 & 42,5 & 45,2 & 53,8 & 280 & 2498 \\
\hline domingo & 42,0 & 4,71 & 3,10 & 39,5 & 42,7 & 45,4 & 54,0 & 308 & 2517 \\
\hline \multicolumn{10}{|c|}{ Por horário do dia } \\
\hline $0: 00$ & 45,5 & 3,32 & 9,62 & 44,5 & 46,1 & 47,0 & 53,8 & 83 & 727 \\
\hline $1: 00$ & 45,6 & 3,19 & 9,96 & 44,8 & 46,2 & 47,2 & 52,9 & 85 & 730 \\
\hline $2: 00$ & 45,9 & 3,62 & 1,83 & 45,2 & 46,4 & 47,3 & 56,9 & 82 & 730 \\
\hline $3: 00$ & 45,7 & 3,44 & 1,93 & 44,9 & 45,9 & 47,0 & 51,2 & 78 & 730 \\
\hline $4: 00$ & 45,7 & 3,56 & 1,95 & 44,9 & 45,9 & 47,2 & 52,6 & 83 & 730 \\
\hline $5: 00$ & 45,1 & 3,20 & 9,62 & 43,6 & 45,1 & 47,2 & 50,6 & 82 & 730 \\
\hline $6: 00$ & 44,4 & 3,77 & 0,83 & 42,8 & 44,8 & 46,7 & 50,4 & 71 & 730 \\
\hline $7: 00$ & 43,2 & 3,90 & 4,57 & 41,5 & 43,4 & 45,5 & 50,5 & 68 & 730 \\
\hline $8: 00$ & 41,5 & 4,35 & 0,73 & 40,0 & 42,0 & 43,5 & 50,6 & 66 & 730 \\
\hline $9: 00$ & 39,2 & 4,60 & 0,61 & 37,4 & 39,5 & 41,4 & 50,1 & 59 & 730 \\
\hline $10: 00$ & 38,2 & 4,71 & 1,39 & 36,2 & 38,7 & 40,5 & 49,6 & 74 & 730 \\
\hline $11: 00$ & 37,9 & 4,68 & 1,49 & 36,1 & 38,5 & 40,2 & 48,0 & 80 & 730 \\
\hline $12: 00$ & 37,4 & 5,09 & 1,56 & 36,0 & 38,0 & 39,8 & 47,5 & 87 & 730 \\
\hline $13: 00$ & 38,0 & 4,44 & 2,37 & 36,5 & 38,3 & 40,5 & 49,9 & 90 & 730 \\
\hline $14: 00$ & 38,2 & 4,58 & 1,66 & 36,7 & 38,5 & 40,8 & 50,0 & 89 & 730 \\
\hline $15: 00$ & 39,1 & 4,77 & 1,73 & 37,2 & 39,6 & 42,2 & 50,3 & 74 & 730 \\
\hline $16: 00$ & 39,7 & 3,95 & 12,45 & 38,3 & 40,0 & 42,0 & 50,5 & 71 & 730 \\
\hline $17: 00$ & 40,2 & 4,03 & 12,19 & 38,8 & 40,7 & 42,8 & 50,2 & 68 & 730 \\
\hline $18: 00$ & 40,1 & 4,03 & 9,52 & 38,4 & 40,4 & 42,5 & 58,0 & 75 & 730 \\
\hline $19: 00$ & 40,9 & 3,78 & 11,01 & 39,6 & 41,5 & 43,0 & 56,8 & 66 & 730 \\
\hline $20: 00$ & 40,8 & 3,78 & 10,87 & 39,7 & 41,4 & 42,9 & 52,4 & 69 & 730 \\
\hline $21: 00$ & 42,3 & 3,97 & 10,01 & 41,1 & 43,1 & 44,6 & 53,8 & 64 & 730 \\
\hline $22: 00$ & 44,1 & 3,77 & 9,60 & 43,2 & 44,6 & 46,0 & 57,4 & 63 & 730 \\
\hline $23: 00$ & 45,0 & 3,37 & 9,33 & 44,1 & 45,5 & 46,6 & 49,2 & 77 & 732 \\
\hline
\end{tabular}


(A) Pressão a montante a cada hora no Norte de Peruíbe de acordo com o mês

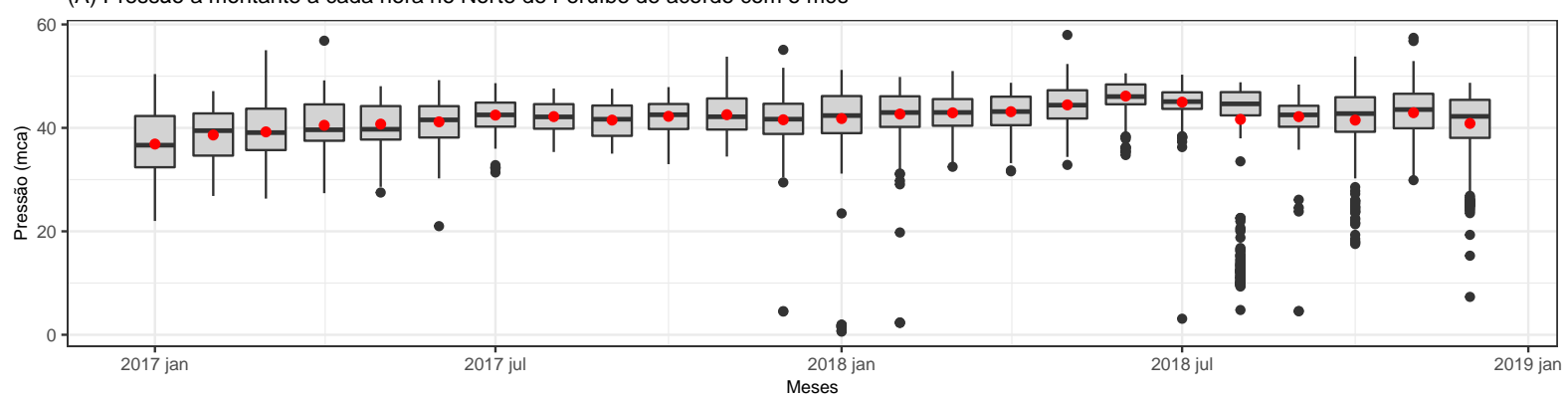

(B) Pressão a montante a cada hora no Norte de Peruíbe de acordo com o horário do dia

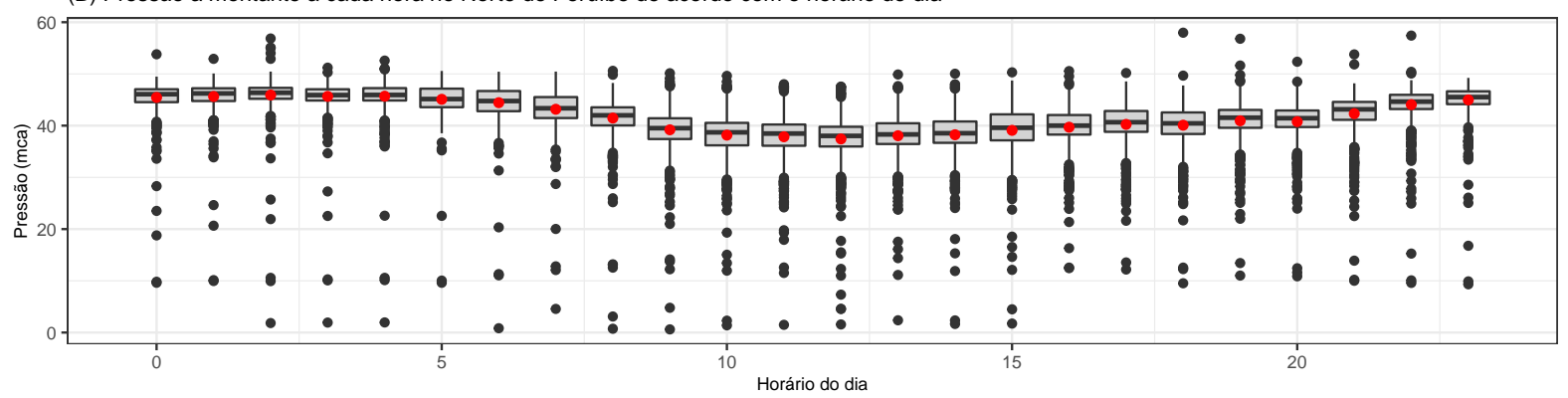

(C) Pressão a montante a cada hora no Norte de Peruíbe de acordo com dia da semana

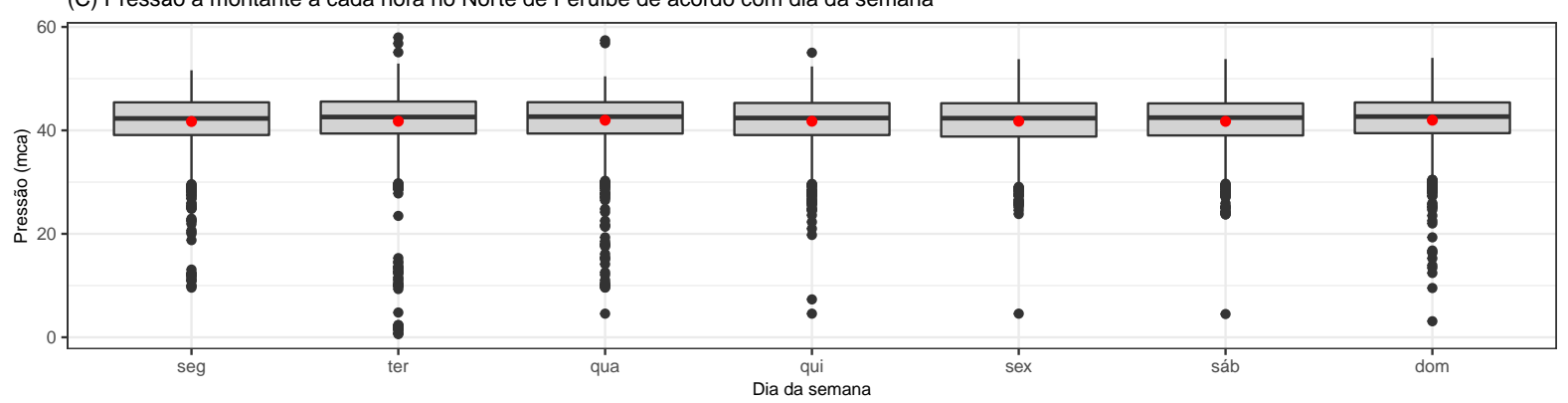

(D) Trecho da série de pressão a montante no Norte de Peruíbe De $1^{\circ}$ a 31 de Julho de 2017

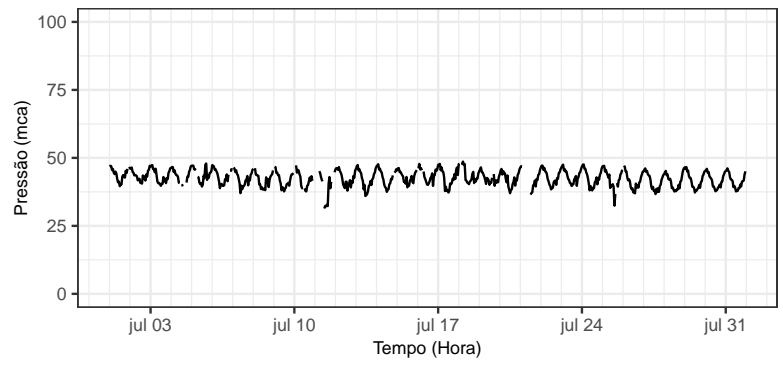

(E) Trecho da série de vazão de pressão a montante no Norte de Peruíb De 15 de dezembro de 2017 a 15 de janeiro de 2018

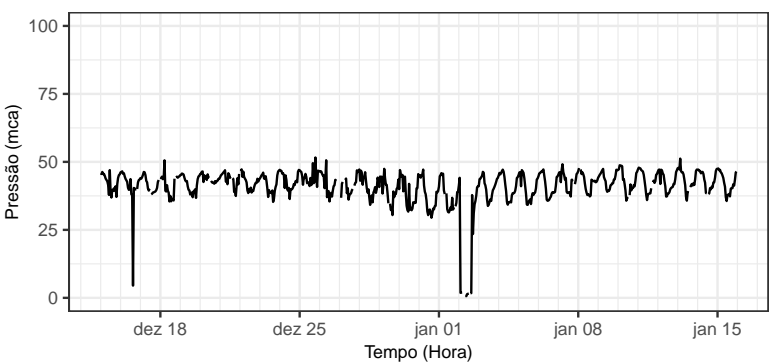

Figura B.11: Painel com alguns gráficos descritivos da série após limpeza primária de pressão a montante ao Norte de Peruíbe. Os gráficos (A), (B) e (C) são boxplots série de vazão em l/s de acordo com mês, horário do dia e dia semana, respectivamente. Os pontos vermelhos são as médias de cada período. Já os gráficos (D) e (E) são trechos selecionados da série. 
(A) Distribuição dos valores omissos da pressão a montante no Norte de Peruíbe de acordo com o mês

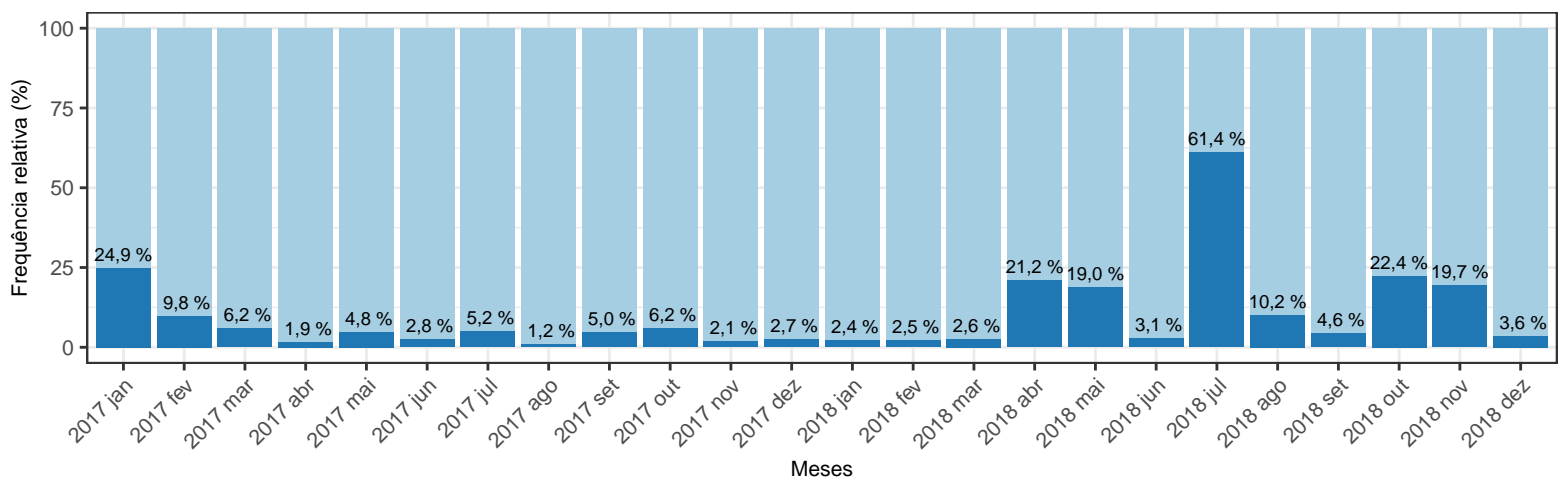

(B) Distribuição dos valores omissos da pressão a montante no Norte de Peruíbe de acordo com o dia da semana

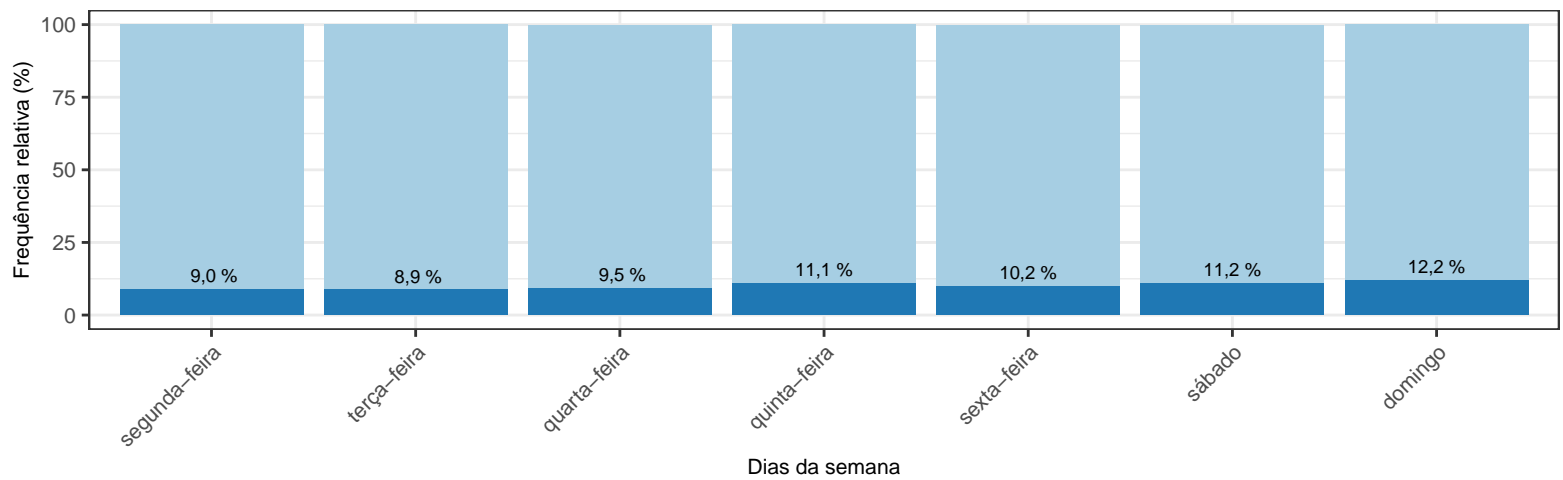

(C) Distribuição dos valores omissos da pressão a montante no Norte de Peruíbe de acordo com o horário do dia

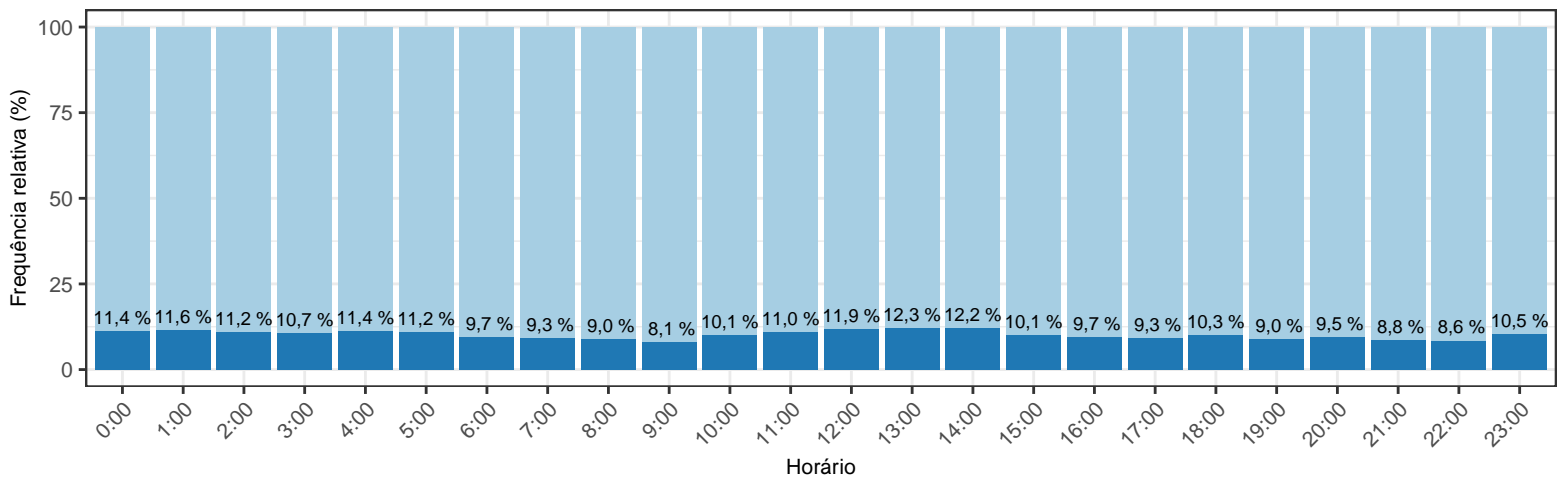

Figura B.12: Painel com alguns gráficos descritivos sobre a distribuição dos valores omissos presentes na série de pressão a montante ao Norte de Peruíbe. O gráfico (A) é a distribuição os valores omissos ao longo dos meses da série; o gráfico (B) é a distribuição os valores omissos de acordo com o dias da semana e o gráfico $(C)$ é a distribuição os valores omissos de acordo com os horários do dia. 
Tabela B.7: Medidas descritivas da série após limpeza primária de pressão a montante ao Sul de Peruíbe. As informações descritivas são apresentadas para a série em sua totalidade e desagregada por períodos mensais, por dias da semana e por horários do dia.

\begin{tabular}{|c|c|c|c|c|c|c|c|c|c|}
\hline Descritiva & Média & Desvio padrão & Mínimo & $1^{\mathrm{O}}$ Quartil & Mediana & $3^{\mathcal{O}}$ Quartil & Máximo & Omissos & Total \\
\hline \multicolumn{10}{|l|}{ Geral } \\
\hline Geral & 43,7 & 3,17 & 4,79 & 42,4 & 44,3 & 45,8 & 58,9 & 2209 & 17519 \\
\hline \multicolumn{10}{|l|}{ Por ano e mês } \\
\hline 2017 jan & 41,6 & 4,09 & 21,93 & 39,4 & 42,7 & 44,5 & 58,9 & 188 & 743 \\
\hline $2017 \mathrm{fev}$ & 42,8 & 2,78 & 32,94 & 41,2 & 43,4 & 45,1 & 47,3 & 87 & 673 \\
\hline 2017 mar & 43,8 & 2,33 & 36,04 & 42,6 & 44,2 & 45,6 & 47,0 & 70 & 744 \\
\hline 2017 abr & 44,5 & 1,81 & 35,82 & 43,2 & 44,9 & 45,8 & 47,4 & 46 & 720 \\
\hline 2017 mai & 44,8 & 1,50 & 38,97 & 43,7 & 45,0 & 45,9 & 48,7 & 60 & 744 \\
\hline 2017 jun & 43,9 & 5,03 & 4,79 & 43,5 & 45,0 & 46,0 & 48,7 & 46 & 720 \\
\hline 2017 jul & 44,6 & 1,81 & 37,51 & 43,2 & 45,0 & 46,1 & 49,1 & 54 & 744 \\
\hline 2017 ago & 44,4 & 1,92 & 27,52 & 43,1 & 44,8 & 45,9 & 47,3 & 39 & 744 \\
\hline 2017 set & 43,2 & 1,96 & 37,05 & 41,5 & 43,2 & 44,8 & 48,1 & 59 & 720 \\
\hline 2017 out & 43,6 & 1,97 & 37,26 & 42,3 & 43,5 & 45,2 & 47,3 & 69 & 743 \\
\hline 2017 nov & 45,0 & 1,93 & 33,94 & 43,6 & 45,3 & 46,6 & 48,8 & 30 & 720 \\
\hline 2017 dez & 44,0 & 2,13 & 36,07 & 42,5 & 44,2 & 45,8 & 48,8 & 72 & 744 \\
\hline 2018 jan & 43,0 & 2,99 & 18,85 & 41,1 & 43,3 & 45,5 & 47,4 & 31 & 744 \\
\hline 2018 fev & 43,9 & 2,45 & 32,38 & 42,5 & 44,1 & 45,8 & 47,5 & 22 & 673 \\
\hline 2018 mar & 44,6 & 1,75 & 38,83 & 43,2 & 44,7 & 46,2 & 48,5 & 28 & 744 \\
\hline 2018 abr & 44,7 & 2,01 & 33,06 & 43,4 & 45,0 & 46,4 & 47,5 & 168 & 720 \\
\hline 2018 mai & 45,1 & 1,76 & 34,97 & 44,1 & 45,4 & 46,4 & 47,7 & 155 & 744 \\
\hline 2018 jun & 45,8 & 1,47 & 36,80 & 45,0 & 46,1 & 46,9 & 47,8 & 43 & 720 \\
\hline 2018 jul & 44,7 & 1,85 & 38,66 & 43,5 & 44,8 & 46,1 & 47,6 & 475 & 744 \\
\hline 2018 ago & 44,9 & 1,85 & 39,49 & 43,7 & 45,0 & 46,4 & 55,8 & 85 & 744 \\
\hline 2018 set & 42,2 & 1,87 & 37,34 & 41,0 & 42,1 & 43,5 & 47,1 & 37 & 720 \\
\hline 2018 out & 41,8 & 7,10 & 12,36 & 40,8 & 43,5 & 45,7 & 49,0 & 163 & 744 \\
\hline 2018 nov & 42,0 & 3,28 & 27,59 & 39,4 & 41,8 & 44,9 & 49,3 & 145 & 719 \\
\hline $2018 \mathrm{dez}$ & 40,4 & 4,59 & 7,20 & 38,4 & 40,7 & 43,5 & 47,9 & 37 & 744 \\
\hline \multicolumn{10}{|c|}{ Por dia da semana } \\
\hline segunda-feira & 43,7 & 2,80 & 27,37 & 42,4 & 44,3 & 45,7 & 49,0 & 297 & 2520 \\
\hline terça-feira & 44,0 & 2,52 & 27,52 & 42,5 & 44,4 & 45,9 & 58,9 & 275 & 2496 \\
\hline quarta-feira & 43,8 & 3,50 & 7,20 & 42,6 & 44,4 & 45,9 & 50,0 & 298 & 2496 \\
\hline quinta-feira & 43,6 & 3,58 & 14,04 & 42,4 & 44,4 & 45,8 & 49,3 & 321 & 2496 \\
\hline sexta-feira & 43,5 & 3,17 & 12,58 & 42,0 & 44,0 & 45,7 & 55,8 & 305 & 2496 \\
\hline sábado & 43,6 & 3,65 & 4,79 & 42,3 & 44,3 & 45,9 & 48,1 & 334 & 2498 \\
\hline domingo & 43,9 & 2,77 & 27,23 & 42,6 & 44,4 & 45,9 & 48,8 & 379 & 2517 \\
\hline \multicolumn{10}{|c|}{ Por horário do dia } \\
\hline $0: 00$ & 45,3 & 2,47 & 5,01 & 44,6 & 45,9 & 46,6 & 48,2 & 124 & 727 \\
\hline $1: 00$ & 45,5 & 2,33 & 4,79 & 44,8 & 46,0 & 46,7 & 47,8 & 116 & 730 \\
\hline $2: 00$ & 45,7 & 1,51 & 36,39 & 45,1 & 46,2 & 46,8 & 48,6 & 112 & 730 \\
\hline $3: 00$ & 45,8 & 2,02 & 9,57 & 45,3 & 46,2 & 46,8 & 48,8 & 110 & 730 \\
\hline $4: 00$ & 45,8 & 1,91 & 11,48 & 45,4 & 46,1 & 46,7 & 49,3 & 109 & 730 \\
\hline $5: 00$ & 45,8 & 1,76 & 12,31 & 45,4 & 46,0 & 46,6 & 49,1 & 99 & 730 \\
\hline $6: 00$ & 45,6 & 1,73 & 13,06 & 45,1 & 45,9 & 46,4 & 49,0 & 95 & 730 \\
\hline $7: 00$ & 45,0 & 2,23 & 12,55 & 44,5 & 45,5 & 45,9 & 47,9 & 82 & 730 \\
\hline $8: 00$ & 44,4 & 2,53 & 12,31 & 43,8 & 44,9 & 45,5 & 48,2 & 71 & 730 \\
\hline $9: 00$ & 42,6 & 3,06 & 10,72 & 41,9 & 43,0 & 44,0 & 47,3 & 68 & 730 \\
\hline $10: 00$ & 41,9 & 3,41 & 7,42 & 41,0 & 42,5 & 43,5 & 48,1 & 78 & 730 \\
\hline $11: 00$ & 41,4 & 3,38 & 7,20 & 40,2 & 42,0 & 43,2 & 50,0 & 79 & 730 \\
\hline $12: 00$ & 41,3 & 3,53 & 7,55 & 40,0 & 42,0 & 43,2 & 47,7 & 103 & 730 \\
\hline $13: 00$ & 41,5 & 3,30 & 14,21 & 40,2 & 42,1 & 43,5 & 47,6 & 103 & 730 \\
\hline $14: 00$ & 42,0 & 3,18 & 12,36 & 40,8 & 42,7 & 43,9 & 47,4 & 98 & 730 \\
\hline $15: 00$ & 42,1 & 3,24 & 12,43 & 41,1 & 42,7 & 43,9 & 58,9 & 88 & 730 \\
\hline $16: 00$ & 42,2 & 2,89 & 13,70 & 41,1 & 42,8 & 43,9 & 55,8 & 90 & 730 \\
\hline $17: 00$ & 42,3 & 2,92 & 13,11 & 41,3 & 42,9 & 44,0 & 47,4 & 85 & 730 \\
\hline $18: 00$ & 42,7 & 3,00 & 12,99 & 41,7 & 43,4 & 44,6 & 47,3 & 82 & 730 \\
\hline $19: 00$ & 43,1 & 3,07 & 14,77 & 42,1 & 43,9 & 45,1 & 47,2 & 75 & 730 \\
\hline $20: 00$ & 43,5 & 2,86 & 15,19 & 42,6 & 44,3 & 45,4 & 47,0 & 76 & 730 \\
\hline $21: 00$ & 44,2 & 2,88 & 16,65 & 43,2 & 45,0 & 46,0 & 47,9 & 75 & 730 \\
\hline $22: 00$ & 44,7 & 2,37 & 29,43 & 43,8 & 45,4 & 46,3 & 48,6 & 91 & 730 \\
\hline $23: 00$ & 45,1 & 2,14 & 29,79 & 44,4 & 45,7 & 46,4 & 48,7 & 100 & 732 \\
\hline
\end{tabular}


(A) Pressão a montante a cada hora no Sul de Peruíbe de acordo com o mês

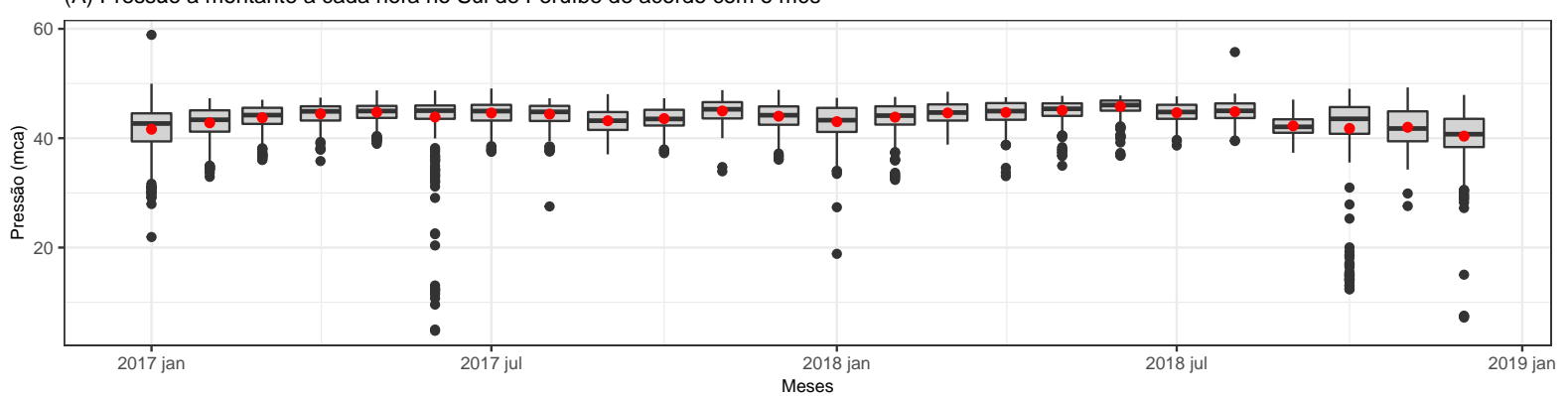

(B) Pressão a montante a cada hora no Sul de Peruíbe de acordo com o horário do dia

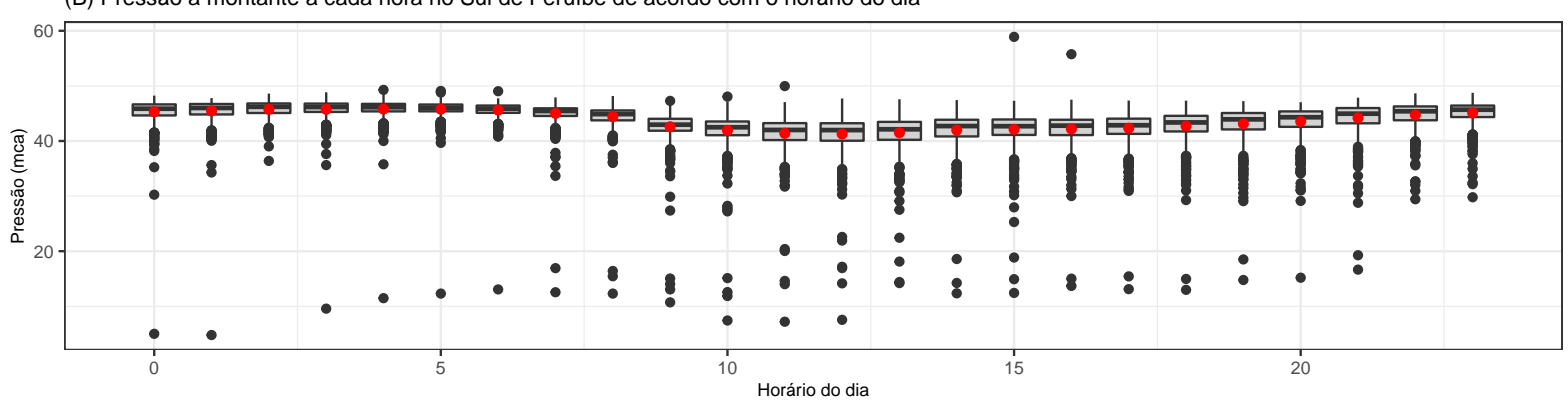

(C) Pressão a montante a cada hora no Sul de Peruíbe de acordo com dia da semana

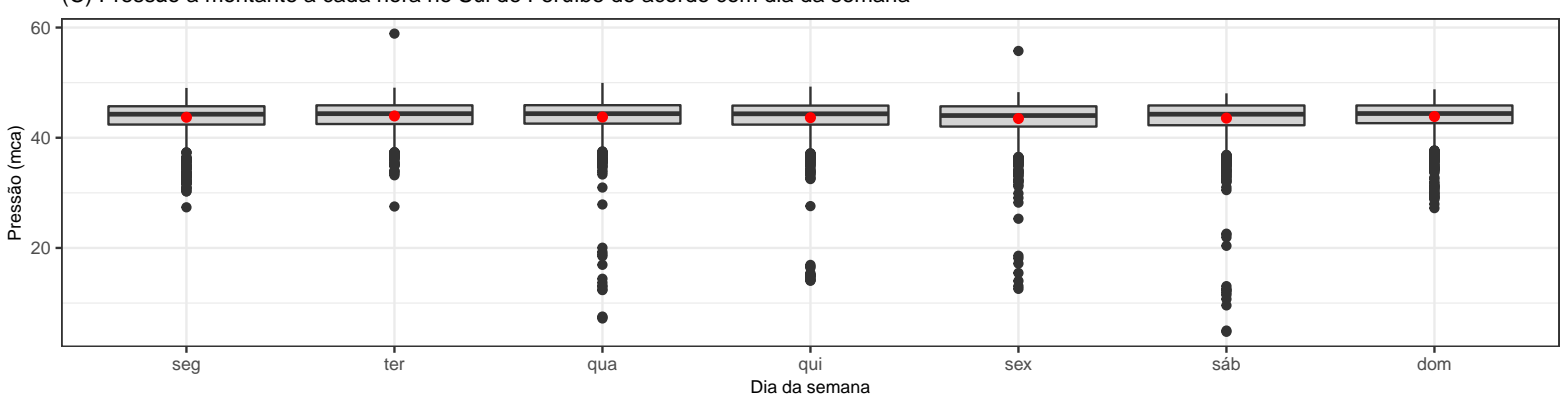

(D) Trecho da série de pressão a montante no Sul de Peruíbe De $1^{\circ}$ a 31 de Julho de 2017

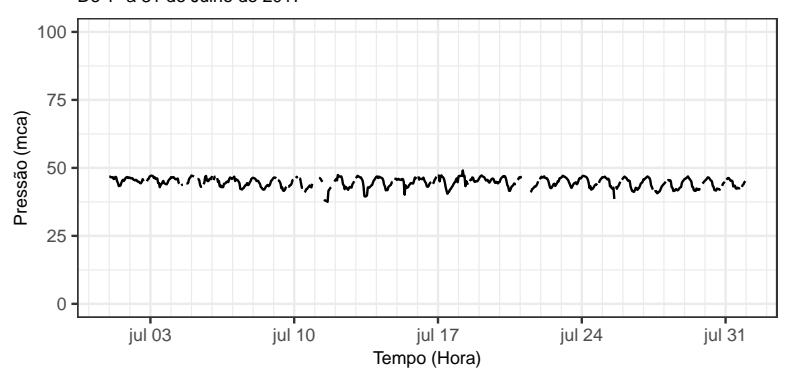

(E) Trecho da série de pressão a montante no Sul de Peruíbe De 15 de dezembro de 2017 a 15 de janeiro de 2018

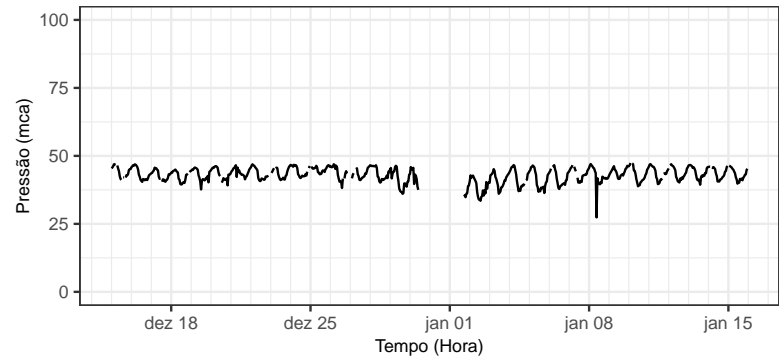

Figura B.13: Painel com alguns gráficos descritivos da série após limpeza primária de pressão a montante ao Sul de Peruíbe. Os gráficos $(A),(B)$ e $(C)$ são boxplots série de vazão em $\mathrm{l} / \mathrm{s}$ de acordo com mês, horário do dia e dia semana, respectivamente. Os pontos vermelhos são as médias de cada período. Já os gráficos (D) e (E) são trechos selecionados da série. 
(A) Distribuição dos valores omissos da pressão a montante no Sul de Peruíbe de acordo com o mês

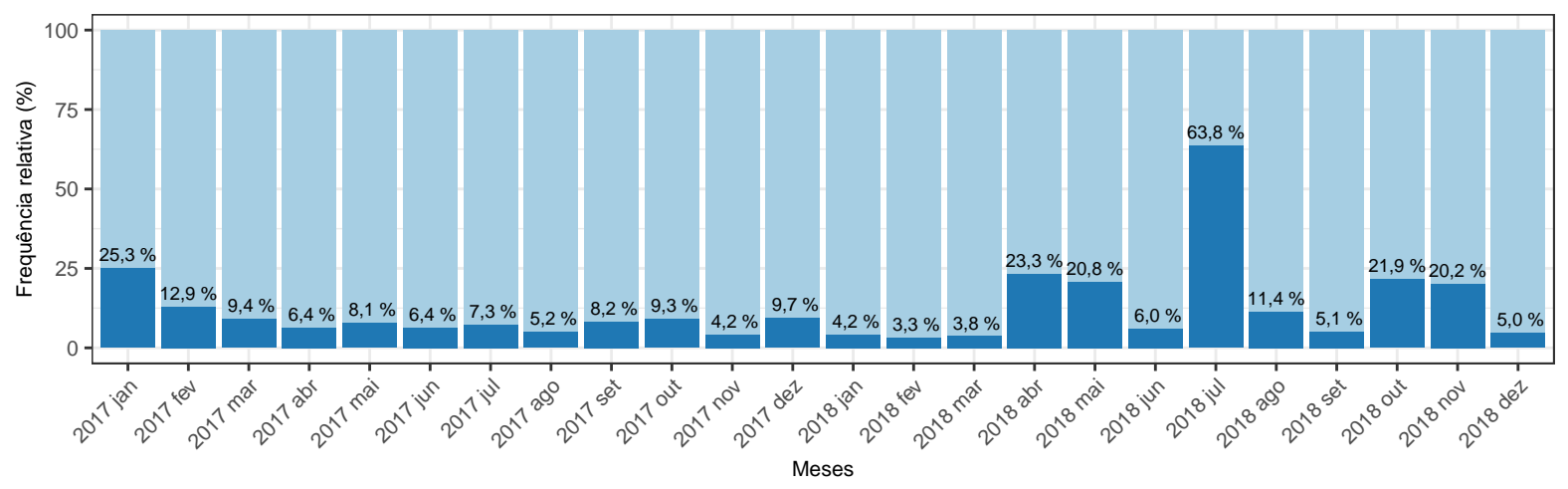

(B) Distribuição dos valores omissos da pressão a montante no Sul de Peruíbe de acordo com o dia da semana

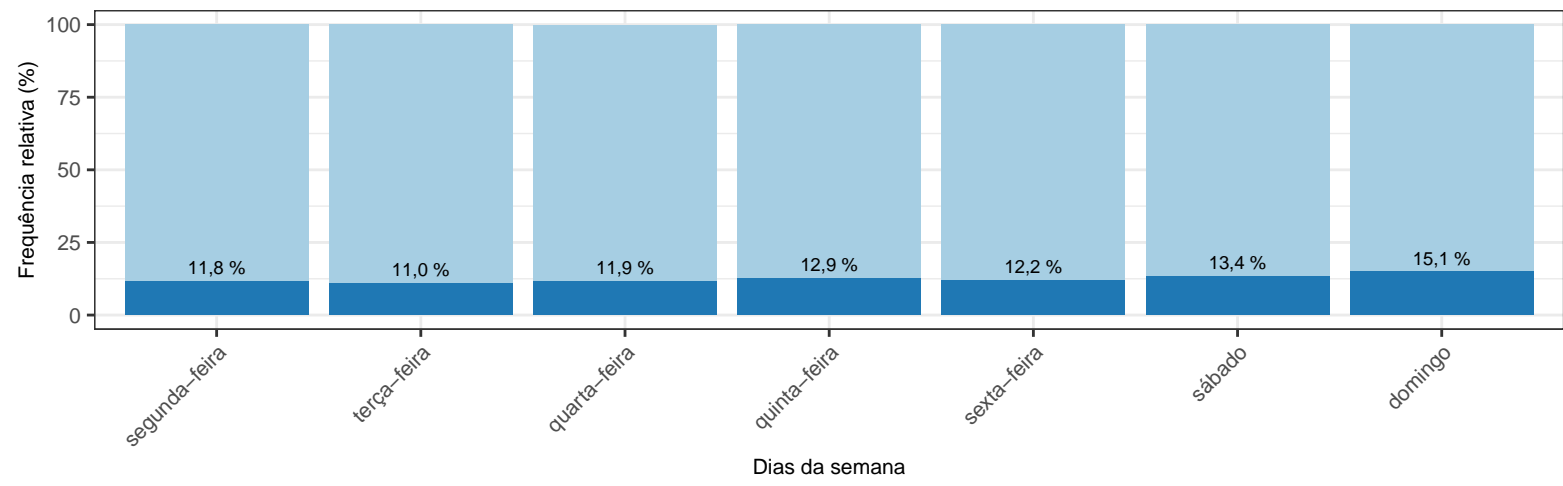

(C) Distribuição dos valores omissos da pressão a montante no Sul de Peruíbe de acordo com o horário do dia

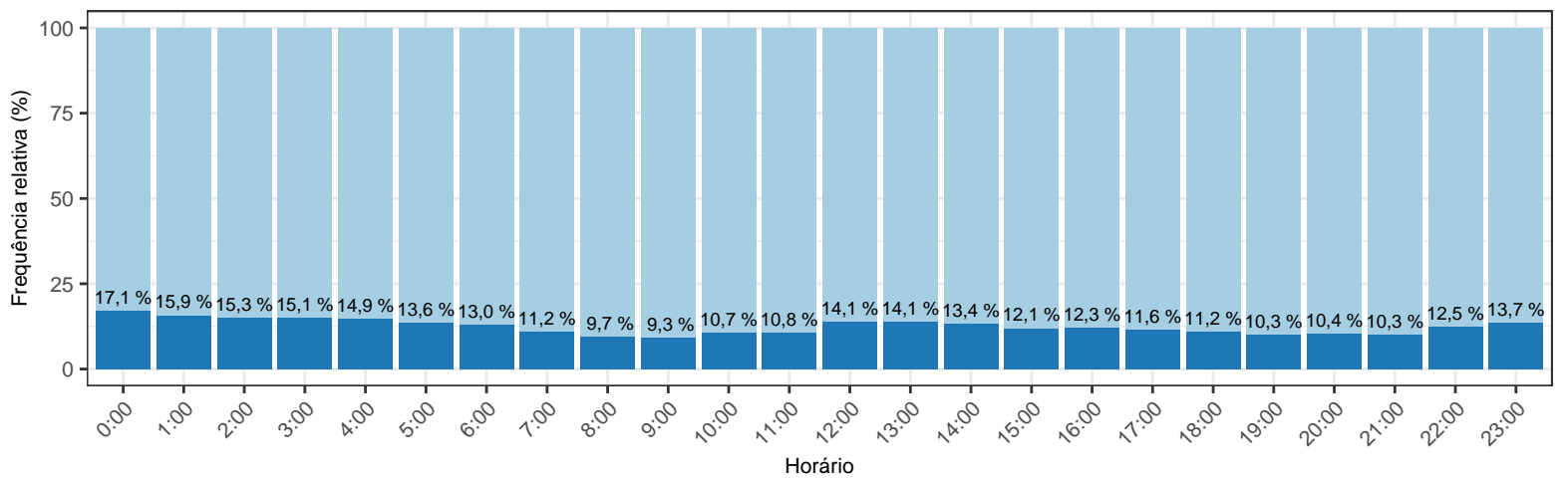

Figura B.14: Painel com alguns gráficos descritivos sobre a distribuição dos valores omissos presentes na série de pressão a montante ao Sul de Peruíbe. O gráfico (A) é a distribuição os valores omissos ao longo dos meses da série; o gráfico (B) é a distribuição os valores omissos de acordo com o dias da semana e o gráfico $(C)$ é a distribuição os valores omissos de acordo com os horários do dia. 
Tabela B.8: Medidas descritivas da série após limpeza primária de pressão a jusante ao Norte de Peruíbe. As informações descritivas são apresentadas para a série em sua totalidade e desagregada por períodos mensais, por dias da semana e por horários do dia.

\begin{tabular}{|c|c|c|c|c|c|c|c|c|c|}
\hline Descritiva & Média & Desvio padrão & Mínimo & $1^{\mathcal{O}}$ Quartil & Mediana & $3^{\mathrm{O}}$ Quartil & Máximo & Omissos & Total \\
\hline \multicolumn{10}{|l|}{ Geral } \\
\hline Geral & 17,0 & 4,59 & 4,05 & 12,72 & 17,70 & 20,3 & 33,8 & 1772 & 17519 \\
\hline \multicolumn{10}{|l|}{ Por ano e mês } \\
\hline 2017 jan & 19,1 & 4,46 & 7,23 & 15,45 & 19,60 & 22,3 & 33,8 & 187 & 743 \\
\hline 2017 fev & 17,8 & 4,63 & 9,91 & 14,40 & 17,92 & 21,7 & 26,0 & 69 & 673 \\
\hline 2017 mar & 17,0 & 4,63 & 6,20 & 12,63 & 17,90 & 20,4 & 26,6 & 53 & 744 \\
\hline 2017 abr & 15,9 & 4,15 & 6,18 & 12,28 & 17,26 & 19,8 & 24,9 & 20 & 720 \\
\hline 2017 mai & 15,6 & 4,07 & 7,25 & 12,03 & 15,92 & 19,7 & 22,4 & 37 & 744 \\
\hline 2017 jun & 16,0 & 4,15 & 8,21 & 12,26 & 17,26 & 19,7 & 23,8 & 21 & 720 \\
\hline 2017 jul & 16,2 & 4,10 & 8,64 & 13,88 & 17,34 & 19,5 & 25,7 & 42 & 744 \\
\hline 2017 ago & 16,3 & 4,08 & 8,96 & 12,50 & 17,53 & 19,7 & 22,5 & 24 & 744 \\
\hline 2017 set & 16,1 & 3,88 & 7,25 & 13,06 & 17,31 & 19,5 & 22,4 & 20 & 720 \\
\hline 2017 out & 14,9 & 4,70 & 5,49 & 9,72 & 14,80 & 19,4 & 24,8 & 18 & 743 \\
\hline 2017 nov & 16,4 & 4,35 & 8,06 & 12,19 & 17,73 & 20,0 & 22,9 & 19 & 720 \\
\hline $2017 \mathrm{dez}$ & 17,0 & 4,63 & 4,05 & 12,54 & 18,19 & 20,7 & 25,4 & 22 & 744 \\
\hline 2018 jan & 18,7 & 4,96 & 4,13 & 14,80 & 19,54 & 22,4 & 27,3 & 7 & 744 \\
\hline 2018 fev & 18,6 & 4,61 & 8,62 & 14,54 & 19,46 & 22,1 & 26,4 & 15 & 673 \\
\hline 2018 mar & 17,7 & 4,73 & 6,54 & 12,63 & 18,46 & 22,1 & 26,6 & 18 & 744 \\
\hline 2018 abr & 17,4 & 4,71 & 7,20 & 12,45 & 18,17 & 21,9 & 26,2 & 155 & 720 \\
\hline 2018 mai & 17,5 & 4,66 & 9,21 & 12,58 & 18,22 & 22,0 & 25,4 & 146 & 744 \\
\hline 2018 jun & 16,5 & 4,00 & 8,86 & 12,14 & 18,00 & 19,9 & 25,7 & 9 & 720 \\
\hline 2018 jul & 15,0 & 4,48 & 7,28 & 11,75 & 15,16 & 18,4 & 25,5 & 456 & 744 \\
\hline 2018 ago & 16,3 & 4,60 & 7,55 & 12,33 & 15,51 & 20,2 & 25,1 & 71 & 744 \\
\hline 2018 set & 16,8 & 4,48 & 6,52 & 12,97 & 16,06 & 21,5 & 23,7 & 22 & 720 \\
\hline 2018 out & 18,3 & 4,58 & 8,67 & 14,79 & 19,46 & 22,2 & 29,0 & 162 & 744 \\
\hline 2018 nov & 18,6 & 4,04 & 8,99 & 15,16 & 19,34 & 22,3 & 28,1 & 146 & 719 \\
\hline $2018 \mathrm{dez}$ & 18,1 & 5,00 & 4,30 & 14,38 & 18,29 & 22,4 & 28,6 & 33 & 744 \\
\hline \multicolumn{10}{|c|}{ Por dia da semana } \\
\hline segunda-feira & 17,1 & 4,58 & 4,13 & 12,83 & 17,75 & 20,3 & 27,2 & 225 & 2520 \\
\hline terça-feira & 16,9 & 4,57 & 4,30 & 12,58 & 17,57 & 20,3 & 27,3 & 230 & 2496 \\
\hline quarta-feira & 16,8 & 4,58 & 4,22 & 12,58 & 17,58 & 20,3 & 26,6 & 226 & 2496 \\
\hline quinta-feira & 17,0 & 4,55 & 6,52 & 12,75 & 17,70 & 20,3 & 29,0 & 270 & 2496 \\
\hline sexta-feira & 17,0 & 4,58 & 6,42 & 12,73 & 17,75 & 20,4 & 26,6 & 242 & 2496 \\
\hline sábado & 17,1 & 4,60 & 5,49 & 13,11 & 17,88 & 20,4 & 28,6 & 253 & 2498 \\
\hline domingo & 17,1 & 4,66 & 4,05 & 13,21 & 17,75 & 20,3 & 33,8 & 326 & 2517 \\
\hline \multicolumn{10}{|c|}{ Por horário do dia } \\
\hline 0:00 & 10,7 & 2,34 & 5,74 & 9,43 & 9,91 & 11,6 & 28,3 & 80 & 727 \\
\hline $1: 00$ & 10,8 & 2,44 & 4,22 & 9,47 & 10,13 & 11,7 & 28,4 & 77 & 730 \\
\hline $2: 00$ & 11,5 & 2,68 & 4,25 & 9,62 & 10,77 & 12,6 & 28,4 & 73 & 730 \\
\hline $3: 00$ & 13,1 & 2,59 & 4,05 & 11,55 & 12,52 & 14,7 & 28,2 & 70 & 730 \\
\hline $4: 00$ & 13,9 & 2,77 & 4,13 & 12,19 & 13,86 & 15,2 & 28,4 & 76 & 730 \\
\hline $5: 00$ & 15,6 & 2,71 & 4,37 & 14,31 & 14,98 & 17,7 & 28,2 & 72 & 730 \\
\hline $6: 00$ & 16,2 & 2,59 & 6,74 & 14,51 & 15,29 & 18,0 & 28,3 & 80 & 730 \\
\hline $7: 00$ & 17,8 & 1,98 & 5,79 & 17,31 & 17,78 & 18,5 & 27,6 & 71 & 730 \\
\hline $8: 00$ & 18,7 & 2,15 & 8,38 & 17,78 & 18,44 & 19,9 & 27,7 & 69 & 730 \\
\hline $9: 00$ & 20,2 & 2,30 & 7,55 & 19,56 & 20,15 & 21,9 & 27,5 & 59 & 730 \\
\hline $10: 00$ & 20,9 & 2,48 & 7,25 & 19,78 & 20,93 & 22,1 & 27,9 & 73 & 730 \\
\hline $11: 00$ & 21,4 & 2,79 & 8,84 & 19,85 & 20,90 & 23,2 & 28,5 & 79 & 730 \\
\hline $12: 00$ & 22,1 & 2,66 & 8,72 & 21,25 & 22,20 & 23,4 & 27,8 & 89 & 730 \\
\hline $13: 00$ & 22,1 & 2,63 & 8,28 & 21,29 & 22,44 & 23,4 & 33,8 & 96 & 730 \\
\hline $14: 00$ & 22,0 & 2,59 & 8,52 & 21,27 & 22,32 & 23,4 & 28,1 & 93 & 730 \\
\hline $15: 00$ & 21,0 & 2,48 & 7,52 & 19,85 & 21,67 & 22,4 & 28,6 & 72 & 730 \\
\hline $16: 00$ & 20,4 & 2,42 & 9,38 & 19,56 & 20,35 & 21,9 & 28,8 & 74 & 730 \\
\hline $17: 00$ & 19,2 & 2,36 & 9,11 & 17,81 & 19,63 & 20,3 & 29,0 & 72 & 730 \\
\hline $18: 00$ & 18,7 & 2,30 & 8,72 & 17,61 & 19,24 & 19,9 & 27,4 & 63 & 730 \\
\hline $19: 00$ & 16,9 & 2,54 & 8,86 & 15,28 & 17,31 & 18,2 & 27,2 & 62 & 730 \\
\hline $20: 00$ & 16,6 & 2,65 & 6,98 & 14,85 & 17,34 & 18,1 & 27,0 & 71 & 730 \\
\hline $21: 00$ & 14,3 & 3,05 & 7,11 & 11,92 & 14,75 & 15,6 & 28,0 & 65 & 730 \\
\hline $22: 00$ & 12,4 & 2,69 & 7,28 & 11,38 & 11,97 & 12,5 & 28,6 & 66 & 730 \\
\hline $23: 00$ & 11,5 & 2,49 & 5,93 & 9,67 & 11,89 & 12,4 & 27,9 & 70 & 732 \\
\hline
\end{tabular}


(A) Pressão a jusante a cada hora no Norte de Peruíbe de acordo com o mês

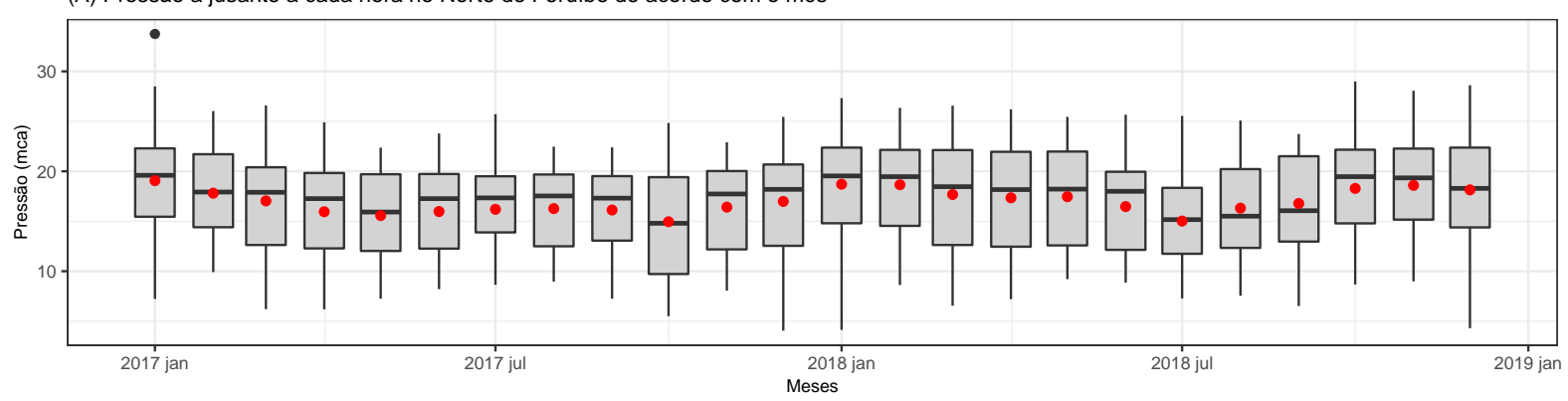

(B) Pressão a jusante a cada hora no Norte de Peruíbe de acordo com o horário do dia

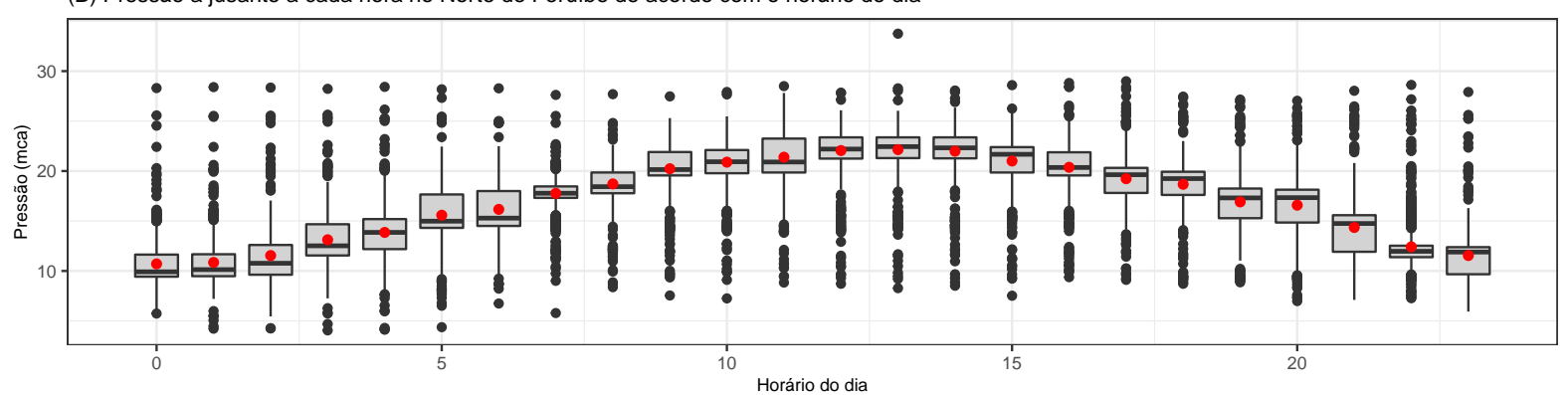

(C) Pressão a jusante a cada hora no Norte de Peruíbe de acordo com dia da semana

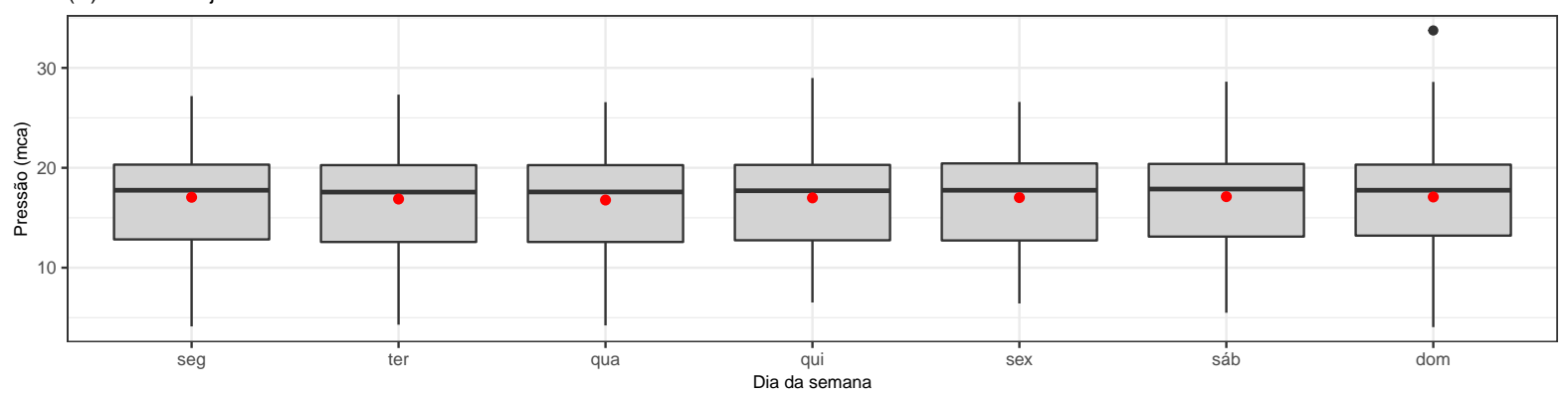

(D) Trecho da série de pressão a jusante no Norte de Peruíbe De 1 a 31 de Julho de 2017

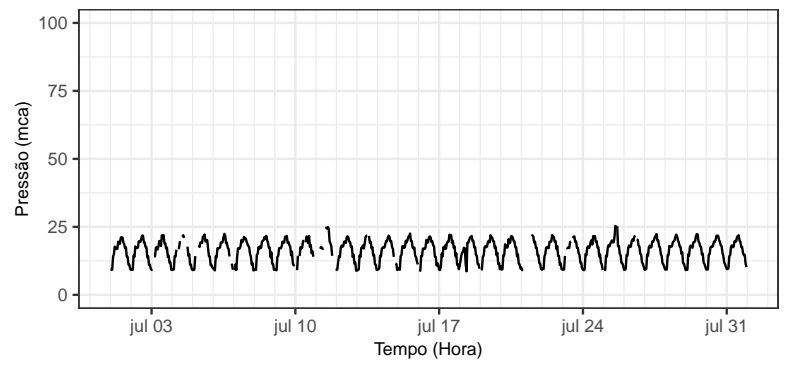

(E) Trecho da série de vazão de pressão a jusante no Norte de Peruíbe De 15 de dezembro de 2017 a 15 de janeiro de 2018

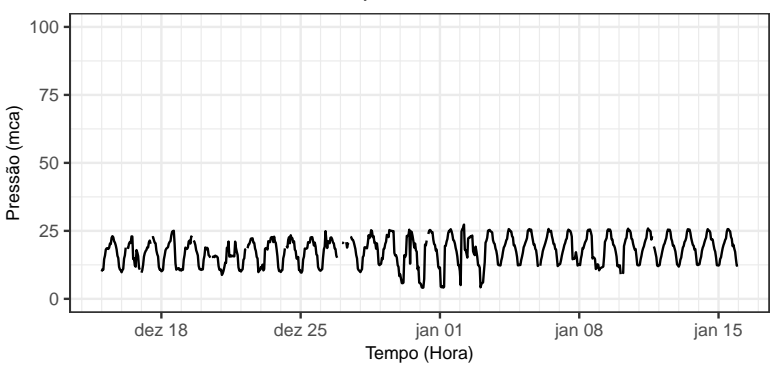

Figura B.15: Painel com alguns gráficos descritivos da série após limpeza primária de pressão a jusante ao Norte de Peruibe. Os gráficos $(A),(B)$ e $(C)$ são boxplots série de vazão em $\mathrm{l} / \mathrm{s}$ de acordo com mês, horário do dia e dia semana, respectivamente. Os pontos vermelhos são as médias de cada período. Já os gráficos (D) e (E) são trechos selecionados da série. 
(A) Distribuição dos valores omissos da pressão a jusante no Norte de Peruíbe de acordo com o mês

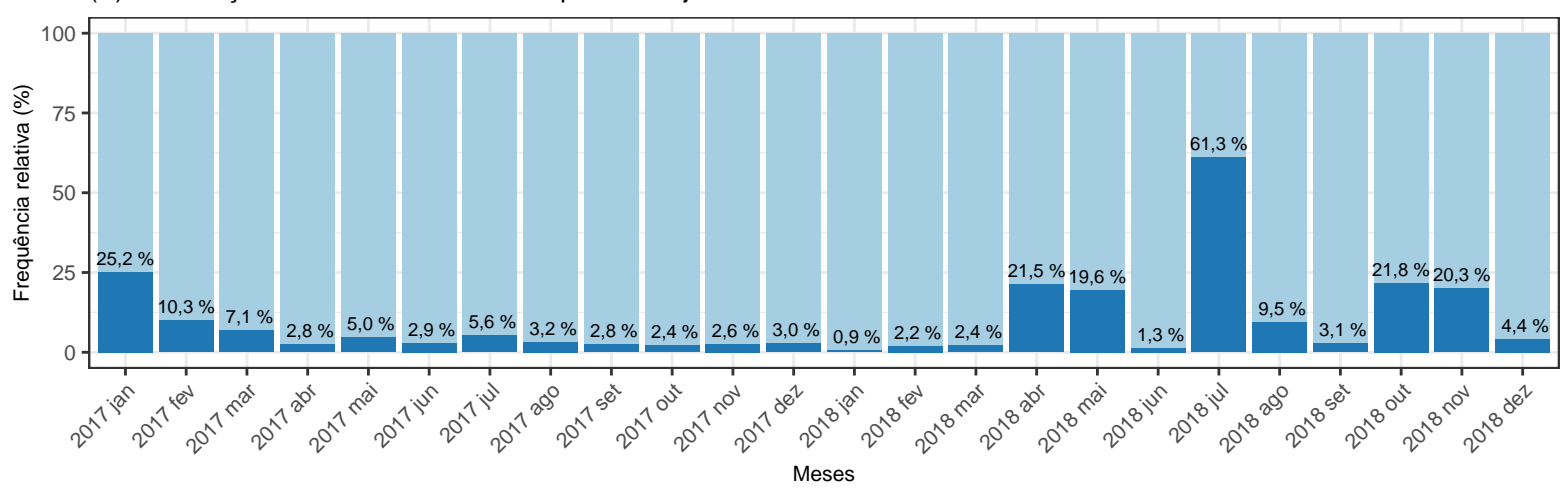

(B) Distribuição dos valores omissos da pressão a jusante no Norte de Peruíbe de acordo com o dia da semana

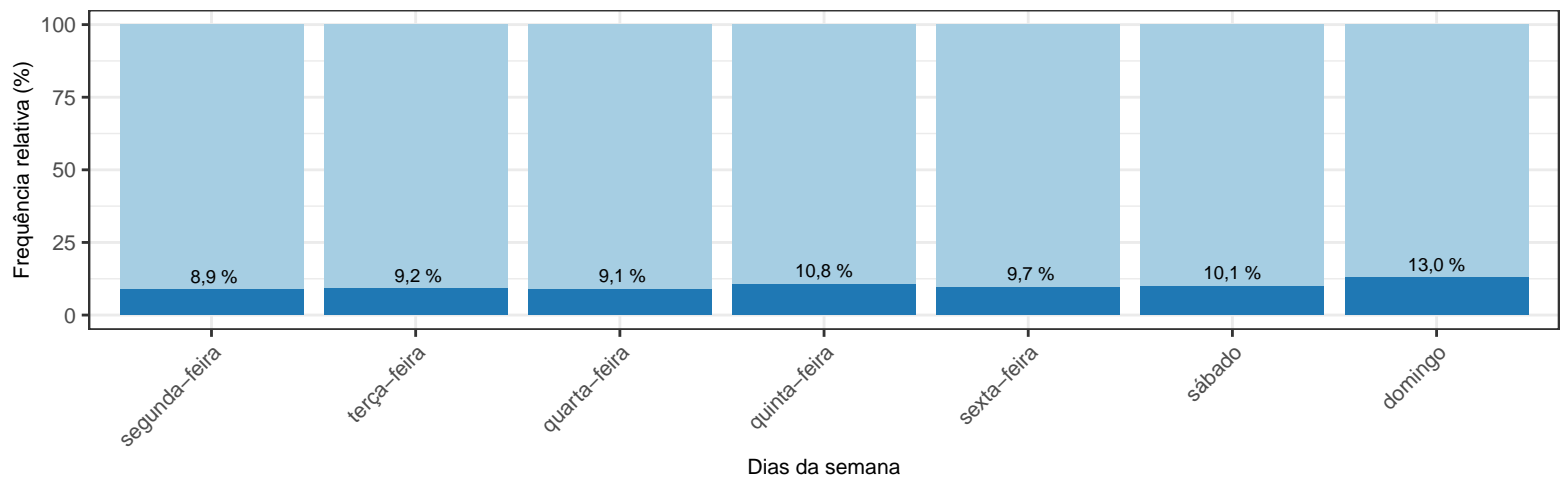

(C) Distribuição dos valores omissos da pressão a jusante no Norte de Peruíbe de acordo com o horário do dia

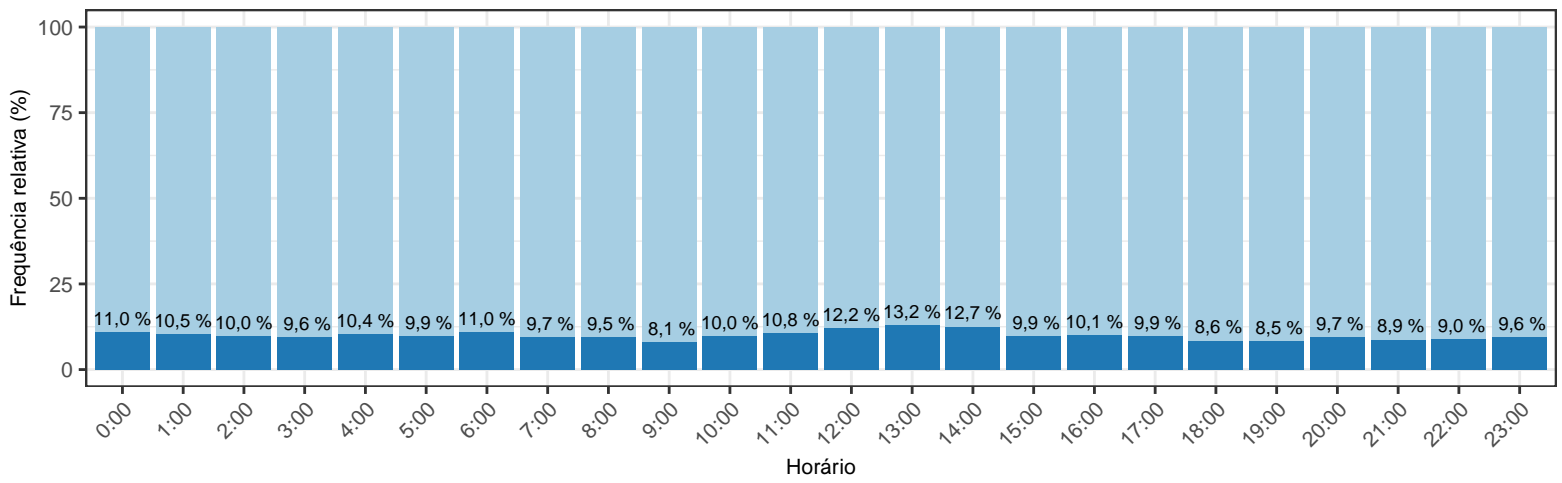

Figura B.16: Painel com alguns gráficos descritivos sobre a distribuição dos valores omissos presentes na série de pressão a jusante ao Norte de Peruíbe. O gráfico (A) é a distribuição os valores omissos ao longo dos meses da série; o gráfico (B) é a distribuição os valores omissos de acordo com o dias da semana e o gráfico $(C)$ é a distribuição os valores omissos de acordo com os horários do dia. 
Tabela B.9: Medidas descritivas da série após limpeza primária de pressão a jusante ao Sul de Peruíbe. As informações descritivas são apresentadas para a série em sua totalidade e desagregada por periodos mensais, por dias da semana e por horários do dia.

\begin{tabular}{|c|c|c|c|c|c|c|c|c|c|}
\hline Descritiva & Média & Desvio padrão & Mínimo & $1^{\mathrm{O}}$ Quartil & Mediana & $3^{\mathcal{O}}$ Quartil & Máximo & Omissos & Total \\
\hline \multicolumn{10}{|l|}{ Geral } \\
\hline Geral & 16,3 & 4,71 & 3,49 & 12,53 & 15,5 & 19,4 & 42,4 & 1743 & 17519 \\
\hline \multicolumn{10}{|l|}{ Por ano e mês } \\
\hline 2017 jan & 19,1 & 4,89 & 7,96 & 15,21 & 18,7 & 22,8 & 30,0 & 192 & 743 \\
\hline $2017 \mathrm{fev}$ & 17,3 & 4,75 & 9,67 & 12,65 & 17,7 & 20,9 & 26,8 & 64 & 673 \\
\hline 2017 mar & 15,8 & 4,44 & 6,28 & 12,29 & 15,2 & 19,0 & 26,2 & 54 & 744 \\
\hline 2017 abr & 14,6 & 3,90 & 6,25 & 11,16 & 14,5 & 17,9 & 26,3 & 16 & 720 \\
\hline 2017 mai & 14,2 & 3,33 & 8,69 & 11,25 & 14,0 & 17,6 & 26,2 & 34 & 744 \\
\hline 2017 jun & 14,8 & 3,88 & 7,11 & 11,48 & 14,7 & 17,9 & 37,2 & 23 & 720 \\
\hline 2017 jul & 15,2 & 3,75 & 9,18 & 12,20 & 15,0 & 18,1 & 42,4 & 40 & 744 \\
\hline 2017 ago & 15,2 & 3,69 & 9,13 & 12,28 & 14,9 & 18,1 & 26,8 & 16 & 744 \\
\hline 2017 set & 15,2 & 3,10 & 8,72 & 12,74 & 14,9 & 17,9 & 22,4 & 21 & 720 \\
\hline 2017 out & 14,4 & 3,64 & 6,62 & 10,67 & 14,6 & 17,6 & 26,0 & 25 & 743 \\
\hline 2017 nov & 14,9 & 3,42 & 8,99 & 11,62 & 14,8 & 17,9 & 21,8 & 14 & 720 \\
\hline 2017 dez & 15,2 & 3,89 & 3,49 & 12,25 & 14,9 & 18,1 & 28,5 & 21 & 744 \\
\hline 2018 jan & 17,9 & 4,84 & 3,57 & 14,12 & 18,2 & 21,6 & 27,4 & 12 & 744 \\
\hline 2018 fev & 17,7 & 4,49 & 7,91 & 14,27 & 18,1 & 20,9 & 29,8 & 17 & 673 \\
\hline 2018 mar & 16,2 & 4,32 & 7,06 & 12,28 & 17,5 & 19,8 & 27,0 & 15 & 744 \\
\hline 2018 abr & 16,0 & 4,29 & 8,23 & 12,36 & 15,3 & 19,8 & 35,7 & 150 & 720 \\
\hline 2018 mai & 16,1 & 3,93 & 8,23 & 12,41 & 17,0 & 19,8 & 25,6 & 140 & 744 \\
\hline 2018 jun & 15,2 & 3,17 & 9,01 & 12,50 & 14,7 & 17,9 & 25,1 & 7 & 720 \\
\hline 2018 jul & 13,9 & 3,75 & 7,99 & 11,11 & 13,8 & 17,2 & 25,6 & 461 & 744 \\
\hline 2018 ago & 15,7 & 3,66 & 8,25 & 12,23 & 15,3 & 19,6 & 23,8 & 69 & 744 \\
\hline 2018 set & 15,9 & 3,34 & 8,25 & 13,09 & 15,7 & 19,3 & 21,2 & 16 & 720 \\
\hline 2018 out & 17,5 & 4,96 & 7,25 & 13,28 & 17,7 & 20,3 & 29,8 & 165 & 744 \\
\hline 2018 nov & 22,4 & 5,73 & 10,96 & 17,04 & 23,8 & 27,9 & 30,2 & 141 & 719 \\
\hline $2018 \mathrm{dez}$ & 22,1 & 6,33 & 4,74 & 16,59 & 23,9 & 27,7 & 35,8 & 30 & 744 \\
\hline \multicolumn{10}{|c|}{ Por dia da semana } \\
\hline segunda-feira & 16,5 & 4,73 & 3,57 & 12,61 & 15,8 & 19,5 & 30,6 & 225 & 2520 \\
\hline terça-feira & 16,4 & 4,68 & 4,74 & 12,61 & 15,4 & 19,4 & 30,1 & 217 & 2496 \\
\hline quarta-feira & 16,2 & 4,68 & 4,22 & 12,48 & 15,3 & 19,2 & 42,4 & 226 & 2496 \\
\hline quinta-feira & 16,2 & 4,49 & 6,47 & 12,55 & 15,5 & 19,1 & 29,6 & 253 & 2496 \\
\hline sexta-feira & 16,5 & 4,88 & 6,28 & 12,53 & 15,7 & 19,5 & 37,2 & 254 & 2496 \\
\hline sábado & 16,4 & 4,81 & 4,42 & 12,50 & 15,6 & 19,4 & 35,8 & 253 & 2498 \\
\hline domingo & 16,2 & 4,68 & 3,49 & 12,50 & 15,5 & 19,4 & 30,0 & 315 & 2517 \\
\hline \multicolumn{10}{|c|}{ Por horário do dia } \\
\hline $0: 00$ & 11,2 & 2,92 & 5,64 & 9,74 & 10,3 & 11,8 & 28,7 & 66 & 727 \\
\hline $1: 00$ & 11,3 & 2,79 & 3,52 & 10,06 & 10,5 & 11,8 & 28,1 & 79 & 730 \\
\hline $2: 00$ & 11,9 & 2,57 & 3,49 & 10,50 & 11,3 & 12,4 & 28,4 & 72 & 730 \\
\hline $3: 00$ & 12,9 & 2,53 & 3,71 & 11,84 & 12,4 & 13,1 & 29,4 & 68 & 730 \\
\hline $4: 00$ & 13,6 & 2,39 & 3,57 & 12,67 & 13,2 & 14,4 & 28,6 & 74 & 730 \\
\hline $5: 00$ & 14,9 & 2,32 & 3,61 & 14,07 & 14,8 & 15,5 & 28,2 & 69 & 730 \\
\hline $6: 00$ & 15,2 & 2,14 & 6,52 & 14,29 & 14,8 & 15,7 & 28,0 & 75 & 730 \\
\hline $7: 00$ & 16,6 & 2,38 & 7,89 & 14,85 & 16,5 & 18,0 & 29,2 & 65 & 730 \\
\hline $8: 00$ & 17,0 & 2,82 & 9,30 & 14,60 & 17,0 & 18,9 & 28,5 & 65 & 730 \\
\hline $9: 00$ & 19,3 & 2,84 & 7,91 & 17,88 & 18,9 & 20,6 & 29,0 & 59 & 730 \\
\hline $10: 00$ & 19,7 & 3,24 & 7,84 & 17,86 & 19,1 & 21,0 & 29,3 & 79 & 730 \\
\hline $11: 00$ & 20,9 & 3,61 & 6,91 & 19,15 & 20,1 & 22,2 & 30,2 & 80 & 730 \\
\hline $12: 00$ & 21,1 & 3,65 & 7,18 & 19,21 & 20,2 & 24,1 & 29,4 & 88 & 730 \\
\hline $13: 00$ & 21,0 & 3,63 & 7,16 & 19,32 & 20,1 & 23,9 & 30,1 & 80 & 730 \\
\hline $14: 00$ & 20,0 & 3,55 & 7,42 & 18,00 & 19,3 & 21,6 & 29,4 & 79 & 730 \\
\hline $15: 00$ & 19,9 & 3,55 & 7,64 & 17,83 & 19,2 & 20,9 & 35,8 & 77 & 730 \\
\hline $16: 00$ & 19,8 & 3,54 & 7,79 & 17,90 & 19,2 & 20,4 & 42,4 & 81 & 730 \\
\hline $17: 00$ & 19,0 & 3,56 & 9,89 & 17,53 & 18,3 & 20,0 & 35,1 & 73 & 730 \\
\hline $18: 00$ & 17,6 & 4,01 & 9,67 & 15,09 & 16,9 & 18,3 & 35,7 & 65 & 730 \\
\hline $19: 00$ & 16,3 & 4,24 & 8,57 & 14,48 & 15,0 & 17,1 & 35,4 & 61 & 730 \\
\hline $20: 00$ & 15,2 & 4,03 & 8,06 & 12,58 & 14,7 & 15,4 & 35,6 & 66 & 730 \\
\hline $21: 00$ & 13,4 & 4,16 & 7,96 & 10,60 & 12,3 & 14,5 & 36,8 & 68 & 730 \\
\hline $22: 00$ & 12,4 & 4,08 & 8,01 & 10,23 & 10,8 & 12,3 & 36,2 & 77 & 730 \\
\hline $23: 00$ & 11,9 & 3,37 & 5,91 & 10,11 & 10,7 & 12,2 & 37,2 & 77 & 732 \\
\hline
\end{tabular}


(A) Pressão a jusante a cada hora no Sul de Peruíbe de acordo com o mês

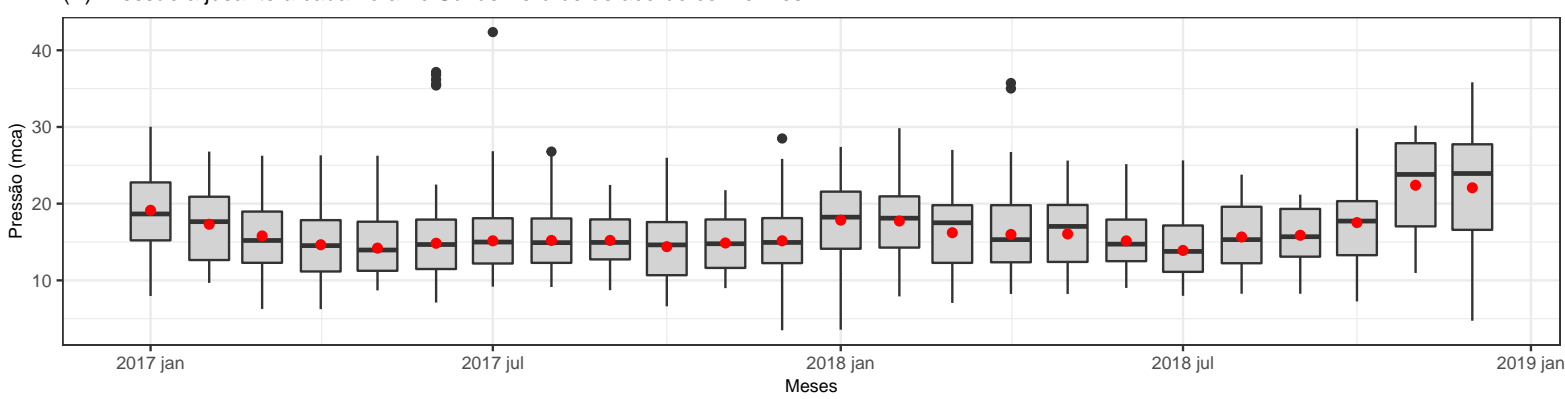

(B) Pressão a jusante a cada hora no Sul de Peruíbe de acordo com o horário do dia

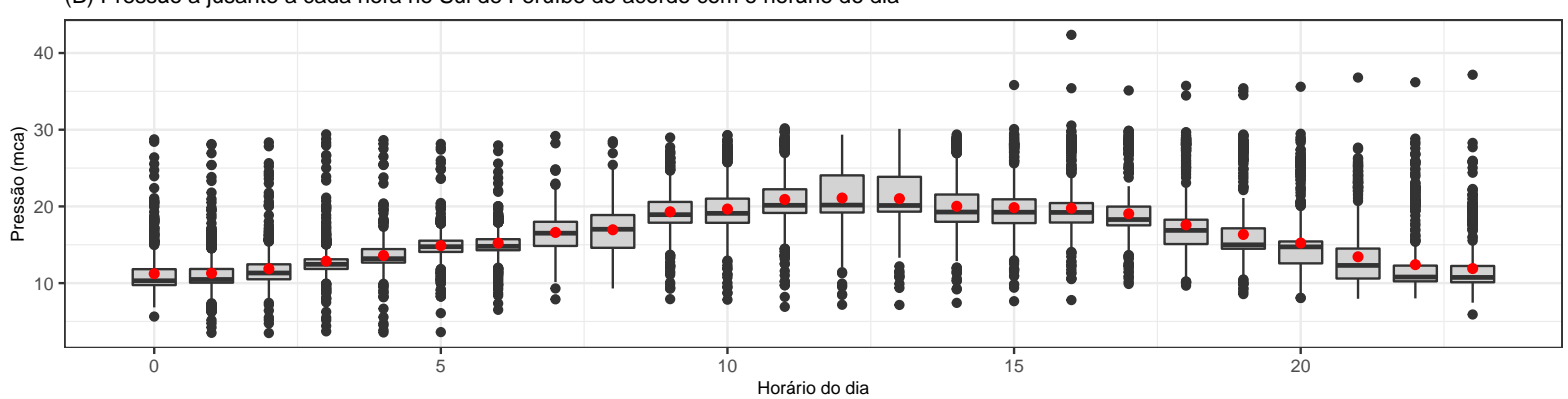

(C) Pressão a jusante a cada hora no Sul de Peruíbe de acordo com dia da semana

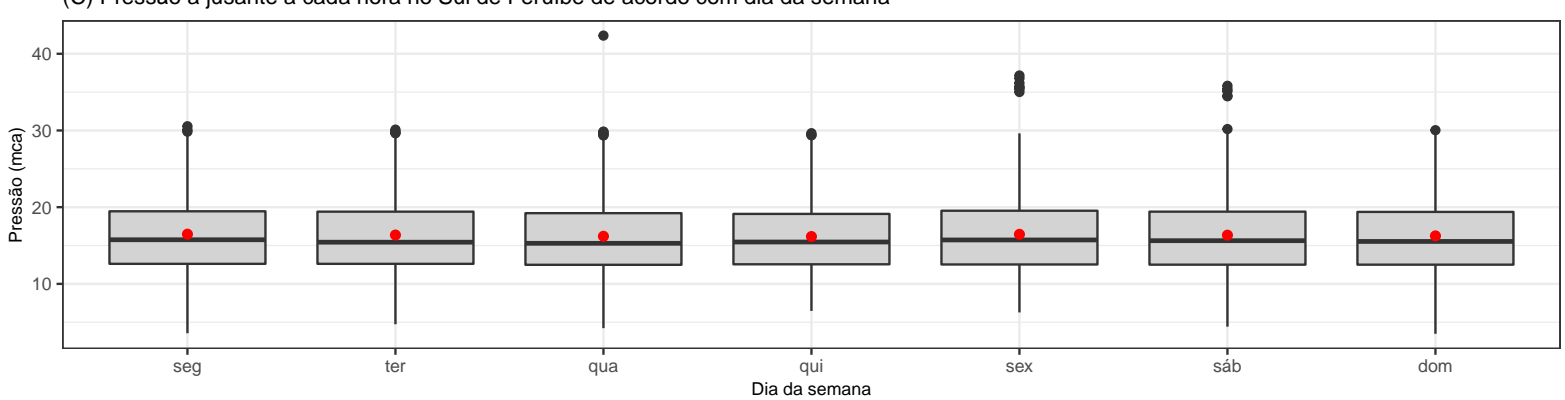

(D) Trecho da série de pressão a jusante no Sul de Peruíbe De $1^{\circ}$ a 31 de Julho de 2017

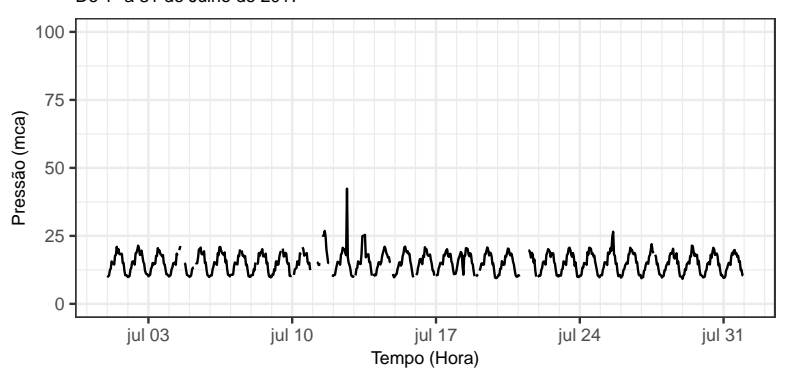

(E) Trecho da série de pressão a jusante no Sul de Peruíbe De 15 de dezembro de 2017 a 15 de janeiro de 2018

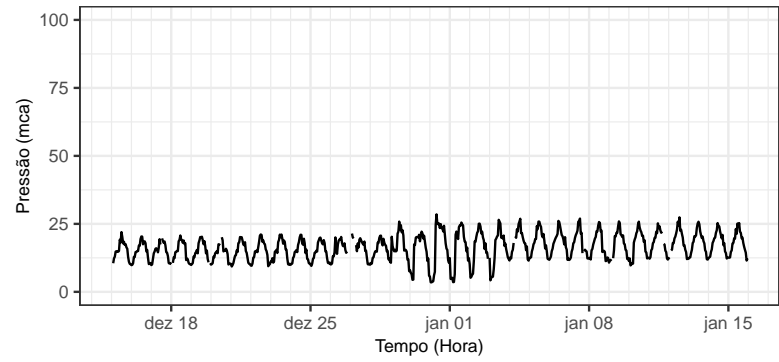

Figura B.17: Painel com alguns gráficos descritivos da série após limpeza primária de pressão a jusante ao Sul de Peruíbe. Os gráficos (A), (B) e (C) são boxplots série de vazão em l/s de acordo com mês, horário do dia e dia semana, respectivamente. Os pontos vermelhos são as médias de cada período. Já os gráficos (D) e (E) são trechos selecionados da série. 
(A) Distribuição dos valores omissos da pressão a jusante no Sul de Peruíbe de acordo com o mês

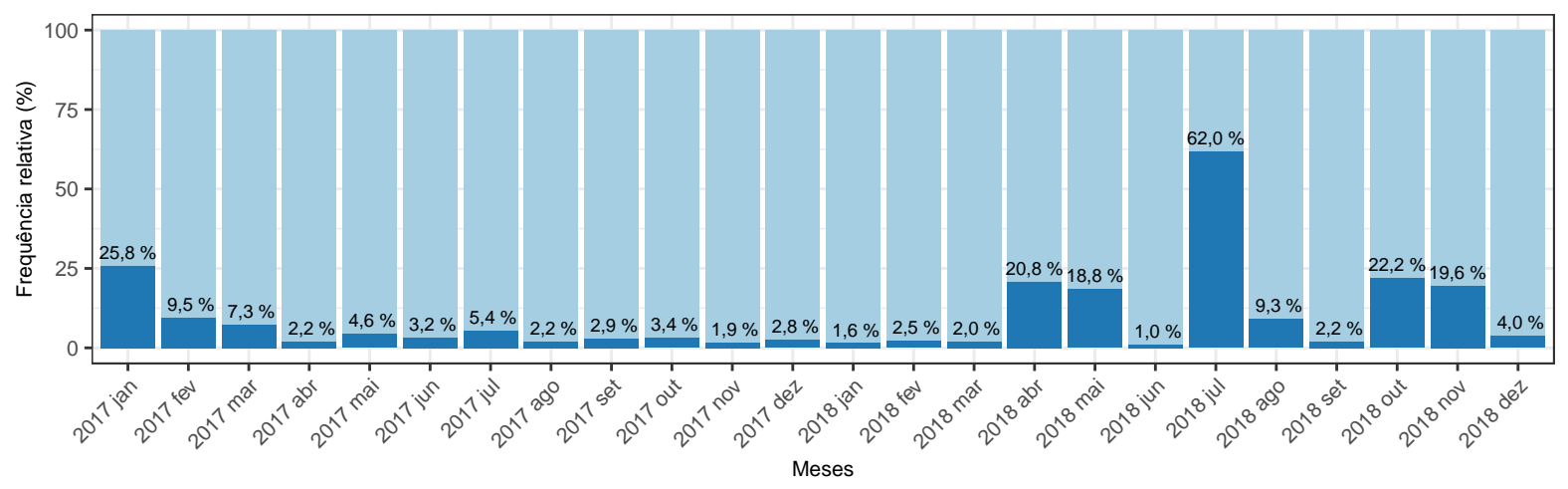

(B) Distribuição dos valores omissos da pressão a jusante no Sul de Peruíbe de acordo com o dia da semana

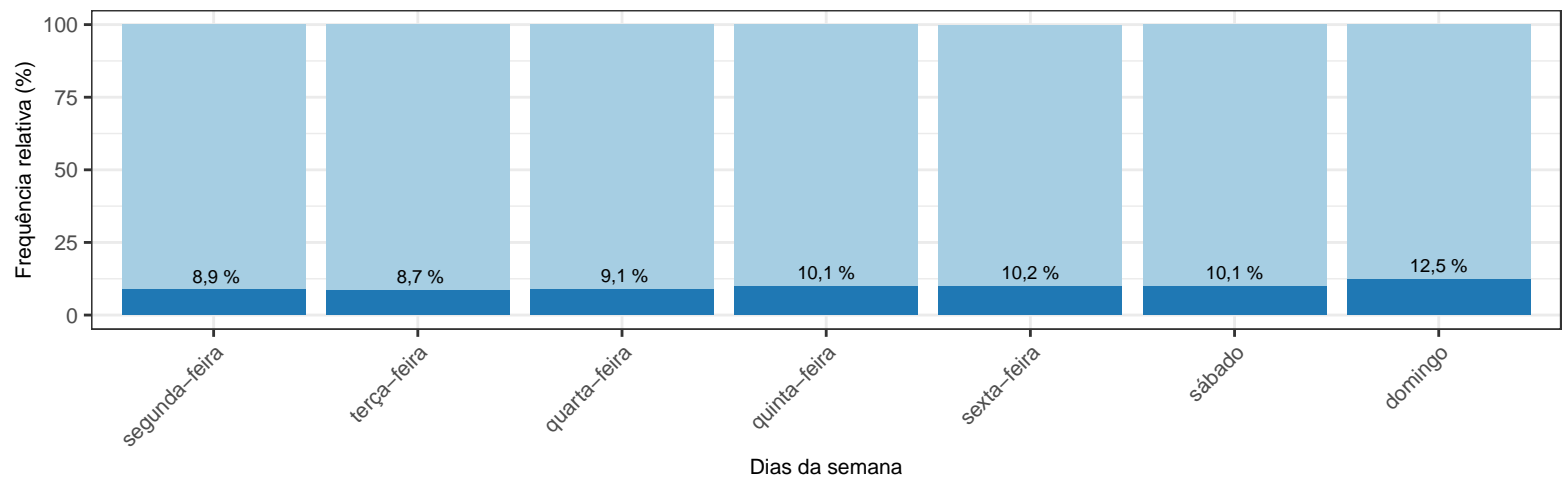

(C) Distribuição dos valores omissos da pressão a jusante no Sul de Peruíbe de acordo com o horário do dia

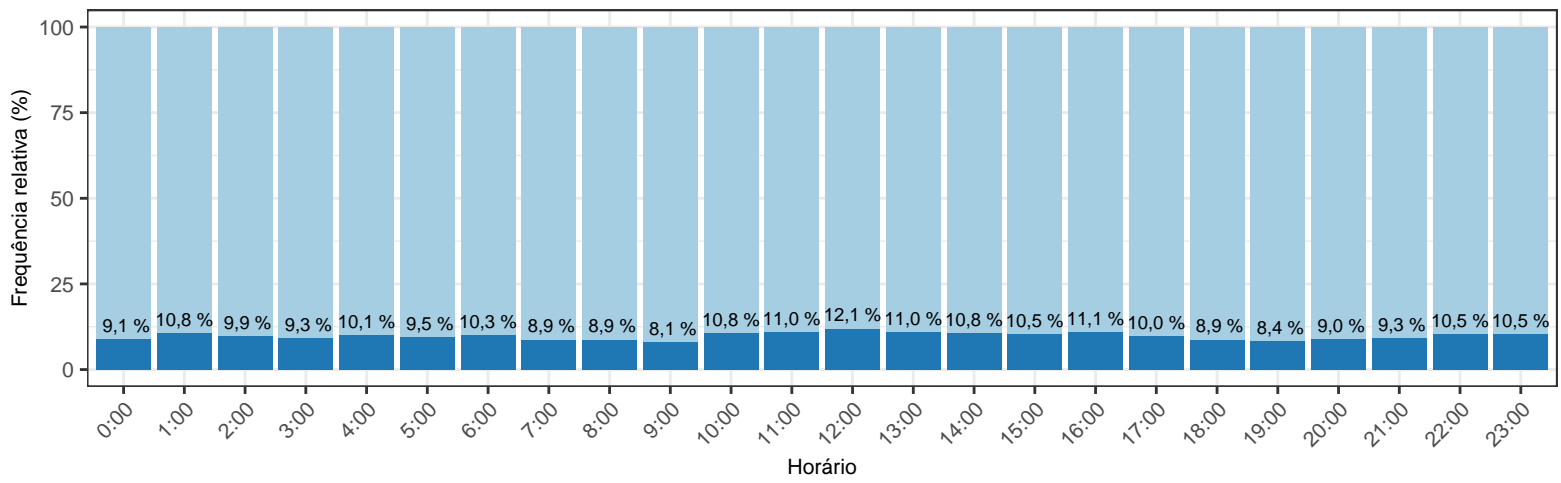

Figura B.18: Painel com alguns gráficos descritivos sobre a distribuição dos valores omissos presentes na série de pressão a jusante ao Sul de Peruíbe. O gráfico (A) é a distribuição os valores omissos ao longo dos meses da série; o gráfico (B) é a distribuição os valores omissos de acordo com o dias da semana e o gráfico (C) é a distribuição os valores omissos de acordo com os horários do dia. 


\section{Apêndice C}

\section{Informações descritivas após tratamento de outliers e preenchimento de omissos}

A seguir são apresentadas um conjunto de tabelas e gráficos descritivos para cada série temporal, sendo organizados da seguinte maneira:

- A Tabela C.1 e a Figura C.1 se referem a série de nível do reservatório de Peruíbe;

- A Tabela C.2 e a Figura C.2 se referem a série de consumo demandado do reservatório de Peruíbe;

- A Tabela C.3 e a Figura C.3 se referem a série de vazão de entrada do reservatório de Peruíbe;

- A Tabela C.4 e a Figura C.4 se referem a série de vazão de saída do reservatório para o Norte de Peruíbe;

- A Tabela C.5 e a Figura C.5 se referem a série de vazão de saída do reservatório para o Sul de Peruíbe;

- A Tabela C.6 e a Figura C.6 se referem a série de pressão a montante no Norte de Peruíbe;

- A Tabela C.7 e a Figura C.7 se referem a série de pressão a montante no Sul de Peruíbe;

- A Tabela C.8 e a Figura C.8 se referem a série de pressão a jusante no Norte de Peruíbe;

- A Tabela C.9 e a Figura C.9 se referem a série de pressão a jusante no Sul de Peruíbe. 
188 Apêndice C. Informações descritivas após tratamento de outliers e preenchimento de omissos

Tabela C.1: Medidas descritivas da série tratada de nivel do reservatório de Peruibe. As informações descritivas são apresentadas para a série em sua totalidade e desagregada por períodos mensais, por dias da semana e por horários do dia.

\begin{tabular}{|c|c|c|c|c|c|c|c|c|c|}
\hline Descritiva & Média & Desvio padrão & Mínimo & $1^{\mathrm{O}}$ Quartil & Mediana & $3^{\mathcal{O}}$ Quartil & Máximo & Omissos & Total \\
\hline \multicolumn{10}{|l|}{ Geral } \\
\hline Geral & 6,74 & 1,26 & 1,48 & 6,22 & 7,04 & 7,61 & 9,32 & 0 & 17519 \\
\hline \multicolumn{10}{|l|}{ Por ano e mês } \\
\hline 2017 jan & 6,30 & 1,18 & 2,75 & 5,59 & 6,63 & 7,24 & 8,28 & 0 & 743 \\
\hline 2017 fev & 6,82 & 0,70 & 3,39 & 6,47 & 6,97 & 7,29 & 7,99 & 0 & 673 \\
\hline 2017 mar & 6,60 & 0,85 & 3,40 & 6,31 & 6,80 & 7,18 & 7,95 & 0 & 744 \\
\hline 2017 abr & 6,79 & 0,57 & 5,21 & 6,40 & 6,85 & 7,23 & 8,06 & 0 & 720 \\
\hline 2017 mai & 6,76 & 0,70 & 3,79 & 6,43 & 6,85 & 7,26 & 8,00 & 0 & 744 \\
\hline 2017 jun & 6,87 & 0,55 & 4,60 & 6,51 & 6,92 & 7,29 & 8,01 & 0 & 720 \\
\hline 2017 jul & 6,67 & 0,74 & 4,00 & 6,19 & 6,85 & 7,23 & 8,10 & 0 & 744 \\
\hline 2017 ago & 6,49 & 0,96 & 2,23 & 6,00 & 6,71 & 7,19 & 8,00 & 0 & 744 \\
\hline 2017 set & 5,52 & 1,18 & 2,80 & 4,59 & 5,53 & 6,47 & 7,88 & 0 & 720 \\
\hline 2017 out & 5,75 & 1,34 & 2,52 & 4,80 & 5,84 & 6,95 & 8,47 & 0 & 743 \\
\hline 2017 nov & 7,36 & 0,80 & 4,40 & 6,97 & 7,50 & 7,95 & 8,46 & 0 & 720 \\
\hline 2017 dez & 6,91 & 1,06 & 3,71 & 6,45 & 7,17 & 7,66 & 8,47 & 0 & 744 \\
\hline 2018 jan & 7,11 & 1,11 & 2,81 & 6,77 & 7,39 & 7,85 & 8,49 & 0 & 744 \\
\hline 2018 fev & 7,36 & 0,87 & 2,57 & 7,11 & 7,53 & 7,91 & 8,49 & 0 & 673 \\
\hline 2018 mar & 7,61 & 0,66 & 4,50 & 7,34 & 7,76 & 8,09 & 8,50 & 0 & 744 \\
\hline 2018 abr & 7,53 & 0,72 & 3,37 & 7,27 & 7,68 & 7,99 & 8,50 & 0 & 720 \\
\hline 2018 mai & 7,58 & 0,60 & 4,92 & 7,24 & 7,68 & 8,02 & 8,50 & 0 & 744 \\
\hline 2018 jun & 7,81 & 0,41 & 6,12 & 7,57 & 7,85 & 8,12 & 8,49 & 0 & 720 \\
\hline 2018 jul & 6,67 & 1,24 & 3,35 & 5,88 & 6,85 & 7,73 & 8,49 & 0 & 744 \\
\hline 2018 ago & 6,65 & 1,65 & 1,95 & 6,18 & 7,20 & 7,88 & 8,50 & 0 & 744 \\
\hline 2018 set & 4,41 & 1,49 & 1,80 & 3,21 & 4,09 & 5,34 & 8,34 & 0 & 720 \\
\hline 2018 out & 6,68 & 1,52 & 1,95 & 6,05 & 7,11 & 7,84 & 8,88 & 0 & 744 \\
\hline 2018 nov & 7,11 & 0,90 & 3,96 & 6,58 & 7,23 & 7,78 & 9,32 & 0 & 719 \\
\hline $2018 \mathrm{dez}$ & 6,34 & 1,45 & 1,48 & 5,55 & 6,65 & 7,38 & 8,49 & 0 & 744 \\
\hline \multicolumn{10}{|c|}{ Por dia da semana } \\
\hline segunda-feira & 6,67 & 1,31 & 1,48 & 6,17 & 6,96 & 7,58 & 8,88 & 0 & 2520 \\
\hline terça-feira & 6,68 & 1,34 & 2,05 & 6,05 & 7,06 & 7,63 & 8,57 & 0 & 2496 \\
\hline quarta-feira & 6,74 & 1,31 & 1,95 & 6,16 & 7,10 & 7,70 & 8,50 & 0 & 2496 \\
\hline quinta-feira & 6,74 & 1,26 & 1,80 & 6,23 & 7,08 & 7,61 & 8,48 & 0 & 2496 \\
\hline sexta-feira & 6,74 & 1,14 & 2,67 & 6,20 & 6,97 & 7,55 & 8,50 & 0 & 2496 \\
\hline sábado & 6,82 & 1,18 & 2,28 & 6,40 & 7,05 & 7,63 & 8,74 & 0 & 2498 \\
\hline domingo & 6,75 & 1,24 & 1,84 & 6,31 & 7,05 & 7,58 & 9,32 & 0 & 2517 \\
\hline \multicolumn{10}{|c|}{ Por horário do dia } \\
\hline $0: 00$ & 6,73 & 1,37 & 1,61 & 6,17 & 7,05 & 7,75 & 8,54 & 0 & 727 \\
\hline $1: 00$ & 6,84 & 1,31 & 1,48 & 6,32 & 7,12 & 7,80 & 8,66 & 0 & 730 \\
\hline $2: 00$ & 6,92 & 1,23 & 1,63 & 6,43 & 7,23 & 7,82 & 8,64 & 0 & 730 \\
\hline $3: 00$ & 7,00 & 1,16 & 2,02 & 6,54 & 7,25 & 7,83 & 8,77 & 0 & 730 \\
\hline $4: 00$ & 7,03 & 1,07 & 2,44 & 6,59 & 7,27 & 7,76 & 9,04 & 0 & 730 \\
\hline $5: 00$ & 7,07 & 1,00 & 2,80 & 6,62 & 7,28 & 7,75 & 9,23 & 0 & 730 \\
\hline $6: 00$ & 7,08 & 0,94 & 2,91 & 6,65 & 7,25 & 7,72 & 9,30 & 0 & 730 \\
\hline $7: 00$ & 7,14 & 0,90 & 2,99 & 6,79 & 7,27 & 7,75 & 9,28 & 0 & 730 \\
\hline $8: 00$ & 7,18 & 0,91 & 3,01 & 6,83 & 7,34 & 7,77 & 9,31 & 0 & 730 \\
\hline $9: 00$ & 7,15 & 0,95 & 2,85 & 6,78 & 7,33 & 7,78 & 9,32 & 0 & 730 \\
\hline $10: 00$ & 7,02 & 1,00 & 2,59 & 6,57 & 7,23 & 7,69 & 9,11 & 0 & 730 \\
\hline $11: 00$ & 6,89 & 1,05 & 2,32 & 6,44 & 7,12 & 7,58 & 8,87 & 0 & 730 \\
\hline $12: 00$ & 6,76 & 1,10 & 2,13 & 6,25 & 7,01 & 7,52 & 8,76 & 0 & 730 \\
\hline $13: 00$ & 6,64 & 1,16 & 1,98 & 6,07 & 6,92 & 7,45 & 8,51 & 0 & 730 \\
\hline $14: 00$ & 6,56 & 1,22 & 1,86 & 5,94 & 6,81 & 7,40 & 8,49 & 0 & 730 \\
\hline $15: 00$ & 6,49 & 1,29 & 1,80 & 5,88 & 6,77 & 7,40 & 8,49 & 0 & 730 \\
\hline $16: 00$ & 6,43 & 1,34 & 1,92 & 5,78 & 6,75 & 7,40 & 8,50 & 0 & 730 \\
\hline $17: 00$ & 6,38 & 1,38 & 1,99 & 5,66 & 6,68 & 7,38 & 8,50 & 0 & 730 \\
\hline $18: 00$ & 6,34 & 1,42 & 1,97 & 5,55 & 6,68 & 7,34 & 8,50 & 0 & 730 \\
\hline $19: 00$ & 6,31 & 1,43 & 1,95 & 5,48 & 6,68 & 7,39 & 8,46 & 0 & 730 \\
\hline $20: 00$ & 6,31 & 1,45 & 2,00 & 5,47 & 6,69 & 7,41 & 8,45 & 0 & 730 \\
\hline $21: 00$ & 6,35 & 1,45 & 2,02 & 5,58 & 6,74 & 7,42 & 8,49 & 0 & 730 \\
\hline $22: 00$ & 6,45 & 1,44 & 2,11 & 5,70 & 6,84 & 7,50 & 8,46 & 0 & 730 \\
\hline $23: 00$ & 6,58 & 1,42 & 1,84 & 5,92 & 6,97 & 7,63 & 8,49 & 0 & 732 \\
\hline
\end{tabular}


(A) Nível do reservatório por hora de acordo com o mês

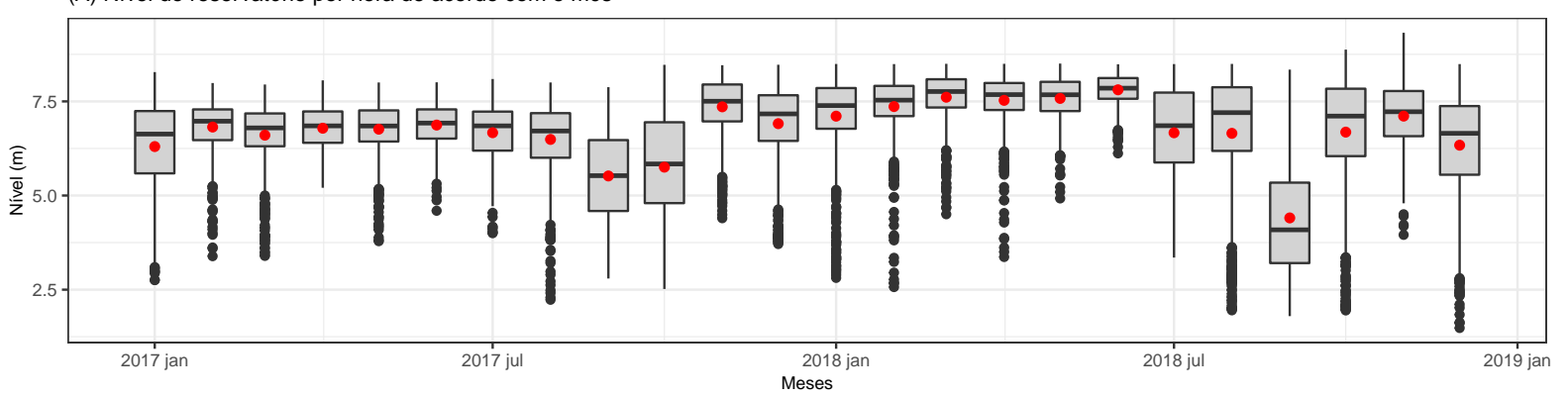

(B) Nível do reservatório por hora de acordo com o horário do dia

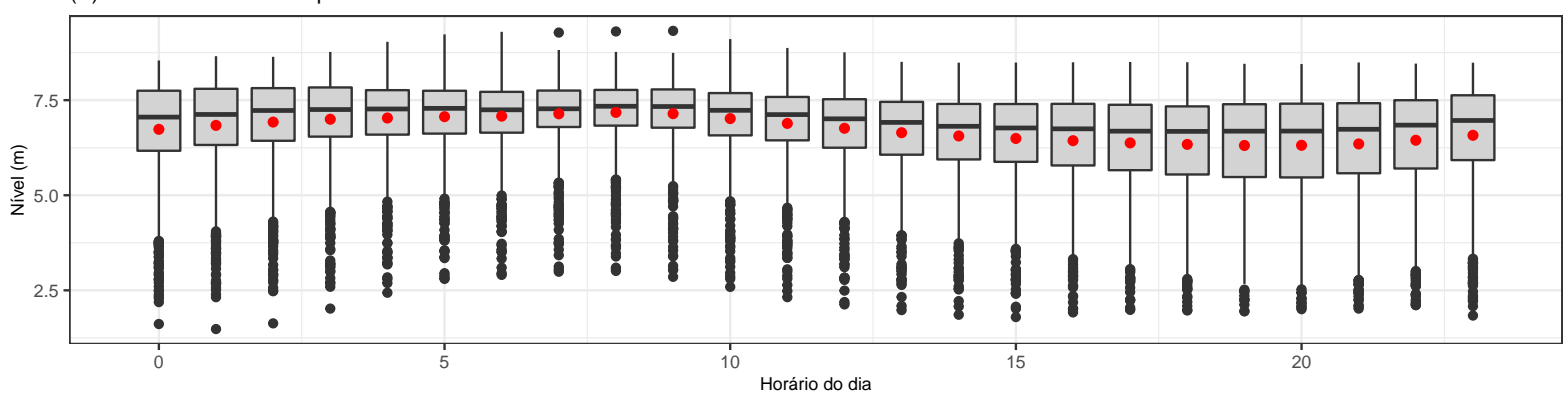

(C) Nível do reservatório por hora de acordo com dia da semana

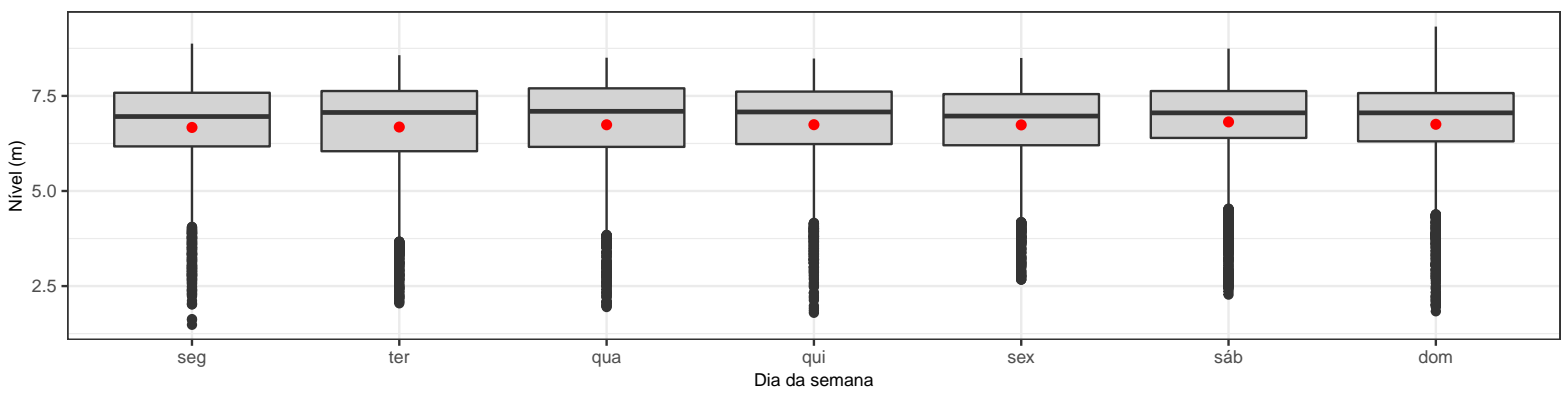

(D) Trecho da série de Nível

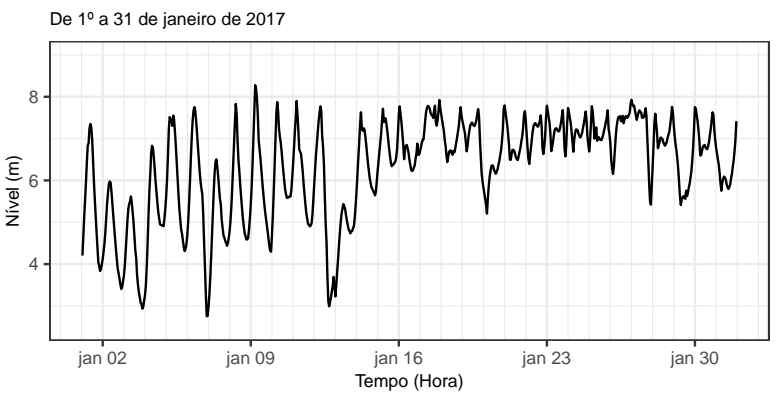

(E) Trecho da série de Nível

De 15 de dezembro de 2017 a 15 de janeiro de 2018

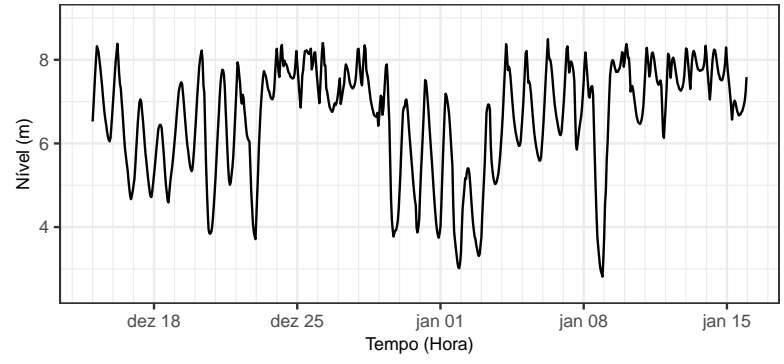

Figura C.1: Painel com alguns gráficos descritivos da série tratada de nível do reservatório de Peruíbe. Os gráficos $(A),(B)$ e $(C)$ são boxplots série de nível em $m$ de acordo com mês, horário do dia e dia semana, respectivamente. Os pontos vermelhos são as médias de cada período. Já os gráficos (D) e (E) são trechos selecionados da série. 
Tabela C.2: Medidas descritivas da série tratada de consumo demandado do reservatório de Perußbe. As informações descritivas são apresentadas para a série em sua totalidade e desagregada por períodos mensais, por dias da semana e por horários do dia.

\begin{tabular}{|c|c|c|c|c|c|c|c|c|c|}
\hline Descritiva & Média & Desvio padrão & Mínimo & $1^{\mathrm{O}}$ Quartil & Mediana & $3^{\mathcal{O}}$ Quartil & Máximo & Omissos & Total \\
\hline \multicolumn{10}{|l|}{ Geral } \\
\hline Geral & 579 & 289 & 0,00 & 349 & 596 & 776 & 1565 & 0 & 17519 \\
\hline \multicolumn{10}{|l|}{ Por ano e mês } \\
\hline 2017 jan & 636 & 287 & 56,31 & 406 & 636 & 837 & 1300 & 0 & 743 \\
\hline $2017 \mathrm{fev}$ & 594 & 274 & 75,38 & 377 & 604 & 802 & 1224 & 0 & 673 \\
\hline 2017 mar & 491 & 275 & 32,07 & 227 & 522 & 703 & 1103 & 0 & 744 \\
\hline 2017 abr & 419 & 244 & 1,64 & 187 & 417 & 645 & 892 & 0 & 720 \\
\hline 2017 mai & 414 & 220 & 0,00 & 208 & 409 & 620 & 825 & 0 & 744 \\
\hline 2017 jun & 430 & 225 & 1,42 & 207 & 417 & 639 & 908 & 0 & 720 \\
\hline 2017 jul & 455 & 231 & 0,98 & 234 & 464 & 662 & 928 & 0 & 744 \\
\hline 2017 ago & 550 & 268 & 86,86 & 331 & 563 & 737 & 1259 & 0 & 744 \\
\hline 2017 set & 684 & 328 & 6,92 & 454 & 682 & 937 & 1300 & 0 & 720 \\
\hline 2017 out & 406 & 243 & 0,00 & 181 & 387 & 625 & 956 & 0 & 743 \\
\hline 2017 nov & 446 & 230 & 56,86 & 209 & 452 & 662 & 867 & 0 & 720 \\
\hline $2017 \mathrm{dez}$ & 489 & 246 & 7,14 & 257 & 490 & 700 & 1157 & 0 & 744 \\
\hline 2018 jan & 586 & 289 & 82,54 & 309 & 604 & 819 & 1251 & 0 & 744 \\
\hline 2018 fev & 694 & 351 & 13,75 & 350 & 744 & 978 & 1488 & 0 & 673 \\
\hline 2018 mar & 691 & 247 & 151,54 & 511 & 744 & 884 & 1164 & 0 & 744 \\
\hline 2018 abr & 694 & 227 & 170,31 & 530 & 710 & 880 & 1212 & 0 & 720 \\
\hline 2018 mai & 706 & 208 & 166,00 & 574 & 734 & 863 & 1223 & 0 & 744 \\
\hline 2018 jun & 688 & 184 & 61,09 & 632 & 726 & 803 & 1077 & 0 & 720 \\
\hline 2018 jul & 639 & 135 & 290,54 & 540 & 648 & 731 & 1147 & 0 & 744 \\
\hline 2018 ago & 565 & 196 & 14,98 & 435 & 551 & 714 & 1047 & 0 & 744 \\
\hline 2018 set & 588 & 223 & 0,00 & 422 & 560 & 776 & 1080 & 0 & 720 \\
\hline 2018 out & 582 & 358 & 0,00 & 273 & 633 & 877 & 1308 & 0 & 744 \\
\hline 2018 nov & 692 & 385 & 0,00 & 327 & 767 & 1017 & 1373 & 0 & 719 \\
\hline $2018 \mathrm{dez}$ & 781 & 373 & 11,05 & 423 & 822 & 1096 & 1565 & 0 & 744 \\
\hline \multicolumn{10}{|c|}{ Por dia da semana } \\
\hline segunda-feira & 575 & 292 & 0,00 & 345 & 587 & 771 & 1447 & 0 & 2520 \\
\hline terça-feira & 564 & 286 & 0,00 & 336 & 582 & 758 & 1308 & 0 & 2496 \\
\hline quarta-feira & 568 & 285 & 0,00 & 334 & 590 & 767 & 1436 & 0 & 2496 \\
\hline quinta-feira & 586 & 291 & 0,00 & 352 & 607 & 785 & 1565 & 0 & 2496 \\
\hline sexta-feira & 598 & 292 & 0,00 & 363 & 619 & 799 & 1524 & 0 & 2496 \\
\hline sábado & 595 & 292 & 0,00 & 365 & 614 & 790 & 1491 & 0 & 2498 \\
\hline domingo & 570 & 281 & 0,00 & 351 & 579 & 754 & 1488 & 0 & 2517 \\
\hline \multicolumn{10}{|c|}{ Por horário do dia } \\
\hline $0: 00$ & 330 & 213 & 0,00 & 151 & 261 & 478 & 972 & 0 & 727 \\
\hline $1: 00$ & 321 & 227 & 0,00 & 144 & 246 & 483 & 953 & 0 & 730 \\
\hline $2: 00$ & 297 & 221 & 0,00 & 119 & 229 & 460 & 866 & 0 & 730 \\
\hline $3: 00$ & 318 & 214 & 0,00 & 149 & 255 & 517 & 865 & 0 & 730 \\
\hline $4: 00$ & 306 & 194 & 0,00 & 168 & 257 & 449 & 867 & 0 & 730 \\
\hline $5: 00$ & 319 & 143 & 22,44 & 211 & 302 & 385 & 915 & 0 & 730 \\
\hline $6: 00$ & 370 & 138 & 69,64 & 273 & 361 & 457 & 958 & 0 & 730 \\
\hline $7: 00$ & 475 & 132 & 14,98 & 384 & 440 & 560 & 1047 & 0 & 730 \\
\hline $8: 00$ & 611 & 162 & 69,18 & 481 & 599 & 718 & 1108 & 0 & 730 \\
\hline $9: 00$ & 812 & 172 & 218,94 & 689 & 776 & 949 & 1299 & 0 & 730 \\
\hline 10:00 & 866 & 198 & 284,62 & 719 & 838 & 1005 & 1450 & 0 & 730 \\
\hline $11: 00$ & 902 & 194 & 374,93 & 758 & 874 & 1022 & 1520 & 0 & 730 \\
\hline $12: 00$ & 892 & 191 & 379,92 & 760 & 861 & 995 & 1565 & 0 & 730 \\
\hline $13: 00$ & 859 & 186 & 284,20 & 733 & 830 & 953 & 1515 & 0 & 730 \\
\hline $14: 00$ & 811 & 188 & 186,61 & 677 & 770 & 911 & 1498 & 0 & 730 \\
\hline $15: 00$ & 776 & 177 & 165,69 & 660 & 743 & 850 & 1475 & 0 & 730 \\
\hline $16: 00$ & 769 & 167 & 305,49 & 649 & 745 & 869 & 1435 & 0 & 730 \\
\hline $17: 00$ & 720 & 172 & 264,32 & 607 & 694 & 807 & 1460 & 0 & 730 \\
\hline $18: 00$ & 688 & 165 & 256,34 & 561 & 669 & 761 & 1361 & 0 & 730 \\
\hline $19: 00$ & 631 & 184 & 135,62 & 505 & 612 & 738 & 1357 & 0 & 730 \\
\hline $20: 00$ & 599 & 204 & 80,43 & 427 & 578 & 768 & 1340 & 0 & 730 \\
\hline $21: 00$ & 465 & 201 & 0,00 & 296 & 484 & 587 & 1325 & 0 & 730 \\
\hline $22: 00$ & 417 & 228 & 0,00 & 221 & 361 & 559 & 1249 & 0 & 730 \\
\hline $23: 00$ & 354 & 221 & 0,00 & 183 & 305 & 483 & 1160 & 0 & 732 \\
\hline
\end{tabular}




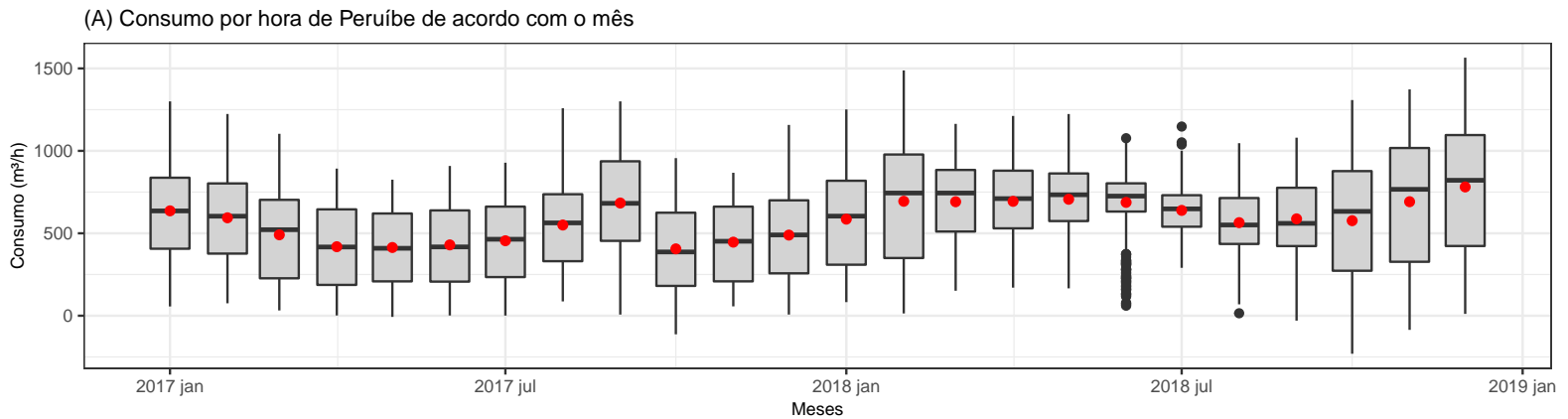

(B) Consumo por hora de Peruíbe de acordo com o horário do dia

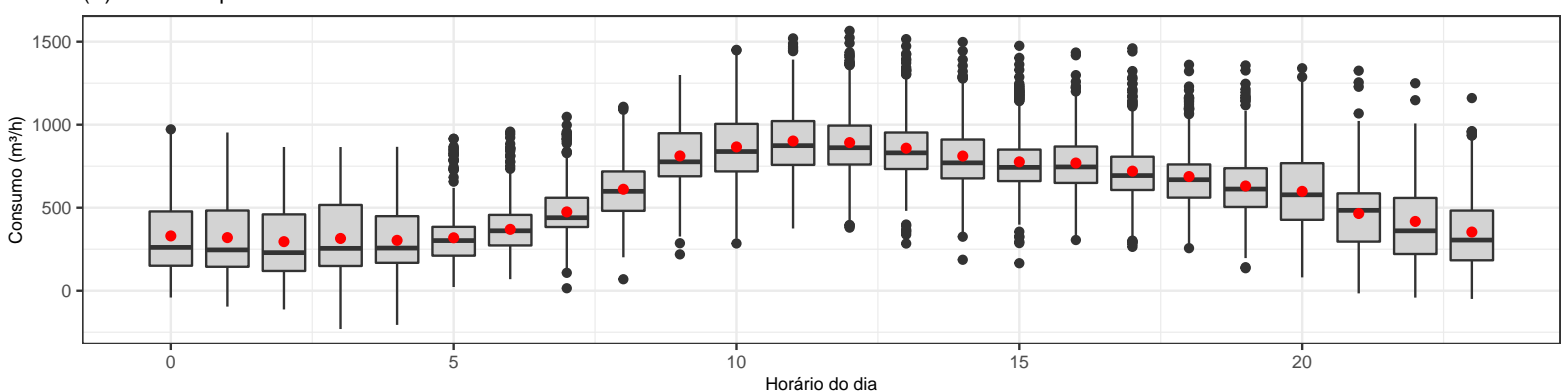

(C) Consumo por hora de Peruíbe de acordo com dia da semana

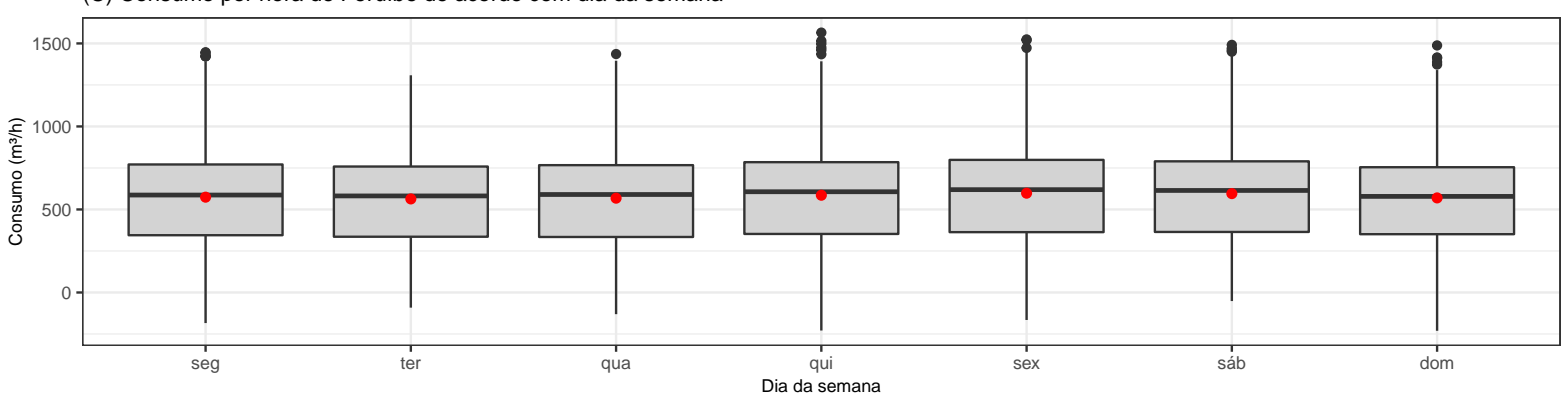

(D) Trecho da série de consumo de Peruíbe

(E) Trecho da série de consumo de Peruíbe De 1ํ a 31 de Julho de 2017 De 15 de dezembro de 2017 a 15 de janeiro de 2018
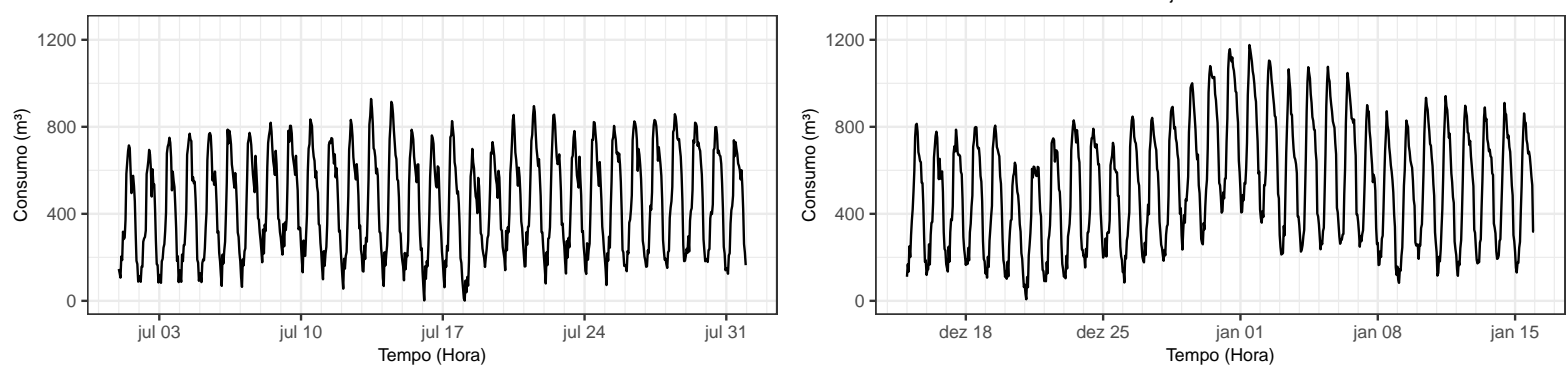

Figura C.2: Painel com alguns gráficos descritivos da série tratada de consumo demandado do reservatório de Peruíbe. Os gráficos $(A),(B)$ e $(C)$ são boxplots série de consumo em $\mathrm{m}^{3}$ de acordo com mês, horário do dia e dia semana, respectivamente. Os pontos vermelhos são as médias de cada perído. Já os gráficos (D) e (E) são trechos selecionados da série. 
Tabela C.3: Medidas descritivas da série tratada de vazão de entrada do reservatório de Peruíbe. As informações descritivas são apresentadas para a série em sua totalidade e desagregada por períodos mensais, por dias da semana e por horários do dia.

\begin{tabular}{|c|c|c|c|c|c|c|c|c|c|}
\hline Descritiva & Média & Desvio padrão & Mínimo & $1^{\mathrm{O}}$ Quartil & Mediana & $3^{\mathcal{O}}$ Quartil & Máximo & Omissos & Total \\
\hline \multicolumn{10}{|l|}{ Geral } \\
\hline Geral & 197 & 48,14 & 57,1 & 168,1 & 216 & 233 & 276 & 79 & 17519 \\
\hline \multicolumn{10}{|l|}{ Por ano e mês } \\
\hline 2017 jan & 233 & 6,63 & 214,2 & 230,9 & 233 & 235 & 250 & 0 & 743 \\
\hline $2017 \mathrm{fev}$ & 225 & 11,64 & 199,7 & 217,5 & 219 & 232 & 270 & 0 & 673 \\
\hline 2017 mar & 224 & 8,64 & 203,7 & 219,1 & 221 & 234 & 248 & 0 & 744 \\
\hline 2017 abr & 225 & 8,27 & 213,4 & 217,7 & 219 & 233 & 247 & 0 & 720 \\
\hline 2017 mai & 217 & 11,16 & 195,0 & 210,1 & 215 & 226 & 244 & 0 & 744 \\
\hline 2017 jun & 217 & 9,54 & 197,3 & 209,1 & 218 & 223 & 238 & 0 & 720 \\
\hline 2017 jul & 177 & 22,28 & 128,3 & 161,9 & 177 & 190 & 236 & 0 & 744 \\
\hline 2017 ago & 153 & 30,01 & 116,8 & 131,0 & 141 & 166 & 234 & 0 & 744 \\
\hline 2017 set & 112 & 24,89 & 81,5 & 95,4 & 103 & 123 & 217 & 0 & 720 \\
\hline 2017 out & 122 & 48,29 & 57,1 & 80,8 & 109 & 163 & 222 & 0 & 743 \\
\hline 2017 nov & 192 & 34,09 & 110,3 & 163,0 & 210 & 217 & 231 & 0 & 720 \\
\hline 2017 dez & 207 & 23,64 & 133,1 & 195,6 & 208 & 225 & 249 & 0 & 744 \\
\hline 2018 jan & 244 & 5,91 & 234,6 & 240,1 & 242 & 244 & 261 & 0 & 744 \\
\hline 2018 fev & 228 & 14,81 & 197,7 & 215,7 & 229 & 238 & 257 & 0 & 673 \\
\hline 2018 mar & 243 & 7,91 & 231,0 & 236,0 & 239 & 250 & 276 & 0 & 744 \\
\hline 2018 abr & 239 & 12,62 & 191,6 & 235,5 & 238 & 250 & 260 & 0 & 720 \\
\hline 2018 mai & 231 & 13,38 & 196,1 & 225,0 & 233 & 240 & 256 & 0 & 744 \\
\hline 2018 jun & 207 & 18,66 & 165,6 & 191,9 & 205 & 221 & 245 & 0 & 720 \\
\hline 2018 jul & 136 & 31,61 & 62,4 & 109,9 & 126 & 159 & 220 & 0 & 744 \\
\hline 2018 ago & 146 & 37,31 & 85,0 & 117,2 & 141 & 174 & 243 & 0 & 744 \\
\hline 2018 set & 115 & 22,12 & 88,8 & 100,8 & 108 & 119 & 201 & 0 & 720 \\
\hline 2018 out & 206 & 42,34 & 87,8 & 206,7 & 219 & 228 & 255 & 0 & 744 \\
\hline 2018 nov & 221 & 13,81 & 163,8 & 215,1 & 218 & 223 & 260 & 0 & 719 \\
\hline $2018 \mathrm{dez}$ & 207 & 31,99 & 74,8 & 203,1 & 216 & 218 & 250 & 79 & 744 \\
\hline \multicolumn{10}{|c|}{ Por dia da semana } \\
\hline segunda-feira & 197 & 47,94 & 66,3 & 169,8 & 216 & 233 & 260 & 24 & 2520 \\
\hline terça-feira & 197 & 47,94 & 66,7 & 168,0 & 216 & 233 & 261 & 0 & 2496 \\
\hline quarta-feira & 195 & 49,58 & 58,5 & 157,1 & 216 & 233 & 276 & 0 & 2496 \\
\hline quinta-feira & 197 & 48,46 & 58,0 & 171,4 & 217 & 233 & 259 & 0 & 2496 \\
\hline sexta-feira & 196 & 48,18 & 57,1 & 176,9 & 216 & 232 & 259 & 7 & 2496 \\
\hline sábado & 197 & 46,95 & 76,3 & 168,1 & 216 & 232 & 259 & 24 & 2498 \\
\hline domingo & 197 & 47,92 & 70,7 & 168,4 & 216 & 234 & 260 & 24 & 2517 \\
\hline \multicolumn{10}{|c|}{ Por horário do dia } \\
\hline $0: 00$ & 199 & 49,16 & 58,0 & 172,7 & 218 & 234 & 258 & 3 & 727 \\
\hline $1: 00$ & 200 & 49,32 & 58,3 & 173,0 & 219 & 235 & 258 & 3 & 730 \\
\hline $2: 00$ & 202 & 49,62 & 59,4 & 178,1 & 220 & 236 & 275 & 3 & 730 \\
\hline $3: 00$ & 202 & 49,70 & 60,2 & 176,1 & 221 & 236 & 272 & 3 & 730 \\
\hline $4: 00$ & 203 & 49,89 & 60,5 & 174,4 & 223 & 237 & 274 & 3 & 730 \\
\hline $5: 00$ & 202 & 49,86 & 61,2 & 175,8 & 221 & 237 & 276 & 3 & 730 \\
\hline $6: 00$ & 201 & 49,56 & 62,6 & 172,9 & 220 & 235 & 274 & 3 & 730 \\
\hline $7: 00$ & 196 & 47,96 & 61,6 & 168,8 & 216 & 233 & 275 & 3 & 730 \\
\hline $8: 00$ & 195 & 47,84 & 62,1 & 168,2 & 216 & 232 & 275 & 3 & 730 \\
\hline $9: 00$ & 195 & 47,35 & 62,8 & 165,8 & 215 & 232 & 274 & 3 & 730 \\
\hline $10: 00$ & 194 & 46,85 & 63,2 & 163,9 & 215 & 231 & 273 & 3 & 730 \\
\hline $11: 00$ & 193 & 46,32 & 63,4 & 164,6 & 214 & 228 & 270 & 3 & 730 \\
\hline $12: 00$ & 193 & 46,10 & 62,2 & 165,9 & 214 & 228 & 269 & 3 & 730 \\
\hline $13: 00$ & 193 & 46,09 & 63,1 & 165,7 & 214 & 227 & 267 & 3 & 730 \\
\hline $14: 00$ & 193 & 46,07 & 63,2 & 166,0 & 213 & 226 & 269 & 3 & 730 \\
\hline $15: 00$ & 194 & 46,34 & 62,4 & 166,6 & 214 & 228 & 267 & 3 & 730 \\
\hline $16: 00$ & 194 & 46,89 & 62,4 & 167,6 & 215 & 229 & 269 & 3 & 730 \\
\hline $17: 00$ & 194 & 46,88 & 59,4 & 166,5 & 215 & 229 & 267 & 4 & 730 \\
\hline $18: 00$ & 194 & 47,40 & 59,5 & 165,4 & 214 & 229 & 256 & 4 & 730 \\
\hline $19: 00$ & 194 & 48,00 & 59,6 & 165,3 & 215 & 231 & 257 & 4 & 730 \\
\hline $20: 00$ & 195 & 48,57 & 59,5 & 167,0 & 216 & 232 & 256 & 4 & 730 \\
\hline $21: 00$ & 196 & 48,93 & 57,1 & 168,5 & 216 & 233 & 256 & 4 & 730 \\
\hline $22: 00$ & 197 & 49,01 & 58,5 & 170,4 & 216 & 233 & 258 & 4 & 730 \\
\hline $23: 00$ & 198 & 49,10 & 58,7 & 171,2 & 218 & 234 & 260 & 4 & 732 \\
\hline
\end{tabular}


(A) Vazão de entrada do reservatório por hora de acordo com o mês

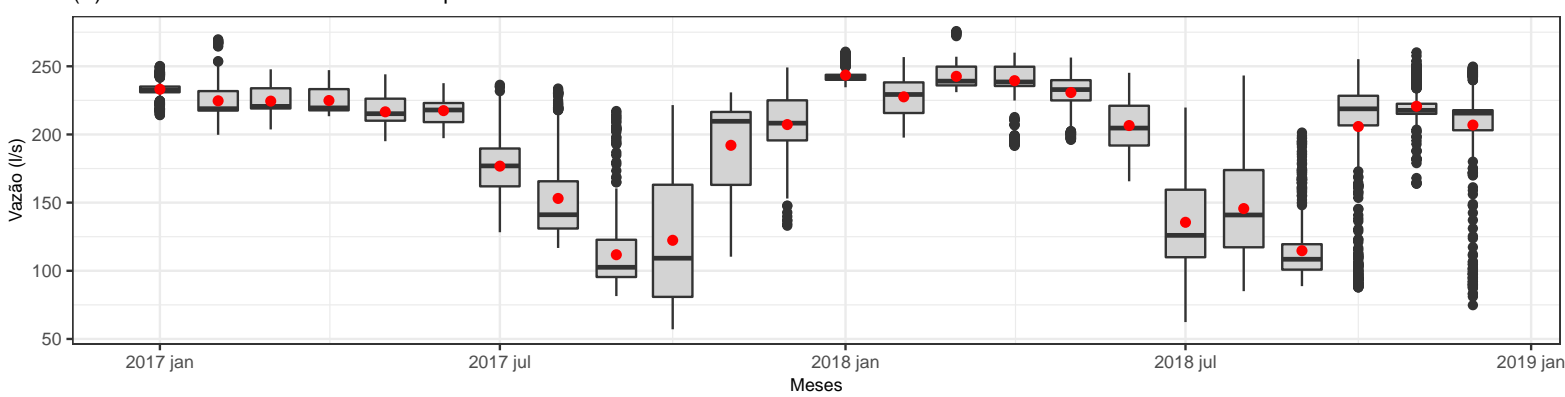

(B) Vazão de entrada do reservatório por hora de acordo com o horário do dia

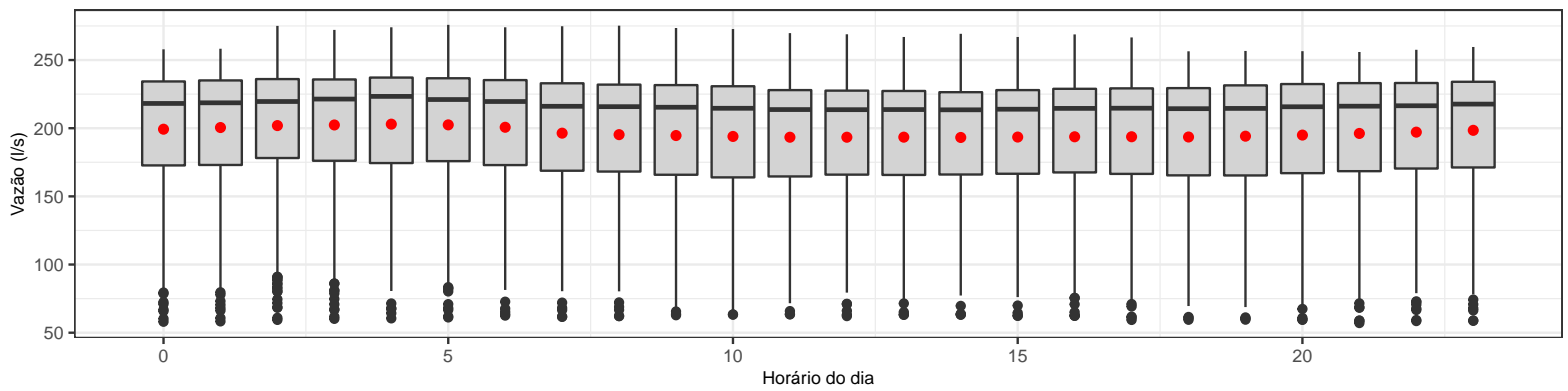

(C) Vazão de entrada do reservatório por hora de acordo com dia da semana

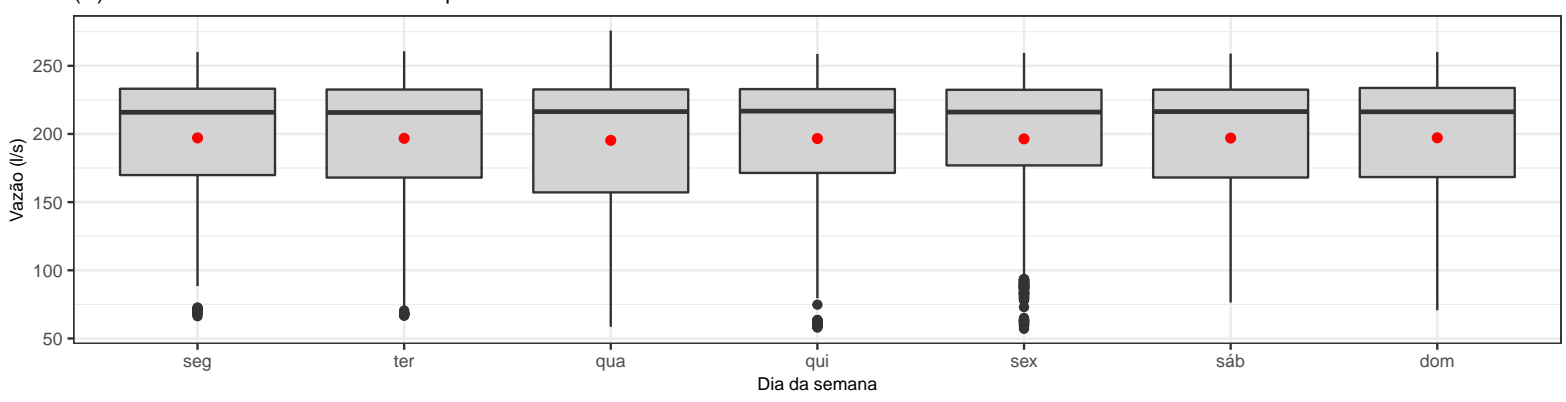

(D) Trecho da série de vazão de entrada De $1^{\circ}$ a 30 de Julho de 2017

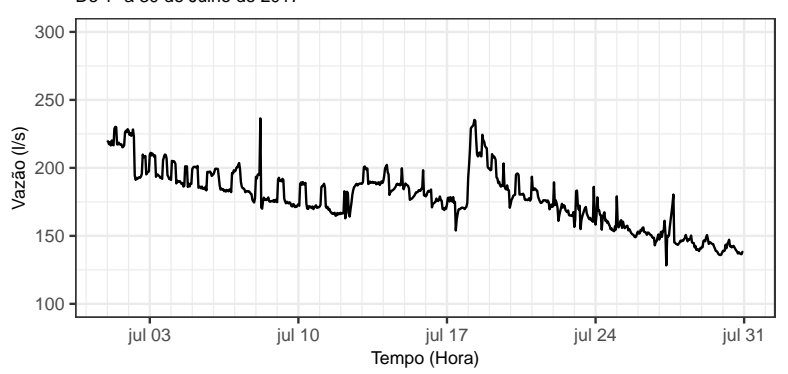

(E) Trecho da série de vazão de entrada De 15 de dezembro de 2017 a 15 de janeiro de 2018

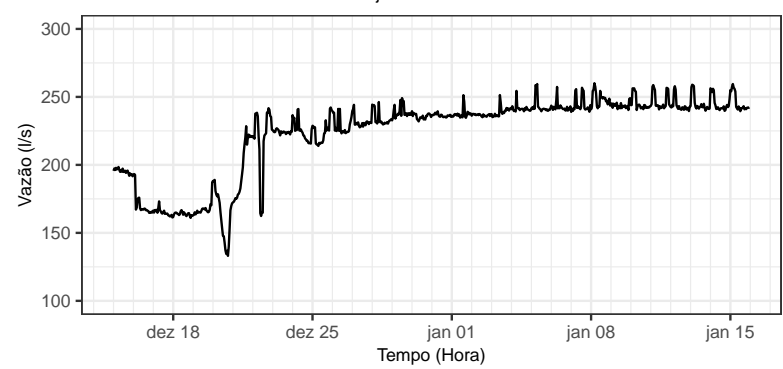

Figura C.3: Painel com alguns gráficos descritivos da série tratada de vazão de entrada do reservatório de Peruíbe. Os gráficos (A), (B) e (C) são boxplots série de vazão em l/s de acordo com mês, horário do dia e dia semana, respectivamente. Os pontos vermelhos são as médias de cada periodo. Já os gráficos (D) e (E) são trechos selecionados da série. 
194 Apêndice C. Informações descritivas após tratamento de outliers e preenchimento de omissos

Tabela C.4: Medidas descritivas da série tratada de vazão de saída do reservatório para o Norte de Peruíbe. As informações descritivas são apresentadas para a série em sua totalidade e desagregada por periodos mensais, por dias da semana e por horários do dia.

\begin{tabular}{|c|c|c|c|c|c|c|c|c|c|}
\hline Descritiva & Média & Desvio padrão & Mínimo & $1^{\mathrm{O}}$ Quartil & Mediana & $3^{0}$ Quartil & Máximo & Omissos & Total \\
\hline \multicolumn{10}{|l|}{ Geral } \\
\hline Geral & 82,7 & 44,6 & 0,00 & 51,95 & 83,2 & 106,9 & 244 & 0 & 17519 \\
\hline \multicolumn{10}{|l|}{ Por ano e mês } \\
\hline 2017 jan & 72,6 & 24,2 & 0,09 & 54,85 & 79,6 & 92,0 & 114 & 0 & 743 \\
\hline 2017 fev & 74,3 & 24,3 & 20,51 & 56,38 & 75,0 & 93,9 & 121 & 0 & 673 \\
\hline 2017 mar & 73,6 & 26,3 & 9,13 & 52,50 & 80,5 & 93,2 & 122 & 0 & 744 \\
\hline 2017 abr & 68,1 & 27,6 & 0,09 & 47,37 & 79,0 & 88,2 & 124 & 0 & 720 \\
\hline 2017 mai & 69,5 & 27,4 & 0,00 & 54,66 & 81,8 & 90,1 & 125 & 0 & 744 \\
\hline 2017 jun & 70,2 & 24,3 & 0,09 & 53,58 & 73,2 & 91,0 & 116 & 0 & 720 \\
\hline 2017 jul & 71,4 & 24,6 & 0,00 & 56,99 & 75,2 & 91,5 & 132 & 0 & 744 \\
\hline 2017 ago & 72,1 & 23,6 & 0,00 & 54,96 & 78,2 & 91,3 & 111 & 0 & 744 \\
\hline 2017 set & 59,9 & 35,1 & 0,00 & 29,93 & 73,7 & 90,0 & 108 & 0 & 720 \\
\hline 2017 out & 55,1 & 34,8 & 0,00 & 23,58 & 64,9 & 86,7 & 119 & 0 & 743 \\
\hline 2017 nov & 69,2 & 26,6 & 0,09 & 47,53 & 79,0 & 91,4 & 106 & 0 & 720 \\
\hline 2017 dez & 65,6 & 26,7 & 0,00 & 42,77 & 71,3 & 86,1 & 117 & 0 & 744 \\
\hline 2018 jan & 68,0 & 41,0 & 0,00 & 34,52 & 66,4 & 86,7 & 194 & 0 & 744 \\
\hline $2018 \mathrm{fev}$ & 110,5 & 53,5 & 0,00 & 62,80 & 121,7 & 154,3 & 229 & 0 & 673 \\
\hline 2018 mar & 118,7 & 42,2 & 0,00 & 92,52 & 125,8 & 154,4 & 231 & 0 & 744 \\
\hline 2018 abr & 113,8 & 41,7 & 0,00 & 84,82 & 120,0 & 148,3 & 211 & 0 & 720 \\
\hline 2018 mai & 119,9 & 40,1 & 0,09 & 86,83 & 128,9 & 154,7 & 191 & 0 & 744 \\
\hline 2018 jun & 110,7 & 37,8 & 12,65 & 83,71 & 117,1 & 136,3 & 227 & 0 & 720 \\
\hline 2018 jul & 108,4 & 40,9 & 0,09 & 79,88 & 114,0 & 134,1 & 240 & 0 & 744 \\
\hline 2018 ago & 87,3 & 49,0 & 0,00 & 44,91 & 82,8 & 132,8 & 186 & 0 & 744 \\
\hline 2018 set & 81,6 & 57,4 & 0,00 & 25,62 & 84,7 & 134,2 & 191 & 0 & 720 \\
\hline 2018 out & 97,0 & 62,1 & 0,00 & 39,26 & 108,0 & 147,3 & 240 & 0 & 744 \\
\hline 2018 nov & 62,9 & 54,2 & 0,00 & 5,47 & 58,1 & 105,1 & 223 & 0 & 719 \\
\hline $2018 \mathrm{dez}$ & 85,1 & 62,9 & 0,00 & 29,21 & 83,0 & 131,9 & 244 & 0 & 744 \\
\hline \multicolumn{10}{|c|}{ Por dia da semana } \\
\hline segunda-feira & 82,3 & 44,4 & 0,00 & 51,82 & 81,9 & 107,4 & 230 & 0 & 2520 \\
\hline terça-feira & 80,4 & 43,6 & 0,00 & 48,90 & 81,7 & 102,0 & 240 & 0 & 2496 \\
\hline quarta-feira & 81,0 & 43,7 & 0,00 & 50,49 & 82,2 & 104,7 & 231 & 0 & 2496 \\
\hline quinta-feira & 84,6 & 44,8 & 0,00 & 53,81 & 85,1 & 113,2 & 238 & 0 & 2496 \\
\hline sexta-feira & 83,9 & 45,5 & 0,00 & 52,27 & 84,1 & 108,9 & 204 & 0 & 2496 \\
\hline sábado & 84,4 & 45,8 & 0,00 & 53,31 & 84,9 & 108,1 & 244 & 0 & 2498 \\
\hline domingo & 82,2 & 44,0 & 0,00 & 52,77 & 82,4 & 103,2 & 240 & 0 & 2517 \\
\hline \multicolumn{10}{|c|}{ Por horário do dia } \\
\hline $0: 00$ & 41,7 & 29,1 & 0,00 & 24,24 & 34,7 & 60,9 & 202 & 0 & 727 \\
\hline $1: 00$ & 40,9 & 31,4 & 0,00 & 20,33 & 32,0 & 66,4 & 217 & 0 & 730 \\
\hline $2: 00$ & 36,4 & 30,2 & 0,00 & 15,38 & 29,1 & 53,1 & 214 & 0 & 730 \\
\hline $3: 00$ & 41,3 & 27,6 & 0,00 & 22,86 & 42,0 & 59,9 & 213 & 0 & 730 \\
\hline $4: 00$ & 36,4 & 26,3 & 0,00 & 14,23 & 35,5 & 54,8 & 213 & 0 & 730 \\
\hline $5: 00$ & 50,9 & 27,0 & 0,00 & 36,44 & 54,9 & 70,8 & 226 & 0 & 730 \\
\hline $6: 00$ & 62,1 & 25,6 & 0,00 & 47,29 & 67,4 & 79,4 & 218 & 0 & 730 \\
\hline $7: 00$ & 76,0 & 23,4 & 0,00 & 70,16 & 78,1 & 89,2 & 189 & 0 & 730 \\
\hline $8: 00$ & 96,6 & 25,5 & 0,00 & 82,22 & 88,7 & 116,6 & 236 & 0 & 730 \\
\hline $9: 00$ & 111,0 & 32,1 & 8,61 & 91,66 & 98,2 & 142,1 & 228 & 0 & 730 \\
\hline $10: 00$ & 119,0 & 35,6 & 12,29 & 93,88 & 101,0 & 154,0 & 229 & 0 & 730 \\
\hline $11: 00$ & 119,2 & 36,6 & 11,57 & 91,28 & 103,1 & 156,7 & 229 & 0 & 730 \\
\hline $12: 00$ & 120,2 & 34,1 & 7,41 & 96,34 & 104,5 & 153,4 & 229 & 0 & 730 \\
\hline $13: 00$ & 117,0 & 33,1 & 10,53 & 94,15 & 102,4 & 148,4 & 225 & 0 & 730 \\
\hline $14: 00$ & 115,4 & 32,7 & 5,99 & 94,83 & 102,5 & 143,4 & 238 & 0 & 730 \\
\hline $15: 00$ & 107,3 & 30,5 & 0,09 & 88,57 & 96,8 & 129,3 & 240 & 0 & 730 \\
\hline $16: 00$ & 104,5 & 33,6 & 0,27 & 82,58 & 91,5 & 133,5 & 235 & 0 & 730 \\
\hline $17: 00$ & 97,3 & 32,6 & 0,00 & 74,99 & 86,2 & 122,4 & 244 & 0 & 730 \\
\hline $18: 00$ & 100,1 & 31,8 & 0,09 & 82,41 & 90,0 & 125,4 & 228 & 0 & 730 \\
\hline $19: 00$ & 97,0 & 39,5 & 0,00 & 69,32 & 84,4 & 124,3 & 233 & 0 & 730 \\
\hline $20: 00$ & 100,7 & 46,2 & 0,09 & 71,42 & 82,4 & 136,5 & 240 & 0 & 730 \\
\hline $21: 00$ & 84,1 & 42,1 & 0,00 & 55,84 & 75,5 & 113,2 & 240 & 0 & 730 \\
\hline $22: 00$ & 59,2 & 33,3 & 0,00 & 39,55 & 53,9 & 79,0 & 232 & 0 & 730 \\
\hline $23: 00$ & 50,3 & 36,0 & 0,00 & 25,30 & 40,6 & 68,3 & 218 & 0 & 732 \\
\hline
\end{tabular}


(A) Vazão de saída por hora para o Norte de Peruíbe de acordo com o mês

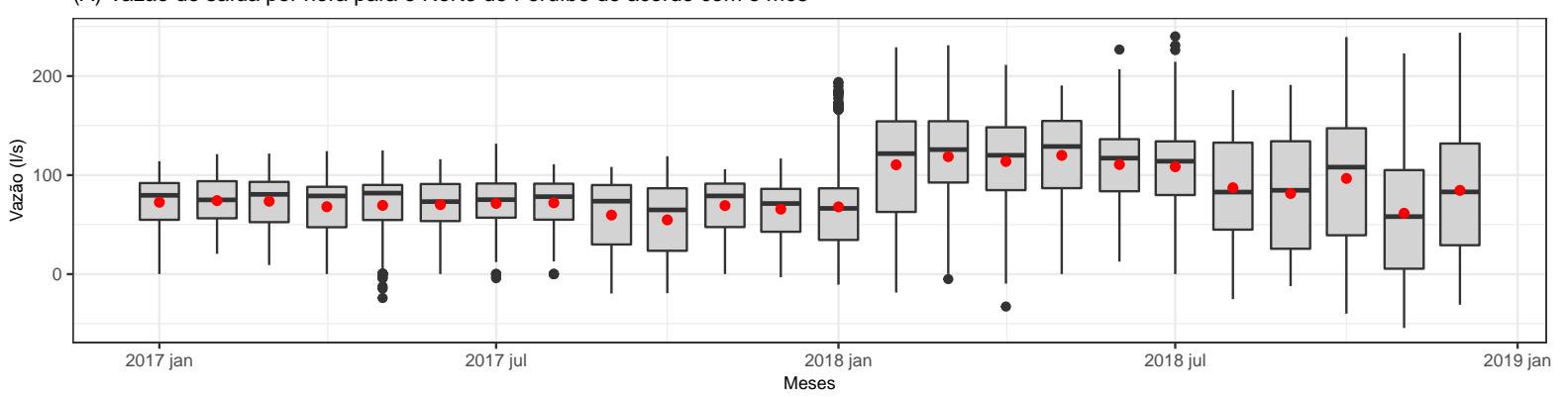

(B) Vazão de saída por hora para o Norte de Peruíbe de acordo com o horário do dia

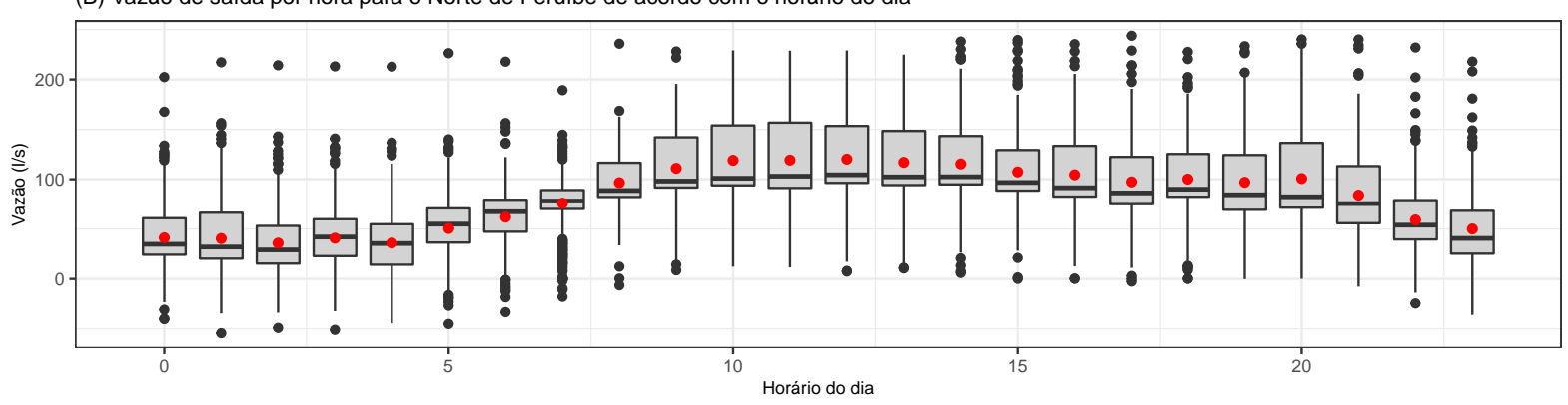

(C) Vazão de saída por hora para o Norte de Peruíbe de acordo com dia da semana

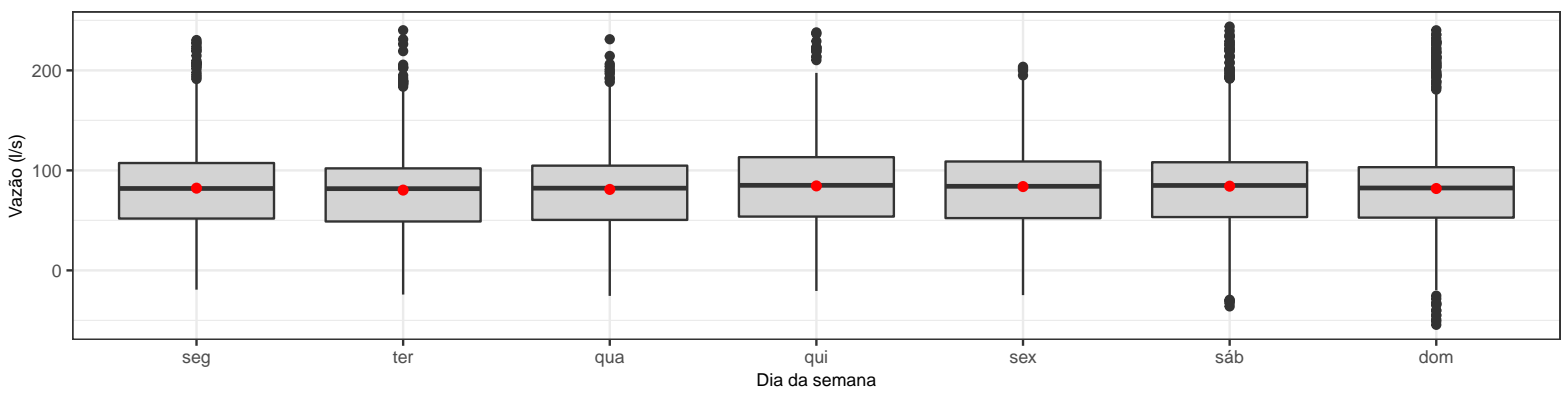

(D) Trecho da série de vazão de saída para o Norte de Peruíbe De 1 a a 31 de Julho de 2017

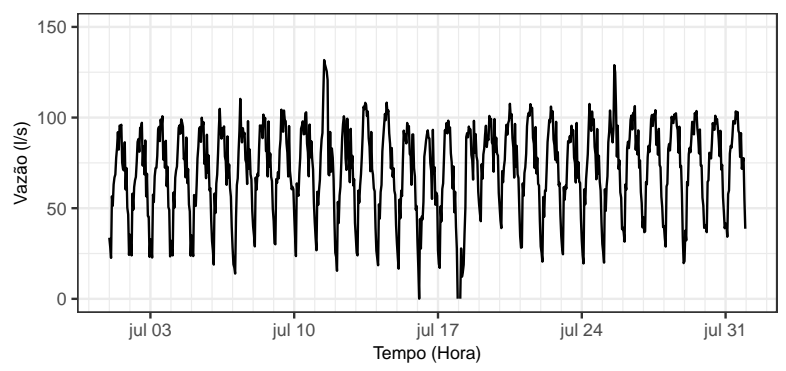

(E) Trecho da série de vazão de saída para o Norte de Peruíbe De 15 de dezembro de 2017 a 15 de janeiro de 2018

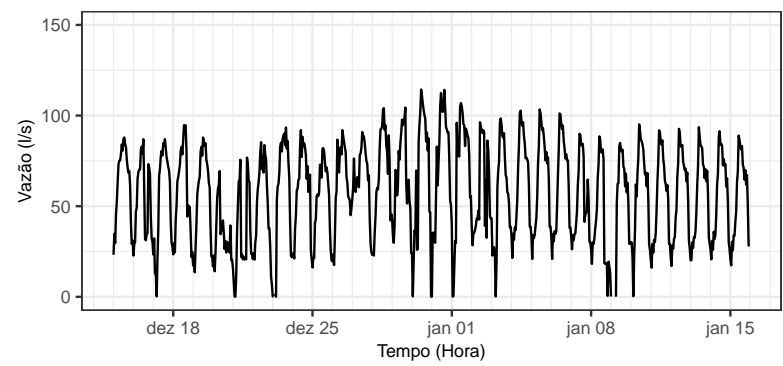

Figura C.4: Painel com alguns gráficos descritivos da série tratada de vazão de saída do reservatório para o Norte de Peruíbe. Os gráficos (A), (B) e (C) são boxplots série de vazão em l/s de acordo com mês, horário do dia e dia semana, respectivamente. Os pontos vermelhos são as médias de cada periodo. Já os gráficos (D) e (E) são trechos selecionados da série. 
196 Apêndice C. Informações descritivas após tratamento de outliers e preenchimento de omissos

Tabela C.5: Medidas descritivas da série tratada de vazão de saída do reservatório para o Sul de Peruíbe. As informações descritivas são apresentadas para a série em sua totalidade e desagregada por períodos mensais, por dias da semana e por horários do dia.

\begin{tabular}{|c|c|c|c|c|c|c|c|c|c|}
\hline Descritiva & Média & Desvio padrão & Mínimo & $1^{\mathrm{O}}$ Quartil & Mediana & $3^{\mathcal{O}}$ Quartil & Máximo & Omissos & Total \\
\hline \multicolumn{10}{|l|}{ Geral } \\
\hline Geral & 74,6 & 56,2 & 0,00 & 28,45 & 69,0 & 108,4 & 299 & 0 & 17519 \\
\hline \multicolumn{10}{|l|}{ Por ano e mês } \\
\hline 2017 jan & 102,5 & 60,7 & 0,00 & 58,21 & 96,9 & 141,9 & 250 & 0 & 743 \\
\hline $2017 \mathrm{fev}$ & 91,2 & 55,2 & 0,00 & 42,98 & 91,0 & 133,2 & 222 & 0 & 673 \\
\hline 2017 mar & 64,2 & 52,9 & 0,00 & 5,51 & 64,9 & 105,6 & 193 & 0 & 744 \\
\hline 2017 abr & 49,6 & 47,1 & 0,00 & 0,61 & 35,9 & 91,7 & 186 & 0 & 720 \\
\hline 2017 mai & 43,5 & 40,6 & 0,00 & 0,73 & 29,4 & 82,9 & 173 & 0 & 744 \\
\hline 2017 jun & 47,4 & 43,1 & 0,00 & 0,61 & 42,6 & 86,9 & 171 & 0 & 720 \\
\hline 2017 jul & 55,7 & 45,9 & 0,00 & 12,88 & 49,5 & 92,6 & 198 & 0 & 744 \\
\hline 2017 ago & 81,8 & 62,1 & 0,00 & 33,07 & 78,0 & 118,5 & 256 & 0 & 744 \\
\hline 2017 set & 136,3 & 74,1 & 0,00 & 89,80 & 136,4 & 192,8 & 271 & 0 & 720 \\
\hline 2017 out & 52,5 & 43,0 & 0,00 & 13,74 & 42,6 & 89,4 & 164 & 0 & 743 \\
\hline 2017 nov & 53,9 & 41,2 & 0,00 & 15,06 & 47,0 & 92,0 & 146 & 0 & 720 \\
\hline 2017 dez & 70,3 & 49,8 & 0,00 & 24,95 & 67,6 & 109,6 & 213 & 0 & 744 \\
\hline 2018 jan & 92,4 & 51,0 & 0,00 & 45,54 & 91,9 & 132,5 & 220 & 0 & 744 \\
\hline 2018 fev & 81,5 & 52,2 & 0,00 & 35,04 & 81,9 & 119,8 & 236 & 0 & 673 \\
\hline 2018 mar & 77,5 & 40,9 & 0,00 & 53,72 & 82,0 & 109,2 & 176 & 0 & 744 \\
\hline 2018 abr & 73,6 & 42,4 & 0,00 & 35,97 & 74,7 & 105,7 & 196 & 0 & 720 \\
\hline 2018 mai & 61,5 & 38,2 & 0,00 & 27,31 & 67,9 & 91,8 & 164 & 0 & 744 \\
\hline 2018 jun & 56,2 & 29,6 & 0,00 & 36,62 & 59,8 & 77,6 & 144 & 0 & 720 \\
\hline 2018 jul & 50,8 & 23,9 & 0,00 & 33,29 & 47,6 & 68,3 & 161 & 0 & 744 \\
\hline 2018 ago & 55,2 & 30,6 & 1,26 & 30,63 & 49,6 & 77,6 & 132 & 0 & 744 \\
\hline 2018 set & 58,1 & 34,8 & 0,00 & 32,64 & 58,2 & 82,7 & 160 & 0 & 720 \\
\hline 2018 out & 69,5 & 54,1 & 0,00 & 26,15 & 60,7 & 102,4 & 212 & 0 & 744 \\
\hline 2018 nov & 120,1 & 64,6 & 0,00 & 67,12 & 137,4 & 170,1 & 237 & 0 & 719 \\
\hline $2018 \mathrm{dez}$ & 146,9 & 64,2 & 0,00 & 95,77 & 156,8 & 196,1 & 299 & 0 & 744 \\
\hline \multicolumn{10}{|c|}{ Por dia da semana } \\
\hline segunda-feira & 74,3 & 57,0 & 0,00 & 27,79 & 68,7 & 106,5 & 264 & 0 & 2520 \\
\hline terça-feira & 71,8 & 54,3 & 0,00 & 26,18 & 68,7 & 104,4 & 250 & 0 & 2496 \\
\hline quarta-feira & 73,0 & 55,4 & 0,00 & 26,97 & 67,5 & 106,6 & 266 & 0 & 2496 \\
\hline quinta-feira & 73,9 & 56,2 & 0,00 & 27,78 & 68,5 & 107,0 & 268 & 0 & 2496 \\
\hline sexta-feira & 76,8 & 56,0 & 0,00 & 29,27 & 71,6 & 113,9 & 260 & 0 & 2496 \\
\hline sábado & 77,5 & 57,0 & 0,00 & 31,63 & 71,4 & 113,1 & 268 & 0 & 2498 \\
\hline domingo & 74,7 & 57,1 & 0,00 & 29,19 & 68,4 & 106,6 & 299 & 0 & 2517 \\
\hline \multicolumn{10}{|c|}{ Por horário do dia } \\
\hline 0:00 & 39,9 & 42,3 & 0,00 & 3,24 & 27,4 & 63,1 & 236 & 0 & 727 \\
\hline $1: 00$ & 37,5 & 39,8 & 0,00 & 6,11 & 26,0 & 53,8 & 183 & 0 & 730 \\
\hline $2: 00$ & 33,1 & 34,0 & 0,00 & 5,86 & 26,0 & 47,7 & 169 & 0 & 730 \\
\hline $3: 00$ & 32,5 & 33,6 & 0,00 & 1,86 & 25,9 & 49,1 & 168 & 0 & 730 \\
\hline $4: 00$ & 29,0 & 33,3 & 0,00 & 0,62 & 19,8 & 46,0 & 193 & 0 & 730 \\
\hline $5: 00$ & 30,3 & 32,3 & 0,00 & 6,38 & 22,2 & 41,1 & 195 & 0 & 730 \\
\hline $6: 00$ & 35,0 & 33,4 & 0,00 & 9,50 & 29,6 & 50,4 & 203 & 0 & 730 \\
\hline $7: 00$ & 56,2 & 37,1 & 0,00 & 29,91 & 50,0 & 74,2 & 224 & 0 & 730 \\
\hline $8: 00$ & 72,8 & 40,2 & 0,00 & 44,58 & 67,2 & 92,1 & 239 & 0 & 730 \\
\hline $9: 00$ & 113,5 & 40,1 & 0,37 & 90,86 & 108,2 & 128,2 & 250 & 0 & 730 \\
\hline 10:00 & 121,7 & 42,1 & 0,43 & 96,77 & 114,7 & 135,9 & 280 & 0 & 730 \\
\hline $11: 00$ & 131,2 & 46,4 & 12,74 & 100,49 & 122,1 & 155,9 & 293 & 0 & 730 \\
\hline $12: 00$ & 127,6 & 46,5 & 20,52 & 97,18 & 116,5 & 154,7 & 295 & 0 & 730 \\
\hline $13: 00$ & 122,0 & 46,5 & 1,59 & 90,93 & 110,0 & 147,2 & 291 & 0 & 730 \\
\hline $14: 00$ & 110,7 & 46,2 & 0,43 & 81,45 & 96,9 & 129,1 & 286 & 0 & 730 \\
\hline $15: 00$ & 110,2 & 45,6 & 0,31 & 82,30 & 97,5 & 128,3 & 286 & 0 & 730 \\
\hline $16: 00$ & 110,8 & 42,7 & 0,37 & 84,98 & 100,5 & 125,1 & 286 & 0 & 730 \\
\hline $17: 00$ & 104,9 & 46,1 & 0,31 & 74,25 & 98,4 & 121,2 & 299 & 0 & 730 \\
\hline $18: 00$ & 92,2 & 47,1 & 0,00 & 63,45 & 78,2 & 109,4 & 296 & 0 & 730 \\
\hline $19: 00$ & 80,7 & 51,3 & 0,24 & 44,69 & 67,2 & 100,4 & 293 & 0 & 730 \\
\hline $20: 00$ & 67,3 & 49,0 & 0,00 & 34,02 & 55,8 & 81,6 & 291 & 0 & 730 \\
\hline $21: 00$ & 46,7 & 50,0 & 0,00 & 8,87 & 26,9 & 71,4 & 274 & 0 & 730 \\
\hline $22: 00$ & 46,0 & 46,0 & 0,00 & 7,11 & 33,5 & 71,1 & 262 & 0 & 730 \\
\hline $23: 00$ & 37,7 & 42,5 & 0,00 & 2,43 & 23,9 & 57,9 & 250 & 0 & 732 \\
\hline
\end{tabular}


(A) Vazão de saída por hora para o Sul de Peruíbe de acordo com o mês

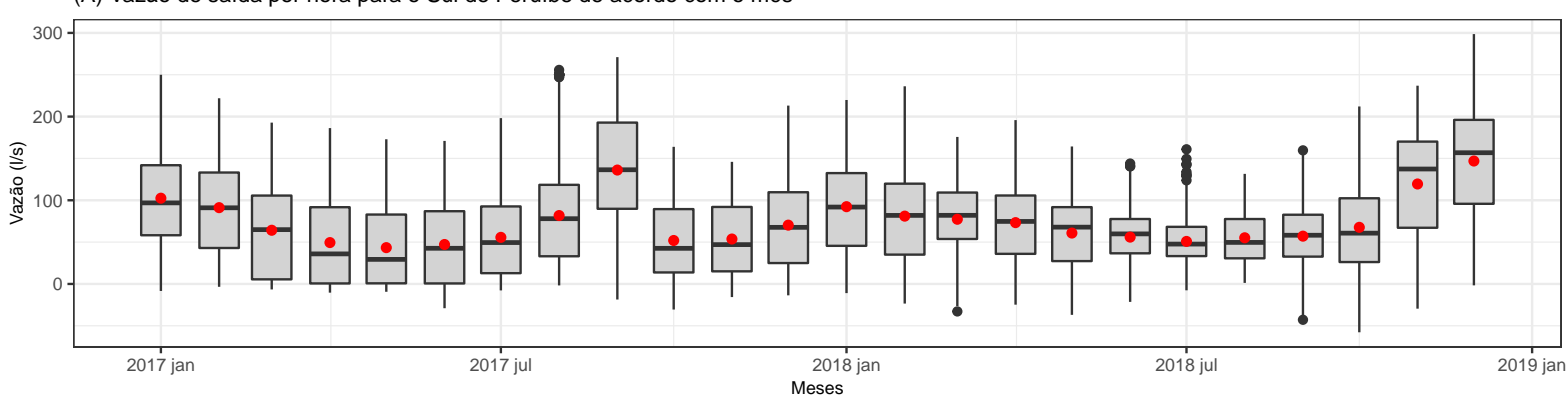

(B) Vazão de saída por hora para o Sul de Peruíbe de acordo com o horário do dia

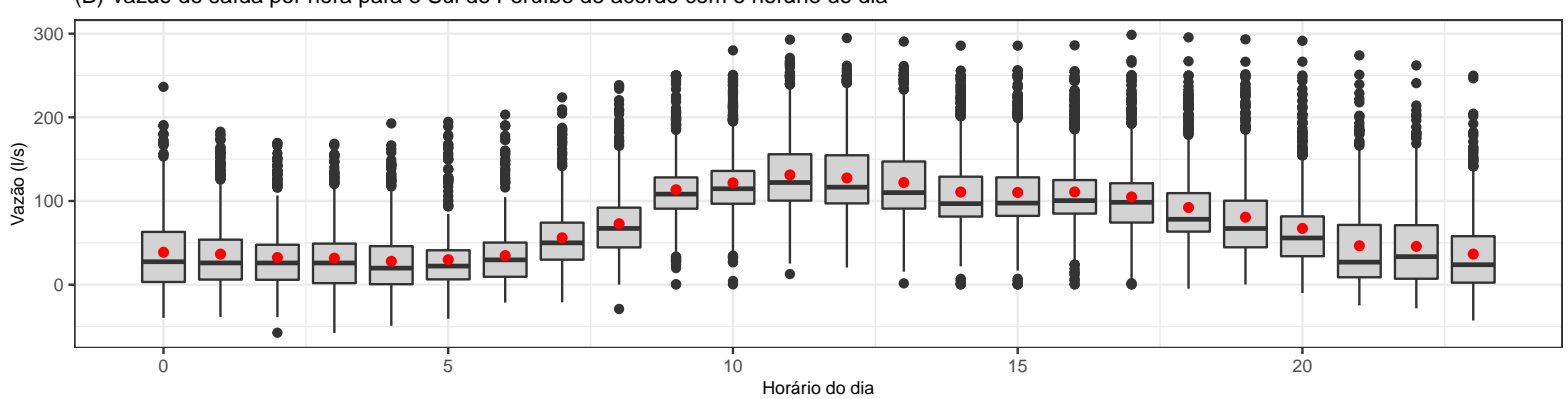

(C) Vazão de saída por hora para o Sul de Peruíbe de acordo com dia da semana

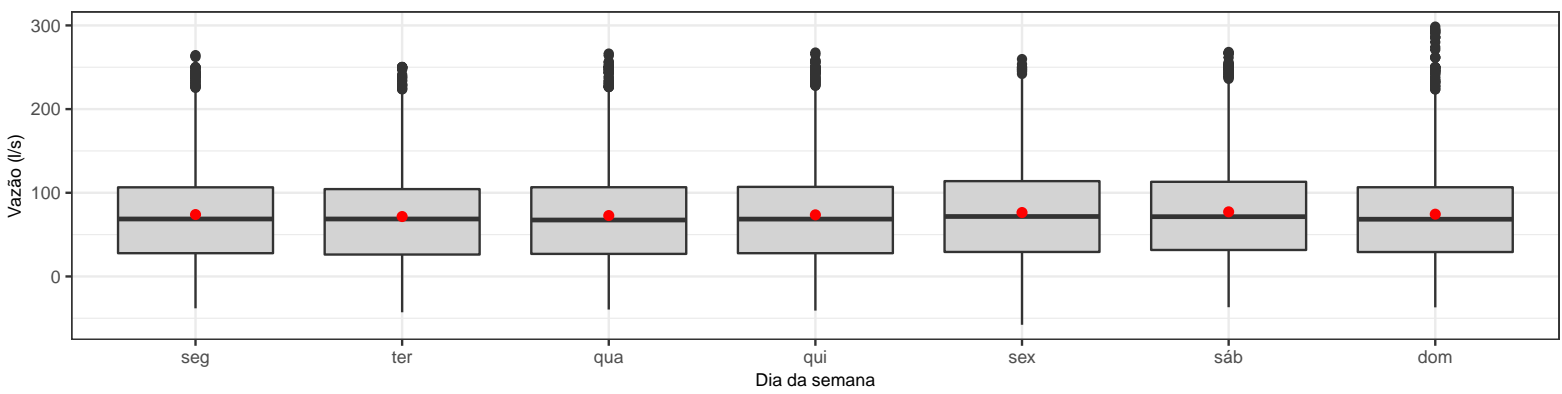

(D) Trecho da série de vazão de saída para o Sul de Peruíbe De $1^{\circ}$ a 31 de Julho de 2017

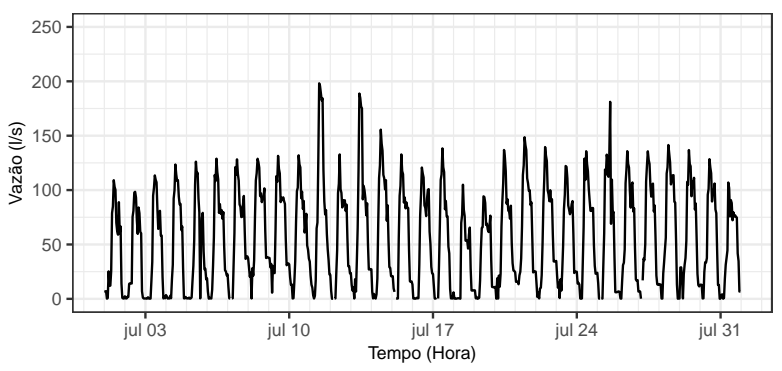

(E) Trecho da série de vazão de saída para o Sul de Peruíbe De 15 de dezembro de 2017 a 15 de janeiro de 2018

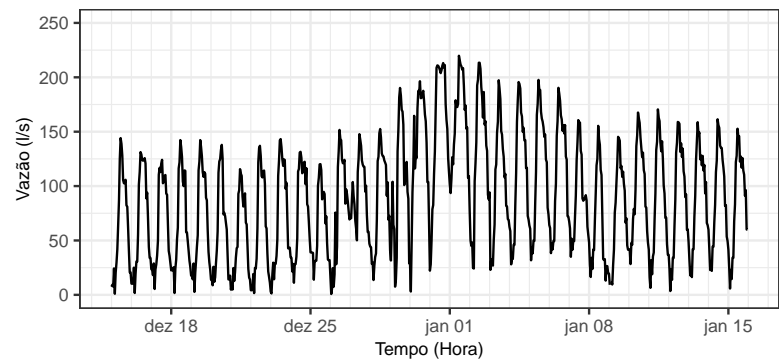

Figura C.5: Painel com alguns gráficos descritivos da série tratada de vazão de saída do reservatório para o Sul de Peruíbe. Os gráficos (A), (B) e (C) são boxplots série de vazão em l/s de acordo com mês, horário do dia e dia semana, respectivamente. Os pontos vermelhos são as médias de cada período. Já os gráficos (D) e (E) são trechos selecionados da série. 
198 Apêndice C. Informações descritivas após tratamento de outliers e preenchimento de omissos

Tabela C.6: Medidas descritivas da série tratada de pressão a montante ao Norte de Peruíbe. As informações descritivas são apresentadas para a série em sua totalidade e desagregada por períodos mensais, por dias da semana e por horários do dia.

\begin{tabular}{|c|c|c|c|c|c|c|c|c|c|}
\hline Descritiva & Média & Desvio padrão & Mínimo & $1^{\mathrm{O}}$ Quartil & Mediana & $3^{\mathcal{O}}$ Quartil & Máximo & Omissos & Total \\
\hline \multicolumn{10}{|l|}{ Geral } \\
\hline Geral & 42,0 & 4,81 & 9,33 & 39,2 & 42,6 & 45,5 & 53,8 & 0 & 17519 \\
\hline \multicolumn{10}{|l|}{ Por ano e mês } \\
\hline 2017 jan & 36,6 & 5,93 & 22,00 & 32,4 & 36,6 & 41,8 & 47,2 & 0 & 743 \\
\hline $2017 \mathrm{fev}$ & 38,6 & 5,01 & 26,84 & 34,7 & 39,2 & 42,7 & 47,1 & 0 & 673 \\
\hline 2017 mar & 39,0 & 5,09 & 26,32 & 35,6 & 39,0 & 43,7 & 52,6 & 0 & 744 \\
\hline 2017 abr & 40,5 & 4,12 & 28,60 & 37,5 & 39,6 & 44,5 & 49,2 & 0 & 720 \\
\hline 2017 mai & 40,6 & 3,84 & 28,60 & 37,7 & 39,7 & 44,0 & 48,1 & 0 & 744 \\
\hline 2017 jun & 41,2 & 3,54 & 30,23 & 38,2 & 41,6 & 44,2 & 49,2 & 0 & 720 \\
\hline 2017 jul & 42,5 & 2,93 & 31,38 & 40,2 & 42,6 & 44,9 & 48,8 & 0 & 744 \\
\hline 2017 ago & 42,2 & 2,77 & 35,34 & 39,9 & 42,2 & 44,6 & 47,6 & 0 & 744 \\
\hline 2017 set & 41,6 & 3,21 & 35,02 & 38,5 & 41,9 & 44,6 & 47,6 & 0 & 720 \\
\hline 2017 out & 42,4 & 3,10 & 32,99 & 39,9 & 42,8 & 44,7 & 47,9 & 0 & 743 \\
\hline 2017 nov & 42,5 & 3,33 & 34,46 & 39,7 & 42,1 & 45,6 & 49,3 & 0 & 720 \\
\hline 2017 dez & 41,6 & 3,67 & 29,45 & 38,9 & 41,8 & 44,6 & 50,6 & 0 & 744 \\
\hline 2018 jan & 42,2 & 4,43 & 22,52 & 39,0 & 42,3 & 46,1 & 51,2 & 0 & 744 \\
\hline 2018 fev & 42,9 & 3,78 & 31,04 & 40,1 & 43,0 & 46,2 & 49,8 & 0 & 673 \\
\hline 2018 mar & 42,9 & 3,11 & 32,48 & 40,4 & 43,0 & 45,6 & 51,0 & 0 & 744 \\
\hline 2018 abr & 43,1 & 3,07 & 34,43 & 40,4 & 42,9 & 45,8 & 49,0 & 0 & 720 \\
\hline 2018 mai & 44,2 & 3,21 & 32,84 & 41,6 & 44,3 & 47,1 & 51,1 & 0 & 744 \\
\hline 2018 jun & 46,1 & 2,65 & 34,75 & 44,5 & 46,0 & 48,4 & 50,5 & 0 & 720 \\
\hline 2018 jul & 46,0 & 3,04 & 36,29 & 44,5 & 46,0 & 48,2 & 52,2 & 0 & 744 \\
\hline 2018 ago & 41,0 & 9,94 & 9,33 & 41,8 & 44,2 & 46,9 & 48,8 & 0 & 744 \\
\hline 2018 set & 42,3 & 2,60 & 35,78 & 40,3 & 42,5 & 44,3 & 48,4 & 0 & 720 \\
\hline 2018 out & 42,1 & 5,66 & 22,17 & 39,3 & 43,0 & 46,4 & 53,8 & 0 & 744 \\
\hline 2018 nov & 43,2 & 4,18 & 30,50 & 40,2 & 43,8 & 46,8 & 52,9 & 0 & 719 \\
\hline $2018 \mathrm{dez}$ & 41,2 & 5,38 & 19,32 & 38,4 & 42,2 & 45,4 & 48,7 & 0 & 744 \\
\hline \multicolumn{10}{|c|}{ Por dia da semana } \\
\hline segunda-feira & 41,8 & 5,19 & 9,60 & 39,1 & 42,4 & 45,5 & 52,1 & 0 & 2520 \\
\hline terça-feira & 42,0 & 5,28 & 9,33 & 39,4 & 42,7 & 45,6 & 52,9 & 0 & 2496 \\
\hline quarta-feira & 42,1 & 4,74 & 11,86 & 39,4 & 42,7 & 45,5 & 51,2 & 0 & 2496 \\
\hline quinta-feira & 42,0 & 4,49 & 22,30 & 39,2 & 42,4 & 45,4 & 51,8 & 0 & 2496 \\
\hline sexta-feira & 42,0 & 4,35 & 25,18 & 39,0 & 42,5 & 45,4 & 51,9 & 0 & 2496 \\
\hline sábado & 41,9 & 4,62 & 23,96 & 39,2 & 42,7 & 45,4 & 53,8 & 0 & 2498 \\
\hline domingo & 42,0 & 4,91 & 12,43 & 39,4 & 42,7 & 45,6 & 52,2 & 0 & 2517 \\
\hline \multicolumn{10}{|c|}{ Por horário do dia } \\
\hline $0: 00$ & 45,6 & 3,21 & 9,82 & 44,5 & 46,1 & 47,1 & 53,8 & 0 & 727 \\
\hline $1: 00$ & 45,8 & 3,11 & 9,96 & 44,8 & 46,2 & 47,3 & 52,9 & 0 & 730 \\
\hline $2: 00$ & 46,1 & 2,98 & 10,57 & 45,2 & 46,4 & 47,4 & 52,9 & 0 & 730 \\
\hline $3: 00$ & 45,8 & 2,96 & 10,09 & 44,8 & 46,0 & 47,2 & 52,0 & 0 & 730 \\
\hline $4: 00$ & 45,9 & 3,13 & 10,13 & 44,8 & 46,0 & 47,5 & 52,6 & 0 & 730 \\
\hline $5: 00$ & 45,2 & 3,19 & 10,04 & 43,6 & 45,3 & 47,3 & 51,2 & 0 & 730 \\
\hline $6: 00$ & 44,6 & 3,42 & 11,31 & 42,8 & 44,9 & 46,8 & 51,0 & 0 & 730 \\
\hline $7: 00$ & 43,4 & 3,63 & 12,80 & 41,5 & 43,4 & 45,7 & 50,5 & 0 & 730 \\
\hline $8: 00$ & 41,8 & 3,80 & 13,09 & 40,0 & 42,0 & 43,8 & 50,6 & 0 & 730 \\
\hline $9: 00$ & 39,5 & 4,23 & 12,23 & 37,5 & 39,6 & 41,6 & 50,1 & 0 & 730 \\
\hline $10: 00$ & 38,4 & 4,36 & 11,97 & 36,2 & 38,8 & 40,6 & 49,6 & 0 & 730 \\
\hline $11: 00$ & 37,9 & 4,53 & 11,53 & 36,1 & 38,5 & 40,3 & 47,7 & 0 & 730 \\
\hline $12: 00$ & 37,8 & 4,41 & 10,99 & 36,0 & 38,1 & 40,0 & 47,5 & 0 & 730 \\
\hline $13: 00$ & 38,2 & 4,31 & 11,14 & 36,4 & 38,4 & 40,6 & 49,9 & 0 & 730 \\
\hline $14: 00$ & 38,4 & 4,33 & 11,89 & 36,5 & 38,6 & 40,9 & 50,0 & 0 & 730 \\
\hline $15: 00$ & 39,2 & 4,43 & 12,11 & 37,1 & 39,6 & 42,2 & 50,3 & 0 & 730 \\
\hline $16: 00$ & 39,7 & 3,98 & 12,45 & 38,1 & 40,0 & 42,1 & 50,5 & 0 & 730 \\
\hline $17: 00$ & 40,3 & 4,09 & 12,19 & 38,7 & 40,8 & 42,9 & 50,2 & 0 & 730 \\
\hline $18: 00$ & 40,2 & 3,89 & 12,26 & 38,4 & 40,6 & 42,7 & 49,7 & 0 & 730 \\
\hline $19: 00$ & 40,9 & 3,92 & 11,01 & 39,5 & 41,6 & 43,1 & 49,8 & 0 & 730 \\
\hline $20: 00$ & 40,9 & 3,72 & 10,87 & 39,8 & 41,5 & 43,0 & 48,5 & 0 & 730 \\
\hline $21: 00$ & 42,4 & 3,85 & 10,01 & 41,1 & 43,2 & 44,7 & 48,2 & 0 & 730 \\
\hline $22: 00$ & 44,1 & 3,62 & 9,60 & 43,2 & 44,7 & 46,0 & 50,4 & 0 & 730 \\
\hline $23: 00$ & 45,0 & 3,31 & 9,33 & 44,1 & 45,5 & 46,7 & 50,4 & 0 & 732 \\
\hline
\end{tabular}


(A) Pressão a montante a cada hora no Norte de Peruíbe de acordo com o mês

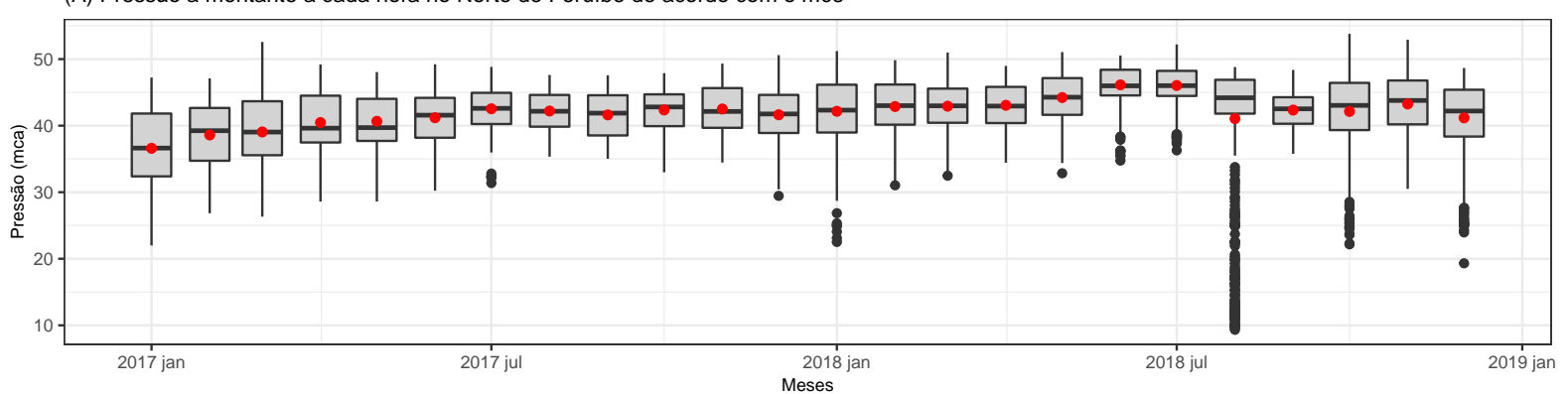

(B) Pressão a montante a cada hora no Norte de Peruíbe de acordo com o horário do dia

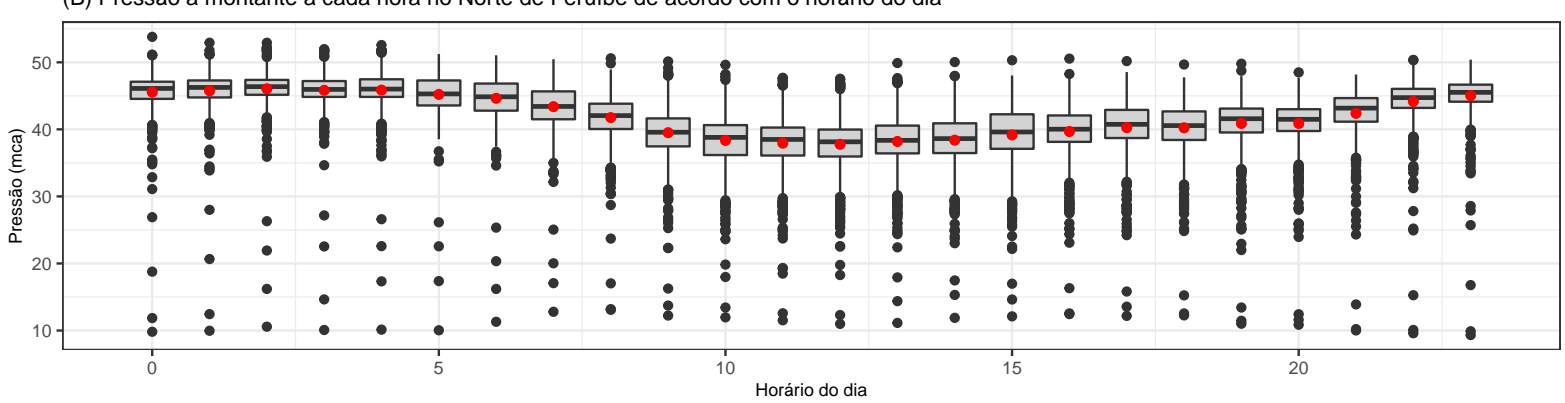

(C) Pressão a montante a cada hora no Norte de Peruíbe de acordo com dia da semana

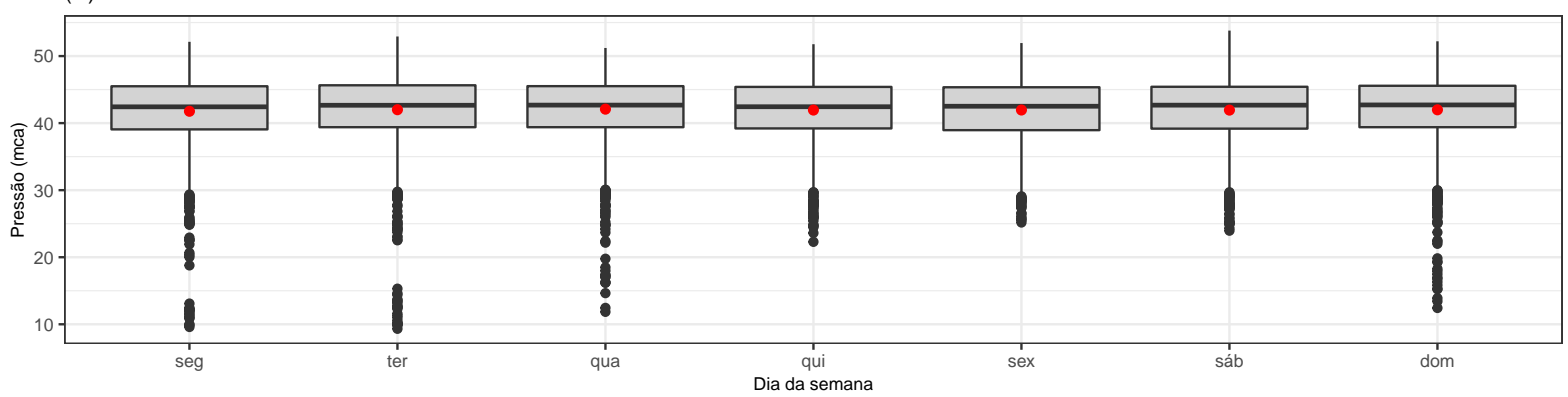

(D) Trecho da série de pressão a montante no Norte de Peruíbe

(E) Trecho da série de vazão de pressão a montante no Norte de Peruíb€ De $1^{\circ}$ a 31 de Julho de 2017

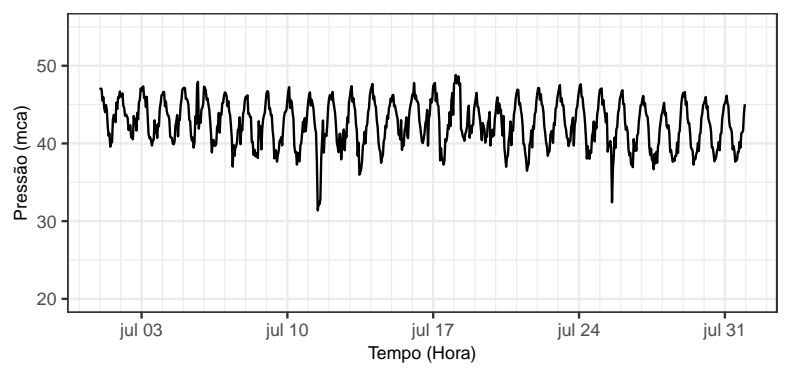
De 15 de dezembro de 2017 a 15 de janeiro de 2018

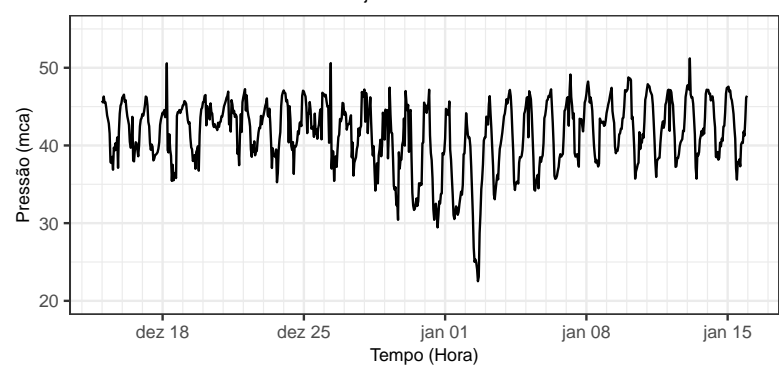

Figura C.6: Painel com alguns gráficos descritivos da série tratada de pressão a montante ao Norte de Peruibe. Os gráficos (A), (B) e (C) são boxplots série de vazão em l/s de acordo com mês, horário do dia e dia semana, respectivamente. Os pontos vermelhos são as médias de cada periodo. Já os gráficos (D) e (E) são trechos selecionados da série. 
Tabela C.7: Medidas descritivas da série tratada de pressão a montante ao Sul de Peruỉbe. As informações descritivas são apresentadas para a série em sua totalidade e desagregada por períodos mensais, por dias da semana e por horários do dia.

\begin{tabular}{|c|c|c|c|c|c|c|c|c|c|}
\hline Descritiva & Média & Desvio padrão & Mínimo & $1^{\mathrm{O}}$ Quartil & Mediana & $3^{\mathcal{O}}$ Quartil & Máximo & Omissos & Total \\
\hline \multicolumn{10}{|l|}{ Geral } \\
\hline Geral & 43,8 & 2,86 & 14,2 & 42,4 & 44,3 & 45,9 & 50,2 & 0 & 17519 \\
\hline \multicolumn{10}{|l|}{ Por ano e mês } \\
\hline 2017 jan & 41,7 & 3,82 & 29,1 & 39,7 & 42,7 & 44,5 & 48,6 & 0 & 743 \\
\hline 2017 fev & 42,9 & 2,65 & 34,3 & 41,3 & 43,4 & 45,1 & 47,3 & 0 & 673 \\
\hline 2017 mar & 43,8 & 2,31 & 36,4 & 42,5 & 44,3 & 45,6 & 47,0 & 0 & 744 \\
\hline 2017 abr & 44,5 & 1,68 & 39,0 & 43,3 & 45,0 & 45,8 & 47,4 & 0 & 720 \\
\hline 2017 mai & 44,8 & 1,46 & 39,5 & 43,7 & 45,0 & 45,9 & 48,7 & 0 & 744 \\
\hline 2017 jun & 44,2 & 2,73 & 31,7 & 43,4 & 44,9 & 46,0 & 47,8 & 0 & 720 \\
\hline 2017 jul & 44,6 & 1,74 & 38,0 & 43,2 & 45,0 & 46,1 & 49,1 & 0 & 744 \\
\hline 2017 ago & 44,5 & 1,80 & 37,6 & 43,2 & 44,9 & 45,9 & 47,3 & 0 & 744 \\
\hline 2017 set & 43,2 & 1,93 & 37,0 & 41,6 & 43,3 & 44,8 & 47,3 & 0 & 720 \\
\hline 2017 out & 43,6 & 1,95 & 37,3 & 42,4 & 43,6 & 45,2 & 47,3 & 0 & 743 \\
\hline 2017 nov & 45,0 & 1,84 & 40,0 & 43,6 & 45,3 & 46,6 & 48,8 & 0 & 720 \\
\hline 2017 dez & 43,8 & 2,55 & 33,6 & 42,3 & 44,0 & 45,8 & 48,8 & 0 & 744 \\
\hline 2018 jan & 43,0 & 2,87 & 33,5 & 41,1 & 43,2 & 45,5 & 47,4 & 0 & 744 \\
\hline 2018 fev & 43,9 & 2,30 & 35,9 & 42,5 & 44,1 & 45,9 & 47,4 & 0 & 673 \\
\hline 2018 mar & 44,6 & 1,73 & 39,6 & 43,2 & 44,7 & 46,2 & 48,5 & 0 & 744 \\
\hline 2018 abr & 44,5 & 1,94 & 38,2 & 43,1 & 44,6 & 46,2 & 47,5 & 0 & 720 \\
\hline 2018 mai & 45,1 & 1,54 & 40,1 & 44,0 & 45,3 & 46,3 & 47,7 & 0 & 744 \\
\hline 2018 jun & 45,9 & 1,22 & 40,6 & 45,0 & 46,1 & 46,9 & 47,8 & 0 & 720 \\
\hline 2018 jul & 45,7 & 2,11 & 38,7 & 44,4 & 46,0 & 47,2 & 49,1 & 0 & 744 \\
\hline 2018 ago & 44,7 & 1,91 & 39,5 & 43,4 & 44,8 & 46,3 & 48,2 & 0 & 744 \\
\hline 2018 set & 42,2 & 1,87 & 37,3 & 40,9 & 42,0 & 43,4 & 47,1 & 0 & 720 \\
\hline 2018 out & 42,1 & 5,72 & 14,2 & 40,3 & 43,6 & 45,7 & 50,2 & 0 & 744 \\
\hline 2018 nov & 42,5 & 3,22 & 34,9 & 40,0 & 42,3 & 45,2 & 49,6 & 0 & 719 \\
\hline $2018 \mathrm{dez}$ & 40,6 & 3,71 & 28,8 & 38,5 & 40,7 & 43,4 & 47,9 & 0 & 744 \\
\hline \multicolumn{10}{|c|}{ Por dia da semana } \\
\hline segunda-feira & 43,8 & 2,80 & 30,3 & 42,4 & 44,4 & 45,8 & 50,2 & 0 & 2520 \\
\hline terça-feira & 44,0 & 2,59 & 30,7 & 42,5 & 44,4 & 46,0 & 50,1 & 0 & 2496 \\
\hline quarta-feira & 43,9 & 2,72 & 26,4 & 42,6 & 44,4 & 45,9 & 49,9 & 0 & 2496 \\
\hline quinta-feira & 43,7 & 3,29 & 14,2 & 42,4 & 44,4 & 45,9 & 48,2 & 0 & 2496 \\
\hline sexta-feira & 43,6 & 2,97 & 23,2 & 42,1 & 44,1 & 45,8 & 48,7 & 0 & 2496 \\
\hline sábado & 43,8 & 2,76 & 30,5 & 42,3 & 44,2 & 45,9 & 49,3 & 0 & 2498 \\
\hline domingo & 43,8 & 2,78 & 28,8 & 42,5 & 44,4 & 45,9 & 49,6 & 0 & 2517 \\
\hline \multicolumn{10}{|c|}{ Por horário do dia } \\
\hline $0: 00$ & 45,3 & 2,15 & 26,4 & 44,5 & 45,9 & 46,7 & 49,5 & 0 & 727 \\
\hline $1: 00$ & 45,5 & 1,95 & 29,3 & 44,9 & 46,0 & 46,7 & 49,6 & 0 & 730 \\
\hline $2: 00$ & 45,7 & 1,83 & 29,3 & 45,0 & 46,2 & 46,8 & 49,6 & 0 & 730 \\
\hline $3: 00$ & 45,8 & 1,71 & 29,0 & 45,3 & 46,2 & 46,8 & 49,7 & 0 & 730 \\
\hline $4: 00$ & 45,8 & 1,66 & 28,1 & 45,3 & 46,1 & 46,7 & 49,8 & 0 & 730 \\
\hline $5: 00$ & 45,8 & 1,60 & 27,5 & 45,4 & 46,0 & 46,7 & 50,2 & 0 & 730 \\
\hline $6: 00$ & 45,7 & 1,56 & 27,4 & 45,1 & 45,9 & 46,5 & 49,9 & 0 & 730 \\
\hline $7: 00$ & 45,1 & 1,71 & 25,2 & 44,5 & 45,5 & 46,0 & 49,6 & 0 & 730 \\
\hline $8: 00$ & 44,5 & 1,93 & 22,4 & 43,6 & 44,9 & 45,6 & 48,7 & 0 & 730 \\
\hline $9: 00$ & 42,8 & 2,21 & 21,5 & 41,9 & 43,0 & 44,1 & 47,3 & 0 & 730 \\
\hline $10: 00$ & 42,1 & 2,54 & 18,5 & 41,1 & 42,5 & 43,6 & 47,2 & 0 & 730 \\
\hline $11: 00$ & 41,5 & 2,83 & 14,6 & 40,2 & 42,0 & 43,3 & 46,9 & 0 & 730 \\
\hline $12: 00$ & 41,5 & 2,89 & 16,2 & 40,2 & 42,0 & 43,3 & 47,1 & 0 & 730 \\
\hline $13: 00$ & 41,6 & 2,92 & 16,3 & 40,3 & 42,1 & 43,5 & 47,6 & 0 & 730 \\
\hline $14: 00$ & 42,0 & 2,94 & 14,2 & 40,9 & 42,7 & 43,9 & 47,4 & 0 & 730 \\
\hline $15: 00$ & 42,1 & 2,85 & 16,8 & 41,0 & 42,7 & 43,9 & 47,3 & 0 & 730 \\
\hline $16: 00$ & 42,1 & 2,72 & 17,4 & 41,0 & 42,8 & 43,8 & 47,5 & 0 & 730 \\
\hline $17: 00$ & 42,4 & 2,67 & 18,8 & 41,3 & 42,9 & 44,1 & 47,4 & 0 & 730 \\
\hline $18: 00$ & 42,8 & 2,64 & 21,0 & 41,7 & 43,4 & 44,6 & 47,3 & 0 & 730 \\
\hline $19: 00$ & 43,2 & 2,72 & 21,6 & 42,0 & 43,8 & 45,1 & 47,7 & 0 & 730 \\
\hline $20: 00$ & 43,7 & 2,62 & 25,4 & 42,7 & 44,3 & 45,5 & 47,9 & 0 & 730 \\
\hline $21: 00$ & 44,3 & 2,56 & 25,1 & 43,2 & 44,9 & 46,0 & 48,6 & 0 & 730 \\
\hline $22: 00$ & 44,8 & 2,41 & 26,9 & 43,8 & 45,4 & 46,3 & 49,0 & 0 & 730 \\
\hline $23: 00$ & 45,1 & 2,29 & 28,0 & 44,3 & 45,6 & 46,5 & 49,1 & 0 & 732 \\
\hline
\end{tabular}


(A) Pressão a montante a cada hora no Sul de Peruíbe de acordo com o mês

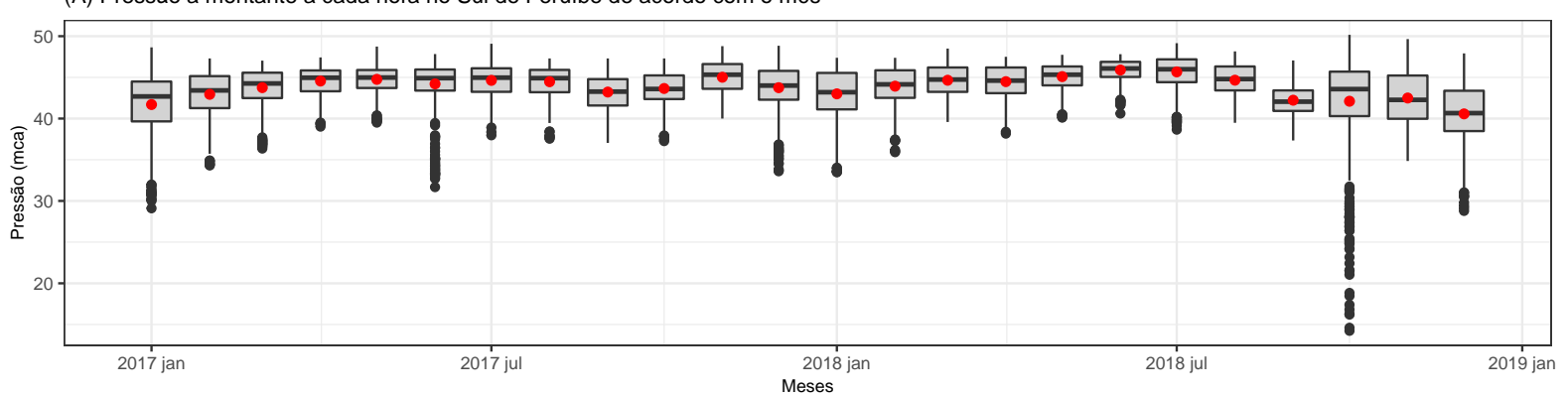

(B) Pressão a montante a cada hora no Sul de Peruíbe de acordo com o horário do dia

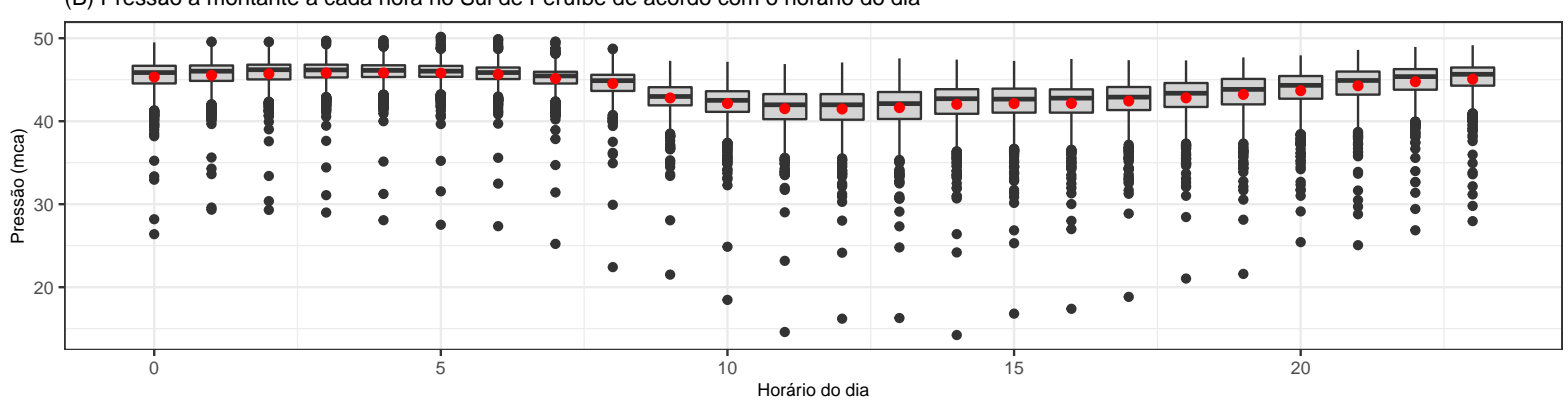

(C) Pressão a montante a cada hora no Sul de Peruíbe de acordo com dia da semana

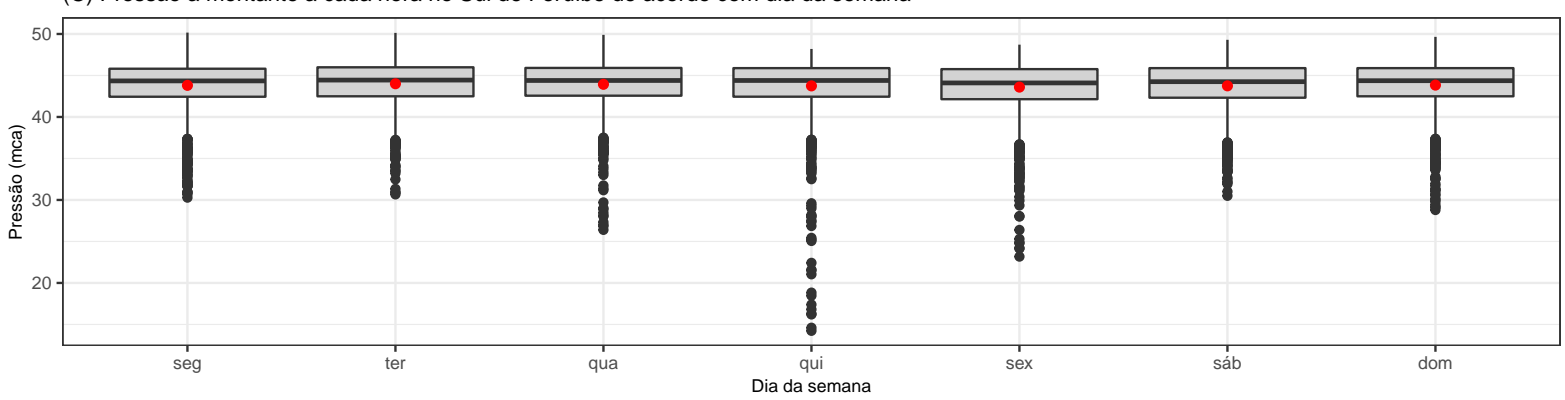

(D) Trecho da série de pressão a montante no Sul de Peruíbe De $1^{\circ}$ a 31 de Julho de 2017

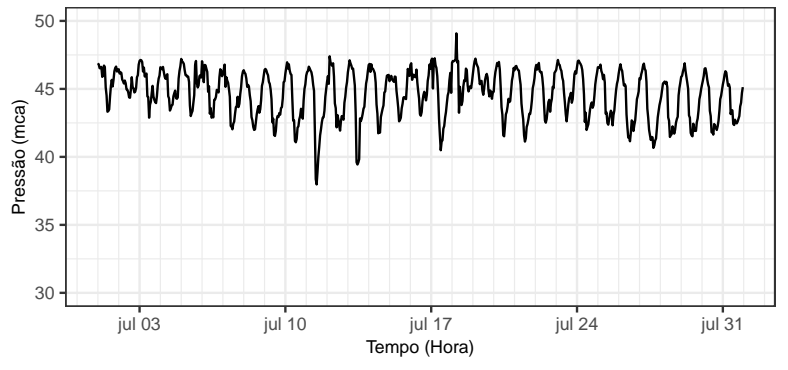

(E) Trecho da série de pressão a montante no Sul de Peruíbe De 15 de dezembro de 2017 a 15 de janeiro de 2018

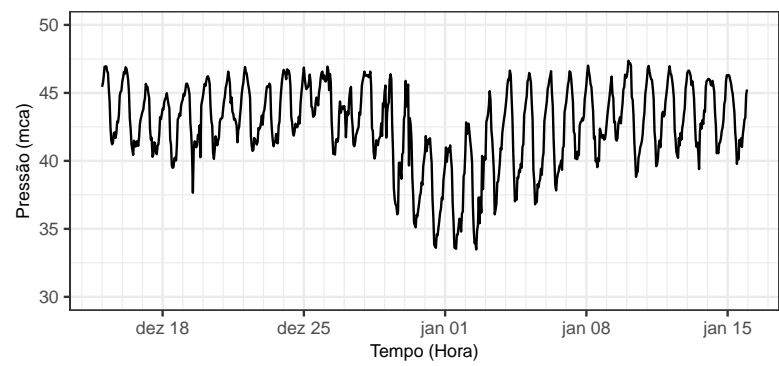

Figura C.7: Painel com alguns gráficos descritivos da série tratada de pressão a montante ao Sul de Peruíbe. Os gráficos (A), (B) e (C) são boxplots série de vazão em l/s de acordo com mês, horário do dia e dia semana, respectivamente. Os pontos vermelhos são as médias de cada periodo. Já os gráficos (D) e (E) são trechos selecionados da série. 
Tabela C.8: Medidas descritivas da série tratada de pressão a jusante ao Norte de Peruíbe. As informações descritivas são apresentadas para a série em sua totalidade e desagregada por períodos mensais, por dias da semana e por horários do dia.

\begin{tabular}{|c|c|c|c|c|c|c|c|c|c|}
\hline Descritiva & Média & Desvio padrão & Mínimo & $1^{\mathrm{O}}$ Quartil & Mediana & $3^{\mathcal{O}}$ Quartil & Máximo & Omissos & Total \\
\hline \multicolumn{10}{|l|}{ Geral } \\
\hline Geral & 17,1 & 4,48 & 5,49 & 13,33 & 17,8 & 20,4 & 29,9 & 2 & 17519 \\
\hline \multicolumn{10}{|l|}{ Por ano e mês } \\
\hline 2017 jan & 19,2 & 4,36 & 10,31 & 15,63 & 19,8 & 22,8 & 28,5 & 2 & 743 \\
\hline 2017 fev & 17,9 & 4,58 & 9,91 & 14,46 & 18,0 & 21,7 & 26,0 & 0 & 673 \\
\hline 2017 mar & 17,2 & 4,65 & 6,20 & 12,67 & 17,9 & 20,6 & 26,6 & 0 & 744 \\
\hline 2017 abr & 15,9 & 4,14 & 6,18 & 12,28 & 17,2 & 19,8 & 24,9 & 0 & 720 \\
\hline 2017 mai & 15,8 & 3,98 & 8,28 & 12,16 & 16,2 & 19,8 & 22,4 & 0 & 744 \\
\hline 2017 jun & 16,0 & 4,18 & 8,21 & 12,23 & 17,3 & 19,8 & 23,8 & 0 & 720 \\
\hline 2017 jul & 16,2 & 4,09 & 8,86 & 13,80 & 17,3 & 19,5 & 25,7 & 0 & 744 \\
\hline 2017 ago & 16,3 & 4,06 & 8,96 & 12,89 & 17,5 & 19,7 & 22,5 & 0 & 744 \\
\hline 2017 set & 16,2 & 3,86 & 7,25 & 13,30 & 17,3 & 19,5 & 22,4 & 0 & 720 \\
\hline 2017 out & 15,3 & 4,49 & 5,49 & 10,49 & 15,4 & 19,4 & 24,8 & 0 & 743 \\
\hline 2017 nov & 16,4 & 4,39 & 8,06 & 11,86 & 17,7 & 20,0 & 22,9 & 0 & 720 \\
\hline 2017 dez & 17,1 & 4,48 & 7,45 & 12,61 & 18,2 & 20,7 & 25,6 & 0 & 744 \\
\hline 2018 jan & 18,8 & 4,66 & 7,61 & 15,16 & 19,5 & 22,3 & 26,0 & 0 & 744 \\
\hline 2018 fev & 18,7 & 4,57 & 8,62 & 14,63 & 19,5 & 22,1 & 26,4 & 0 & 673 \\
\hline 2018 mar & 17,6 & 4,68 & 6,54 & 12,60 & 18,4 & 22,1 & 25,7 & 0 & 744 \\
\hline 2018 abr & 17,6 & 4,62 & 7,20 & 12,65 & 18,3 & 22,0 & 25,6 & 0 & 720 \\
\hline 2018 mai & 17,6 & 4,63 & 9,21 & 12,72 & 18,3 & 22,0 & 25,4 & 0 & 744 \\
\hline 2018 jun & 16,4 & 3,90 & 9,26 & 12,18 & 17,9 & 19,9 & 25,1 & 0 & 720 \\
\hline 2018 jul & 16,3 & 3,86 & 7,40 & 13,10 & 16,7 & 19,9 & 25,2 & 0 & 744 \\
\hline 2018 ago & 16,0 & 4,45 & 7,55 & 12,47 & 15,4 & 19,9 & 23,9 & 0 & 744 \\
\hline 2018 set & 16,9 & 4,38 & 7,03 & 13,69 & 16,8 & 21,4 & 23,7 & 0 & 720 \\
\hline 2018 out & 18,4 & 4,49 & 8,67 & 14,90 & 18,8 & 22,1 & 29,9 & 0 & 744 \\
\hline 2018 nov & 18,8 & 4,09 & 9,18 & 15,35 & 19,4 & 22,4 & 28,2 & 0 & 719 \\
\hline $2018 \mathrm{dez}$ & 17,9 & 4,49 & 7,59 & 14,38 & 18,0 & 22,1 & 28,6 & 0 & 744 \\
\hline \multicolumn{10}{|c|}{ Por dia da semana } \\
\hline segunda-feira & 17,1 & 4,43 & 6,18 & 13,77 & 17,8 & 20,4 & 26,4 & 0 & 2520 \\
\hline terça-feira & 17,0 & 4,47 & 6,54 & 12,84 & 17,7 & 20,3 & 26,5 & 0 & 2496 \\
\hline quarta-feira & 16,9 & 4,44 & 6,20 & 12,84 & 17,6 & 20,2 & 25,9 & 0 & 2496 \\
\hline quinta-feira & 17,1 & 4,45 & 7,03 & 13,28 & 17,8 & 20,4 & 28,0 & 0 & 2496 \\
\hline sexta-feira & 17,1 & 4,48 & 6,42 & 13,21 & 17,8 & 20,4 & 26,6 & 0 & 2496 \\
\hline sábado & 17,1 & 4,51 & 5,49 & 13,53 & 17,8 & 20,4 & 27,5 & 0 & 2498 \\
\hline domingo & 17,3 & 4,59 & 5,98 & 13,94 & 17,8 & 20,5 & 29,9 & 2 & 2517 \\
\hline \multicolumn{10}{|c|}{ Por horário do dia } \\
\hline $0: 00$ & 10,7 & 2,04 & 6,18 & 9,45 & 10,0 & 11,8 & 20,6 & 0 & 727 \\
\hline $1: 00$ & 10,8 & 1,93 & 5,49 & 9,52 & 10,3 & 11,9 & 19,6 & 1 & 730 \\
\hline $2: 00$ & 11,5 & 2,11 & 5,98 & 9,69 & 11,0 & 12,6 & 19,0 & 1 & 730 \\
\hline $3: 00$ & 13,0 & 1,95 & 7,25 & 11,67 & 12,6 & 14,6 & 19,7 & 0 & 730 \\
\hline $4: 00$ & 13,8 & 2,19 & 7,28 & 12,21 & 13,8 & 15,1 & 20,0 & 0 & 730 \\
\hline $5: 00$ & 15,6 & 2,27 & 7,84 & 14,33 & 15,1 & 17,6 & 22,0 & 0 & 730 \\
\hline $6: 00$ & 16,1 & 2,28 & 8,67 & 14,55 & 15,4 & 17,9 & 23,4 & 0 & 730 \\
\hline $7: 00$ & 17,8 & 1,75 & 11,11 & 17,29 & 17,8 & 18,5 & 23,6 & 0 & 730 \\
\hline $8: 00$ & 18,8 & 1,91 & 11,76 & 17,78 & 18,5 & 19,9 & 25,6 & 0 & 730 \\
\hline $9: 00$ & 20,4 & 1,97 & 11,97 & 19,54 & 20,2 & 21,9 & 27,6 & 0 & 730 \\
\hline $10: 00$ & 21,1 & 2,13 & 12,67 & 19,80 & 21,2 & 22,1 & 28,5 & 0 & 730 \\
\hline $11: 00$ & 21,6 & 2,48 & 13,10 & 19,88 & 21,3 & 23,3 & 29,0 & 0 & 730 \\
\hline $12: 00$ & 22,3 & 2,24 & 13,01 & 21,22 & 22,3 & 23,4 & 29,8 & 0 & 730 \\
\hline $13: 00$ & 22,3 & 2,17 & 13,63 & 21,30 & 22,6 & 23,4 & 29,9 & 0 & 730 \\
\hline $14: 00$ & 22,2 & 2,12 & 13,82 & 21,27 & 22,5 & 23,4 & 29,9 & 0 & 730 \\
\hline $15: 00$ & 21,3 & 2,07 & 12,75 & 19,90 & 21,7 & 22,5 & 29,6 & 0 & 730 \\
\hline $16: 00$ & 20,6 & 1,99 & 12,15 & 19,64 & 20,6 & 21,9 & 28,9 & 0 & 730 \\
\hline $17: 00$ & 19,4 & 2,11 & 10,19 & 17,90 & 19,8 & 20,4 & 28,4 & 0 & 730 \\
\hline $18: 00$ & 18,9 & 1,94 & 11,48 & 17,66 & 19,4 & 20,0 & 27,4 & 0 & 730 \\
\hline $19: 00$ & 17,1 & 2,28 & 9,21 & 15,37 & 17,5 & 18,3 & 26,4 & 0 & 730 \\
\hline $20: 00$ & 16,7 & 2,26 & 8,33 & 14,90 & 17,5 & 18,2 & 25,8 & 0 & 730 \\
\hline $21: 00$ & 14,4 & 2,64 & 7,11 & 12,21 & 14,8 & 15,7 & 23,9 & 0 & 730 \\
\hline $22: 00$ & 12,3 & 1,97 & 7,33 & 11,40 & 12,0 & 12,6 & 21,2 & 0 & 730 \\
\hline $23: 00$ & 11,5 & 2,03 & 6,42 & 9,82 & 12,0 & 12,4 & 20,5 & 0 & 732 \\
\hline
\end{tabular}


(A) Pressão a jusante a cada hora no Norte de Peruíbe de acordo com o mês

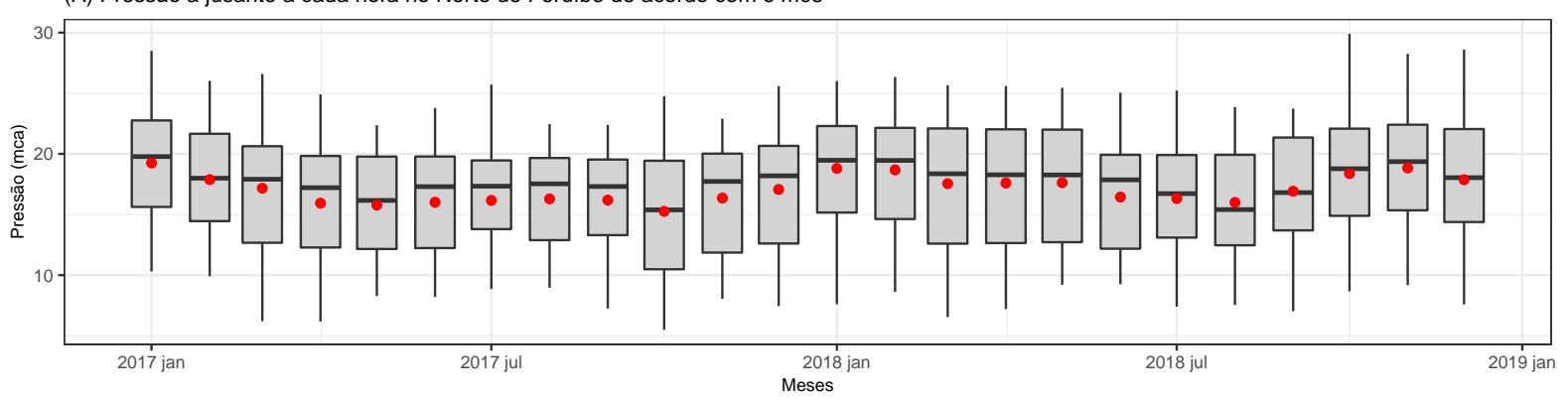

(B) Pressão a jusante a cada hora no Norte de Peruíbe de acordo com o horário do dia

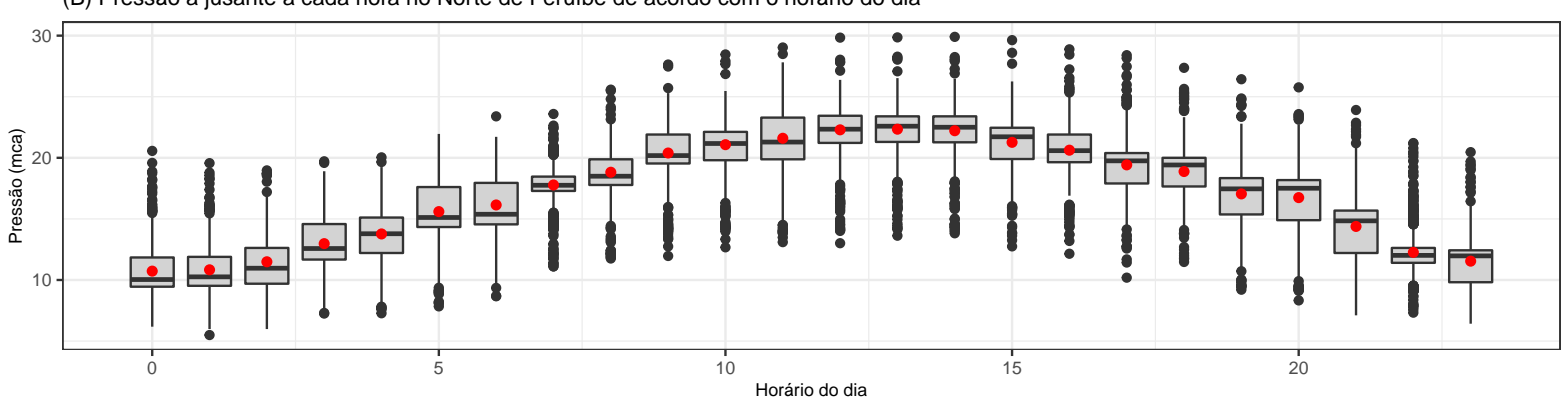

(C) Pressão a jusante a cada hora no Norte de Peruíbe de acordo com dia da semana

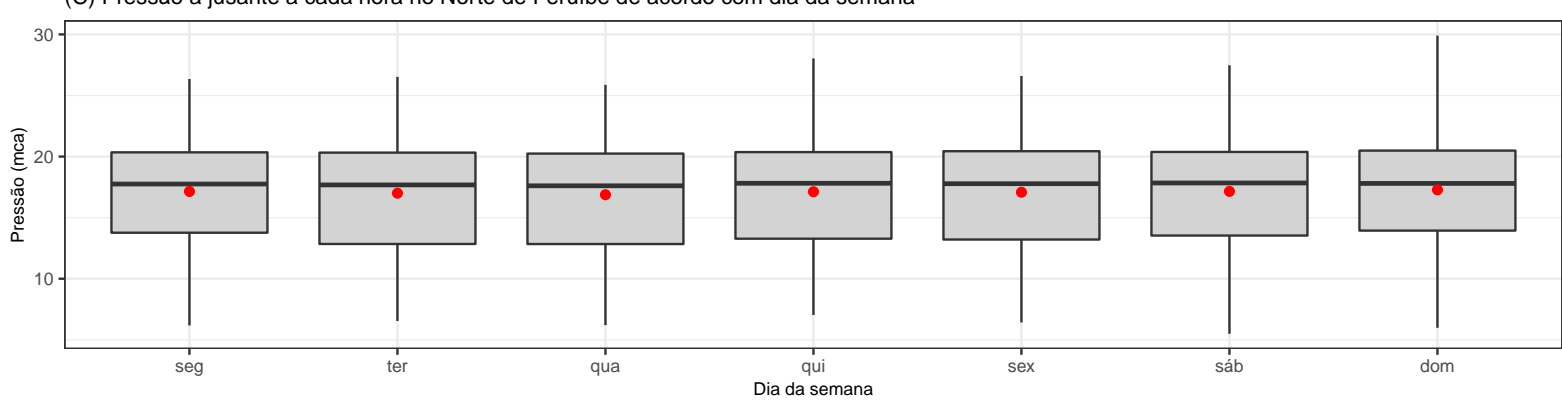

(D) Trecho da série de pressão a jusante no Norte de Peruíbe De $1^{\circ}$ a 31 de Julho de 2017

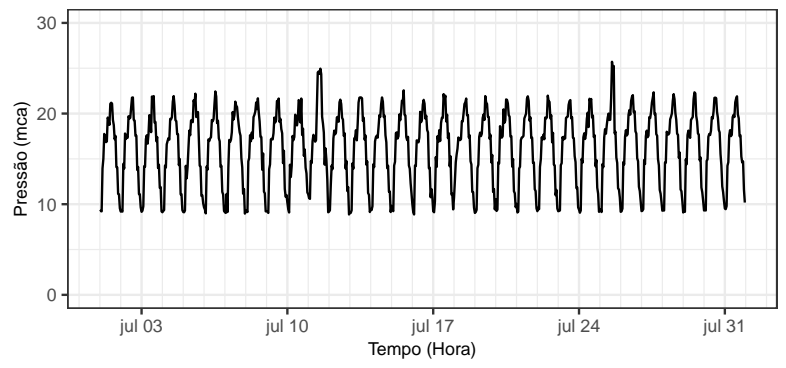

(E) Trecho da série de vazão de pressão a jusante no Norte de Peruíbe De 15 de dezembro de 2017 a 15 de janeiro de 2018

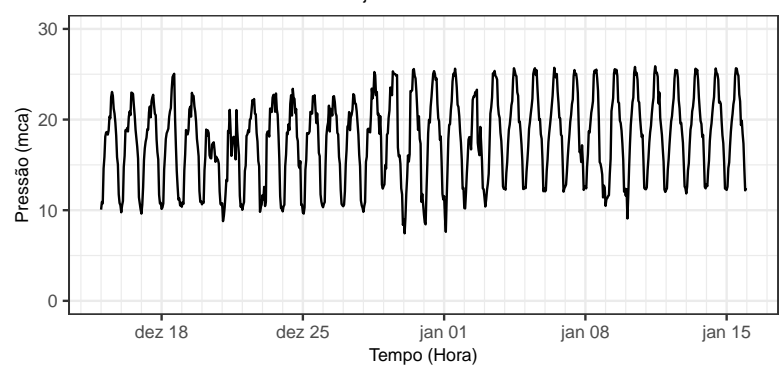

Figura C.8: Painel com alguns gráficos descritivos da série tratada de pressão a jusante ao Norte de Peruíbe. Os gráficos (A), (B) e (C) são boxplots série de vazão em l/s de acordo com mês, horário do dia e dia semana, respectivamente. Os pontos vermelhos são as médias de cada periodo. Já os gráficos (D) e (E) são trechos selecionados da série. 
Tabela C.9: Medidas descritivas da série tratada de pressão a jusante ao Sul de Peruß̋e. As informações descritivas são apresentadas para a série em sua totalidade e desagregada por períodos mensais, por dias da semana e por horários do dia.

\begin{tabular}{|c|c|c|c|c|c|c|c|c|c|}
\hline Descritiva & Média & Desvio padrão & Mínimo & $1^{\mathrm{O}}$ Quartil & Mediana & $3^{\mathcal{O}}$ Quartil & Máximo & Omissos & Total \\
\hline \multicolumn{10}{|l|}{ Geral } \\
\hline Geral & 16,4 & 4,61 & 3,49 & 12,63 & 15,6 & 19,4 & 35,1 & 0 & 17519 \\
\hline \multicolumn{10}{|l|}{ Por ano e mês } \\
\hline 2017 jan & 19,1 & 4,80 & 7,96 & 15,24 & 18,6 & 22,4 & 30,0 & 0 & 743 \\
\hline 2017 fev & 17,4 & 4,68 & 9,67 & 12,80 & 17,8 & 20,9 & 26,8 & 0 & 673 \\
\hline 2017 mar & 15,8 & 4,43 & 6,28 & 12,29 & 15,3 & 19,1 & 26,2 & 0 & 744 \\
\hline 2017 abr & 14,6 & 3,83 & 6,25 & 11,15 & 14,4 & 17,8 & 26,2 & 0 & 720 \\
\hline 2017 mai & 14,3 & 3,25 & 8,69 & 11,52 & 14,2 & 17,7 & 25,6 & 0 & 744 \\
\hline 2017 jun & 14,7 & 3,47 & 7,11 & 11,35 & 14,7 & 17,9 & 22,5 & 0 & 720 \\
\hline 2017 jul & 15,0 & 3,54 & 9,18 & 12,04 & 15,0 & 18,1 & 25,4 & 0 & 744 \\
\hline 2017 ago & 15,1 & 3,54 & 9,13 & 12,23 & 14,9 & 18,0 & 26,5 & 0 & 744 \\
\hline 2017 set & 15,2 & 3,11 & 8,72 & 12,74 & 14,9 & 18,0 & 22,4 & 0 & 720 \\
\hline 2017 out & 14,4 & 3,50 & 6,62 & 11,06 & 14,6 & 17,6 & 22,5 & 0 & 743 \\
\hline 2017 nov & 14,9 & 3,42 & 8,99 & 11,62 & 14,8 & 18,0 & 21,8 & 0 & 720 \\
\hline 2017 dez & 15,0 & 3,80 & 3,49 & 11,97 & 14,8 & 18,0 & 25,8 & 0 & 744 \\
\hline 2018 jan & 17,8 & 4,79 & 3,57 & 13,41 & 18,1 & 21,5 & 27,4 & 0 & 744 \\
\hline 2018 fev & 17,7 & 4,35 & 8,23 & 14,16 & 18,1 & 20,9 & 26,6 & 0 & 673 \\
\hline 2018 mar & 15,9 & 4,11 & 7,06 & 12,23 & 17,3 & 19,7 & 26,1 & 0 & 744 \\
\hline 2018 abr & 16,3 & 4,19 & 8,77 & 12,62 & 17,1 & 19,9 & 28,4 & 0 & 720 \\
\hline 2018 mai & 16,1 & 3,88 & 8,23 & 12,55 & 17,3 & 19,8 & 25,6 & 0 & 744 \\
\hline 2018 jun & 15,1 & 3,03 & 9,01 & 12,59 & 14,8 & 17,9 & 25,0 & 0 & 720 \\
\hline 2018 jul & 14,6 & 3,12 & 6,77 & 12,23 & 14,4 & 17,4 & 23,7 & 0 & 744 \\
\hline 2018 ago & 15,5 & 3,42 & 8,25 & 12,56 & 15,2 & 18,6 & 23,8 & 0 & 744 \\
\hline 2018 set & 15,9 & 3,31 & 8,25 & 13,14 & 15,7 & 19,3 & 21,2 & 0 & 720 \\
\hline 2018 out & 17,7 & 4,77 & 8,33 & 13,69 & 18,0 & 20,4 & 29,8 & 0 & 744 \\
\hline 2018 nov & 22,4 & 5,77 & 10,68 & 16,77 & 23,9 & 27,9 & 30,2 & 0 & 719 \\
\hline $2018 \mathrm{dez}$ & 22,3 & 5,71 & 7,50 & 17,66 & 23,6 & 27,6 & 35,1 & 0 & 744 \\
\hline \multicolumn{10}{|c|}{ Por dia da semana } \\
\hline segunda-feira & 16,5 & 4,59 & 3,57 & 12,67 & 16,0 & 19,4 & 30,6 & 0 & 2520 \\
\hline terça-feira & 16,4 & 4,58 & 5,18 & 12,65 & 15,5 & 19,4 & 30,1 & 0 & 2496 \\
\hline quarta-feira & 16,2 & 4,54 & 4,22 & 12,58 & 15,4 & 19,1 & 29,8 & 0 & 2496 \\
\hline quinta-feira & 16,2 & 4,48 & 6,47 & 12,63 & 15,6 & 19,2 & 29,6 & 0 & 2496 \\
\hline sexta-feira & 16,3 & 4,64 & 6,28 & 12,58 & 15,8 & 19,4 & 29,6 & 0 & 2496 \\
\hline sábado & 16,4 & 4,71 & 5,91 & 12,63 & 15,8 & 19,4 & 35,1 & 0 & 2498 \\
\hline domingo & 16,5 & 4,73 & 3,49 & 12,72 & 15,8 & 19,6 & 30,0 & 0 & 2517 \\
\hline \multicolumn{10}{|c|}{ Por horário do dia } \\
\hline $0: 00$ & 11,2 & 2,68 & 5,64 & 9,74 & 10,3 & 12,0 & 25,6 & 0 & 727 \\
\hline $1: 00$ & 11,3 & 2,42 & 3,52 & 10,08 & 10,6 & 12,2 & 25,1 & 0 & 730 \\
\hline $2: 00$ & 11,8 & 2,08 & 3,49 & 10,55 & 11,4 & 12,6 & 23,6 & 0 & 730 \\
\hline $3: 00$ & 12,8 & 1,91 & 3,71 & 11,87 & 12,5 & 13,3 & 23,9 & 0 & 730 \\
\hline $4: 00$ & 13,6 & 1,89 & 3,57 & 12,70 & 13,2 & 14,4 & 23,2 & 0 & 730 \\
\hline $5: 00$ & 14,9 & 1,97 & 6,08 & 14,09 & 14,8 & 15,6 & 25,0 & 0 & 730 \\
\hline $6: 00$ & 15,3 & 1,96 & 8,67 & 14,31 & 14,8 & 15,9 & 27,2 & 0 & 730 \\
\hline $7: 00$ & 16,6 & 2,34 & 7,89 & 14,90 & 16,6 & 18,0 & 29,2 & 0 & 730 \\
\hline $8: 00$ & 17,1 & 2,73 & 9,30 & 14,63 & 17,2 & 19,0 & 28,2 & 0 & 730 \\
\hline $9: 00$ & 19,4 & 2,69 & 10,16 & 17,88 & 18,9 & 20,8 & 29,0 & 0 & 730 \\
\hline $10: 00$ & 19,8 & 3,07 & 9,86 & 17,88 & 19,2 & 21,1 & 29,3 & 0 & 730 \\
\hline $11: 00$ & 21,0 & 3,47 & 10,21 & 19,10 & 20,1 & 22,4 & 30,2 & 0 & 730 \\
\hline $12: 00$ & 21,2 & 3,51 & 8,45 & 19,19 & 20,2 & 24,0 & 29,4 & 0 & 730 \\
\hline $13: 00$ & 21,1 & 3,51 & 10,87 & 19,30 & 20,1 & 23,9 & 30,1 & 0 & 730 \\
\hline $14: 00$ & 20,1 & 3,46 & 9,28 & 18,00 & 19,4 & 21,7 & 29,4 & 0 & 730 \\
\hline $15: 00$ & 19,9 & 3,38 & 9,79 & 17,88 & 19,4 & 20,9 & 29,4 & 0 & 730 \\
\hline $16: 00$ & 19,8 & 3,33 & 10,53 & 18,00 & 19,3 & 20,4 & 31,2 & 0 & 730 \\
\hline $17: 00$ & 19,1 & 3,52 & 10,57 & 17,48 & 18,3 & 20,0 & 35,1 & 0 & 730 \\
\hline $18: 00$ & 17,7 & 3,92 & 9,67 & 15,12 & 17,2 & 18,3 & 34,5 & 0 & 730 \\
\hline $19: 00$ & 16,4 & 4,07 & 8,57 & 14,51 & 15,1 & 17,2 & 34,5 & 0 & 730 \\
\hline $20: 00$ & 15,2 & 3,80 & 8,06 & 12,60 & 14,8 & 15,5 & 29,5 & 0 & 730 \\
\hline $21: 00$ & 13,3 & 3,80 & 7,66 & 10,65 & 12,4 & 14,5 & 27,7 & 0 & 730 \\
\hline $22: 00$ & 12,2 & 3,52 & 6,78 & 10,23 & 10,9 & 12,3 & 27,6 & 0 & 730 \\
\hline $23: 00$ & 11,8 & 3,02 & 5,91 & 10,13 & 10,8 & 12,3 & 28,3 & 0 & 732 \\
\hline
\end{tabular}


(A) Pressão a jusante a cada hora no Sul de Peruíbe de acordo com o mês

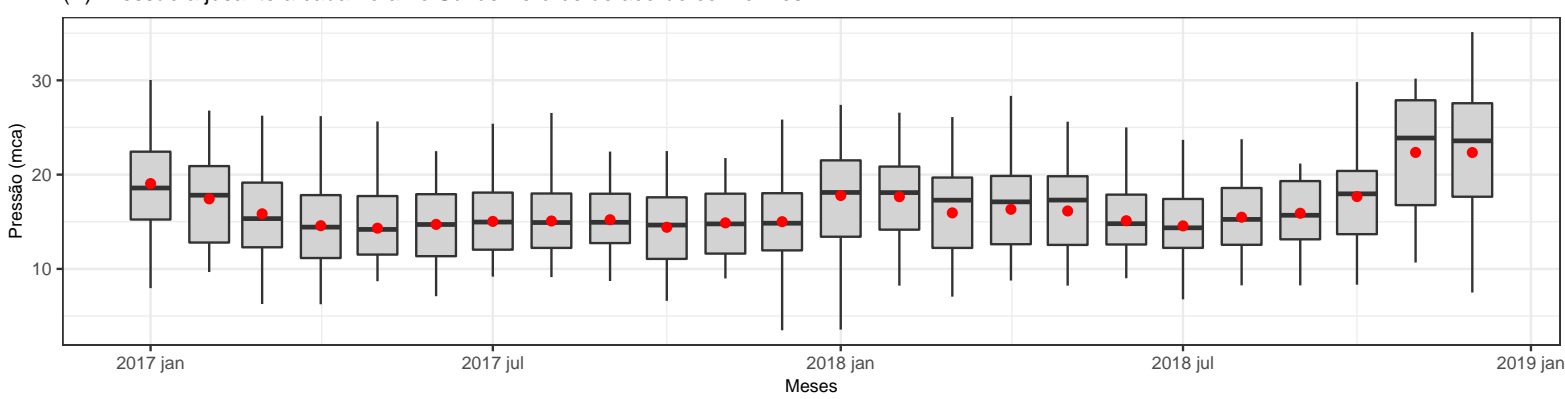

(B) Pressão a jusante a cada hora no Sul de Peruíbe de acordo com o horário do dia

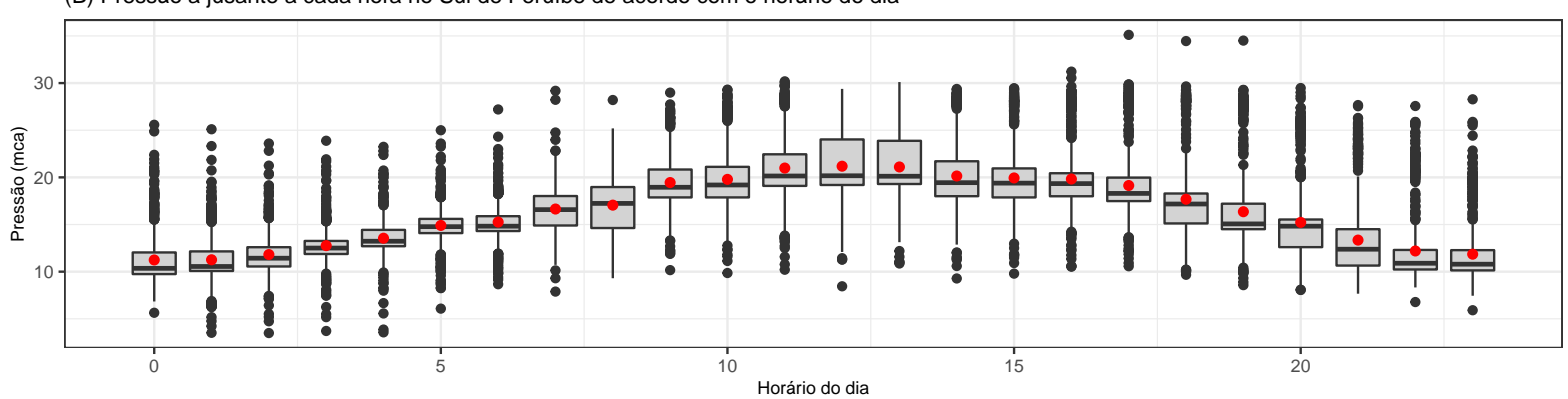

(C) Pressão a jusante a cada hora no Sul de Peruíbe de acordo com dia da semana

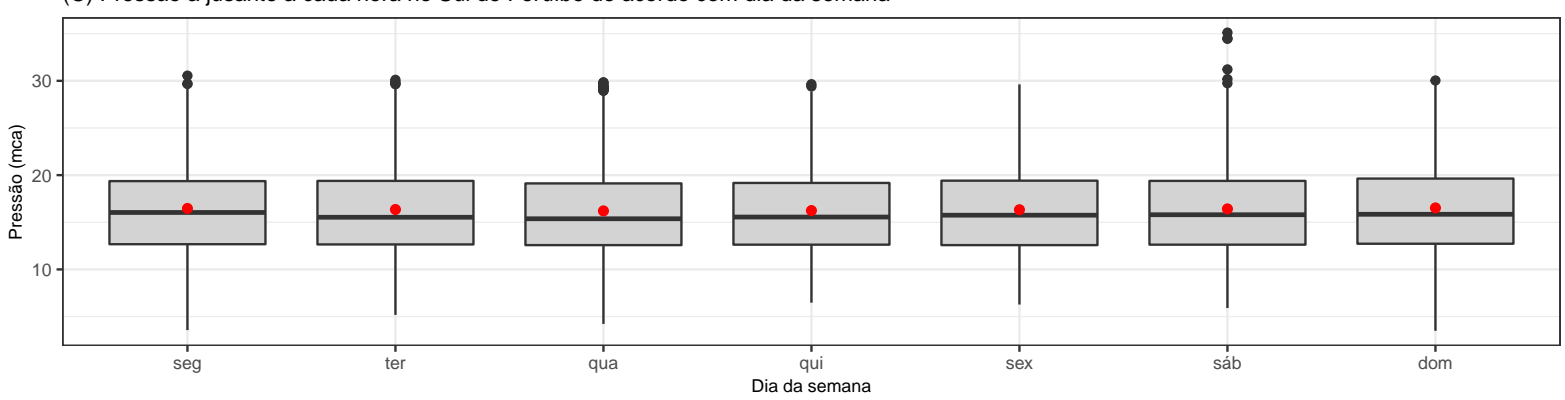

(D) Trecho da série de pressão a jusante no Sul de Peruíbe De $1^{\circ}$ a 31 de Julho de 2017

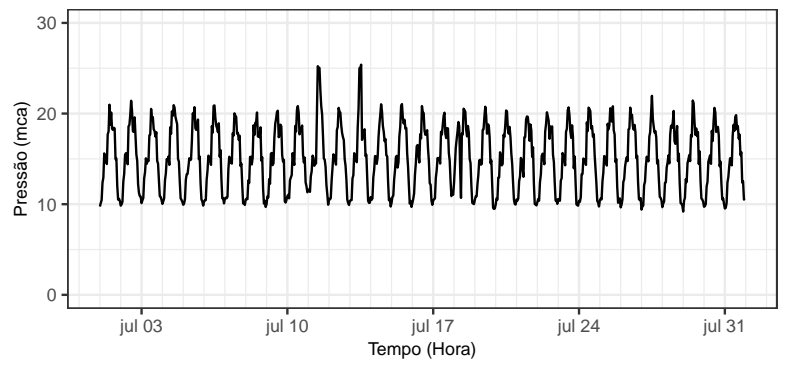

(E) Trecho da série de pressão a jusante no Sul de Peruíbe De 15 de dezembro de 2017 a 15 de janeiro de 2018

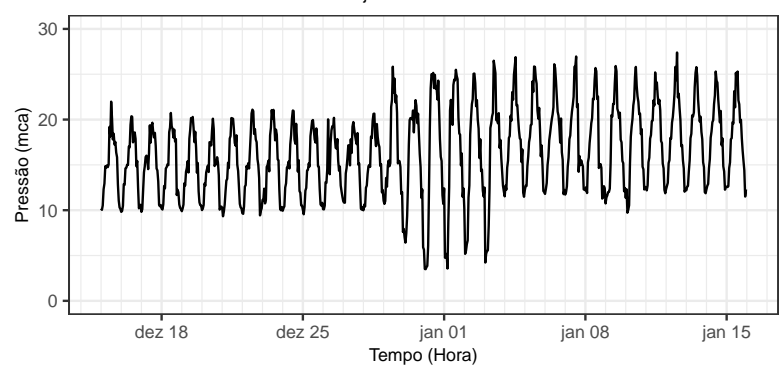

Figura C.9: Painel com alguns gráficos descritivos da série tratada de pressão a jusante ao Sul de Peruíbe. Os gráficos (A), (B) e (C) são boxplots série de vazão em l/s de acordo com mês, horário do dia e dia semana, respectivamente. Os pontos vermelhos são as médias de cada período. Já os gráficos (D) e (E) são trechos selecionados da série. 


\section{Referências Bibliográficas}

[AACSLO18] A. Antunes, A. Andrade-Campos, A. Sardinha-Lourenço e M. S. Oliveira. Short-term water demand forecasting using machine learning techniques. Journal of Hydroinformatics, 20(6):1343-1366, 2018. 1

[BAD05] John Bougadis, Kaz Adamowski e Roman Diduch. Short-term municipal water demand forecasting. Hydrological Processes, 19(1):137-148, 2005. 1

[Bar15] Rui Barrela. Data reconstruction of flow time series in water distribution networks. Tese de Doutorado, Universidade de Lisboa, 2015. 2, 133

[BC64] G. E. P. Box e D. R. Cox. An Analysis of Transformations. Journal of the Royal Statistical Society. Series B (Methodological), 26:211-252, 1964. 7

[BJR13] George E.P. Box, Gwilym M. Jenkins e Gregory C. Reinsel. Time series analysis: Forecasting and control: Fourth edition. wiley, may 2013. 12

[CCMT90] Robert B Cleveland, William S Cleveland, Jean E McRae e Irma Terpenning. STL: A Seasonal-Trend Decomposition Procedure Based on Loess (with Discussion). Journal of Official Statistics, 1990. 10

[CH95] Fabio Canova e Bruce E Hansen. Are Seasonal Patterns Constant Over Time? A Test for Seasonal Stability. Journal of Business 63 Economic Statistics, 13(3):237252, 1995. 17

[CL93] Chung Chen e Lon-Mu Liu. Joint Estimation of Model Parameters and Outlier Effects in Time Series. Journal of the American Statistical Association, 88(421):284297, 1993. 23

[CW20] Microsoft Corporation e Steve Weston. doParallel: Foreach Parallel Adaptor for the 'parallel' Package, 2020. 47

[DF81] David A. Dickey e Wayne A. Fuller. Likelihood Ratio Statistics for Autoregressive Time Series with a Unit Root. Econometrica, 49(4):1057-1072, 1981. 15, 17

[dLHS11] Alysha M. de Livera, Rob J. Hyndman e Ralph D. Snyder. Forecasting time series with complex seasonal patterns using exponential smoothing. Journal of the American Statistical Association, 106(496):1513-1527, 2011. 20, 22

[DP14] Cláudia Cristina Dos Santos e Augusto José Pereira Filho. Water Demand Forecasting Model for the Metropolitan Area of São Paulo, Brazil. Water Resources Management, 28(13):4401-4414, 2014. 1

[DS98] Norman R. Draper e Harry Smith. Applied Regression Analysis. Wiley-Interscience, New York, NY, $3^{\text {a }}$ edição, 1998. 9

[Fox72] A. J. Fox. Outliers in Time Series. Journal of the Royal Statistical Society: Series B (Methodological), 34(3):350-363, 1972. 23 
[Gue93] Victor M. Guerrero. Time-series analysis supported by power transformations. Journal of Forecasting, 12(1):37-48, 1993. 8

[GW11] Garrett Grolemund e Hadley Wickham. Dates and Times Made Easy with \{lubridate\}. Journal of Statistical Software, 40(3):1-25, 2011. 47

[HA19] R.J. Hyndman e G. Athanasopoulos. Forecasting: principles and practice. OTexts, Melbourne, Australia, $3^{\text {a }}$ edição, 2019. 8, 9, 18

$\left[\mathrm{HAB}^{+} 20\right]$ Rob Hyndman, George Athanasopoulos, Christoph Bergmeir, Gabriel Caceres, Leanne Chhay, Mitchell O'Hara-Wild, Fotios Petropoulos, Slava Razbash, Earo Wang e Farah Yasmeen. \{forecast\}: Forecasting functions for time series and linear models, 2020. 46

[Haf16] Ryan Hafen. stlplus: Enhanced Seasonal Decomposition of Time Series by Loess, 2016. 47

[Hy195] Svend Hylleberg. Tests for seasonal unit roots general to specific or specific to general? Journal of Econometrics, 69(1):5-25, 1995. 17

[Kas20] Alboukadel Kassambara. ggpubr: 'ggplot2' Based Publication Ready Plots, 2020. 47

[KNNL05] Michael H. Kutner, Christopher J. Nachtsheim, John Neter e William Li. Applied Linear Statistical Models. McGraw-Hill Irwin, New York, NY, $5^{\mathrm{a}}$ ed edição, 2005. 9

[KPSS92] Denis Kwiatkowski, Peter C.B. Phillips, Peter Schmidt e Yongcheol Shin. Testing the null hypothesis of stationarity against the alternative of a unit root. How sure are we that economic time series have a unit root? Journal of Econometrics, 54(1-3):159-178, 1992. 15,17

[MT06] Pedro A. Morettin e C Toloi. Análise de Séries Temporais. Blucher, São Paulo, $3^{\text {a }}$ edição, 2006. 12

[MW20a] Microsoft e Steve Weston. foreach: Provides Foreach Looping Construct, 2020. 47

[MW20b] Kirill Müller e Hadley Wickham. tibble: Simple Data Frames, 2020. 47

[OCSB88] Denise R Osborn, A P L Chui, Jeremy P Smith e C R Birchenhall. SEASONALITY AND THE ORDER OF INTEGRATION FOR CONSUMPTION. Oxford Bulletin of Economics and Statistics, 50(4):361-377, 1988. 17

[Per88] Pierre Perron. Trends and random walks in macroeconomic time series: Further evidence from a new approach. Journal of Economic Dynamics and Control, 12(2):297332, 1988. 15,17

[PGAF19] E. Pacchin, F. Gagliardi, S. Alvisi e M. Franchini. A Comparison of Short-Term Water Demand Forecasting Models. Water Resources Management, 33(4):1481-1497, 2019. 1

$\left[\mathrm{QPC}^{+} 10\right]$ J. Quevedo, V. Puig, G. Cembrano, J. Blanch, J. Aguilar, D. Saporta, G. Benito, M. Hedo e A. Molina. Validation and reconstruction of flow meter data in the Barcelona water distribution network. Control Engineering Practice, 18(6):640-651, 2010. 2

[R C20] R Core Team. R: A Language and Environment for Statistical Computing. R Foundation for Statistical Computing, Vienna, Austria, 2020. 46

[RMK16] Vasja Roblek, Maja Meško e Alojz Krapež. A Complex View of Industry 4.0. 2016. 1 
[RPFL17] Hector Rodriguez, Vicenç Puig, Juan J. Flores e Rodrigo Lopez. Flow meter data validation and reconstruction using neural networks: Application to the Barcelona water network. 2016 European Control Conference, ECC 2016, páginas 1746-1751, 2017. 1

[RSt20] RStudio Team. RStudio: Integrated Development Environment for R. RStudio, PBC., Boston, MA, 2020. 46

[RY08] Rob J. Hyndman e Yeasmin Khandakar. Automatic Time Series Forecasting: The forecast Package for R. Journal of Statistical Software, 27(3):22, 2008. 17, 19, 46

[SS17] Robert H. Shumway e David S. Stoffer. Time Series Analysis and its Applications: With R Examples. Springer, Binding, edition 4t edição, 2017. 19

[TR88] Tsay e Ruey. Outliers, Level Shifts, and Variance Changes in Time Series. Journal of Forecasting, 7(1):1-20, 1988. 23

$\left[\mathrm{WAB}^{+} 19\right]$ Hadley Wickham, Mara Averick, Jennifer Bryan, Winston Chang, Lucy D'Agostino McGowan, Romain François, Garrett Grolemund, Alex Hayes, Lionel Henry, Jim Hester, Max Kuhn, Thomas Lin Pedersen, Evan Miller, Stephan Milton Bache, Kirill Müller, Jeroen Ooms, David Robinson, Dana Paige Seidel, Vitalie Spinu, Kohske Takahashi, Davis Vaughan, Claus Wilke, Kara Woo e Hiroaki Yutani. Welcome to the $\{$ tidyverse\}. Journal of Open Source Software, 4(43):1686, 2019. 47

[WFHM20] Hadley Wickham, Romain François, Lionel Henry e Kirill Müller. dplyr: A Grammar of Data Manipulation, 2020. 47

[WH20] Hadley Wickham e Jim Hester. readr: Read Rectangular Text Data, 2020. 47

[Wic16] Hadley Wickham. ggplot2: Elegant Graphics for Data Analysis. Springer-Verlag New York, 2016. 47

[Wic19] Hadley Wickham. stringr: Simple, Consistent Wrappers for Common String Operations, 2019. 47

[Wic20] Hadley Wickham. tidyr: Tidy Messy Data, 2020. 47

[WSH06] Xiaozhe Wang, Kate Smith e Rob Hyndman. Characteristic-Based Clustering for Time Series Data. Data Mining and Knowledge Discovery, 13(3):335-364, 2006. 17

[Yos02] Olga Satomi Yoshida. Modelo a tempo real com filtro de erros de transmissão de dados e previsão em curto prazo da demanda de água em áreas urbanas. Relatório técnico, IPT - Instituto de Pesquisas Tecnológicas do Estado de São Paulo, São Paulo, 2002. 1

[Zhu20] Hao Zhu. kableExtra: Construct Complex Table with 'kable' and Pipe Syntax, 2020. 47

[ZW06] Eric Zivot e Jiahui Wang. Modeling financial time series with S-PLUS@. Springer, New York, NY, $2^{\text {a }}$ edição, 2006. 24 